\title{
KURZGEFASSTES LEHRBUCH \\ DER PSYCHIATRIE
}

\author{
$\operatorname{roN}$ \\ JOHANNES LANGE t
}

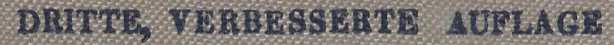

vols

AUGUST BOSTROEM

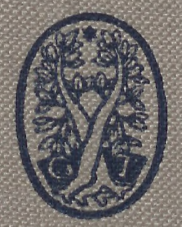

GEORG THIEME - VERLAG - LEIPZIG 


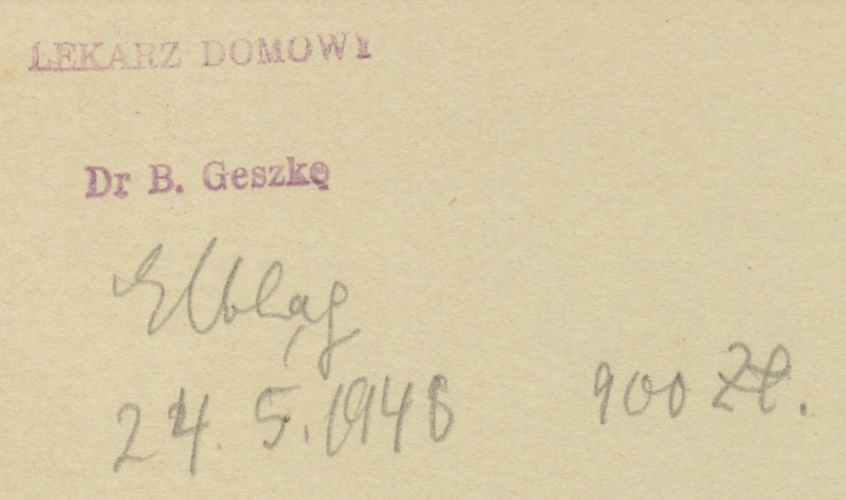


1487

2195

Anto: Goow 
KURZGEFASSTES LEHRBUCH

DER PSYCHIATRIE 
4h.

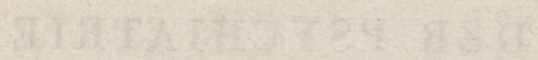




\title{
KURZGEFASSTES LEHRBUCH DER PSYCHIATRIE
}

\author{
VON \\ Professor Dr. JOHANNES LANGE $†$
}

DRITTE, VERBESSERTE AUFLAGE

VON

DR. AUGUST BOSTROEM

PROFESSOR DER PSYCHIATRIE UND NEUROLOGIE

IN LEIPZIG

MIT 4 ABBILDUNGEN

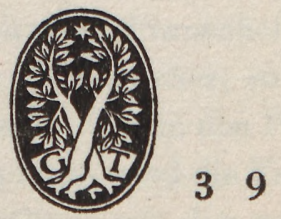

GE OR G THIEME/VERLAG/LEIPZIG 

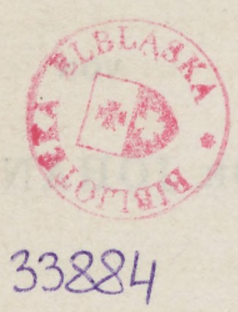

Alle Rechte,

insbesondere das der Ubersetzung in fremde Sprachen, vorbehalten

Copyright 1939 by Georg Thieme, Leipzig, Germany
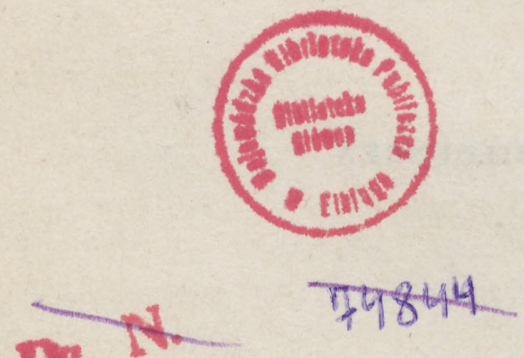

$$
616.89(07)=M 2,2
$$




\section{Vorwort zur dritten Auflage}

Am 11. August 1938 ist Joh annes Lange gestorben. Trotz seines schweren Leidens hat er sich mit unvergleichlicher Willenskraft bis zum letzten Augenblick seiner wissenschaftlichen Tätigkeit hingegeben. Mit der Arbeit für die neue Auflage seines Lehrbuches hatte er bereits begonnen; leider war es ihm aber nicht vergönnt, die Durchsicht zu vollenden; immerhin konnte der allgemeine Teil noch von ihm zum Druck vorbereitet werden.

Wenn ich jetzt der Aufforderung des Verlages folgend die neue Auflage übernommen habe, so betrachte ich dies in erster Linie als eine Verpflichtung dem toten Freunde gegenüber. Es war mein Bestreben, das Lehrbuch in seinem Sinne weiterzuführen. Umfangreiche Änderungen, die auf Grund unserer inzwischen gewonnenen neueren Erfahrungen nötig waren, erforderte im wesentlichen nur das Kapitel der Epilepsie; weiter mußte den verschiedenen Neuerungen auf dem Gebiete der einschlägigen Gesetzgebung Rechnung getragen werden. Auch habe ich mich bemüht, Wünschen, die von der Kritik geäußert waren, zu entsprechen.

Frau Dr. Lange-Cosack danke ich auch an dieser Stelle herzlich für ihre Mithilfe und für die Übernahme der Korrekturen.

Königsberg i. Pr., den 22. Februar 1939

Bostroem

\section{Vorwort zur ersten Auflage}

Die außerordentlich raschen Fortschritte der Medizin zwingen den angehenden Arzt, sich immer nachdrücklicher mit den medizinischen Hauptfächern, Innerer Medizin und Chirurgie, Frauenheilkunde und Pathologischer Anatomie, zu beschäftigen. Die Nebenfächer, so wichtig sie sind, geraten damit in Gefahr, zu kurz zu kommen. Wer in den Prüfungen nach den Quellen des Wissens in den Nebenfächern fragt, wird die Feststellung machen müssen, daß die große Mehrzahl der Prüflinge mit den vorhandenen umfangreichen Lehrbüchern keine oder nur ganz oberflächliche Bekanntschaft gemacht hat. Dies liegt gewiß nicht an der Qualität der Bücher, aber auch der 
Studierende hat keine Schuld. Der Kandidat befindet sich nun einmal in zeitlicher und vielfach auch wirtschaftlicher Notlage, die ihm nicht erlaubt, eines der empfohlenen Lehrbücher rechtzeitig zu beschaffen und während der klinischen Vorlesung durchzuarbeiten.

Dies kurzgefaßte Lehrbuch sucht hier Abhilfe zu schaffen. Es soll dem Mediziner die unangenehme Notwendigkeit, sein Wissen ausschließlich aus Kompendien zu beziehen, ersparen, ihn aber zugleich durch seinen bescheidenen Umfang und seine sachliche Beschränkung instand setzen, die lebendigen Eindrücke der psychiatrischen Klinik zu vertiefen. Die Darstellung bemüht sich, jeweils an normale seelische Geschehnisse anzuknüpfen und damit auch die Beschäftigung mit psychologischen Fragen anzuregen. Die Erörterung ungeklärter Probleme ist grundsätzlich vermieden worden. Ein Lehrbuch für Studierende kann nicht zugleich für den angehenden Fachmann bestimmt sein.

Breslau, im Mai 1935

Johannes Lange

\section{Vorwort zur zweiten Auflage}

Die neue Auflage ist wesentlich früher, als ich erwartet hatte, nötig geworden. Dabei hat das Buch zahlreiche kleine Veränderungen erfahren, der Umfang ist aber nur um wenige Abschnitte vermehrt worden. So wurde dem Kapitel „Progressive Paralyse ${ }^{66}$ eine Behandlung der Liquorsyndrome angefügt, die Hirngeschwülste sind neu besprochen, die anatomischen Abschnitte umgearbeitet, dem letzten Hauptkapitel allgemeine Gesichtspunkte für die Diagnose eingegliedert; endlich wurden dem Buch kurze Literaturhinweise und ein Register beigegeben. Ich hoffe, damit alle wesentlichen Wünsche der Kritik erfüllt zu haben.

Breslau, im März 1936

Johannes Lange 


\section{Inhaltsverzeichnis}

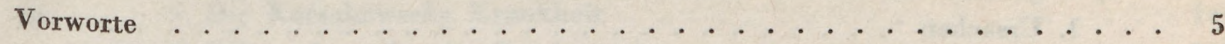

Einleitung ...................... 11

A. Allgemeine Psychiatrie ................ 13

I. Allgemeine Symptomatologie . . . . . . . . . . . . . 13

a) Störungen des Trieblebens. . . . . . . . . . . . . . 13

b) Störungen der Affektivität . . . . . . . . . . . . . . 28

c) Störungen des Gegenstandsbewußtseins . . . . . . . . . . 32

1. Störungen der Wahrnehmung. Sinnestäuschungen . . . . . . . . 32

2. Störungen der Begriffe . . . . . . . . . . . . 38

3. Formale Denkstörungen. . . . . . . . . . . . . 39

4. Inhaltliche Denkstörungen. . . . . . . . . . . 43

5. Störungen des Bewußtseins ............. . . 49

$\alpha)$ Die Benommenheit 49 . $\beta$ ) Die delirante Bewußtseinstrübung 50 .

$\gamma$ ) Eingeengtes Bewußtsein 50. $\delta$ ) Das Unbewußte 51.

6. Störungen der mnestischen Funktionen . . . . . . . . . 52

$\alpha)$ Störungen des Gedächtnisses 54. $\beta$ ) Psychogene Amnesie 55. $\gamma$ ) Reproduktionsstörungen 55. $\delta$ ) Störungen der Merkfähigkeit 56. $\varepsilon$ ) Erinnerungstäuschungen 56 .

7. Intelligenzstörúngen . . . . . . . . . . . . 58

II. Ursachen des Irreseins . . . . . . . . . . . . . . . . . . . 59

a) Exogene Krankheitsursachen . . . . . . . . . . . . . . . . . 59

b) Endogene Krankheitsursachen . . . . . . . . . . . . . . 62

c) Erblichkeit . . . . . . . . . . . . . . . . . . 64 64

III. Struktur der Psychosen ................ 67

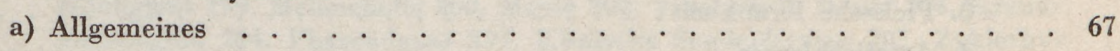

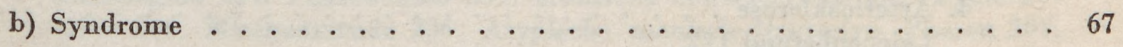

1. Exogene Syndrome und Bewußtseinsstörungen ........ 68

Benommenheit 70. Delirium 70. Amentia 71. Dämmerzustand 71.

2. Spasmodische Syndrome . . . . . . . . . . . . . 72

Der epileptische Anfall 72. Der tetanische Anfall 72. Der hysterische Anfall 73.

3. Dyskinetische Syndrome. . . . . . . . . . . . 73

Der Stupor 73. Die Hyperkinese 74. Der katatone Symptomenkomplex 74.

4. Die Halluzinose . . . . . . . . . . . . . . . . . 74 


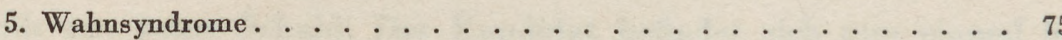

Das paranoische Syndrom 75. Paraphrenes Syndrom 75. Wahnhafte Einbildung 76.

6. Emotionelle Syndrome . . . . . . . . . . . . 76 Das depressive Syndrom 76. Das Angstsyndrom 76. Das manische Syndrom 77. Dranghafte Verstimmungen 77.

7. Nervöse Syndrome . . . . . . . . . . . . . . . . 77 Das neurasthenische Syndrom 77. Das hypochondrische Syndrom 78. Zwangssyndrom 78. Das hysterische Syndrom 78. Die Querulanz 78. Das Depersonalisationssyndrom 78.

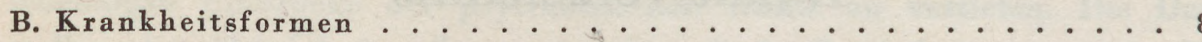

a) Angeborene und früherworbene Schwachsinnszustände (Oligophrenien) . . 81

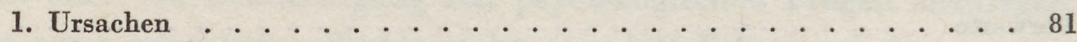
Idiotie 82. Imbezillität 82. Debilität 84. Verhältnisblödsinn 84. Episodische Erkrankungen 84.

2. Schwachsinnszustände infolge nachgewiesener Hirnschädigungen . . . 85 Therapie 85.

3. Sonderformen der Oligophrenie .............. . 86 Mongolismus 86. Kretinismus 87. Amaurotische Idiotie 87.

4. Erkennung. . . . . . . . . . . . . . . . . . . 88

b) Psychische Störungen nach Gehirnverletzungen . . . . . . . . . . . . 89 Hirnerschütterung 89. Hirnquetschung 91. Traumatische Epilepsie 92.

c) Progressive Paralyse . . . . . . . . . . . . . . . . . . . . . . . 92

Symptomatologie 92. Einfach-demente, klassische 96. Depressive, agitierte, Lissauersche Paralyse 97. Verlauf 97. Leichenbefund 98. Behandlung 99.

Pathogenese 101. Juvenile Paralyse 102. Erkennung 102. Anhang: Liquorsyndrome 103.

d) Psychosen bei Lues cerebri . . . . . . . . . . . . . . . 105 Hypochondrische Reaktionen 106. Neurasthenie 106. Meningitis 106. Gefäßlues 107. Epilepsie 108. Halluzinosen 108. Erkennung 108.

e) Encephalitis epidemica. . . . . . . . . . . . . . . 109 Akute Bilder 109. Chronische Folgezustände 110. Enzephalitis bei Kindern 110. Behandlung 111. Erkennung 112.

f) Psychische Störungen des höheren Lebensalters . . . . . . . . . 112

1. Senile Demenz . . . . . . . . . . . . . . . . . . 112 Varianten der senilen Demenz 115. Senile Depression 115. Presbyophrenien 116. Seniles Paranoid 116.

2. Alzheimersche Krankheit . . . . . . . . . . . . . . 117

3. Picksche Krankheit. . . . . . . . . . . . . . . . . . . . 119

4. Arteriosklerose . . . . . . . . . . . . . . . . . . . . 120 Leichenbefund 122.

5. Hypertonie . . . . . . . . . . . . . . . . 123

6. Präsenile Seelenstörungen . . . . . . . . . . . . . 123

g) Huntingtonsche Chorea .................. 124

h) Andere Hirnerkrankungen . . . . . . . . . . . . 125

Enzephalitisformen 125. Meningitiden 126. Multiple Sklerose 127. Chorea minor 127. Paralysis agitans 128. Athetose 128. Hirngeschwülste 128. 
i) Psychische Störungen bei akuten Infektionen, bei Erkrankungen innerer Organe und bei Allgemeinerkrankungen . . . . . . . . . . . . 129

1. Infektionskrankheiten . . . . . . . . . . . . . . . 130

2. Erkrankungen innerer Organe .............. 131

3. Allgemeinerkrankungen ................. . 132

4. Stoffwechselerkrankungen - Endokrine Störungen . . . . . . 133

5. Generationsphasen . . . . . . . . . . . . . . . 136

k) Alkoholismus . . . . . . . . . . . . . . . . . . . . 137

1. Der akute Rausch. - Pathologische Rauschzustände. . . . . . . . 137

2. Der chronische Alkoholismus . . . . . . . . . . . . . . . 138

3. Delirium tremens. . . . . . . . . . . . . . . 140

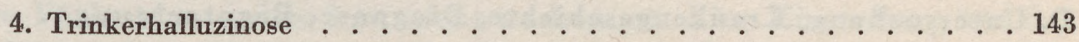

5. Die Korsakowsche Krankheit . . . . . . . . . . . . . . . . . . . 144

6. Eifersuchtswahn der Trinker . . . . . . . . . . . 145

7. Alkoholepilepsie . . . . . . . . . . . . . . 146

1) Suchten ......................... . . . . . . . . . . . . . . . . . . . . . . . . . . . .

1. Morphinismus . . . . . . . . . . . . . . . . 146

2. Heroinismus . . . . . . . . . . . . . . . 150

3. Kokainismus . . . . . . . . . . . . . . . . 150

m) Psychische Störungen bei anderen Vergiftungen . . . . . . . 152

1. Gewerbliche Gifte. . . . . . . . . . . . . 152

2. Arzneimittel . . . . . . . . . . . . 153

n) Die genuinen Epilepsien und die symptomatischen Epilepsien . . . . 155

Allgemeines 155. Der elementare Krampf 156. Petit mal 157. Genese des epileptischen Anfalles 157. Dämmerzustände 158. Delirien 159. Atypische Dämmerzustände und Delirien 159. Besonnene Dämmerzustände 159. Verstimmungen 160. Wandertrieb 160. Die Persönlichkeitseigenart und die Demenz des Epileptikers 161. Verlauf 164. Soziale Beurteilung 165. Der Leichenbefund 166. Behandlung 166. Die Abgrenzung der symptomatischen Epilepsien 167.

o) Schizophrenie . . . . . . . . . . . . . . . . . . 169

Affektivität 171. Handeln 173. Trugwahrnehmungen 175. Wahnideen 177.

Delirante Zustände 180. Sprechen und Schreiben 180. Störungen der Persönlichkeit 181. Körperliche Störungen 182. Krankheitsbeginn 183. Hebephrenie 183. Katatonie 184. Paranoide Demenz 184. Beispiele 184. Paranoide Demenz 186. Milde paranoide Demenz 189. Prämorbide Persönlichkeit 190. Körperbau 191. Verlauf und Prognose 191. Paraphrenien 193. Tod und Leichenbefund 194. Behandlung 195. Erkennung 196. Ursachen 198.

p) Das manisch-depressive Irresein . . . . . . . . . . . . . 199

Häufigkeit 199. Melancholie 200. Manie 202. Verworrene Manie 204. Krankheitsbeginn 204. Phasendauer 204. Klinische Sonderformen 205. Zyklothymien 206. Mischzustände 206. Atypische manisch-depressive Phasen 207. Degenerationspsychosen 207. Verlauf und Ausgänge 208. Ursachen 209. Körperbau 209. Zykloidie 210. Exogene Faktoren 210. Behandlung 211. Erkennung 213.

q) Die psychopathischen Persönlichkeiten ........... . . 214

Allgemeines 215. Ursachen 215. Körperliche Störungen 216. Hyperthyme 217. Depressive 217. Selbstunsichere 218. Zwangsmenschen 218. Fanatische 220. Stimmungslabile 221. Geltungsbedürftige 222. Gemütlose 224. Haltlose 225. Explosible 225. Asthenische 226. 
r) Abnorme seelische Reaktionen . . . . . . . . . . . . . . . 227

Allgemeines 227. Psychogene Depression 228. Angstreaktionen und Angstneurose 229. Schreckreaktionen 229. Paranoische Reaktionen und Entwicklungen 230. Paranoia 233. Verfolgungswahn der Schwerhörigen 234. Gefangenenwahnsinn 234. Psychogene Bewußtseinsveränderungen 235. Psychogene körperliche Symptome 237. Traumatische Neurose 239. Induziertes Irresein 241. Geschlechtliche Verirrungen 241.

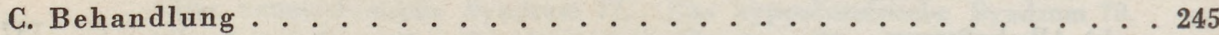

Vorbeugung 245. Eheschließung 245. Psychotherapie 24.7. Freud 247. Adler 24.8. Selbstmordgefahr 24.9. Wahrhaftigkeit 250. Anstalt 250. Zwang 251. Angehörige 252. Schlafmittel 252. Schwangerschaftsunterbrechung 254.

D. Untersuchung, Krankengeschichte, Diagnose, Begutachtung . . . . 255 Untersuchung 256. Krankengeschichte 258. Diagnose 259. Begutachtung 262.

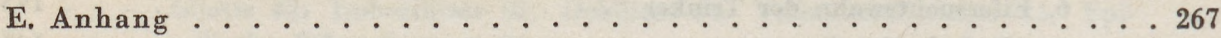

1. Intelligenzprüfung nach Binet-Simon ............ 267

2. Untersuchung des psychischen Zustandes nach Sommer .......... 268

3. Münchener Fragebogen. . . . . . . . . . . . . . . . . . . 269

F. Literaturhinweise . . . . . . . . . . . . . . . 272

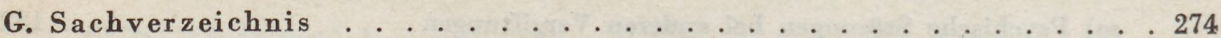




\section{Einleitung}

Die Psychiatrie bietet dem Studierenden deshalb ganz besondere Schwierigkeiten, weil er mit dem Rüstzeug, das er sich in den anderen. klinischen Fächern erworben hat, nicht auskommt. Eine Einstellung auf das Seelenleben, wie sie die geistige Erkrankung erfordert, ist dem gesunden Menschen fremd. In der übrigen Medizin kommen zwar alle seelischen Auswirkungen der körperlichen Erkrankung zur Sprache, soweit sie in einer dem Gesunden verständlichen Ebene liegen, und auch die Wandlungen, welche die körperliche Krankheit unter dem Einfluß von Angst, Erwartung und Krankheitswünschen erfährt, werden bei der Bedeutung der Unfallskrankheiten heute dem angehenden Mediziner sehr bald vertraut. Alle diese Tatsachen kehren in der Psychiatrie zwar wieder; sie machen hier aber nur einen bescheidenen Teil des Gegenstandsbereiches aus.

Gewiß verwertet auch das psychiatrische Denken weithin die Methoden, welche die innere Klinik erarbeitet hat, und die klar abgrenzbaren Krankheitsformen sind auch unțer den Gesichtspunkten, welche in der übrigen Medizin alleinige Geltung haben, nach allen Richtungen gesichert. Auch die pathologische Physiologie und Anatomie haben im Laufe der letzten Jahrzehnte zunehmend an Boden gewonnen. Aber es sind nicht körperliche Störungen, welche die Kranken in die psychiatrische Klinik führen, sondern ganz vorwiegend unverständliche seelische Äußerungen, und in großen Gebieten der Psychiatrie sind es diese allein, die gestatten, Krankheitsformen von einheitlicher Symptomatologie, einheitlichem Verlauf und gleichem Ausgang gegeneinander abzugrenzen. Bei einem Teil dieser Erkrankungen dürfen wir für die Zukunft die Auffindung der ursächlichen körperlichen Störungen und vermutlich auch die Klarstellung wohlgekennzeichneter histopathologischer Prozesse erwarten. In weiten Gebieten der Seelenstörungen aber haben wir keinen Anlaß, überhaupt nur nach pathologisch-anatomischen Prozessen zu suchen. Eine Fülle von Krankheitsgeschehnissen, welche die psychiatrische Klinik beschäftigt, ist offenbar ganz einfach Ausdruck von je abnormer Gesamtkonstitutionen, die nach pathologisch-anatomischen Gesichtspunkten wohl ebensowenig faßbar werden dürften, wie jene Fülle von körperlichen Konstitutionen, die als Varietäten der Norm erscheinen.

In allen diesen Fällen können diagnostische und prognostische Erwägungen also lediglich an die seelischen Äußerungen anknüpfen. Diese in ihrer besonderen Art zu erfassen, dafür fehlt dem Mediziner, wenn er zum ersten Male in die psychiatrische Klinik kommt, meist jede Vorbereitung, und vielen Ärzten bleibt die Fähigkeit, hier zu einer, wenn auch bescheidenen, Sachkenntnis vorzudringen, für alle Zeit vorenthalten. Offenbar setzt der Erwerb eines Sachverständnisses mindestens in dem gleichen Maße eine 
besondere anlagegemäße Eignung voraus, wie etwa die fruchtbare chirurgische Tätigkeit, nur daß sie auf einem ganz anderen Gebiete liegt. Dennoch muß jeder Arzt mindestens in großen Umrissen mit der Fülle möglicher seelischer Krankheitserscheinungen vertraut werden, wenn er erfolgreich tätig sein will. Nicht bloß das Los der ihm anvertrauten Kranken, auch das Wohl der Gemeinschaft steht in Gefahr. Seelische Krankheit bedeutet für den Betroffenen in der Regel ein Schicksal, das sein gesamtes Leben beschattet, da die große Mehrzahl der seelischen Erkrankungen und vor allem auch der grob abnormen Konstitutionen nicht heilbar und in den sozialen Auswirkungen von der schlimmsten Bedeutung ist. Meist werden zugleich nicht bloß die Kranken selbst, sondern auch die Herkunftsfamilien in schwerster Weise belastet. Bei der außerordentlichen Bedeutung, welche die Erblichkeit gerade im Bereiche der Seelenstörungen hat, hat zudem die Gemeinschaft dringend zu fordern, daß die Geisteskranken bekannt und sachverständiger Beobachtung zugeführt werden. Sie läuft sonst Gefahr, an den Lasten zu ersticken, welche die seelischen Unzulänglichkeiten bedingen. Dabei ist nicht bloß an die Gesundheitsfürsorge im engeren Sinne, an die in ihrem Umfang immer zunehmende Anstaltsbedürftigkeit zu denken, sondern auch an das soziale Unheil, das von der Fülle psychopathischer und geisteskranker Persönlichkeiten ausgeht. Unsere Fürsorgeerziehungsanstalten, Arbeitshäuser, Gefangenenanstalten, Trinkerheilstätten sind zu einem sehr erheblichen Teil von Menschen bevölkert, die in das Bereich der Psychiatrie gehören.

Die Häufigkeit der Geisteskrankheiten und der groben anlagegemäßen Unzulänglichkeiten kann man aus der offiziellen Statistik nur ganz unzureichend erfassen. Im Jahre 1930 wurden beinahe 310000 Kranke in Anstalten für Geisteskranke, Epileptiker, Idioten, Schwachsinnige und Nervenkranke verpflegt gegenüber nur 240000 im Jahre 1913. Aber auch die Zahl von 1930 bleibt um ein Mehrfaches hinter der Wirklichkeit zurück. Allein gegen $2 \%$ der Schulpflichtigen dürften schwachsinnig im Sinne der Krankheit „Angeborener Schwachsinn" sein. Wir haben allen Anlaß anzunehmen, daß zwischen 5 und $10 \%$ der Menschen nach ihrer Persönlichkeit so unzulänglich sind, daß sie selbst unter ihrer abnormen Verfassung ihr Leben lang leiden oder durch ihre unerfreulichen Wesenszüge die Gemeinschaft stören, d. h. daß sie als psychopathisch betrachtet werden müssen. Umfangreichen Auszählungen entspricht es denn auch, daß gegen $10 \%$ aller Menschen im Laufe des Lebens Bekanntschaft mit dem Psychiater machen. Für den angehenden Arzt ist es also eine dringende Notwendigkeit, sich mit der Psychiatrie in dem Umfang vertraut zu machen, der seinen Fähigkeiten nur irgend entspricht. Nur dann kann er erreichen, was vom Arzt allgemein gefordert wird: aus bestem Wissen und Gewissen heraus der Gemeinschaft zu dienen und dem einzelnen Leidenden zu helfen.

Die folgende Darstellung sucht nach Möglichkeit an die normalen menschlichen Regungen anzuknüpfen und Brücken für das Verständnis auch der grob abnormen Erscheinungen zu bauen. Im übrigen beschränkt sie sich darauf, allenthalben das Wesentliche zu geben. Wer sich mit der unendlichen Formenfülle abnormen seelischen Geschehens vertraut machen will, muß zu einem der großen Handbücher greifen. 


\title{
A. Allgemeine Psychiatrie
}

\section{Allgemeine Symptomatologie}

\author{
a) Störungen des Trieblebens
}

Hineingestellt in eine Umwelt, deren erlebbarer Ausschnitt an Gliederung und Umfang mit den Lebensräumen auch der höchsten anderen Lebewesen kaum vergleichbar ist, erlebt der Mensch doch die gleichen treibenden Grundkräfte in sich, die er in allen höheren Tieren am Werke sieht. Auf das biologische Ziel der Selbsterhaltung sind die Triebkräfte von Hunger und Durst, Angriff und Flucht, Tätigkeitsdrang (Antrieb) und Schlaftrieb gerichtet; mit dem Ziel der Arterhaltung hängen die drängenden Kräfte des Geschlechtslebens, die Triebe zum geschlechtlichen Angriff wie zur Hingabe, zur Brutpflege wie zur Geborgenheit im allgewaltigen mütterlichen Schutz zusammen. Hunger und Durst werden in der Gegenwart nur in Zeiten der Not in ihrer überwältigenden Triebkraft kenntlich (Anthropophagie in den russischen Hungergebieten); auch die mit dem Gefahrenschutz verbundenen Triebe des rücksichtslosen Angriffs und der wilden Panik treten bei der zunehmenden Einstellung auf Lebenssicherung nur noch unter Ausnahmebedingungen zutage. Ableitungen und Verkleidungen dieser Triebkräfte spielen jedoch im Zusammenwirken mit höheren Trieben in jedem menschlichen Dasein eine wesentliche Rolle. Der in uns lebendige Drang zum Tun, zum Regen unserer Kräfte ist in seiner Allgegenwart nur dort deutlich spürbar, wo er behindert wird (Langeweile, Gefangenschaft, Krankheitszustände, in der Ermüdung), und auch der Schlaftrieb muß sich in der gehetzten Gegenwart Vergewaltigungen gefallen lassen, die ihm seine selbstverständliche Zielsicherheit nehmen können. Demgegenüber schafft die Sexualität in jedem Menschenleben Perioden des Drangs von entscheidender Bedeutung, ganz abgesehen davon, daß sie in der Zeit der Reife ständig im Hintergrund des Erlebens spürbar bleibt. Brutpflegetrieb und jenes Verlangen nach Geborgenheit vollends, die in der Zeit der Mutterschaft wie der frühen Kindheit auch beim zivilisierten Menschen selten bzw. nie versagen, sie bleiben in Abwandlungen das ganze Leben über wirksam.

Über diesen Grundtrieben, deren körperliche Verankerung allzeit oder doch in gewissen Perioden zugleich mit den seelischen Ausstrahlungen bewußt wird, spüren wir in uns andere Kräfte, weniger elementar, weniger in ihrer körperlichen Grundlegung faßbar, dafür aber stetiger und für das Alltagsleben bedeutsamer. Ich meine die Triebe, die unsere Beziehungen zu den Menschen, und jene, welche die übrige Welt um uns herum zum Ziel haben. Triebe zur Teilnahme, zur Kommunikation, zur Ein- und Unterordnung wie zur Beherrschung der menschlichen Mitwelt sind schon im 
kleinen Kinde deutlich. Hingabe an den anderen, Herrschaft über den anderen, Selbsthingabe und Selbstbehauptung, sie sind die Pole der triebhaften Zuwendung zum Nächsten, die in tausend Abwandlungen und Mischungsverhältnissen das ganze menschliche Leben überdauern. Während die Grundtriebe, die sich um Selbst- und Arterhaltung gruppieren, durch Befriedigung vorübergehend immer wieder abgestellt werden können, kommen die Kräfte, welche die zwischenmenschlichen Beziehungen beherrschen, nie ganz zur Ruhe. Wir finden hier jenes Hin und Her, jene umschichtige Ablösung und Durchdringung der Triebziele, die unser Seelenleben in einem ständigen Fluß erhält.

Aus der Hinwendung zum anderen und dem Trieb zur Teilnahme sind die objektiven geistig-seelischen Mächte entstanden, die als Sprache, als Recht, als Religion, als Sitte mit ihren Forderungen den treibenden Kräften in uns den Rahmen geben, Sonderziele bezeichnen und Fesseln anlegen. Sie sind ein Niederschlag der Gesamtheit zwischenmenschlicher Beziehungen, von Menschengruppe zu Menschengruppe verschieden, mit der Entwicklung wandelbar, aber für den einzelnen in seiner Zeit verpflichtend wie die von innen treibenden Kräfte selbst und wie die objektive Welt, an deren Schranken wir gebunden sind.

Auch zur außermenschlichen Welt um uns fühlen wir uns getrieben. Wenn beim niederen Tier wenigen bestimmten Situationen ebenso wenige bestimmte instinktive Verhaltensweisen zugeordnet sind, ist das menschliche Weltbild reich und frei geworden. Das Tier ist mit seiner Umwelt, aus der sich nur die möglichen Triebziele herausheben, eins. Beim Menschen aber ist die Erfassung der Welt in ihrer Gliederung selbst zum Triebziel geworden. Das menschliche Ich hat sich von der Welt gesondert, ja selbst das eigene Ich kann sich zum Ziele seiner geistigen Triebe machen, sich aus sich herausstellen. Mit dieser Entwicklung hat sich der Mensch weit über das Tier erhoben. Die gleiche äußere Situation läßt zahllose Handlungsmöglichkeiten $\mathrm{zu}$, darunter auch die Bremsung des äußeren Handelns, die als Denken im Inneren erscheint. Das Tun wird zunehmend zum Denken, das immer weitere Ausschnitte der Welt sich erschließt und sich der ganzen Vergangenheit wie großen Abschnitten der Zukunft anzupassen vermag. Die schon bei höheren Tieren faßbare ${ }_{2}$ Neugier $^{66}$ wird beim Menschen zu einem seinen viel reicheren Fähigkeiten angepaßten Drang, der Welt schauend sich hinzugeben, sie denkend zu erfassen und handelnd zu gestalten. Als Neugier erscheint sie nur noch beim Primitiven und beim Kind; sie wird zum Wissens- und Wissenschaftsdrang in seinen verschiedensten Gestaltungen beim begabten reifen Menschen. Auch für diese Entwicklung sind die objektiven Niederschläge der zwischenmenschlichen Beziehungen von entscheidender Bedeutung, zumal als Sprache, die weithin die Bahnen des Denkens festlegt.

Alle diese Triebkräfte erleben wir in uns und zugleich als in spezifischer Weise uns gehörig, aus unserem Ich hervorgehend, von unserem Ich einheitlich zusammengefaßt. Handelnd werden wir immer durch ein Triebziel bestimmt, das mit unserem Ich verschmilzt und die gesamten Werkzeuge des Seelenlebens auf das Triebziel einstellt, alle anderen Triebziele aber zum Hintergrund des Erlebens macht. Bei den allermeisten Alltagshandlungen 
freilich, im nebenläufigen Geschehen, in der Durchführung von einmal gefaßten Entschlüssen taucht unser bewußtes Ich unter, unser Tun wird scheinbar geradlinig durch Gegenstände und Situationen aus den unbewußten oder minder bewußten determinierenden Tendenzen der triebhaften Zielsetzung bestimmt. Auch der Großteil der Zuwendungen des Alltags außerhalb der bewußten Aufgaben ist einfach triebhaft; eine Sonderung von Ich und Welt wird dabei nicht deutlich. Unser Ich tritt aber klar hervor allenthalben dort, wo sich dem Fluß des Tuns Widerstände in den Weg stellen, die aus anderen Triebrichtungen stammen; zum ausgesprochenen voll erlebten Wollen vollends, zur Entscheidung kommen wir nur, wenn mehrere Triebziele um den Vorrang streiten. Das Ich verschmilzt dann nach einem Kampf der Motive (Triebziele) schließlich mit jenem Triebziel, das bei der besonderen Lage und bei dem Gesamt der in uns lebendigen Triebhaltungen allein eine Vereinheitlichung gestattet. Dies geschieht mit einem eigenartigen Erleben der Freiheit, der Entscheidung, und nur dann kommt es zugleich zu dem spezifischen Erlebnis des „Ich will“". Die konkurrierenden Triebziele treten in den Hintergrund des Erlebens, freilich ohne endgültig zu verschwinden; in anderen Lagen treten sie erneut hervor. Alle unsere inneren und äußeren Handlungen können durchkreuzt werden durch Triebkräfte, die, vital bedeutsam, sich im entscheidenden Augenblick elementar hervordrängen (Gefahrenschutz, Hunger, wachsende Sexualspannung) und jeweils den ganzen Menschen in Anspruch nehmen.

Auf jeden Fall erleben wir uns, denkend, handelnd, uns zuwendend, immer als ganz; alle Werkzeuge des Seelenlebens und unser Körper werden durch unsere Ziele, unsere Absichten, die übernommenen Aufgaben vereinheitlicht. Dabei bleiben freilich hinter den aktuellen Stellungnahmen und Handlungszielen in ständiger Bereitschaft jene elementaren Bedürfnisse, die mit den Grundtriebkräften des Seelenlebens zusammenhängen und zu jeder Zeit sich plötzlich den gesamten Apparat dienstbar machen können. Es ist, als ob ein bestimmtes $\mathrm{Maß}$ seelischer Kräfte zur Verfügung stände, das jeweils zum größten Teil dem vom Willen erfaßten Triebziel zugewandt ist, während ein kleinerer Teil alle anderen möglichen Ziele, und zwar je nach dem Grade ihrer vitalen bzw. historisch-aktuellen Bedeutsamkeit, in verschiedener Besetzung in Bereitschaft hält. Ganz selten, etwa in den höchsten Graden sachlicher Vertiefung oder aber sexueller Erregung, ist für den Hintergrund so wenig seelische Kraft verfügbar, daß selbst der Gefahrenschutz versagt. Im durchschnittlichen Erleben bleibt viel von der vorhandenen Kraft im seelischen Hintergrund; nur dort, wo wir anstrengend uns bemühen, sei es in körperlicher Arbeit, sei es im geistigen Schaffen, sei es im anschauenden Aufgehen, wird der Vordergrundsanteil größer, der des seelischen Hintergrundes bescheidener. Dieser Verteilungsschlüssel wechselt von Augenblick zu Augenblick; er ist zudem in seiner Variationsbreite vom Gesamtzustand (Frische und Erschöpfung) abhängig und von Mensch zu Mensch in erheblichem Maße verschieden. Beim Denken sprechen wir hier von Konzentrationsfähigkeit, die eine außerordentlich große wie auch eine so geringe sein kann, daß der Hintergrund nur wenig dunkler ist als der Vordergrund, und die vor allem auch in ihrer Dauer beim einzelnen wie von Mensch zu Mensch den größten Schwankungen unterliegt. 
Ein sehr wesentlicher Teil normaler seelischer Nöte wie seelischer Störungen kommt dadurch zustande, daß ständig mehrere unvereinbare Triebziele gleich bedeutsam um den Vorrang kämpfen und eine Vereinheitlichung vorübergehend oder auf die Dauer unmöglich machen. Insbesondere die Forderungen des Sexualtriebes wie jene des Geltungstriebes können die einheitliche Entwicklung nach wertvolleren Lebenszielen hin stören.

Ist mithin auch beim Menschen alles Erleben triebhaft, so besteht doch ein sehr wesentlicher Unterschied gegenüber dem höheren Tier darin, daß bei uns die triebhaften Zuwendungen ganz vorwiegend auf den inneren Bahnen des Denkens und Anschauens abgebremst und nicht zum äußeren Tun werden. Die Rudimente des äußeren Handelns bleiben aber im Ausdruck, im weitesten Sinne des Wortes, faßbar, nicht bloß im Sprechen, das schon eine Art äußeren Handelns darstellt, sondern auch in Mimik und Pantomimik und in jeder Form rudimentärer motorischer Entäußerung. So wissen wir, daß etwa die Belichtung eines Auges eine tonische Gesamtänderung des Körpers herbeiführt, ohne daß es zu eigentlicher Zuwendung kommen muß. In der Regel aber bringen alle Sinneseindrücke, die sich durch ihre Stärke oder ihre vitale Bedeutsamkeit vom Hintergrund abheben, Zuwendungen auch motorischer Art mit sich, sei es auch nur Augenbewegungen, Anspannung des Trommelfells usw., ganz abgesehen davon, daß jeweils auch das gesamte vegetative System auf die Eindrücke anspricht.

Im Vordergrund des Seelenlebens führt die Abbremsung des Tuns zu einer klareren Gegenstandserfassung, im Hintergrund aber zur Gesamtreaktion des Gefühls. Entspricht der Gesamtheit des Hintergrundes die jeweilige Stimmung, die vom Körperzustand, von der Nachdauer von Erlebnissen usw. entscheidend beeinflußt wird, so läßt sich davon jeweils ein dem Gegenstand angepaßtes besonderes Gefühlserlebnis unterscheiden. In diesem fehlen nie Regungen der Lust oder Unlust; deutlich werden aber meist auch Regungen der Spannung oder Lösung, der Erregung oder der Beruhigung, die teils der Stimmung entstammen, teils vom Gegenstand in spezifischer Weise ausgelöst werden, je nachdem er zum Handeln drängt oder umgekehrt, je nachdem er triebhafte Spannungen verstärkt oder aber zu deren Lösung beiträgt. Besonders starke Gefühle bezeichnet man als Affekte. Über all dies in eigenem Zusammenhang mehr.

Vom triebhaften Handeln her gesehen entspricht alles Geistige einer Bremsung, vom Geistigen her, das auf ein restloses schauendes Aufgehen oder aber denkendes Nachschaffen der Welt ausgeht, alles Handeln einem Kurzschluß.

Je unreifer das Seelenleben, also in der frühen Kindheit und beim primitiven Menschen, um so eher setzen sich triebhafte Zuwendungen im Handeln durch, um so rascher löst ein Triebziel das andere ab. Mit der Reifung des Seelenlebens wächst die Fähigkeit, das Handeln zu verhalten; um so fester und stetiger werden zugleich die Ziele. Im Verein damit wandeln sich die vorwiegenden Triebgegenstände selbst. Bleiben die vitalen Ziele auch im reifen Alter immer lebendig, so bestimmen doch die von den Beziehungen zu den Mitmenschen kommenden Forderungen und die Aufgaben der denkenden Nachschaffung der Welt immer entscheidender die Bühne des Erlebens. Nicht mehr in triebhaftem Angriff oder angstvoller Flucht, nicht mehr in 
geradlinigem Zugriff oder triebhaftem Fortschieben, vielmehr immer mehr im Rahmen der Gemeinschaftsforderungen und der Aufgaben, die von gegenständlichen Sachverhalten ausgehen, geschehen die zunehmend bewußten, willentlichen Zuwendungen, bald mehr im Sinne der Selbstbehauptung, denkend, gestaltend, handelnd, bald mehr in jenem der Selbsthingabe, schauend, fühlend, widerhallend. Immer häufiger vollzogen werden diese Zuwendungen zu Gewohnheiten, die nun auch ohne willentliche Anstrengung verbindlich bleiben und stetig nach einer klaren und fast automatisch wirksamen Rangordnung den Alltag bestimmen. Die seelischen Kräfte werden damit für immer neue Ziele verfügbar. Mit dem Alter, bald früher, bald später, versiegt das seelische Wachstum; Neues wird immer weniger zum Erstrebten; alte starrer werdende Gewohnheitseinstellungen beherrschen den seelischen Apparat; die Sexualziele verschwinden, ja vielfach kommt es zum Aufgeben aller Ziele jenseits der vitalen Forderungen des Alltags, lange bevor das eigentliche Altern beginnt.

Unterschiede in der Stärke der Triebkräfte überhaupt (verfügbare seelische Energie), der Gradausprägung der einzelnen Triebe, der Fähigkeit zur Vereinheitlichung wie zur Bremsung bedingen einen wesentlichen Teil der Charakter- und Persönlichkeitsunterschiede.

Es gibt allgemein triebschwache (asthenische) wie triebstarke (sthenische) Menschen, wobei je nach der relativ vorherrschenden Neigung zur Selbstbehauptung oder Selbsthingabe und je nach dem dominierenden Triebgebiet wiederum ganz verschiedene Persönlichkeiten zustande kommen. In pathologischen Ausprägungen kennen wir asthenische Menschen mit Neigung zur Selbstbehauptung als gewisse Typen der Unechten, der Lügner und Schwindler, der "Nervösen ${ }^{66}$, während die nicht egoistischen Asthenischen gern zum willenlosen Spielball aller Arten von Einflüssen, vor allem fremder Menschen werden. Sthenische werden zu Tyrannen, Organisatoren, Führern und Propagatoren fremder Werte oder aber zu Menschen, die sich bedingungslos einordnen und in ihren Pflichten aufgehen.

Je nach dem vorherrschenden Triebgebiet finden wir die Typen der Frau und des Mannes im idealen Sinne, des bequemen Genießers wie des materielle Werte erraffenden Machthungrigen, des dienenden Bruders oder des von der Karitas Geprägten wie des tätigen Menschenfreundes, des Bücherwurms oder ästhetischen Genießers wie des schaffenden Gelehrten, Ingenieurs und Künstlers. Pathologische Persönlichkeitsgestaltungen entstehen bei exzessiven Ausprägungen bestimmter Triebrichtungen, auf sexuellem Gebiete etwa Satyrnaturen und Nymphomane, auf dem Gebiete der Lebenstriebe gewisse Draufgänger wie schwächliche Feiglinge, Lebenshungrige wie Lebensmüde, überwache, allzeit lebendige, und apathische, verschlafene Menschen, auf religiösem Gebiete die Schwärmer, auf ästhetischem die unausgeglichenen Künstlernaturen, auf geistigem die weltfremden zerstreuten Gelehrten. Pathologisch sind aber vor allem auch die Menschen mit Wertlücken, d.h. solche, bei denen bestimmte Triebgebiete überhaupt nicht oder zu schwach entwickelt sind, so etwa bei Fortfall der triebhaften Hinwendung zum anderen die Gemütlosen, und entsprechend die areligiösen Menschen, die musikalischen, bildnerischen Idioten, die bei guten Gaben geistig uninteressierten Banausen.

2 Lange + -Bostroem, Psychiatrie, 3. Aufl. 
An der Fähigkeit zur Vereinheitlichung liegt es, ob es zur Verhaftung der Triebrichtungen in einer bestimmten. Wertskala kommt und somit zur Ausreifung einer geschlossenen Persönlichkeit. Für diese ist kennzeichnend, daß jedes Handeln sich auf dem Hintergrund einer im wesentlichen gleichbleibenden, an bestimmten Werten verankerten, hierarchisch gegliederten ${ }_{9}$ Gesinnung ${ }^{66}$ abspielt, so daß Handlungen nicht mehr möglich sind, die dieser Gesinnung widersprechen. Zu einer festen Gliederung des triebhaften Gesinnungshintergrundes kommt es erst im Laufe der Entwicklung, bald eher, bald später. Solche Persönlichkeiten sind ihrer selbst stets gewiß, auch wenn sie nicht bewußt, nach Abwägung von Motiven handeln. Welcher Art sie auch sein mögen, ihre Mitmenschen wissen, woran sie mit ihnen sind. In der Kindheit und Jugendzeit, aber auch bei vielen Erwachsenen ist dieser Gesinnungshintergrund nicht so fest, stetig und so hierarchisch gegliedert. Ja, völlig ausgereifte Menschen sind recht selten. Beim großen Durchschnitt kann es zu plötzlichen Wandlungen auch im späteren Leben kommen (Bekehrungen, ,gerettete Trinker" ${ }^{6,}$ plötzliches Abbiegen in verbrecherisches Verhalten, seelische Entwurzelung), bald aus anlagebestimmten Verschiebungen der Triebgrundlagen heraus, bald unter dem Einfluß starker Erlebnisse. Im letzteren Falle darf freilich angenommen werden, daß schon vor der Bekehrung (hl. Augustin) im Hintergrund des Erlebens keine Einheitlichkeit mehr da war, daß vielmehr Triebziele allmählich angewachsen waren, die nunmehr bei Gelegenheit eines bestimmten Erlebnisses die Dominante erhielten. Daß aus einem ehedem geschlossenen Menschen plötzlich ein völlig zerrissener wird, kommt nur unter organisch-pathologischen Bedingungen vor. Dagegen kennen wir als abnorme Typen solche, die es niemals zu eigentlichen Gesinnungen bringen, wechselwarme Menschen, bei denen jedes mögliche Triebziel und selbst schon geringe äußere Einflüsse jeweils rasch vorübergehend das gesamte Verhalten bestimmen. Nicht bestimmte Triebziele, nicht ein bestimmter Hintergrund, vielmehr gerade die Veränderlichkeit und Bestimmbarkeit ist für diese Art Haltloser kennzeichnend. Hierher gehören manche haltlose Kriminelle, die dann oft willige Gefängnisinsassen und gute Ehemänner sind, aber auch zahllose Mitläufer auf allen Wertgebieten, „Politiker $^{66}$, die jeweils für die einflußreichste Partei sind, Kunstschwärmer, die immer auf die letzten Neuheiten schwören usw. Unter pathologischen Bedingungen kommt es zur Aushöhlung und zum Zerfall des Gesinnungshintergrundes bei vielen organischen Hirnkrankheiten, vor allem bei chronischen Vergiftungen (Alkoholismus und Morphinismus), aber auch bei arteriosklerotischen und syphilogenen Hirnstörungen, wie im Beginne schizophrener Erkrankungen, in denen allerdings nicht selten die alte Wertskala bewußt in Frage gestellt wird.

Zur Vereinheitlichung kommt es auch dort nicht, wo immer wieder vitale Triebe elementar durchbrechen, die mit dem Gesinnungshintergrund nicht vereinbar sind, so bei manchen sexuell Triebhaften, überhaupt beim sog. impulsiven Irresein. Hier entladen sich dem gesunden Seelenleben und der Habitualverfassung des Betroffenen selbst fremde Triebregungen meist ganz überraschend (Davonlaufen, Brandstiftungen, Kindestötungen). Die Sinnlosigkeit solcher Handlungen, denen kein natürliches Triebziel entspricht, ist kennzeichnend und weist zugleich auf die Genese hin. Es gehört zur seelischen 
Reifung, daß die ursprünglichen Triebziele gewissen Wandlungen unterliegen. Aus der frühkindlichen Zuwendung zur Mutter erwächst jene zu den Mitmenschen überhaupt, und auch in unsere religiösen Haltungen gehen Anteile jener Zuwendung ein. Unsere sexuellen Triebregungen können Einengungen auf ganz bestimmte enge Ausschnitte (fetischistische) erfahren, aber auch diffus werden und sich etwa nicht bloß auf andere und nicht bloß auf ein Geschlecht beziehen, sie können verschmelzen mit Triebkomponenten aus anderen Bereichen (Aggression), und sie können endlich den eigentlichen Gegenstand verlieren und an irgendeinen Ersatz verankert werden (reiner Fetischismus, Sadismus, Onanie). Besonders dort, wo der Triebbefriedigung unüberwindbare Hemmungen entgegenstehen, kommt es zu solchen Entgleisungen (für manche Lustmörder ist etwa die Unfähigkeit zur Sexualentspannung auf gewöhnlichem Wege, für Exhibitionisten und Onanisten jene, zum anderen hinzufinden, entscheidend). Beim impulsiven Irresein ist es wohl vielfach die Abdrosselung triebhafter Kräfte oft sexueller, aber auch anderer Natur durch die den Vordergrund bestimmenden Gesinnungen, welche jenen den normalen Zugang zum Handeln versperrt, sie auf unverständliche Ziele abschiebt und damit ihren Durchbruch erleichtert.

Voraussetzung ist freilich weiter das im ganzen Triebleben herrschende Gesetz, daß durch das Handeln jeweils alle anderen Triebregungen in den Hintergrund gedrängt, und so weit in den Hintergrund verdrängt werden können, daß sie sich im Bewußtsein nicht mehr durchsetzen. Für gewisse Triebziele ist dies bei jedem ausgereiften Menschen notwendig, wenn die soziale Eingliederung gelingen soll. Der dem Kind selbstverständliche Trieb wegzunehmen etwa wird von jedem normalen Erwachsenen verdrängt, ebenso wie meist auch jener zur blinden Aggression, Triebregungen, die höchstens bei besonderen Gelegenheiten sich in einem Strebensgefühl zu erkennen geben mögen. Für den gesitteten Menschen wird ein besonderer Aufwand von ,Verdrängungsenergie ${ }^{66}$, eine habituell stark kontrastierte VordergrundsHintergrundsverteilung dort nötig, wo einzelne dieser Triebregungen nicht so selbstverständlich im Hintergrund des Erlebens verschwinden. Gerade hier kann es zu Fehlhandlungen kommen, wie sie für das impulsive Irresein kennzeichnend sind.

Eine gewisse Verwandtschaft mit diesen Störungen haben auch die Zwangserscheinungen. Hier kommt es zu einem ständigen, nie oder doch in längeren Perioden nicht zu befriedigenden Kampf zwischen der sozialen Eingliederung und den höheren Werten zugewandten und von der Persönlichkeit bejahten Gesinnungen und damit nicht vereinbaren, trotzdem lebendigen Triebregungen. Meist handelt es sich dabei offenbar um abnorme sexuelle Triebhaltungen sadistischer oder anderer perverser Natur. Die volle Verdrängung gelingt nicht; aber es kommt oft zu einer Verschiebung der Triebziele, so daß nunmehr unsinnige und von der Person abgelehnte, aber doch nicht verwerfliche, auch als unsinnig erkannte Strebungen oder Gedanken (Zwangswaschen, Zwangsreinigen, Zwangsioapulse der verschiedensten Art, Zähl- und Kontrollierzwang usw.) hervordrängen. Die Verdrängung des vital bedeutsamen eigentlichen Triebes macht sich zugleich in Angst geltend. Aus der seelischen Gesamtlage, in der nicht selten die eigentlichen Triebregungen noch dunkel bewußt sind, erwachsen dann sekundär 
Zwangsgedanken und -handlungen, die der Abwehr der Angst dienen und aus der Angst vor der Angst entstehen.

Im Bewußtsein und für die Umgebung ohne weiteres kenntlich bleibt jene mangelnde Vereinheitlichung der selbstunsicheren, ewig entschlußunfähigen Psychopathen, die nur gedrängt zu handeln vermögen. Ähnliche Störungen treten vorübergehend auch in endogenen Krankheitszuständen auf.

Endlich kann es bei Menschen, die diesen letzten wie der Gruppe der Zwangsmenschen nahestehen, zu dauernder oder doch lang anhaltender mangelnder Vereinheitlichung dadurch kommen, daß ein Triebziel, das zum Gesinnungshintergrund nicht paßt, sich in einer schwachen Stunde einmal durchgesetzt hat. Diese Entgleisung besteht vor der Wertskala nicht; dennoch entsprechen ihr drängende, meist verdrängte Kräfte aus dem Hintergrund des Erlebens nur allzusehr. Die Erinnerung an die Entgleisung verschmilzt mit jenen drängenden Kräften zu einem dauernden, quälenden Widerpart der vorwiegenden Gesinnung und der dieser Gesinnung entsprechenden Verhaltensweisen. Alles seelische Geschehen wird durch diesen Konflikt vergiftet, der, selbstwertvermindernd, das Aufkommen einer selbstsicheren, im Handeln vereinheitlichten Persönlichkeit unterbindet.

Mit der Ausprägung der Fähigkeit zur Bremsung der Triebregungen überhaupt hängt es zusammen, ob ein Mensch als ,bewußter ${ }^{66}$ oder ,triebhafter $^{6}$ bezeichnet werden darf. Alles Erleben, alles Handeln ist letzten Endes triebhaft, und alles triebhafte Handeln ist im Wachen von Bewußtsein begleitet. Auch beim bewußten Menschen sind die gewöhnlichen Zuwendungen, die Alltags- und Gewohnheitshandlungen, einfache Triebhandlungen; aber bei ihnen kommt es sehr viel häufiger zu einem Abbremsen des vorwiegenden Strebens im Bewußtsein, zu einer Kontrastierung mit möglichen anderen triebhaften Zuwendungen, zu eigentlichen bewußten Willenserlebnissen, als beim triebhaften Menschen, der dabei eine genau so geschlossene Persönlichkeit sein kann. Der Mann ist durchschnittlich bewußter als die Frau, der Erwachsene als das Kind, der Kultivierte als der Primitive. Es gibt aber auch pathologische Ausprägungen bewußter Menschen, bei denen kein Handeln unreflektiert erfolgt, die immer weithin den Hintergrund mobilisieren und bei denen alles Handeln blaß, vermittelt, überlegt, kühl erscheint. Triebhafte Menschen dagegen handeln immer aus dem Augenblick heraus, unmittelbar, oft hemmungslos. Gewisse hypomanische Persönlichkeiten sind hier vor allem ins Auge zu fassen, während den Gegenpol die kalten, bedächtigen, rechnenden Ichmenschen darstellen.

Eine kurze Erörterung über die Entwicklung des Trieblebens wird manches bisher Gesagte noch deutlicher machen. So hat etwa der reife Sexualtrieb eine verwickelte Geschichte. Dem Kind fehlt eine eigentliche Sexualität noch ganz. Aus der Phase der triebhaften, lustvollen Zuwendung zum eigenen Körper und aus der allgemeinen Zuwendung zum anderen Menschen differenziert sich in der weiteren Pubertätszeit auf seelischem Gebiete über eine oft kaum merkliche Durchgangsperiode der Zuwendung zu etwa gleichaltrigen gleichgeschlechtlichen Genossen eine spezifische Zuwendung zum anderen Geschlecht. Mit den gleichgeschlechtlichen Altersgenossen verbindet den Jugendlichen dann zunehmend die Richtung auf gemeinsame sachliche Ziele. Zugleich, ein wenig später oder nachher, erwachsen aus dem Körper 
die spezifischen sexuellen Regungen, die anfänglich, noch wenig zielbestimmt, richtungsunklar, den eigenen Körper zum Ziel nehmen können, aber in der Regel sich bald dem anderen Geschlecht zuwenden, vielfach zunächst noch unverbunden neben jener seelischen Wendung, bis dann beide im gereiften Sexualleben miteinander verschmelzen. Bei diesem komplizierten Entwicklungsgang und den Hemmungen, die der Sexualbetätigung von außen her erwachsen, gibt es zahllose Störungsmöglichkeiten. So kann die sexuelle Erregung sich ganz an den eigenen Körper binden. Auch ohne dies kann sich auf seelischem Niveau jene autoerotisch-narzißtische Komponente entwickeln, die manche eitle, egozentrische Menschen auszeichnet. Während die gereifte Sexualität den Partner nicht bloß als Phantom nimmt, sondern als Geschlechtsgenossen, mit dem die sexuelle Entspannung erstrebt wird, einschließt, bleibt zahlreichen Menschen jenes letzte Triebziel versperrt; autoerotische Tendenzen behalten das Übergewicht und führen unter Umständen zu Störungen des Ablaufes der Sexualhandlung, der Libido und der Potenz. Es kann ferner, vor allem bei Menschen, die auch somatisch heterosexuelle Züge tragen, jene Durchgangsperiode der Zuwendung zum Gleichgeschlechtlichen sich verewigen, so daß es zu klarer Homosexualität kommt; es können sich neben den heterosexuellen homosexuelle Strebungen erhalten, ja, in Andeutungen bleiben sie wohl im Hintergrund des Erlebens recht vieler Menschen lebendig, und schließlich gibt es unbedingt klar ausregulierte, ausschließlich auf das andere Geschlecht gerichtete Persönlichkeiten. Auf dem geschilderten Wege gibt es jedoch noch weitere Klippen. Wie der eigene Körper zum Triebziel werden kann, so vermögen auch Umstände, die nur lose und zufällig mit dem Sexualziel zusammenhängen, das eigentliche Ziel zu verdrängen. So kann etwa die sexuelle Entspannung gebunden werden an äußere Umstände, die zufällig die erste sexuelle Erregung begleiteten (Qualität des ersten Partners, seine Kleidung, spezifische Sinnesreize, starke Erregung, notwendige Aggression, beschämende Umstände, körperliche Mißhandlungen usw.), so daß es zu den verschiedensten qualitativen Abirrungen des Sexualtriebes kommt, allerdings wohl nie ohne eine entsprechende unzureichende Veranlagung. Es entspricht dies ja all dem, was schon oben über die ${ }_{\text {} P \text { Perversion }}$ der Triebziele ${ }^{66}$ überhaupt gesagt wurde.

In sehr ähnlicher Weise kann auch die Entwicklung der sozialen Triebe entgleisen bzw. mangelhaft ausreifen. Die Beziehung zwischen Mutter und Kind bzw. zwischen Eltern und Kind ist es, die ganz vorwiegend die erste Entwicklung der sozialen Regungen bestimmt. Die Mutter ist dem Kleinkind nicht nur allmächtiger Schutz und Erfüllerin aller Wünsche, sondern auch das Objekt der ersten Zuwendung zum anderen überhaupt. Sie ist aber auch die erste, welche die Erfüllung von Wünschen, die Befriedigung von Triebregungen versagen muß. Es kommt zu einem Machtkampf zwischen der Stärke der triebhaften, unreflektierten positiven Zuwendung und Bindung des Kindes und den feindseligen aggressiven Regungen, welche die Versagung hervorruft. Die Kampfmittel des Kindes (Geschrei, Gekränktsein, Bewegungssturm, Wegbleiben, Trotz, mangelnde Nahrungsaufnahme, Entleerung lediglich in Abhängigkeit von besonderen Vergünstigungen usw.), sie alle verharren in ähnlicher oder wenig abgewandelter Form auch in den Beziehungen zu den anderen Menschen dort, wo der Sieg der positiven 
Zuwendung zum anderen über die Eigenliebe nicht gelingt. Noch mehr als die Mutter, wenn auch in der Regel auf einem anderen Niveau der seelischen Entwicklung, wird der Vater zum Versager von Wünschen, zum Feind, der mächtig und schwer verwundbar ist. An ihm werden die feineren aggressiven Tendenzen entwickelt, die von der bedingungslosen, triebverdrängenden passiven Unterordnung bis zum kalten Haß gehen, aber auch die erste unreflektierte, dann immer bewußtere positive Bindung. In dieser Auseinandersetzung werden alle wesentlichen Züge der Triebhaltungen lebendig, die im späteren Leben verharren und den Umgang mit den Mitmenschen bestimmen. Kaum weniger wichtig sind die Beziehungen zu älteren und jüngeren Geschwistern. Es sei aber betont, daß Mutter und Vater wie Geschwister ersetzt werden können durch andere Pflegepersonen und Gefährten. Gewiß sind für diese Entwicklung die Gefährten und Pfleger in ihrer besonderen Art von nicht unerheblicher Bedeutung; welche Entfaltung die sozialen Triebe der Jugendlichen erfahren, wird aber vor allem bestimmt durch das, was in der Anlage enthalten ist. Über die Anteile beider - der Anlage wie der Entwicklungsphantome - herrscht nach wie vor der Streit. Jedenfalls erscheinen auch im späteren Leben Eltern und Geschwister oder deren Ersatz als die Modelle, die für die Verhaltensweisen anderen Menschen gegenüber bestimmend sind.

Auch die triebhafte Zuwendung zur Welt kann entgleisen. Wir bemächtigen uns der Welt im Handeln und auf dem Umwege über das abgebremste Handeln in inneren und äußeren nachbildenden und darstellenden Denkhandlungen. Schon früh in der Kindheit lernt das Kind die volle Triebbefriedigung durch angedeutete Nachbildung zu ersetzen (Finger im Mund oder Zulp an Stelle von Mutterbrust und Flasche). Immer oder doch in jedem reflektierten Erleben müssen wir später die Triebziele gedanklich vorwegnehmen, um den Weg zu ihrer Erreichung zu finden. Bei Fortbestehen oder Überwuchern jener Neigung zur Ersatzbefriedigung durch gedankliche Vorausnahme in Phantomen kommt es zu unfruchtbaren Wachträumereien, bei egoistischen, geltungssüchtigen Menschen aber zu Lüge und Großtun, Schwindel und Betrug, auf sexuellem Gebiete zur bildbelebten Onanie, beim gedanklichen Nachschaffen zu wirklichkeitsfremden Ideologien, kurz, allenthalben zu Scheinbefriedigungen, wobei bald mehr die Umwelt getäuscht, bald mehr auf Kosten des echten Selbstwerterlebens gesündigt wird. In pathologischen Zuständen, dort, wo auch der Apparat versagt, entstehen so Wahnbildungen und Sinnestäuschungen, die übrigens mit dem Traume, einem vom Standpunkt des Wacherlebens her pathologisch anmutenden Geschehen, Berührungspunkte haben.

Sind es gerade Unterschiede und Anomalien des Trieblebens, welche die Fülle der Charaktere und der psychopathischen Persönlichkeiten kennzeichnen, so bleibt auch keine tiefergreifende seelische Erkrankung ohne Einfluß auf das Triebleben. Schon jede körperliche Krankheit, die das Allgemeinbefinden überhaupt beeinträchtigt, stört das Triebleben entscheidend. Eine allgemeine Abschwächung der nach außen gerichteten Zuwendungen ist die Folge, ein Zurückziehen der Triebenergien auf die lebenserhaltenden und schützenden seelischen Regungen (Abwehr jeder Belastung); mit 
zunehmender Krankheit werden aber auch dieseRegungen gradweise abgebaut. Jede Beeinträchtigung der das Leben tragenden Atmungs- und Herzfunktionen bringt Angst mit sich, jene undifferenzierte affektive Verfassung, die jede Behinderung und Bedrohung vitaler Triebe begleitet (auch bei der Behinderung der sexuellen Triebe ist Angst häufig).

Ausgebreitete Hirnerkrankungen, insbesondere Vergiftungen, pflegen in den höheren Graden gleichfalls eine Herabsetzung aller Triebregungen, bis zu deren Erlöschen, mit sich zu bringen. Im übrigen kommt es auf Art und vorwiegenden Angriffspunkt der Gifte an, ob diese oder jene Triebregungen gehemmt oder enthemmt werden. Morphin etwa hemmt vorwiegend die vitalen Triebe, und durch deren Minderung lassen sich auch die Veränderungen in den übrigen Zuwendungsbereichen erklären (erleichterter Gedankenfluß bei unzureichender Vordergrunds-Hintergrundsbildung). Der Alkohol hemmt demgegenüber in geringeren Vergiftungsgraden ganz vorwiegend die höheren Triebfunktionen, während die vitalen Triebe enthemmt werden.

Bei lokalen Hirnerkrankungen haben vor allem Schädigungen des tiefen Hirngraus (insbesondere Encephalitis epidemica) sehr ausgesprochene Folgen für das Triebleben. So kommt es besonders im Kindesalter zu einem Übermaß an Antrieb überhaupt, zu Drangzuständen, die sich in impulsiven, ungebremsten Entladungen auf den verschiedensten Gebieten (überstürzte Zuwendungen jeder Art, soziale Fehlhandlungen, Gewalttätigkeiten, sexuelle Entgleisungen) äußern. Beim Erwachsenen leidet umgekehrt der Antrieb generell, so daß eine Reduktion schon der einfachsten Zuwendungen, und nicht bloß Akinese (Ausfall an spontanen Handlungen), sondern Hypobulie (Verarmung des Willens) überhaupt eintritt, die freilich vereinzelt durch impulsive Akte unterbrochen werden kann. Auch verbirgt sich hinter der vermeintlichen Leere nicht ganz selten eine gestaltlose Unruhe, die gelegentlich in primitivem Bewegungsdrang offenkundig wird.

Auch Schädigungen des Stirnhirns haben eine besonders ausgesprochene Wirkung auf das Trieb- und Willensleben. Bilder allgemeiner Stumpfheit und Abulie (Willenlosigkeit) finden sich neben solchen, in denen es bei Verlust der höheren Triebregungen zur Enthemmung niederer Triebe kommt, und es scheint im Stirnhirn außerdem jene Stelle zu liegen, welche die Gewichtsverteilung der Gesinnungsgrundlagen wie die richtige VordergrundsHintergrundsbildung des Seelenlebens überhaupt garantiert. Bei Störungen im Stirnhirn kann es so zu Entgleisungen auf den allerverschiedensten Leistungsgebieten, bei der Eingliederung und Reproduktion von Erinnerungsmaterial wie beim Denken, beim Werten und Handeln kommen. So sehen wir Kurzschlußhandlungen, Taktlosigkeiten, mangelnde Ernstwertung, mancherlei soziale Entgleisungen. Es kann endlich vom Stirnhirn her eine vorwiegende Enthemmung vitaler Triebregungen eintreten (sexuelle, Entleerungsimpulse, Heißhunger). Bei Zerstörung des größeren Teiles beider Stirnhirne verfügt der Kranke noch, wenn auch launenhaft, über seinen gesamten geistigen Erwerb, ja er kann geistreich sein, aber immer nur dann, wenn er Handlungen verteidigt, die aus den allein übrig gebliebe asozialen und sexuellen Triebregungen (dabei Impotenz) entstam Brickner). 
Ganz allgemein gilt für gröbere Hirnerkrankungen, daß sie eine Reduktion der höheren Triebregungen, die zu allgemeiner Stumpfheit und Verarmung führt, gleichzeitig mit einer Enthemmung vor allem der erregenden und aggressiven Affekte mit sich bringen. Es handelt sich hier, wie es scheint, um vorübergehende Stauungen nicht verwertbarer Triebenergien, die dann plötzlich einmal elementar hervorbrechen.

Die Störungen der übrigen Hirnapparate werden besser in anderem Zusammenhange besprochen.

Auch die endogenen Seelenstörungen verändern das Triebleben. In den manischen Erregungen finden wir eine Steigerung aller Triebregungen, eine erhöhte Ansprechbarkeit, der eine geringere Nachhaltigkeit und ein rascher Wechsel parallel gehen. In der klassischen Manie sind nicht nur die vitalen Triebe gesteigert (Sexualität, allgemeiner Tätigkeitsdrang), auch auf höherem seelischen Niveau finden wir quantitativ ein Plus in der Ideenflucht und der erleichterten Auslösung aller Zuwendungen. Dem entspricht eine erhöhte Handelnsbereitschaft. Persönlichkeitsunterschiede bringen es mit sich, daß die allgemeine Enthemmung sich äußerlich in recht verschiedener Weise darstellen kann; es scheinen aber auch qualitative Unterschiede im körperlichen Krankheitsgeschehen Einfluß auf die Symptomgestaltung zu haben.

Ganz im Gegensatz zu den manischen Erregungen finden wir in Verstimmungen aller Art, besonders aber in der endogenen Melancholie, eine Hemmung aller Triebregungen, insbesondere der vitalen Triebe selbst; es ist, als ob dem gesamten Seelenleben - und übrigens auch vielen vitalen, nicht bewußtseinsfähigen Funktionen - eine unzureichende Energie zur Verfügung stände. Wir sehen daher eine allgemeine, alle Einstellungen betreffende Hemmung, wobei im übrigen, ganz wie in der Manie, qualitativ fremde Triebregungen nicht hervortreten und auch der Zusammenhang des Seelenlebens nicht zerreißt. In der Regel kommt auch das, was die ursprüngliche Persönlichkeit ausmacht, zu klarem Ausdruck, so daß also die Gesinnungen ebenso wie die Rangordnung der Triebziele keinen sichtlichen Schaden leiden.

Ganz anderes sehen wir bei den schizophrenen Erkrankungen. Auch hier gibt es freilich allgemeine Erregungen wie allgemeine Hemmungen, aber bei den ersteren bleibt nicht mehr der Zusammenhang mit der alten Persönlichkeit gewahrt; persönlichkeitsfremde, leere, sinnlose Impulse herrschen vor (sog. impulsive Akte), leere und vertrackte Bewegungen, die keine Handlungsansätze mehr bedeuten (Parakinesen), ausdrucksnahe Bewegungsabläufe ohne entsprechende seelische Erlebnisse treten auf und kehren immer in der gleichen Form wieder (Stereotypien). Zugleich werden Bewegungen, Sprache und Gestik unnatürlich (Manieren), ein Zeichen dafür, daß wahrscheinlich auch dem Gesunden fremde Triebhaltungen bei den Schizophrenen eine Rolle spielen. Dies gilt auch für die häufigen Grimassen, die in der Regel nicht mehr auf die Umgebung berechnet erscheinen. Bei den schizophrenen Zuständen von Reglosigkeit - St u por - ist die Sperrung vielfach nicht allgemein. Sie betrifft oft nur den Bewegungsapparat oder große Teile desselben (so können etwa Handbewegungen, kann das Sprechen freibleiben); es ist, als ob jeder Bewegungsantrieb erloschen wäre; auch die Schließmuskeln können den Dienst versagen. Oder aber es kommt zwar nicht zu Bewegungen, 
aber die gesamte Muskulatur ist gespannt; jeder passiven Bewegung wird ein ,triebhafter", vielfach offenbar nicht bewußter Widerstand entgegengesetzt (schlaffer, gespannter, negativistischer Stupor). Dabei kann hier und dort ein reiches, wenn auch schizophrenes Gedankenleben stattfinden; manche natürlichen Zuwendungen können plötzlich den schlaffen Stupor wie die allgemeine Spannung durchbrechen usw. Gelegentlich fehlen alle Sprachantriebe (Mutismus), oder sie werden abgesperrt, wie denn überhaupt der Negativis mus, d.h. die triebhafte Verneinung natürlicher Regungen wie äußerer Anregungen, in der Schizophrenie eine wesentliche Rolle spielt. Beim Fehlen aller spontanen eigengeformten Willensregungen kann es zu Echoerscheinungen kommen, triebhaftem Wiederholen wahrgenommener oder vorgemachter Bewegungen oder sprachlicher Äußerungen (Ech opraxie, Echolalie), oder mitten aus dem Negativismus heraus wird jeder Anregung plötzlich haltlos nachgegeben (Befehlsautomatie, blindes Beibehalten passiv gegebener Stellungen), gelegentlich mit dem Symptom der wächsernen Biegsamkeit (Flexibilitas cerea), eines Muskelverhaltens, das neurologisch einem leichten Rigor ähnelt. Das Modell des Negativismus haben wir in der individuellen Entwicklungskurve im kindlichen Trotz, der offenbar für die Willensbildung von großer Bedeutung ist und ebenso sinnlos, leer, ,triebhaft", elementar erscheinen kann wie der Negativismus der Schizophrenen. Hier wie bei den Stereotypien (auf sprachlichem Gebiete kennen wir neben den Stereotypien auch die Verbigeration, länger dauernde sinnlose sprachliche Produkte, die stereotyp wiederkehren oder in denen doch sinnlose Stereotypien immer wiederkehren) könnte man an die Enthemmung von Triebregungen bzw. Triebgewohnheiten denken, die, in der individuellen Entwicklung von vitaler Bedeutsamkeit, im reifen Seelenleben aber längst höheren Trieborganisationen Platz gemacht haben. Ihr Hervortreten würde also einem Abbau dieser höheren Organisationen entsprechen:

Mit solchen Annahmen kommen wir nicht aus bei den Manieren, bei manchen impulsiven Akten, vor allem aber bei vielerlei inneren Erlebnissen der Schizophrenen, die dafür sprechen, daß dem Gesunden allzeit fremde Triebregungen durch den Krankheitsprozeß erst geschaffen werden. Wir sehen nicht nur, daß normale Triebziele in fremdartiger Weise erstrebt werden oder daß ihnen abnorme Affekte entsprechen, wir hören auch, daß es plötzlich zu einer Umkehrung der Triebrichtungen mancherlei Gegenständen gegenüber kommt, daß Strebungsgefühle an früher Abgelehntes sich knüpfen und umgekehrt. Vor allem aber wissen wir aus dem inneren Erleben des Kranken, daß die Gesinnungen sich verändern, lange ehe dies nach außen erkennbar wird, daß eine katastrophale oder schleichende Verschiebung der Wertskala erfolgt, daß allmählich Wertlücken immer deutlicher und schließlich vorwiegend Dinge angestrebt werden, die der früheren Persönlichkeit des Kranken völlig fremd sind. So erlöschen nicht selten die positiven Bindungen an die Mitmenschen, besonders an die allernächsten, am ehesten, es kommt zu einer Verschiebung und später meist zu einer Verarmung der geistigen Triebe, ja oft erleiden auch, vielfach auf vertrackten Umwegen mit Verschiebung der Triebziele, die vitalen Regungen eine zunehmende Einbuße. Im geistigen Leben ersetzen immer mehr die gedanklichen Vorwegnahmen das wirklichkeitsentsprechende Denken. Das Handeln erlischt, während bei fast allen 
Schizophrenen diese oder jene Triebregungen und Strebungen in seltsamer Weise unberührt stehenzubleiben scheinen oder sogar eine wesentliche Verstärkung erfahren (tadellose oder übertriebene äußere Formen bei totalem geistigem Verfall, isolierte positive Zuwendungen zu Dingen und Einzelpersonen bei sonstigem Erkalten). Auch bei günstigem Verlauf, dort, wo das geistige Weltbild als solches nicht oder doch nicht merklich Schaden leidet, wo sozial eine volle Regulation gelingt, sehen wir Veränderungen im Triebleben, Umstellungen, Verarmungen, Verschiebungen der Persönlichkeit und der Wertgebiete bei Schizophrenen doch regelmäßig. Die Schizophrenie schafft offenbar hier zuerst und auch am entschiedensten erhebliche Wandlungen.

Manche negativistische Erscheinungen, die Flexibilitas cerea, viele Parakinesen gleichen klinisch Störungen, die man bei groben Hirnerkrankungen als Gegenhalten (Kleist), Rigor, choreiforme und athetoide Bewegungsformen wiederfindet. Hier verschwimmt die Grenze zu den neurologischen Erkrankungen nicht nur insofern, als in der äußeren Erscheinung keine Unterschiede mehr bestehen; vielmehr werden solche Bewegungen mitunter auch erlebt, wie die neurologischen Zwangsbewegungen, Krämpfe, choreatische und athetotische Erscheinungen, die dem Streben keinen Raum lassen bzw. überhaupt nur als Geschehen konstatiert werden. Hier zugleich wird die Grundlage aller triebhaften Regungen deutlich, denen immer Motorisches beigeordnet ist und die sich der außerbewußten Reflexmechanismen bedienen. Ja, bei manchen Reflexen, beim Gähnen, Husten, Räuspern, beim Saugreflex, beim Schlucken, beim Blinzeln usw. kann man fragen, ob sie zu den einfachen Reflexvorgängen, deren Ablauf bemerkt, oder zu den triebhaften Mechanismen gehören, deren Entstehen von spezifischen Erlebnissen begleitet ist. Alle diese ${ }_{\text {,Reflexe }}^{66}$ haben bald mehr den Charakter des Triebhaften, bald mehr des Reflektorischen. Einzelne Reflexe bekommen nachträglich, wie die Entleerungsreflexe, einen triebhaften und schließlich willkürlichen Überbau oder aber sie verlieren den Reflexcharakter völlig wie das Saugen, oder aber sie werden aus triebhaften Geschehnissen nachträglich zu einfachen Reflexen wie das Blinzeln. Aber nicht nur hier verschwimmen die Grenzen. Wir kennen Menschen, die ihre Pupillen willkürlich verengern und erweitern können usw.; manche Koordinationsleistungen haben bald reflektorischen, bald ganz vorwiegend triebhaften Charakter. Kurz, die ganze niedere Motorik ist an das Triebhafte eng geschaltet.

Mit ihr zugleich das vegetative Geschehen, auch soweit es die Muskeln betrifft. Ich verweise hier auf das eigenartige Korrelat, das die Antriebsverarmung in der Muskelstarre findet. Aber auch sonst sehen wir Vegetatives eng mit dem Triebhaften verbunden. Wir erleben die rein körperlichen Sexualspannungen, aus denen das triebhafte spezifische Streben erwächst; wir wissen, wie unser Bewegungsdrang weitgehend von der vegetativen Gesamtverfassung abhängt; wir kennen die Abhängigkeit des Trieblebens von den Drüsen innerer Sekretion (Reizbarkeit und Erregbarkeit bei Basedow, Torpidität, Apathie bei Myxödem, allgemeiner Triebverfall bei Addison, Triebverarmung bei Hypogenitalismen, Wertverschiebungen bei gewissen Hypophysenerkrankungen). Zugleich ist unzweifelhaft, daß mit Einstellungen aller Ârt nicht nur vaskuläre Veränderungen an einzelnen Orten einhergehen, 
sondern daß Blutverschiebungen im ganzen Körper stattfinden, daß bei erregenden Vorkommnissen, aus denen Angriff oder Flucht triebhaft erwachsen, das ganze sympathische System mobilisiert wird, wie umgekehrt mit dem Schlaftrieb Umstellungen im parasympathischen Apparat erfolgen. Wir kennen die enge Abhängigkeit gewisser Drüsenleistungen von triebhaften Einstellungen wie beim Weinen und beim Appetit (Magensaft, Speichelabsonderung) usw. und wir wissen, wie auch hier die Grenzen zwischen triebgekoppelten vegetativen Reflexmechanismen und bewußtem Ingangsetzen dieser vegetativen Leistungen wenigstens bei manchen abnormen Menschen (einzelne vegetativ Stigmatisierte) verschwimmen (willkürliches Tränenvergießen, willkürliche oder doch autosuggestive Blutverschiebungen und Änderungen der Gefäßdurchlässigkeit usw.). Kurz, es besteht nicht nur eine enge Koppelung seelischer Mechanismen an körperliches Geschehen, sondern allenthalben ein Verschwimmen der Grenzen, sei es in der individuellen Entwicklung, sei es bei besonderen Persönlichkeiten habituell, sei es unter dem Einfluß von eigentlichen Krankheitsvorgängen. So kennen wir beim Abbau höherer Leistungen ein erneutes Hervortreten des Saugreflexes (ausgebreitete organische Hirnerkrankungen) und des Greifreflexes: hier wird das im ausgereiften Leben willkürliche oder triebhafte Greifen wieder zum reinen Reflexgeschehen, ähnlich wie bei rein neurologischen Erkrankungen mit dem Abbau höherer Zusammenordnungen niedere, sonst verdeckte Reflexmechanismen wieder zutage treten. In ähnlicher Weise haben wir uns das Auftreten gewisser Bewegungsstürme beim Hysterischen (Wut, Strampeln, hysterische Anfälle) oder das triebhaft-vegetative Bewegungsgeschehen bei anderen hysterischen Anfällen, wo der Koitusreflexmechanismus leerläuft, und das Zustandekommen mancher Stuporen nach Art des Totstellreflexes bei Tieren vorzustellen, nur geschieht hier die Ausschaltung von Hemmungen auf seelischem Wege. Bei den gleichen Kranken (sog. Hysterischen) sehen wir auch nach dem Vegetativen hin die Grenze der willkürlich-triebhaften-autosuggestiven Einflüsse sich erweitern (autosuggestive Hautblutungen, Stigmatisationen, Erröten und Erblassen, Beeinflußbarkeit von Magen und Darmmotilität, der Menstruation, des Hautturgors usw.).

Endlich sei noch das Verschwimmen der Grenzen bewußten bzw. triebhaften Tuns zum reinen Reflexgeschehen für das alltägliche motorische Tun beleuchtet. Einmal in Gang gesetzt, können wir fortgehen, ohne dies auch nur im leisesten zu beachten, ja zu bemerken. Wir atmen, ohne in der Regel davon zu wissen, und nur Behinderungen des Atmens lassen Triebhaftes aufleuchten. Selbst bei den klarsten, vom eigentlichen Willenserlebnis begleiteten Vordergrundsbildungen geschieht, abgesehen von der Bewegungseinleitung, das Motorische von selbst, ja, wenn wir die Aufmerksamkeit auf die einzelnen Teilakte richten, stören wir sie eher, als daß wir sie fördern. Die meisten komplizierten Bewegungen können wir in vollem Bewußtsein triebhaft ablaufen ' lassen, wie wir sie zu anderen Zeiten rein reflektorisch, ohne jede Bewußtseinsbegleitung, höchstens mit nachträglicher Konstatierung geschehen sehen. Der wesențiche Teil des motorischen Handelns spielt sich außerhalb jeden Bewußtseins ab, auch jenes Handeln, das anfänglich mühselig, Schritt für Schritt. Griff für Griff, gelernt werden mußte. Davon ist später mehr zu sagen. 


\section{b) Störungen der Affektivität}

Triebbefriedigung bringt seelische Erlebnisse lösender, beruhigender, lustvoller Art mit sich, Triebhemmung dagegen bedeutet neben Spannung und Erregung, die dem Anwachsen der Triebenergien und der Bremsung im Motorium entsprechen, Unlust und Angst. Die Gefühle der Lust und Unlust hängen also in engster Weise mit dem Triebleben zusammen; sie haben aber auch eine mehr oder weniger klare gegenständliche Seite insofern, als sie den Triebzielen zugewandt sind und von ihnen ihre besondere Färbung bekommen.

Die gegenständliche Seite tritt freilich ganz zurück bei den psychiatrisch wichtigsten affektiven Erlebnissen, den Vitalgefühlen, die offenbar die seelische Seite des jeweiligen vegetativen Gesamtzustandes sind, zugleich aber aus dem großen Reservoir der Triebkräfte überhaupt schöpfen, dem noch undifferenzierten Antrieb, der in alle motorischen Abläufe und alle Zuwendungen eingeht. Unbehinderter Ablauf der Antriebe bedeutet Lust, freie, rasche Bewegung ein Gefühl glückhafter Leichtigkeit, während umgekehrt Hemmung des Antriebs von unlustvoller Spannung begleitet ist. Die Vitalgefühle bzw. das Vitalgefühl, das den vegetativen Gesamtzustand widerspiegelt, speist ganz vorwiegend den gefühlsmäßigen Hintergrund unseres Erlebens, die Stimmung.

Auf dem Hintergrund der Stimmung spielen sich mannigfache Gefühlserlebnisse, gewissermaßen in anderen Schichten, ab. Am lebhaftesten sind jene „sinnlichen“ Gefühle, die den empfindungsmäßigen Anteilen unserer Wahrnehmungen zugeordnet sind. Hierher gehören die gefühlsmäßigen Anteile der protopathischen Sensibilität (Schmerz, Temperatur). Überhaupt scheint der Hautzustand sehr wichtig für das Gefühlsleben. Demnächst sind von besonders deutlichen Gefühlswirkungen die Empfindungen der niederen Sinnesorgane, und von den höheren sind die spezifisch sinnlichen Qualitäten, Helligkeit, Farben, ausgesprochene Tonhöhen und Lautstärken, wirksamer als alles, was den höheren Gestaltaufbau bedingt.

Hier kommen wir schon in den Bereich der mit geistigen Vorgängen verbundenen $\mathrm{G}$ efühle. Von ihnen erscheinen durchschnittlich am lebhaftesten jene, die aus unseren Beziehungen zu anderen Menschen erwachsen. Gefühlsvorgänge verbinden sich auch mit unseren eigentlichen geistigen Innenvorgängen. Sind die geistigen Gefühle durchschnittlich den vitalen und sinnlichen an Einfluß unterlegen, so können sie doch in vital weniger bewegten Zeiten und beim ausgereiften Menschen nicht selten auf eine gewollte Umstellung hin beim Denken wie beim schauenden Aufgehen etwa in einem Kunstwerk eine große Lebhaftigkeit gewinnen, den Bewußtseinsraum ausfüllen und nachhaltig im Stimmungshintergrund widerhallen. In der geistigen Schicht treten zugleich Gefühlscharaktere hervor, die in der vitalen fehlen: Wärme, Innigkeit, Schwere, Tiefe, Regungen, die unsere triebhaften Zuwendungen zu Werten begleiten.

Alles Gefühlsmäßige steht in außerordentlich engem Zusammenhang. Die vitale Stimmung ist im allgemeinen dafür entscheidend, für welche Gefühlsregungen aus anderen Schichten wir besonders zugänglich sind; ja sie drosselt nichtverwandte Gefühle aus höheren Schichten vielfach ab. Die für 
die Lebenssicherung wichtigen sinnlichen Gefühle freilich setzen sich auf jedem Stimmungshintergrund durch, soweit nicht pathologische Verhältnisse in Frage kommen. Die Stimmung kann aber ihrerseits durch starke Gefühlserlebnisse der geistigen und vor allem sinnlichen Schicht entscheidend beeinflußt werden.

Besonders lebhafte Gefühlsregungen, in denen unerledigte Triebkräfte sich anmelden und die zur Entladung im Handeln drängen, bezeichnet man als Affekte. Sie sind die dem Handeln zugewandte Seite der Affektivität. Bei ihnen sind auch die körperlichen Begleiterscheinungen, die sich bei allen Gefühlen nachweisen lassen, besonders lebhaft, nämlich die Einflüsse auf Atmung und Herzschlag, die Ausdrucksbewegungen und die Tendenz zur Vereinheitlichung der Gesamtmotorik in der Zuwendung. Ja, die Affekte haben für das Seelenleben etwa die Funktion, wie die Stellreflexe für das Bewegungsgeschehen, sie vereinheitlichen und richten den seelischen Gesamtapparat. Sie finden auch einen starken Widerhall in dem an sich ungerichteten vitalen Stimmungshintergrund. Threm dem Handeln zugewandten Charakter entspricht es, daß im primitiven Seelenleben eine scharfe Trennung zwischen Affektausdruck und Handeln nicht mehr möglich ist. Unsere Ausdrucksbewegungen sind Rudimente von Triebhandlungen.

Dem „stellenden" Widerhall im Körperlichen entspricht die Wirkung der Affekte auch auf die gegenständliche Seite des Bewußtseins. Alle dem auslösenden Erlebnis gleichsinnigen und affektverwandten Inhalte erfahren eine Förderung, alle entgegenstehenden werden gehemmt, so daß gerade die Affekte die Vereinheitlichung der Person zum Handeln vorbereiten und dadurch ihre Triebnähe verraten.

Alle auftauchenden Inhalte zeigen zudem nur die affektverwandte Seite. So wird unsere gesamte gegenständliche Welt durch die Affekte nachhaltig beeinflußt, am deutlichsten Gedächtnis und Erinnerungen, mit denen die Affekte noch wesentlich freier schalten als mit den Wahrnehmungen. Die Bedeutung der Affekte wird gesteigert dadurch, daß sie die auslösenden Ereignisse überdauern. So wirken sie entschiedener auf die Stimmung zurück und erleichtern die vorstellungsmäßige Wiederkehr der Ereignisse. Auf der anderen Seite können sie sich so auch an Gegenstände knüpfen, die nicht in innerer Beziehung zu den auslösenden Ereignissen stehen. Gerade dadurch werden Verdrängungen erleichtert und kommen die Verschiebungen zustande, die schon beim Triebleben besprochen wurden.

Die Unterschiede der Persönlichkeiten prägen sich bei dem nahen Zusammenhang zwischen Triebleben und Affektivität auch in Art, Grad und Skala der Affizierbarkeit aus, ja, man kann diese Unterschiede ebensogut von der Seite der Affektivität wie von jener des Trieblebens her betrachten. Insbesondere die Wertlücken kann man als Mängel der Affizierbarkeit ansehen (Fehlen moralischer, ästhetischer Gefühle usw.). Es ist natürlich, daß Menschen mit ausgesprochener Triebhaftigkeit bei starker Bremsung besonders lebhafte Gefühlserlebnisse haben müssen usw. Hier kann ganz auf die Behandlung des Trieblebens verwiesen werden.

Alle Krankheitsvorgänge, welche das Triebleben in Mitleidenschaft ziehen, haben entsprechende Wirkungen auch auf die Affektivität. Eine besondere Besprechung erfordern hier nur die Störungen der Vitalgefühle, 
die im Bereiche der Seelenstörungen eine außerordentlich wichtige Rolle spielen. Thre Art ist zunächst einmal kennzeichnend für viele Persönlichkeiten aus diesem Bereich. Es gibt Menschen, die dauernd dysphorisch, depressiv, andere, die lebhaft, heiter sind und solche, deren Vitalgefühl dauernd ein ruhiges, lustvolles ist, wobei weitere Unterschiede davon abhängen, ob die verwandten Affekte weniger oder mehr gebahnt werden und wie weit die Beeinflußbarkeit des vitalen Stimmungshintergrundes durch Gemütsbewegungen geht. Durch ausgezeichnete vitale Grundstimmungen charakterisierte Persönlichkeiten kommen vor allem im Bereiche des manisch-depressiven Irreseins als Hypomelancholische und Hypomanische vor.

Im vitalen Stimmungshintergrund machen sich schon alle körperlichen Krankheiten bemerkbar, und gleich dem Triebleben wird auch durch Gifte das Vitalgefühl vielfach in spezifischer Weise verändert (Alkohol-, Morphineuphorie).

Endogene Seelenstörungen, vor allem wiederum das manisch-depressive Irresein sind am deutlichsten gerade in den Einflüssen auf die Vitalgefühle zu fassen: so macht den Stimmungshintergrund der Melancholie eine schwere, tiefe Trauer, jenen der Manie eine eigenartige Euphorie aus, deren besondere Färbungen durch Art und Grad der Triebhemmung und -erregung bestimmt werden. Gerade hier fließen Vitalgefühl und Triebhaftigkeit eng zusammen, so daß es gleichgültig erscheint; ob man die Gesamtverfassung von der Trieboder von der Affektseite her charakterisiert.

Auch im übrigen kann im wesentlichen auf die Ausführungen über die Triebe verwiesen werden. Es muß aber hervorgehoben werden, daß qu alit a tiv abnorme Gefühls- und Affekterlebnisse, vor allem aus der seelischen und geistigen Schicht, häufig bei schizophrenen Erkrankungen und bei den symptomatologisch verwandten Degenerationspsychosen vorkommen: Gefühlserlebnisse des Begnadetseins, eigenartige Glücks- und Grauenserlebnisse, Erlebnisse des Klarsehens, des Gequält- und Getroffenseins. Ähnliche Gefühlsregungen scheinen auch einige Alkaloide mit sich zu bringen, die in jüngster Zeit eingehend untersucht wurden (Meskalin, Haschisch).

Ein sehr wesentlicher Teil unserer Triebregungen muß abgebremst werden, und zwar um so mehr, je reifer wir werden. Daher überwiegen im späteren Leben die depressiven Gemütsregungen. Das Kind ist durchschnittlich heiterer als der Erwachsene, der Primitive als der Kulturmensch, die Frau als der Mann. Depressives überwiegt ferner zunehmend, wenn es nicht gelingt, die Triebenergien zu ,sublimieren ${ }^{6}$, d.h. solchen Wertgebieten zuzuwenden, in denen Triebbefriedigung möglich ist. Wir sind aber auch dem äußeren Schicksal preisgegeben und damit notwendig Geschehnissen ausgesetzt, die uns plötzlich wesentliche Triebziele nehmen (Tod geliebter Menschen, äußere Hindernisse in Lebensplänen usw.). Unharmonische Menschen, die in besonderem Maße Triebbehinderungen ausgesetzt sind, überwiegen zudem die harmonischen. Wäre nicht letzten Endes der ursprüngliche, anlagegemäße, vitale Hintergrund, der die Erlebniswirkungen übertönt, entscheidend, so würde der Habitualzustand wohl aller Menschen ein depressiver sein. Im krankhaften Seelenleben spielen jedenfalls depressive bzw. Unlustaffekte eine außerordentlich viel größere Rolle als euphorische. Schon traurige Erlebnisse rufen, um so stärker, je verwandter der vitale Hintergrund ist, langdauernde 
tiefe Verstimmungen bei vielen Menschen hervor. Hier ist von entscheidender Bedeutung die Beeinflussung des Stimmungshintergrundes selbst. Eine Verschiebung der Stimmung nach der dysphorischen Seite hin taucht auch alle anderen Erlebnisse in ein entsprechendes Licht. Dazu kommt, daß auch alle affektverwandten Erinnerungen eine Förderung erfahren. Abnorme langdauernde Depressionen gehören zu den häufigsten krankhaften Vorkommnissen. Naturgemäß sind es Versagungen auf vitalen Gebieten, die besonders leicht solche Verstimmungen herbeiführen: Verlust von Liebeszielen, Enttäuschung im Liebesleben, Gefangenschaft, Berufskonflikte, Sorgen, aber auch Schwierigkeiten, die aus dem Zusammenleben mit unseren Mitmenschen erwachsen: fortdauernder Streit, mangelnde Anerkennung, Ehrenkränkungen, Kränkungen des Rechtsbewußtseins, endlich bei geistig gerichteten Menschen Störungen im gedanklichen Schaffen, Enttäuschung bei großen mit Hoffnung begonnenen Arbeiten. Eine vergiftende Wirkung haben aber vor allem auch beschämende Entgleisungen, Zurückbleiben hinter dem gesteckten Ziel, unlösbare Triebkonflikte, die als mit depressivem Affekt geladene „Komplexe ${ }^{66}$ in den Stimmungshintergrund eingehen, allzeit bewußtseinsfähig bleiben und gierig alles Affektverwandte an sich ziehen oder aber, gewaltsam verdrängt, auf allen möglichen Nebenwegen als Zwänge, als impulsive Entladungen und Fehlhandlungen usw. zum Durchbruch kommen.

In anderer Weise kann bei entsprechend veranlagten Persönlichkeiten eine quälende Versagung zu immer stärkerer Affektspannung führen, die dann blind in wilden motorischen Akten sich entlädt (Zuchthausknall, plötzliche Gewalthandlungen, Suizide, Heimwehdelikte, Brandstiftungen, Kindstötungen usw.).

Hier allenthalben begegnen wir einer Bereitschaft der Affekte, sich über das veranlassende Erlebnisbereich auszudehnen und an alles anzuknüpfen, was nur irgendwie affektverwandt erscheint. Dabei kann das ursprüngliche Erlebnis selbst ganz zurücktreten, ja aus dem Bewußtsein verschwinden, „,verdrängt ${ }^{66}$ werden. Wir kennen Ähnliches aus den Zuständen der „Gereiztheit" und Reizbarkeitdes Alltagslebens. Veranlassung ist hier oft ein Erlebnis, das nicht handelnd verarbeitet werden kann, so daß entladungsbereite Triebenergien in den Hintergrund gedrängt werden. Gerade diese machen den dysphorischen Affekt zu einem, „gereizten ${ }^{66}$. Aus dieser Gesamtverfassung heraus kommt es zu Aggressionen, oft nur im Ausdruck, mitunter im Handeln, meist jedoch nur im gedanklichen Geschehen, die alles in Mitleidenschaft ziehen, was nur irgend affektverwandte Noten anschlägt. Es ärgert uns dann alles. Dies kommt in noch viel ausgesprochenerem Maße in krankhaften Zuständen, vor allem wieder aus dem Bereiche des manisch-depressiven Irreseins (Mischzustände), aber auch bei der Schizophrenie und den organischen Psychosen vor. Gerade bei den letzteren geht infolge von Apparatestörungen manche aggressive Triebenergie in den Hintergrund ein, um unvermittelt bei allen möglichen Gelegenheiten zum Durchbruch zu kommen. 


\section{c) Störungen des Gegenstandsbewußtseins}

\section{Störungen der Wahrnehmung. Sinnestäuschungen}

Jeweils nur jener Ausschnitt der Umwelt, auf den wir uns einstellen, auf den wir unsere Aufmerksamkeit richten, erscheint uns klar, deutlich und räumlich und zeitlich durchsichtig gegliedert. Dem Hintergrund, von dem sich dieser Ausschnitt abhebt, fehlt die Klarheit, Deutlichkeit und Gliederung des Vordergrundes, wenngleich auch dort Abschattungsgrade bestehen. Bei intensiver Einstellung auf Optisches etwa bleiben die zahllosen Sinnesempfindungen der Körperoberfläche, des Geruchs, des Geschmacks, ja auch des Gehörsinnes in einem wenig strukturierten Dunkel. Sie sind aber gleichwohl da und jeder biologisch wichtige Sinneseindruck kann aus dem Dunkel plötzlich hervortauchen und uns nun völlig in Anspruch nehmen, ein anwachsender Schmerz ebenso wie eine Geruchsempfindung oder ein Anruf mit dem eigenen Namen, der leiser sein kann, als die uns sonst umgebenden Geräusche. Bei den höchsten Graden der Aufmerksamkeit kann der gesamte Hintergrund so sehr abgedunkelt werden, daß wir ,zerstreut" erscheinen, d.h. daß auch wichtige Dinge unsere Aufmerksamkeit nicht an sich ziehen. Die ,Zerstre uth eit " ist nur die andere Seite jener „Fess elung“6 der Aufmerksamkeit, die uns in pathologischem Maße bei manchen schizophrenen Psychosen begegnet.

Das gegenständliche Rohmaterial unserer Wahrnehmungen, die Empfindungen, liefern uns die Sinnesorgane, jene der Haut, Geruch, Geschmack, Gehör und Gesicht, also Tast-, Wärme-, Kälte-, Schmerz- usw. Eindrücke. Doch erhält dieses Rohmaterial offenbar schon in den Sinnesendstätten selbst eine gewisse Gliederung, am wenigsten deutlich die Eindrücke der Hautsinnesorgane, am klarsten jene von Gesicht und Gehör. Dabei haben die Eindrücke der niederen Sinne die klarsten Beziehungen zum Affektleben (Schmerz ist ebenso Gefühl wie Empfindung), und in den Hintergrund des Erlebens gehen die Eindrücke der niederen Sinnesorgane viel stärker mit ihrer affektiven Resonanz, als in ihrer gegenständlichen Natur ein. Dennoch empfinden wir einen Tasteindruck, es sei denn bei besonderer Einstellung, nicht einfach als solchen, sondern als Tasteindruck an dieser bestimmten Stelle der Körperoberfläche, ebenso einen Schmerz, und den meisten Empfindungen an der Körperoberfläche und von unseren Gelenken her sind zudem Bewegungen unmittelbar zugeordnet. So spielt sich die komplizierte Gleichgewichtsregulation meist ohne jede Bewußtseinsbeteiligung und ohne jede ,aktive" Zutat ab. Auch manche Signalreize erreichen nur eine niedere Bewußtseinsstufe; sie lösen unmittelbar sinnvolle Bewegungen aus : wir jagen eine Fliege fort, fassen nach einer schmerzenden Stelle, schütteln uns usw., ohne daß unsere Aufmerksamkeit merklich in Anspruch genommen wird. Kurz, die vitalen Eindrücke der niederen Sinne haben eine sehr nahe Beziehung zum Motorium.

Anders bei den höheren Sinnen: unsere Gesichtseindrücke sind räumlich klar durchstrukturiert. In ihnen sind Bewegungen gewissermaßen abgefangen, gebremst. Bei röhrenförmigem Gesichtsfeld müssen wir die Stelle des deutlichsten Sehens um die Konturen der Gesichtsdinge herumführen, um ihre Gestalt zu erfassen. Für die Eindrücke des normalen Auges sind diese, unter 
gewissen pathologischen Bedingungen notwendigen Transportbewegungen in eine simultane Gestalt gebannt. Ähnliches sehen wir bei der Gestalterfassung von der Hand her; auch hier ersetzen die Lokalzeichen die möglichen Bewegungen. Störungen, welche die Sinnesflächen wie die Bahnen zu den primären Sinnesendstätten im Hirn befallen, lassen diese primären Gestalten zerfallen, oder sie führen zu verzerrten Gestalten neben Sinneserlebnissen, die einen qualitativ von den gewöhnlichen Wahrnehmungen abweichenden Charakter haben (Wahrnehmungsanomalien). Tasteindrücke etwa bekommen eine kalorische Note oder erscheinen als einfache kalorische Reize überhaupt ohne räumliche Zuordnung. Farben fließen über die Konturen hinåus, Ungefärbtes erscheint in Farben und umgekehrt, räumliche Beziehungen verzerren sich, Gegenstände werden zu groß (Makropsie) oder zu klein (Mikropsie) oder verzerrt (Dysmegalopsie) gesehen; sie erscheinen bei normaler Größe zu fern (Porropsie), zu intensiv oder zu matt.

Die Ausschnitte der Umwelt, denen wir uns zuwenden, sind aber nicht bloß qualitativ, räumlich und zeitlich gestaltete Sinneskomplexe, sie werden vielmehr für uns zu Gegenständen, d.h. sie bekommen eine ganz bestimmte Bedeutung, fordern in ganz bestimmter Weise zum äußeren oder inneren Handeln heraus; kurz, sie haben einen biologischen Stellenwert. Daß überhaupt und welche Sinneskomplexe sich als Gegenstände herausheben, hat offenbar zunächst mit allgemein biologischen Zielen, sodann aber mit unserer Erziehung zu tun. Das Tier hat überhaupt nur Gegenstände von hoher biologischer Bedeutsamkeit, und auch diese nur in bestimmten Situationen. So erkennt etwa die Spinne die Fliege nur im Netz, während diese außerhalb des Netzes einfach zum Fluchtreflex führt. Die anfliegende Biene findet den nur wenig verschobenen Eingang zum Stock nicht, sie ist in starkem Maße an die komplexe Situation gebunden usw. Der Mensch hat unendlich mehr Zuwendungsbereitschaften; schon die Sinnesendflächen liefern reichere Gliederungen; vor allem aber hebt die Sprache zunächst gleichbleibende, dann ähnliche, dann bedeutungsverwandte Sinneskomplexe der allerverschiedensten, umfassendsten Art mit gleichbleibenden Zeichen heraus, so daß praktisch alles sinnesmäßig Erfaßbare oder ursprünglich so Vermittelte zum Gegenstand zu werden vermag. Der gegebene Sinneskomplex wird also zum Gegenstand als Inbegriff möglichen, ganz bestimmten Tuns, und durch die Sprache zugleich jederzeit erweckbar und handlich. Wir sehen hier wieder jenen Erfolg des aufgeschobenen Handelns, das uns allenthalben, so eben noch bei der Einrichtung unserer höheren Sinnesorgane selbst, begegnete. Zugleich wird deutlich, daß Gegenstände, d. h. die Inhalte unserer Wahrnehmungen, nicht mehr bloß ein Sinnesorgan angehen, sondern immer den ganzen Menschen, und daß sie in ihrer Gestalt nicht nur den aktuellen Menschen, sondern zugleich dessen Entwicklung und gesamte Vergangenheit voraussetzen.

Den aktuellen Menschen insofern, als je nach der augenblicklichen Verfassung und dem augenblicklichen Ziel jeweils bestimmte, von Augenblick zu Augenblick aber wechselnde Seiten eines Gegenstandes hervortreten: Mein Bücherschrank etwa kann von mir bald wahrgenommen werden als braun und breit und vielfächerig, bald als Arbeit aus eingelegter Birke, bald als soeben erst bezahlt, bald - dem Möbeltischler - als gute oder schlechte, 
nachahmenswerte oder reparaturbedürftige Arbeit, dem Botaniker als Inbegriff des Wissens um Pflanzengeographie und Wachstumsbedingungen der Birken usw. Hier wird zugleich deutlich, daß auch Erziehung und Geschichte jedes einzelnen eine wesentliche Bedeutung schon für die Wahrnehmung zukommt. Dem Urwaldbewohner wird ein Bücherbrett ganz einfach als Gegenstand aus Holz erscheinen, der freilich, zunächst wenigstens, seine Neugier erregt.

Daß all dies möglich ist, setzt Gedächtnis voraus, und für die Einordnung anschaulicher Gegenstände eine besondere Form von Gedächtnis, die Vorstellungstätigkeit. Jeder Sinneseindruck hinterläßt eine Spur, hat eine mnemische Wirkung, wie überhaupt alles, was irgendeine Reaktion an unserem Körper auslöst. So führt die Infektion etwa zu einer Neueinstellung des Organismus, welche die Reinfektion abändert; so werden unsere Muskeln geübt, so geht eine komplizierte Bewegung bei Wiederholung leichter vonstatten usw. Eine Wirkung sehr ähnlicher Art ist es offenbar, daß wahrgenommene Gegenstände eine Spur hinterlassen, die wir beleben können in einer Vorstellung. Der Gegenstand erscheint dabei nicht im Raum draußen, im Wahrnehmungsraum, sondern in uns, im Vorstellungsraum; wir können ihn verlebendigen, und bei großem Bemühen erreichen wir, daß in der Vorstellung Anschauliches, Empfindungsmäßiges sehr lebhaft anklingt. Die Fähigkeit, solche anschaulichen Vorstellungen zu erzeugen, wechselt von Person zu Person, vor allem aber mit dem Lebensalter. Es gibt Menschen mit sinnlich sehr lebhaften Vorstellungen, etwa optischer, andere mit solchen akustischer Art. In der Jugend scheint die Bereitschaft zur Entwicklung wahrnehmungsnaher Anschauungsbilder, die sich aber doch in Einzelheiten von den Wahrnehmungen unterscheiden (so durch willkürliche Veränderlichkeit oder aber durch mangelnde Farbentreue und Erscheinen in einem anderen als dem Wahrnehmungsraum), besonders ausgeprägt zu sein, und bei manchen Typen scheint sie auch in der Adoleszenz, ja im erwachsenen Alter fortzudauern (Eidetik; Jaensch, je nach der Art der Anschauungsbilder sollen. zugleich bestimmte Beziehungen zur vegetativen Beschaffenheit bestehen, willkürlich wandelbare Bilder beim Basedowoiden, starre, farblose beim Tetanoiden). Die Fähigkeit zur Produktion solcher lebhaftester Anschauungsbilder kann gelegentlich, etwa bei Schizophrenen, auch in schizophren gefärbten Paralysen, wieder hervortreten, und zwar neben der Bereitschaft zu eigentlichen Trugwahrnehmungen.

Beim gesunden Erwachsenen sind die Vorstellungen durchschnittlich sinnlich wenig lebhaft, dadurch aber, insbesondere wieder unter Mithilfe der Sprache, besonders beweglich. Ihr bewußtes Auftauchen spielt nur beim eigentlichen Wiedererkennen eine Rolle, das zustande kommt, wenn Wahrnehmung und eine halb vergessene Vorstellung sich decken. Aber auch im übrigen sind die Vorstellungen, wenn auch weniger aufdringlich, für die Wahrnehmungsvorgänge von außerordentlicher Bedeutung. So nehmen wir etwa Farben weithin nicht nach ihren wahrnehmungsmäßigen Merkmalen, sondern nach ihrem Vorstellungscharakter wahr (Gedächtnisfarben); so sehen wir den perspektivisch verzeichneten Gegenstand ohne Rücksicht auf das Netzhautbild, so nehmen wir "Größen" ohne Rücksicht auf die Größe der Netzhautbilder wahr u. a. m. Vor allem aber ergänzen wir unsere Wahrnehmungen weithin 
durch Vorstellungsbestandteile, und unser Erinnerungsbesitz durchdringt in einem Maße die aktuelle Wahrnehmungswelt, daß wir uns in der Regel keine Rechenschaft davon geben. Foerster und Loewy haben etwa gezeigt, daß wir in bestimmten Restitutionsstadien von Sensibilitätsstörungen dort, wo soeben nichts oder nur undifferenzierte Sinneserlebnisse zustande kamen, plötzlich tadellose Angaben machen, wenn wir vorher vorstellungsmäßig (es kommt warm oder kalt) eingestellt sind.

Besonders deutlich wird der Einfluß der Vorstellungen, wo sie unsere Wahrnehmungen verfälschen, ,illusion ${ }^{6}{ }^{66}$ umgestalten. Beim Lesen übersehen wir zahlreiche Druckfehler und ergänzen fehlende Worte. Insbesondere gestaltet die Erwartung, eine bestimmte Person auftauchen zu sehen, die Wahrnehmungsbilder auch sehr unähnlicher Menschen um, oder sie macht einen beliebigen akustischen Reiz zum Namensanruf (Unaufmerksamkeits- und Erwartungsillusionen). Vor allem aber hat der Affekt die Wirkung, unsere Wahrnehmungen illusionär umzugestalten. In der Nacht sind ängstliche Menschen geneigt, jeden Baumstumpf zum drohenden Strolch, jedes Geräusch in sich annähernde Gefahren umzuillusionieren. Bei starken Massenaffektwirkungen kommt es unter Umständen selbst zum gemeinsamen Illusionieren ganzer Gruppen von Menschen (Engel von Mons). In stärkstem Maße können krankhafte Affekte die Illusionsneigung erhöhen. So hört der ängstliche, von Selbstvorwürfen geplagte Melancholische aus den Reden seiner Umgebung, ja sogar aus seinem eigenen Herzschlag Vorwürfe heraus, so deutet er ein Geräusch im Nebenzimmer als Rasseln der Gefängnisketten oder als Vorbereitungen zu seiner wohlverdienten Hinrichtung (Affektillusionen). Illusionen sind also verfälschte Wahrnehmungen; sie setzen tatsächliche Wahrnehmungen voraus.

Unsere Vorstellungstätigkeit kann zwar sehr verschieden lebhaft sein, auch bei großer anschaulicher Lebendigkeit aber behalten wir das Bewußtsein, daß wir vorstellen, daß es sich um Eigenleistungen handelt, selbst dann, wenn sich affektbeladene Vorstellungen unliebsam vordrängen und sich nicht oder doch immer nur vorübergehend verscheuchen lassen. Auf jeden Fall bleibt uns das Bewußtsein der Freiheit. Dies geht verloren bei den sog. Pseudohalluzinationen. So sind die hierher gehörigen "Truggebilde" vieler Schizophrener oft von großer sinnlicher Lebendigkeit, und in dieser Beziehung wahrnehmungsnah oder sogar -treu. Zugleich bleibt das Bewußtsein erhalten, daß es sich nicht um eigentliche Wahrnehmungen handelt, sondern um Gebilde, die sich im Eigenraum abspielen. Vom Willen sind sie aber nicht abhängig. Sie erscheinen vielmehr nach Gesetzen, die außerhalb der Wirkungsbreite bewußter Einstellungen liegen, und sie haben infolge ihres sinnlich lebhaften Charakters oder ihrer affektiven Eindringlichkeit eine Wirkung auf Denken und Handeln, die bloßen Vorstellungen in der Regel abgeht. Gerade Schizophrene leiden in besonders ausgeprägtem Maße an solchen Pseudohalluzinationen des Gesichts, aber auch des Gehörs. Im Gegensatz zu den Illusionen setzen die Pseudohalluzinationen also keine Wahrnehmungsvorgänge voraus; es handelt sich vielmehr um Produkte des krankhaften Vorstellungslebens, die auch ihren Inhalten nach den Stempel des Gesamtzustandes tragen. Manche Pseudohalluzinationen haben nur eine geringe sinnliche Lebendigkeit, andere dagegen sind in dieser Beziehung so 
lebhaft wie Wahrnehmungen, ja sie können sinnlich besonders eindringlich sein. Gelegentlich lernen Kranke Bedingungen herzustellen, in denen Pseudohalluzinationen besonders leicht auftauchen oder auch verschwinden. Das Fremdartige, Wahrnehmungsnahe und im einzelnen Undirigierbare bleibt jedoch auch dann.

Krankhafte Produkte der Vorstellungstätigkeit können schließlich auch Wahrnehmungscharakter erhalten, also leibhaftig werden, wie unsere Wahrnehmungen, und in den Außenraum verlegt werden, so daß die Kranken tatsächlich nicht Vorhandenes wahrzunehmen meinen. Daß es solche falschen Wahrnehmungserlebnisse, echte Halluzinationen, gibt, ist zu Unrecht bezweifelt worden. Sehr viele Gesunde kennen aus den Perioden vorm Einschlafen her optische und akustische Erlebnisse, die bis in das volle Erwachen hinein von Wahrnehmungen ununterscheidbar bleiben, wenngleich die Korrektur durch das Urteil meist gelingt. Vor allem aber beweisen die Erfahrungen Amputierter an ihren Phantomgliedern unzweideutig, daß es unter Umständen zur Wahrnehmung der abgesetzten Glieder kommt, die so lebendig und so treu ist, daß aus diesen halluzinatorischen Erlebnissen heraus grobe Fehlhandlungen entstehen. Freilich sind hier mannigfache pathologische Bedingungen nachweisbar : vom Stumpf gehen tatsächlich Reize aus; der Gliedverlust ist von großer affektiver Bedeutsamkeit; zur vollen Täuschung und zu Fehlhandlungen kommt es offenbar nur, wenn die Aufmerksamkeit anderweitig in Anspruch genommen ist. Endlich zeigt das Phantomglied bei Beachtung Merkmale, die dem intakten Glied nicht zukommen : es wird etwa verkürzt, nur in einzelnen Teilen, an den Rumpf herangerückt, kurz, irgendwie anders erlebt. Das ändert nichts an dem Wahrnehmungscharakter des Erlebens.

Auch die Halluzinationen der Kranken sind inhaltlich vielfach von affektiver Bedeutung, und sie haben in dieser oder jener Hinsicht nach ihrer sinnlichen Lebhaftigkeit oder ihren räumlichen Verhältnissen, oder in der Eigentümlichkeit der Erscheinungsweise, nicht selten Merkmale, die dem Kranken gestatten, sie von den gewöhnlichen Wahrnehmungen zu unterscheiden. Ganz ähnlich wie beim Phantomglied mögen ferner pathologische Bedingungen schon in den peripheren Sinnesorganen und in den primären Endstätten im Hirn gegeben sein, wie wir insbesondere nach den ausgedehnten Meskalinversuchen der letzten Jahre vermuten dürfen. Endlich sind die Halluzinanten selbst nicht einfach normale Menschen, ihr gesamtes Erleben ist pathologisch; auch ihre Wahrnehmungen selbst mögen sich von jenen Gesunder unterscheiden ebenso wie ihr Denken. Dennoch kann nicht fraglich sein, daß echte Halluzinationen, die man nicht anders denn Wahrnehmungen ohne Objekt nennen kann, bei seelisch Kranken eine wesentliche Rolle spielen, insbesondere bei Schizophrenen, aber auch in den Halluzinosen bei Syphilis, bei Paralyse und bei Vergiftungen durch Alkohol und Kokain.

Hier sind zu nennen die „Stim men ${ }^{66}$ vieler Schizophrener, die bei klarem Bewußtsein und voller Besonnenheit, Wort für Wort, mit bestimmten Klangcharakteren, aus bestimmten Entfernungen usw. gehört werden können. Gleiches begegnet uns bei den Halluzinosen im engeren Sinne. Auch optische Halluzinationen, die den Hintergrund verdecken, farbentreu und gehörig in den Raum eingeordnet sind, kommen, wenn auch seltener, vor. Das gleiche haben wir auf dem Gebiete des Geruchs und Geschmack sowie für manche haptische 
Erlebnisse anzunehmen, wenngleich es hier überall schwer ist, Illusionäres auszuscheiden. An dem halluzinatorischen Charakter der „Stimmen ${ }^{66}$ wird dadurch nichts geändert, daß sie bei manchen Kranken nur auftauchen, wenn besondere Vorbedingungen erfüllt sind, also etwa neben den Stimmen, klar davon unterschieden, das Tropfen der Wasserleitung gehört wird (sog. Reflexhalluzinationen). Auch das unter Umständen unsichere Realitätsurteil ändert nichts an dem Wesen der Erscheinungen.

Im einzelnen Falle kann es freilich schwer sein, Illusionen, Pseudohalluzinationen und echte Halluzinationen voneinander zu scheiden; ja, mit dem Wort "Stimmen" werden von den Kranken manchmal auch Erlebnisse benannt, die einen eigentlichen Wahrnehmungscharakter nicht mehr haben, sondern eigenartige unanschauliche Gedankenprodukte darstellen, den Wahrnehmungen insofern ähnlich, als sie, wie diese, von außen, ,gemacht ${ }^{66}$, nicht als Produkt des eigenen Denkens erscheinen.

Endlich werden mit Halluzinationen oft verwechselt Produkte der spielerischen Phantasietätigkeit der Kranken, die bewußt undeutliche Wahrnehmungen zum Ausgangspunkt wählen (Pareidolien). Auch der Gesunde kann in wirre Tapetenmuster, in graue Gemäuer, in die Wolkenbildungen am Himmel Phantasiegebilde wechselnder Art hineinsehen. Jedermann hat dies in Krankheitszuständen schon getan. Auch der Schizophrene benützt nicht selten solche Gelegenheiten, seiner krankhaften Phantasie, die durch eine besondere Sinnesansprechbarkeit unterstützt werden mag, freies Spiel zu lassen und Pareidolien zu erleben, die er dann spielerisch als tatsächliche Wahrnehmungen erklärt oder die er nachträglich in der Erinnerung mit Wahrnehmungen verwechselt.

Von dem bisher erwähnten Sinnestrug sind zu unterscheiden jene Sinneserlebnisse, die in Zuständen veränderten Bewußtseins zustande kommen. Der Gesunde erlebt Ähnliches in seinen Traumbildern und in den sog. hypnagogen Halluzinationen, d.h. den bildmäßigen Erlebnissen am Rande des Schlafes. Alle diese Erscheinungen, vor allem die Traumbilder, haben nicht den Charakter von vollen Wahrnehmungen, denn es fehlt in ihnen etwas sehr Wesentliches, nämlich der Bezug auf ein wohlstrukturiertes Ich, das im Traum mehr oder weniger verloren geht. Zudem sind die Traumbilder bei all ihrer sinnlichen Lebhaftigkeit doch zugleich flüchtig, wandelbar und in ihrem ewig wechselnden Sinn, in ihrer buntschillernden gegenständlichen Bedeutung von den immer irgendwie sinnklaren Wahrnehmungen wohl zu unterscheiden. Traumbilder haben aber auch mit Vorstellungen nicht viel gemein. Wir haben nicht das Bewußtsein der Freiheit ihnen gegenüber, wir sind vielmehr passive Zuschauer, und sie erscheinen nicht im Vorstellungsraum. Endlich sind sie sinnlich viel lebhafter als die gewöhnlichen Vorstellungen. Mehr oder weniger traumähnliche Erlebnisse kennzeichnen vor allem die Delirien, bei denen das Bewußtsein getrübt, die Erfassung der Außenwelt behindert, die Fähigkeit zur Konzentration, zur bewußten Vereinheitlichung aufgehoben oder doch schwer gestört ist. Die Trugerlebnisse der Delirien verschwinden daher auch in den Perioden erhöhter Konzentration, während sie bei weiterem Absinken des Bewußtseins, ganz wie im Tiefschlaf, untergehen. Der Gesamtzustand muß in allen Krankheitsfällen, die zu Sinnestrug führen, berücksichtigt werden. 


\section{Störungen der Begriffe}

Die Vorstellungen können, wie erwähnt, in verschieden starkem Ausmaße anschauliche Elemente enthalten. Je freier sie davon werden, je mehr sie sich von der einzelnen sinnlichen Erfahrung entfernen und zum Kristallisationspunkt des allen entsprechenden sinnlichen Einzelerfahrungen Gemeinsamen werden, um so blasser werden sie, um so mehr werden sie zu Begriffen, d.h. zu Repräsentanten von Bedeutungen, von Anweisungen für mögliches Handeln und Denken, zu. Trägern des Wissens von Sachverhalten. Die Sprache hat bei dieser Entwicklung eine ganz hervorragende Bedeutung insofern, als sie in der stammesgeschichtlichen Entwicklung des menschlichen Denkens wie in jener des individuellen Seelenlebens Kristallisationspunkte schafft, an die das immer klarere Bedeutungsbewußtsein gebunden wird. Das Wort wird zum Repräsentanten des Begriffes, und in unserem Bewußtsein ist das Wort selbst oft der einzige anschauliche Repräsentant tiefgegliederter Sachverhalte, umwittert freilich von den im Begriff verdichteten, zahllos möglichen Anweisungen zu bestimmten Verhaltensweisen in bestimmten Situationen.

Die Entwicklung der Sprache gestattet zugleich, mit den Worten Begriffe einzufangen, die nicht aus unmittelbar Anschaulichem gewonnen sind, sondern Beziehungen zwischen Ich und Gegenständen sowie zwischen verschiedenen Gegenständen, also von vornherein Unanschauliches, zum Inhalt haben, etwa die Beziehungen der Gleichheit und Verschiedenheit, des vorn und hinten, oben und unten, der Zahl, der Wirkung und der Ursache. So wird die Sprache als der große Zeichenträger für Begriffe zu einem außerordentlich beweglichen und plastischen Werkzeug des Denkens, das mit wenig Aufwand gestattet, verwickeltste Zusammenhänge festzulegen, mitzuteilen oder aufzunehmen. Dabei ist von jedem Wort und jedem Begriff aus die Rückkehr zur Anschauung, zur Bilderfülle, die er umschließt, möglich, wie umgekehrt der genaue Weg zum Denken und Handeln aufgezeigt.

Klare Begriffe sind das Kennzeichen hochentwickelten Seelenlebens. In der Kindheit sind die mit Worten vermittelten Begriffe noch lange Zeit eng mit jenen Einzelerfahrungen verbunden, mit denen das Wort zum ersten Male verknüpft wurde. So kommt es, daß etwa das Wort Vater zunächst einmal auf alle ähnlichen, alle großen männlichen Wesen, Anwendung findet und erst allmählich den einen bestimmten Vater bezeichnet, zunächst noch mit jenem Dunstkreis von Zuwendung und Abwehr, ohne die der Vater für das Kind nicht existiert, um endlich zum Träger des Begriffs Vater = Erzeuger zu werden. Bei einem Begriff aber, der eine solche bedeutsame affektive Geschichte hat, ist auch für den Erwachsenen der Weg zur Geschichte des Begriffes noch frei. Tatsächlich reden wir jeden alten Mann gern mit Vater an, den lieben Gott wie den Vorgesetzten, Gegenstände, die einen Teil der mit dem Vater verbundenen Affekte zugleich mit einzelnen gleichartigen, anschaulichen Elementen in sich vereinen.

Die Fähigkeit zur Begriffsbildung ist ferner ein Maß der Intelligenz. Bei Geistesschwachen werden viele höhere Begriffe gar nicht gebildet; die meisten bleiben verschwommen, unscharf; Denken und Handeln bleiben konkret, anschaulich gebunden, kommen von den Ursprungssituationen nicht 
los und führen nicht zu jenen Freiheitsgraden, welche ein reiches Begriffsleben mit sich bringt. Frauen bleiben durchschnittlich in ihrer Begriffsbildung hinter Männern zurück, vor allem affektiv gebundener. Im übrigen gibt es von Mensch zu Mensch starke Unterschiede der Begriffswelt insofern, als der Weg vom Begriff zum Anschaulichen ganz verschieden weit ist. Neben Menschen, die mit Vorliebe in anschauungsfernen Begriffen denken, gibt es solche, deren Begriffe bei aller Sicherheit doch immer anschauungsnah, bildhaft, blutvoll erscheinen (Schizothyme und Zyklothyme). In noch stärkerem Maße als das Kind, das ja in eine hochausgebildete Sprache hineinwächst und damit die Möglichkeiten zu scharfer Begriffsbildung vermittelt bekommt, ist das Begriffsleben wie die Sprache der Primitiven anschauungs-, situations- und vor allem affektgebunden. Hier kann das gleiche Wort ganz Verschiedenes bedeuten, etwa alles, was aus einer bestimmten, immer wiederkehrenden Situation heraus oder unter dem Einfluß von Gebräuchen und Sitten den gleichen Affektwert hat. Wo die Sprache nicht trennt, da fließen auch die Begriffe ineinander. Der gleiche werdende Begriff kann ferner nach den verschiedensten Richtungen hin anschaulich gebunden bleiben (Seele im Kopf, Seele im Herzen, Seele im Bauch), ohne sich lange Zeit von den Anschauungsgrundlagen freimachen zu können. Auch viele unserer Begriffe sind ihre in die Urzeit zurückreichende Geschichte noch nicht losgeworden und zum mindesten noch so affektnah, daß meist jede Klarheit aufhört, sobald nur das Begriffszeichen, das Wort, erklingt (Gott, Seele, Leben usw.).

Der Gesunde erlebt es im Traume, wie der Weg, auf dem Begriffe entstehen, wieder anschaulich und lebendig wird. Im Traum können gänzlich unanschauliche Begriffe sich plötzlich in eine Kette anschaulicher Bilder auflösen. So tritt etwa aus dem Vaterbegriff wieder der Bestandteil des drohenden Riesen hervor. Begriffe werden vom Traum durch Symbole dargestellt, und sie werden wieder zum wirklichen Begreifen. Allenthalben dort, wo es zu traumhaftem Seelenleben kommt, also vor allem in den Delirien, aber auch in der Amentia, finden wir einen ähnlichen Zerfall der Begriffe. Bei klarem Bewußtsein sehen wir einen weitgehenden Begriffszerfall nur im schizophrenen Seelenleben. Hier löst sich nicht selten das Wort gänzlich von seiner eigentlichen Bedeutung ab; es kann gleichzeitig die heterogensten Bedeutungen haben. Auch die Begriffe selbst verändern sich; es bilden sich unter Umständen neue, starre, ganz unverständliche Begriffe, oder aber die Begriffe werden zerfließlich, und bei jedem Mal meint das gleiche Wort ganz Verschiedenes oder es bleibt im besten Fall irgendein affektiver Akzent der gleiche. Es löst sich also weithin, insbesondere gegenüber Menschen und Dingen, die affektiv bedeutsam sind, das Begriffsleben ab von jenen Sachverhalten und Gesetzmäßigkeiten, die vor der Krankheit für die Begriffsbildung verbindlich waren.

\section{Formale Denkstörungen}

Denken ist inneres Handeln. Wir betätigen uns dabei nicht unmittelbar an den Dingen um uns, sondern an den durch gebremstes Tun in uns entstandenen Bildern und deren Residuen und begrifflichen Zuisammenfassungen.

Stellen wir uns darauf ein, nichts innerlich zu tun, nicht zu denken, legen wir uns etwa zum Schlafen nieder, dann bleibt das Bewußtsein nicht 
leer, es beginnt vielmehr eine mehr oder weniger geordnete, schließlich zerfließende Bilderschau: Vorstellung reiht sich an Vorstellung; allmählich treten immer mehr anschauliche Elemente hervor, welche die Vorstellungen wahrnehmungsnahe machen (hypnagoge Halluzinationen), schließlich zerfließen auch diese Bilder in einen ungeordneten Nebel von Fetzen der Anschauung und des Begriffslebens, die einem Chaos gleichen. Im wachen Seelenleben freilich halten bei ähnlicher Bremsung des aktiven Denkens die äußeren und die inneren Bilder zusammen; sie bleiben wirklichkeitsgerecht, und bei näherem Zusehen können wir feststellen, daß sie sich aneinanderreihen nach den "Gesetzen der Assoziation", d.h. Ähnliches, partiell Gleichartiges, schließt sich an Ähnliches; Affektverwandtes taucht nacheinander auf oder an die Anschauung reihen sich Erinnerungen, und eine Erinnerung weckt die andere, die zeitlich oder sachlich eng mit ihr verbunden ist. Bei dieser Bilderschau läßt sich feststellen, daß eigentlich alles Seelische mit allem anderen verbunden, assoziiert ist, daß von jedem Erlebnis der Weg zum anderen frei ist und zugleich, daß eigentlich alles Seelische unter der Oberfläche des Bewußtseins irgendwie lebendig ist, bewußtseinsfähig lebt (s. unten).

Auch bei der bewußten Ausschaltung einer planvollen Direktion der Bilderschau kommt es doch immer wieder zu leisen, bewußten, aktiven Direktiven, ganz abgesehen davon, daß Stimmung, vorangehendes Erleben und Situation wesentlich mit über die Bilder bestimmen, die im Bewußtsein auftauchen. Noch deutlicher wird dieser Einfluß unserer Einstellungen, wenn wir uns etwa vornehmen, an einen bestimmten Kreis von Tatsachen zu denken, etwa an eine Reise. Diese Einstellung braucht vielfach gar nicht bewußt festgehalten zu werden; dennoch werden bei ganz passivem Verhalten nur die entsprechenden Bilder an uns vorbeiziehen. Ganz ähnlich bringen es bestimmte Situationen, in denen wir uns dem Assoziieren überlassen, etwa ein oberflächliches gesellschaftliches Gespräch mit sich, daß bestimmte verpönte Dinge nicht auftauchen, sondern nur "gesellschaftsfähige“".

Kurz, die leiseste Form aktiver Einstellung öffnet das Bewußtsein einem bestimmten Kreis von Bildern und sperrt es für einen sehr viel umfangreicheren anderen. Dies alles geschieht in der Regel durch eine einmalige „Schaltung", die dann selbsttätig weiterarbeitet.

Zum eigentlichen Denken gehört, wie zum Handeln, immer ein Ziel, eine A ufgabe. Von dieser Aufgabe gehen Schaltungen, determinierende Tendenzen aus, die den Zustrom seelischen Materials immer enger machen und nur ganz bestimmtes, zur Aufgabe passendes seelisches Material zulassen, alles andere aber absperren. Je schwieriger die Aufgabe, desto bewußter muß die Sperrung des nicht Zugehörigen erfolgen, desto sicherer muß die Schleuse arbeiten, durch die nur Passendes hindurch soll. Aktives Denken ist also aufgabebewußtes, willentliches Gliedern seelischen Materials zur Erfüllung irgendeines vorausgenommenen Ziels. Reiht sich beim Assoziieren seelisches Material gewissermaßen in der Breite aneinander, so wird es beim Denken in der Tiefe gegliedert. Dabei muß doch, je umfassender die Denkaufgaben sind, ein je weiterer Ausschnitt der äußeren oder inneren Wirklichkeit denkend nachgebildet werden soll, ein desto umfangreicheres seelisches Material mobil gemacht werden. Unsere schwierigen Denkhandlungen gehen nicht 
geradlinig vor sich; vielmehr geschieht im Denken ganz das gleiche, was zur Vollendung einer komplizierten motorischen Handlung nötig ist; wir probieren, machen Bewegungsansätze, verhalten uns vorstellend, wahrnehmend, begrifflich erlebend, bis alles zu allem paßt und die Aufgabe gelöst ist. Ganz ähnlich findet das Infusor in fortdauernden Probierbewegungen die biologisch zweckmäßige Richtung; nur ist beim Denken das Probieren nach innen verlegt.

Zu den höchsten Denkleistungen kommt es nur dort, wo wir neue Sachverhalte zu bewältigen haben, sei es, daß wir bisher nicht Zusammengebrachtes unter einem neuen Begriff sinnvoll zusammenfassen, sei es, daß wir aus einem vermeintlich unlösbaren Ganzen Neues herausnehmen. Binden und Lösen, Synthese und Analyse (Legato-Stakkato) sind die Haupttätigkeiten unseres Denkapparates. Denkleistungen primitiverer Art stecken schon in unseren gewöhnlichen Wahrnehmungen drin; wir spüren sie nur nicht mehr als solche. Etwas höherstehende Denkleistungen kehren auch in unserem gewöhnlichen Alltagsverhalten immer wieder. Meist handelt es sich dabei aber nur um einfache, gewohnheitsmäßige und daher erleichterte Aktualisierung von Wissensdispositionen und um die Anwendung von Begriffen und Regeln, die zu unserem Erinnerungsschatz gehören, wie bei den schwierigeren Rechenleistungen und bei den geistigen Alltagsaufgaben aus dem eigensten Gegenstandsbereich.

Im Bereiche des Denkens gibt es die verschiedensten Störungen. Zunächst einmal kann es gehemmt sein, d. h. unser Bemühen führt überhaupt nicht zum Erfolg oder die Denkergebnisse werden doch verlangsamt, gegen große Widerstände gewonnen. Dabei fehlt auch der zum Denken notwendige Zustrom von Vorstellungsmaterial, das, soweit es auftaucht, zugleich blasser, farbenärmer ist als für gewöhnlich. Wir kennen solche Denkhemmungen vor allem aus depressiven Seelenverfassungen her, am eindringlichsten aus der Melancholie, in der ja jedes Handeln gehemmt wird.

Unter den Denkstörungen wird im allgemeinen auch die Perseveration abgehandelt. Gemeint ist die stete Wiederkehr der gleichen Gedanken etwa bei verblödeten Epileptischen, deren Einstellungen überhaupt durch zähes Haften gekennzeichnet sind. Als Perseveration bezeichnet man aber vor allem auch die stete fälschliche Wiederkehr des gleichen Wortes, der gleichen äußeren Handlung als Antwort auf die verschiedensten Frage- bzw. Aufgabestellungen. Das Bemühen entgleist dabei im Sinne eines einmal zusammengestellten Gelegenheitsapparates, der bei einer vorangehenden Situation sinnvoll und zweckentsprechend war. Dieser Apparat kann nicht abgestellt werden; er bestimmt für kürzere oder längere Zeit allein über das, was geschieht. Solche Perseverationen findet man bei Aphasischen und Apraktischen, überhaupt bei Kranken mit schweren Hirnschäden. Der Aphasische findet also etwa eine Bezeichnung richtig, gebraucht sie fortab aber auch für alle anderen Gegenstände. Dem Agraphischen kommt immer wieder der gleiche Buchstabe in die Feder, obgleich er etwas anderes schreiben will.

Demgegenüber nennt man Stereotypien die triebhafte, sich gegen das bewußte Denken oder außerhalb der eigentlichen Denksituationen durchsetzende Wiederkehr der gleichen, oft sinnlos erscheinenden Gedanken, Worte, Wortbruchstücke, Wortneubildungen, aber auch von leeren Bewegungen und 
eigenartigen Handlungen. Wir haben es hier offenbar mit dem Durchbruch von Iterativmechanismen zu tun, auf denen sich das normale Seelenleben, sie beherrschend, aufbaut. Versagt beim Perseverieren der Exekutivapparat den Dienst bei Menschen, die ganz allgemein verlangsamt sind, so haben wir es bei den Stereotypien mit der Enthemmung tiefer triebhafter Mechanismen zu tun.

Eine Erscheinung organischer Hirnschädigung ähnlich der Perseveration ist die Umständlichkeit. Das geordnete Denken entwickelt von den auftauchenden Inhalten nur jene, die für die Aufgabelösung unerläßlich sind; der Umständliche aber hat jeden Blick für das Wesentliche verloren; er führt jeden auftauchenden, mit dem Thema nur locker verbundenen Inhalt in der ganzen Breite aus; er kommt nicht vom Fleck, ohne doch dabei den Faden zu verlieren.

Demgegenüber speist sich die Weitschweifigkeit aus einem relativen Versagen der determinierenden Tendenzen, einem gesteigerten Äußerungsdrang und der vielfach vermehrten Fülle auftauchender Bilder. Der Weitschweifige ist immer in Gefahr, das Denkziel zu verlieren. Es kommt dabei wie bei der Umständlichkeit, zu einer gewissen , Nivellierung ${ }^{66}$ der Inhalte insofern, als das eigentliche Denkziel abweichend vom gesunden Denken sein Übergewicht verliert.

In stärkstem Maße finden wir eine solche Nivellierung bei der eigentlichen Ideenflucht, die uns gleich der Weitschweifigkeit besonders im manischen Seelenleben begegnet. In den höchsten Graden der Ideenflucht wird jeder auftauchende Inhalt zum neuen Denkziel, so daß es schließlich zum einfach assoziierenden Aneinanderreihen von Inhalten kommt. Jedes Glied wird vom vorangehenden bestimmt und bestimmt von sich aus das nachfolgende. Schon das erste und das dritte Glied haben aber nichts mehr miteinander zu tun. Diese ziellose Gedankenflucht wird bald mehr von flüchtigen Zuwendungen zu äußeren Eindrücken (Ablenkbarkeit), bald aus dem Anstrom innerer Bilder unterhalten. In geringeren Graden der Ideenflucht verlieren die Kranken immer wieder den Faden und das etwa durch eine Frage oder durch einen Vorsatz angeregte Denkziel wird daher nicht erreicht oder doch nur dann, wenn eine unmittelbare Lösung möglich ist.

Als Hypermetamorphose bezeichnet man die triebhafte Zuwendung zu jedem Vorkommnis in der Umgebung, das sich irgendwie aus dem Strom der ständig vorhandenen Eindrücke heraushebt; jeder neue Sinneseindruck wird gewissermaßen zum Signal, erzwingt die Zuwendung auch gegen den Willen des Kranken. Der Hypermetamorphose begegnen wir besonders in schizophrenen Erregungen.

In der Bewußtseinstrübung kommt es im Zusammenhang mit dem traumhaften Begriffszerfall zum sog. ink oh ärent en Denken, das dem widerspruchsvollen Traumdenken gleicht. In das inkohärente Denken gehen sehr häufig ideenflüchtige Elemente ein, um so mehr, je mehr Begriffe und Bilder noch zusammenhalten und je stärker die gleichzeitige Erregung ist.

Schließlich ist das schizophrene Seelenleben durch das zerfahrene Denken, die Zerfahrenheit, gekennzeichnet. Bewußtseinsklarheit bei zerfallenden Begriffen neben solchen, die noch intakt erscheinen, Versagen der Einstellung auf geordnetes Denken überhaupt, abrupter Wechsel des Denkziels, Abgleiten 
auf heterogene Inhalte bei Festhalten des Denkschemas, Starre im Festhalten des Denkziels neben Versagen der determinierenden Tendenzen: all das in buntem Durcheinander und in raschem Wechsel macht das schizophrene Denken bizarr, sprunghaft, unlogisch, chaotisch. Die schizophrenen Entäußerungen werden unter Umständen noch fremdartiger dadurch, daß auch die Sprache ihre eigenen Wege gehen kann und für richtige Begriffe falsche Worte, für schizophrene Begriffe aber Worte, die für gewöhnlich anderes meinen, setzt, und als endlich mit noch intakten Begriffen fremdartige affektive Einstellungen verbunden sein können. Bei all dem kann die äußere Form der Rede bei den Schizophrenen durchaus geordnet erscheinen. „Viele schizophrene Äußerungen kann man damit kennzeichnen, daß der größte Unsinn in der Form der sinnvollen Rede vorgebracht wird ${ }^{66}$ (Bumke). Ein kennzeichnendes Symptom des schizophrenen Denkens ist die Sperrung des Gedankenganges, die besonders deutlich wird, wo noch keine höhergradige Zerfahrenheit besteht. Bei vorhandenem Aufgabebewußtsein erscheint dem Kranken plötzlich der Gedankengang unterbrochen, das Bewußtsein leer, der Vorstellungsnachschub abgestellt; mit dem Nichtpassenden wird zugleich alles Passende abgesperrt. Gelegentlich wird dies Geschehen zugleich als von außen gemacht, als , ,Gedankenentzug ${ }^{66}$, erlebt. Auf der anderen Seite können fremde, zum Gedankengang nicht passende Inhalte sich aufdrängen, und zwar mit dem Erlebnis der Vergewaltigung des Denkens, als „eingegebene ${ }^{66}$, „gemachte $e^{66}$ Gedanken.

\section{Inhaltliche Denkstörungen}

Unser Denken hat letzten Endes die Aufgabe, die Wirklichkeit um uns und in uns begrifflich nachzubilden. Diese Nachbildung gelingt auch der Wissenschaft im besten Falle in den bescheidenen Grenzen, die mit unseren Anlagen und bei der Entwicklung des objektiven Geistes gegeben sind. Immerhin zeigen Technik und Naturwissenschaft, daß menschliches Denken zu einer weitgehenden Beherrschung der Natur führt. Im Bereiche des Alltags vollends leitet das Denken den Gesunden weithin ziemlich sicher. Dennoch ist unser Denken auch im übersehbaren Kreis oft genug nicht wirklichkeitsgerecht; der Erfolg zeigt dann, daß wir falsch gedacht haben. Wir sprechen hier von Irrtum und sind in der Regel bereit, den Irrtum zu korrigieren.

Jenseits der Grenzen unserer Sinne freilich lassen sich unsere Denkergebnisse an der Wirklichkeit nicht nachprüfen. Hier ist der Bereich der Weltanschaung und des Glaubens und der Philosophie im engeren Sinne. Glauben und Weltanschauung aber sind immer von starken Affekten getragen, und die entstehenden Weltbilder sind weitgehend affektiv bestimmt, so sachlich sie sich geben mögen. Auch aus der weiteren Vergangenheit her ragen affektbeladene Reste früheren Gruppenglaubens als Aberglauben in die Gegenwart fast jedes einzelnen hinein, in ländlichen Kreisen mehr als in der Stadt, bei Ungebildeten mehr als bei geistig Geschulten. Doch schützt vor Aberglauben auch höchste Geisteskraft und Schulung nicht grundsätzlich; die 7 und die 13 fehlen auch in den kultiviertesten Hotels als Zimmernummern; die Sternschnuppe und mancherlei Geste, das Klopfen am Tisch und das „Unberufen $^{66}$, sie bedeuten zahllosen Menschen mehr, als sie eingestehen wollen. 
Auf dem Lande darf man aber auch noch an Hexen glauben, wie in akademischen Zirkeln an Geistermanifestationen aus Zeitungspapier.

Besonders häufigen Irrtümern sind wir ausgesetzt beim Umgang mit unseren Mitmenschen. Tote Dinge können nicht lügen. Alle Menschen tun dies, sei es auch nur in ,gesellschaftlicher ${ }^{66}$ Form. Wir alle werden erzogen, unsere Affekte zu beherrschen und zu verbergen; Angst zu zeigen ist ebensowenig anständig wie in anderen Situationen erotische Begierde oder offene Geringschätzung. Wenn wir wohlerzogen sind, kann man uns fast nie anmerken, was wirklich in uns vorgeht. Sehen wir uns unsere Mitmenschen nicht sehr genau an, dann werden wir uns überall täuschen und als „Dummköpfe ${ }^{66}$ auf alles hereinfallen. Nur der ,Menschenkenner ${ }^{66}$ sieht oft durch das Unechte des mimischen Ausdrucks hindurch, wo die gesprochene Lüge selbst nicht durchschaubar ist. So kommt es, daß über unsere Einstellung zu den Mitmenschen und zu deren Äußerungen schon normalerweise weithin ,Persönliches ${ }^{66}$ bestimmt; Erfahrung macht uns auch im besten Falle nicht fähig, Irrtümer zu vermeiden. „Vorgefaßte", unkorrigierbare „Meinungen" sind daher verständlich und weit verbreitet. Sie können, wenn sie in bescheidenem Umfang auftreten, nicht als abnorm angesehen werden. Verständlich ist auch, daß an die Beziehungen zu unseren Mitmenschen Irrtümer, auch solche krankhafter Natur, besonders häufig angeknüpft werden.

Irrtümer als solche sind also allgemein menschlich. Irrtümer, die infolge ihrer krankhaften Voraussetzungen der Korrektur durch Vernunftgründe nicht zugänglich sind, nennen wir Wahnideen. Bei manchen sog. primären Wahnideen Schizophrener wird die pathologische Natur in der Art des Zustandekommens ebenso wie in den unverständlichen Inhalten besonders deutlich. Hier wird plötzlich zwischen irgendwelchen Gegenständen eine wahnhafte, verharrende und unkorrigierbare Beziehung gestiftet; sie ist für den Kranken unvermittelt da, zugleich mit dem Bewußtsein der unumstößlichen Gewißheit. Er hört etwa einen Trompetenton und weiß zugleich über jeden Zweifel sicher, daß er mit diesem Ton soeben zum König gewählt worden ist. Argumentieren hilft nicht; der Kranke weiß um die Bedeutung des Tons so gewiß wie daß $2 \times 2=4$ ist. Im Denken des Kranken, in seinen Hoffnungen und Wünschen mag die wahnhafte Beziehung freilich vorbereitet sein. Der Augenblick aber bringt die wahnhafte Gewißheit in die Wahrnehmung eingeschlossen. Ebensolche Gewißheiten können auch mit auftauchenden Vorstellungen und Bewußtheiten verbunden sein.

Diese Vorkommnisse treten oft im Verein mit einer beim Kranken für kürzere oder längere Zeit fortdauernden Neigung zur ,primären Eigenbeziehung ${ }^{6}$ auf (C. Neißer). In Zuständen, die von der primären Eigenbeziehung beherrscht sind, rücken alle Gegenstände und Vorkommnisse in eine besondere Bedeutsamkeit; alles, was geschieht, geht den Kranken in einer besonderen Weise an: jede Miene, jede Geste in der Umgebung, das Rauschen der Bäume, das Rieseln der Quelle, das Zwitschern der Vögel, wie die Tatsache, daß hier zwei Stühle so und zwei Kästen so angeordnet sind. Den Seelenverfassungen, die hier in Frage kommen, können wir uns von mehreren normalen Erlebnisweisen her wenigstens annähern. Ich denke an die innere Lage, in der wir sind, wenn wir mit schlechtem Gewissen in einen Kreis von Menschen kommen, die , ,vielleicht ${ }^{66}$ etwas ${ }_{\text {,ahnen }}{ }^{66}$ könnten; ähnlich zeigen unsere 
Heiterkeit oder unsere Gereiztheit uns in Menschen und Dingen immer neue affektverwandte Merkmale. Hier allenthalben sind die Beziehungen der Dinge zu uns geändert. Dennoch ist die „,primäre ${ }^{66}$ Eigenbeziehung bestimmt etwas grundsätzlich anderes und trotz der genannten Ähnlichkeiten uneinfühlbar.

Näher in das Bereich des Nacherlebbaren führen die affektiven Wahnideen, die wahnhaften Ideen im Sinne von Jaspers. Insbesondere auf dem Boden der traurigen krankhaften Verstimmung kommt es über Befürchtungen hinweg, die sich nicht verscheuchen lassen, und immer mehr zu beherrschenden überwertigen Ideen werden, zu einem Schwanken des Realitätsbewußtseins. Der Kranke ist dann bald überzeugt, daß die Befürchtungen sich schon bewahrheitet haben, bald zweifelt er wieder; man spricht hier von "mobilen ${ }^{66}$ Wahnideen. In dem folgenden Stadium der wahnhaften Ideen sind die Befürchtungen und die Inhalte der Selbstvorwürfe zur Gewißheit geworden; überall wird das Schlimmste unkorrigierbar, für Vernunftgründe unzugänglich, felsenfest geglaubt. Demgegenüber kommt der Kranke in manischen Verfassungen in der Regel über eine zu hohe Selbsteinschätzung nicht hinaus, oder es bleibt doch wenigstens bei Größenideen im Sinne ,mobiler" Wahnideen. Nur dort, wo zugleich mit der heiteren Verstimmung eine erhebliche geistige Schwäche besteht, vor allem bei paralytischen Erregungen, entstehen manchmal echte, unkorrigierbare Größenideen, oft sehr üppiger Natur, die auch beim Abklingen der heiteren Erregung festgehalten werden können. Auch in der paralytischen Erregung verrät sich freilich der „mobile“ Charakter der Ideen meist in ihrer Steigerungsfähigkeit und Beeinflußbarkeit durch Launen und Stimmungsschwankungen auch unbeträchtlicher Natur.

Kann man bei den bisher genannten Wahnkranken ihre Wahninhalte nicht oder doch nur mit ganz vorübergehendem Erfolg durch Gegengründe erschüttern, so ist dies anders bei der noch verbleibenden Gruppe von Paranoiden, die selbst sehr häufig große geistige Anstrengungen machen, ihre Wahnideen mit den Widersprüchen der Umgebung und der eigenen Kritik in Einklang zu bringen und gegen die Wirklichkeit zu sichern. Am besten geht man hier von den Querulanten aus. Nach irgendeiner tatsächlichen oder vermeintlichen Kränkung seines Rechtsbewußtseins versucht der Querulant immer erneut, eine Berichtigung des Unrechts herbeizuführen. Von Behörden, Staatsanwaltschaft, Gerichten, Obergerichten, Ministerien immer erneut abgewiesen, kommt er schließlich zu dem unkorrigierbaren Irrtum, die Richter, die eigenen Anwälte seien bestochen, die Zeugen hätten Meineide geleistet, man unterdrücke ihn, den Kranken, deshalb, weil man nicht Gefahr laufen wolle, den Sumpf der Justiz an die Öffentlichkeit zu bringen. Hier haben wir das Modell jener geistigen Arbeit vor uns, die auch manche primäre Wahnidee nachträglich so umkleidet, daß der ursprüngliche Ausgangspunkt kaum mehr erkennbar ist hinter all dem verständlichen Beiwerk, das jeder nachzuerleben vermag.

Primäre Verfolgungsideen Schizophrener und Paraphrener erfahren nicht selten solche verständliche sekundäre Bearbeitung. Der unkorrigierbare, krankhaft entstandene Irrtum wird dadurch scheinbar auch logisch unangreifbar gemacht und in eine geschlossene wahnhafte Weltanschaung hinübergerettet. In ganz ähnlicher Weise ergreifen auch die Verfolgungsideen 
vom Sensitiven Besitz. Der Kranke hat sich irgendeine ihm allein bekannte Entgleisung zuschulden kommen lassen; er hat zunächst die Befürchtung, die Umgebung könnte darum wissen. Dadurch wird er unsicher und in seinem Verhalten unausgeglichener; er zieht sich zurück. Aus seiner überwertigen Idee heraus hört er in Bemerkungen, die in der Umgebung geäußert werden, Anspielungen, und schließlich wird alles Mißgeschick, das der Kranke in seiner Verfassung selbst anrichtet oder zufällig erfährt, zu einem immer deutlicheren Beweis dafür, daß die Umgebung den Kranken seiner Verfehlung wegen mißachtet und verfolgt. Hier werden also Selbstvorwürfe nach außen projiziert und kommen nach mannigfacher geistiger Verarbeitung als Verfolgungen durch andere zum Kranken zurück.

Als Muster von Größenideen, die in ähnlicher Weise ein verständliches Kleid bekommen, sei etwa der Erbschaftswahn genannt. Bei diesen Kranken knüpft an die fadenscheinige Überlieferung von einer Erbschaft oder an den Zeitungsbericht, der von einem gleichnamigen Erblasser spricht, zunächst die Hoffnung, dann die wahnhafte Gewißheit an, Erbe irgendeines großen Vermögens zu sein. Die durchsichtigsten Lügennachrichten, Geschwätz, Erinnerungsfälschungen stützen die Überzeugung; aile noch so handgreiflichen Mißerfolge können sie nicht erschüttern, und der Kranke sieht sich bei der Abwehr seiner Ansprüche bald einem Komplott von Gegnern gegenüber, die ihm aus reinstem Eigennutz die Erbschaft streitig machen. Gerade die allgemeine Ablehnung, die er erfährt, wird ihm zum Beweis seiner vermeintlichen, durch das große Vermögen bedingten Bedeutung. Ganz ähnlich ist es mit dem Wahn, ein Prophet, der Messias, von hoher Abstammung, ein großer Erfinder zu sein. Es ist nur die Frage, ob zur Entstehung solcher Wahnentwicklungen die psychopathische Grundlage ausreicht oder ob es sich nicht vielmehr um krankhafte, wenn auch milde Prozesse handelt. Nicht ganz vereinzelt sind jedenfalls jene paranoischen Entwicklungen, die an ein einschneidendes äußeres Erlebnis anknüpfen, wie beim Querulanten an eine Rechtskränkung. So besteht für den primitiven Erbfolger meist tatsächlich eine dunkle Überlieferung, der Verfolgte erfährt irgendein durch fremdes Verschulden bedingtes Mißgeschick, eine unberechtigte Zurücksetzung. Besonders wirksam ist auch chronisches Leiden unter einer unerträglichen und unbehebbaren Lage (Gouvernanten, ehrgeizige kleine Beamte, die wegen einer kleinen Nachlässigkeit gemaßregelt werden usw.). Hier erscheint dann auch das erste Auftreten des Irrtums so verständlich und das Festhalten an den Wahnideen zunächst so natürlich, daß man versucht ist, ohne einen Krankheitsprozeß allein mit dem Verstehen, mit dem Nacherleben, auszukommen, allerdings nicht ohne die Voraussetzung einer besonderen anlagegemäßen Bereitschaft zu ,vorgefaßten“" Meinungen und zur Gedankenverkrampfung.

Demgegenüber kann nicht zweifelhaft sein, daß die große Mehrzahl der besonnenen Wahnbildungen auf dem Boden schizophrener Prozesse entsteht und sich an primäre Wahnideen anschließt. Nicht ganz selten sind es auch Sinnestäuschungen oder Halluzinationen in der Erinnerung, die sekundär wahnhaft verarbeitet werden, aus neuen Sinnestäuschungen, neuen Erinnerungsfälschungen und allmählichen Triebverschiebungen immer weitere Nahrung erhalten, um dann freilich, oft erst nach langen Jahren, mit dem fort- 
schreitenden schizophrenen Zerfall zerfahrener, zusammenhangsloser, wirklichkeitsfremder zu werden.

Nahm man früher die Inhalte der meisten Wahnideen als gegeben und unerklärbar hin, um sich nur über die wenigen ,verständlichen ${ }^{66}$ paranoischen Entwicklungen Gedanken zu machen, so hat vor allem die Psychoanalyse uns gelehrt, daß wohl alle Wahninhalte ,aus dem Herzen“ stammen und auf die Befreiung aus einer unerträglichen inneren Lage abzielen. Daß der Wahnerbe mit der wahnhaften Gewißheit einer goldenen Zukunft sich über die bittere Gegenwart, über Anfeindungen und Ungerechtigkeiten hinwegtröstet, daß der wirtschaftlich, wissenschaftlich und sozial Erfolglose sich über das eigene, selbstverschuldete Versagen hinwegtäuscht, wenn er die Schuld den ungerechtfertigten Machinationen bitterer Feinde zuschieben kann, das alles ist verständlich. Wie Kretschmer gezeigt hat, bedeuten auch die Anfeindungen, die der Sensitive erlebt, eine Befreiung insofern, als sie das tatsächliche eigene Unrecht reichlichst sühnen und das Selbstgefühl aufrütteln, indem sie dem Kranken zeigen, daß er besser ist, als das Gewissen ihn glauben lassen mag. Aber auch die unmenschlichen Machinationen, denen Schizophrene ausgesetzt sind, lassen sich verständlich machen, wenn man Begriffszerfall, Symbolbildung und Sprachlaunen dieser Kranken berücksichtigt. Die Eigenart des schizophrenen Seelenlebens bringt es freilich mit sich, daß eigentliche Beweise für solche Deutungen nicht möglich sind. Man wird aber gut tun, alle Wahninhalte auch unter diesem Gesichtspunkt zu betrachten. Endlich lassen auch die melancholischen Wahnideen eine verständliche Deutung zu. Das Wissen um tiefstes biologisches Versagen, die Hemmung, die so viele Melancholische zunächst erleben als ein unentrinnbares Schicksal, wird mit dem Wahn fortgeschoben in das Bereich des Wandelbaren, der Freiheit, des Moralischen: „Ich bin biologisch nicht so minderwertig; meine Schuld ist es, wenn ich so bin; ich kann meine Schuld büßen und dann wieder beginnen."

Die Herkunft aller Wahninhalte aus dem Herzen, aus Hoffnungen, Wünschen und Befürchtungen, wird besonders deutlich bei pathologischen Vorkommnissen, die nicht mehr den Namen Wahnideen verdienen, sondern als "Wahnhafte Einbildungen ${ }^{66}$ der Degenerierten bezeichnet werden. Bei hysterischen Psychopathen kommt es in unerträglichen Situationen (besonders im Gefängnis) und meist aus abnormen Bewußtseinszuständen heraus zur Äußerung üppiger Größenideen oder aber unsinniger Verfolgungsideen, die den Wachträumereien Jugendlicher ähneln. Diese spielerisch vorgebrachten, meist rasch wechselnden und beeinflußbaren Ideen, die wohl manchmal dem Schwindel sehr nahe stehen, entrücken den Kranken der bitteren Wirklichkeit, und sie verschaffen ihm zugleich den Vorteil, sich nach Belieben benehmen zu können oder in der Krankenabteilung Zuflucht zu finden. In tieferen Bewußtseinstrübungen mögen sie auch dem wirklich Wahnhaften sich annähern, wenn sie wohl auch immer Widerspruch aus dem Innern der Kranken selbst erfahren und eine sofortige Umstellung auf die Wirklichkeit bei günstigen äußeren Verhältnissen gestatten.

Im Bereiche des Glaubens, der Überzeugung, d. h. allenthalben dort, wo eine Berichtigung an der Wirklichkeit grundsätzlich unmöglich ist, ist die überwertige Idee zu Hause, die freilich eine pathologische Bedeutung 
erst dort erhält, wo sie das Handeln in vernunftwidriger Weise abirren läßt. Wir alle haben gewisse überwertige Ideen, d.h. Gedankeninhalte, die sich immer wieder hervordrängen, unser gesamtes Denken beeinflussen und den Ausschlag geben, wo Gründe versagen. Überwertige Ideen, etwa solche religiöser Art, fallen jedoch nicht auf in einer gleichgerichteten Gemeinschaft, etwa in einer Sekte oder in einer größeren politischen Gruppe. Sie werden auffällig erst dort, wo sie den Träger in Widerspruch zu seiner menschlichen Umgebung bringen, d. h. sie setzen immer aktive Menschen voraus. So handelten und duldeten die Kriegsdienstverweigerer unter einer überwertigen Idee; wir sehen ähnliches jetzt bei manchen unentwegten Friedensfreunden, Nahrungsmittelfanatikern, Aposteln der Nacktkultur und der ungeschorenen Haare und Bärte. Von jenen überwertigen Ideen her kommt es gern zu falschen Urteilen auch auf abgelegenen Gebieten, zu einer von der Norm abweichenden Wertskala und zur ungerechten, voreingenommenen Beurteilung aller Mitmenschen. Hier allenthalben handelt es sich wohl darum, daß die überwertige Idee dem Selbstbewußtsein des Trägers eine billige Steigerung vermittelt, oder aber auch darum, daß sie dem Betroffenen eine besondere Stellung in einer kleinen Gruppe gibt. Die lautesten Schreier sind aber in der Regel nicht die wertvollsten. Bei diesen letzteren reicht die überwertige Idee bis an den Kern der Persönlichkeit heran. Im lauten Schreien aber ist immer Unechtes, Krampf, Gebärde. „F an atiker“ solcher Art fallen leicht um, wenn sich ihnen irgendein neuer alarmierender Stoff zu einer überwertigen Idee anbietet. Gerade hier ist die billige Selbsterhöhung allzu deutlich. Im Bereiche der Psychopathologie begegnen uns Träger überwertiger Ideen besonders im paranoischen Lager als Erfinder, Sektenstifter und politische Querköpfe.

Kann die überwertige Idee nicht ohne Beziehung zum Tun, zum Ausdruck, zum Träger abgehandelt werden, so die Zwangsideen nicht ohne jene zum Trieb- und zum Affektleben. Die Definition Westphals: „Zwangsvorstellungen sind Vorstellungen, die, ohne daß ihre normale Gefühlsbetonung das erklärt, unter dem Gefühl des Zwanges in das Bewußtsein treten, sich durch Willensanstrengungen nicht verscheuchen lassen und deshalb den Ablauf von Vorstellungen hindern und durchkreuzen, obwohl sie vom Kranken stets als ohne Grund dominierend und meist auch als inhaltlich falsch und als krankhaft anerkannt werden ", gilt vollinhaltlich eigentlich nur für gewisse „normale ${ }^{66}$ Vorkommnisse. Es kann etwa ein Vers, eine Melodie sich immer wieder unverscheuchbar in den Gedankengang eindrängen, vor allen in Zuständen der Ermüdung. Pathologische Zwangsvorstellungen aber sind immer von Angst begleitet. Sie werden zudem wohl als solche, d. h. als ,inhaltlich falsch" erlebt, aber in der Regel ist sich,der Kranke doch der triebhaften Hintergründe bewußt, aus denen die Zwangsinhalte herauswachsen. In der Definition ist nur Formales gegeben, das Affektive und das Inhaltliche sind aber wichtiger, weil sie auf die Genese hinweisen, nämlich auf nicht restlos verdrängungsfähige Triebregungen, die mit der Gesinnung, mit der bewußt verfolgten Lebenslinie nicht vereinbar sind. Nicht wenige Zwangsvorstellungen (Auftauchen von häßlichen Worten und Flüchen, Zahlenzwang, der zwanghafte Gedanke, etwas nicht richtig gemacht zu haben) knüpfen an normale Vorkommnisse an. Bei Zwangskranken aber, die unter 
ihren Zwängen wirklich schwer leiden, sind die auftauchenden Vorstellungen nur Masken, unter denen nicht ganz verdrängte Gedanken und Impulse zur Oberfläche drängen. Es ist hier zu Verschiebungen gekommen, wie sie ja im gesamten Triebleben als zur Entwicklung des ausgebildeten Seelenlebens nötige Einrichtungen allenthalben am Werke sind. Hinter der Zwangsvorstellung, schmutzig zu sein, die mit Recht abgelehnt wird und trotzdem zum Waschen führt, steckt eine tatsächliche oder triebhaft gewünschte moralische Beschmutzung, hinter dem Ausstoßen obszöner Worte das Vordrängen obszöner, aber anders gerichteter Impulse. In der Regel sind Zwangsvorstellungen und -befürchtungen (Phobien) nur das Kompromiß zwischen der Einstellung auf eine volle soziale Eingliederung und den damit nicht vereinbaren, aber doch nicht ganz zu verdrängenden Triebregungen, meist sexueller und aggressiver Natur. Die besondere Bereitschaft zur Verschiebung entspricht der schizoiden Anlage der meisten Zwangskranken. Endlich muß beachtet werden, daß nicht ganz selten von Menschen, die vor den Forderungen der Wirklichkeit in die Krankheit flüchten, auch Zwangsvorstellungen als mehr oder weniger gutgeheißene Ausflüchte gewählt werden.

\section{Störungen des Bewußtseins}

Bewußtsein kann zunächst einmal die Tatsache psychischer Vorgänge im Gegensatz zum Unbeseelten bedeuten. Wenn wir hier von Bewußtsein sprechen, so meinen wir die Gesamtheit seelischer Vorgänge in einem gegebenen Zeitpunkt. Bewußtseinsstörungen kann man bei dieser Fassung des Begriffs nicht schon annehmen, wenn überhaupt irgendein seelischer Vorgang abnorm abläuft. Der Akzent liegt vielmehr auf der Gesamtheit, auf dem Ganzen der seelischen Vorgänge und Zusammenhänge, das abgeändert sein muß und das am klarsten immer hervortritt an der Abänderung des Gegenstandsbewußtseins, wobei freilich auch alles andere Seelische verändert ist.

Das Gegenstandsbewußtsein hat schon in der Norm einen verhältnismäßig geringen Umfang. Klar, hell und deutlich können nur wenige Gegenstände (etwa 5) zugleich erfaßt werden, während um diesen Blickpunkt des Bewußtseins herum weniger klare und deutliche Eindrücke sich nach dem Rande des Bewußtseins hin verlieren. Unser Bewußtseinsumfang wechselt mit unserem Gesamtzustand; er wird mit der Müdigkeit enger, nimmt nach der Lebenshöhe mit zunehmendem Lebensalter stetig ab und zeigt nicht unerhebliche Unterschiede von Mensch zu Mensch. In den Bewußtseinsstörungen sind aber nicht nur Umfang und Helligkeit des Gegenstandsbewußtseins gestört, sondern die Gesamtheit der seelischen Vorgänge überhaupt. Wir unterscheiden mehrere Formen von Bewußtseinsstörungen.

\section{๔) Die Benommenheit}

Diese läßt sich am ehesten kennzeichnen als die bei hochgradiger Erschwerung aller seelischen Vorgänge bestehende dauernde Bereitschaft zu traumlosem Einschlafen. Die Aufmerksamkeit ist nur schwer erweckbar, Wahrnehmungen erfolgen verlangsamt, mühselig und unvollkommen, der Umfang des Bewußtseins ist vermindert. Die unvollkommenen Eindrücke 
hinterlassen keine bleibenden Spuren; sie werden nicht oder nur ganz kurz gemerkt und sind später nicht mehr erweckbar. Aber auch das Vorstellungsmäßige ist vermindert an Fülle und Klarheit; es fällt den Benommenen nichts ein; sie zeigen keinerlei seelischen Antrieb, ihre Affektivität schweigt, ihr Bewußtsein ist entleert. Auch die primitiven Bewegungsantriebe liegen darnieder, kurz der gesamte Bewußtseinsstrom ist zugleich verlangsamt, erschwert und abgedrosselt, so daß jeweils nur wenig Seelisches vorgeht. Die leichtesten Grade der Benommenheit gleichen mehr oder weniger Hemmungszuständen, doch unterscheiden sie sich von ihnen durch die Störungen des Merkens und die nachfolgende Erinnerungslosigkeit oder doch schattenhafte Erinnerung und die ständige Bereitschaft, einzudösen. Die schwersten Formen der Benommenheit gehen in das Koma über.

\section{$\beta$ ) Die delirante Bewußtseinstrübung}

enthält zwar auch die Elemente der Benommenheit, vor allem die Merkstörung, die Erschwerung der Auffassung und aller zielgerichteten Vorgänge. Zugleich bestehen aber mehr oder weniger deutliche motorische Erregung, Begriffszerfall im Sinne des traumhaften Denkens und triebhafte Zuwendungen bei reichlicher, oft visualisierter inkohärenter Vorstellungsproduktion, halluzinatorischen, pseudohalluzinatorischen und wahnhaften Erlebnissen. Die Außenwelt wird dabei nur flüchtig, stückhaft erfaßt, illusionär verkannt und durch pseudohalluzinatorische Erlebnisse verfälscht. In manchen Delirien überwiegt die Inkohärenz die Erscheinungen, die ins Bereich der Benommenheit gehören, während bei zunehmender Tiefe des Delirs die Benommenheit immer mehr zunimmt. Zumeist dauert dabei die motorische Erregung an; sie äußert sich schließlich nur noch in unkoordinierten, elementaren Bewegungen, Greifakten (Flockenlesen), Grimassen, Muskelzuckungen.

Weiter kennen wir Verfassungen des

$$
\gamma) \text { eingeengten Bewußtseins, }
$$

Dämmerzustände verschiedener Art. Hier erscheint entweder ein Teil der Person und ihrer Disposition unwirksam oder aber das Gegenstandsbewußtsein auf einen engen Kreis eingeschränkt und die ganze übrige Welt abgeblendet.

Zustände der letzteren Art kann man sich am deutlichsten vor Augen führen an manchen Boxern, die ,groggy" geschlagen sind. Diese parieren und schlagen, oft noch sehr gefährlich und zielsicher; sie gehen nicht zu Boden und befolgen alle Regeln des Rings; aber sie finden nicht mehr in ihre Ecke, gehen etwa Arm in Arm mit dem Gegner und haben später keine oder falsche Erinnerungen an den Zustand. Hier ist also das Bewußtsein gewissermaßen auf vitalste Anforderungen eingeengt, der Gesamtzustand aber zugleich von dem habituellen so abgesetzt, daß der Zugang in der Erinnerung nicht mehr möglich ist. Ähnliche Zustände kann man bei Epileptikern, bei manchen Hirngeschädigten (nach Unfällen) usw. sehen.

In anderen Dämmerzuständen ist nicht so sehr das Gegenstandsbewußtsein eingeengt, vielmehr steht, meist bei lebhaften Affekten, eine einseitige Verkennung und zugleich unvollkommene Erfassung der Umwelt im Sinne 
des Affekts (Angst, Schrecken) im Vordergrund, während wichtige Triebfedern der Person, insbesondere gewohnte Hemmungen, nicht zur Verfügung stehen. Diese sind wie ausgelöscht, so daß es zu Fehlhandlungen, etwa schlimmen Gewalttaten, kommen kann. Auch für diese Dämmerzustände besteht nachträglich Amnesie.

Haben wir es hier mit den Folgen organischer Hirnveränderungen zu tun, so unterscheiden sich davon die "Dämmerzustände ${ }^{66}$ der Hysterischen in entscheidender Weise. Auch in diesen Zuständen können Stücke der Person und Erinnerungen abgeschaltet sein, und die Außenwelt wird nur in einem engen Ausschnitt erlebt oder aber verkannt. Dies geschieht aber ganz systematisch im Sinne von Hoffnungen und Wünschen; es wird allés abgeblendet, was die Lage unerträglich macht; auf der anderen Seite aber wird von innen her, aus der Phantasie, so viel in die Welt hineingezaubert, daß das „Arrangement ${ }^{66}$, das Zweckhafte, das bewußtseinsnahe Nachschieben nicht verkannt werden kann.

Den hysterischen, katathymen Dämmerzuständen steht nahe der eingeengte Bewußtseinszustand der Hypnose, in dem nur noch Rapport mit dem Hypnotiseur besteht. Dieser übernimmt die Rolle, die Wunsch und Phantasie im hysterischen Dämmerzustand spielen.

Mit einem hochgradig eingeengten Bewußtsein haben wir es endlich im Schlaf zu tun, in dem wir immer für spezifische Reize bewußtseinsfähig bleiben und mancherlei willkürliche Leistungen vollbringen (Blasen-, Darmbeherrschung; der Müller wacht beim Stillstand der Mühle, die Mutter beim Schreien des Kindes auf, während sonst der größte Lärm nicht stört).

In dersog. on eiroid en (=traumähnlichen) Bewußtseinsstörung entspricht die Erfassung der Außenwelt etwa jener in den Delirien; das innere Erleben ist aber nicht so stückhaft und dissoziiert wie dort; vielmehr kommt es etwa nach Art der hysterischen Dämmerzustände zu zusammenhängenden, affektbeladenen, szenenhaften Erlebnissen, die freilich schließlich doch unerfüllt abreißen. Solche Zustände begegnen uns besonders bei seltenen, sog. degenerativen, endogenen Psychosen.

\section{ס) Das Unbewußte}

In der Hypnose bekommt jemand den Auftrag, genau nach drei Tagen, wo immer er sich auch befinde, den Rock auszuziehen. Er tut dies tatsächlich und begründet die ihm selbst und seiner Umgebung unbegreifliche Handlung mit einem plötzlichen Antrieb oder mit einer fadenscheinigen, zurechtgemachten Ausrede, an die er selbst nicht recht glaubt. Den hypnotischen Auftrag hat er vergessen.

Ich will jemand, der in Gefahr ist, anzustoßen, zurufen: passen Sie auf! - sage aber: passen Sie acht! Ihm und mir selbst fällt unmittelbar darauf ein, daß er mir acht Mark schuldig ist, woran ich selbst bei dem Ausruf nicht gedacht hatte.

Ich schreibe an einen alten Freund von gemeinsamen Erinnerungen; im Datum finde ich den Namen jener Stadt, in der ich mich wohlgefühlt habe, nicht den meines Aufenthaltsortes, wo ich unglücklich bin.

Solche Tatsachen, insbesondere auch die Inhalte des Traums, haben Freud zu der Annahme geführt, daß es ein „unbewußtes ${ }^{66}$ Seelenleben gebe 
und daß unser Bewußtsein immer nur einen bescheidenen Ausschnitt der tatsächlichen seelischen Vorgänge enthalte. Weithin werde der Inhalt unseres Bewußtseins von diesem Unbewußten her bestimmt. Die Zensur, eine kritische Instanz, die ihre Bedeutung von unserem Leitbild, dem Ideal-Ich, erhalte, lasse zum Bewußtsein eben nur diesem Ideal-Ich Entsprechendes zu und täusche uns allenthalben über unsere letzten wirklichen Motive.

Man kann darüber streiten, ob und wieweit die Annahme eines solchen Unbewußten unsere Einsichten fördert, darf aber nicht vergessen, daß viel von dem, was Freud dem Unbewußten zuschreibt, tatsächlich nicht unbewußt, sondern nur am Rande unseres Bewußtseins ist, unbeachtet, fortgeschoben, aber trotzdem da. Wir wissen zudem aus vielfältiger Erfahrung, daß uns im gegebenen Augenblick nicht alle unsere Motive tatsächlich einfallen, auch wenn wir uns nachträglich deutlich $\mathrm{zu}$ erinnern vermögen, daß solche vergessenen Motive uns einmal stark beschäftigt haben; wir können an unseren Wahrnehmungen und Handlungen nachträglich ablesen, daß in ihnen Erinnerungen wirksam waren, die klar und deutlich nicht durchs Bewußtsein gegangen sind. Jede unserer Vorstellungen ,umwittert ${ }^{66}$ eine „Sphäre ${ }^{66}$ von Erinnerungen, Denkansätzen, Handlungskeimen, die, schattenhaft, flüchtig, unbeachtet, im Fortgang des Denkens erinnerungsunsicher versinken. Es ist also sicherlich viel von dem bewußt, was Freud dem Unbewußten zuschreibt.

Auf der anderen Seite rechnet Freud zum Unbewußten tatsächlich vorhandene, aber , verdrängte ${ }^{66}$ Regungen, d.h. solche, über die wir uns nicht gern Rechenschaft geben, und andere, die nur als körperliche Dispositionen Bestandteile der Person sind und damit in jede Zuwendung und alles Denken mit eingehen. Gerade hier aber muß gefragt werden, ob man noch das Wort Bewußtsein gebrauchen, von unbewußtem Psychischen reden darf.

Wie man sich aber auch zum Unbewußten stellen möge, es bleibt Freuds entscheidendes Verdienst, alle diese Tatsachen hervorgehoben und als wirksam aufgezeigt zu haben, so daß wir sie nun kennen und zu berücksichtigen vermögen.

\section{Störungen der mnestischen Funktionen}

Alle Einwirkungen, die den Organismus treffen, führen nicht bloß zu den unmittelbaren Reaktionen, sie verändern den Organismus auch bleibend in dem Sinne, daß die nächste gleichartige Einwirkung auf spezifisch veränderte Bedingungen trifft. Hier liegt die Quelle von all dem, was wir biologisch als Allergie, körperlich als Übung und Gewöhnung kennen. Der geübte Muskel wird kräftiger, der gewohnte unwichtige Reiz verliert an störender Eindringlichkeit, der biologisch wichtige Eindruck bekommt immer deutlicheren Signalcharakter; oft gebrauchte Funktionen laufen erleichtert, mit geringerem Kraftaufwand und sicherer ab.

Auf seelischem Gebiete sprechen wir von ,Engrammen ${ }^{66}$, Erinnerungsspuren, die sich zum Teil nur indirekt (etwa in Ersparnissen der Lernzeit) nachweisen lassen, zum Teil als Gedächtnis- und Merkleistungen unmittelbar deutlich sind. Die Spuren der früheren Eindrücke können im Laufe des seelischen Geschehens belebt, zu bewußten, willkürlichen Erinnerungen 
werden, oder aber sie tauchen unwillkürlich, assoziativ angeregt an geeigneter Stelle, gelegentlich auch überraschend und scheinbar unvermittelt auf. Die allermeisten und wichtigsten Gedächtnisspuren gehen in unsere Wahrnehmungsvorgänge und in den gewohnten alltäglichen Ablauf des seelischen Geschehens untrennbar und als solche unmerkbar ein. Das Gedächtnis hält die Gegenwart mit der Vergangenheit zusammen und ist eine ganz wesentliche Voraussetzung für die Konstituierung der sich selbst gleichbleibenden bewußten Persönlichkeit. Eine Leistung des Gedächtnisses ist auch jenes Zeitgitter der Vergangenheit, das uns den Überblick über unser vorangegangenes bewußtes Leben und die klare Einordnung aller wesentlichen Ereignisse ermöglicht. Das Gedächtnis hat auch an unserem Zeitgefühl, offenbar infolge der allmählich verblassenden Spuren aller unwichtigen Randerlebnisse, einen entscheidenden Anteil; es ermöglicht aber auch die Gliederung der soeben erlebten Zeit, wie vor allem beim Erfassen von Rhythmen deutlich wird. Seelenleben ohne Gedächtnis wäre nur vorstellbar als ein Gewirr sinnlicher Eindrücke, als fortgesetzte Gegenwart ohne Vergangenheit, aber auch ohne Zukunft; denn auch die Zukunft ist ohne bewußte Vergangenheit nicht denkbar.

Endlich und vor allem kann man all das, was wir ins Leben mitbringen, nicht anders auffassen als ein organisiertes Ganzes von Gedächtnisspuren, die in der phylogenetischen Entwicklung geschaffen sind, ohne daß wir dabei Stellung zu nehmen brauchen zu der Frage der Vererbung erworbener Eigenschaften.

Dem bewußten Gedächtnis verfügbar ist im großen und ganzen nur das, was "aufmerksam", bei klarem Bewußtsein wahrgenommen und erlebt wurde. Daß auch nicht klar Aufgefaßtes dennoch Spuren hinterläßt, hat man in Traumexperimenten ( $\mathrm{P} \ddot{\mathrm{tz}} \mathrm{l})$ und Lernversuchen innerhalb des epileptischen Dämmerzustandes aufzeigen können. Im allgemeinen aber ist Voraussetzung für die Erinnerungsbildung der normale Bewußtseinszustand. Es ist eine heuristisch wertvolle, aber nicht beweisbare Behauptung, daß von dem einmal bewußt Erlebten gar nichts verlorengehen könne, d. h. daß die Gesamtheit unserer Erinnerungen erst mit unserem Tode verschwinde. Tatsache ist, daß die große Mehrzahl der Menschen aus der frühen Kindheit keine Erinnerungen mehr hat und daß mit dem Fortschreiten der Zeit nur die großen und wichtigen Einzelerlebnisse dem Gedächtnis ständig verfügbar bleiben, während alles Unwichtige vergessen wird oder doch nicht mehr erweckbar ist. Von den zahllosen Einzeleindrücken des Alltags behalten wir tatsächlich nur sehr wenige erinnerungsfähig; wir erinnern uns nur an die besonders herausgehobenen Einzelheiten; alles andere verschwindet in den allgemeinen Dispositionen, die als Übung, Gewohnheit, Routine usw. uns dienstbar sind.

Allerdings gelingt es uns in der Regel bei besonderer Willensanstrengung, auch unwichtige Einzelheiten eine Zeitlang noch zu erwecken. Dabei besteht aber immer die Gefahr, daß die Erinnerungen durch Denk- und Erlebensgewohnheiten verfälscht und durcheinandergeworfen werden. Überhaupt unterliegen unsere Erinnerungen in noch stärkerem Maße als unsere Wahrnehmungen Veränderungen, an denen unsere Selbstwerthaltung, unsere Gewohnheiten, Affekte und Stimmungen, vor allem Stolz und Eigenliebe, einen entscheidenden Anteil haben. Im Durchschnitt wird Peinliches schlechter 
behalten als Angenehmes oder es wird doch stärker umgestaltet im Sinne unserer Eigenliebe, während Angenehmes und Ehrenvolles in der Erinnerung gern wächst.

Wir unterscheiden innerhalb des Gedächtnisses zunächst einmal das Gedächtnis im engeren Sinne als die Summe der überhaupt vorhandenen Erinnerungen und die Dispositionen, die über Umfang und Genauigkeit dieser Erinnerungen bestimmen, sodann die Merkfähigkeit als jene Funktion, welche neue Eindrücke dem Gedächtnis hinzufügt, d.h. also die Fähigkeit, neues Gedächtnismaterial zu erwerben, endlich die Reproduktionsfähigkeit als die Bereitschaft, Erinnerungsspuren zu beleben, über unser Gedächtnis bewußt zu verfügen.

Diese drei Anteile des mnestischen Gesamtapparates können getrennt voneinander gestört werden.

\section{«) Störungen des Gedächtnisses}

Störungen des Gedächtnisses werden häufiger angenommen als dies berechtigt ist. Nur grobe organische Hirnschäden führen zur Vernichtung von Gedächtnisbesitz. Hirnherde zerstören vor allem Spezialapparate, deren Organisation eine Wirkung mnestischer Vorgänge ist. So wird etwa bei gewissen sensorischen Aphasien das akustische Gedächtnis für Sprachlaute oder auch nur für eine fremde Sprache beeinträchtigt, freilich nicht nur dies. Bei gewissen motorischen Aphasien leiden jene Gedächtnisdispositionen, die vorhanden sein müssen, um das innerlich erklingende Wort in Sprachlaute umzusetzen; bei einer Sonderform der optischen Agnosie erleiden die optischen Vorstellungen schwere Einbuße. Hier allenthalben handelt es sich freilich nicht um reine Gedächtnisstörungen; vielmehr sind Denken, Handeln und Einstellungen zugleich in spezifischer Weise mit geschädigt.

Mit reinen Gedächtnisstörungen haben wir dagegen zu tun bei jenen nicht sehr zahlreichen Fällen, wo durch eine schwere, meist toxische, gelegentlich auch traumatische Hirnschädigung eine unter Umständen Jahre umfassende Erinnerungslücke (retrograde Amnesie) zustande kommt. Dann erscheint der gesamte jüngere Gedächtnisbesitz einfach ausgelöscht, fortgewischt, auch solcher, der in Zeiten voller Bewußtseinsklarheit erworben wurde. In der Regel umfaßt die Amnesie aber nur kürzere Zeitspannen; immer ist es der jüngste Besitz, der verlorengeht; es wird nicht ein beliebiges Stück der Vergangenheit ausgelöscht.

Auch bei nicht so elementaren organischen Hirnschäden leidet der jüngste Besitz am meisten. Wo, wie bei senilen Erkrankungen, der Gedächtnisschwund allmählich beginnt, da gehen vorwiegend die Erinnerungen des späteren Alters zugrunde, die weniger wichtigen zuerst, dann auch die wichtigen, während die Jugenderinnerungen in großer Klarheit und Breite auftauchen und gerade das in hellem Licht strahlt, was bei vollentwickeltem Triebleben zu wirklichem Besitz wurde. Auch dann aber, wenn die jüngste Vergangenheit immer mehr dahinschwindet, bleiben die von der Übung geschaffenen Apparate und bleibt das Begriffssystem noch unberührt, kurz, all das, was der Anschaulichkeit entbehrt. Es ist, als ob aus den Maschen jener Apparatur alles Lebendige herausfiele. Ein Seniler und Arteriosklerotiker mit bochgradiger Gedächtnisstörung kann also unter Umständen noch gescheit und geistreich über hohe 
und höchste Probleme sprechen, aber nur ganz spärliche anschauliche Erinnerungen erwecken.

\section{B) Psychogene Amnesie}

Wo plötzlich aus der weiteren Vergangenheit eine Wegstrecke ausgelöscht wird, da handelt es sich immer um seelisch bedingte Störungen, um erlebnisbedingte Verdrängungen. Besonders kenntlich wird dies vielfach dadurch, daß auch in diesen amnestischen Lücken nur jene Dinge ganz ausgelöscht erscheinen, die mit einem bestimmten Erlebnis zusammenhängen, während anderes noch verfügbar ist. Um die Auslöschung von Spuren handelt es sich dabei nicht. Das vermeintlich Ausgelöschte kann bald darauf in anderer Situation, nach Lösung der ursächlichen Konflikte, in der Hypnose, plötzlich wieder da sein.

Bei den meisten Erkrankungen, bei denen man Gedächtnisstörungen annimmt, stehen tatsächlich im Vordergrund die

\section{$\gamma$ ) Reproduktionsstörungen,}

zu denen sich freilich in bescheidenem Ausmaße auch solche des Gedächtnisses gesellen. Bei den Reproduktionsstörungen ist der Gedächtnisbesitz tatsächlich vorhanden; er steht aber nicht immer oder sogar nur unter besonderen Bedingungen zur Verfügung; die Erinnerungsspuren sind nicht beliebig und nicht automatisch erweckbar. Wir alle erleben Reproduktionsstörungen, wenn uns etwa ein wohlbekannter Name oder ein wohlbekanntes Wort rechtzeitig einmal nicht einfällt, oder wenn wir zwar genau wissen, daß wir uns etwas vorgenommen haben, ohne uns doch zu erinnern, was. Der Name, das Vorhaben fallen uns dann plötzlich wieder ein. Vielfach sind es affektive Gründe, welche die Reproduktion hemmen. Auch bei der gröberen organischen Reproduktionsstörung spielen solche Anlässe eine nicht unerhebliche Rolle; doch müssen wir zugleich auch eine Beeinträchtigung der Spuren selbst annehmen, die nicht mehr dem gewohnten Denken verfügbar sind, von anderer Seite her aber erweckbar bleiben. Besonders kennzeichnend ist hier die amnestische Aphasie, bei der Gegenstandsbezeichnungen nicht gefunden werden, während die Dinge selbst erkannt und die Bezeichnungen auch ohne weiteres verstanden werden. Wir haben es bei der Reproduktionsstörung überhaupt vor allem mit einer Denkstörung zu tun, nicht so sehr mit jener der mnestischen Dispositionen selbst. Dafür spricht auch die Tatsache, daß mit der Reproduktionsstörung Hand in Hand zu gehen pflegen Störungen jener Gitter, welche das Denken in jedem anschaulichen Material schaffen muß, um es verfügbar zu machen.

So ist bei den meisten Reproduktionsstörungen das Zeitgitter in schwerer Weise gestört; es tauchen wohl amorphe, zum Teil auch detaillierte Erinnerungen auf, aber sie können zeitlich nicht mehr eingeordnet werden oder erscheinen an falscher Stelle, wie andererseits zu dem mühselig festgehaltenen Zeitgitter die anschaulichen Erinnerungen nicht auftauchen. Wir müssen auch durch unsere Raumwelt gedankliche Gitter gelegt denken, die als solche gestört werden können und zur Behinderung der Reproduktion räumlicher Inhalte führen, und umgekehrt. Endlich ist auch unsere gegenständliche Welt durch Begriffsgitter gegliedert. Diese Gitter verlieren ihre Zuverlässigkeit, 
ihre Stabilität und damit gewissermaßen ihre magnetische Kraft zunächst für das Erinnerungsmaterial und erst bei schwereren Störungen auch für das Wahrnehmungsmaterial.

Um vorwiegende Reproduktionsstörungen handelt es sich etwa bei den hauptsächlichen Gedächtnismängeln der Paralyse. Hier ist ja vor allem die zeitliche Einordnung der an sich oft intakten Erinnerungen gestört, während mit der Festigung des Zeitgitters in der Remission das vermeintlich verlorene Material wieder verfügbar wird. Aber auch bei den Korsakow-Zuständen spielt die beschriebene Denkstörung eine außerordentlich bedeutsame Rolle; sie kann sogar ganz im Vordergrund stehen, während in anderen Fällen daneben doch auch tatsächliche Gedächtnisausfälle anzunehmen sind. Insbesondere bei der Restitution von Korsakow-Zuständen sehen wir, daß sich zunächst wieder die Gitter herstellen, aber anfänglich leer und ohne ihre Kristallisationskraft, daß aber dann allmählich auch das anschauliche Erinnerungsmaterial wieder zuzuströmen beginnt.

\section{ס) Störungen der Merkfähigkeit}

Vom Gedächtnis und der Reproduktion ganz unabhängig kann die Merkfähigkeit gestört sein. Bei allen organischen Psychosen kommt es zu einer solchen Beeinträchtigung der Fähigkeit, neues Gedächtnismaterial zu speichern. In der Bewußtseinstrübung wird dies zum Teil auf indirektem Wege dadurch bedingt, daß es nur zu unscharfen, unklaren Wahrnehmungen, zu flüchtigen und schattenhaften seelischen Prozessen überhaupt kommt. In der Bewußtlosigkeit wird natürlich gar nichts aufgenommen, was gemerkt werden könnte. Aber daneben kann doch offenbar das Merken selbst gestört sein. Dem bewußtseinsklaren Kranken gelingt etwa mühelos, fünf, sechs, auch mehr Einzeleindrücke unmittelbar zu reproduzieren; aber nach kurzer Zeit ist alles ausgelöscht; auch auf Umwegen ist nichts, auch keine Spur mehr von dem nachweislich aufgenommenen Material festzustellen. Ganz isoliert ist eine solche Störung bisher nur in einem berühmten Fall von CO-Vergiftung durch Grünthal und Störring beschrieben worden. Hier besteht tatsächlich, abgesehen von der intakten fernen Vergangenheit, nur noch eine fortdauernde punktförmige Gegenwart. In weniger ausgeprägten Formen kennen wir Merkstörungen bei allen organischen Hirnveränderungen diffuser Art, also bei Paralyse, seniler Demenz, Arteriosklerose und Vergiftungen. Es muß beachtet werden, daß es dabei allenthalben auch zu ,Gitter ${ }^{66}$-Störungen kommt. In der Merkunfähigkeit haben wir damit vielleicht nur eine Seite jener zentraleren Störung vor uns. Das neue Material kann nicht mehr an den Gittern verankert werden, weil diese schon Schaden gelitten haben, obgleich sie noch eine Ordnung der wahrnehmungsmäßigen Gegenstandswelt, des Altbesitzes an Erinnerungen und des Handelns ermöglichen.

\section{ع) Erinnerungstäuschungen}

Unsere konkreten Erinnerungen sind nicht ,,treu ${ }^{66}$. Im allgemeinen bleibt jedoch die affektive Umgestaltung in bescheidenen Grenzen und wir behalten lange Zeit hindurch ein Gefühl dafür, daß mancherlei geläufige Erinnerungen nicht völlig der ehemals erlebten Wirklichkeit entsprechen. Insbesondere vor Gericht, wenn die Schwurhand gehoben werden muß, stellt sich dem von 
Gewissen und Angst geschärften Blick manche bunte Erinnerung plötzlich als unscharf heraus und zahlreiche, der Eitelkeit und der geschäftigen Phantasie entstanmende Einzelheiten fallen ab. Es gibt Menschen, deren Erinnerungen katathymen Umgestaltungen besonders leicht erliegen (Jägerlatein); von einzelnen Menschen wissen wir ganz genau, daß ihre Erzählungen nur zu 5-75\% ernst genommen werden können, und es gibt Frauen und seltener Männer, die lügen, wenn sie den Mund aufmachen. Wir sprechen dann von Pseudologie und haben immer das unangenehme Gefühl, daß diese Abnormen selbst so ganz genau zwischen spielerischem Phantasieprodukt, absichtlichem, auf Täuschung berechnetem Schwindel und Erinnerung für gewöhnlich nicht unterscheiden, wenn sie dazu an sich auch durchaus fähig sind. Es gibt aber unzweifelhaft Psychopathen (Pseudologia phantastica), bei denen tatsächliche Erinnerungen, phantastische Umgestaltungen solcher und ursprünglich zweckvolle Erfindungen ganz den gleichen Stellenwert bekommen, so daß es den Betroffenen, zum mindesten unter gewissen Umständen, nicht mehr möglich ist, sich selbst in ihrer Vergangenheit zurechtzufinden und Lüge von Tatsache zu trennen. Hier fehlt offenbar das „Gewissen" des Gedächtnisses, das unseren Erinnerungsraum in der gleichen Weise von fremden, unwirklichen Inhalten reinhält, wie unsere Wahrnehmungswelt in der Regel rein gehalten wird von Einbrüchen sinnlich lebhafter Vorstellungen von pseudohalluzinatorischem Charakter.

Jedem Normalen geschieht es, freilich recht selten, daß in ihm Bilder auftauchen, die er nicht recht einzuordnen vermag; es bleibt zweifelhaft, ob es sich um tatsächliche, weit zurückreichende Erinnerungen, ob um die Erinnerung an Traumerlebnisse oder aber um ursprüngliche, oft erinnerte Phantasien handelt. Bei manchen Schizophrenen kommt es zu Zeiten gehäuft zu Einfällen, die - als Halluzinationen der Erinnerung - mit dem Charakter tatsächlicher Erinnerungen auftreten und die Vorgeschichte, inhaltlich meist in spezifischer Weise, so umgestalten, wie die gegenwärtige Wirklichkeit von Halluzinationen umgestaltet wird.

Zugleich, bei manchen Kranken auch allein, sehen wir eine ausgedehnte grobe Umgestaltung tatsächlicher Erinnerungen, deren realer Kern unter den Zutaten fast verlorengehen kann, während in wieder anderen Fällen nur neue Bedeutungen an die Erinnerungen anknüpfen, die nun selbst einen falschen Erinnerungscharakter annehmen. Solche Kranke bezeichnen ihre Erlebnisse dieser Art gern als Einfälle; man könnte sie auch Illusionen der Erinnerung nennen.

Ganz anderer Natur sind die Konfabulationen, die bei Kranken mit schweren Merkstörungen an der Tagesordnung sind. Die Merkunfähigkeit führt zu Lücken in der Erinnerung, die dann auf Drängen oder auch spontan mit Erfindungen gefüllt werden. Diese Konfabulationen knüpfen inhaltlich meist an den gewöhnlichen früheren Alltagslauf an oder aber es werden tatsächliche frühere Einzelerinnerungen bei gestörtem Zeitgitter fälschlich in die Lücke eingesetzt. Endlich kann es bei gestörtem Bewußtsein, Begriffszerfall und desorganisiertem Triebleben zur Produktion üppiger, unsinniger und unwahrscheinlicher konfabulatorischer Inhalte kommen, die oft traumhaften Charakter haben. Gelegentlich werden auch deutlich erinnerte Trauminhalte als tatsächliche Erinnerungen wiedergegeben. 
Vereinzelt haben viele Normale, etwa in Zuständen der Ermüdung, das Gefühl des Déjà vu, d.h. sie erfahren den Eindruck, das soeben Erlebte schon einmal in genau der gleichen Weise erlebt zu haben. Manche Psychopathen leiden sehr oft unter diesem peinlichen Erlebnis. Weiter gibt es Schizophrene, die durch lange Zeit hindurch von jedem einzelnen Vorkommnis erklären, daß sie es in genau der gleichen Form vor langer Zeit erlebt hätten. Sie vermeinen also, ganze Lebensstrecken zu wiederholen. In solchen Fällen fehlt aber das Gefühl des Befremdens, das dem gewöhnlichen Déjà vu eigentümlieh ist. Das ganze Geschehen hat eher einen wahnhaften Charakter.

Als reduplizierende Paramnesie bezeichnet man die Tatsache, daß manchen organisch Hirngestörten eine einheitliche Zeitstrecke gewissermaßen in Bruchstücke zerfällt. Obgleich mit ihnen nichts Ungewöhnliches geschieht, behaupten sie doch fälschlich, schon früher einmal in dem gleichen Bett und in dem gleichen Krankenhaus gewesen zu sein. Oder aber sie schildern aktuelle oder aber zurückliegende Szenen als soeben und vor langer Zeit schon einmal in ähnlicher oder gleicher Weise erlebt. Zugleich bestehen freilich wohl immer auch andere organische Störungen der Merkfähigkeit, der Orientierung (amnestische Lücken usw.), so daß jeder Einzelfall dieser Art nur durch eine nähere Analyse in seiner Entstehung geklärt werden kann.

\section{Intelligenzstörungen}

Intelligenz bedeutet die Fähigkeit, die Gegenstände in ihrem Zusammenhang zu übersehen, d.h. Ganze zu sehen, aber auch anschauliche Ganze zu gliedern, zu binden und zu lösen, sodann entsprechend diesen Einsichten zu handeln bzw. begrifflich zu formulieren. Je größere Zusammenhänge überblickt werden, je mehr Gewohntes zur neuen Aufgabe wird, um so größer ist die Intelligenz. In beiden Fällen haben wir wiederum eine Auswirkung jenes Prinzips, das die menschliche Entwicklung bestimmt und darauf hinwirkt, das Handeln immer weiter hinauszuschieben.

Voraussetzung für eine durchschnittliche Intelligenz sind Gedächtnis, Auffassungsdispositionen und ${ }_{9}$ Gitter ${ }^{6}$-Bildungen. Schon der Erwerb der Sprache setzt Fähigkeiten zu lösen und zu binden voraus, Sprachlaute als Ganze herauszulösen, Sprachantriebe zu Ganzen zusammenzubinden. Wo es nicht zur Sprachentwicklung kommt, da liegen tiefe, angeborene oder auch früh erworbene Schwachsinnszustände vor, es sei denn, daß wir es mit besonderen Herdstörungen zu tun haben. Im allgemeinen ist der Reichtum der Sprachentwicklung als ein Maßstab der Intelligenz brauchbar, soweit die Sprache nicht begriffsleer bleibt und lediglich die Reproduktion nicht begriffenen fremden Gedankengutes wird.

Genies sind Menschen, die entscheidende neue Zusammenhänge sehen, Idioten solche, die Einsichten überhaupt nicht zu gewinnen vermögen. Zwischen Genie und Idioten findet sich eine unendliche quantitative und qualitative Mannigfaltigkeit der Intelligenz, wobei die große Mehrzahl bei geringen quantitativen Unterschieden dadurch gekennzeichnet ist, daß ihre Intelligenz ihnen gestattet, ihr Denken den Forderungen des Alltags anzupassen und, bei besonderer Schulung, nachdenkend auf einzelnen Gebieten 
die Grenzen zu erreichen, welche die geistigen Wegfinder abzustecken unternehmen. Dabei sind die qualitativen Unterschiede bedeutend. Es gibt vorwiegend anschaulich und vorwiegend begrifflich gerichtete Intelligenzen, technische und psychologische, Spezialbegabungen auf bildnerischem, musikalischem, mathematischem, sprachlichem Gebiete. Fast jeder Mensch ist partiell schwach begabt, also etwa ein darstellerischer Idiot oder ein musikalischer oder ein mathematischer Imbeziller. Es gibt rasche und langsame Intelligenzen, begrifflich scharfe und gefühlsmäßig intuitive, theoretische und praktische, tiefe und breite, weltkluge psychologische und weltfremd ideologische Intelligenzen, $d . h$. hier überall spielen Interessen, Temperaments- und Charaktereigenschaften eine ebenso große Rolle wie Quantität und Gliederung der mnestischen und anschaulichen Dispositionen.

Schwachsinn nehmen wir dort an, wo diese Dispositionen trotz erzieherischer Maßnahmen nicht ausreichen, die durchschnittliche Schulbildung zu erwerben und die Forderungen eines gelernten Berufes zu bewältigen. Je nach dem Zurückbleiben hinter diesen Zielen sprechen wir von Dummheit, Debilität, Imbezillität, Idiotie.

Demgegenüber bedeutet „Demenz" den erworbenen Schwachsinn, d. h. den Verlust früher vorhandener intellektueller Funktionen, die Verarmung des Weltbildes infolge geistiger Krankheit. Je nach der Art des Krankheitsprozesses und dem Sitz und der Ausbreitung der Hirnveränderungen unterscheiden wir verschiedenste Demenztypen. Aus dem großen Topf der Demenzen nehmen wir aber die eigentlichen Herdstörungen, die Ausschaltungen hochorganisierter Spezialapparate, nämlich die Aphasien, die Agnosien und die Apraxien, heraus.

\section{Ursachen des Irreseins}

\section{a) Exogene Krankheitsursachen}

Gesundheit bedeutet Anpassung an die in erheblicher Breite schwankenden durchschnittlichen Lebensreize, Krankheit eine nicht mehr zureichende Anpassung, so daß es nicht mehr zur Erreichung der für Art und Individuum gesetzten Lebensziele kommt. Anpassung kann unmöglich werden, wenn die Lebensreize das durchschnittliche Maß überschreiten, oder aber wenn die Anpassungsbreite der Person dauernd unzulänglich ist oder doch vorübergehend wird. Im ersteren Falle wird jeder Mensch erkranken, im letzteren Falle werden schon durchschnittliche Lebensreize zur Erkrankung zu führen vermögen. Die Anpassungsbreite bleibt auch im Einzelleben nicht immer die gleiche. Vor allem aber zeigt sie von Person zu Person quantitativ und qualitativ die erheblichsten Unterschiede. Stets entsteht Krankheit, auch die seelische, aus dem Wechselspiel zwischen inneren Voraussetzungen und äußeren Einwirkungen, wobei bald die ersteren, bald die letzteren von vorwiegender Bedeutung sind, beide aber in jedem Falle Berücksichtigung verdienen.

Beim Vorwiegen der äußeren Schäden sprechen wir von exogenen Erkrankungen, bei jenem der inneren Voraussetzungen von endogenen 
Leiden und Anomalien. Nicht immer ist die Einordnung einer Erkrankung in die eine dieser beiden Gruppen leicht; ja manche Krankheitsformen kann man zu der einen und zu der anderen Gruppe stellen. In weitesten Bereichen aber macht die Zuteilung keine Schwierigkeiten.

So gehören vor allem die durch äußere Schäden hervorgerufenen Hirnerkrankungen zu den exogenen Leiden. Neben den groben Hirntraumen, die eine Hirnerschütterung (Commotio) und -zertrümmerung (Contusio) herbeiführen und je nach dem Sitz der Schäden die verschiedensten Bilder machen, sind hier an erster Stelle die infektiösen Erkrankungen zu nennen. Die Enzephalitiden der verschiedensten Art (Encephalitis epidemica, Enzephalitis nach Pockenimpfung, Allgemeininfektionen) rufen im akuten Stadium besonders Delirien hervor, können aber auch zu bleibenden Defekten führen. Insbesondere wenn sie im frühen Kindesalter oder intrauterin auftreten, kommt es unter Umständen zu Schwachsinn und Persönlichkeitsmängeln. Von den Meningitiden gilt das gleiche, zumal sie ja meist das Hirn mehr oder weniger mitbeteiligen. In diese Gruppe gehört auch ein großer Teil der luischen und metaluischen Hirnerkrankungen (Meningitis und Meningoencephalitis luica, Paralyse).

Die Lues cerebri leitet schon hinüber zu den mancherlei Gefäßerkrankungen auf infektiöser, toxischer und autotoxischer Grundlage. Hier ist neben der Gefäßlues besonders die Hirnarteriosklerose zu nennen, die man insofern, als sie sich nicht am Hirnparenchym, sondern am Gefäßsystem abspielt, als exogene Krankheit bezeichnen kann, aber zu den endogenen Leiden rechnen muß, wenn man das Gehirn als Gesamtorgan ins Auge faßt. In der Tat spielen gerade bei der Arteriosklerose Anlagefaktoren eine wesentliche Rolle, wenngleich man auch die Art der Lebensreize nicht ganz außer acht lassen darf.

Zum Teil über grobe Störungen des Gefäßapparates hinweg wirken auch manche Gifte, vor allem der Alkohol in der Polioencephalitis haemorrhagica superior und das Kohlenoxyd. Sie können das Hirn aber auch unmittelbar schädigen, wie der Alkohol im Rausch, wie Morphin, Atropin, Hyoszin und die in jüngster Zeit viel studierten Rauschmittel Meskalin und Haschisch, die eigenartige, kurzdauernde Psychosen herbeiführen. Chronisch mißbrauchte Gifte, vor allem wiederum der Alkohol, aber auch die Schlafmittel der Barbitursäurereihe (Veronal, Medinal, Luminal, Phanodorm) führen, selten, zu groben Seelenstörungen, offenbar auf dem Umwege über ätiologische Zwischenglieder, d.h. Stoffwechselstörungen, für die wohl Leber- und Nierenschädigungen eine Rolle spielen. Aber auch ganz andersartige Giftwirkungen können zu Seelenstörungen Anlaß geben, so die toxischen Produkte, die bei der Urämie oder bei der akuten gelben Leberatrophie entstehen; ferner gewisse schwere Diabetesformen und die Hypoglykämie, die wir insbesondere in den Insulinkuren kennengelernt haben. Auch Hunger, Übermüdung und Erschöpfung dürften zum Teil über Veränderungen der Stoffwechsellage zu seelischen Wirkungen führen.

Allen den bisher genannten Schäden, die unmittelbar oder mittelbar am Hirn angreifen und hier zu anatomisch greifbaren Veränderungen führen, ist gemein, daß sie im Seelenleben zu den sog. „,exogenen Reaktionstyp e n" führen. In Krankheitszuständen dieser Art finden wir Merkstörungen, Bewußtseinsveränderungen und daneben solche der "vitalen" Person, d.h. Störungen der Antriebe, der Schlaf-Wachregulation, überhaupt des Trieb- 
lebens, aber auch Stimmungsverschiebungen. Alle diese Symptome begleiten die gröberen psychotischen Symptomenkomplexe, sind aber selbst in den leichtesten Formen exogener Seelenstörung, den echten Neurasthenien, den hyperästhetisch-emotionellen Zuständen nachweisbar.

Die Ursachengruppen, die wir nun zu besprechen haben, machen solche Wirkungen überhaupt nicht mehr oder doch nur in ihren stärksten Graden. Damit kommen wir zugleich zu jenen Seelenstörungen, in denen innere Momente den Ausschlag geben. Als exogene Krankheitsursachen können vor allem noch die ausgesprocheneren endokrin-vegetativen Leiden wirken, so der Basedow und das Myxödem, die Tetanie, der Addison und gewisse Hypophysenerkrankungen. Aber beim Addison haust meist die Tuberkulose im Körper, und es kommt zu groben somatischen Störungen neben dem Ausfall der Nebennierenprodukte. Die Hypophysenstörungen aber sind oft nicht so sehr durch den Ausfall der Hormone als durch Art und Sitz des Prozesses im Schädelinnern (Tumor, Enzephalitis) wirksam, so daß wir hier tatsächlich nicht rein endokrine Erkrankungen vor uns haben. In ihren leichteren Formen gehören die endokrinen Störungen zu den „Anomalien“, die viel besser von der Seite der inneren Voraussetzungen her betrachtet werden. In dieser Hinsicht haben sie aber eine sehr erhebliche Bedeutung. Kastraten und Eunuchoide sind leistungsschwach, wenn auch oft sehr fleißig, wenig aktiv und zu Ausweichreaktionen geneigt. Die Basedowoiden und Hyperthyreotischen kennen wir als erregbar, beweglich, zu lebhaften Gefühlsreaktionen und besonderen Anschauungsbildern geneigt. Demgegenüber zeigen die Tetanoiden eine ausgesprochene Organbereitschaft zu psychogenen Störungen neben starren Anschauungsbildern; die Hypophysären sind gern von einer oberflächlichen, torpiden Euphorie, kurz, allenthalben haben wir es mit Wesenszügen zu tun, die sich viel eher als persönliche Eigentümlichkeiten denn als Krankheitserscheinungen auffassen lassen, und die als solche in genetisch andersartige Seelenstörungen eingehen oder deren Zustandekommen erleichtern.

Endlich wirken seelische Krankheitsursachen so gut wie immer nur bei anlagegemäß gegebenen oder anderweitig vorbereiteten Gesamtverfassungen, äußerst selten einmal allein. Wenn Hoche sagt, daß jeder Mensch hysteriefähig sei, so ist dies gewiß richtig; nur muß man hinzudenken: unter ganz besonderen Bedingungen, also etwa in Zuständen der Erschöpfung oder wenn der Erkrankende toxisch vorbereitet oder sonst organisch leicht geschädigt ist. Bei der großen Mehrzahl der seelischen Krankheitsursachen ist das krankmachende Erlebnis nicht viel mehr als die Gelegenheit zum Erkrankungsbeginn. Eine Ausnahme macht wohl nur der Schreck, der, zumal bei großen Katastrophen, Erdbeben, Springflut, Feuersbrünsten, Explosionen, sehr zahlreiche Menschen abnormisiert, offenbar auf dem Umwege über ausgebreitete Gefäßreflexe und eine überreichliche Ausschüttung von Adrenalin ins Blut. In solchen Fällen sind meist auch die körperlichen Erscheinungen sehr ausgeprägte, und es kann bei Disponierten (alte Leute mit nicht mehr recht intaktem Gefäßsystem) auch zu tödlichen Erkrankungen (Delirien, Dämmerzuständen organischen Gepräges) kommen. Im Kriege sind solche organischen Schreckfolgen vor allem von Ärzten hinter der Front beschrieben worden; an der Front habe ich nichts davon gesehen. Hier waren vorwiegend junge Leute. 
Die meisten seelischen Krankheitsursachen im Sinne einmaliger Erlebnisse kommen erst auf dem Boden chronischer Lebenskonflikte zur Wirkung. Diese aber sind immer oder doch so gut wie immer Ausdruck von ursprünglichen Anpassungsmängeln. Oder aber es werden Menschen betroffen, die zwar keine eigentlichen leidvollen Lebenskonflikte haben, aber sonst unzulänglich sind (Gefangenschaft). Das Kennzeichnende dieser Seelenstörungen ist, daß ihnen der organische Kern des exogenen Syndroms fehlt, daß sie vom Erkrankenden her gesehen immer einen Sinn und vom Beobachter aus betrachtet meist einen Zweck erkennen lassen. Dies gilt nicht nur für die Stimmungsänderungen, Affekte und gedanklichen Inhalte, sondern auch für die motorischen und vegetativen Entäußerungen, die in der Regel als Verstärkungen auch dem Normalen verfügbarer Reaktionen erscheinen (hysterische Erregungen, Stuporen, Lähmungen, Sinnesausschaltungen usw.).

In diesem ganzen Bereich sprechen wir von „psychogenen“ Krankheitserscheinungen und meinen damit, daß sie nach Art und Inhalt durch affektbeladene Gedankeninhalte bestimmt erscheinen. Bei den gleichfalls hierher gehörigen abnormen Reaktionen haben wir den Gesamtverlauf im Auge, die ursächliche und inhaltliche Beziehung zum Ausgangserlebnis und endlich die Tatsache, daß hier eine Person abnorm reagiert hat, sich mit einer seelischen Tatsache in abnormer Weise auseinandersetzt. Wo es der reagierenden Person zugleich auf einen äußeren Krankheitsgewinn ankommt, nennen wir die psychogenen Reaktionen "hysterische“. Für diese Diagnose ist also immer Zweckhaftes, Willensmäßiges Voraussetzung. Bei Krankheiten aus seelischen Ursachen finden wir am Hirn Veränderungen nicht. Das Seelenleben erscheint nur anders geschaltet, anders in der Funktion; man nennt diese Seelenstörungen daher auch „funktionelle“, mit einem Ausdruck, der am besten vermieden werden sollte.

\section{b) Endogene Krankheitsursachen}

Endogene Krankheitsursachen sind alle jene Bereitschaften, die ursprünglich in der Person angelegt sind, wenn sie vielleicht auch erst in späteren Entwicklungsstadien zur Auswirkung kommen. Hierher gehören schon die besonderen Bereitschaften der einzelnen Lebensalter, der Geschlechtsund der Stammeszugehörigkeit. So stellen etwa Pubertät und Involutionszeit besonders kritische Phasen dar, in denen auch der "Normale" ganz ohne leichteste Störung kaum besteht. Zumal in der Pubertät kommt es, abgesehen von der Reifung der Sexualdrüse, zu einer Umwertung aller Werte, zu einer Neuorientierung gegenüber der Welt, wie vor allem dem eigenen und dem anderen Geschlecht. Dazu treten beim Arbeiter und Handwerker noch die neuartigen Aufgaben des Berufs und die auch äußerliche Emanzipation vom Elternhaus. Wohl kein Reifender bleibt von neuen Stimmungen und dem ersten Ansturm seiner sexuellen Triebregungen so unberührt, daß die Ausreifung sich ganz ohne vorübergehende Unruheerscheinungen, unmerklich, vollzöge. Bei disharmonisch Angelegten kommt es in der Pubertät vielfach zum ersten deutlichen Ausdruck der Unzulänglichkeit, und um die gleiche Zeit melden sich nicht selten auch die sog. endogenen Psychosen an. 
Nicht weniger kritisch ist bei den Frauen die Zeit des Klimakteriums, in dem neben dem Erlöschen der Keimdrüsenfunktion mit dessen mancherlei vegetativen Folgeerscheinungen auch seelisch erhebliche Forderungen an die Person herantreten, die mit dem ,Verblühen" verbundenen Verzichte, das herandrängende Wissen um Versäumtes, die Einbuße an Liebe und Bewunderung, die Last von Pflichten (für Kinder und Mann), denen innere Voraussetzungen nicht entsprechen, vor allem aber auch der drückend sichtbare Niedergang von Interessen und geistiger Leistungsfähigkeit. Auch hier ist also ein wohlvorbereiteter Boden für mancherlei seelische Konflikte und zugleich die nächst der Pubertät häufigste Ansatzstelle für die Auswirkung eigentlicher endogener Krankheitsanlagen.

Daneben hat jedes Lebensalter seine besonderen Krankheitsbereitschaften, zum Teil deshalb, weil die Entwicklung allmählich mit immer neuen äußeren Krankheitsursachen in Berührung bringt, die Frau mit dem Gestationsgeschäft und den damit häufig verbundenen Infektionen, den Mann mit Alkohol, Nikotin und gewerblichen Giften, beide mit der Syphilis. Im höheren Lebensalter kommt es zur Involution des Gefäßsystems, zu Organerkrankungen, vor allem aber auch zum Abbau des Gehirns selbst, das mit dem Menschen altert, nicht selten sogar rascher als der Gesamtkörper.

Die beiden Geschlechter sind an den einzelnen Krankheiten in verschiedenem Ausmaß beteiligt. Ganz allgemein kann man sagen, daß Gifte, Traumen und vor allem die Syphilis den Mann stärker bedrohen, und daß andererseits der Frau aus ihrer Bereitschaft zu stärkeren Gemütsbewegungen größere Gefahren erwachsen. So erkranken Frauen häufiger an dem großen Kreis der Gemütsleiden, Männer an Paralyse, Epilepsie, Alkoholschäden sowie auch Arteriosklerose, während die Schizophrenie bei den Geschlechtern wohl gleich häufig auftritt. Im ganzen Bereiche der Seelenstörungen erscheint die Erregbarkeit der Frau erheblich größer (Frauen brauchen ein Vielfaches an Beruhigungsmitteln), und erotische und religiöse Komplexe beherrschen sie in weitaus stärkerem Maße, während der Mann durch Berufskonflikte und die Sorge um die Familie am meisten belastet erscheint.

Auch die Stammeszugehörigkeit ist von Bedeutung insofern, als die endogenen Krankheitsanlagen eine sehr verschiedene Ausbreitung zu haben scheinen. So erkranken etwa die westeuropäischen Juden sehr viel häufiger an den endogenen Psychosen (manisch-depressives Irresein und Schizophrenie) als die umgebenden Bevölkerungen, seltener dagegen an Alkoholismus und Epilepsie; entsprechend ihrer andersartigen sozialen Gliederung ist bei ihnen auch die Paralyse sehr verbreitet. Die Schwaben und die Sachsen haben eine ausgesprochene Neigung zu Depressionen (die Sachsen zugleich zu abnormen depressiven Reaktionen) und damit auch eine große Selbstmordneigung, die Badener und Pfälzer Bevölkerung, in geringerem Maße auch die Bayern, sind demgegenüber zu Erregungen, insbesondere auch zu Manien, disponiert. Bei den Oberschlesiern findet sich eine besonders große Neigung zu gewissen (pseudodementen) Reaktionen, die von allen Beobachtern einmütig festgestellt wurde und die vielleicht im Zusammenhang steht mit dem Mischcharakter der Bevölkerung und deren recht mäßiger durchschnittlicher intellektueller Veranlagung. Was in dieser verschiedenartigen Erkrankungs- 
bereitschaft deutlich wird, das findet sich auch im Durchschnittsbild der Bevölkerungen als Stammeseigentümlichkeit wieder.

\section{c) Erblichkeit}

Damit kommen wir zu den erblichen Grundlagen der Persönlichkeit, wie insbesondere auch der erblichen Seelenstörungen. Die wichtigsten Tatsachen der Erblehre können hier als bekannt vorausgesetzt werden.

Über die Erblichkeit und den Erbgang vieler körperlicher Merkmale, auch pathologischer, wissen wir recht gut Bescheid. Von den am gröbsten greifbaren pathologischen Erbanomalien, etwa der Polydaktylie, her wissen wir zugleich, daß eine erhebliche Variationsbreite besteht und daß keineswegs jeder Anlageträger äußerlich krank sein muß. Ein erbliches Merkmal muß sich also nicht absolut sicher manifestieren, und die Manifestationswahrscheinlichkeit kann eine ganz verschiedene sein. Auch seelische Züge sind unzweifelhaft erblich. Wir wissen dies von der "Intelligenz" im allgemeinen aus großen Massenuntersuchungen und ausgedehnten Familienerhebungen, kennen die Erblichkeit mancher Spezialbegabungen (Musikerfamilie Bach, Mathematiker Bernoulli). Wir wissen ferner, daß Goethe nicht bloß mit Lucas Cranach und dem hochbegabten europäischen Fürstenhaus, sondern auch mit den Brüdern Schlegel, mit den Grimms, mit Rudolf Binding und Sigrid Onegin verwandt ist. Kurz, allenthalben ist die Erblichkeit seelischer Anlagen deutlich, doch fast auf keinem Gebiete sind wir soweit, bestimmte Erbgänge aufzuzeigen. Dies gelingt schon deshalb nicht so rasch, weil die abzugrenzenden physiologischen und klinischen Merkmale wohl selten auf reinlich erkennbare Einzelanlagen zurückführen.

Dennoch ist im Bereiche der endogenen Seelenstörungen die Forschung so weit gediehen, vor allem unter der Führung von Ernst Rüdin und seinen Schülern, daß wir schon recht Bestimmtes wissen. Wir kennen ein dominantes Erbleiden in der Chorea Huntington, ein einfach rezessives in der Myoklonusepilepsie. Wir wissen, daß ein großer Teil des erblichen Schwachsinns mit Wahrscheinlichkeit rezessiv ist und daß es wohl auch dominante leichtere Schwachsinnsformen gibt. Beim manisch-depressiven Irresein spielen, neben rezessiven, offenbar auch dominante Faktoren eine Rolle (wir haben es hier mit einer Polymerie zu tun). Bei der Schizophrenie hat man lange an einen dihybriden rezessiven Erbgang gedacht; dann wieder schien vieles für einfache Rezessivität zu sprechen und neuerdings sind Stimmen aufgetaucht, die eine wenn auch unvollkommene Dominanz vermuten. Die Dinge sind jetzt noch im Fluß; immerhin meint Luxenburger auch heute, daß Rezessivität wahrscheinlicher sei als Dominanz.

Man hat daran gedacht, daß manche Psychopathen im Umkreis der Schizophrenie intermediäre Typen sein könnten (die Schizoiden), und die gleiche Vermutung ist für die ausgesprochenen Temperamente im Umkreis des manisch-depressiven Irreseins berechtigt; endlich haben wir im Bereiche der Epilepsie in gewissen explosiv-erregbaren Menschen und anderen, die in vielen Einzelzügen Epileptikern gleichen (umständlich, pedantisch, klebrig), Typen vor uns, die, freilich nicht näher bekannte, Erbbeziehungen zu den ausgebildeten Formen der Epilepsie haben. Die hier in Angriff genommenen Forschungen werden die Erblehre allmählich immer weiter aus jenem un- 
fruchtbaren Anhäufen von Tatsachen herausführen, das die Forschung früher belastete.

Früher pflegte man die erbliche Belastung eines Menschen festzustellen, indem man alles, was einigermaßen auffällig in seinem Blutkreis war, herausgriff und zusammenzählte. Ja, man war geneigt, erbliche Belastung in manchem Falle gleich Krankheit zu setzen. Die Erfahrung, daß in einzelnen Familien die aufeinanderfolgenden Generationen immer schwerere Krankheiten zeigten, bis sie mit Idioten erloschen, faßte man zu der Lehre der Degeneration zusammen, nach der einmal von seelischen U̇beln befallene Stämme dem unentrinnbaren Schicksal verfallen schienen (Morel). Die Gegenprobe zeigte, daß auch die Gesunden erblich stark „belastet ${ }^{66}$ sind, ja daß der Unterschied gar kein sehr erheblicher ist, wenn man große Gruppen von Kranken solchen Gesunder gegenüberstellt.

Ủber der Quantität der belastenden Faktoren wurde die Qualität ganz übersehen, bis dann mit besonderem Nachdruck erst in der Mendelschen Ära dieser Gesichtspunkt zur Geltung kam. Ausgedehnte Familienuntersuchungen und die Anwendung statistisch einwandfreier Methoden (hier ist in der psychiatrischen Erblehre wichtig insbesondere die Geschwistermethode, welche die Tatsache berücksichtigt, daß bei gleicher Erblage neben Geschwisterschaften mit lauter Kranken auch solche ohne Kranke vorkommen) haben entscheidenden Gewinn gebracht. Die jüngste Zeit hat dann besonders die Zwillingsmethode entwickelt, welche die Familienuntersuchungen in wesentlichen Punkten ergänzt, Auskunft über die Manifestationswahrscheinlichkeit von Erbübeln und Einblick in die Mitwirkung äußerer Faktoren an Entstehung und Gestaltung erblicher Erkrankungen verspricht.

Auch gegenwärtig beachtet man natürlich alle ,belastenden ${ }^{66}$ Faktoren. Das Hauptaugenmerk gilt aber zunächst dem qualitativ Gleichartigen, zu dem alle anderen Befunde dann in Beziehung gesetzt werden. So zählt man etwa in Schizophrenensippen als Nachkommen der Schizophrenen 10\% wiederum Schizophrene, daneben aber etwa 40\% psychopathische Menschen, zum großen Teil bestimmten Gepräges, daneben eine Tuberkulosehäufigkeit, die jene der Durchschnittsbevölkerung übersteigt, während sich im Umkreis Manisch-Depressiver zahlreiche Zykloide und Zyklothyme finden und auffällig häufig auch Stoffwechselleiden (Diabetes, Gicht).

Endlich ist hinzuweisen auf die Häufigkeitsbeziehungen zwischen bestimmten Körperbautypen und den großen Formenkreisen des manischdepressiven Irreseins, der Schizophrenie und der Epilepsie. Während der pyknische Körperbau unzweifelhaft bei Manisch-Depressiven sehr viel häufiger ist als in der Durchschnittsbevölkerung, scheint die Epilepsie athletische und dysplastische Typen zu bevorzugen. Schizophrene endlich sind vielleicht nicht häufiger leptosom als der Durchschnitt; an ihrer Vorliebe für ausgesprochen asthenische Formen habe ich aber keinen Zweifel, und auch dysplastische Typen dürften in der Durchschnittsbevölkerung seltener sein als bei Schizophrenen.

Es kommt also heute nicht mehr, wie noch vor zwei Jahrzehnten, auf die Feststellung der allgemeinen Belastung an, sondern auf die Heraushebung zahlreicher, wohl gekennzeichneter Einzelheiten im erblichen Umkreis der Kranken, die diagnostisch-prognostisch und genetisch von zunehmender Be- 
deutung sind. So ist es heute möglich geworden, Erbeinflüsse auch dort aufzuzeigen, wo heterogene Krankheiten ablaufen. Bei manisch-depressiv belasteten Arteriosklerotikern und Paralytikern etwa lassen sich häufig besonders klare affektive Syndrome feststellen, und Schizophrene, die a uch zirkulär belastet sind, zeigen nicht selten einen zirkulären Verlauf ihrer Erkrankung, oder aber eine Symptomatologie, welche den Krankheitsfall aus dem großen Durchschnitt in kennzeichnender Weise heraushebt, oder endlich eine ungewöhnliche Widerstandskraft gegen die zerstörende Wirkung der Grundkrankheit. Auch der Körperbau gibt gewisse prognostische Hinweise insofern, als etwa bei Manisch-Depressiven mit asthenischem Körperbau die Phasen auffallend lang dauern, bei pyknischen Schizophrenen andererseits die Prognose nicht selten eine ungewöhnlich gute ist.

Sehr große Schwierigkeiten macht der Erblehre noch der große Kreis der abnormen und psychopathischen Persönlichkeiten. Psychopathien sind regelwidrige Dauerverfassungen von den verschiedensten Gradausprägungen; es gibt hier keine scharfe Grenze gegenüber der Norm, aber auch zwischen den einzelnen psychopathischen Anomalien nicht. Der einzelne kann Träger verschiedener ungünstiger Dauereigentümlichkeiten sein; und die psychopathische Wesensart läßt sich meist nur dort klar erfassen, wo sie ihren Träger in irgendeiner Form sozial auffällig macht. Im übrigen ist eine sehr genaue und langdauernde Bekanntschaft erforderlich, wenn der Erbaufbau mit einiger Aussicht auf stichhaltige Ergebnisse erforscht werden soll. Praktisch ist dies nur in einem sehr beschränkten Kreis von Menschen möglich. Dazu kommt, daß die gleichen klinischen Äußerungsformen genetisch ganz Verschiedenes bedeuten können, und daß vermutlich die meisten normalen und psychopathischen seelischen Eigenschaften polymer sind, also auf mehrere Erbeinheiten zurückgehen. Psychopathische Wesenszüge werden also unter Umständen immer neu aufgebaut werden und ebenso wieder verschwinden, ganz einfach nach dem Gesetz der Amphimixis, die gelegentlich besonders ungünstige Lose zusammenmischt dort, wo das Ausgangsmaterial im ganzen vortrefflich erscheint. Dennoch kann kein Zweifel sein, daß manche ausgesprochen psychopathische Wesenszüge bestimmte, einheitliche, erbliche Eigentümlichkeiten darstellen. So sehen wir in manchen Familien gleiche Formen hysterischer Krankheitsbereitschaften, asozialer Wesenszüge u. a. immer wiederkehren. Andererseits gestattet nicht ganz selten die Analyse der Blutsverwandtschaft, den Aufbau komplizierter psychopathischer Anomalien aufzuklären. Wir kennen „antinome“ Charakterstrukturen, in denen von den beiden Eltern übernommene, miteinander unverträgliche Erbeigenschaften im Kampf liegen, so daß der Betroffene nicht zur Ruhe kommt und in einzelnen Lebensperioden oder auch dauernd zu bestimmten psychopathischen Reaktionen neigt. Insbesondere $Z$ wangsmenschen scheinen solche antinomische, in ihrem Erbaufbau gut verfolgbare Charakterstrukturen zu haben. 


\section{Struktur der Psychosen}

\section{a) Allgemeines}

Die Diagnose stellen wir in der Psychiatrie nach dem ursächlichen (pathogenetischen) Hauptfaktor. Wir sprechen also von Alkoholdelirium, weil es zu einer bestimmten Art des Delirs nur bei alten Schnapstrinkern kommt. Dabei wissen wir aber, daß das Delir auch bei diesen erst dann ausbricht, wenn sie noch von anderen Schäden betroffen werden, also etwa an einer Bronchitis oder einer Pyelitis erkranken, einen Knochenbruch oder ein anderes Trauma erleiden. Ganz ähnlich ist es weithin im Bereiche der Seelenstörungen. Zusatzursachen können sich auch im klinischen Bilde ausprägen, und in diesem finden wir regelmäßig auch sonst zahlreiche Einzelzüge, die nicht auf die Hauptursache zurückführen, sondern auf andersartige Bedingungen hinweisen, unter denen der Erkrankende zugleich steht. So machen sich Persönlichkeit und Erblage, Lebensalter und Geschlecht, Rassenzugehörigkeit und Lebensgewohnheiten, aktuelle Erlebnisse wie individuelle Geschichte in den Krankheitserscheinungen bemerkbar. Im Erscheinungsbild der Paralyse etwa kommt zum Ausdruck, daß der Kranke viel getrunken hat, daß er ein gebildeter Mensch ist oder besonders viel mit Zahlen zu tun hatte, daß er ein heiteres Temperament und daß er schon über 50 Jahre alt ist. Alle diese Umstände, die auf das klinische Bild Einfluß gewinnen, ja unter Umständen die Wirkung der Hauptkrankheitsursache verdecken, nennen wir pathoplastische. Besonders wichtig können für die Erscheinungsweise einer geistigen Erkrankung die Erlebniszusammenhänge werden, die das Leben bis zum Ausbruch der Psychose mitgestaltet haben. So kann sich etwa auf den durch eine beginnende Schizophrenie aufgelockerten Boden eine abnorme seelische Reaktion a ufp fropfen und den eigentlichen Krankheitsprozeß zunächst ganz verdecken. Nicht selten vermag ferner ein eingreifendes seelisches Erlebnis die ersten Erscheinungen einer endogenen Erkrankung heraufzuführen, die Erkrankung zu „provozieren“", wenngleich in den meisten Fällen dieser Art der Zusammenhang umgekehrt sein dürfte, d. h. ein Ereignis wird zum vermeintlich krankmachenden Erlebnis nur dadurch, daß der Krankheitsvorgang schon im Ablauf begriffen ist und die Reaktionsweise verändert hat. Immerhin kommt es vor, daß auf eine heterogene Einwirkung, etwa eine schwere Infektionskrankheit oder ein Hirntrauma, die endogene Seelenstörung so unmittelbar folgt, daß man an der provokatorischen Wirkung jener Einflüsse nicht wohl zu zweifeln berechtigt ist. Im allgemeinen ist aber bei der Annahme solcher Zusammenhänge größte Vorsicht geboten. Mindestens müssen unmittelbare zeitliche Beziehungen gegeben sein; ein längerer Zwischenraum zwischen äußeren Schäden und endogenen Leiden schließt den ursächlichen Zusammenhang aus.

\section{b) Syndrome}

Der Mannigfaltigkeit der Ursachen entspricht keineswegs eine ebensolche Vielfältigkeit der Erscheinungsformen des Irreseins. Vielmehr hat unser Organismus nur eine verhältnismäßig beschränkte Zahl von Reaktions- 
formen bereit, die auf die verschiedensten Ursachen in annähernd der gleichen Weise ansprechen. Dabei besteht eine deutliche Beziehung bestimmter Reaktionsformen (Syndrome) zu bestimmten Gruppen von Ursachen. Auf der anderen Seite hängt es mit spezifischen Anlagen zusammen, daß beim einzelnen ganz bestimmte Reaktionsformen auf die allerverschiedensten Ursachen hin zutage treten. So kommt es etwa bei manchen Menschen mit epileptischem Erbgut zu Bewußtseinstrübungen nicht bloß bei Infektionskrankheiten und Allgemeinleiden, sondern auch dann, wenn die Betroffenen an manisch-depressivem Irresein leiden, in den Phasen dieser Krankheit oder im Verlaufe schizophrener Prozesse. Und bei Schizoiden nehmen alle Seelenstörungen (etwa die Paralysen) gern ein schizophrenes Gepräge an. Dies muß aber nicht so sein; manchmal sind nur einzelne Züge im Sinne der Erbanlage auffällig, und nur selten gleichen die pathoplastischen Syndrome völlig den endogenen Krankheitsbildern; in der Regel zeigen sie auch unverkennbare Wirkungen der Hauptursache.

In dieser Hinsicht sind die Beziehungen der Syndrome zu den pathogenetischen Hauptfaktoren viel klarere.

\section{Exogene Syndrome und Bewußtseinsstörungen}

Die enzephalopathischen Syndrome entstehen dadurch, daß unter dem Einfluß äußerer Schäden Hirngewebe zugrunde geht. Mehr oder weniger umschriebene Herde erzeugen bei sonst rüstigem Hirn Ausfälle von Werkzeugen des Seelenlebens, und je nach dem Sitz des Schadens entstehen die verschiedenen aphasischen Syndrome, die optisch-agnostisch-räumlichen Störungen, die Apraxien, die Syndrome des Parietallappens, endlich die Stirnhirnsyndrome, in denen affektive und triebhafte Störungen die Hauptrolle spielen, daneben aber wohl immer auch die Herrschaft über die seelischen Werkzeuge leidet. Gegenwärtig ist ein Streit darüber, ob mit jenen Ausfällen bestimmter Hirnapparate jeweils dem Seelenleben nur bestimmte Werkzeuge entfallen, oder aber ob es sich immer um Gesamtstörungen handelt, die nur an bestimmten Verrichtungen zum deutlichsten Ausdruck kommen. Vermutlich ist die Frage falsch gestellt. Ein Werkzeugausfall schädigt natürlich immer auch die Gesamtheit des Seelenlebens insofern, als er sich in allen seelischen Leistungen bemerkbar macht. Auf der anderen Seite kann nicht fraglich sein, daß jeweils der Werkzeugausfall im Vordergrund steht. In den meisten Fällen handelt es sich zudem gar nicht um einen scharf umschriebenen Schaden in einem rüstigen Gesamthirn, sondern um lokal betonte Ausfälle an einem auch allgemein geschädigten Hirn.

Den ausgebreiteten diffusen Hirnerkrankungen entsprechen die verschiedenen Syndrome der Demenz, denen, wenn wir von der schizophrenen Demenz absehen, gemeinsam ist eine Schädigung der mnestischen Funktionen (Gedächtnis, Merken, Reproduktion), die Einengung des Horizontes, die Erschwerung der Auffassung und die Verarmung des Denkens. Mit dem Fortschreiten der Demenz können immer weniger Zusammenhänge erfaßt, Gesamteindrücke immer weniger gegliedert werden; die Neigung zum Haften tritt hervor und die Affekte erlangen eine zunehmende Bedeutung für Denken und Handeln. Nur weil auch die Affektivität darniederliegt und das Triebleben 
verarmt, wird dies nicht immer deutlich. Je nach den Krankheitsprozessen, die zur Demenz führen, lassen sich verschiedenartige Demenztypen unterscheiden, die im speziellen Teil Besprechung finden sollen.

Um eine besondere Form der Demenz handelt es sich beim a mnestisch en Symptomenkomplex. Hier steht äußerlich im Vordergrund die schwere Störung der Merkfähigkeit, infolge deren alle Eindrücke sofort ausgelöscht werden, so daß es zur groben zeitlichen und räumlichen Desorientierung und zu Erinnerungslücken kommt, die durch Konfabulationen ausgefüllt werden. Daneben besteht aber erschwerte Auffassung und meist auch geringes Interesse, wie überhaupt die Affektivität vielfach (nicht immer) darniederliegt oder doch verarmt und vereinseitigt erscheint. Wohl aber kann es zu einer lebhaften Bewegungsunruhe kommen, die sich in die unklar aufgefaßte Umgebung hinein in leeren, stereotypen Handlungen erschöpft. Kennzeichnend für den amnestischen Symptomenkomplex ist, daß die Begriffe nicht oder doch nicht in einem der Störung der Merkfähigkeit vergleichbaren Maße Schaden leiden. Die Kranken können also über Alltägliches und Vertrautes treffend urteilen und schlagfertig antworten. Dennoch zeigt sich, daß zum mindesten das Zeitgitter immer grob gestört ist, so daß es zu falschen Einordnungen kommt und in schweren Fällen Gegenwart und weitere Vergangenheit unentwirrbar sich durchdringen. Die weitere Vergangenheit jenseits der amnestischen Lücke hält viel besser zusammen als die Gegenwart. Fehlauffassungen und -urteile sind nicht selten durch diese Diskrepanz erklärlich. In der Regel sind aber neben dem Zeitgitter auch die anderen Gitter nicht mehr dicht, $d . h$. formal halten sie vielfach noch, aber das Material wird ihnen mangelhaft zugeordnet. Amnestische Syndrome kommen bei allen diffusen Hirnschäden vor, besonders oft bei senilen Rindenverödungen, bei schwerem Alkoholismus und anderen Vergiftungen, aber auch bei Paralyse und ausgebreiteten Erkrankungen der kleinen Hirngefäße. Es ist möglich, daß auch lokale Hirnerkrankungen zu amnestischen Bildern führen. Ga mper hat hier an das Corpus mammillare gedacht, das er bei alkoholischem Korsakow regelmäßig und am stärksten geschädigt fand.

Ausdruck leichterer Allgemeinschäden des Hirns ist das neurasthenische Syndrom, das wir auch als hyperästhetisch-emotionellen Schwächezustand in der Rekonvaleszenz nach schweren Infektionen, nach Hirntraumen, aber auch in anderen Erschöpfungszuständen antreffen, etwa nach langen Perioden der Schlaflosigkeit oder der Überlastung mit Arbeit bei starken affektiven Ansprüchen. Geistige Arbeit als solche, auch wenn sie noch so anstrengend ist, führt nicht zu Neurasthenie; sie tut dies aber bei gleichzeitiger Mißhandlung des Körpers mit Genußmitteln, besonders Alkohol, Nikotin, und Reizmitteln wie starkem Kaffee. Zum neurasthenischen Syndrom gehören zunächst einmal körperliche Störungen, Veränderungen der Reflexerregbarkeit, vasomotorische Labilität, Neigung zu Magen-Darmerscheinungen, Kopfdruck u. a.m. Dazu tritt eine Veränderung der Ansprechbarkeit für Sinneseindrücke, die ungedämpfter, störender erscheinen. Wir haben es hier wohl mit einem Ausdruck der Gesamtveränderung zu tun, die sich in mangelnder Konzentrationsfähigkeit und Ermüdbarkeit äußert und alle geistige Arbeit erschwert, die zugleich weniger interessiert macht, weniger lebendig aufnehmen und damit auch behalten läßt, so daß es auch 
zu Klagen über Merkstörungen und fehlendes Gedächtnis kommt. Weiterhin wird die Stimmung verdrossen, unlustig, gespannt, reizbar; Affekte und vor allem Affektäußerungen können nicht mehr hinreichend beherrscht werden, und schließlich machen sich je nach der Konstitution des Erkrankten auf diesem allgemein gelockerten Boden die besonders ansprechbaren psychopathischen Reaktionsformen breit; leichte paranoide Ideen, leichte Zwangserscheinungen treten hervor, gelegentlich auch stärkere Verstimmungen.

Diese echte Neurasthenie unterscheidet sich ihrer Entstehung und ihrem Verlauf nach entscheidend von der konstitutionellen Neurasthenie, d. h. einer Dauerverfassung, die bei wenig widerstandsfähigen, asthenischen, ermüdbaren Menschen oder aber schlecht disziplinierten oder doch wenigstens schlecht erzogenen zur Gewohnheitshaltung werden kann, mit der sie sich nach Möglichkeit allen unangenehmen Anforderungen entziehen. Die gleichen Menschen können aber bei anderen Gelegenheiten mehr leisten als der Durchschnitt; sie sind neurasthenisch gewissermaßen nur nach Bedarf. Dem echten Neurastheniker dagegen gelingt wohl einmal unter ganz besonderen Umständen, seiner Behinderungen mit aller Willensanstrengung so weit Herr zu werden, daß er nicht versagt. Eine Abhängigkeit seines Befindens von der Laune kennt er aber im Gegensatz zum konstitutionell Neurasthenischen nicht. Immerhin ist verständlich, daß der konstitutionell Neurasthenische unter allen den Umständen, die zur echten Neurasthenie führen, in der Regel besonders leicht erliegt.

\section{Benommenheit}

In der Benommenheit besteht die Neigung, traumlos einzuschlafen. Die Schwelle für alle Sinnesreize ist erhöht. Aber auch im Kranken selbst geht nichts vor; sein Innenleben schweigt oder ist von Gedankenbruchstücken und schattenhaften Gefühlen erfüllt, die ihn nicht zum Stellungnehmen, zum Handeln bringen. Lebhaftere Sinnesreize führen verlangsamt zur Wahrnehmung, die dann gehörig sein kann, nicht aber der Ausgangspunkt selbständigen seelischen Fortschreitens wird. Schwierigere Sachverhalte übersieht der Kranke auch bei lebhafter Aufmerksamkeit nicht. Sein Denken bricht ab, wird bruchstückhaft, da die unzureichende Energie jeweils rasch erlahmt. Nur das Reinlichkeitsbedürfnis führt in der Regel noch zu entsprechendem Handeln. In den tieferen Somnolenzzuständen schweigt auch dies. In der Benommenheit wird nichts gemerkt, schon deshalb nicht, weil in der Regel fast nichts erlebt wird. Aber auch das wenige Erlebte versinkt, wohl weil es nicht zur Gesamterfahrung in Beziehung tritt.

\section{Delirium}

Im Delirium ist auf der inneren Bühne bewegtes Leben, und auch die Motorik ist belebt. Die inneren Erlebnisse sind dabei aber traumhaft-chaotisch. Visionen herrschen weitaus vor und sie nehmen die phantastischen Formen an, die wir aus dem Traum kennen. Es kann auch zu, seltenen, Gehörstäuschungen, häufiger zu solchen des Gleichgewichtsapparates und des Gemeingefühls kommen. Für die Außenwelt sind die Schwellen erhöht wie bei der Benommenheit. Was zur Aufnahme gelangt, ist schattenhaft und wird im 
Sinne der traumhaften Innenerlebnisse illusionär verfälscht. Im Gegensatz zur Benommenheit ist die Affektivität lebhaft und den Inhalten offenbar im wesentlichen adäquat. Wo es zum Handeln kommt, geschieht dies im Sinne der traumhaft veränderten Innen- und Außenwelt. Oft besteht nur eine mehr oder weniger lebhafte Unruhe amorphen Charakters, die „moussitierend ${ }^{66}$ wird (Flockenlesen), je mehr im Delir die darin stets verborgenen Elemente der Benommenheit zunehmen.

Das Delir hat nicht immer die gleiche Tiefe; es nimmt meist am Abend zu, während am Tage die Kranken klarer sind, mehr von Außendingen aufnehmen, weniger von innen erleben und sich im ganzen mehr leichteren Benommenheitszuständen annähern.

\section{Amentia}

Je stärker die Elemente der Benommenheit abnehmen, während doch die Schwellen nach dem traumhaften Innenleben erniedrigt bleiben, je mehr auf der anderen Seite der Kranke sich um die Bewältigung der Außenwelt bemüht, während doch eine volle Kohärenz des Denkens und Erlebens noch nicht gelingt, um so deutlicher nimmt das krankhafte Syndrom den Charakter der Amentia an. Inkohärenz im Sinne der traumhaften Denkstörung, Ratlosigkeit als Ausdruck angestrebter, aber nicht gelingender Wirklichkeitsbewältigung sind in jeder Amentia enthalten. Daneben herrschen bald mehr die traumhaften halluzinatorischen Erlebnisse, welche die Wahrnehmungen verfälschen, im äußeren Bilde vor, bald kommt es, wohl entsprechend anlagemäßiger Bereitschaft, zu katatonen Zügen; oder aber die Inkohärenz tritt rein in Erscheinung. Oft sehen wir auch wahnhafte Deutungen der verfälschten Außenerlebnisse, die ihrerseits das Erleben entscheidend mitbestimmen können. Je mehr in der Amentia die Bewußtseinstrübung zunimmt, um so mehr nimmt das Bild das Gepräge des Delirs an, während in den klareren Zeiten Inkohärenz und wahnhafte Einstellungen neben der bald mehr, bald weniger ausgeprägten Ratlosigkeit das Bild beherrschen. Die Gemütsbewegungen sind im übrigen den Erlebnissen angemessen; auch das Handeln entspricht dem Gesamtzustand.

Vom Delir werden, wenn überhaupt, nur Bruchstücke in der Erinnerung erhalten, für die Amentia besteht wenigstens für längere Episoden Amnesie, während für andere Zeiten relativ gute Erinnerung möglich ist. Das Delir dauert meist nur Tage oder höchstens Wochen, die Amentia mindestens Wochen, meist aber Monate.

\section{Dämmerzustand}

Von dem Kernsyndrom der Benommenheit führt nach einer ganz anderen Richtung der Dämmerzustand fort. Auch hier ist das Bewußtsein verändert; die Außenwelt kann nicht in gehöriger Weise aufgenommen werden; das Bewußtsein ist von einem stark affektbeladenen Innenleben erfüllt, durch das die Außenwelt verfälscht wird. Meist sind es Angst oder Wut, das Gefühl, in bestimmter Weise bedroht oder angegriffen, gemeint zu sein, die das Wahrnehmen und Handeln bestimmen und korrigierende Erlebnisse absperren. 
Dabei braucht das äußere Verhalten nicht grob auffällig zu sein, wenn wohl auch die Wahrnehmungen nicht klar und vollkommen sind. Das Denken ist verlangsamt und bruchstückhaft, wie bei der Benommenheit, soweit nicht der zentrale Affekt und die damit verbundenen Inhalte Zusammenhänge schaffen. Dämmerzustände dauern meist nur Stunden oder auch wenige Tage, schließen, wie die Delirien, in der Regel mit Schlaf ab und hinterlassen meist volle Amnesie. Wenn ein Dämmerzustand länger dauert, so nähert er sich auch dem Erleben nach immer mehr dem Delir an. Siehe im übrigen unter Symptomatologie.

\section{Spasmodische Syndrome \\ Der epileptische Anfall}

Nach einer ,Aura“ (Vorboten sensibler, sensorischer, affektiver, gelegentlich auch motorischer Art) oder auch ohne solche kommt es zugleich mit tonischer Starre des ganzen Körpers zu tiefem Bewußtseinsverlust. Die tonische Starre geht nach wenigen Sekunden in klonische, mehr oder weniger rhythmische Zuckungen der Glieder, der Gesichts- und Augenmuskulatur über. Die motorische Phase des Anfalls dauert 1 bis wenige Minuten. Zugleich sind die Pupillen weit und starr. Vielfach besteht nachher Babinski, die Bauchdeckenreflexe fehlen oft, es kommt im Anfall häufig zu Zungenbiß (blutiger Schaum), zur Blasen-, selten zur Darmentleerung. Manche Kranke ohne Aura stürzen rücksichtslos hin und ziehen sich dabei ernste Verletzungen zu. An das klonische Stadium kann sich noch eine Phase „großer ${ }^{66}$ Gliederbewegungen anschließen. Manchmal geht die Bewußtlosigkeit gleich in den terminalen Schlaf über. Häufiger kommt es zum Schlaf erst nach vorübergehendem allmählichem Erwachen aus der Bewußtlosigkeit.

Der epileptiforme Anfall kann auch rudimentär (nur unter tonischen, nur unter vereinzelten klonischen Erscheinungen, als Schwindelanfall, ohne tiefe Bewußtlosigkeit) verlaufen. Diese rudimentären Anfälle gehen ohne scharfe Grenze in die ,kleinen" Anfälle (petit mal) über, Bewußtseinstrübungen von Sekundendauer mit oder ohne leichte motorische Reizerscheinungen.

Anfälle, die von einem Hirnherd ausgehen, Jacksonsche Anfälle, beginnen mit Zuckungen oder Blick-, Kopf-, Körperwendungen entsprechend dem Herd. Gehen sie von einem Herd in der vorderen Zentralregion aus, dann verbreiten sich die Zuckungen nach der Anordnung der Rindenfelder auf der kontralateralen Körperseite, beteiligen dann vielfach auch die andere Körperhälfte. Zugleich tritt oft Bewußtlosigkeit ein, die aber auch ganz fehlen kann.

Epileptische Anfälle zeigen immer tiefgreifende Hirnstörungen an. Sie kommen daher vorwiegend, außer bei der genuinen Epilepsie, bei den organischen Hirnerkrankungen vor, unter besonderen Bedingungen auch einmal bei den endogenen Psychosen und nur unter Mitwirkung von toxischen Schäden bei psychopathischen Menschen.

\section{Der tetanische Anfall,}

der mit Steifigkeit besonders der Extremitätenenden und der Gesichtsmuskulatur, unter Umständen auch der Gesamtmuskulatur bei gleichzeitigen lebhaften Parästhesien auch über die krampfenden Partien hinaus einhergeht, 
zeigt vor allem Stoffwechselstörungen an. Das Gehirn bzw. das Zentralnervensystem ist nur Erfolgsorgan. Immerhin ist es nicht ganz unbeteiligt, wie aus halbseitigen und noch enger lokalisierten Anfällen hervorgeht. Vereinzelt zeigen sich so Hirnherde (Parietalhirn?) an.

Außer bei der Tetanie (Insuffizienz des Parathyreoidea-Apparates mit Steigerung der elektrischen, mechanischen, chemischen Muskelerregbarkeit) sehen wir tetanische Erscheinungen besonders bei der Hyperventilation, unter Umständen auch im Rahmen hysterischer Anfälle. Ihrer Natur nach kommen sie auch sonst gelegentlich bei allen Seelenstörungen vor.

\section{Der hysterische Anfall}

Es handelt sich um Bewegungsstürme, die unter dem Einfluß von Gemütsbewegungen zustande kommen, mit mehr oder weniger tiefer Bewußtseinstrübung einhergehen und meist irgendwie den Charakter übertriebener und ungeordneter Ausdrucksbewegungen der verschiedensten Art (Angst, Wut, sexuelle Erregung usw.) erkennen lassen. Nur selten ahmen sie epileptiforme Anfälle nach. Es fehlen aber auch dann die organischen Erscheinungen (Pupillenstarre, Babinski, meist auch Sezessus und wirklicher Zungenbiß). Vor allem lassen sich die Ausdruckserscheinungen durch äußere Einflüsse nach jeder Richtung hin beeinflussen. Sie können also gesteigert oder auch jäh abgebrochen, durch Suggestionen in ihrem Ausdruckscharakter abgeändert werden usw. Hysterische Anfälle finden wir im gesamten Bereiche der Seelenstörungen. Es handelt sich um "Primitivreaktionen", die anzeigen, daß der Betroffene mit einer stürmischen Gemütsbewegung auf gewöhnliche Weise nicht fertig wird. In der Regel sind es von je primitive oder irgendwie geschädigte (Alkohol, leichtere organische Hirnschäden) Menschen, die zu den früher viel häufigeren hysterischen Bewegungsstürmen neigen.

\section{Dyskinetische Syndrome \\ Der Stupor}

Stupor nennt man alle Zustände völliger Bewegungslosigkeit, in denen außer den Atembewegungen und, meist, Augenbewegungen nichts oder so gut wie nichts Motorisches geschieht. Auch die Entleerungen läßt der Stuporöse vielfach unter sich. Verfassungen hochgradiger Bewegungsverarmung nennt man substuporös. Wo nur die Spontanbewegungen ausfallen, während auf Anregungen von außen die Bewegungen ungehindert vonstatten gehen, sprechen wir von Akinesen. Es gibt schlaffe Stuporen, in denen die aufgehobenen Glieder wie tot niederfallen, als Ausdruck vor allem schwerer Melancholien oder hysterischer Störungen, und gespannte Stuporen, in denen weite Muskelgebiete sich in Dauerspannung befinden (abgehobener Kopf) oder doch bei allen passiven Bewegungen sich sofort anspannen (Gegenhalten). Besonders Unterkiefer, Beugemuskulatur des Halses, Stamm, proximale Abschnitte der Gliedmaßen, zumal Adduktoren, sind befallen. Gespannte Stuporen sind vielfach katatoner Natur und kommen daneben bei organischen Gehirnkrankheiten (Paralyse) vor. Stuporen der verschiedensten Art, dann meist zugleich irgendwie beeinflußbar, begegnen uns als psychogene Reaktionen nicht ganz selten bei Untersuchungsgefangenen. 


\section{Die Hyperkinese}

Die Hyperkinese ist beherrscht von einem Übermaß an Bewegungen ohne Zweckcharakter, „Pseudospontanbewegungen ${ }^{66}$, die einfache Gliederbewegungen, Parakinesen, kurzschlüssige Bewegungen, die sich der Gegenstände in der Umgebung bemächtigen, sein, aber auch an Ausdrucksbewegungen, Reaktivbewegungen, Zweckbewegungen erinnern können. Echopraxie und Echolalie, Verbigeration und Iterationen aller Art gehören hierher. Von den Kranken wird vielfach weder der Bewegungsdrang selbst noch die Umgebung beachtet. Das Bewußtsein ist in der Regel leicht verändert, die zeitliche Orientierung unzureichend. Oft kommt es zu illusionären Erlebnissen. Auch optische Trugwahrnehmungen elementarer Art kommen vor. Die Inhalte der sprachlichen Äußerungen sind monoton. Die Affektivität ist vielfach farblos. Doch fehlen flüchtige Affektäußerungen nicht. Die Erinnerung an die hyperkinetischen Zeiten bleibt, wenigstens anfänglich, verschwommen.

Hyperkinesen zeigen, ebenso wie die Mehrzahl der gespannten Stuporen, meist tiefgreifende Störungen an. Am häufigsten sind sie Ausdruck der Schizophrenie. Sie begegnen uns aber auch bei Paralysen, epileptischen Ausnahmezuständen, in symptomatischen Psychosen. Seltener sind sie Ausdruck schwerer zirkulärer Phasen. Es gibt aber auch dem weiteren zirkulären Kreis angehörige periodische Hyperkinesen, die vielleicht eine lokalisierte Anlageschwäche voraussetzen.

Von Hyperkinesen sprechen wir nur, wo die Bewegungen den gekennzeichneten eigenartigen ,psychomotorischen" Charakter haben.

Hyperkinese und Stupor haben offenbar nahe Beziehungen zueinander. Sie lösen einander häufig ab, ganz ähnlich wie Manie und Melancholie.

\section{Der katatone Symptomenkomplex}

Gerade hier finden wir Stupor und Hyperkinese, nacheinander, auch in plötzlichem unvermitteltem Wechsel oder in eigenartigen Durchdringungen: wilde Gliederbewegungen bei voller Stummheit, hyperkinetischen Rededrang bei sonstiger Bewegungslosigkeit. Im übrigen rechnet man Stereotypien, Grimassen, Manieren, Befehlsautomatie (Flexibilitas), Echolalie, Echopraxie, impulsive Akte, negativistisches Widerstreben, Verbigeration, Sperrungen zu den katatonen Erscheinungen. In der Regel sehen wir solche Bilder in den katatonen Verlaufsformen der Schizophrenie. Dann fehlen auch die kennzeichnenden Veränderungen der Affektivität und die feineren Züge des Negativismus meist nicht. Katatone Syndrome können aber auch als Ausdruck organischer Hirnerkrankungen (Paralyse, Arteriosklerose) auftreten. Wo es im Verlauf zirkulärer Erkrankungen zu katatonen Syndromen kommt, wird man entsprechende Teilanlagen oder ursächliche Zusatzfaktoren (toxische, zerebrale) zu vermuten haben.

\section{Die Halluzinose}

Im Mittelpunkt der Halluzinose finden wir Gehörstäuschungen von großer sinnlicher Lebhaftigkeit (Stimmen) mit meist unangenehmen Inhalten, die, unter lebhafter Angst, wahnhaft verarbeitet werden. Dabei 
besteht volle Besonnenheit. Am reinsten kommt die Halluzinose bei Schnapsalkoholisten vor. Aber auch bei Schizophrenen, bei der Lues cerebri, bei malariabehandelten Paralytikern, als symptomatische Psychosen, gelegentlich auch als Ausdrucksformen des manisch-depressiven Irreseins finden wir Halluzinosebilder, endlich als kennzeichnend gefärbte psychogene Reaktionen in der Haft. In der Regel erlauben Verlauf wie Symptome, die neben dem Halluzinosesyndrom bestehen, die Diagnose der Grundkrankheit ohne Mühe. Die Halluzinose zeigt regelmäßig tiefergreifende Störungen an, auch wenn sie als psychogene Haftreaktion auftritt. Hier muß wohl neben der besonderen Anlage die tiefgreifende Änderung aller Lebensumstände, wie sie die Haft mit sich bringt (Schlafstörungen, Isolierung, besondere Ernährungsverhältnisse usw.), ursächlich mit in Rechnung gesetzt werden.

\section{Wahnsyndrome}

Das paranoische Syndrom

Paranoische Wahnbildung liegt dort vor, wo bei voller Besonnenheit und Erhaltung der Ordnung und Klarheit im Denken, Wollen und Handeln auf rein kombinatorischem Wege eine langsam progrediente, systematisierte Wahnbildung zustande kommt, die schließlich das gesamte Denken beherrscht und unter alleiniger Mitwirkung von Erinnerungsfälschungen schließlich zu einer kranken Weltanschauung, zur „Verrücktheit ${ }^{66}$ führt. Sinnestäuschungen und primäre affektive Störungen fehlen im paranoischen Geschehen ebenso wie die eigentlichen Denkstörungen. Den Ausgangspunkt paranoischer Wahnbildungen bilden meist Schicksalswunden, auch dort, wo paranoische Episoden auf dem Boden anderer Erkrankungen, beginnender Schizophrenien, als Entwicklungen auf dem Boden schizophrener Defekte, traumatischer Hirnveränderungen, in zirkulären Mischphasen zustande kommen. Am reinsten finden wir paranoische Entwicklungen und Reaktionen bei eigenartigen psychopathischen Persönlichkeiten als Antwort auf unbehebbare Lebenskonflikte.

\section{Paraphrenes Syndrom}

Hier erscheinen im Gegensatz zu den gewöhnlichen, mit Wahnbildungen einhergehenden Formen der Schizophrenie Affektivität und Willensfunktionen ungestört, die Persönlichkeit also erhalten. Die Wahnbildungen selbst können anfangs leidlich systematisiert und inhaltlich nicht unmöglich sein, werden aber zunehmend zerfahren und uneinfühlbar, d. h. nehmen immer mehr schizophrenen Charakter an, und zugleich kommt es zu meist akustischen Trugwahrnehmungen (Stimmen) und vielfach auch zu körperlichen Beeinflussungserlebnissen.

Paraphrene Syndrome finden wir meist erst bei Menschen in der Nähe der Rückbildungszeit. Rückbildungsvorgänge spielen in ihrer Genese wohl eine Rolle. Die Mehrzahl dieser Bilder gehört wesensmäßig wohl zur Schizophrenie. Doch finden sich paraphrene Syndrome auch als Ausdruck des manisch-depressiven Irreseins (hier sind dann meist doch die affektiven Veränderungen deutlich), aber auch als Episoden bei organischen Hirnerkrankungen. 


\section{Wahnhafte Einbildungen}

sind flüchtige spielerische, meist in ihren Inhalten rasch wechselnde und beeinflußbare, vielfach phantastische Wirklichkeitsverfälschungen, hinter denen in der Regel die Persönlichkeit nicht ganz steht. Meist treten sie als Reaktionen Gefangener auf, die sich damit über die Wirklichkeit hinwegtäuschen und zugleich auf Krankheitsgewinn anderer Art aus sind. Bei entscheidender Änderung der Lage (Befreiung, Versetzung) verschwinden sie in der Regel schlagartig. Das Bewußtsein der Kranken ist vielfach leicht getrübt. Ähnliche Wahnspielereien sehen wir auch bei manchen Schizophrenen, in manischen Erregungen, bei hysterisch stigmatisierten Persönlichkeiten in Konfliktslagen anderer Art. Auch auf dem Boden leichterer organischer Hirnveränderungen können sie als psychogene Überlagerungen sich einstellen.

\section{Emotionelle Syndrome}

\section{Das depressive Syndrom}

Die Kennzeichen der echten Depression sind traurige Verstimmung mit in der Regel ängstlichem Einschlag und Hemmung im Handeln und Denken. In den leichtesten Formen sind vor allem Entschlußfähigkeit und Initiative gehemmt und das Denken ist blaß, farblos und mühselig. Es fällt den Kranken wenig ein. Die traurige Verstimmung färbt alle Lebenserfahrungen, Zukunft und Vergangenheit trübe. Hoffnungslosigkeit, Gewissensskrupel, Versündigungs-, Verarmungs-, Minderwertigkeitsideen sind in allen schweren Depressionen vorhanden; Verfolgungsideen gehören dagegen nicht zum Bilde der echten Depression.

Dieses depressive (melancholische) Syndrom ist meist Ausdruck manischdepressiver Erkrankungen, kommt aber auch bei allen organischen Hirnerkrankungen und im Verlaufe von Schizophrenien, selten auch auf epileptischer Grundlage, besonders wohl dann vor, wenn eine entsprechende Veranlagung gegeben ist. Es muß also stets nach den Zeichen der Grundkrankheit gefahndet werden; das Syndrom als solches hat keine diagnostische Bedeutung.

Auch die normale erlebnisbedingte Traurigkeit kann zum Darniederliegen der Entschlußfreudigkeit und zur Einengung des Denkens auf die auslösenden Erlebnisse führen. Echte Hemmung, die beim melancholischen Syndrom immer einen vitalen Hintergrund hat (s. d.), ist aber selten und kommt wohl nur bei Veranlagten vor. Die abnormen depressiven Erlebnisreaktionen haben einen meist ,"nervösen ${ }^{66}$ und demonstrativen Charakter. Besonders die Selbstanklagen sind unecht. Sie fordern Widerspruch heraus.

\section{Das Angstsyndrom}

Hier steht die, meist anfallsweise sich verstärkende, tiefe Angst ganz im Mittelpunkt, die mit den entsprechenden vegetativen Erscheinungen (weite Pupillen, Herzsensationen, Störungen der Herzschlagfolge) und Wirkungen auf das Ausdrucksgeschehen einhergeht, wie wir sie von der ja keinem Gesunden ganz fremden Angst her kennen. Wir finden also ängstliche Abwehr und gespannte Erwartung oder lebhafte Ausdrucksbewegungen (Jammern, Händeringen, ziellose motorische Unruhe), die sich verstärken bei vermeintlich gefahrdrohender Beeinflussung und Annäherung. Kommt es anfallsweise zur 
Verstärkung der Angst, dann kann sich das Bewußtsein trüben oder es engt sich doch ein. Es kommt unter Umständen zu sinnlosen Abwehrhandlungen, zum planlosen Fortdrängen, zu wilden Selbstbeschädigungsversuchen. Die Inhalte der Angstsyndrome sind anfänglich meist gestaltarm. Bei Ausbildung ganz bestimmter ängstlicher Befürchtungen (Verfolgung, hypochondrische Inhalte) pflegt die Angst allmählich nachzulassen. Das Angstsyndrom finden wir besonders bei den endogenen Psychosen, vor allem der Schizophrenie und als Ausdruck melancholischer Phasen. Es begegnet uns aber auch bei den organischen Psychosen (Paralyse, Arteriosklerose, präsenile und senile Erkrankungen).

\section{Das manische Syndrom}

Heitere, jedenfalls expansive Verstimmung bei großer affektiver Ansprechbarkeit überhaupt, Willenserregung (Tätigkeits- und Mitteilungsdrang, Abbau von Hemmungen) sowie Auflockerung des Denkens im Sinne der Ideenflucht (Ablenkbarkeit, Flüchtigkeit) kennzeichnen das manische Syndrom. Meist ist das Selbstbewußtsein gehoben, das Weltbild entsprechend der Stimmung gefärbt. Zu eigentlichen Wahnideen bringen es Manische nicht, wenn auch zum Renommieren und zu Größenspielereien. Über das Vorkommen des manischen Syndroms kann alles wiederholt werden, was vom echten depressiven Syndrom gesagt wurde. Bei organischer Grundlage (symptomatische Psychose, Paralyse) treten in der Ideenflucht meist deutliche inkohärente Züge hervor.

Reaktiv im Sinne abnormer seelischer Reaktionen kennen wir Zustände, die den Namen manisches Syndrom verdienen, nicht.

\section{Dranghafte Verstimmungen}

Als solche sind hier zusammengefaßt meist kurz (Tage, Wochen) dauernde dysphorische Verstimmungen, denen die eigentliche Hemmung fehlt, die vielmehr zur Entladung im Sinne reizbaren Aufbegehrens, explosibler Zornmütigkeit, mißmutiger Abwehr oder aber zu Heimwehreaktionen, besonders Davonlaufen, drängen. Es kann auch zu Gewalttaten, Brandstiftungen, sexuellen Entgleisungen (Exhibieren), vor allem aber zu Betäubungsversuchen (Alkohol, Morphin) kommen. Solche Verstimmungen finden wir bei manchen Psychopathen, besonders in der Pubertät, bei Epileptikern, aber auch bei Hirngeschädigten aller Art. Nicht selten ist dabei das Bewußtsein eingeengt oder ganz leicht getrübt.

\section{Nervöse Syndrome}

\section{Das neurasthenische Syndrom}

(Zustände von Ermüdbarkeit bei erhöhter Empfindlichkeit, Neigung zu Mißempfindungen aller Art und Mißstimmung) finden wir als Ausdruck von Dauerverfassungen wie als vorübergehende Reaktion auf besondere Belastungen, wie endlich im gesamten Bereiche der Seelenstörungen, vor allem im Beginn oder als Abschluß endogener Psychosen und organischer Hirnveränderungen. Dem Syndrom als solchem kann man seine Genese nicht ansehen. Wir sind ihm schon bei den enzephalopathischen Syndromen begegnet. 


\section{Das hypochondrische Syndrom}

Die auf den verschiedensten Wegen entstehende Besorgnis, an diesem oder jenem Leiden krank zu sein, lenkt die Aufmerksamkeit auf die auch bei Gesunden selten fehlenden ständigen Sensationen aus dem Bereiche des Körpers, besonders des vermeintlich erkrankten Organs, am häufigsten der Eingeweide im engeren Sinne (daher Hypochondrie) und des Herzens. Durch die Aufmerksamkeitszuwendung entsteht eine zunehmende Virtuosität, solche Leibreize wahrzunehmen. Damit steigert sich die Angst, und die unheilvolle Wirkung dieses Zirkels wird noch erhöht dadurch, daß die meist vegetativen Funktionen gerade auf affektive Vorgänge hin besonders lebhaft ansprechen. So kommt es zu der zunächst überwertigen Angst, ernstlich krank zu sein, und bei entsprechender Veranlagung oder geeigneter Grundkrankheit zu wahnhaften hypochondrischen Überzeugungen. Hypochonder pflegen ihre gesamte Lebensführung auf die vermeintliche Krankheit einzurichten und ohne Beruhigung von Arzt zu Arzt zu laufen.

Das hypochondrische Syndrom wächst auf dem Boden ängstlich-depressiver Verfassungen. Schon bei psychopathischen Persönlichkeiten, besonders vegetativ Stigmatisierten, ist es häufig. Aber auch alle depressiv gefärbten Seelenstörungen können unter dem Bilde hypochondrischer Syndrome verlaufen, die je nach der Grundkrankheit verschieden ausgestaltet zu sein pflegen. Bei organischen Psychosen finden wir häufig „nihilistischen ${ }^{66}$ Anstrich. (Ganze Organe sind nicht mehr da, verfault, der ganze Mensch ist weg, ganz klein geworden, schon gestorben; bei der Schizophrenie sehen wir die abenteuerlichsten Inhalte; die Glieder werden zersägt, der Penis nach innen gezogen, dann herumgewirbelt usw.)

Für das

\section{Zwangssyndrom}

sei auf den allgemeinen Teil und die Besprechung der Anankasten verwiesen. Zwangserscheinungen finden wir häufig bei Psychopathen bestimmten Gepräges, aber auch in Phasen des manisch-depressiven Irreseins, als Ausdruck beginnender schizophrener Prozesse, seltener auch bei organischen Hirnleiden.

\section{Das hysterische Syndrom (siehe unter abnorme Reaktionen)}

Hysterische Syndrome begegnen uns ebenso wie Hypochondrie und Neurasthenie im gesamten Bereich der Seelenstörungen. Sie zeigen immer eine seelische Lage an, in der auf Krankheitsgewinn irgendwelcher Art abgezielt wird (S. 235).

\section{Die Querulanz}

(siehe unter abnorme seelische Reaktionen, wo auch über die echten und symptomatischen Formen gesprochen ist [S. 231]).

\section{Das Depersonalisationssyndrom}

Die Kranken kommen sich verändert vor, unwirklich, wie Automaten. Es ist, als ob der Körper nicht ihnen gehörte; die eigene Stimme, das eigene Spiegelbild erscheinen ihnen fremd. Das Handeln ist mechanisch, das Ich 
steckt nicht drin, auch in den Wahrnehmungen und Vorstellungen nicht, denen der Kranke wie ein teilnahmsloser Zuschauer zusieht. Es ist, als ob Watte in den Ohren, eine Glasscheibe vor den Dingen wäre. Die anderen Menschen sind fern wie die Dinge. Meist klagen die Kranken beweglich über die Veränderung. Am häufigsten bei gewissen egozentrischen, willensschwachen, „psychasthenischen ${ }^{6}$, nervösen Menschen mit Neigung zu depressiven Verstimmungen finden wir die Depersonalisation, doch auch als Ausdruck beginnender schizophrener Prozesse, bei zirkulären Depressionen, seltener auch bei leichten organischen Hirnveränderungen und in epileptischen Ausnahmezuständen.

Die herausgehobenen Symptomenkomplexe oder Syndrome haben also ausnahmslos keine diagnostische Bedeutung: vielmehr kehren sie als „Einheiten mittlerer Ordnung ${ }^{66}$ bei den verschiedensten Krankheitsvorgängen in der gleichen Weise wieder. Immerhin sind sie nicht gleichwertig. Die nervösen und einen Teil der emotionellen Syndrome finden wir freilich im gesamten Bereiche der Seelenstörungen von den organischen Hirnerkrankungen bis zu den abnormen seelischen Reaktionen. Demgegenüber zeigen die enzephalopathischen Syndrome, der epileptische Anfall und die meisten Syndrome der Bewußtseinstrübung grobe Hirnschädigungen an, während die anderen Symptomenkomplexe eine mittlere Stellung einnehmen. Es hängt nach Kraepelin offenbar vom Grade der Schädigung ab, welche Syndrome als Ausdruck einer Enthemmung allgemein vorhandener ursprünglicher Werkzeuge des Seelenlebens Aussicht haben, in Erscheinung zu treten. Daneben freilich spielt, wie erwähnt, auch die Veranlagung eine Rolle, die ,individuelle zerebrale Beschaffenheit" (Hoche), die es mit sich bringt, daß bestimmte Syndrome leichter ansprechen. Kleist denkt sogar an jeweils bestimmte Auslösungsstätten. Er unterscheidet Hirnmantelsymptomenk omplexe (amnestischer Symptomenkomplex, Begriffs- und Sprachzerfall, Halluzinose u. a.) und Hirnstammsyndrome (Dämmerzustände, Delir, Schlafsucht, Schlaflosigkeit, triebhafte Verstimmungen, hypochondrische, paranoische, emotionelle Syndrome, dyskinetische Syndrome). Die letzteren sollen nicht bloß nach ihrer Symptomatologie, sondern auch nach Verlaufsweise, Dauer, Rückbildungsfähigkeit und Aufeinanderfolge weitgehend eigengesetzlich verlaufen (kurze Dauer der Delirien und Heilbarkeit, Wechsel von Stupor und Hyperkinese, von Manie und Depression, von Schlafsucht und Schlaflosigkeit u. a. m.). Alle diese Gesichtspunkte lassen sich vereinen. Sie heben die verschiedensten diagnostischen, ursächlichen, genetischen und prognostischen Anhaltspunkte heraus und sind heuristisch im Verein geeignet, unser Wissen zu vertiefen. 


\section{B. Krankheitsformen}

Die hier gegebene Einteilung der Seelenstörungen hält sich eng an die Diagnosentabelle des Deutschen Vereins für Psychiatrie, die das Ergebnis einer eingehenden Beratung von Sachverständigen darstellt. Wenn es möglich gewesen ist, eine solche Diagnosentafel unter vollem Einverständnis der Beteiligten aufzustellen, so ist dies in einem entscheidenden Maße das Verdienst Emil Kraepelins, der in einem Leben unermüdlicher Forschertätigkeit unter dem Einfluß seiner gewaltigen Persönlichkeit und seines genialen Scharfblicks die Grundlage der psychiatrischen Formenlehre vor allem im Bereiche der endogenen Psychosen geschaffen hat und nahezu an jeden Baustein unseres heutigen Wissens nachdrücklich die Hand angelegt hat.

Die Einteilung der Krankheitsformen hält sich im wesentlichen an die ursächlichen Hauptfaktoren. Sie schreitet fort von Leiden, die Ausdruck unzulänglicher Hirnanlagen und -entwicklungen (Schwachsinn) oder grober traumatischer Hirnschäden sind, zu Krankheitsbildern, die im Gefolge entzündlicher Hirnvorgänge entstehen. Auch in den folgenden Gruppen haben wir es mit ausgebreiteten anatomischen Hirnveränderungen zu tun, die gesetzmäßig oder doch häufig auch von seelischen Störungen begleitet sind. Hier allenthalben begegnen uns auch neurologische Krankheitserscheinungen, und in den seelischen Krankheitsbildern spielen die enzephalopathischen Syndrome und die epileptischen Krämpfe die Hauptrolle.

Bei den folgenden Krankheitsgruppen, die, wie Infektionen, Allgemeinerkrankungen und Vergiftungen, den gesamten Körper betreffen, leidet doch auch das Hirn unmittelbaren oder mittelbaren Schaden. Unter den Krankheitserscheinungen spielen die exogenen Reaktionstypen, vor allem die Syndrome der Bewußtseinsstörungen, eine wesentliche Rolle; doch erlangt die ursprüngliche Veranlagung mit ihren besonderen Krankheitsbereitschaften eine zunehmende Bedeutung, zumal bei den Suchten, den Endokrinopathien, aber auch bei den Stoffwechselleiden.

Für Epilepsie, Schizophrenie und manisch-depressives Irresein sind abnorme Anlagen entscheidend. Exogene Reaktionsformen spielen nur noch in der Epilepsie eine wesentliche Rolle, und die Wirkung des Krankheitsvorganges läßt sich auch am Hirn ablesen. Demgegenüber fehlt dem manisch-depressiven Irresein jede pathologische Anatomie und den Krankheitserscheinungen können wir uns verstehend annähern. Nach Erscheinungsformen und Hirnbefund steht die Schizophrenie zwischen den anderen beiden Erbleiden.

Mit den psychopathischen Persönlichkeiten und den abnormen seelischen Reaktionen endlich kommen wir bis dicht an den Bereich der Norm. Zu den abnormen Erscheinungen, mit denen wir es hier zu tun haben, haben wir von eigenem Erleben her Zugang. 


\section{a) Angeborene und früherworbene Schwachsinnszustände}

\section{(Oligophrenien)}

\section{Ursachen}

Unter dem Namen Oligophrenien werden alle angeborenen und früh erworbenen Schwachsinnszustände zusammengefaßt. Dem Grade nach unterscheidet man Idioten, d. h. solche Geistesschwache, die nicht schulfähig werden, Imbezille, Schwachsinnige mittleren Grades, die zwar bis zu einem gewissen Grade bildungsfähig sind, aber doch noch nicht die Volksschule mit Erfolg zu besuchen vermögen, und Debile, d.h. die leichtesten Formen des Schwachsinns, die ohne Grenze in die einfache Dummheit hinüberführen.

Die meisten Idiotien sind exogener Entstehung. Es kommen hier vor allem intrauterine und frühkindliche Hirnprozesse in Frage (Enzephalitiden, schwere traumatische Hirnzerstörungen, grobe, durch Keimschäden herbeigeführte Bildungsfehler des Hirns, in den ersten Monaten der Gravidität einwirkende Schädigungen). Wir finden dann auch mannigfache grobe Hirnanomalien (Mikro- und Makrogyrie, Porenzephalie), mitunter auch solche, die schon im Schädelbau sichtbar werden (Mikrozephalie, Makrozephalie). Auch die konnatale Lues kann sich als Idiotie äußern.

Wie die Idiotie, so können auch Imbezillität und Debilität durch im intra- oder extrauterinen Leben erworbene Hirnschäden entstehen, ohne daß diese im klinischen Bilde nachweisbar sein müssen. Die große Mehrzahl der mittleren und leichteren Schwachsinnszustände ist aber erblicher Entstehung. Wir wissen dies insbesondere aus Zwillingsuntersuchungen, die eine weit überwiegende Konkordanz der Eineiigen, eine vorwiegende Diskordanz der Zweieiigen ergeben. Planmäßige Erblichkeitsuntersuchungen nach modernen Methoden zeigen in Ergänzung dieses Befundes, daß der erbliche Schwachsinn zum Teil wohl dem einfach rezessiven Erbgang folgt, zum Teil aber geschlechtsgebunden rezessiv dihybrid, d. h. an zwei Erbanlagen gebunden ist, von denen eine in einem autosomen, die andere im Geschlechtschromosom enthalten ist. In einzelnen eingehenden Untersuchungen ist gerade dieser Erbgang sehr wahrscheinlich gemacht worden. Er erklärt die besonders ungünstige Erbprognose von Söhnen schwachsinniger Mütter und die Tatsache, daß es unter den Schwachsinnigen mehr Männer als Frauen gibt. Möglich ist auch das Vorkommen anderer dihybrid-rezessiver Formen, und für die leichtesten Grade des erblichen Schwachsinns ist Dominanz nicht unwahrscheinlich. Manches spricht dafür, daß nicht einfach eine Anlage zu Schwachsinn vererbt wird, sondern bestimmte Schwachsinnsgrade und bestimmte Schwachsinnsformen.

Ziemlich übereinstimmend fand man unter den Geschwistern Schwachsinniger $15-20 \%$ wiederum schwachsinnig, wenn beide Eltern normalsinnig waren, $40-50 \%$, wenn ein Elternteil, über $90 \%$, wenn beide Eltern schwachsinnig waren.

Der Schwachsinn ist außerordentlich verbreitet. In Deutschland müssen etwa $2 \%$ aller Kinder die Hilfsschule besuchen. Damit sind bestimmt noch nicht alle Debilen erfaßt, die zu einem wohl nicht unerheblichen Teil durch die Normalschule hindurchgeschleppt werden dürften.

6 Lange $\dagger$-Bostroem, Psychiatrie, 3. Aufl. 


\section{Idiotie}

Idioten lernen zu einem erhehlichen Teil nicht sprechen. In ihren schwersten Formen müssen sie ihr Leben lang wie kleine Kinder behütet und besorgt werden. Kommt es zur Sprachentwicklung, so bleibt die Sprache doch arm, meist agrammatisch und artikulatorisch mangelhaft. Auch der Gang und die übrigen Körperbewegungen bleiben in der Regel unbeholfen und schwerfällig. Vielfach sehen wir bei Idioten Stereotypien der verschiedensten Art. Manche Idioten bleiben torpid, bewegungsarm. Ihr Interesse ist durch nichts zu erregen. Sie beachten die Umgebung gar nicht, reichen nicht die Hand, lernen nie selbständig essen, stopfen nur alles in den Mund, bleiben unsauber. Andere sind demgegenüber lebhaft, rastlos, fassen alles an, um es fortzuwerfen oder hartnäckig zu zerstören (Apathische und erethische Formen, die übrigens auch bei der Imbezillität unterschieden werden). Bei höheren Idioten kommt es zum einfachsten geistigen Erwerb. Sie kennen ihre Pfleger, ihr Spielzeug, lernen Gegenstandsbezeichnungen, melden ihre Bedürfnisse an und besorgen sich in den einfachsten Dingen selbst.

\section{Imbezillität}

Den Grad der Imbezillität pflegt man an Intelligenztestreihen zu bestimmen. Diese sehen für jedes kindliche Lebensalter eine Gruppe von Prüfungsaufgaben vor, die von normalen Kindern bewältigt werden. Als Intelligenzalter bezeichnet man jene Altersstufe, für die alle Tests gelöst werden, als Intelligenzquotienten den Quotienten aus Intelligenz- und Lebensalter. Am bekanntesten ist die Aufgabenreihe von Binet und Simon, die im Anhang wiedergegeben ist. Mit solchen Methoden kann man freilich nur ein sehr ungefähres Bild der geistigen Leistungsfähigkeit gewinnen, da der erwachsene Imbezille tatsächlich viel mehr Erfahrungen gesammelt hat, als ein Kind der entsprechenden Altersstufe, auf der anderen Seite aber über viel geringere Möglichkeiten verfügt als das Kind.

Bei Imbezillen sind, mit Ausnahmen, schon Merkfähigkeit und Gedächtnis mehr oder weniger unzureichend. Sie prägen sich also auch einfachsten Erfahrungsstoff schlecht ein und behalten ihn nicht als sicheren Dauerbesitz. Ihre mnestischen Leistungen werden aber vor allem dadurch schlecht, daß ihnen das sog. topische Gedächtnis mehr oder weniger fehlt, d. h. sie sind unfähig, klare Begriffe zu bilden, die dem Normalen die Verfügung über seinen Gedächtnisbesitz und die Aufnahme neuen Materials erleichtern.

Soweit das Verständnis reicht, ist die gröbste sinnliche Erfahrung vielfach nicht schlecht. Darüber hinaus kann mancher Imbezille sich rein mechanisch auch Dinge aneignen, für die ihm jedes Verständnis fehlt. Vereinzelt gibt es erstaunliche Dressurleistungen dieser Art und jedem Erfahrenen ist dieser oder jener imbezille Gedächniskünstler bekannt. Aber solcher Wissensstoff bleibt tot. Der Imbezille vermag nur die einfachsten Zusammenhänge zu übersehen. Er bleibt verständnislos vor allem Neuen und Ungewohnten; er vermag aus seinen Erfahrungen keine Regel, keine Begriffe abzuleiten, mit denen er sich in neuen Situationen zurechtfindet. Gesamteindrücke gliedern sich ihm nicht, bekommen für ihn keinen Sinn. Wohlbekannte Einzelheiten vermag er in neuen Zusammenhängen nicht wiederzuerkennen, auch nicht in ihren 
Beziehungen zu erfassen. Er klebt an der rein sinnlichen Erfahrung. Das Angelernte bleibt leere Form, wird ihm nicht zum Werkzeug.

Imbezille erwerben daher nur die bescheidensten Kenntnisse. Nur sinnlich wahrnehmbare Dinge ihres engen Umkreises werden ihnen näher bekannt, aber sie haben schon große Mühe, zu jenen Algemeinbegriffen zu gelangen, die dem Konkreten nahestehen. Abstrakte Begriffe bleiben ihnen fremd oder doch äußerst unklar und im besten Falle an konkrete Einzelerlebnisse geknüpft, von denen kein Weg zur freien Verwendung führt. Dort, wo der Imbezille Einzeldinge gut kennt, versteht er noch, sie zu beschreiben und sein Wissen mitzuteilen. Außer im allerengsten Kreis, wo er mit lauter wohlbekannten Dingen zu tun hat, versagt das Urteil, besonders auch über die Absichten der Menschen, mit denen der Imbezille zu tun hat.

Er ist daher meist in hohem Maße beeinflußbar, suggestibel, wo man sich an seinen kleinen Vorteil, seine Eitelkeit, seine triebhaften Regungen wendet. Auf der anderen Seite ist er eigensinnig und unbeeinflußbar, wo nicht engste persönliche Motive, sondern Einsicht und allgemeine Werte in Frage kommen. Der Imbezille ist daher oft ein ahnungsloses Werkzeug bei kriminellen Absichten anderer, wird aber auch von selbst häufig genug kriminell, weil er zur Ausbildung allgemeiner ethischer Haltungen aus Verständnislosigkeit nicht gelangt, sondern von den kleinlichen Vorteilen des Augenblicks und primitiven Triebregungen bestimmt wird. So kommt es häufig zu unüberlegtem Diebstahl und Rückfallsdiebstahl, zu kindischen Betrugsversuchen, für die ihm die Einsicht abgeht, vor allem aber auch zu kurzschlüssigen Gewalt- und Racheakten. Er schießt einen Menschen tot, der ihn beleidigt hat, zündet den Hor des Dienstherrn an, weil dieser ihn tadelte oder schlug, oder auch weil er gegen seinen Willen zum Bleiben und Arbeiten gezwungen wurde. Schwachsinnige Dienstboten haben aber auch schon Gift oder anderes Ungenießbares ins Essen ihrer Herrschaft getan, um sich von dem Dienst oder der unbequemen Herrschaft zu befreien. Auch Sexualdelikte, besonders an Kindern, an Greisinnen, an Tieren, exhibitionistische Akte können bei Imbezillen vorkommen. Die gleichen Imbezillen mögen dabei gutmütig, freundlich und vor allem anhänglich an jene sein, die es gut mit ihnen verstehen. Gerade deshalb sind sie auch besonders leicht auszunützen und vor allem auszubeuten, wenn sie Werte in den Händen haben. Andere sind störrisch, bockig, kalt, hinterlistig, roh. Überall ist es aber vor allem der Mangel an Einsicht, der ihr Versagen bedingt, natürlich neben den Mängeln auf anderen Gebieten des Seelenlebens, die, in ganz verschiedener Form der Ausprägung, bei keinem Imbezillen fehlen. Imbezillität ist eine allgemeine seelische Entwicklungshemmung, die auf dem Gebiete des Verstandeslebens nur besonders leicht faßbar ist.

Imbezille versagen im Leben, wenn sie nicht in Beschäftigungszweigen Unterkommen finden, die keinerlei Anforderungen an ihre geistige Leistungsfähigkeit stellen. Nicht selten finden wir sie als Landarbeiter und Handlanger einfachsten Niveaus. Hier können sie auch aushalten, wenn sie in gemütlicher Hinsicht gut beanlagt, fleißig und kräftig sind. Unter den heutigen Verhältnissen sind sie meist arbeitslos, viele kommen auf die Landstraße oder ins Gefängnis, Frauen werden Prostituierte. Unter den Gefängnisinsassen, aber auch unter den Fürsorgezöglingen finden wir einen hohen Prozentsatz mehr 
oder minder Schwachsinniger. Andere werden mit immer wiederkehrenden Organbeschwerden chronische Krankenhausläufer.

Imbezille schweren Grades freilich kommen in der Regel überhaupt nicht zum Beruf. Sie werden überall fortgeschickt, bleiben dann schließlich in der Familie, wo die Verhältnisse günstig sind, oder enden in der Anstalt.

\section{Debilität}

Alles, was über die leichteren Formen der Imbezillität gesagt wurde, gilt auch für die Debilität. Immerhin werden die Debilen oft in der Volksschule noch mitgeschleppt. Ihr besseres Gedächtnis, vor allem aber ihre relativ gute formale Begabung machen dies möglich. Wenn sie auch nicht das Endziel der Schule erreichen, so bleiben sie doch nur einige Klassen zurück. Ja, viele Debile können sogar in Mittelschulen lange aushalten und mit Nachhilfe, Geduld und ein wenig schlechtem Gewissen der Lehrer selbst Abschlußprüfungen bestehen. Das Schicksal der Debilen erfüllt sich erst, wenn sie die Schule verlassen haben, dann also, wenn sie wenigstens in bescheidenem Umfang selbständig denken und handeln müssen. Sind sie charakterologisch ordentlich, dann bleiben sie einfach stecken, lernen im Beruf nicht aus und werden an windstillen Posten im Leben verbraucht. Auffällig werden aber rasch die psychopathischen Debilen, solche mit Geltungssucht, hysterische, erregbare, haltlos-faule, verlogene, pseudologistische, mürrische, unlustige Debile, die bei unzureichenden Leistungen auch noch durch ihren Charakter anstoßen. Sie gehen dann alle erdenklichen Wege des Versagens; sie fliehen in die Krankheit, ergreifen auf höherem wirtschaftlichem Niveau Berufe, in denen es klare Leistungsmaßstäbe nicht gibt (,Künstler ${ }^{66}$, „Heilkundige ${ }^{66}$ usw.). Viele geraten auf die schiefe Ebene, werden Landstreicher, geraten in soziale Konflikte aller Art, fallen der Fürsorge anheim. Jugendliche psychopathische Debile finden wir zahlreich in Fürsorgeerziehungsanstalten. Nicht ganz selten begegnen uns Debile heute auch in gehobenen Berufen, in die sie mit Nachhilfe aller Art gelangt sind.

Eine besondere Gruppe der Oligophrenen sind die Verhältnisblödsinnigen. Es handelt sich hier um Debile mit gutem mechanischen Gedächtnis, formaler Gewandtheit und einer gewissen, vielfach großen Regsamkeit und starkem Selbstbewußtsein, die bescheidene Aufgaben zu bewältigen imstande wären, durch ihre Geltungssucht und ihre Initiative aber auf Gebiete getrieben werden, denen sie nicht gewachsen sind. Hier vermögen sie zwar ge legentlich durch ihr quantitativ großes Wissen zu blenden; näherem Zusehen ergibt sich aber, daß keiner der Begriffe, mit denen sie um sich werfen, für sie klar ist. Im besten Falle können sie nur in ihren Reden und ihrem Auftreten täuschen. In konkreten Situationen, wo es auf Verstand und selbständiges Urteil ankommt, versagen sie gröblichst. Solche Verhältnisblödsinnige begegnen uns oft genug in Gesellschaften, lächerliche, unter Umständen auch sehr lästige Erscheinungen, an deren bornierter Arroganz jede Kritik und jede Abwehr zuschanden wird, die aber doch immer wieder andere Dumme finden.

\section{Episodische Erkrankungen der Oligophrenen}

Verstimmungen sind bei den Schwachsinnigen nicht selten, und zwar hauptsächlich in Formen, die in ihrer Erscheinungsweise jenen der Epi- 
leptiker gleichen. In der Nachpubertätszeit begegnen uns ferner Drangzustände, wie sie auch bei jugendlichen Enzephalitikern vorkommen, nur daß sie bei Oligophrenen später aufzutreten pflegen. Aus solchen, den Kranken unverständlichen quälenden Drangzuständen heraus kommt es zum Davonlaufen, aber auch zu Gewalttätigkeiten und anderen Delikten. Die häufigen hysterischen Ausnahmezustände bei Imbezillen und Debilen tragen die Kennzeichen der geistigen Schwäche. Ganserzustände vor allem sind von je Minderbegabten, daneben auch erworbenen leichteren Defektzuständen vorbehalten. Manche Imbezille und Idioten sind zugleich epileptisch und haben dann neben Krämpfen auch epileptische Äquivalente. Endlich kann sich auf die Imbezillität eine Hebephrenie aufpfropfen (Pfropfhebephrenie). Hat man früher gemeint, daß es sich dabei um enge ursächliche Zusammenhänge handle, so geht doch aus neuen Erblichkeitsuntersuchungen hervor, daß es sich um das Zusammentreffen der beiden Anlagen handelt. Pfropfhebephrenien sind häufig, weil schwachsinnige wie hebephrene Sippen sozial herabsinken und ihre Angehörigen sich dann auf tiefem Niveau besonders leicht zusammenfinden. Ähnlich erklären sich wohl zum Teil die zahlreichen psychopathischen Anomalien bei den Oligophrenen.

\section{Schwachsinnszustände infolge von nachgewiesenen Hirnschädigungen}

In seelischer Hinsicht unterscheiden sich die angeborenen bzw. früherworbenen Schwachsinnszustände, die durch äußere Ursachen entstehen, im späteren Lebensalter nicht von den erblichen Formen, so daß sich eine besondere Besprechung erübrigt. Von den exogenen Ursachen, die zum Schwachsinn führen, ist vor allem die konnatale Lues zu nennen, die, zumal in Großstädten, einen nicht unerheblichen Anteil zu den Oligophrenien stellt. Vorgeschichte, serologische Untersuchung, auch jene der Eltern, Pupillenstörungen, die zahlreichen körperlichen Stigmata der konnatalen Lues werden aber die Diagnose sicherstellen. Auch Geburtsschäden führen, zumal bei Frühgeburten, unter Umständen zu Schwachsinnszuständen. Sodann kommen vor allem frühkindliche Infektionen des Hirns und der Hirnhäute als Ursachen des Schwachsinns in Frage. Herdstörungen, besonders die zerebrale Kinderlähmung, seltener auch andere Hirnsymptome (Athetose) und Hydrozephalus werden meist die Diagnose der erworbenen Oligophrenien ermöglichen.

\section{Therapie}

Der Schwachsinn ist als solcher unbeeinflußbar. Imbezille kommen in der Normalschule nicht fort und müssen in Sondereinrichtungen, den Hilfsschulen, dressiert und geschult werden. Auch nach der Schulentlassung geht die Sonderfürsorge in Fortbildungsschulen fort, die ihrem Niveau angepaßt sind. Besonders wichtig ist die geeignete Berufsberatung. In der Regel hat es keinen Sinn, Hilfsschüler in Handwerkslehrstellen zu geben. Die allermeisten erreichen das Lehrziel nie. Selbst wo die Gesellenprüfung unter besonders günstigen Bedingungen gelingt, bleiben die Kranken wegen unzulänglicher Leistungen doch meist nicht im erlernten Beruf, sondern sinken zum Tagelohn herab. Es ist also angezeigt, die Oligophrenen von vornherein in Berufen 
unterzubringen, in denen noch bescheidene Aussichten zum Fortkommen bestehen. Nach dem Gesetz zur Verhütung erbkranken Nachwuchses sind die Oligophrenien anzeigepflichtig und ist die Unfruchtbarmachung durchzuführen. Der Gesetzgeber wendet mit Recht gerade bei der Oligophrenie strenge Maßstäbe an. Nur wo der angeborene Schwachsinn sich mit aller Sicherheit auf äußere Schäden zurückführen läßt, kann von der Sterilisation abgesehen werden.

Heiratswünschen erblicher Oligophrener soll der Arzt dringend widerraten. Wo ein Debiler eben noch allein für sich selbst zu sorgen vermag, wird er in Schwierigkeiten geraten, sobald er noch die Lasten für die Ehefrau zu tragen hat, die häufig genug dann auch unzulänglich sein wird. Oligophrene Mädchen versagen im Haushalt vielfach grob.

Manchen Oligophrenen muß man durch die Entmündigung davor schützen, ausgebeutet zu werden. Vor dem Strafgericht wird man den Imbezillen ohne weiteres den Schutz des $\S 51$ zugestehen. Bei den Debilen kommt es stets auf die Gesamtheit ihrer Eigenschaften an, also neben dem Grad der Debilität und der Einsichtsfähigkeit auch auf das Vorhandensein psychopathischer Anomalien und die Wirkung von Zusatzschäden (Alkohol, Ausnahmezustände), ob man sie strafrechtlich verantwortlich machen kann oder nicht.

Bei jedem Oligophrenen wird man die Wassermannsche Reaktion anstellen und gegebenenfalls spezifisch behandeln.

\section{Sonderformen der Oligophrenie}

\section{Mongolismus}

Mongoloide sind besonders häufig Kinder alter Mütter (oft über 40 Jahre), letzte Glieder langer Geschwisterreihen, erste oder einzige Kinder; doch muß dies nicht so sein. Über die Entstehungsbedingungen wissen wir Sicheres nicht. Rein erblich ist die Krankheit nicht; es ist aber möglich, daß erbliche Momente eine gewisse Rolle spielen, unter Umständen auch für die Beschaffenheit der Uterusschleimhaut. Die Mongoloiden sind in ihrer Gesamtentwicklung geschädigt. Schon gleich nach der Geburt fallen sie durch ihren kleinen runden Schädel, ihr flaches Gesicht mit der meist kleinen, stumpfen Nase, den schmalen, schräg aussehenden Lidspalten, den roten, abgezirkelten Flecken auf den Wangen, oft auch auf der Nase, der großen, rissigen Zunge, die zum Munde herauskommt, auf. Alle diese Merkmale treten später noch deutlicher hervor. Die Glieder bleiben schlaff und überstreckbar; der Bauch ist vorgewölbt; meist besteht ein Nabelbruch. Häufig sind konnatale Herzfehler, und fast regelmäßig zeigen die Kranken eine Anfälligkeit für Infektionen, besonders auch die Tuberkulose, an der die Mongoloiden häufig früh sterben. Das erreichte Durchschnittsalter ist gering, wenn es auch einzelne alte Mongoloide gibt. Das Körperwachstum bleibt meist, vielfach allerdings nicht sehr erheblich, zurück. Die nicht ganz seltenen gleichzeitigen Erscheinungen des Myxödems verschwinden mit der Schilddrüsenbehandlung. Geistig entwickeln die Mongoloiden sich sehr langsam. Anfangs stumpf und torpide, entfalten sie in der Regel bald eine gewisse Regsamkeit. Sie werden lustig und zutunlich und neigen zu Späßen und Scherzen. Nicht selten ist eine deutliche Freude an Musik. Die Sprachentwicklung bleibt unvollkommen, die Stimme rauh. Wegen ihrer mangelnden, sprunghaften Aufmerksamkeit und ihrer zappeligen, unernsten 
Lebhaftigkeit werden sie oft nicht einmal hilfsschulfähig. Im späteren Lebensalter treten die typischen körperlichen Kennzeichen ein wenig zurück. Es kann auch zu einer bescheidenen geistigen Nachreife kommen. Über die leichte Imbezillität hinaus entwickeln sich aber nur vereinzelte Mongoloide.

Immerhin gibt es seltene Formes frustes des Mongolismus, bei denen eine befriedigende geistige Entwicklung gelingt. Manche Mongoloide scheinen durch Röntgenbestrahlung des Gehirns gefördert zu werden.

Kretinismus

Bei der Entstehung des Kretinismus spielt die Zerstörung oder doch schwere Schädigung der Schilddrüse während der Fötalentwicklung oder im frühen Kindesalter eine wesentliche Rolle. Beim sporadischen Kretinismus sind es verschiedenartige Schäden (Lues, Blutung usw.), welche die Thyreoidea vernichten. Für den endemischen Kretinismus, der besonders in gewissen Alpengebieten, Wallis, Steiermark, Kärnten, Allgäu, im Odenwald und Schwarzwald zu Hause ist, scheint die Bodenformation und die Art des Bodenaufschlusses ursächlich wichtig zu sein. Doch ist dem Schilddrüsenschaden, der oft nur im Kropf zum Ausdruck kommt, wohl noch ein Hirnschaden koordiniert. Außer dem Mxyödem, das besonders in der Jugend ausgeprägt ist, um später einer runzeligen Beschaffenheit der trockenen Haut zu weichen, finden sich schwere Wachstumsanomalien, die sich am Skelett ausprägen: Zwergwuchs infolge unzureichender Apposition der spät oder gar nicht verknöchernden Epiphysenlinien, Verkümmerung der Schädelbasis, die zu einer Verbreiterung der Schädelkapsel und zu eingesunkener Nasenwurzel führt, Wirbelsäulenwachstumsstörungen, tatzenartige Entwicklung der Hände. Dazu kommt Vortreten des Leibes mit Nabelbruch. Die Haare sind derb und struppig, die Geschlechtsentwicklung bleibt aus oder ist unvollkommen, der Grundumsatz ist herabgesetzt. Die Kretinen frieren leicht. Sie bleiben motorisch schwerfällig und plump, ihre Stimme ist rauh und oft krächzend, ihre Sprachentwicklung ist meist unzureichend. Sie können Idioten sein, aber auch eine bescheidene geistige Entwicklung selbst bis in die Breite der Norm hinein erlangen. Meist sind sie träge, aber gutmütig, freundlich, zutunlich, humorvoll.

Der sporadische Kretinismus wird durch Schilddrüsenmedikation oft günstig beeinflußt, ja, er kann geheilt werden, wenn die Behandlung früh einsetzt und stetig durchgeführt wird. Beim endemischen Kretinismus läßt sich zum mindesten auf körperlichem Gebiete Günstiges erreichen. Geistig bleibt der Erfolg in der Regel gering.

\section{Amaurotische Idiotie}

Die infantile Form der Krankheit ist ein einfach rezessives Erbleiden, das hauptsächlich bei Nachkommen von Ostjuden beobachtet wird. Bei den normal geborenen Kindern kommt es schon in den ersten Jahren zu einer tiefen Verblödung mit Erblindung, der eine eigenartige Augenhintergrundsveränderung: mattweiße Aufhellung mit kirschrotem Fleck an der Stelle der Makula entspricht. Die Glieder werden schlaff, die Muskeln schwinden. Es kann aber auch zu Spannungen und Krämpfen kommen. Der Tod tritt in 
wenigen Jahren ein. Gelegentlich verbindet sich die Krankheit mit der PickNiemannschen lipoidzelligen Splenohepatomegalie.

Von der infantilen unterscheidet sich die juvenile Form der amaurotischen Idiotie, die bei Nichtjuden vorkommt und nicht zu der oben erwähnten, sondern anderen Augenhintergrundsveränderungen führt: gelbgraue, schließlich gelbblasse Papillen mit fadendünnen Gefäßen, ferner gelbliche, runde, dichtstehende Herde, schließlich Retinitis-pigmentosa-Bilder. Die Kinder entwickeln sich bis zum 5.-8. Lebensjahr normal. Dann tritt im Laufe von 1-2 Jahren Erblindung ein. Gleichzeitig oder etwas später macht sich ein geistiger Rückgang geltend, der langsam, aber stetig zunimmt, zum Verlust aller Kenntnisse und schließlich zu tiefem Blödsinn führt. Früh kommt es zu epileptischen Anfällen, die im späteren Verlauf häufiger werden. Auf neurologischem Gebiete entwickeln sich extrapyramidale Erscheinungen: kleinschrittiger Gang, Hockstellung, Rigor, Akrozyanose und Salbengesicht, während Pyramidenstörungen erst spät oder gar nicht hervortreten. Die Kranken erfahren ferner eine fortschreitende artikulatorische Sprachstörung mit logoklonem Überhasten. Viele zeigen bei zunehmendem Schwachsinn Bewegungsstereotypien oder aber Bewegungsarmut. Es handelt sich nach den Untersuchungen von Sjögren um eine monohybrid-rezessive Erbkrankheit, die mit der infantilen Form nichts zu tun hat. Es gibt auch Spätformen der amaurotischen Idiotie. In erblicher Hinsicht sind Beziehungen zur Retinitis pigmentosa und zu gewissen Ohrübeln anzunehmen.

Die amaurotischen Idiotien zeigen spezifische Nervenzellveränderungen, nämlich enorme Aufblähungen durch Speicherung lipoider Stoffe.

\section{Erkennung}

Das Gesetz zur Verhütung erbkranken Nachwuchses stellt schon im Rahmen des angeborenen Schwachsinns selbst recht schwierige differentialdiagnostische Aufgaben. Nur die erblichen Formen des angeborenen Schwachsinns unterliegen dem Gesetz. Es gilt also, die exogen entstandenen Oligophrenien von den erblichen zu unterscheiden. Aus dem Schwachsinn als solchem kann man seine Entstehungsgeschichte nicht ablesen. Die frühzeitige Untersuchung des Blutes, nicht selten auch kennzeichnende neurologische Störungen (Pupillenstarre) und die mannigfachen körperlichen Zeichen der konnatalen Lues werden die hierher gehörigen Fälle meist unschwer erkennen lassen. Wo der Schwachsinn Folge grober traumatischer Schäden, besonders von Geburtsschäden ist, wird man neben dem Schwachsinn grobe Herderscheinungen selten vermissen. Hierher gehören vor allem viele Little-Zustände, die zerebrale Kinderlähmung. In der gleichen Form äußern sich vielfach auch die Folgen frühkindlicher Enzephalitiden. Die Meningitis hinterläßt nicht selten Hydrozephalus und Lähmung einzelner Hirnnerven. Häufig wird auch die eingehende Anamnese, insbesondere der plötzliche Stillstand nach anfänglich normaler Entwicklung unter dem Einfluß eines Infekts oder im Zusammenhang mit einem kurzdauernden Krampfleiden den Verdacht des exogenen Schwachsinns nahelegen. In manchen Fällen bringt erst die Enzephalographie Klarheit, wenn sie grobe Anomalien der liquorführenden Räume zeigt. 
Gegenüber anderen Krankheiten machen die Oligophrenien erheblicheren Grades nur dann Schwierigkeiten, wenn die Kranken gerade an einer episodischen Störung leiden. Die objektive Anamnese wird in der Regel die Schwierigkeiten beheben. Bei der Pfropfhebephrenie sind meist die Zeichen des Schwachsinns neben jenen der Schizophrenie deutlich ausgeprägt; vor allem aber zeigt die Vorgeschichte die schubartige kennzeichnende Veränderung des von je schwachsinnigen Kranken.

Die Debilität verrät sich häufig am deutlichsten aus der Lebensführung, zumal bei den besonders gut geschulten Kranken, die ein gutes Gedächtnis haben und formal gewandt sind.

Im frühen Kindesalter ist die Erkennung der leichtesten Schwachsinnsgrade wohl meist unmöglich, jene der mittleren Grade oft schwer, da nicht ganz selten auch bei später normalen Kindern die Sprachentwicklung sich nicht unerheblich verzögert. Bei Kindern, die mangelhafte Pflege genossen haben, muß man mit der Annahme von Schwachsinn äußerst vorsichtig sein. Ein sehr erheblicher Entwicklungsrückstand kann bei geeigneter Pflege in außerordentlich kurzer Zeit eingeholt werden. Durchschnittlich bleiben Kleinkinder aus Handarbeiterkreisen in der Sprachentwicklung erheblich hinter jenen zurück, die besondere Pflege genießen. Im Kleinkindesalter wird man überhaupt sehr vorsichtig mit der Prognosestellung sein müssen.

\section{b) Psychische Störungen nach Gehirnverletzungen}

Bei der einfachen Hirnerschütterung (Commotio cerebri) kommt es zu Bewußtlosigkeit, Pulsverlangsamung und Erbrechen, das freilich nicht in allen Fällen aufzutreten braucht. Die Pathogenese der Kommotio ist immer noch unklar. Vielleicht handelt es sich um eine ausgebreitete vasomotorische Disregulation, vielleicht um eine Erschütterung der Medulla, die reflektorisch zu Bewußtseinsausschaltung und Vagusreizung führt. Schwere Kommotio führt zu retrograder Amnesie, und zwischen die volle Bewußtlosigkeit und das Erwachen schiebt sich ein mehr oder weniger langdauernder Zustand der Benommenheit ein.

Nach besonders tiefen Kommotionen ohne grobe Hirnquetschung, bei denen freilich in der Regel doch kleine Kontusionsherde vorliegen dürften, und bei Prädisponierten (Alkohol, höheres Lebensalter) können sich mit dem Erwachen aus der vollen Bewußtlosigkeit, im ganzen selten, delirante Zustände ausbilden. Meist handelt es sich um Situationsdelirien, in denen die Kranken bei mehr oder weniger schwerer Benommenheit im Sinne ihrer gewöhnlichen Beschäftigung oder auch in anderer Weise halluzinieren, besonders optisch, aber auch haptisch und akustisch, unruhig aus dem Bett drängen, ihre Umgebung verkennen und gelegentlich gewalttätig werden. Immer sind Auffassungs-, Denk- und Merkstörungen grob ausgeprägt. Die Kranken sind verlangsamt, schwerfällig; sie perseverieren; häufig sind Konfabulationen, die auch üppig und produktiv werden können; gelegentlich sieht man reduplizierende Paramnesie. Solche Zustände können unter Schwankungen Tage, Wochen, ja Monate anhalten.

Als weitere Kommotionsfolgen begegnen uns manchmal Dämmerzustände, in denen die Kranken geordnet erscheinen, zusammenhängend reden und 
handeln, aber dennoch in ihrer Orientierung gestört, in ihrer Auffassung der Vorgänge um sie herum verändert sind und für die nachträglich volle Amnesie besteht. Aus solchen, meist kurzdauernden, Dämmerzuständen heraus kann es zu plötzlichen Gewalttätigkeiten kommen.

Nach dem Abklingen der Bewußtlosigkeit im Gefolge leichter Kommotionen wird nicht selten jede grobe Störung vermißt. Neurasthenische Erscheinungen freilich bleiben auch hier noch eine Zeitlang bestehen. Demgegenüber hinterlassen schwere Formen der Hirnerschütterung und die eigentlichen Kommotionspsychosen länger fortdauernde Störungen gröberer Art. Vor allem sind Merkfähigkeit und Konzentrationsfähigkeit in erheblichem Maße beeinträchtigt, und dazu gesellt sich hochgradige Ermüdbarkeit. Die Konzentrationsstörung äußert sich in Abreißen und Entschwinden der Gedanken, Sprunghaftigkeit, Unfähigkeit, verwickeltere Zusammenhänge zu übersehen. Kennzeichnend sind ferner ausgesprochene Reproduktionsstörungen, die sich mit den Merkstörungen vergesellschaften. Auf diese Weise entstehen Korsakowbilder, also amnestische Symptomenkomplexe, bei denen häufig auch Konfabulationen vorkommen. Zugleich besteht in der Regel Mangel an Initiative, Abneigung gegen jede geistige Leistung, Ruhebedürfnis, apathische Stimmung, die bei Beanspruchung in Gereiztheit und Verdrossenheit umschlägt. Niemals fehlen Kopfschmerzen, Kopfdruck, Überempfindlichkeit gegen Sinnesreize, Asthenopie, Ohrensausen, vasomotorische Störungen, Blutdruckschwankungen, Pulslabilität, Steigerung der Sehnenreflexe, Schwindel, der sich zu Ohnmachtsanwandlungen steigern kann, Schlafstörungen, Unfrische, Alkoholintoleranz. In abnehmender Deutlichkeit bleiben diese Beschwerden als neurasthenisches Syndrom noch Monate bestehen; doch kommt es bei der Kommotio, auch wenn sie schwer war, zu allermeist in Jahresfrist zur Restitution. In sehr schweren Fällen können freilich noch längere Zeit Neigung zu Kopfschmerzen, Reizbarkeit, unter Umständen auch Alkoholintoleranz und erhöhte Ermüdbarkeit bei besonderer Beanspruchung bestehen bleiben.

Außerordentlich häufig schließen sich psychogene und hysterische Störungen an Hirntraumen an. Dies mag zum Teil an der hirntraumatischen Veränderung selbst liegen, die für psychogene Manifestationen geeignet macht, insbesondere den Gemütsbewegungen einen stärkeren Widerhall verschafft. Vor allem ist es aber die Unfallsituation und sind es Entschädigungswünsche, welche die Beschwerden verewigen und die anfänglich krankhaften Mechanismen in den Dienst von Strebungen stellen, die mit dem Trauma nichts zu tun haben. Während die traumatische Torpidität vielfach solche Störungen zunächst nicht aufkommen läßt, treten sie mit der objektiven Besserung immer deutlicher hervor. Diese Tatsache macht es schwierig, zwischen echten und unechten hirntraumatischen Folgen zu unterscheiden. Immer wird man dort, wo echte Konzentrationsstörungen und ein Rest des amnestischen Symptomenkomplexes noch nachzuweisen sind, auch den ,hysterischen ${ }^{66}$ Störungen den Krankheitswert nicht absprechen können. Wo mit dem Zurücktreten der eigentlichen Hirnsymptome und nach einem störungsfreien Intervall im zeitlichen Zusammenhang mit der Rentenbegutachtung neurasthenische und hysterische Züge in verstärktem Ausmaße erst hervortreten, da fehlt in der Regel der echte Hintergrund. 


\section{Hirnquetschung (Contusio)}

Schon bei schweren sog. Kommotionen dürften kleine Quetschungsherde meist nicht fehlen. Gelegentlich kann man solche an Geruchs- und Gleichgewichtsstörungen organischer Art auch nachweisen. Andere Prädilektionsstellen der Quetschung bleiben stumm oder bringen eine Neigung zu Ohnmachtsanwandlungen mit sich (Schädigung des Temporalpols). Umfangreichere Kontusionen machen sich in Herderscheinungen bemerkbar, die von der allerverschiedensten Art sein können. Von den Aphasien, Apraxien, Agnosien und Lähmungen kann hier nicht die Rede sein. Sie gehören in das Bereich der Neurologie. Wichtig ist aber, die Stirnhirnschäden eigens hervorzuheben, weil sie sich besonders häufig in seelischen Krankheitserscheinungen auswirken. Wir finden Störungen der Spontaneität, mangelnde Ernstwertung des Zustandes und der Gesamtlage, Störungen des Takts und des Anstandes, Veränderungen der Stimmungslage, bald nach der euphorischunkritischen, bummelwitzig-faseligen Seite hin, bald im Sinne der Gereiztheit, Erregbarkeit und Enthemmung, endlich - und zwar besonders häufig Zustände von torpid-mürrischer Apathie. Solche Kranke sind untätig, sitzen oder liegen herum, sind gedankenlos, lassen sich schwer antreiben. Spontane Antriebe fehlen oder erlöschen sofort. Bei einzelnen guten Leistungen, die bei vorübergehender voller Konzentration gelingen, bleibt die Gesamtleistungsfähigkeit doch gering; sie ist vor allem ungleichmäßig, launisch, durch Konzentrationsmängel, Gedankenabreißen und Reproduktionsstörungen beeinträchtigt. Oft besteht auch ein Ausfall der Sprachinitiative. Dazu fehlen selten kennzeichnende Störungen des Gleichgewichts. Die Stirnhirnschädigungen äußern sich also vorwiegend als Persönlichkeitsveränderungen. Diese sind wesentlich rückbildungsfähig, wenn auch recht hartnäckig, wo der Schaden kein allzu schwerer war. Bei großen Ausfällen (Durchschüsse mit großen Zertrümmerungen) hinterbleiben irreparable Persönlichkeitswandlungen.

Wandlungen solcher Art fehlen bei Schäden im Parieto-Okzipitalbereich.

Diese Kranken erscheinen in ihrer Persönlichkeit ganz unverändert oder zeigen eine bemerkenswerte, vielleicht etwas stille Ausgeglichenheit. Auch leichtere Herdstörungen brauchen im Alltagsleben nicht hervorzutreten, wenn nicht gerade aphasische Erscheinungen das Bild beherrschen. Der näheren Untersuchung ergeben sich aber Agraphie, Alexie, Raumsinn- und Rechenstörungen oft grober Art, die man im Gespräch mit den Kranken nicht vermutet. Schäden in den ,stummen ${ }^{6}$ Partien der rechten Hirnhemisphäre brauchen sich nicht deutlich bemerkbar zu machen. Wohl aber sind Ermüdbarkeit und erhöhte affektive Erregbarkeit auch dann meist deutlich. Immerhin sind Herde in der linken Hirnhälfte auch in dieser Hinsicht regelmäßig von größerer Bedeutung als solche in der rechten. In den Delirien nach schweren Hirnkontusionen vermischen sich die Herdstörungen mit den psychotischen Allgemeinsymptomen oft in unentwirrbarer Weise.

Im Gefolge der Kontusionen kann es zu schweren Hirndruckerscheinungen kommen, seltener auch bei einfachen Kommotionen. Solche Kranke muß man, wenn nicht etwa gröbere Blutungen zu befürchten sind, durch Lumbalpunktionen - oft wiederholt - entlasten. Sie ergeben anfangs blutigen, später xanthochromen Liquor, der unter erhöhtem Druck abfließt. Im Gefolge 
der Hirnquetschung entstehen manchmal akute Blutungen, die sich in zunehmendem Hirndruck und stetig tiefer werdendem Koma, unter Umständen auch epileptischen Krämpfen, äußern. In solchen Fällen muß trepaniert werden.

Von den Folgen der Hirnquetschung muß endlich noch die

\section{traumatische Epilepsie}

genannt werden, die meist im ersten halben Jahr, in abnehmender Häufigkeit aber auch viel später, ja erst nach mehr als einem Jahrzehnt sich einstellen kann. In der Regel wird sich der Zusammenhang der Epilepsie mit der Hirnschädigung aus dem Herdcharakter der Anfälle ergeben. Die Jackson-Anfälle (s. Syndrome) werden also auf den am neurologischen Befund vielfach ablesbaren örtlichen Hirnschaden hinweisen. Immerhin braucht dies nicht der Fall zu sein, und zumal im späteren Verlauf traumatischer Epilepsien können die Anfälle typischen generalisierten epileptiformen Anfällen gleichen. Immerhin ist auch dann oft genug nach den Anfällen der neurologische Befund ausgesprochener. Absenzen und andere Äquivalente sind bei der traumatischen Epilepsie zwar seltener als bei der genuinen. Sie kommen aber vor, und das gleiche gilt für die epileptische Persönlichkeitsveränderung, die sehr deutlich werden kann. Häufig ist eine solche Entwicklung aber nicht.

Zur traumatischen Epilepsie kommt es nur bei einem kleinen Bruchteil der Menschen, die von geschlossenen Hirnverletzungen betroffen wurden. Wir müssen annehmen, daß auch hier zumeist eine anlagegemäß erhöhte Krampfbereitschaft besteht. In anderen Fällen sind es wohl die Spätveränderungen an den Hirnnarben, vielfach im Zusammenhang mit toxischen Schäden, zumal Alkoholismus, die schließlich zu Krämpfen führen. Die Ausschneidung der Hirnnarben bringt nicht selten Heilung oder doch wesentliche Besserung. Sehr viel häufiger als nach geschlossenen sind die traumatischen Epilepsien nach offenen Hirnverletzungen, zumal Hirnschüssen. Hier droht auch die Gefahr des Spätabszesses. Nach einfachen Kommotionen kommt es zur Epilepsie nicht. Doch mag vereinzelt die genuine Epilepsie durch Hirnerschütterungen manifest werden.

\section{c) Progressive Paralyse}

(Dementia paralytica)

Die Paralyse ist eine der häufigsten Geisteskrankheiten, und zwar bei Männern sehr viel häufiger als bei Frauen. Unter den Männern wiederum sind besonders die mittleren Altersklassen betroffen. Das wirtschaftliche Niveau der Paralytiker ist durchschnittlich höher als das der meisten anderen Geisteskranken. Es hängt dies offenbar mit dem höheren Heiratsalter der betroffenen Menschengruppe zusammen, das zugleich erhöhte Ansteckungsgefahren mit sich bringt.

\section{Symptomatologie}

Der Eindruck einer meist schon in den Gesichtszügen faßbaren dementen Schlaffheit lenkt beim Paralytiker die Aufmerksamkeit sofort auf den körperlich neurologischen Befund, aus dem in der Regel die Diagnose gemacht wird, während der seelische Zustand gelegentlich auch sehr erfahrene Ärzte 
in die Irre führt. Vor allem Pupillenstörungen werden selten vermißt, um so seltener, je weiter die Krankheit fortgeschritten ist. Neben häufiger Anisokorie und meist leichten Entrundungen und Verziehungen der Pupillen steht im Vordergrund die reflektorische Pupillenstarre, das Argyll-Robertsonsche Phänomen, also fehlende Licht- bei erhaltener oder sogar gesteigerter Konvergenzreaktion. Oft ist, anfangs, die Lichtreaktion auch nur träge oder wenig ausgiebig. Absolute Pupillenstarre ist selten und kommt wohl nur vor, wenn Erscheinungen von Hirnlues vorausgegangen sind. Völliges Fehlen von Pupillenanomalien ist ganz selten.

Auch Störungen der tiefen Reflexe fehlen selten. Entweder finden wir Reflexsteigerungen, besonders gesteigerte Patellar- und Achillessehnenreflexe bei fehlenden oder nur recht verwaschenen anderweitigen Pyramidenzeichen (so ist Babinski in der Regel nur unmittelbar nach paralytischen Anfällen nachweisbar). Die Reflexsteigerung entspricht der Beteiligung der Seitenstränge an dem Krankheitsprozeß (Seitenstrangparalyse). Oder aber Patellarund Achillessehnenreflexe sind abgeschwächt, fehlen häufig auch ganz im Zusammenhang mit dem Ergriffensein der Hinterstränge (Hinterstrang-, Taboparalyse). Leichte Ataxie vermissen wir bei Paralyse selten.

Auffälliger ist die Veränderung des Sprechens. Die Sprache ist meist schon im gewöhnlichen Gespräch verwaschen, unscharf artikuliert, mühselig, verlangsamt, und es kommt hie und da zum Silbenstolpern, zur Vorwegnahme oder aber zur Perseveration einzelner Laute und Silben. Man kann sich die artikulatorische Sprachstörung deutlicher machen dadurch, daß man schwierige Worte (Testworte) aussprechen läßt. Zugleich ist in der Sprache vielfach ein Tremor merkbar. Bei fortgeschrittenen Paralysen wird die Sprache zu einem unverständlichen Lallen. Ähnliche Veränderungen erleidet die Schrift. Die Schriftzüge werden unsicher, zitternd, unsauber. Die Schrift ist unordentlich auch in der Verteilung auf den Raum, Buchstaben, Silben und Worte werden ausgelassen, versetzt, verdoppelt.

Beim Sprechen werden die in der Ruhe müden, ausdruckslosen, schlaffen Züge durch wetterleuchtende Gesichtsverziehungen (mimisches Beben) belebt, und oft findet sich auch wirklich ein Zittern der Lippen und der Zunge. Bei schwierigen Worten kommt es gern zu grimassierenden Gesichtsverzerrungen.

Diesem Verlust an Spannung und Koordination, der in Sprache, Schrift und Mimik besonders deutlich ist, kann man meist auch in allen übrigen Bewegungsleistungen des Kranken nachweisen. So ist der Gang oft plump, schwerfällig, mühsam, langsam, und das gleiche gilt für alle Hantierungen. Überall ist Schwäche und Einbuße an den höchsten Koordinationsleistungen.

Bei solchem körperlichem Befund wird die Diagnose Paralyse meist richtig sein. Sie wird vollends gesichert durch die serologische Untersuchung. Im Blut ist die Wassermannsche Reaktion nahezu ausnahmslos positiv, im Liquor immer, und zwar fast regelmäßig schon bei niedrigen Liquorportionen $(0,2)$. Dazu findet sich Pleozytose, und zwar Vermehrung der Lymphozyten, meist in bescheidenen Grenzen (10-100), und Eiweißvermehrung. So ist die Nonne-Apeltsche Reaktion fast immer positiv, und die Kolloidreaktionen (Mastix, Goldsol) ergeben kennzeichnende Kurven: bei den großen Liquordosen Ausfällung, die bei den kleineren rasch abnimmt. (Siehe im übrigen unter Anhang: Liquorsyndrome.) 
Das seelische Bild der Paralyse ist dasjenige der organischen Demenz, freilich mit einigen mehr oder weniger kennzeichnenden Zügen. Wir finden also Merk-, Gedächtnis- und Reproduktionsstörungen, erschwerte und wenig stetige Aufmerksamkeit, verlangsamte, mühsame Auffassung, vielfach flüchtige, unvollkommene Wahrnehmungen, verengtes geistiges Gesichtsfeld, mangelnden Überblick, Verlangsamung und Erschwerung des Denkens, Unfähigkeit, nicht ganz leichte Gedankengänge zu Ende zu denken, mehr oder weniger, bei ausgesprochener Paralyse meist hochgradige Urteilsschwäche. Dabei ist der Affekt eigenartig haltlos und labil, leicht beeinflußbar und je nach den angeregten Inhalten von Tränen zu Heiterkeit, von tiefem Schmerz zu strahlender Euphorie umkehrbar. Bei der überwiegend häufigen dementen Form ist das spontane Interesse gering, die Kranken sind stumpf, ohne Initiative, ohne Ausdauer und Zielstrebigkeit in der Durchführung ihrer Entschlüsse. Auch das Seelenleben trägt jene Züge haltloser und unkoordinierter Schlaffheit, die im körperlichen Befund so hervortreten.

Dem mangelnden Überblick, der Urteilsschwäche und der Enthemmung niederer Antriebe, die mit der Abschwächung der höchsten Leistungen einhergeht, entspricht es, daß der Paralytiker oft antwortet, wo er gar nicht gemeint ist, oder doch Worte wiederholt, die er in der Umgebung hört (Echolalie), daß er sich in plumper Weise gern ,hineinmischt", aber auch, daß er sich wahllos Gegenstände (Eß- und Rauchwaren) aneignet, die ihm nicht gehören. Fast regelmäßig ist ein Verlust an Takt, der sich in einfacher Nachlässigkeit, Distanzlosigkeit, aber auch in groben Entgleisungen kundtun kann. Beim Darniederliegen der höheren geistigen Leistungen haben die Gemütsbewegungen einen besonders starken Einfluß auf Tun und Denken. Der Paralytiker wird also im Zorn maßlos, im Kummer hemmungslos, und in seiner Kritiklosigkeit ist er allen Einflüssen zugänglich, wo sie nur seinen primitiven Wünschen entgegenkommen. Oft wird der Paralytiker durch einen plötzlich angeregten Wunsch zu den unsinnigsten Handlungen getrieben; er beobachtet dann auch die wichtigsten Gegenmotive nicht, die er bei ruhiger Einstellung noch durchaus zur Verfügung hat. Ein Paralytiker, dessen Schamgefühl an sich nicht Schaden gelitten hat, kann also etwa in Gegenwart der Kinder plötzlich Sexualverkehr von seiner Frau verlangen oder nackt vor ihnen seine Notdurft verrichten; er bringt es fertig, in Gegenwart des Eigentümers dessen Eßwaren an sich zu nehmen und sie vor dessen Augen unter seinem Kittel zu verbergen.

Besondere Schwierigkeiten hat der Kranke beim Operieren mit Zahlen und bei der zeitlichen Gliederung seiner Erlebnisse in der Vergangenheit. Auch jene, die sonst noch ganz leidliche Leistungen aufweisen und ihr Wissen im wesentlichen zur Verfügung haben, versagen häufig, wenn sie ihr Heiratsalter, ihr Alter zur Zeit irgendeines anderen einschneidenden Ereignisses nicht wissen, sondern ausrechnen sollen. Gleiche Schwierigkeiten haben sie bei allen, vor allem angewandten Rechenaufgaben, bei denen es nicht bloß auf Wissensaktualisierung ankommt.

Sinnestäuschungen sind bei unbehandelten Paralysen selten. Sie kommen aber gelegentlich vor, besonders in Zuständen der Bewußtseinstrübung. Demgegenüber sind Wahnideen häufig. Sie tragen die Farbe der Grundstimmung und der geistigen Schwäche zugleich und sind in der Regel unstabil, beeinflußbar, 
besonders steigerungsfähig und in ihren Inhalten oft von Augenblick zu Augenblick wechselnd. Vielfach haben sie den Anstrich der Maßlosigkeit. Gold und Edelsteine, Kaiser und Gott, auf der anderen Seite völlige Vernichtung, Totsein, Fehlen von Kopf und Geschlechtsglied, Darm und Herz, Teufel und schwerste Verbrechen spielen eine große Rolle. Dabei behalten die Wahnideen immer eine gewisse Nähe zu den Inhalten unserer kindlichen Phantasie und nehmen selten die Absonderlichkeit schizophrener Wahnideen an.

Der Verlauf der unbehandelten Paralyse geht nach einer immer größeren geistigen Schwäche hin. In allen Verlaufsabschnitten der Krankheit, den ersten kennzeichnenden Störungen lange, oft Jahre vorauseilend, im Beginn und im weiteren Verlauf der Paralyse kann es zu Anfällen kommen. Nicht selten sind apoplektische Halbseitenlähmungen, die auch aus voller Gesundheit eintreten und für die kennzeichnend ihre Flüchtigkeit ist. Die anfangs massive Lähmung verschwindet im Laufe eines oder ganz weniger Tage. Ebenso kann eine Aphasie, selten auch einmal eine optische Agnosie verlaufen. Typische epileptiforme Anfälle sind gleichfalls häufig, ja, es kann sich unvermittelt einmal eine lange Serie solcher, ein Status paralyticus, einstellen. Nicht selten trägt dieser Status die Kennzeichen einer Häufung von JacksonAnfällen. Nur ein Glied oder eine Körperhälfte krampft, aber sie krampft mit verschiedener Intensität und oft bei erhaltenem oder nur mäßig getrübtem Bewußtsein, Stunden, ja Tage hindurch. Gelegentlich krampft auch nur eine Gesichtsseite, oder es kommt lediglich zu klonischem Augenzucken. Solche mehr oder weniger langdauernden, oft unvollkommenen Jackson-Anfälle können auch isoliert auftreten. Nicht ganz selten sind auch einfache, tiefe, rasch vorübergehende Ohnmachten. Endlich kennen wir auch anfallsartige kurzdauernde Verwirrtheiten, Erregungen, Dämmerzustände, Delirien, d. h. der paralytische Anfall spielt sich hier ganz auf seelischem Gebiete ab.

Neben den körperlichen und seelischen Symptomen, die für die Diagnose von besonderer Bedeutung sind, haben wir noch andere $\mathrm{zu}$ nennen, die in keinem paralytischen Verlauf ganz fehlen. Auf körperlichem Gebiete ist zunächst die Beteiligung des Gefäßsystems zu nennen; besonders häufig sind Aortenstörungen (hier findet man oft auch Spirochäten) im Sinne einerAortenlues und einer Lues der Aortenklappen. Selten vermissen wir allgemeine trophische Störungen, Abmagerung, aber auch überraschenden Fettansatz, Störungen der Blasenfunktion (Pollakisurie, Urinretention, auf die stets geachtet werden muß, neben unablässigem freiwilligem Harnabgang), Störungen der sexuellen Appetenz und Potenz, die im Anfang oft gesteigert sind, dann aber nachlassen oder sich voneinander dissoziieren, so daß bei gesteigerter Appetenz die Potenz erlischt. Häufig ist eine Neigung zu Dekubitus schon in frühen Stadien, eine erhebliche Gewebsschwäche, die sich in Neigung zu Hautblutungen bemerkbar macht, große Knochenbrüchigkeit. Manchmal sehen wir einzelne periphere Nervenlähmungen (Ptosis), meist Sensibilitätsstörungen, besonders Analgesie, die teils durch Unaufmerksamkeit vorgetäuscht, teils organisch bedingt ist, meist aber wohl einer Kombination beider Störungen entspricht. In manchen Fällen von Paralyse, besonders von Tabesparalyse, kommt es zu Optikusatrophie und zu Blindheit, die manche Paralytiker verleugnen (diese Nichtwahrnehmung der eigenen Blindheit, wie überhaupt von groben Defekten, etwa Lähmungen, wird als Antonsches Symptom bezeichnet). 
Der Verlauf der unbehandelten Paralyse ist etwas verschieden, je nach der klinischen Sonderform, in der sie sich darstellt. Die häufigste Gestaltung ist die einfach demente Paralyse, die wohl dem Wirken des paralytischen Krankheitsvorganges auf Menschen ohne besonders paratliegende Bereitschaften entspricht, während manische, depressive, agitierte, katatone Paralysen offenbar besonders bei Kranken auftreten, die eine entsprechende Disposition in den paralytischen Prozeß mitbringen. Immerhin kann wohl auch der paralytische Prozeß bei besonderer Lokalisation solche selteneren Bilder hervorrufen, auch ohne entsprechende spezifische Veranlagung. Die wesentlichen Erscheinungen der dementen Form, das Achsensyndrom, bleibt auch in den Sonderformen der progressiven Paralyse deutlich.

Die einfach demente Paralyse ist durch den Schwachsinn beherrscht. Hier finden sich alle die oben genannten Symptome des geistigen Verfalls in reiner Ausprägung. Wahnideen spielen keine oder eine bescheidene Rolle. Dagegen sind Anfälle verhältnismäßig häufig. Sie können das Bild einleiten und dann rasch zu recht ausgeprägten Erscheinungen des Schwachsinns führen, während sonst die Entwicklung oft eine langsame und schleichende ist. Viele einfach demente Paralytiker sind einfach stumpf, ohne eine ausgesprochenere Grundstimmung. Eine recht große Gruppe von ihnen zeigt aber die eigenartige Euphorie, die so kennzeichnend für die Paralyse ist, langanhaltend und rein; freilich ohne daß dabei die starke Labilität der Stimmung fehlt.

Noch vor wenigen Jahrzehnten häufig, ist die sog. klassische, die expansive oder manische Form der Paralyse seitdem recht selten geworden. Vielleicht hängt das damit zusammen, daß die Lues und damit die Paralyse früher stärker Menschen jener Schicht befiel, in der zirkuläres Erbgut sehr verbreitet ist, während jetzt solche Unterschiede nicht mehr bestehen. Die klassische Paralyse kann mit depressiver Verstimmung beginnen; häufiger setzt sie gleich mit heiterer Erregung ein, die sich rasch steigert und mit der Produktion eines üppigen, unsinnigen Größenwahns (Megalomanie) einhergeht. Dieser zeigt zugleich die Züge des Schwachsinns und jene eigenartige Beeinflußbarkeit des paralytischen Wesens. Den Kranken, der behauptet, zehn Häuser zu besitzen, kann man leicht zum Besitzer der ganzen Stadt machen. Hat er soeben noch von seiner ehelichen Treue trotz gewaltiger Potenz gesprochen, so kann er im nächsten Augenblick bei Anregung behaupten, er habe in einer Nacht 10, nein 20, nein 100 Frauen befriedigt und er werde sich die 1000 schönsten Mädchen aus der Stadt aussuchen. Der Paralytiker ist zugleich Gott und Kaiser und Schmeling; er braucht nur auf den Tisch zu klopfen und die Polen geben Westpreußen und die Franzosen Elsaß-Lothringen her und Amerika schickt 1000 mit Gold beladene Schiffe ab. Dabei ist die Stimmung gehoben, strahlend, selig, aber die Kranken sind doch zugleich reizbar und leicht gerührt. Der Redestrom ist ein ideenflüchtiger, zeigt aber doch meist zugleich die Züge der Inkohärenz und oft auch des Haftens, das mit zunehmender Demenz immer mehr hervortritt, so daß der ehemals strahlend-euphorische, beweglich-erregte Paralytiker nunmehr mit lallender Stimme, kaum verständlich, nur noch stereotyp die Reste seiner ehemaligen expansiven Ideen vorbringt: 1000 Zentner Gold. Expansive Paralysen zeigen eine gewisse Neigung 
zu Spontanremissionen, vielleicht gerade solche mit besonders ausgesprochener zirkulärer Veranlagung.

Nicht häufig ist die ausgesprochen depressive Form der Paralyse, die, mit einer unbestimmten neurasthenisch gefärbten Episode beginnend, rasch zu einer vielfach eigenartig starren und zugleich leeren Depression führt. Neben Versündigungsideen, die sich gern auf die Lues und die eheliche Treue beziehen, aber auch andere Inhalte haben können, und Verarmungsideen, die in der Regel freilich wenigstens der Richtung nach berechtigt sind, treten besonders hypochondrische Ideen hervor, die ihrem Ausmaß und Inhalt nach oft ganz unsinnig sind. Der Kranke ist gar nicht mehr da, hat keinen Kopf, kein Genitale mehr, ist einen Zentimeter groß; der Kopf ist ganz leer, voll Eiter. Der Schlund ist zugewachsen und ebenso der Darm. Es ist kein Herz, keine Lunge, kein Magen mehr da usw.; der Kranke ist schon tot, hundertmal gestorben. Nicht selten sind auch vage Verfolgungsideen. Mitunter sind die Kranken depressiv-stuporös. Auf der anderen Seite können sie trotz unsinnigster Kleinheitsideen (Mikromanie) ganz heiter und aufgeräumt, ja galgenhumoristisch, sarkastisch sein, so daß dann die Wahninhalte einen unechten Eindruck machen. Es gibt auch zirkuläre Verläufe bei der Paralyse, bei denen die expansive Erregung von einer Depression abgelöst wird oder umgekehrt.

Vereinzelt verlaufen Paralysen auch unter dem Bilde katatoner Stuporen oder katatoner Erregungen, die beide meist nicht lange Zeit andauern.

Endlich ist zu nennen die seltene agitierte Form der Paralyse, die unter der Entwicklung einer sehr schweren, rasch ansteigenden, mit nichts zu bekämpfenden Erregung, vielfach bei verworrenem Größenwahn, gelegentlich auch wilden mikromanen Ideen, außerordentlich rasch, in wenigen Tagen oder Wochen zum Tod im Status paralyticus oder an einer interkurrenten Erkrankung (Dekubitus, Phlegmone, Schluckpneumonie) führt.

In manchen Fällen von Paralyse finden wir ausgesprochene Herderscheinungen, besonders Aphasien, seltener auch optisch-räumlich-agnostische Bilder, während die allgemeine paralytische Demenz gering bleibt oder, anfänglich, ganz fehlt. Anatomisch ist der paralytische Hirnprozeß in solchen Fällen in den entsprechenden Rindenstellen besonders ausgesprochen. Man spricht hier von Herdparalyse bzw. von Lissauerscher Paralyse.

\section{Verlauf}

Je eingehender man die Vorgeschichte der Paralytiker durchforscht, um so weiter kann man in der Regel ihr Wetterleuchten zurückverfolgen. Oft ist es eine Jahre zurückliegende Ohnmacht, eine kurzdauernde Sprachstörung, also irgendein anfallsartiges Geschehen, das nachträglich als paralytisches Zeichen gedeutet werden muß. Im weiteren Fortgang fällt am ehesten ein Nachlaß der Merkfähigkeit auf und eine zunehmende Zerstreutheit. Der Kranke verlegt wichtige Gegenstände, hält Verabredungen nicht ein, begeht plötzliche Unbegreiflichkeiten, während er sonst noch gar nicht aufzufallen braucht. Immerhin lassen Spontaneität und Tatkraft früh nach. Im altgewohnten Gleise geht die Arbeit noch; an Neues kann der Kranke sich aber nicht mehr gewöhnen; außerhalb der Arbeit ist er interesselos, stumpf geworden. Vor allem ist er müde und zugleich nervös, leicht gereizt, 
empfindlich. Er selbst kommt sich erschöpft vor. Der Ehepartner, die guten Freunde und Kollegen bemerken auffällige Taktlosigkeiten, zunehmende Saloppheit, Faulbeit, Unbekümmertheit. Unbegreifliche Entgleisungen führen nicht zu einem entsprechenden affektiven Widerhall. Nicht selten fällt eine zunehmende sexuelle Appetenz oder aber ein mehr oder weniger rascher Nachlaß der Potenz auf. Schließlich meldet sich die Sprachstörung an, „Flüchtigkeiten" in der Schrift tauchen auf, dazu Unordnung in der Geschäftsführung, Kritiklosigkeit bei der Beurteilung von Geschäften und Menschen. Fehlschläge werden stumpf, ohne Gegenwehr hingenommen; die eigenartige Schwäche des Paralytikers wird immer deutlicher, bis dann dienstliches Versagen, ein schwerer Anfall, eine ganz grobe Taktlosigkeit, eine unbegreifliche Handlung oder aber die Häufung kleiner Vergehen an Krankheit, nicht mehr bloß an U̇bermüdung denken läßt.

Ist die Paralyse erst einmal deutlich, so führt sie, unbehandelt, in 1 bis 3 Jahren über immer tiefer werdenden Blödsinn und zunehmenden körperlichen Verfall hinweg zum Tode. Nur verhältnismäßig selten, besonders bei der expansiven Form, kommt es zu Remissionen, die auch einmal lange Jahre anhalten können und dann vielfach das Bild der ,stationären Paralyse ${ }^{66}$, d. h. eines mäßigen, aber kennzeichnenden Schwachsinns, darbieten. In den letzten Stadien der Krankheit treten die Zeichen der Großhirnzerstörung, ja der Enthirnung, immer deutlicher hervor. Die Kranken liegen steif, kontrakturiert, unfähig zu Zweckbewegungen, lallend, mit rhythmischem Zähneknirschen im Bett. Primitive Reflexe (Saugreflex, oraler Einstellungsreflex, Greifreflex) zeigen den endgültigen Ausfall der Großhirnfunktionen an. Das zuvor oft steil angestiegene Körpergewicht (Polyphagie, Störung vegetativer Zentren) stürzt jäh ab. Neigung zu Dekubitus, Knochenbrüchigkeit, Störungen der Blasen- und Mastdarmfunktionen, Versagen des Herzens, Anfallsserien stellen sich ein und führen den Tod herbei.

\section{Leichenbefund}

Die luische Aortitis ist bei Paralyse sehr häufig. Die Hirnschale zeigt eine Verdickung vorwiegend der Kompakta. Regelmäßig besteht mehr oder weniger deutlicher Hydrocephalus externus. Die Hirnhäute sind verdickt und milchig getrübt, dabei oft mit der Hirnoberfläche verwachsen. Das Hirn ist verkleinert, die Windungen sind verschmälert und treten infolge der Vertiefung der Furchen deutlicher hervor. Vielfach zeigt das Stirnhirn, in dem sich auch mikroskopisch meist die schwersten Veränderungen finden, schon makroskopisch die deutlichste Atrophie. Nächstdem sind das Parietal- und Temporalhirn befallen, während Okzipital- und Zentralregion weitgehend verschont sind. Das Hirngewicht kann um Hunderte von Grammen vermindert sein. Beim Zerlegen findet man Hydrocephalus internus und Knötchenbildung an den Ventrikelwänden (Ependymitis granularis). Das mikroskopische Bild zeigt eine ausgebreitete Enzephalitis. Neben einer oft mäßigen Meningitis treten besonders Gefäßinfiltrate in der Hirnrinde hervor, die sich bei stärkerer Vergrößerung aus Lymphozyten und besonders zahlreichen Plasmazellen zusammengesetzt erweisen (infiltrative Veränderungen). Zugleich ist eine Vermehrung der Gliazellen festzustellen, zumal der Mikroglia

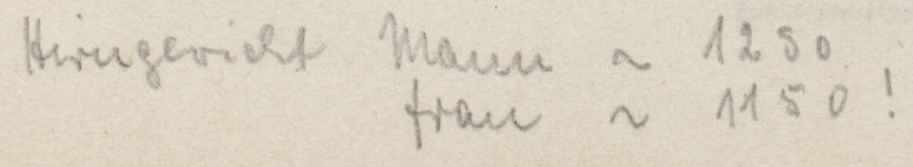


in Form der von Nißl sogenannten Stäbchenzellen, aber auch der Makroglia, die durch vermehrte Faserbildung dem Gesamtorgan eine derbere Konsistenz. gibt (proliferative Veränderungen. Der Name Hirnerweichung ist falsch.). Die Ganglienzellen sind mehr oder weniger gelichtet, das Rinden mark ist weitgehend geschwunden (degenerative Veränderungen). Durch die Ausfälle kommt es späterhin zur Schichtenverwerfung, die bei den schwersten Fällen bis zur Auflösung der kennzeichnenden Rindenstruktur führen kann. Mit der Rinde ist immer zugleich das Striatum befallen und in schwächerem Grade auch das andere Grau. Am Rückenmark findet man grobe degenerative Veränderungen am Weiß, und zwar vorwiegend am Hinterstrang bei Taboparalyse, im Seitenstrang bei Seitenstrangparalyse, meist aber in beiden.

Nach der erfolgreichen Infektionsbehandlung bleiben die Parenchymausfälle bestehen, während die Entzündungserscheinungen verschwinden. Immerhin findet man regelmäßig noch Plasmazellen, die ein Ausdruck chronischer Entzündung sind.

Ist bei fortgeschrittenen Fällen am Sektionstisch schon der makroskopische Befund recht kennzeichnend, so kann man die Diagnose sofort sicherstellen durch die Eisenreaktion von Spatz. Das eisenhaltige Pigment (Paralyseeisen) ist an die kleinen Rindengefäße gebunden. ,Man schneidet vom frisch sezierten Gehirn flache Scheiben aus dem Stirnlappen heraus und übergießt diese mit Schwefelammonium. Es treten dann bereits nach einer Viertelstunde, später noch deutlicher, durch die Entstehung von Schwefeleisen geschwärzte, kaum stecknadelkopfgroße Stellen im Rindengrau hervor, welche Abschnitten von Hirngefäßen entsprechen. " Diese Eisenreaktion kommt fast ausschließlich bei Paralyse vor.

\section{Behandlung}

Wagner v. Jaureggs Großtat, die Einführung der Malariatherapie, führt auf die Beobachtung zurück, daß gelegentlich schwere, mit langanhaltendem hohem Fieber verbundene Eiterungen erhebliche Remissionen, ja Heilungen ausgesprochener paralytischer Bilder herbeiführten. Heute wird man überall dort die Malariatherapie durchführen, wo der Allgemeinzustand und insbesondere der Zustand des Gefäßsystems die eingreifende Maßnahme gestattet. 5-10 ccm Blut eines fiebernden Malariakranken werden subkutan oder intravenös (dann ist die Inkubationszeit oft verkürzt) injiziert. Oft kommt es in den ersten Tagen zu einem leichten Fieberanstieg (Resorptionszacke); nach 5-8-21 Tagen, gelegentlich noch später, beginnen dann die Tertianaanfälle, von denen man unter ständiger Kontrolle des Kreislaufes 8-10-12 vorbeigehen läßt. Dann wird mit Chinin kupiert (Chin. hydroch. oder binaur.), die ersten 3 Tage je $1 \mathrm{~g}$, dann 8 Tage je $1 / 2 \mathrm{~g}$, dann wieder für 3 Tage $1 \mathrm{~g}$. Zugleich beginnt die kombinierte Bismogenol-Salvarsankur; etwa alle 3 Tage Neosalvarsan erst 0,3 , dann 0,45 , dann 0,6 fortlaufend bis etwa $5 \mathrm{~g}$, alle 3 Tage 0,5 Bismogenol bis zu $12 \mathrm{~g}$. Bald nach dem Ende der Fieberkur wird der Liquor kontrolliert. Weist er noch keine deutliche Besserung auf, so kann man die spezifische Behandlung mit einer Pyriferkur kombinieren. Am Ende der spezifischen Behandlung wird erneut der Liquor kontrolliert, und das Gleiche geschieht nach Ablauf je eines halben Jahres fortlaufend, bei stetig günstigem Befund später nach Ablauf je eines Jahres. 
Statt Malaria tertiana kann man mit gleichem Erfolg Rekurrens verwenden, die den Vorteil hat, auf Mäusen fortgezüchtet werden zu können, und längerdauernde, dabei nicht allzu hohe Fieberzacken zu setzen. Gefährlicher ist die Verwendung von Sodoku (Rattenbißfieber), das den luischen ähnliche Exantheme macht. Ich habe danach ausgezeichnete Remissionen, aber auch manchen Todesfall gesehen, während die Todesfälle nach Malaria bei der nötigen Sorgfalt zu den größten Seltenheiten gehören. Wo nämlich eine nennenswerte Gefahr von seiten des Herzens vorliegt, sollte man nicht lebende Erreger, sondern Pyrifer verwenden, das in steigender Keimzahl (50-500 Millionen Keime) gegeben wird und recht gute, starke, aber mit der Keimzahl regulierbare Fieberbewegungen macht.

In jüngster Zeit ist man dazu übergegangen, mit Kurzwellendiathermie lediglich am Hirn Überhitzung herbeizuführen; die Erfolge bleiben abzuwarten.

Die Aussichten der Fiebertherapie sind nicht ganz so günstig, wie man anfänglich erhoffte. Immerhin kommt es in einem Drittel bis einem Viertel der Fälle zu Remissionen, die praktisch einer Genesung gleichen. In einem Viertel der Fälle wird der Ablauf der Paralyse nicht merklich beeinflußt. Beim Rest kommt es wohl zu Remissionen; aber diese sind bescheidener in ihrem Ausmaß und vielfach kurz in ihrer Dauer.

Auch bei den ausgezeichneten Remissionen, die zur Wiederherstellung der Berufstätigkeit, selbst in sehr gehobenen Berufen, führen, kehrt der Kranke oft nicht ganz zu seinem früheren Selbst zurück. Manch einer erscheint glücklicher daran als vorher; er hat Hemmungen verloren, die ihn vor der Krankheit einengten, ist unbesorgter, heiterer, gemütlicher geworden. Bei anderen wirkt eine ähnliche Abänderung aber ungünstig; sie werden ein wenig leichtfertig, unernster, unkonzentrierter, ermüdbarer, verwaschener in ihrem Wesen. - Mangelnder Ernst, größere Schlaffheit und Beeinflußbarkeit, Bestimmbarkeit, Verlust an Initiative und Zähigkeit, Tatkraft und geistiger Frische sind es, die in verschiedenem Maße auch die schlechteren Remissionen kennzeichnen, bei denen zugleich Kritik, Urteil, Gedächtnis, Merkfähigkeit eine deutliche Einbuße dauernd zeigen. Manche remittierten Paralytiker entsprechen den von früher bekannten stationären Paralysen, bei denen ein deutlicher paralytischer Zustand stationär bleibt.

Während die Sprachstörungen vielfach eine wesentliche Besserung erfahren, ebenso wie die Schriftstörungen, bleiben Pupillen- und Reflexanomalien meist unverändert. Ataxie und Koordinationsstörung bessern sich meist, vielfach in erheblichem Maße, ebenso die Liquorbefunde. Am ersten zeigt der Rückgang der Pleozytose den Behandlungserfolg an, sodann der Ausfall der Wassermannschen Reaktion, die im Liquor zunächst nur noch bei großen Liquormengen, dann überhaupt nicht mehr nachweisbar ist. Das Gesamteiweiß vermindert sich, auch die Nonnesche Reaktion erfährt fast immer eine Besserung, wenn sie auch selten ganz verschwindet. Hartnäckig sind oft die Mastixkurvenveränderungen, die, wenn auch abgeschwächt, meist bestehen bleiben und nur schwer wirklich normalen Verhältnissen Platz machen.

Gar nicht wenige Kranke erfahren wohl eine weitgehende Besserung der Liquorbefunde, der neurologischen Erscheinungen, besonders auch der Sprachstörung und des Achsensyndroms; trotzdem erscheinen sie nach der 
Behandlung kränker als zuvor, weil sich neue Störungen bei ihnen eingestellt haben, nämlich halluzinatorisch-paranoide Bilder von oft schizoformem Anstrich, die eine große Hartnäckigkeit haben, ja, bis zu paralytischen Rückfällen lange Jahre hindurch unbeeinflußbar bestehen können. Man hat hier an Veränderungen des paralytischen Prozesses im Sinne der Lues cerebri und an ein vorwiegendes Befallensein von Schläfen- und Scheitellappen gedacht, wohl zu Unrecht. Eher handelt es sich um stationäre Defekte, unter anderem a $\mathrm{ch}$ in den genannten Hirngegenden, aber nicht bloß in diesen, die das Fortbestehen gerade solcher, lokalisatorisch vielleicht auflösbarer, Bilder herbeiführen.

\section{Pathogenese}

Die Paralyse ist eine luische Hirnerkrankung, die freilich erst lange, durchschnittlich etwa 10-15 Jahre, nach der Infektion zu beginnen pflegt. Früher als 3 Jahre nach der Infektion tritt kaum je Paralyse auf, während sehr lange Intervalle bis zu 3-4 Jahrzehnten keine Seltenheit sind. Immerhin scheinen jugendliche Paralytiker mit relativ kurzen Intervallen häufiger zu werden. Im allgemeinen ist der Ablauf der Paralyse um so ungünstiger und die Inkubationszeit um so kürzer, je älter der Kranke bei Beginn der Paralyse ist.

Früher hielt man die Paralyse für eine metaluische Erkrankung, im Sinne etwa der postdiphtherischen Lähmung, d. h. man nahm Toxinwirkungen an. Noguchi wies aber 1913 Spirochäten im paralytischen Hirn nach, und Jahnel zeigte, daß es sich hier um einen regelmäßigen Befund handelt, wenn er oft genug auch nur mit Mühen zu erheben ist. Wir haben es also mit einer syphilitischen Enzephalitis zu tun, und zwar im Tertiärstadium. Die Tatsache, daß andere tertiäre Erscheinungen bei der Paralyse fast immer fehlen, und der Umstand, daß der paralytische Prozeß der spezifischen Behandlung nicht zugänglich ist, heben ihn aber von den gewöhnlichen tertiären Erscheinungen ab. Man hat daher die Bezeichnung quartäre Syphilis vorgeschlagen.

Woran es liegt, daß der eine Syphilitiker paralytisch wird, der andere nicht, weiß man nicht. Jedenfalls bekommt nur ein Bruchteil der Syphilitiker Paralyse, sicher nicht mehr als $10 \%$, wahrscheinlich viel weniger. Dabei machen einen Katarrh der Liquorwege wohl alle Luiker im sekundären Stadium durch. Es kann an den Spirochäten liegen, daß Paralyse entsteht, und man denkt in diesem Zusammenhang an eine besonders neurotrope Lues. Es gibt in der Tat manche Beobachtungen, die solche Möglichkeiten nahelegen: zahlreiche Erkrankungen quartärer Art (auch Tabes) bei einer bestimmten Infektionsquelle. Es kann aber auch an der Konstitution der Betroffenen liegen, die erkranken. Auch nach dieser Richtung spricht manche Beobachtung. So kenne ich eine Familie, in der zwei Schwestern und Kinder von beiden erkrankten. Die Tatsache, daß Sekundärerscheinungen bei späteren Paralytikern außerordentlich selten sind, auch bei unbehandelten, läßt sich für beide Auffassungen verwerten.

Jedenfalls wissen wir heute noch nichts Bestimmtes über die Pathogenese der Paralyse. 


\section{Juvenile Paralyse}

Ein bescheidener Bruchteil der Kinder mit konnataler Lues erkrankt, ob sie nun behandelt wird oder nicht, später an Paralyse, und zwar nach der üblichen Inkubationszeit, also nach 8-10-15 Jahren, auch später. Meist handelt es sich um die einfach demente Form der Paralyse, die sich vielfach aus unmerklichen Anfängen (Nachlassen der Schulleistungen, mangelnde Frische der Kinder) entwickelt und, unbehandelt, vielfach lange Jahre hinzieht. Häufig sind paralytische Anfälle und Serien von solchen. Neurologisch finden wir die gleichen Erscheinungen wie bei den Erwachsenen, und auch alles sonst entspricht dem Bilde der gewöhnlichen Paralyse. Häufiger als dort scheinen aber eigentliche hirnsyphilitische Veränderungen (Epilepsie, grobe Herde) der Paralyse vorauszugehen, und diese haben nicht selten auch eine atypische Lokalisation (subkortikale Bilder). Die Behandlung ist die gleiche, die Aussicht auf Erfolg geringer als bei den erwachsenen Paralytikern.

\section{Erkennung}

In den typischen Fällen ist die Erkennung der Paralyse leicht. Sprachstörung und die schon im Ausdruck faßbaren Erscheinungen der Demenz werden sofort zur Pupillenuntersuchung und damit zur serologischen Kontrolle führen. Aus der Demenz oder dem neurologischen Befund allein, aber auch aus dem typischen serologischen Befund allein kann man die Diagnose nicht machen. Den paralytischen serologischen Befund treffen wir vereinzelt auch ohne alle Anzeichen der Demenz an und es fehlen hier auch paralytische Hirnveränderungen. Wir sprechen dann von Präparalyse, die natürlich behandlungsbedürftig ist und genau so behandelt werden soll wie die Paralyse selbst. Die Demenz kann in sehr ähnlicher Form bei allen ausgebreiteten, frontal akzentuierten Hirnerkrankungen, zumal der Lues cerebri (Pseudoparalyse), aber auch bei Arteriosklerose, bei schwerem Diabetes mit arteriosklerotischen Störungen vorkommen. Auch die Picksche Krankheit macht der Paralyse ähnliche Bilder und dies gilt auch für gewisse Tumoren im Stirnhirnbereich (etwa Meningiome der Olfactoriusrinne). In allen diesen Fällen führt der kennzeichnende neurologische Befund meist zur endgültigen Sicherung durch die Liquorkontrolle.

Andererseits läßt auch der neurologische Befund allein die Diagnose Paralyse nicht zu. Die reflektorische Pupillenstarre finden wir bei der Tabes, ganz selten auch einmal bei der Encephalitis epidemica. Die artikulatorische Sprachstörung begegnet uns in Formen, die der paralytischen sehr ähnlich sind, bei bulbären und pseudobulbären leichteren Schäden (Schlafmittelvergiftungen, Alkoholismus usw.). Entscheidend ist immer nur das $\mathrm{Zu}$ sammentreffen der seelischen, neurologischen und serologischen Kennzeichen der Paralyse.

Im übrigen denke man bei allen seelischen Veränderungen, auch bei scheinbar einfachen neurasthenischen Klagen von Männern im mittleren Lebensalter sogleich an die Paralyse. Nie darf die körperliche Untersuchung versäumt werden. Die Wassermannsche Reaktion sollte man dann immer anstellen. 
Wer den Gedanken an die Paralyse nicht vergißt, wird auch bei vermeintlich noch so klaren endogenen Syndromen nicht in Gefahr kommen, eine Paralyse zu übersehen. Gerade hier ist die Erkennung besonders wichtig, weil zumal die manischen Bilder meist inzipiente Paralysen manifest machen und der Behandlung daher besonders günstige Aussichten bieten. Schwierigkeiten können entstehen, wo die Manie sich mit Tabes vergesellschaftet. Für die Behandlung macht dies aber keinen Unterschied.

Manchmal ist unter dem Bilde der senilen Demenz die Paralyse nicht erkennbar, da die kennzeichnenden neurologischen Erscheinungen wenig ausgeprägt sein können.

Wo bei Arteriosklerose der Blut-Wassermann positiv ist, kann die Diagnose nur aus dem Liquorbefund gemacht werden.

Die Differentialdiagnose gegenüber der Lues cerebri soll dort besprochen werden.

\section{Anhang:}

\section{Liquorsyndrome}

An dem Ausbau der Liquordiagnostik hat die Psychiatrie bedeutenden Anteil. Die für die meisten Fälle ausreichende Untersuchung berücksichtigt Liquordruck, Farbe, Zellzahl, Gesamteiweißgehalt, Globulingehalt, WaR. und das Verhalten des Liquors cholesterinierten Organextrakten (Flockungen) und kolloidalen Lösungen gegenüber.

Der Liquordruck soll beim liegenden ruhigen Menschen $150 \mathrm{~mm}$ Wasser nicht übersteigen. Auch Werte bis zu $200 \mathrm{~mm}$ halte ich nur dann für abnorm, wenn sonst noch ein Zeichen des Hirndrucks vorhanden ist.

Die Farbe ist in der Norm wasserklar. Frische Blutbeimengungen, wie sie bei der Punktion entstehen, werden beim Zentrifugieren dadurch erkannt, daß die rötliche Farbe verschwindet. Bei alten Blutbeimengungen bleibt der Liquor auch dann gelblich bis bräunlich (xanthochrom).

Die Zellzahl soll in der Norm 4-6 Zellen (Lymphozyten) im Kubikmillimeter nicht überschreiten. Meist bleibt sie darunter. 10 Zellen sind sicher pathologisch. Gezählt wird bei gleichzeitiger Färbung der Leukozyten und Zerstörung der Erythrozyten in der Kammer von Fuchs-Rosenthal; diese faßt 3 cbmm; es ist üblich, die in der Kammer festgestellte Zahl anzugeben; also etwa sechs Drittel.

Im normalen Liquor finden sich nur Spuren Eiweiß $(0,02-0,03 \%)$. Nach Art eines zuerst von Nißl verwandten Verfahrens wird der Liquor mit Esbachs Reagens in besonders graduierten Röhren zentrifugiert. Ein Teilstrich entspricht bei der gebräuchlichen Methode von $\mathrm{K}$ afka-Samson 0,024. \% Eiweiß.

Die Globuline werden am besten nach Nonne-Apelt durch Mischung gleicher Mengen Liquors und gesättigter Ammonsulfatlösung bestimmt. Normaler Liquor bleibt klar. Globulinvermehrung bringt innerhalb von 3 Minuten Opaleszenz bis Trübung und Fällung. In ähnlicher Weise läßt sich die Vermehrung der Eiweißkörper mit Sublimat und Karbolsäure bestimmen. Doch sind diese Reaktionen zu empfindlich. 
Die WaR. wird mit steigenden Liquormengen $(0,2-1,0)$ ausgewertet. Doch sind auch Methoden mit kleineren Mengen ausgearbeitet $(0,05-0,25)$.

Cholesterinierte Organextrakte bleiben mit normalen Liquoren klar. Bei Lues des Zentralnervensystems kommt es zu Flockungen (Methoden von Sachs-Georgi mit cholesteriniertem Rinderherzextrakt, von Meinicke, Müllers Ballungs-Reaktion).

Endlich werden bestimmte kolloidale körperfremde Lösungen (Goldsol, Mastix) durch normalen verdünnten Liquor nicht verändert, wohl aber

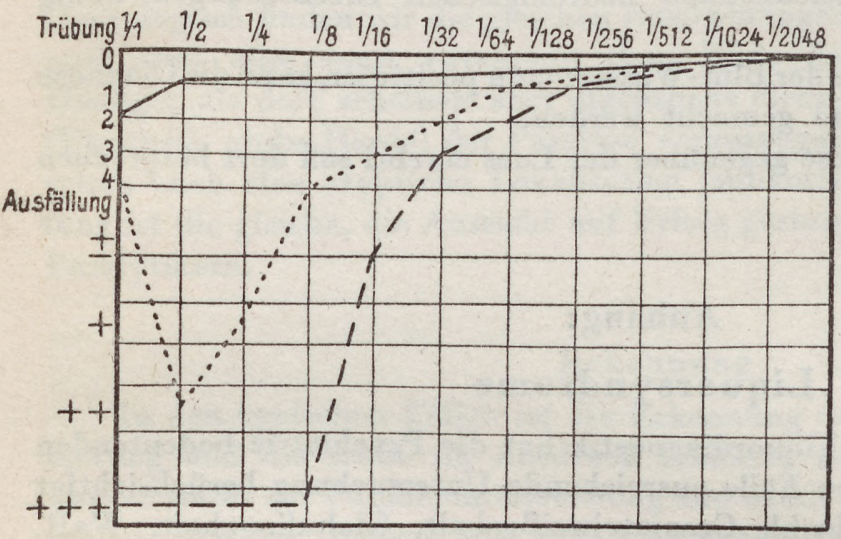

Abb. 1. Mastixreaktion.

- - Paralysekurve .... Lueszacke

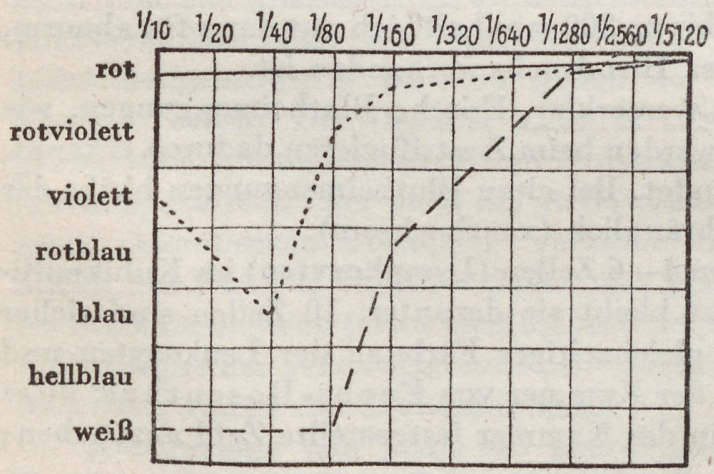

Abb. 2. Goldsolreaktion.

- - Paralysekurve. .... Lueszacke durch pathologischen, und zwar werden lange Liquorverdünnungsreihen (mit Kochsalzlösung) zu gleichen Mengen den Solen zugesetzt.

Psychiatrisch wichtig sind die folgenden Liquorsyndrome, die ich hier durch die Blutbefunde ergänze:

Paralyse: BlutWassermann in mehr als $90 \%$ positiv. Druck leichterhöht.Farbeklar. Bis etwa 200/3 Zellen, meist weniger, selten mehr, vorwiegend Lymphozyten, wenigerPlasmazellen und andere Zellen. Gesamteiweiß vermehrt auf das Doppelteund mehr. Opaleszenz bis Trübung bei den Globulinreaktionen WaR. stark + schon bei 0,2 . Flockungen stark + . Die Kolloidreaktionen ergeben maximale Ausfälle in den erstenRöhrchen (s. Abb.).

Tabes: Blut-Wassermann in der Mehrzahl der Fälle + , doch nicht so häufig wie bei der Paralyse. Liquorbefunde im ganzen wie bei der Paralyse mit folgenden Ausnahmen: der Druck ist normal, die Zellzahl durchschnittlich etwas geringer, die WaR. erst bei höheren Konzentrationen $(0,6-1,0)$ positiv. Die Kolloidreaktionen ergeben einen unvollständigen Ausfall am Anfangsteil der Kurve wie bei der Lues (s. Abb.).

Syphilitische Meningitis: WaR. in Blut und Liquor bei 0,2 stark positiv. Druck erhöht. Xanthochromie kommt vor. Starke Zellvermehrung, 
oft 1000 und mehr Zellen. Starke Gesamteiweißvermehrung. Bei den Kolloidreaktionen nach rechts verschobene Zacke, selten Paralysebilder.

Andere Luesformen: Blut-Wassermann oft negativ. Liquor-Wassermann erst bei höheren Konzentrationen positiv, oft erst bei 1,0, recht selten bei 0,2 . Druck normal bis leicht erhöht. Farbe meist klar. Zellvermehrung, meist unter 100/3. Globuline und Flockungen mäßig +. Bei den Kolloidreaktionen Zacke im Anfangsteil der Reihen (s. Abb.).

Bei Frühlues (Lues II) findet man oft mäßige Zellvermehrung, Globulinvermehrung, geringe Lueszacken in den Kolloidkurven, positive WaR. bei starker Konzentration. Dabei ist aberWaR. im Blut stark +.

Meningitis: Drucksteigerung, nicht selten Fibringerinnsel, besonders bei tuberkulöser Meningitis, während bei der epidemischen $\mathrm{Me}$ ningitis das Aussehen oft trüb ist. Starke Zellund Eiweißvermehrung. Kolloidreaktionen zeigen Zacken und Kurven vom Meningitistyp (s. Abb.). Der Zuckergehalt ist vermindert (normal 45-75 mg\%), die WaR. negativ.

Tumor cerebri: Druck oft erhöht, nicht seltenleichtePleozytose, häufig stärkere Eiweißvermehrung, häufig kleine Kolloidzacke.

Bei den Spätzuständen der Encephalitis epidemica (während

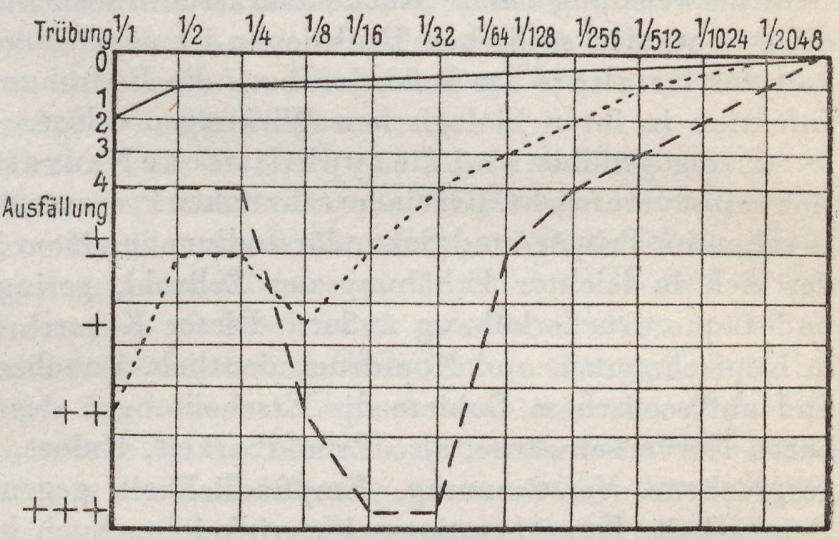

Abb. 3. Mastixreaktion. Meningitiskurven

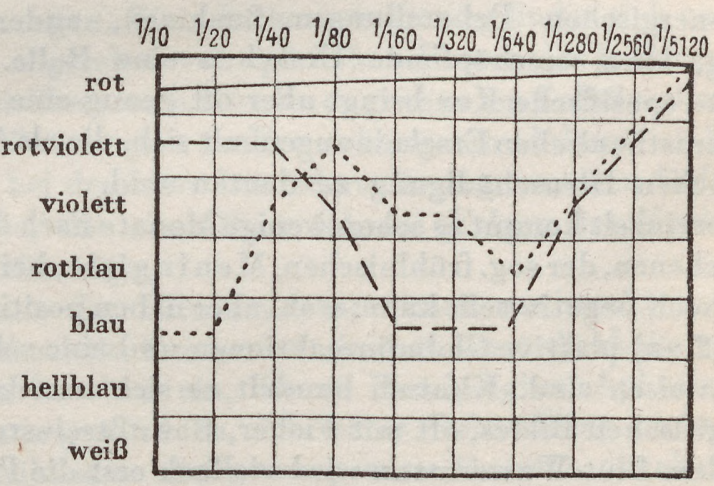

Abb. 4. Goldsolreaktion. Meningitiskurven der akuten Erkrankung finden sich meist entzündliche Erscheinungen geringen Grades) ist der Zucker oft an der oberen Grenze der Norm oder vermehrt.

\section{d) Psychosen bei Lues cerebri}

Die Erkenntnis, syphilitisch angesteckt zu sein, führt sehr häufig zu vorübergehenden reaktiven Verstimmungen, seltener, bei konstitutionell Nervösen, bei hypochondrisch veranlagten Depressiven, auch bei Menschen 
mit leichten zwangsneurotischen Zügen, zu ausgesprochenen langdauernden hypochondrischen Reaktionen, die gerade deshalb so hartnäckig sind, weil serologische Kontrollen sich ja nicht vermeiden lassen. Hier gilt es, um von allem Anfang an Polypragmasie zu vermeiden, einen unbeirrbaren Behandlungsplan festzulegen. Ganz ähnliche seelische Reaktionen sieht man bei entsprechend veranlagten Menschen, die sich nur einmal in Gefahr gebracht haben, syphilitisch infiziert zu werden, oder bei denen ein Arzt den Verdacht ausgesprochen hat (Luophobie). Besonders häufig ist die Angst vor Gehirnerweichung und Rückenmarksschwindsucht. Wesentlich für alle diese abnormen seelischen Reaktionen ist neben der betroffenen Persönlichkeit das Erlebnis der Infektion bzw. die Bedrohung durch diese, nicht die Infektion in ihren biologischen Wirkungen selbst.

Demgegenüber wird die syphilitische Neurasthenie durch die Infektion selbst verursacht. Bei einem sehr hohen Prozentsatz der Syphilitiker kommt es schon im Primär- und Sekundärstadium zu einem „meningealen Katarrh“", der sich in leichter Erhöhung der Zellzahl, geringer Globulinvermehrung und Liquordruckerhöhung äußert. Dieser Katarrh wird klinisch vor allem in Kopfschmerzen und Kopfdruck deutlich. Daneben finden wir oft Anämie und auf seelischem Gebiete die Erscheinungen der Neurasthenie, der reizbaren Nervenschwäche, also Ermüdbarkeit, Unlust, mehr oder weniger ausgesprochene Verstimmung, Empfindlichkeit gegen Eindrücke aller Art, Reizbarkeit, Konzentrationsschwierigkeiten. Auch hier kommt es natürlich mit auf die betroffenen Persönlichkeiten an, wie sich die syphilitische Neurasthenie im einzelnen äußert. Oft ist es wohl auch nicht der meningeale Katarrh allein, der das Symptomenbild bestimmt. Daneben spielen die oft sehr energischen Behandlungsmaßnahmen, andere Leiden, Arbeitsüberlastung, kurz, erschöpfende Ursachen eine Rolle. Eine regelrecht durchgeführte spezifische Kur bringt aber oft genug eine entscheidende Besserung der neurasthenischen Erscheinungen mit sich, die als Ausdruck einer leichtesten organischen Hirnschädigung zu deuten sind.

Vereinzelt kommt es schon wenige Monate nach der Infektion zu einer ausgesprochenen, der sog. frühluischen, M en in gitis, bei welcher der Blut-Wassermann noch negativ sein kann, wohl aber neben positivem Liquor-Wassermann (von 0,2 an) positive Globulinreaktionen und eine sehr starke Zellvermehrung nachzuweisen sind. Klinisch handelt es sich um das akute Einsetzen eines meningitischen Bildes, oft mit Fieber, Bewußtseinstrübung und Delirien. Bei fehlendem Blut-Wassermann wird vielfach erst die Punktion die Diagnose ermöglichen. Bei tatkräftiger spezifischer Behandlung, die aber unbedingt bald wiederholt werden muß, ist die Prognose dieser Meningitis im ganzen günstig.

Die Erscheinungen der eigentlichen Hirnlues leiten sich letzten Endes alle von der bei einem relativ kleinen Teil der Luiker, und zwar in den ersten Jahren nach der Infektion im Tertiärstadium sich ausbildenden chronischen Meningitis her, die freilich manchmal auch akutere Erscheinungen macht. Die Meningitis, meist basal, und hier meist von der Basalzisterne her sich ausbreitend, greift zugleich auf die basalen Hirnnerven, dann aber auch auf die Hirnsubstanz und vor allem auf die großen und mittleren Gefäße über, und schließlich kommt es in seltenen Fällen auch zu einer Endarteriitis der kleinen Gefäße. Kleinere und ganz selten große Gummen kommen vor. 
Die Basalmeningitis ist in ihren akuteren Stadien durch hochgradige, besonders auch nächtliche Kopfschmerzen, gelegentliche Krämpfe, manchmal leichte meningitische Reizerscheinungen, dann aber vor allem durch Paresen im Gebiet des Okulomotorius, des Trochlearis, des Fazialis, oft auch durch Optikusstörungen (Pupillenstörungen, Neuritis) gekennzeichnet. Auf seelischem Gebiete findet man entsprechend dem oft vorhandenen Hirndruck exogene Reaktionstypen, Benommenheit, gelegentlich auch Delirien, morosgereizte, seltener euphorische Stimmung. Auch hier wirkt energische spezifische Behandlung oft rasch und läßt alle Krankheitserscheinungen zurücktreten.

Die sehr seltenen großen Gummen unterscheiden sich nach ihrer Symptomatologie im wesentlichen nicht von den Hirntumoren. Nur die spezifischen Liquorveränderungen ermöglichen die Diagnose.

Für die eigentliche Hirnlues, die Gefäßerkrankungen, sind kennzeichnend Herderscheinungen und Demenzzustände. Auf neurologischem Gebiete findet man besonders oft absolute Pupillenstarre oder doch -trägheit, selten reflektorische Starre, Lähmungen einzelner Hirnnerven, zumal des VII., auf serologischem Gebiete: Zellvermehrung, oft bescheiden, manchmal bis zu mehreren 100 Zellen, leichte Gesamteiweißvermehrung, Globulinvermehrung (Nonne +), Wassermannsche Reaktion in höheren Liquorkonzentrationen $(0,6,1,0$, gelegentlich auch 0,4), Lueszacke bei den Kolloidreaktionen, also Ausfällungen bei mittleren Konzentrationen der Kolloidlösung, nicht erst bei den niederen wie bei anderen Meningitiden, und nicht vollkommene.

Anatomisch kennzeichnet sich die Gefäßerkrankung durch Infiltration aller Gefäßwandschichten mit Lymphozyten, wobei zunächst die Adventitia am stärksten befallen ist. Weiter kommt es zur Entwicklung von Intimabeeten, die das Lumen verengen. Diese Intimawucherung findet sich nach Abklingen der Entzündung, abgesehen von spärlichen Resten der Infiltration, in den Spätstadien allein. Bei dieser nach $\mathrm{He}$ ubner genannten Gefäßveränderung kommt es oft zu Kreislaufstörungen, zu Erweichungen und damit zu Schlaganfällen. Erkrankt sind bei der Lues besonders die sogenannten Gefäßäste, d. h. die größeren Gefäße, die zum Hirn führen (Folgen der Meningitis), weniger die kleinen Gefäßzweige.

Die häufigsten Formen der Hirnlues setzen nach uncharakteristischen Vorboten (erhöhte Ermüdbarkeit, Reizbarkeit, leichte Persönlichkeitsveränderung) mit apoplektischen Insulten ein, die zu Hemiplegien, Aphasien usw. führen. Die Herderscheinungen bilden sich unter Behandlung nicht selten weitgehend zurück. Es bleibt aber häufig eine gewisse Demenz, die eben nachweisbar, aber auch recht ausgesprochen sein und vor allem weiter fortschreiten kann. Gerade in den letzteren Fällen finden wir gern eine gewisse Euphorie und einen deutlicheren Mangel an Initiative. Im übrigen zeigen sich Merkund Gedächtnisstörungen, Einengung des geistigen Horizontes, leichte bis schwere Urteilsschwäche und oft auch verwaschene Herderscheinungen. Krankheitsgefühl, ja -einsicht kann im Gegegensatz zur Paralyse selbst bei schweren Demenzzuständen erhalten bleiben.

Manche Formen von Hirnlues beginnen schleichend und schreiten zu immer tieferen paralyseähnlichen Defekten fort, ohne daß es jemals zu den alarmierenden apoplektischen Insulten kommt. Vielfach finden wir dann auch eine bulbäre oder pseudobulbäre oder paralyseähnliche Sprachstörung. 
Leichtere Herderscheinungen werden jedoch auch in diesen paralyseähnlichen Fällen selten vermißt. Meist dürfte es sich bei diesen syphilitischen Pseudoparalysen um Erkrankungen der kleinen Hirngefäße handeln.

Man muß wissen, daß bei allen Formen der Hirnlues epileptische Anfälle vorkommen können. Es gibt aber auch eine syphilitische Epilepsie im engeren Sinne, bei der neben den epileptischen Anfällen nur Pupillenstörungen und die serologischen Reaktionen die Natur der Erkrankung anzeigen. Äquivalente werden meist vermißt. Auch die syphilitische Epilepsie führt wahrscheinlich auf die Erkrankung kleiner Hirngefäße zurück. Die spezifische Behandlung bringt mitunter Heilung. Besonders bei konnataler Hirnlues kommt eine solche syphilitische Epilepsie vor.

Weiter sehen wir bei akuteren hirnsyphilitischen Erkrankungen gelegentlich auch Psychosen vom exogenen Reaktionstyp: Delirien, Amentiaformen, zirkuläre, halluzinatorische Bilder, die mit leichteren neurologischen Erscheinungen einhergehen können und ihre syphilitische Natur durch den serologischen Befund und die Wirkung der spezifischen Behandlung verraten. Nicht selten bleiben aber leichtere organische Defekte zurück.

Endlich gibt es bei gleichzeitiger Tabes, aber auch ohne solche, mehr chronisch verlaufende paranoide und halluzinatorische Bilder, die offenbar syphilitischer Natur sind. Der Ausdruck ,Tabespsychosen ${ }^{6}$ erscheint nicht berechtigt, weil nicht die Tabes, sondern ein luischer Hirnprozeß Ursache der Psychose ist. Übrigens spielen hier, wie auch bei den akuteren Syndromen, neben der Lues nicht selten andere ursächliche Umstände, insbesondere Alkoholabusus, Traumen, Nierenschädigungen, Herzstörungen eine gewisse Rolle.

Bei nicht wenigen Kranken scheint die Lues die Entwicklung arteriosklerotischer Vorgänge zu beschleunigen, so daß schon Menschen im mittleren Lebensalter ( 4.0 Jahre und wenig mehr) an arteriosklerotischen Störungen chronisch fortschreitender Natur erkranken. Meist ist dann die Wassermannsche Reaktion im Blut noch positiv, im Liquor dagegen negativ.

\section{Erkennung}

Die Epilepsien auf dem Boden der Lues und die akuten meningitischen Erkrankungen wird man manchmal nur serologisch diagnostizieren können. Wegen der Behandlungsaussichten soll man also in jedem Falle eine Liquorkontrolle vornehmen.

Schwierig oder ganz unmöglich kann die Unterscheidung der Arteriosklerose von der apoplektischen Hirnlues sein, wenn bei der Arteriosklerose zugleich die Wassermannsche Reaktion im Blut positiv ist oder die Hirnlues erst im späteren Lebensalter deutlich wird. Im übrigen scheint die Arteriosklerose durch die Lues nicht selten beschleunigt zu werden. Häufig werden freilich kennzeichnende Pupillenstörungen auf der einen, eine allgemeine Arteriosklerose auf der anderen Seite die eine oder die andere Diagnose wahrscheinlich machen.

Auch gegenüber der Paralyse kann die Lues der kleinen Hirngefäße vielfach nicht recht abgetrennt werden. In seelischer Hinsicht ist hervorzuheben, daß in der Regel beim Luiker die Krankheitseinsicht doch nicht völlig fehlt. Vielfach finden sich übrigens auch bei der Lues der kleinen Gefäße doch zugleich gröbere Herde, die höchstens eine Verwechslung mit der Lissauerschen Paralyse zulassen. 
Für die meningitischen Formen der Hirnlues ist das vorwiegende Befallensein der Augenmuskeln gegenüber den Schädigungen von Fazialis und Hypoglossus bei der Paralyse hervorzuheben. Auch die Kopfschmerzen und die Klopfschmerzhaftigkeit des Schädels finden sich bei der Paralyse nicht so ausgesprochen wie bei der Hirnlues.

Im übrigen müssen die serologischen Befunde meist den Ausschlag geben, die freilich vereinzelt auch im Stich lassen können.

Die Behandlung ist jene der Lues. In vielen Fällen, vor allem bei den Erkrankungen der kleinen Gefäße, wird man eine Malariakur, oft mit Erfolg, durchführen.

\section{e) Encephalitis epidemica}

Diese Krankheit, die wohl auch in früheren Jahrhunderten in kleineren Epidemien aufgetreten ist, hat sich seit dem Weltkrieg (der erste Fall wurde 1915 beobachtet) über ganz Europa und Amerika verbreitet und viele Zehntausende zu chronisch Siechen gemacht. Den Erreger kennen wir nicht. Das Leiden tritt aber gern zusammen mit der Grippe auf, die vielleicht ihr Schrittmacher ist.

Nach den uncharakteristischen Vorboten einer Allgemeininfektion kommt es, mit den Epidemiewellen wechselnd, bald mehr zu lethargischen, bald mehr zu hyperkinetischen Bildern. Bei der Encephalitis lethargica (v. Economo) steht im Vordergrund die meist mit Augenmuskelstörungen verbundene Schlafsucht. Die Kranken können Wochen und Monate hindurch fortgesetzt schlafen, bleiben aber erweckbar und sind dann geordnet, aber oft desorientiert; sie können trotz Weckreizen aber auch somnolent oder delirant oder auch inkohärent sein. Nach dem Erwecken schlafen sie unter zunehmender Schläfrigkeit rasch wieder ein. In den Wachpausen nehmen sie Nahrung zu sich und verrichten ihre Bedürfnisse. Nicht selten sind sie unrein. Oft träumen sie, wenigstens zeitweise, lebhaft; andere sind immer wieder ausgesprochen delirant, und zwar nimmt das Delir gern die Form des Beschäftigungsdelirs mit raschem Situationswechsel an. Bei den schweren Fällen vertieft sich der Schlaf, die Erweckbarkeit nimmt ab und im anwachsenden Koma kann schließlich der Tod eintreten. In den weitaus überwiegenden gutartigen Fällen nimmt die Schlafneigung allmählich ab. Übertriebenes Schlafbedürfnis, das sich oft anfallsweise äußert, kann aber noch Jahre fortbestehen, bis sich dann vielfach parkinsonistische Folgezustände herausbilden. In anderen Fällen kommt es zu langdauernden Perioden von Schlaflosigkeit oder solchen von Schlafverschiebung, die bei Kindern auch als akutes Syndrom auftreten kann. Solche Kinder sind am Tage schläfrig oder sie schlafen wirklich, um dann in der Nacht sich fortgesetzt zu wälzen, mit den Kissen herumzuwursteln, aus dem Bett zu gehen, zu pfeifen, zu singen, stereotype Reden zu führen, kurz eine dranghafte Unruhe zu zeigen, die sich aller vorhandenen Objekte und Betätigungsmöglichkeiten bemächtigt. Das Bewußtsein ist dabei meist unklar.

Bei den hyperkinetischen Formen, die sich gelegentlich aus Schlafzuständen heraus entwickeln oder in sie übergehen, oft aber auch allein auftreten, sehen wir choreiforme, athetoide oder rhythmisch-myoklonische 
Unruhezustände, oft zugleich mit hartnäckiger Schlaflosigkeit und heftigen Schmerzzuständen im ganzen Körper oder einzelnen Körperteilen. Viele Hyperkinetische leiden an lebhaften wechselnden Delirien und an nicht endenwollenden und qualvollen Wälzzuständen, die mit lebhaften dysphorischen Affekten, seltener mit heiterer Stimmung einhergehen, im Gegensatz zu den lethargischen Zuständen, in denen meist eine seltsame affektive Indolenz besteht und die Delirien als etwas Selbstverständliches hingenommen werden. Die Hyperkinesen können viele Wochen andauern; manchmal sind sie von kurzer Dauer; vereinzelt nehmen sie ein katatones Gepräge an.

Lethargische wie hyperkinetische Syndrome können über emotionellhyperästhetische Schwächezustände von meist längerer Dauer zur Genesung hinüberführen. Sie können aber auch unmittelbar in die akinetisch-rigide Form des Parkinsonismus übergehen; endlich - und das ist wohl die häufigste Verlaufsform - kann es zu Jahre dauernden Zuständen leidlicher Gesundheit, in denen die Kranken freilich immer noch über leichte Schlafstörungen, mangelnde Frische, Empfindlichkeit, Ermüdbarkeit, Kopfschmerzen zu klagen haben und die Reste der neurologischen Störungen fortbestehen, und dann erst allmählich zur Herausbildung des Parkinsonismus kommen. Bei diesem beherrschen äußerlich Rigor und Akinese das Bild; daneben bestehen vegetative Störungen der verschiedensten Art (Salbengesicht, Störungen der Speichelsekretion), oft auch gleichzeitig Hyperkinesen in Form von Tremor oder einzelnen iterativen Erscheinungen (Schnalzen, hyperkinetische Atemstörungen, Schnaufen, dranghaftes Schreien, Umherwandern, Torticollis usw.). Weiter sehen wir häufig Blickkrämpfe und manchmal voll ausgebildete oder doch angedeutete narkoleptische Erscheinungen. Psychisch sind die Kranken meist verändert. Ein Teil ihres Mangels an äußerlich sichtbarem Tun mag mit der durch den Rigor bedingten motorischen Behinderung zusammenhängen; daneben scheinen aber vielfach Antrieb und Initiative zu fehlen und auch die Affektivität hat Schaden gelitten. Die innere Anteilnahme, die Resonanzfähigkeit hat abgenommen. Zahlreiche Kranke, die bei Fremdanregung noch zu ordentlichen Leistungen kommen, tun von sich aus gar nichts. Viele sind nicht bloß körperlich, sondern auch seelisch verlangsamt (Bradyphrenie). Dagegen leiden die mnestischen Funktionen, Auffassung und Urteil als solche in der Regel nicht.

Vereinzelt begegnen uns neben motorischen (s. oben) auch seelische Zwangserscheinungen verschiedener Art, besonders im Verein mit den Schauanfällen. Seltener finden wir auch paranoide und paranoid-halluzinatorische Bilder, die paraphrenes Gepräge annehmen können, wie eigentliche schizoforme Psychosen von langer Dauer. Das Hervortreten des Parkinsonismus schützt vor der Verwechslung mit schizophrenen Prozessen.

Bei manchen Erwachsenen macht sich neben dem Rigor und der ,Bradyphrenie $^{66}$. eine dranghafte Unruhe bemerkbar, welche die Kranken fortdrängen, herumlaufen, immer etwas fordern, anfassen, hartnäckig kleinliche Ziele verfolgen läßt. Wir sehen dies um so eher, je jünger die Betroffenen sind.

Bei Kindern und Jugendlichen sind solche Zustände klebriger dranghafter Unruhe besonders häufig. Symptome des Parkinsonismus können dabei ganz fehlen, treten aber allmählich in der Regel doch hervor. Manche dieser langdauernden Drangpsychosen haben einen ausgesprochen manischen An- 
strich, nur daß die kennzeichnende manische Heiterkeit fehlt und die Zuwendung zu den Dingen nicht so sehr eine interesse-betonte, als vielmehr eine mehr tätig-motorische ist. Unter Umständen kann aber die Unterscheidung von der Manie unmöglich sein.

Häufiger als die maniformen sind die psychopathieähnlichen Bilder mit Enthemmung nach der verschiedensten Richtung hin. Solche Jugendliche spielen unablässig Streiche; sie mischen sich in alles hinein, machen sich an jeden heran, schmeicheln dem Arzt und den Pflegepersonen, allen Erwachsenen, um dann heimtückisch zuzuschlagen; sie necken andere Kranke, stehlen wie die Raben, sind auch sexuell enthemmt, onanieren, sind obszön, machen sich mit geschlechtlichen Absichten an Tiere, an Gleichgeschlechtliche, an Jugendliche und Hilflose heran. Gelegentlich kommt es zu wahren Gewalttaten. Dabei wird das Tun oft als dranghaft, als nicht der Persönlichkeit entsprechend erlebt und vielfach bereut. Es kann auch ebensoviel Gutes wie Bösartiges getan werden. Manche Kranke haben aber Freude an ihren Bosheiten, vielleicht im Zusammenhang mit den mannigfachen Maßregelungen, die sie erfahren. Oft bestehen Schlafstörungen. Neurologische Symptome können ganz fehlen. - Die Prognose dieser Zustände ist nicht gut. Gewiß bessern sich manche Fälle im Laufe der Jahre weitgehend. Sehr viele gehen aber allmählich in parkinsonistische Starrezustände über, in denen mindestens anfänglich der Drang noch fortdauert.

In den akuten Zuständen findet man meist Liquordruckerhöhung, Pleozytose, erhöhten Liquorzuckerspiegel. Der letztere wird auch später noch oft gefunden.

In akuten Stadien soll man den Versuch machen, mit großen Dosen Rekonvaleszentenserum zu behandeln. Bei den Schlafstörungen, besonders bei den Schlafverschiebungen, wirken chemische Schlafmittel oft unruhesteigernd. Hier sind physikalische Hilfsmittel (Bäder, Packungen) angezeigt.

Beim Parkinsonismus kann man mit Skopolamin (Gaben von mehreren Zehntel Milligramm bis zu 1 oder $2 \mathrm{mg}$ am Tage) und Atropin (man muß allmählich weit über die Maximaldosis bis zu 5 , ja $7 \mathrm{mg}$ am Tage ansteigen und die Optimaldosis bei jedem einzelnen Kranken vorsichtig ertasten) symptomatisch leidliche Ergebnisse bekommen. Neuerdings wird wegen der geringeren Nebenwirkungen die sogenannte bulgarische Kur bevorzugt. Das Präparat, ein Perkolat der bulgarischen Belladonnawurzel, ist unter der Bezeichnung ,Homburg $680^{66}$ im Handel; man beginnt mit 1-2 Tropfen täglich und steigt bis höchstens $3 \times 10$ Tropfen allmählich; gleichzeitig soll vegetarische Diät gegeben werden. Auch Stramonium wirkt manchmal günstig, seltener Harmin. Zugleich darf man nie Bewegungsübungen und seelische Beeinflussung unterlassen. Beim Fortschreiten der Erscheinungen wird man versuchen, mit Metallen (Quecksilber, Silber, Gold) den weiterglimmenden Prozeß aufzuhalten. Heilungen gibt es in den Spätstadien wohl nicht; doch erlebt man leidliche Stillstände.

Anatomisch ist das Höhlengrau und sind die großen Hirnganglien erkrankt. In den Spätstadien finden sich Zerstörungen in dem schwarzen Anteil der Substantia nigra. 


\section{Erkennung}

Darüber ist schon oben manches gesagt. Die typischen spätenzephalitischen Syndrome sind vor allem gegenüber anderen organischen Hirnerkrankungen, die zu Parkinsonismus führen können, abzugrenzen. Die Paralysis agitans gehört einer wesentlich späteren Altersstufe an, als die Mehrzahl der Enzephalitiker, die ganz vorwiegend im jugendlichen Lebensalter erkranken. Die Lues wird man serologisch, meist aber auch an Pupillenstörungen erkennen, die nur selten in für die Lues typischen Formen bei der Enzephalitis vorkommen. Wenn grobe Hirntraumen einmal zu Rigor und Tremor führen, dann fehlen in der Regel auch andere, der Enzephalitis fremde Herderscheinungen nicht. Die seltenen Parkinsonbilder bei der Huntingtonschen Chorea und beim Wilson wird man nach der persönlichen und vor allem auch nach der Familienvorgeschichte abtrennen können, abgesehen von Einzelzügen der neurologischen Symptomatologie, die hier nicht besprochen werden sollen.

Die paranoid-halluzinatorischen Syndrome gehen mit parkinsonistischen Erscheinungen einher; im übrigen wird man hier wie bei den psychopathieähnlichen Störungen der Kinder diagnostisch auch die Vorgeschichte, besonders das akute enzephalitische Krankheitsbild mit seinen Störungen des Schlafs heranzuziehen haben.

Die akute Enzephalitis selbst kann, wenn sie nicht unter einem der typischen Syndrome verläuft, außerhalb der Epidemiezeiten schwerlich als Encephalitis epidemica erkannt werden. Man wird bei allen enzephalitischen Bildern, welche die bekannten Syndrome darbieten und typische Liquorveränderungen zeigen, die Vermutungsdiagnose stellen. Doch soll man sich hüten, bei jeder Grippe, die mit Kopfschmerzen einhergeht, gleich von „Hirngrippe $^{66}$ zu sprechen, wie dies so häufig geschieht. ${ }_{9}$ Hirngrippe ${ }^{66}$, d. h. Encephalitis epidemica, darf man nur bei typischen Syndromen und Liquorkontrolle bescheinigen.

Auch das der akuten Infektion folgende ,neurasthenische ${ }^{66}$ Stadium kann vielfach nur im Zusammenhang mit der Vorgeschichte oder dann geklärt werden, wenn sich schon die ersten parkinsonistischen Störungen bemerkbar machen.

\section{f) Psychische Störungen des höheren Lebensalters}

\section{Senile Demenz}

Auch hochbetagte Greise können geistig rüstig bleiben, wenngleich eine gewisse Einengung der Interessen, eine allmählich zunehmende Starrheit, ein Mangel an Beweglichkeit und Überblick und ein Nachlassen der Gedächtnisleistungen zu den normalen Kennzeichen des Alters gehören, ebenso wie jene Weisheit des Alters, das Unberührtbleiben durch Ereignisse, die in jüngeren Jahren lebhaften gemütlichen Widerhall gefunden hätten. Bei nicht wenigen Greisen aber altert das Hirn rascher als der übrige Organismus; bei ihnen kommt es zu höheren Graden von Greisenblödsinn, ehe der Organismus den Betrieb einstellt. Wir haben es offenbar mit erblichen Störungen zu tun. Die Anlage, alt zu werden, und jene zu voraneilender seniler Involution des Hirns müssen zusammentreffen. Die letztere prägt sich offenbar häufig in von je bestehenden Mängeln der seelischen Persönlichkeit aus. Auffallend viele 
später senil Demente sind psychopathische Persönlichkeiten. Nicht selten finden wir bei ihnen senil-demente Geschwister und hören von langdauernden Schwachsinnszuständen im höheren Lebensalter auch bei den Eltern.

Im Beginn des Greisenblödsinns stellen wir nur die Kennzeichen des normalen Greisentums fest, die sich dann mehr oder weniger rasch, häufig fast schubweise im Zusammenhang mit irgendwelchen groben äußeren Schäden (Pneumonie, Schenkelhalsbruch, Tod eines nahen Angehörigen) verstärken. Im Vordergrund steht bei dem ausgeprägten Bilde der senilen Demenz die Merkschwäche, die den Kranken rasch alle Tagesereignisse vergessen läßt und schließlich die ganze nahe Vergangenheit mehr oder weniger auslöscht. Die letzten Lebensjahre des Kranken sind für ihn so gut wie nicht mehr vorhanden, wenn auch in der Regel einige Erinnerungsinseln erhalten bleiben. Im weiteren Verlauf wird noch mehr von der Vergangenheit ausgelöscht; die Erinnerungen, die dem Kranken verfügbar sind, gehören dann immer früheren Lebensperioden an, bei Männern gern der Militärzeit, bei Frauen den im Elternhaus verbrachten Jahren. Sie können sich dann mit ihrem Mädchennamen nennen. Freilich sind die späteren Gedächtnisspuren vielfach doch nicht ganz vernichtet. Störungen der Reproduktion spielen eine große Rolle. Man kann also unter Umständen eine Greisin in demselben Gespräch sich soeben noch gebärden sehen, als ob sie ein junges Mädchen wäre, gleich darauf aber vom Tod eines Kindes oder des Ehemannes und dann wieder davon erzählen hören, daß sie vor eine Stunde ein zweites Töchterchen geboren habe.

Die Gedächtnisstörungen sind freilich vielfach nicht so hochgradig; aber die Merkstörungen sind immer ausgeprägt. So kommt es, daß der Senile oft Menschen nicht kennt, mit denen er täglich zu tun hat, daß er alle seine Habseligkeiten verlegt und nicht wiederfindet, daß er im Tageslauf nicht recht Bescheid weiß, und daß er sein Bett, seine Kleider dann nicht wiedererkennt, wenn er nicht in der gewohnten Umgebung ist. Dabei ist er meist auch örtlich desorientiert oder seine Orientierung ist doch unvollkommen und die zeitliche ist meist grob gestört.

Immerhin bleibt eine nicht unerhebliche geistige Beweglichkeit in der Regel lange bestehen. Man kann sich mit den Kranken meist leidlich geordnet unterhalten, richtige Urteile über einfache Sachverhalte bekommen und Gebildete über eine frühere literarische Erscheinung, Handwerker über ihre frühere Tätigkeit vernünftig erzählen hören. Dabei ist die Aufmerksamkeit manchmal ausgezeichnet und die Kranken können sehr schlagfertig erscheinen; schwierigere Dinge verstehen sie aber nicht; sie fassen oft auch unvollkommen und je nach dem gerade im Mittelpunkt des Denkens stehenden Inhalt falsch auf. Spontan kümmern sie sich nicht um das, was um sie herum vorgeht. Ihre Gedächtnislücken füllen sie gern mit "Verlegenheitskonfabulationen" aus, die bei der großen Merkschwäche von Augenblick zu Augenblick wechseln, aber im allgemeinen wirklichkeitsnahe bleiben.

Das Interesse der Kranken ist immer stark eingeengt. Die kleinen Besitztümer, die Wohnung oder doch Teile daraus, der eigene körperliche Zustand, die Mahlzeiten spielen die Hauptrolle. Viele Senile schleppen ihre Habseligkeiten mit sich herum und neigen dazu, Wertloses zu sammeln. Im Rahmen ihres Interessenkreises entwickeln sie oft lebhafte Affekte, insbesondere Zorn

8 Langef-Bostroem, Psychiatrie, 3. Aufl. 
und Gereiztheit, aber auch Kummer und Freude. Darüber hinaus Gemütsbewegungen zu erhalten, ist meist schwierig. Der Tod auch naher Angehöriger, wichtige sachliche Verluste, schreckliche Vorkommnisse, die sich vor ihren Augen abspielen, gehen spurlos an ihnen vorüber. Sie fassen sie gar nicht auf, und wenn sie dies doch fertig bringen, dann scheint oft jeder gemütliche Widerhall zu fehlen. Freilich gelingt es dann doch gelegentlich eifrigem Bemühen, den Kranken die Bedeutung der Vorkommnisse klarzumachen, und dann sehen wir manchmal auch lebhafte gemütliche Reaktionen, wenn sie auch flüchtig bleiben. Dagegen fassen die Senilen Kränkungen, besonders solche ihrer sozialen und geschlechtlichen Ehre, meist gut auf, wo die Demenz nicht zu weit fortgeschritten ist. Sie merken diese Kränkungen auch und tragen dann lange nach.

Bei manchen Kranken kommt es im Beginn des Blödsinns zu einem Aufleben des Sexualtriebes und bei dem bestehenden Schwachsinn dann auch gelegentlich zu sexuellen Delikten an Kindern. Der Sammeltrieb kann sie zu törichten kleinen Diebstählen und die Zornmütigkeit zu unüberlegten Bedrohungen und Tätlichkeiten bringen.

Viele Senile sind ganz stumpf; sie sitzen betätigungslos herum oder bleiben liegen und verwahrlosen, wenn sie sich selbst überlassen sind, bald ganz. Andere aber sind sehr lebhaft und fortgesetzt beschäftigt. Sie streichen herum und sammeln alles, was sie in die Finger bekommen, kramen fortgesetzt in der Wohnung herum, haben unablässig aufzuräumen und bringen alles durcheinander. Dabei sind sie meist von einer außerordentlichen Hartnäckigkeit, Eigensinnigkeit und Unbeeinflußbarkeit. Auch wenn sie geistig noch regsamer sind, halten sie an ihren engstirnigen Ansichten zäh fest. Oft sind sie schmutzig, geizig und gönnen ihren Angehörigen nicht das trockene Brot. Auf der anderen Seite machen Schwachsinn und Merkschwäche sie auch den plumpesten Suggestionen zugänglich, die sich ihre Eigenheiten, ihren Eigensinn und ihren Geiz zunutze machen. Eigensinn und erhöhte Suggestibilität gehen hier wie überall zusammen. Auf diese Weise findet die Erbschleicherei gerade bei Senilen ein günstiges Betätigungsfeld.

Im späteren Verlauf des Greisenblödsinns wird die Fähigkeit, die Umwelt aufzufassen und sich mit ihr geordnet in Beziehung zu setzen, immer unvollkommener. Der stumpfe Senile hat nur noch ein dumpfes, schattenhaftes Innenleben; er muß gefüttert und in allem besorgt werden. Dies gilt auch für den senil Erregten, der fortgesetzt in seinem Bette kramt, Tücher und Kissen zusammenrollt und entrollt, daraus Pakete macht, die er forttragen will, sein Laken und seinen Kopfkissenüberzug , wäscht ${ }^{66}$ oder schließlich nur noch stereotype Bewegungen macht, deren Sinn nicht einmal zu erraten ist. In diesem Stadium bringt jeder Versuch, den Kranken zu füttern, zu baden, sein Bett zu wechseln, heftige, zornmütige oder auch ängstliche Abwehr hervor, die zugleich unbeeinflußbar bleibt, weil der Kranke nicht mehr versteht, was mit ihm vorgeht. Auch nächste Angehörige werden dann meist nicht mehr erkannt.

Im Verlaufe der senilen Demenz kommt es oft zu Verwirrtheitszuständen und Delirien, auch schon in den früheren Stadien, anfänglich besonders nachts oder schon am Abend und am späten Nachmittag. Die Umgebung wird dann nicht mehr erkannt oder in bestimmter Weise verkannt, traumhafte Erlebnisse 
beherrschen das Denken und Handeln des Kranken, meist ängstliche und unangenehme Inhalte, die ihn zur Abwehr, zur Flucht, zu Toben und Schreien und zu unverständlichem Handeln bringen. Solche delirante Episoden können Stunden, aber auch Tage und Wochen fortdauern. Wenn sie mit lebhafter Erregung einhergehen, sind sie immer gefährlich für das Leben des Kranken.

Der Schlaf ist bei den Senilen in der Regel schlecht. Oft sind sie am Tage müde, da sie in der Nacht herumgeistern, in den Zimmern umhersuchen, unter das Bett flüchten, alle Schränke und Kästen aufmachen usw. Ist ihnen offenes Licht und Feuer zugänglich oder der Gashahn, dann sind sie und ist ihre Umgebung gefährdet.

Den Beginn der senilen Demenz festzustellen, ist vielfach schwer. Bei näherem Zusehen stellt sich in der Regel heraus, daß zwar die zunehmende Merkschwäche es ist, welche die ersten groben Entgleisungen mit sich bringt, daß aber vielfach schon lange vorher ${ }_{\text {"Charakterveränderungen }}{ }^{6}$ eingetreten sind. Dabei handelt es sich wohl mehr darum, daß zunehmende Erstarrung im Verein mit egozentrischer Einengung und "Altersweisheit ${ }^{66}$ die bisher durch Erziehung und Konvention verdeckten Wesenszüge deutlicher an den Tag bringt. So wird Sparsamkeit zum Geiz, Ordnungsliebe zur Pedanterie, Festigkeit zum Starrsinn, Reizbarkeit zum Zornmut. Die Dämpfung, welche die Reife herbeigeführt hatte, gerät in Verlust und dieser Verlust ist es auch, der primitive Regungen, unter anderem auch sexuelle, wieder entfesselt. Bei diesen Persönlichkeitsveränderungen muß man, wenn sie deutlich sind, den Beginn der senilen Demenz ansetzen, auch in forensischer Beziehung.

\section{Varianten der senilen Demenz}

Ausgeprägte Depressionszustände sind bei Greisen nicht selten. Die traurig-ängstliche Verstimmung erreicht freilich selten die Tiefe und Echtheit der endogenen Melancholien. Auch fehlt meist die so eigenartige Ansprechbarkeit für andere Gemütswerte, die bei der Melancholie in der tiefsten Depression und Hemmung fast nie vermißt wird. Der Affekt ist leerer, starrer; oft besteht zugleich erhebliche Reizbarkeit, und nicht selten sind hysterischtheatralische Züge. Auch die Hemmung fehlt oder ist doch nie so ausgesprochen und vital wie bei der Melancholie. Verarmungsideen sind häufig und können sehr gewichtig werden; im Vordergrund stehen aber hypochondrische Wahnideen und Versündigungsideen, welche die Kennzeichen des Organischen haben: also unsinnig, ungeheuerlich, enorm, nihilistisch, mikromanisch sind. Die ganze Welt ist aufgegessen, ist nicht mehr da, der Körper, der Magen, der Kopf ist weg, der Kranke, sein Kopf, seine Hände, seine Glieder sind ganz klein; alles ist verfault; er hat die ganze Welt gestohlen, mit allen Frauen gehurt usw. Die Ideen sind dabei äußerst eintönig und werden gern in ganz der gleichen Weise vorgebracht, oft auch noch, wenn gar kein rechter Affekt mehr da ist. Genauere Untersuchung deckt bei den Kranken die Kennzeichen des Greisenblödsinns auf: Merk- und Gedächtnisschwäche, Einengung, Auffassungsschwierigkeiten. Immerhin brauchen diese nicht sehr ausgesprochen zu sein. Senile Depressionen können lange Zeit anhalten, Monate, Jahre, dann aber abheilen, so daß man von einer - relativen - Genesung sprechen kann. 
Die Symptome der senilen Demenz freilich heilen nicht ab und können sich im Laufe der Krankheit sehr verstärken.

Viel seltener sind senile manische Zustände, bei denen vor allem die Erregung, die öde Geschwätzigkeit, der ununterbrechbare Redestrom, die dürftigen und albernen Prahlereien hervortreten, während der echte manische Affekt meist fehlt und statt dessen eine eigensinnige Erregbarkeit und schwächliche Aggressivität das Bild beherrschen. Bei manchen einfachdementen Greisen sind wohl die erhöhte Geschäftigkeit und die fast immer ausgeglichen heitere Stimmung als manische Symptome aufzufassen. Viele dieser Kranken sind von je hypomanische Menschen. Bei ihnen entwickelt sich gern ein kennzeichnendes Gesamtbild, das sich auch durch den lang sich hinziehenden Verlauf von den gewöhnlichen Formen der senilen Demenz abhebt. Bei weitgehender Erhaltung der Persönlichkeit, ungewöhnlicher gemütlicher Ansprechbarkeit und großer geistiger Regsamkeit und Beweglichkeit wird die Symptomatologie beherrscht durch die Merkschwäche, die mit Desorientierung und Konfabulationen einhergeht. Es handelt sich also um Korsakowsche Syndrome bei großer vitaler Frische, die im Gegensatz zu deren erheblicher Einbuße bei der Mehrzahl der Korsakow-Zustände steht. Man bezeichnet solche Bilder auch als Presbyophrenien. Sie können mit gewissen Schwankungen lange Jahre fortbestehen. Die Kranken werden manchmal nur bei ihren wiederkehrenden deliranten Verwirrtheitszuständen anstaltsbedürftig.

Bei den ausgeprägten senilen Depressionen und Manien ist nicht selten das Vorkommen von affektiven Psychosen in der Verwandtschaft festzustellen. Gelegentlich sind bei diesen Kranken psychogene Depressionen schon vorausgegangen.

Natürlich gibt es auch echte zirkuläre Erkrankungen, Melancholien und ganz selten Manien im Senium. Die Vorgeschichte klärt den Sachverhalt auf. Die Dauer dieser zirkulären Psychosen braucht nicht besonders ausgedehnt zu sein, ist es aber vielfach.

Recht kennzeichnend ist das Krankheitsbild des senilen Paranoids. Es handelt sich fast immer um Menschen, die von jeher ein wenig stachelig, mißtrauisch, querköpfig und erregbar waren und deren Eigenart vom Beginn der Involution an immer deutlicher und unerfreulicher hervortrat. Bei ihnen bringt dann die zunehmende Vergeßlichkeit im Verein mit dem Nachlassen der Sinnesorgane ausgesprochene paranoide Störungen hervor, lange, oft viele Jahre, ehe der eigentliche Greisenblödsinn deutlich wird. Sie bleiben also geistig beweglich, auf Abwehr bedacht, und können auch recht geschlossene Wahnsysteme bilden. Vor allem wähnen die Kranken sich bestohlen, aber auch belästigt, in ihrer sexuellen Ehre und in ihrem Leben bedroht. Ihr Mißtrauen läßt sie alle Wertgegenstände verstecken, ihre Vergeßlichkeit die Verstecke vergessen. Allmählich werden auch weniger wertvolle Dinge versteckt und verkramt, bis schließlich in der Wohnung ein unbeschreiblicher Wirrwarr herrscht. So verschwinden erst Schmuck und Geld, dann Trauring und Sparkassenbuch, dann Wäsche und kleinere Einrichtungsgegenstände, ja schließlich Bettwäsche und Federn aus dem Kopfkissen und selbst notwendige Kleidungsstücke. Die Kranken bringen Schlösser an der Tür an, zu denen sie den Schlüssel verlieren, nehmen ihre Kassette unter vielfachen 
Verschluß; auch hier geraten die Schlüssel in Verlust. Immer wieder muß der Schlosser kommen, immer neue Schlösser werden angebracht. Wenn dann einmal vorübergehend die Tür offenstand, dann muß alles doppelt versteckt werden und dann wurde schlechthin alles gestohlen. Dazu wird die Wasserleitung und die Spülung im Klosett verstopft, durch die Türritze kommen Nebel, giftige Gase. Der Ofen ist verstopft und raucht, der Gashahn wird von den Feinden aufgedreht. Nachts wird gepoltert und Grammophon gespielt, das Geschirr zerschlagen und beschmutzt, kurz, es wird unsäglicher Unfug angerichtet. Alles dies tun Nachbarn, mit denen Feindschaft herrscht, die Kinder oder entferntere Angehörige, die möglichst rasch die Erbschaft antreten wollen, ein Feind des längst verstorbenen Mannes, der sich in den Besitz von Papieren bringen will und, wenn er sie nicht findet, anderes mitnimmt und aus Rache Angriffe auf das Leben macht. Der senile Paranoide fühlt sich so immer bedroht, und er reagiert nicht nur mit passiver Abwehr, verbarrikadiert sich also, öffnet nie die Wohnungstür oder doch nur zu unmöglichen Stunden; er schimpft und poltert nachts auch selbst, schlägt einmal zu oder geht zur Polizei und zeigt seine Verfolger an. Den Angehörigen, den Fürsorgern, der Polizei bietet sich, sobald einmal die Dinge so weit gediehen sind, in der Wohnung des vereinsamten Paranoiden ein unbeschreibliches Bild der Unordnung und Verwahrlosung; denn der Senile hat natürlich auch alles aufgehoben, was in Monaten und Jahren in seine Wohnung gekommen ist. Lebt er mit anderen zusammen, dann bringen Mißtrauen und Feindschaft, Anschuldigungen und Anzeigen, Krach und Schlägereien rascher eine Internierung mit sich.

Solche Kranke können in der Anstalt recht geordnet, gewandt und mit Nachdruck ihre Anklagen vorbringen und Einwände widerlegen. Sie machen vielfach durch ihr Wesen und ihre nicht einmal erhebliche Merkschwäche einen sehr rüstigen und fast intelligenten Eindruck. Erfreuliche Menschen sind sie freilich nie. In der neuen Umgebung treten die Wahnideen manchmal an Bedeutung zurück. In der Regel beginnen die Belästigungen auch hier bald, insbesondere wenn der Kranke wie so häufig auch seine senilen körperlichen Mißempfindungen (Herz, Genitale) auf seine Verfolger bezieht. Die Krankheit zieht sich unter Schwankungen oft viele Jahre hin. Eine tiefe Demenz braucht nicht einzutreten. Genetisch bestehen wahrscheinlich engere Beziehungen zur Schizophrenie.

Die pathologisch-anatomischen Befunde bei der senilen Demenz werden im Anschluß an die Alzheimersche Krankheit besprochen.

\section{Alzheimersche Krankheit}

Die Krankheit ist selten. Sie beginnt durchschnittlich wesentlich eher als die gewöhnliche senile Demenz, meist im 6. oder im Anfang des 7. Lebensjahrzehnts, und führt im Laufe der Jahre zu einem besonders tiefen Blödsinn. Bei sonst noch ausgezeichneter Haltung sind es in der Regel einzelne grobe Fehlhandlungen, welche auf die Krankheit aufmerksam machen. Auch der Kranke selbst kann sie nicht recht erklären. Bald treten Merk-, Gedächtnisund vor allem Reproduktionsschwäche hervor. Der Kranke ist sich der Veränderung mehr oder weniger bewußt, geängstigt und ratlos. Zunehmend melden 
sich dann Störungen, die in den Bereich der Aphasie, der Apraxie und der Agnosie hineingehören: Verständigungsschwierigkeiten, Wortverwechslungen, Paraphasien, Wortfindungsstörungen, ideatorisch-apraktische Erscheinungen, also grobe Fehlhandlungen schon beim Ankleiden, bei den Alltagsverrichtungen, dazu Nichterkennen gebräuchlicher Gegenstände und selbst naher Angehöriger, grobe räumliche Desorientierung. Diese Fehlleistungen sind nicht so massiv, vor allem viel launischer und von Augenblick zu Augenblick wechselnder als bei den eigentlichen Herdstörungen (verwaschene Herderscheinungen). Dabei bleibt die äußere Haltung, Höflichkeit, Takt überraschend lange gewahrt, vor allem aber die gemütliche Ansprechbarkeit. In nicht zu schweren Entwicklungsstadien kann man eigentlich noch alle Gemütsbewegungen aus den Kranken hervorholen. Allmählich nimmt der allgemeine Blödsinn zu; die Kranken sind dann, sich selbst überlassen, vielfach von einer gewissen ratlosen Heiterkeit oder auch recht stumpf oder selten moros, Stereotypien treten immer mehr hervor, Reiben, Wischen, Kramen, Waschen; es kommt zum Singsang, aber auch zu gelegentlichem Schimpfen, das oft eine kennzeichnende Auflösung der Sprache, Logoklonie, erkennen läßt, d. h. rhythmisches Wiederholen der letzten Silben des jeweils rasch zu Ende kommenden Sprachimpulses. Bei Einwirkungen von außen zeigen die Kranken bis zuletzt eine oft zornmütige Reizbarkeit, die sich in schimpfenden, unartikulierten, logoklonischen Verlautbarungen, heftigem planlosem $\mathrm{Zu}$ schlagen und Aufschreien kundgibt. Bei planmäßigem geduldigem Vorgehen (klagendes oder zärtliches Einsprechen) kann man aber auch bei tiefem Blödsinn noch zartere Gemütsregungen hervorzaubern. Körperlich finden sich oft Muskelspannungen, die nicht klar als pyramidale gekennzeichnet sind, gelegentlich Kontrakturen, vereinzelt auch epileptische Anfälle.

In diesen Fällen, die sich klinisch nach ihrem Gesamtverlauf zu einer recht wohl gekennzeichneten Gruppe zusammenschließen, findet man regelmäßig eine schwere Erkrankung der Gesamtrinde, in der reichlich Drusen und vor allem eine kennzeichnende Form der Neurofibrillenveränderung (Alzheimersche) nie fehlen, neben den gewöhnlichen Zeichen der senilen Demenz, nämlich der allgemeinen Atrophie, die aber nicht sehr ausgesprochen sein muß. Drusen (Plaques) und Alzheimersche Neurofibrillenveränderung, die sich mit Silberimprägnationsverfahren nachweisen lassen, sind der menschlichen Gehirnrinde eigen. Die letztere begegnet uns gelegentlich auch bei anderen chronischen Leiden (etwa beim Parkinsonismus nach Encephalitis epidemica).

Die Atrophie der senilen Demenz verrät sich in einer hochgradigen Verkleinerung des Gehirns (Abnahme des Gewichts, Klaffen der Furchen) und beruht auf einem langsam fortschreitenden Zugrundegehen der Nervenzellen und ihrer Fortsätze. Zugleich sind die faserbildenden Bestandteile des Stützgewebes vermehrt (das Hirn ist daher härter als normal). Auch bei der senilen Demenz finden sich Drusen und Neurofibrillenveränderungen, doch nicht in der Ausbreitung und in dem Maße wie beim Alzheimer. Die Zeichen der einfachen Atrophie mit reichlicher Pigmentbildung (gelbes Abnutzungspigment, Lipofuscin, das schon früh im Leben nachweisbar ist, im Alter aber in großen Haufen einen wesentlichen Teil des Zelleibes füllt) herrschen bei der gewöhnlichen senilen Demenz in der Regel vor. 


\section{Picksche Krankheit}

Anatomisch handelt es sich hier nicht um eine Erkrankung der Gesamtrinde wie bei der senilen Demenz und beim Alzheimer, sondern um eine einfache hochgradige Atrophie ohne Drusen und Fibrillenveränderung, welche die oberflächlichen Rindenschichten in mehr oder weniger wohl abgegrenzten Hirnteilen (Lappenatrophie), nämlich im Stirnlappen (hier bleibt aber die Zentralregion verschont) und daneben bzw. in anderen Fällen allein im Temporallappen (außer Querwindungen, Ammonshorn und meist dem hinteren Teil der 1. Schläfenwindung) und Teilen des Parietalhirns betrifft. Regelmäßig ist die weiße Substanz stark mitbefallen. Es sind vorwiegend die entwicklungsgeschichtlich höchst entwickelten, menschlichsten Hirnapparate, die Schaden leiden. Manchmal nehmen aber auch tiefe Hirnteile an der Atrophie teil (Streifenhügel, Substantia nigra). Die Krankheit ist mit erheblicher Wahrscheinlichkeit erblich, und zwar dominant. Sie beginnt vielfach schon recht früh, im 5 . und 6. Lebensjahrzehnt, nicht selten aber auch später; der älteste bekannte Fall erkrankte im 72. Lebensjahr.

Entsprechend dem Verschontbleiben der primitiven Hirnapparate bleiben auch die niederen geistigen Leistungen merkwürdig gut und lange erhalten. Diese Kranken können also noch im Stadium recht tiefen Blödsinns vielfach gut merken, leichte Rechenaufgaben überraschend schnell und richtig lösen, bringen auf Fragen gute Schulkenntnisse vor, fassen gut auf und entwickeln vorübergehend eine ausgezeichnete Aufmerksamkeit, wenn man sie in Anspruch nimmt. Dabei werden aber sehr rasch die geistige Initiative, die spontane Aufmerksamkeit wie die Fähigkeit zum intelligenten Verhalten gestört. Produktive geistige Leistungen werden bald unmöglich. Sich selbst überlassen erscheinen die Kranken völlig ausgeleert. Auf Fragen reagieren sie zwar vielfach noch rasch, aber ohne Rücksicht auf die Richtigkeit.

Je nach dem Befallensein des Stirnhirns bzw. der hinteren Hirnteile treten verschiedenartige Herdstörungen immer deutlicher hervor. Beim Stirnhirnpick findet sich anfangs häufig eine grobe Enthemmung; wir sehen dann kleine Diebstähle, Taktverlust, Distanzlosigkeit; in der Arbeit grobe Nachlässigkeit, Faulheit, Insubordination, zu Hause Roheit, Schamlosigkeit, Gefräßigkeit, sexuelle Enthemmung. Bald macht sich der Verlust an Initiative immer deutlicher geltend ; insbesondere leidet die Sprachinitiative; der Kranke wird einsilbig, spricht lange Zeit überhaupt nichts, sitzt stumpf und beschäftigungslos da oder treibt eine mechanische, sinnlose Beschäftigung. Aufgerüttelt antwortet er einsilbig, ohne Rücksicht auf den Sinn der Frage, mit blödem Lachen oder auch einmal gereizt. Die Haltung wird müde, schlaff, der Gang langsam, schwerfällig, oft vornübergebeugt. Ohne Pflege verkommt der Kranke rasch. Schließlich wird er völlig hilflos und muß besorgt und gefüttert werden.

Beim Schläfenlappenpick kommt es zu einer gewissen Sprachenthemmung; die Reden werden aber agrammatisch und paraphasisch. Der Kranke faßt Sprachliches nicht oder unvollkommen auf und zeigt oft einen Rededrang, in dem ,stehende Redensarten " immer wiederkehren, im übrigen aber Wortarmut und amnestische Störungen deutlicher werden. Kann anfangs 
auch sonst noch eine gewisse Geschäftigkeit bestehen, bleibt die Affekterregbarkeit noch für lange Zeit erhalten, so gerät doch auch hier allmählich jeder Ansatz zu wirklichem Handeln in Verlust und das Ende ist wie beim Stirnhirnpick tiefster hilfloser Blödsinn.

Den Beginn der Pickschen Krankheit bilden in der Regel uncharakteristische nervöse Störungen, Kopfschmerzen, Zerstreutheit, Unfähigkeit zur Konzentration, Verstimmung, eine gewisse Ängstlichkeit. Grobe äußere Schäden lassen sich nicht nachweisen oder sind schon Folge der beginnenden Krankheit.

Die Krankheit wird am häufigsten mit der Paralyse verwechselt. Aber es fehlen alle kennzeichnenden neurologischen Symptome. Blut und Liquor zeigen normale Befunde. Klarheit bringt wenistens bei vorgeschrittenen Fällen nicht selten das Enzephalogramm, das Hydrocephalus internus und reichlich Luft über den befallenen Lappen ergibt.

\section{Arteriosklerose}

Die Arteriosklerose hat eine eigentlich psychiatrische Bedeutung nur dann, wenn sie vorwiegend zur ausgebreiteten Erkrankung der kleinen Hirngefäße führt. In der Mehrzahl der Fälle stehen arteriosklerotische Organerkrankungen (Herz und Niere) und Herdstörungen im Vordergrund.

Auch dann fehlen freilich die allgemeinen Kennzeichen der zerebralen Arteriosklerose meist nicht ganz. Den Beginn macht sehr häufig eine depressivängstliche, hypochondrische Zuwendung zu dieser oder jener Organstörung oder zum Altern und zum allgemeinen Leistungsnachlaß überhaupt. Das Seelenleben ist immer irgendwie dysphorisch, dabei verlangsamt und müde. Im Vordergrund des subjektiven Leidens stehen alle möglichen Beschwerden: Kopfschmerzen, bald ein wirklicher Schmerz, bald mehr ein Druck oder eine Schwere, eine Spannung, ein Benommenheitsgefühl von deutlicher körperlicher Note. Dazu gesellen sich Schwindelerscheinungen, die sehr häufig in verschiedener Schwere auftreten, oft mit Ohrensausen und -klingen verbunden, Extrasystolen, kardiale Sensationen. Ferner kommt es gelegentlich zu Ohnmachten, manchmal auch zu einzelnen schweren Anfällen. Frühzeitig tritt ferner eine Schlafstörung auf, meist erschwertes Einschlafen, aber auch zerhackter, unruhiger Schlaf und allgemeine Schlafverkürzung. Die Kranken liegen stundenlang wach. Als Folge dieser Schlaflosigkeit sehen die Kranken meist auch ihre erhöhte Ermüdbarkeit an.

Diese führt schon zu den eigentlichen seelischen Symptomen hinüber. Die Kranken spüren die allgemeine Leistungsabnahme sehr deutlich. Sie brauchen längere Zeit zu altgewohnter Tätigkeit, müssen Pausen einschieben, sind nie recht frisch. Ihr Gedächtnis läßt sie im Stich. Zur rechten Zeit fallen ihnen auch wichtige Dinge nicht ein. Neues Gedächtnismaterial haftet unvollkommen oder wird rasch vergessen. Die Schwierigkeiten auch einfacher Leistungen, die früher spielend bewältigt wurden, erscheinen unüberwindlich.

Der alltägliche Dienst verbraucht die ganze Kraft; der Kranke tut sonst gar nichts mehr und kann schließlich auch die gewohnten Aufgaben nicht mehr bewältigen. Dabei ist er niedergeschlagen, hoffnungslos, moros, übertrieben besorgt um Kleinigkeiten. Verdrießliches wird er nicht mehr los. Er 
wird reizbarer, empfindlicher, zornmütiger, aber zugleich leichter gerührt, kurz affektinkontinent.

Vergeßlichkeit und Gedächtnisschwäche nehmen immer mehr zu, ebenso Verlangsamung und Ermüdbarkeit. Der Kranke vermag schwierigere Sachverhalte überhaupt nicht mehr, einfachere nur noch mit Mühe zu übersehen. Immerhin wahrt er die äußere Haltung; er versteht es zunächst, sich zu entlasten, seine Tätigkeit seiner Leistungsfähigkeit anzupassen. Aber später nimmt auch die Urteilsschwäche zu, und damit wird auch das Gefühl für die eigene Hilflosigkeit bestechlicher.

Doch bleibt auch bei schweren arteriosklerotischen Hirnstörungen die Persönlichkeit in der Regel noch lange Zeit leidlich erhalten. Einen raschen Verfall bringt oft erst die Entfernung aus dem gewohnten Dienst, die Versetzung in andere Umgebung, der Verlust des Lebenspartners mit sich. Der Kranke ist dann nicht selten bald völlig hilflos. Er wird eigensinniger, reizbarer, rücksichtsloser, mürrisch-aggressiv, poltrig und zugleich haltlos seinen affektiven Regungen preisgegeben. Verlangsamung und Perseveration werden immer deutlicher. Neben der allgemeinen Demenz kann man zunehmende herdmäßige Ausfälle feststellen: aphasische, apraktische, agnostische Störungen.

Nicht selten steigert sich die Niedergeschlagenheit der Arteriosklerotiker zu eigentlichen Depressionen. Meist haben die Depressionen, vielleicht im Zusammenhang mit Herzstörungen, eine gewisse ängstliche Note. Hypochondrische Wahnideen von organischem Anstrich, nihilistische Ideen stehen im Vordergrund, doch sind nicht selten auch Versündigungsideen, die Amt, Arbeit und Familie betreffen können. Die Tendenz zur Selbstbeschädigung kann sehr groß sein. Nicht wenige dieser depressiven Arteriosklerotiker gehen durch Suizid zugrunde. Vereinzelte Gehörstäuschungen, ja selbst ausgesprochen halluzinoseähnliche Bilder kommen vor. Der depressive Affekt verblaßt in der Regel nach mehr oder weniger langer Zeit. Die depressiven Ideen werden eintöniger und weniger deutlich, und damit kommt es häufig zu einer leeren Euphorie bei Reizbarkeit und Erregbarkeit.

Allen arteriosklerotischen Störungen ist gemein, daß sie in leichten Schwankungen verlaufen. Langdauerndes Ausspannen, Zurücktreten der Organstörungen pflegen Remissionen mit sich zu bringen. Es kommt aber auch zu Schwankungen im Befinden, für die eine Ursache nicht aufgedeckt werden kann.

Das Bild der arteriosklerotischen Demenz wird wesentlich geändert durch flüchtige oder bleibende Herdstörungen und die mehr oder weniger ausgesprochene Neigung zu deliranten Zuständen, die wohl auch durch Herdstörungen bzw. durch flüchtige allgemeine Störungen der Blutversorgung des Hirns bedingt sind.

Sehr lange ziehen sich vielfach jene Arteriosklerosen hin, bei denen es zu immer neuen kleinen Erweichungen besonders im Hirnstamm kommt. Hier treten artikulatorische Sprachstörungen besonders deutlich hervor, ferner Affektinkontinenz und Zwangsaffekte (Zwangslachen, Zwangsweinen), pseudobulbärparalytische Erscheinungen, leichte Thalamusstörungen, vegetative Anomalien, striäre Symptome. Später kommt es, wenn zugleich Hypertonie besteht, unter Umständen zu einer tödlichen Herdblutung 
mit Einbruch in den Ventrikel. Vielfach sind es Pneumonien, die dem Leben ein Ende setzen.

Das gleiche gilt für immer neue kleine Herde, Erweichungen, Blutungen, Nachblutungen im Bereiche der hinteren Äste der Arteria cerebri media, die besonders Sprachstörungen, leichte apraktische Erscheinungen, Alexie, Agraphie usw. mit sich bringen.

Demgegenüber sind Blutungen in die innere Kapsel nicht selten von vornherein massiv und von irreparablen Störungen begleitet, auch in der seelischen Persönlichkeit. Hier macht dann oft eine neue Blutung dem Leben ein Ende.

Die Behandlung entspricht dem Vorgehen der inneren Medizin.

\section{Leichenbefund}

Nach dem 40. Lebensjahr ist die Arteriosklerose ein fast regelmäßiger Befund, an den zuerst befallenen Stämmen und Ästen durch Starre, Wandverdickung und Atheromatose (gelbliche Einlagerungen) kenntlich, in den später betroffenen intrazerebralen Zweigen (besonders in den langen striolentikulären, am wenigsten in den kurzen Rindenzweigen) dadurch, daß die Gefäße als starre Rohre hervortreten.

Ausgeprägtere Arteriosklerose führt wohl immer zu Sauerstoffmangel und dadurch zu Leistungsbeeinträchtigung. Die groben Ernährungsstörungen werden in Erweichungsherden erkennbar, die ein Kennzeichen der Arteriosklerose sind. Im ersten Stadium der Erweichung kommt es zur Nekrose, die, je nachdem eine Blutung eintritt oder nicht, hämorrhagisch oder anämisch ist. Das Gewebe ist geschwollen, weich, in der Zeichnung verwaschen, im NißlBild schlecht färbbar (Erbleichung). Das nekrotische Gewebe demarkiert sich und wird in der zweiten Phase abgebaut und verflüssigt, und zwar durch Stützgewebszellen (vorwiegend Elemente der Gefäßwände, aber auch Glia), die sich durch Aufnahme lipoidhaltiger Abbaustoffe zu Körnchenzellen (im Nißl-Bild Gitterzellen) umbilden und als Fettkörnchenzellen im Sudan- oder Scharlachbild in gewaltigen roten Massen erscheinen. Diese Zellen gehen zugrunde und im Endstadium findet man eine mit lockerem Netzwerk durchzogene Höhle, deren Wände bei vorangehender Blutung noch bräunlich verfärbt erscheinen.

Im Gegensatz zu den Folgen von Hirntraumen, deren Herde kuppenständig sind und die Hirnhäute mit einbeziehen, finden sich die arteriosklerotischen Herde häufig auch in den tiefen Windungstälern und schädigen die Pia nicht.

Am häufigsten sind Erweichungen im Bereiche der Äste der Arteria cerebri media (Sylvii) und es kommt je nach dem befallenen Ast unter Umständen zu recht charakteristischen Ausfällen. Ferner sind häufig Erweichungen im Bereiche der Arteriae striolenticulares, die zu Schäden in Stammganglien und Pyramidenbahn führen. Ganz kleine Rindenherde machen unter Umständen keine Höhlen, sondern Glianarben (perivaskuläre Gliose). Nur die größeren von Ästen abhängigen Erweichungen geben sich in Insulterscheinungen zu erkennen.

Große Massenblutungen kommen wohl nur bei Hypertonikern vor und zwar kommt es dann wohl tatsächlich zur Zerreißung von Gefäßen und die Blutung hält sich nicht an das Gebiet eines Gefäßzweiges. Die Hypertonie mag oft eine Ursache der Arteriosklerose sein. 


\section{Hypertonie}

Die Hypertonie, der arterielle Hochdruck, wird in jüngster Zeit immer strenger von der Arteriosklerose getrennt, so häufig die beiden Leiden auch gemeinsam vorkommen. Die Hypertonie ist es, die mannigfache Beschwerden schon im Klimakterium und in der ganzen Involutionszeit macht, vor allem dann, wenn der Hochdruck labil ist, Schwankungen unterliegt. Zumal von klimakterischen und postklimakterischen Frauen hören wir von ,Nervosität ${ }^{66}$, Ängstlichkeit, innerer Unruhe, Unlust, Empfindlichkeit, Erregbarkeit. Wir können an ihrem fahrigen, hastigen, dabei hypochondrischen, oft eigenartig hartnäckigen, manchmal aggressiven Wesen, an den sichtbaren vasomotorischen Erscheinungen, die Hypertonie ablesen, auch ohne Blutdruckmessung. Dazu kommen mannigfache Beschwerden von seiten des Herzens, tachykardische Anfälle, Migräneanfälle, Schwindelanfälle, kurzdauernde Bewußtseinstrübungen, flüchtige Herderscheinungen. Vor allem entstehen aber Schlaganfälle und nicht ganz selten auch epileptische Anfälle, bei denen man neben dem labilen Hochdruck meist eine anlagegemäß erhöhte Krampfbereitschaft und oft auch noch Zusatzreize (Alkohol, Blei, Traumen) annehmen muß. Die seelischen Störungen, die uns bei der reinen Hypertonie begegnen, haben gemeinsam den Charakter anfallsartig auftretender, oft nur ganz kurz dauernder, grundsätzlich reversibler Erscheinungen. An Syndromen überwiegen erregte Dämmerzustände, hyperkinetische Bilder und endlich Episoden tiefer Depression.

\section{Präsenile Seelenstörungen}

Unter Präsenium versteht man jene nicht scharf abgrenzbare Zeit, die sich bei Frauen zwischen das Klimakterium und die ersten deutlichen Erscheinungen des senilen bzw. arteriosklerotischen Verfalls einschiebt. Bei Männern wird man den Beginn auf die Zeit des ersten spürbaren Leistungsnachlasses ansetzen müssen. Im übrigen haben wir es hier vorwiegend mit Frauen zu tun, die in dieser Lebensperiode weit häufiger erkranken als Männer. Fehlen auch bei den letzteren die Erscheinungen der sexuellen Involution nicht, so ist das Klimakterium der Frauen doch ein Geschehen, das sich viel deutlicher als Einschnitt in der Lebenskurve abzeichnet und schon in der Breite der Norm fast regelmäßig mit zum mindesten leichteren vegetativen und nervösen Störungen einhergeht. Zugleich werden auch seelisch sehr erhebliche Ansprüche an die verblühende Frau gestellt, die, zumal wenn sie unverheiratet ist, ihre letzten Hoffnungen auf Eheglück entschwinden sieht, aber auch in der Ehe aus verständlichen Gründen eine gewisse Erschütterung ihrer Lage erlebt.

Gerade im Klimakterium sind Depressionszustände sehr häufig, die, auch wenn sie dem manisch-depressiven Irresein angehören, häufig gewisse Eigentümlichkeiten haben. Statt der Hemmung finden wir nicht selten Erregung; häufig ist die Angst besonders ausgesprochen. Paranoide Ideen können sehr ausgeprägt sein, die hypochondrischen Befürchtungen in ihrer Art sich organisch gefärbten annähern. Endlich schließen sich diese Depressionen so häufig an äußere Anlässe an, daß darin kein Zufall gesehen werden kann, um so weniger, als in zahlreichen Fällen auch hartnäckige hysterische und sog. degenerative Züge hervortreten (man sprach früher von Hystero- 
melancholie). Die zeitliche Prognose dieser Fälle ist durchschnittlich schlechter als jene der typischen Bilder, die gleichfalls im Klimakterium beobachtet werden. Früher trennte man die oben gekennzeichneten Depressionen als "Involutionsmelancholie“ vom manisch-depressiven Irresein ab.

Sicher gibt es depressive Psychosen in der Zeit nach dem Klimakterium, die gar nichts mit dem zirkulären Irresein zu tun haben, sondern in den weiteren Bereich der Schizophrenie hineingehören dürften. Sie zeichnen sich durch ihren hartnäckigen Verlauf, eine eigenartige Starre des schließlich verblassenden depressiv-angstvollen Affekts, durch ablehnende, negativistische Züge aus, und gehen in eigenartig leere, wenn auch depressiv gefärbte, Schwächezustände über, in denen Mißtrauen, ein gewisser Autismus, eine Einengung des Horizontes deutlich werden.

Nicht ganz selten treten die negativistischen Züge und zugleich andere katatone Zeichen noch mehr hervor. Auch Wahnbildungen und Sinnestäuschungen von schizoformem Gepräge stellen sich ein. Wir sprechen in diesen Fällen, die abheilen, aber auch in Schwächezustände übergehen können, von Spätkatatonien. Die Beziehungen zur Schizophrenie sind noch nicht gesichert, aber doch wahrscheinlich.

In vielen Depressionen dieser Zeit machen sich zunehmend die Erscheinungen der Arteriosklerose bemerkbar. Die Krankheitsbilder bekommen dann eine entsprechende Färbung. Die Depression selbst heilt, wenn auch oft nach längerer Dauer, unter Umständen erst nach langen Jahren, ab, während die Folgen der arteriosklerotischen Veränderungen in den Erscheinungen einer organischen Persönlichkeitsveränderung fortbestehen.

Endlich sind, vor allem wiederum bei Frauen, paranoide Psychosen in der Zeit nach dem Klimakterium besonders häufig. Inhaltlich spielen Eifersucht wie sexuelle Beeinträchtigungen eine große Rolle. $\mathrm{Zu}$ einem nicht unerheblichen Teil handelt es sich um spät ausbrechende paranoide Demenzen, vor allem aber um paraphrene Prozesse (siehe dort), zum Teil aber auch um paranoische Spätentwicklungen von je paranoider Menschen. In manchen Fällen dürfte die Wahnbildung erst auf dem Boden der beginnenden organischen Hirnveränderungen zustande kommen. Die Prognose dieser Störungen ist ungünstig. Nur in jenen Fällen, deren entscheidende Grundlage eine manische oder depressive Phase ist - dann ist das Krankheitsbild fast immer durch die entsprechende Stimmung und oft durch Hemmung bzw. Erregung und Ideenflucht gekennzeichnet -, folgt die Prognose jener des zirkulären Irreseins.

Scharfe Grenzen gibt es auf diesem ganzen Gebiete nicht. Konstitutionelle endogen-psychotische, organische Faktoren durchflechten sich fast allenthalben. Der einzelne Krankheitsfall kann nur durch Analyse der ursächlichen Faktoren einigermaßen durchsichtig gemacht werden. Daneben freilich dürfte es auch verschiedenartige, seltene spezifische Prozesse geben.

\section{g) Huntingtonsche Chorea}

Die Huntingtonsche Chorea ist ein dominantes Erbleiden. Von den Kindern der Kranken ist durchschnittlich die Hälfte krank. Diejenigen, welche gesund bleiben, haben lauter gesunde Kinder. Die Krankheit könnte aber wohl nur dann ausgemerzt werden, wenn alle Angehörigen von Chorea- 
familien auf Fortpflanzung verzichteten oder doch mindestens alle, die irgendwelche Zeichen von Nervosität darbieten. Die Krankheit selbst beginnt nämlich in der Regel recht spät, überwiegend zwischen dem 31. und 45. Lebensjahr, nicht ganz selten auch schon im dritten Lebensjahrzehnt und bis zum 60. Lebensjahr. Jedenfalls haben die Kranken meist schon Kinder, wenn das Erbleiden unverkennbar in Erscheinung tritt.

Im Vordergrund des Krankheitsbildes steht die über den ganzen Körper ausgebreitete choreatische Bewegungsstörung, die sich mit Koordinationsstörungen kombiniert. Die Hypotonie ist meist geringer als bei der Chorea minor, und wohl im Zusammenhang damit sind auch die choreatischen Bewegungen nicht so blitzartig, langsamer, der Athetose ähnlicher als bei der infektiösen Chorea. Gelegentlich kombinieren sich hypokinetische Erscheinungen mit der Hyperkinese; so kann bei schwerer Chorea Amimie bestehen oder die Hyperkinese kann immer deutlicher akinetischen Erscheinungen Platz machen, ja manche Abkömmlinge aus Chorea-Huntington-Familien zeigen ein von Anfang an langsam fortschreitendes akinetisch-rigides Syndrom.

Psychisch fehlen in seltenen Fällen alle Störungen. Die meisten Kranken sind von je psychopathisch, nervös, erregbar, manche paranoid, sexuell anspruchsvoll, asozial, mürrisch-moros. Im Beginn der Krankheit verstärken sich diese Wesenszüge. Es kommt zu einer ausgesprochenen Stimmungslabilität, und dazu gesellen sich die langsam fortschreitenden Zeichen einer organischen Demenz, zunehmende Stumpfheit bei hervortretenden egozentrischen Neigungen, Merk- und Gedächtnisstörungen, Erschwerung der Aufmerksamkeit, der Auffassung, Urteilsschwäche und Einengung des Horizontes. Anscheinend hängt ein Teil der seelischen Störungen, vor allem das seltsam sprunghafte Denken, das oft inkohärente Züge trägt, mit einer Einstellungsstörung zusammen, die motorisch bedingt ist und zu der allgemeinen Bewegungsstörung gehört. Daneben leidet aber die Kombination, die Verknüpfung seelischen Materials in einheitliche Akte Schaden. In manchen Fällen, in einzelnen Familien bei zahlreichen Angehörigen, entwickeln sich psychotische Bilder, Verfolgungs- und Eifersuchtsideen und halluzinatorische Erscheinungen. Die Stimmung der Kranken ist vorwiegend mürrisch-gereizt, depressiv, selten gehoben, expansiv. Dem entspricht es, daß Größenideen selten sind.

Die Huntingtonsche Chorea nimmt einen langsam progredienten Verlauf, die Bewegungsstörung ebenso wie die Demenz. Motorische und seelische Störungen können aber verschieden schwer bleiben. Eine wirksame Therapie gibt es nicht.

Anatomisch ist die Huntingtonsche Chorea gekennzeichnet durch einen degenerativen Prozeß, der in der Rinde am stärksten die vierte Schicht, vorwiegend aber das subkortikale Grau betrifft, vor allem das Striatum in seinem kleinzelligen Anteil, aber auch das Pallidum und andere subkortikale Zentren sowie den Nucleus dentatus des Kleinhirns.

\section{h) Andere Hirnerkrankungen}

Enzephalitisformen (außer der Encephalitis epidemica)

Die Endhirnenzephalitis (Strümpell-Leichtensternsche Form), die sich bei allen möglichen Infektionen, besonders Influenza, Typhus, Fleckfieber, Endokarditis u. a., sodann im Anschluß an die Impfung, endlich bei schweren 
toxischen Schäden (Salvarsan) entwickeln kann, ist gekennzeichnet durch Kopfschmerzen, Brechneigung, Fieber, allmählich zunehmende Benommenheit, Sopor. Häufig sind Delirien, seltener andere exogene Reaktionstypen. Viele Kranke bekommen epileptiforme Anfälle und andere Reizerscheinungen, insbesondere choreiforme und myoklonische Zuckungen. Es treten auch andere, oft flüchtige Herderscheinungen, Augenmuskellähmungen, Gliedparesen usw., zutage. Der Ausgang ist in vielen Fällen der Tod. Es kommen aber auch, besonders bei den Impfenzephalitiden, häufig Heilungen vor. Gelegentlich führt ein sog. Delirium acutum, eine mit tiefer Bewußtseinstrübung verbundene verworrene Erregung, rasch zum Tode.

Auch die Stammhirnenzephalitis (Wernickesche Polioenzephalitis) kann infektiöser Entstehung sein; vor allem aber führt der Alkoholismus, seltener auch chronischer Mißbrauch von Schlafmitteln der Barbitursäurereihe zu solchen Bildern. Freilich handelt es sich dann nicht um echte Enzephalitis, d. h. Entzündungsvorgänge. Die Störungen hängen vielmehr von eigenartigen Gefäßveränderungen, Wucherung der Gefäßwandzellen, die von Blutungen begleitet sein können, ab. Befallen sind das Mittelhirn um den Aquädukt herum und das Grau, das den dritten Ventrikel einschließt; aber auch Thalamus und Corpus mammillare sind betroffen. Auch hier kommt es zu zerebralen Allgemeinerscheinungen (Kopfschmerzen, Erbrechen, Schwindel), sodann zu Augenmuskelstörungen, Pupillenstörungen, seltener anderen Hirnnervenläsionen, zu bulbärer Sprache, unter Umständen auch Ataxie und anderen subkortikalen Herderscheinungen (Chorea), auf seelischem Gebiete zu Delirien und besonders zur Schlafsucht und unter Umständen zunehmender Benommenheit. Mit der Besserung treten die Symptome des amnestischen Symptomenkomplexes immer deutlicher hervor. Oft begegnen uns im Gefolge der Wernickeschen Enzephalitis vegetative Störungen (Adipositas, Abnahme von Libido und Potenz, Veränderungen des Haarkleides), die wohl auf Schäden im Höhlengrau zurückzuführen sind. Auch diese Enzephalitisform führt nicht selten zum Tode.

\section{Meningitiden}

Neben den eigentlichen meningitischen Erscheinungen (Kopfschmerzen, Überempfindlichkeit gegen Sinnesreize aller Art, Nackenstarre, Trismus, Opisthotonus, Zuckungen) kommt es zu Somnolenz und zunehmendem Sopor und Koma, vielfach mit deliranten Erscheinungen und mit Krämpfen. Dem Ausbruch der akuten Meningitis tuberculosa gehen in vielen Fällen langdauernde Prodromalerscheinungen voraus, besonders bei Kindern, die sich allmählich in ihrem Charakter verändern, mißmutig, unlustig, mürrisch, empfindlich, dabei stumpf, apathisch werden und abends und nachts subdelirant sein können. Auch bei Erwachsenen können durch Monate Reizbarkeit, Verstimmung, Schlafstörungen, Zerstreutheit, Vergeßlichkeit, Müdigkeit, Initiativelosigkeit vorausgehen, bis dann mit den eigentlichen meningitischen Erscheinungen die zunehmende, oft delirante Benommenheit hervortritt. Nicht ganz selten beherrschen anfänglich Herderscheinungen das Bild. Heilungen sind bei der tuberkulösen Meningitis sehr selten. 
Bei der Polysklerose sehen wir schon im akuten Anfang vereinzelt kurzdauernde exogene Reaktionen. Doch geschieht dies sehr selten, wie überhaupt eigentliche Psychosen bei der multiplen Sklerose zu den Ausnahmen gehören. Immerhin kommen, vielleicht im Zusammenhang mit entsprechenden Veranlagungen, affektive Bilder (manische und depressive), paranoide und schizoforme Psychosen gelegentlich vor, und an epileptische Anfälle schließen sich manchmal delirante Erscheinungen an. Im übrigen finden wir im Beginn der multiplen Sklerose oft hysteriforme Störungen und hysterische Überlagerungen. Das ist so zu erklären, daß sich die Patienten oft schon krank fühlen, bevor die neurologischen Symptome erkennbar sind; der Umstand, daß solche Kranke dementsprechend nicht als krank anerkannt werden, veranlaßt sie oft, hysterische Erscheinungen zu produzieren. Später entwickelt sich in schweren Formen immer deutlicher eine Demenz, die freilich meist bescheiden bleibt und sich in Verlangsamung, Erschwerung der geistigen Leistungen, in Merk- und Gedächtnisstörungen äußert. Auffallend ist in der Mehrzahl der Fälle eine gelassene Euphorie, die in seltsamem Gegensatz zu den schweren neurologischen Störungen steht. Immerhin ist damit doch oft Affektinkontinenz vergesellschaftet. Manche Polysklerotische sind auch launenhaft, gereizt, andere mürrisch-depressiv. Im späteren Verlauf sehen wir nicht selten Zwangslachen und Zwangsweinen.

\section{Chorea minor}

Hier stehen Veränderungen der Affektivität ganz im Vordergrund. Die Kranken sind in ganz besonderem Maße für alle affektiven Reize ansprechbar und zeigen dementsprechend auch lebhafte, rasch wechselnde Affekterregungen. Von wildem Zorn können sie sofort zu strahlender Heiterkeit kommen. Durch das Übermaß von Ausdrucksbewegungen, die gern einen vertrackten Charakter annehmen und so nicht mehr ohne weiteres als Ausdruckserscheinungen erkennbar sind, kann das Bild um so mehr den hyperkinetischen Motilitätspsychosen sich annähern, als vielfach auch eine inkohärente Denkstörung besteht und in keinem Falle ein Spontaneitätsverlust vermißt wird,' der die Kranken auch bei starker reaktiver Erregung ruhig im Bette aushalten läßt. Nicht selten folgt dem hyperkinetischen ein akinetisches Stadium nach. Unter den häufigen Psychosen bei Chorea wiegen weitaus Delirien und Amentiaformen vor, welche durch die choreatische Bewegungsunruhe einen besonderen Anstrich bekommen.

Die Chorea minor heilt weitaus in der Mehrzahl der Fälle ab. Betroffen sind viel mehr weibliche als männliche Jugendliche. Bei genauer Untersuchung von Erwachsenen, die ehemals Chorea durchgemacht haben, kann man vielfach noch choreiforme Verlegenheitsbewegungen feststellen. Die Betroffenen klagen selbst darüber, wie auch über eine gewisse Affektübererregbarkeit und gelegentlich selbst übẹr leichte Einstellstörungen beim Denken, die in der Chorea selbst eine erhebliche Rolle spielen. Die Chorea kann sich im Laufe des Lebens mehrfach wiederholen. 


\section{Paralysis agitans}

Hier kommt es zu Erscheinungen des Parkinsonismus, wie sie bei der Encephalitis epidemica beschrieben worden sind. Doch bleiben diese meist milder als dort. Dafür treten oft sehr früh lange sich hinziehende, torpide, hypochondrisch gefärbte Depressionen auf, in denen es manchmal auch zu wahnhaften Deutungen der zahlreichen körperlichen Mißempfindungen kommt. Die Prognose dieser Depressionen ist zweifelhaft; nicht ganz selten kommt es aber zu weitgehenden Besserungen, zum mindesten zu erheblichen Schwankungen. Manische Zustandsbilder sind selten.

Natürlich stellt sich bei vielen von diesen alten Leuten allmählich auch ein seniler Verfall (Demenz, Verwirrtheiten) ein.

\section{Defektzustände mit Athetose}

Abgesehen von der häufigen Beschränktheit bzw. Imbezillität, die auf dem Boden der Grundkrankheit entstanden ist, zeichnen sich die Athetotiker gern durch eine eigenartig heitere, scherzhafte Zufriedenheit, durch Freundlichkeit, Zutraulichkeit, Kindlichkeit, oft verbunden mit einer gewissen Eitelkeit und Selbstzufriedenheit, seltener mit Dreistigkeit, Verschlagenheit, Mangel an Takt aus. Viele machen durch diese Wesenszüge einen beschränkteren Eindruck, als den Prüfungsergebnissen entspricht. Die eigenartige Heiterkeit steht wiederum in grobem Widerspruch zu dem oft schweren neurologischen Krankheitsbild. Erwähnt sei, daß Athetotiker nicht immer schwachsinnig sind.

\section{Hirngeschwülste}

Je früher die Hirngeschwülste erkannt werden, um so weniger häufig werden ausgesprochene seelische Störungen beobachtet werden. Wo es zu deutlichem Hirndruck kommt, fehlt auch eine Beeinträchtigung des Seelenlebens nicht, wenn man nur danach fahndet. $\mathrm{Zu}$ den frühen Erscheinungen gehören bei geeignetem Sitz (besonders Nähe der Zentralregion und Temporalhirn) epileptiforme Anfälle, nicht selten vom Jackson-Typ. Mit dem beginnenden Hirndruck setzt die Bewußtseinsveränderung im Sinne der einfachen Benommenheit ein, die je nach der Schwere des Druckes von den leichtesten Graden der Schwerbesinnlichkeit bis zu tiefer Somnolenz, Sopor und Koma führen kann. Wohl im Gefolge länger dauernder leichterer Hirndruckzustände kommt auch der amnestische Symptomenkomplex häufig vor, nicht selten mit heiterer Grundstimmung. Die genaue Anamnese ergibt bei vielen Tumoren als erste Mahnungen Veränderungen der gemütlichen Erregbarkeit, zugleich mit erhöhter Ermüdbarkeit im Sinne des neurasthenischen Syndroms. Im späteren Verlauf werden vereinzelt auch alle anderen exogenen Syndrome und katatoniforme Zustände beobachtet, während homonome Krankheitsbilder im Sinne melancholischer oder manischer Verstimmungen und paranoischer Zustände zu den Ausnahmen gehören.

$\mathrm{Zu}$ diesen vorwiegend exogenen Syndromen gesellen sich je nach dem Sitz des Hirntumors psychische Symptome, von denen für die Stirnhirntumoren und solche Geschwülste, die auch Stirnhirnwirkungen entfalten, die Moria, der Verlust der Ernstwertung, und Akinese, für die nach hinten gelegenen Tumoren Aphasie, Apraxie und Agnosie genannt werden sollen. 
Balkentumoren machen häufig früh geistige Schwächezustände, Geschwülste der Gehirnbasis (Zwischenhirnwirkungen) Schlafzustände.

Die Lokaldiagnose des Hirntumors ist in der Regel eine rein neurologische. Sie kann vielfach schon früh aus einzelnen neurologischen Lokalsymptomen gestellt werden, wenn die klinischen Hilfsuntersuchungen, besonders Röntgenographie und Enzephalographie, rechtzeitig angewandt werden. Leider sind meist schon die schweren Allgemeinerscheinungen vorhanden: Kopfschmerzen, Pulsveränderungen, Erbrechen, Stauungspapille und dann auch die Anfänge der Benommenheit, wenn ein ernster Tumorverdacht auftaucht.

\section{i) Psychische Störungen bei akuten Infektionen, bei Erkrankungen innerer Organe und bei Allgemeinerkrankungen}

(Symptomatische Psychosen)

Alle erheblichen Umwälzungen im Gesamtorganismus können auch das Seelenleben in Mitleidenschaft ziehen, offenbar dadurch, daß die Schutzkräfte, über die das Hirn für gewöhnlich in reichem Maße verfügt, dauernd oder doch vorübergehend versagen. Insbesondere Allgemeininfektionen und Stoffwechselleiden kommen hier in Frage. Freilich bleibt unser Wohlbefinden durch keinen dieser schwereren Allgemeinschäden ganz unberührt: Abgeschlagenheit, Müdigkeit, Konzentrationsschwierigkeiten, Mangel an Initiative, Unlust und Reizbarkeit, Überempfindlichkeit gegen plötzliche Sinneseindrücke und Schlafstörungen sind die regelmäßigen Begleitsymptome jeder ernsteren Bedrohung der Gesundheit. Wir kennen diese Erscheinungen besonders aus dem Beginn von Infektionen, auch solcher, die nicht mit Organmißempfindungen einhergehen.

Aus diesem Anfangsstadium führen besonders schwere Schäden den geraden Weg über Somnolenz und Koma zum Tode. Bedingungen, die wir im einzelnen noch nicht übersehen, können bei weniger schwerer Schädigung aber auch psychotische Bilder erzeugen, die bei dieser ganzen Gruppe von Erkrankungen bestimmten Syndromen, den sog. exogenen Reaktionstypen Bonhoeffers, entsprechen, nämlich Delirien, Dämmerzuständen, Amentiabildern, Halluzinosen, dem amnestischen Symptomenkomplex und, in mildester Gestalt, dem hyperästhetisch-emotionellen Schwächezustand, d. h. der echten Neurasthenie. Bei deren Entstehung spielen unter anderem sicherlich persönliche Eigentümlichkeiten eine gewisse Rolle. So gibt es Menschen, die mehrfach im Leben im Anschluß an verschiedenartige äußere Schäden die gleichen exogenen Reaktionstypen bekommen, und wir finden dann gelegentlich, daß eine solche Reaktionsbereitschaft auch bei Blutsverwandten vorkommt. Auf der anderen Seite wissen wir, daß manche Infektionen, etwa Diphtherie und Tetanus, niemals exogene Syndrome zur Folge haben, obgleich sie ja sonst sehr erhebliche nervöse Wirkungen entfalten können, andere dagegen sehr häufig, etwa Typhus und Chorea. Weiter ist nicht zu bezweifeln, daß manche Allgemeinschäden mit Vorliebe ganz bestimmte Syndrome oder doch symptomatische Psychosen mit ganz bestimmter Färbung zur Folge haben, wie etwa wiederum die Chorea oder auch 
die Tuberkulose, die Urämie und die akute gelbe Leberatrophie. Am deutlichsten wird dies bei den akuten Alkoholpsychosen, die bestimmt auf dem Umwege über körperliche Allgemeinschäden zustande kommen, aber dennoch ihr recht kennzeichnendes Gesicht behalten. Auf jeden Fall haben wir es mit schwer entwirrbaren Verhältnissen zu tun, unter denen persönliche Eigenart, Art, Schwere, Einsatztempo und wahrscheinlich auch Angriffspunkt der Störungen eine Rolle spielen.

Bis auf den emotionell-hyperästhetischen Schwächezustand und die Halluzinose finden wir bei allen exogenen Reaktionstypen die Zeichen des allgemeinen Hirnschadens in Veränderungen des Bewußtseins und der mnestischen Funktionen, und selbst bei den genannten Schwächezuständen und der Halluzinose sind noch kaum merkliche Verdünnungen dieser Störungen nachweisbar.

Über die exogenen Syndrome ist im allgemeinen Teil nachzulesen.

\section{Infektionskrankheiten}

Fast alle Infektionskrankheiten führen gelegentlich zu symptomatischen Psychosen. Eine Ausnahme machen nur Diphtherie und Tetanus, während andere Krankheiten besonders auch das Seelenleben in Mitleidenschaft ziehen, insbesondere der Typhus abdominalis, aber auch das Fleckfieber. Zahlenmäßig ist ferner die Grippe stark beteiligt, aber wohl nur deshalb, weil in Epidemiezeiten nur wenige Menschen von dieser Infektion verschont bleiben und damit auch sehr viele symptomatisch labile Personen krank werden. Die Pneumonie geht gern mit Delirien einher, besonders die Pneumonie der Alkoholiker, die viele Pneumoniekandidaten stellen und deren Delirien dann gern eine alkoholische Färbung annehmen.

Während der Infektion selbst haben die symptomatischen Psychosen meist den Charakter des Deliriums, das mit der Fieberbewegung schwerer und leichter wird. Doch können auch Amentiabilder, Dämmerzustände, Halluzinosen während der Infektion selbst beginnen. Meist fällt deren Einsatz aber in die Zeit der Entfieberung oder sie beginnen im Ausgang der Fieberperiode. Auch in dieser Zeit aber, besonders nach sehr schweren Infektionen, sehen wir manchmal noch Delirien, sogenannte Kollapsdelirien. Sehr häufig sind die flüchtigen Delirien der Kinder bei den akuten Exanthemen. Auch das Erysipel macht gern Delirien, insbesondere wenn es sich im Bereiche des Gesichts und des behaarten Kopfes abspielt. Bei der Malaria kommt es zu deliranten Episoden gern im Fieberanstieg und auf der Höhe des Fiebers, gelegentlich aber auch erst im fieberfreien Intervall und nach Abschluß der Fieberzeit. Vereinzelt entstehen Delirien auch schon, bevor der erste Fieberanfall einsetzt.

Bei septischen Erkrankungen besteht regelmäßig Benommenheit, zum mindesten leichten Grades. Fehlen der Benommenheit soll Sepsis ausschließen lassen. Daneben sehen wir auch Delirien und andersartige symptomatische Psychosen.

Eine gewisse Eigenart haben die nicht seltenen symptomatischen Psychosen bei Gelenkrheumatismus insofern, als sie gern unter dem Bild einer unlustig stuporösen Benommenheit mit auffallender Körperschwäche und wechselnd starken deliranten Erlebnissen verlaufen und häufig Monate 
anhalten, um über einen ganz leicht umdämmerten euphorischen Zustand abzuklingen. Im Beginn des Gelenkrheumatismus sehen wir gelegentlich epileptiforme Erregungen und kurzdauernde Dämmerzustände. Die symptomatischen Psychosen bei Grippe haben auffallend häufig einen depressivängstlichen Anstrich. Hier scheinen auch rein depressive Bilder vorzukommen, die nicht bloß ausgelösten endogenen Psychosen entsprechen. Der Keuchhusten führt wohl nicht als solcher zu symptomatischen Psychosen, wohl aber entstehen in seinem Verlauf mitunter Blutungen im Hirn und in den Hirnhäuten und damit zerebrale Herderscheinungen, auch epileptiforme Anfälle.

Selten sind die eigentlichen symptomatischen Psychosen bei Tuberkulose, außer bei den Meningitiden und den akuten ausgedehnten pneumonischen Erkrankungen. Wohl aber führt die Tuberkulose zu Abnormisierungen, die teils durch das chronische, zur Untätigkeit zwingende Kranksein und die damit verbundenen Milieuschäden bedingt sein mögen (Probleme des Zauberbergs), teils aber doch wohl einer spezifischen toxischen Noxe ihren Ursprung verdanken. Hier ist die leichtfertige, oft erotisierte Euphorie der Tuberkulösen zu nennen, die besonders bei schwerer Kranken auch subfinal beobachtet wird, oft im Wechsel mit nörgeliger, mißmutiger und empfindlicher Gereiztheit, die auch allein vorkommen kann. Dabei ist zu berücksichtigen, daß sehr viele Tuberkulöse von je psychopathische Menschen sind. Die psychische Symptomatologie der Miliartuberkulose entspricht, soweit es nicht zur Meningitis kommt, jener der Sepsis.

Die Lyss a führt, noch bevor die neurologischen Erscheinungen deutlich werden, zu Zuständen ängstlicher Unruhe und tiefer Niedergeschlagenheit, die allmählich einer immer zunehmenden Überempfindlichkeit auf allen Sinnesgebieten weichen. Unter Fieberanstieg entstehen dann die charakteristischen Schlingkrämpfe und Erstickungsanfälle, die mit immer wiederkehrenden angstvoll wilden Erregungen, Fortdrängen, Sichanklammern, Toben und sinnlosem Schreien einhergehen können. Allmählich trübt sich dann das Bewußtsein; Delirien, Verwirrtheiten treten auf, anfänglich noch mit Erregung, später mit zunehmender Lähmung, in der schließlich der Tod eintritt. Das Ganze spielt sich in wenigen Tagen ab. Die durch Impfung abgeschwächten Infektionen haben vielfach entsprechend mildere seelische Begleiterscheinungen. Bei der allgemein verbreiteten großen Angst vor der Wutkrankheit sind psychogen-hysterische Bilder nach Hundebissen nicht selten.

\section{Erkrankungen innerer Organe}

Herzerkrankungen sind besonders häufig bei alternden Menschen, und manches, was man dem kranken Herzen zuschreibt, geht tatsächlich auf Rechnung der Hirnarteriosklerose oder aber der Urämie oder der Lues. Immerhin sind die Herzkranken häufig egozentrisch, launenhaft, reizbar, schreckhaft, verdrossen, von leicht ängstlicher Unruhe, von ängstlichen Träumen geplagt. Kommt es zu Psychosen, dann nehmen diese meist den Charakter ängstlicher Delirien an, die mit dem Grade der Dekompensation Schwankungen unterliegen. Ängstlich-delirante Erscheinungen sind es auch, die andere im Ablauf begriffene Psychosen von Herzkranken (Manie, Depression) färben können. Nicht ganz selten kommt es zu längerdauernden 
ängstlich-deliranten oder amentiellen Bildern nach rascher Ausschwemmung von Ödemen und Stauungserscheinungen.

Die Zusammenhänge zwischen Magen-Darmerkrankungen und exogenen Psychosen sind noch gänzlich unklar. Akute Enteritiden sind wie kaum andere Körperleiden geeignet, Mattigkeit, Schlaffheit, Schlafneigung, Konzentrationsstörungen herbeizuführen zusammen mit starken Unlustgefühlen. Regelmäßig ist auch der Ikterus von Müdigkeit, Apathie, Mangel an Initiative begleitet, wobei zugleich eine gewisse Reizbarkeit bestehen kann. Kommt es im Zusammenhang mit Ikterus zu Delirien, verworrenen Erregungen, Krämpfen, dann handelt es sich fast immer um akute gelbe Leberatrophie, die ganz ohne seelische Störungen wohl nie abläuft.

Urämie. Bei der echten Urämie (Harnstoffretention) sehen wir Zustände der Initiativelosigkeit, geistige Schwäche, Stumpfheit, Verlangsamung, die allmählich sich vertiefend und unter leichten motorischen Reizerscheinungen zu Benommenheit, Sopor und Tod führen. Gelegentlich entstehen matte Delirien. Manche Urämische sind von einer stumpfen Euphorie beherrscht. Der körperliche Verfall, Abmagerung, Kachexie, braune Zunge, urinöser Geruch, Erbrechen, Magendarmerscheinungen stehen im Vordergrund. Selten sind einzelne epileptische Anfälle.

Demgegenüber handelt es sich bei der Pseudourämie um Störungen des Gefäßsystems, die mit Nierenerkrankungen aller Art einhergehen, Hirndruck- und Stauungserscheinungen auf der einen, ischämische Störungen auf der anderen Seite. Der epileptiforme Krampf beherrscht die Krankheitsbilder. Ihm gesellen sich Dämmerzustände von epileptischer Färbung; aber auch andere exogene Bilder der verworrensten Prägung vom Delir bis zur Amentia, von der epileptiformen Erregung bis zum halluzinatorischen Paranoid. Alle diese Syndrome zeigen Schwankungen. Es kann immer wieder zu Zeiten relativer Aufhellung und geordneten Verhaltens kommen, in denen freilich die nähere Untersuchung zum mindesten leichte Zeichen des amnestischen Symptomenkomplexes aufdeckt. Sehr häufig begegnen wir bei den akuten und chronischen Pseudourämien zerebralen Herderscheinungen der verschiedensten Art.

\section{Allgemeinerkrankungen}

Die Erschöpfung als solche führt zu eigentlichen Psychosen nicht. Im Zusammenhang mit erschütternden seelischen Erlebnissen kann es jedoch zu psychogenen Erregungen und Dämmerzuständen kommen, wie sie etwa im Kriege nicht selten waren, um sehr rasch abzuklingen. Bei schizoiden Persönlichkeiten treten vereinzelt auch schizoforme reaktive Psychosen von kurzer Dauer auf (schizoider Reaktionstyp). Erscheinungen der echten Neurasthenie (s. o.) sind in der Erschöpfung nicht selten dann, wenn Überanstrengung und chronische gemütliche Belastungen, womöglich auch noch verbunden mit Nikotin- und Alkoholabusus, zusammentreffen.

Eigentliche Psychosen entstehen häufig beim Zusammentreffen von Erschöpfung mit Inanition (Belagerung von Przemysl, Hungersnöte): leichte psychische Erregung mit mangelnder Konzentrationsfähigkeit, dann Umdämmerung, Schwerbesinnlichkeit, Desorientierung, Delirien, die meist eigenartig apathisch sind. In Rußland ist es in den Hungersnöten des letzten Jahrzehnts zu Nekrophagie, ja zu Menschenfresserei gekommen. 
Eine zunehmend große Bedeutung haben die symptomatischen Psychosen bei der perniziösen Anämie, besonders in deren subfinalen Stadien, die oft mit benommener, manchmal heiter gefärbter Erregung, Delirien, aber auch mit chronisch sich hinziehenden ängstlich-paranoiden Bildern einhergehen können. Bei leichteren Perniziosaerkrankungen überwiegen demgegenüber depressive Psychosen, denen alle exogenen Züge fehlen können. Ja, solche Depressionen gehen manchmal der Blutkrise voraus und sie heilen mit der Leber-Magentherapie ab. Selten sind zirkuläre Verläufe, etwas häufiger chronische paranoide Psychosen, die auch die Besserung des körperlichen Befundes überdauern können. In der Regel finden wir bei den psychotischen Begleiterscheinungen der Blutkrankheit auch die Symptome einer leichteren oder schwereren funikulären Myelose.

Bei akuten schweren Blutverlusten habe ich als Truppenarzt vereinzelt verworrene ängstliche Erregungen gesehen. Alle diese Verwundeten sind noch auf dem Verbandplatz oder auf dem Transport gestorben. Auch bei reichlichen Magenblutungen kommen vereinzelt exogene Bilder vor.

Pella gra. Die Pellagra, die zu eigenartigen Hautveränderungen (Hände, Nase, Hals, Fußrücken), erst Rötung und Schwellung, dann Schuppung, besonders im Frühjahr und Herbst, führt, hat sonst vieles mit der Perniziosa gemein; Magendarmstörungen, endokrine Anomalien, funikuläre Erscheinungen. Psychiatrisch hat sie eine noch größere Bedeutung. Nicht selten sind hysteriforme Bilder, vor allem aber außerordentlich bunte exogene Psychosen von vorwiegend amentiellem Anstrich, die bald mehr delirantes, bald mehr halluzinoseartiges Gepräge annehmen und gern mit Selbstmordideen, Drangzuständen und gelegentlichen epileptiformen Erregungen einhergehen. In den Inhalten spielen Feuer, Brennen, Wasser eine große Rolle. Schließlich kann es zum amnestischen Symptomenkomplex von inkohärent-delirantem Typ und dann zum Tode kommen. Die Pellagra ist gerade in Anstalten nicht selten. Sie gibt dann den meist schizophrenen Grundprozessen einen exogenen Anstrich.

Beim Karzin om, besonders gern bei jenen des Rektums, überhaupt des Magendarmkanals, entstehen, wohl im Zusammenhang mit Inanition, Kachexie und Vergiftung durch toxische Zerfallsprodukte der Geschwülste, nicht ganz selten matte Delirien, die auch zuerst postoperativ auftreten können. Auch dämmerige Erregungen kommen vor, seltener andere Bilder. Im allgemeinen sind es nur sehr schwere Operationen, die zu Psychosen führen, und auch von diesen tut es nur ein verschwindender Prozentsatz.

\section{Stoffwechselerkrankungen}

\section{Endokrine Störungen}

Der Basedow, der in der Regel bei von je nervösen Menschen auftritt, unter Umständen in ursächlichem Zusammenhang mit starken gemütlichen Erregungen, führt regelmäßig zu einer seelischen Abnormisierung: innere Unruhe, Hast, Überempfindlichkeit gegen Sinnesreize aller Art, Konzentrationserschwerung, Stimmungsänderung, Affektlabilität, insbesondere Reizbarkeit, Erregbarkeit mit jähen Schwankungen im Sinne übertriebener Heiterkeit. Auf dem Boden dieser Veränderung kommt es nicht selten zu hysterischen und anderen psychogenen Erscheinungen. Darüber hinaus scheint der Basedow 
geeignet, Phasen des manisch-depressiven Irreseins auszulösen, insbesondere manische Syndrome, die freilich eine Note der unruhigen Basedowhast gern behalten. Auch depressive Erregungen sind nicht selten. Schließlich kann der Basedow in seinen schweren Formen, besonders gegen Ende des Lebens, zu schweren exogenen Reaktionstypen vom Charakter bunter Delirien und schwerer amentieller Verwirrtheit, oft mit katatonen Zügen, führen, welche lange Zeit einen manischen Anstrich behalten können. Schwere exogene Psychosen bei Basedow sind fast immer als schlechtes prognostisches Zeichen zu werten.

Beim Myxödem beherrscht außerhalb der nicht sehr häufigen akuten Psychosen die Verlangsamung alles seelischen Geschehens das Krankheitsbild, meist auf dem Hintergrund eines apathisch-müden, vielfach etwas mürrischen Gemütszustandes. Beim Fortschreiten der Krankheitserscheinungen kommt es dann zu zunehmender Somnolenz und gelegentlich mit Krämpfen zu Koma und zum Tode. Manchmal schieben sich auch Erregungen ein. Besonders bei interkurrentem akutem Myxödem, wie es bei klimakterischen Frauen im Zusammenhang mit erheblichen Belastungen des Körpers auftritt, entstehen mitunter rasch abklingende Halluzinosen und delirante Zustände, die mit und ohne Erregung ablaufen können. Vereinzelt sind auch andere exogene Reaktionstypen beschrieben worden. Bei den zirkulären Bildern handelt es sich wohl meist um ausgelöste Phasen des manisch-depressiven Irreseins.

Bei schwerer Tetanie sind epileptiforme Anfälle nicht selten. Auch hysterische Krämpfe kommen bei tetanisch Stigmatisierten vor, bei denen die Hyperventilation rasch zu tetanischen Krämpfen führt. Manche Hysterische benützen ihre tetanische Bereitschaft, um durch Hyperventilation sehr eindrucksvolle Krampfbilder zu demonstrieren. Umgekehrt können sich Tetaniebereite, die es im Leben nicht leicht haben, nur schwer von hysterischen Manifestationen freihalten. Bei schweren, dann meist tödlichen Tetanien (insbesondere postoperativen) sind zwei Typen exogener Psychosen beobachtet worden, einmal Zustände einfacher zunehmender Benommenheit, in denen die Inanspruchnahme zu mürrisch-gereizter Abwehr führt, sodann Bilder vom Typ der Amentia von manisch-inkohärentem Anstrich, mit wilder Erregung und rapiden Affektbewegungen.

Hypophyse. Hypophysenstörungen sind oft Symptome von Neubildungen, die ihrerseits zu zerebralen Allgemeinerscheinungen führen. Die dann entstehenden Syndrome haben mit der Hypophyse selbst wohl wenig zu tun. Immerhin verbindet sich die Dystrophia adiposo-genitalis gern mit heiter-gelassener, etwas indolenter Gesamtverfassung, die bei größerer Lebhaftigkeit auch scherzhaft-humorvoll, erethisch werden kann. Akromegale sind eher moros, langsam, verhaltener, zum Teil auch sehr reizbar. Bei den seltenen Fällen hypophysärer Kachexie (Atrophie des Vorderlappens) sieht man Stumpfheit und Mangel an Initiative).

Beim Addison bilden Muskelschwäche, Müdigkeit und hochgradige Ermüdbarkeit, depressive Grundstimmung und Überempfindlichkeit gegen Sinnesreize den Hintergrund der seltenen exogenen Psychosen von meist delirantem Gepräge, für die wohl nicht der Addison als solcher, sondern die Grundkrankheit verantwortlich ist.

Kastration. Man hat früher fälschlich Beziehungen des Keimdrüsenverlustes zur Epilepsie angenommen. Solche bestehen bestimmt nicht. Die 
Kastration kann ganz ohne sichtbare Folgen bleiben. Meist verlieren die Betroffenen aber an Initiative, sie werden ermüdbarer und kommen oft in neurasthenische Störungen und depressive Verfassungen hinein, die zum Teil mit dem endokrinen Verlust zusammenhängen, zum Teil aber auch erlebnismäßig bedingt sind. Schwere nervöse Störungen treten sehr bald nach der Kastration wohl nur bei von je psychopathischen und neuropathischen Menschen auf. Aber auch bei vielen anderen kommt es um das 40. Lebensjahr herum zu Erscheinungen, die denen des schweren weiblichen Klimakteriums gleichen. Zur Auslösung von endogenen Psychosen führt die Kastration nicht.

Diabetes. Anlage zu Diabetes und zu zirkulärem Irresein treffen nicht ganz selten bei einem Menschen zusammen. Diabetes ist in der Aszendenz Zirkulärer, manisch-depressives Irresein in jener von Diabetischen nicht selten. Ich halte einen inneren Zusammenhang für wahrscheinlich. VieleZirkuläre haben erhöhten Blutzucker und scheiden in der Depression vorübergehend Zucker aus. Umgekehrt sehen wir beim Diabetes nicht ganz selten Depressionen, die Schwankungen entsprechend der Schwere des Diabetes zeigen. Auch ein Vikariieren von Zuckerausscheidung und Depression ist beschrieben worden.

Diabetes ist eine Erkrankung vor allem der höheren Altersstufen. Exogene Zustände, die sich bei den alten Leuten finden, sind daher wohl oft nicht Ausdruck des Diabetes, sondern der Arteriosklerose, gelegentlich auch der Hirnlues. Doch kommen bei diabetischer Polyneuritis, selten, paralyseähnliche Bilder vor, die bei geeigneter Behandlung verschwinden können. Als Einleitung des Komas beobachtet man vereinzelt ängstlich-delirante Unruhezustände. Auch die Insulintherapie, die zu Hypoglykämie führt, kann Bewußtseinsveränderungen erzeugen und schwankende exogene Reaktionstypen mit unterhalten.

Die Fettsucht vom Dercumschen Typus ist sehr häufig von neurasthenischen Störungen begleitet, auf die sich gern hysterische Bilder aufpfropfen.

Für die Zusammenhänge zwischen Gicht und zirkulärem Irresein gilt Ähnliches wie für den Diabetes. Ganz unabhängig davon geht bei manchen Gichtikern dem Anfall ein depressives Stadium voraus, in dem die Schmerzen sich anmelden. Ich habe ferner bei Depressiven Gichtanfälle erlebt, die zu einer schlagartigen Besserung der Melancholie führten.

Sauerstoffmangel. Der Sauerstoffmangel, wie er bei Lungenerkrankungen, besonders aber bei Erstickung (Lawine, Strangulation) auftritt, kann ohne für den Kranken erkennbaren U̇bergang plötzlich zu Bewußtlosigkeit führen. Der Lufthunger bringt aber häufiger langsam zunehmende quälende Angst mit sich. Beim Erwachen aus der Bewußtlosigkeit nach Lawinenverschüttung und Strangulation kommt es zunächst zu Muskelzuckungen, oft auch zu epileptischen Krämpfen, dann zu starker Jaktation mit Fortdrängen, Abwehr, einförmigen, ausfahrenden Greif- und Wischbewegungen, sodann zu unruhiger Verwirrtheit. Allmählich oder rasch hellt sich dann das Bewußtsein auf; aber es bleiben zunächst noch Müdigkeit und Schlafbedürfnis. Die Verwirrtheit, die einem epileptischen Dämmerzustand weitgehend ähneln kann, dauert in manchen Fällen längere Zeit. Nach Strangulationen bleiben manchmal schwere zerebrale Störungen zurück.

In erheblichem Maße verminderter Luftdruck (in großen Höhenlagen, wie sie beim Fliegen erreicht werden) führt gleichfalls, z. T. sicher auf dem Wege über den Sauerstoffmangel, zu seelischen Veränderungen neben den 
körperlichen Störungen der Bergkrankheit (Zittern, Ataxie, Übelkeit, Erbrechen, Zyanose). Es kommt, bald eher, bald später, zu Schläfrigkeit, Apathie, Unlust, manchmal auch zu läppischer Heiterkeit. Die Gedächtnisfunktionen leiden ebenso wie die höheren geistigen Leistungen. Vielleicht spielt neben der Sauerstoffnot auch die Steigerung des Liquordrucks, die dem Sinken des Luftdrucks parallel geht, eine Rolle.

\section{Generationsphasen}

Die Menstruation führt bei vielen Frauen zu Mißempfindungen, aber auch zu Niedergeschlagenheit, Reizbarkeit, Erregbarkeit, Überempfindlichkeit gegen Sinnesreize, auf der anderen Seite zu Müdigkeit und Schlaffheit, so daß die gewohnte Leistungsfähigkeit vor und während der Blutung nicht erreicht wird. Bei einem Bruchteil der Frauen stellt die Menstruation jeweils Höhepunkte der Frische und des Wohlbefindens dar. Psychopathische Reaktionsbereitschaften treten nicht selten gerade während der Menses und vorher sehr deutlich zutage. Die Selbstmordneigung ist während der Menstruation erhöht. Eigentliche menstruelle Psychosen gibt es nicht. Wohl aber zeigen im Ablauf begriffene Erregungen während der Menses häufig Exazerbationen, und epileptische Anfälle treten gerade um die Zeit der Menses gern ein. In der Menarche, dann wieder im beginnenden Klimakterium können schleichende Prozesse ausschließlich während der Menstruationszeit grobe Erscheinungen machen, so daß der Eindruck menstrueller Psychosen entsteht. Früher oder später verrät sich aber die ursächliche Unabhängigkeit der Störungen von den mit der Blutung verbundenen Umwälzungen im Körperhaushalt.

Gravidität. Geisteskrankheiten während der Schwangerschaft sind nicht häufig. Immerhin können zirkuläre Depressionen, seltener manische Erregungen, sodann auch Schizophrenien in der Schwangerschaft ausbrechen und Epilepsien eine Verschlimmerung erfahren oder aber sich bessern. Dabei sind gerade die letzten Monate vor der Geburt bevorzugt, jene Monate, in denen auch Polyneuritiden und Eklampsie sich einzustellen pflegen. Gewisse ursächliche Beziehungen sind darnach nicht auszuschließen. Es kann aber keine Rede davon sein, daß die Schwangerschaft eine irgendwie entscheidende Hilfsursache für die Entstehung endogener Psychosen darstellt. Dagegen sind leichte Verstimmungen, die den Gemütsschwankungen im Bereiche der Norm entsprechen, bei Graviden sehr häufig. Bei ungewollter Gravidität endlich kommt es zu mannigfachen psychogenen Störungen, Erregungen, hysterischen Stürmen, reaktiven Depressionen. Die letzteren können so schwer werden, mit so hartnäckiger Nahrungsverweigerung und schließlich Inanition einhergehen, daß, in ganz seltenen Fällen, Unterbrechung der Schwangerschaft angezeigt sein kann, weil das Leben der Graviden gefährdet ist. Hervorgehoben werden muß aber, daß auch bei ungewollter Schwangerschaft, besonders also bei illegitimer Schwängerung, sehr häufig mit den ersten Kindsbewegungen die mütterlichen Regungen alle seelischen Nöte überwinden und die Abwehr einer natürlichen freudigen Erwartung des Kindes Platz macht.

Bestehende chronische Psychosen werden in der Regel durch die Generationsphasen nicht beeinflußt. 
Bei der immer sehr ernsten Polyneuritis kommt es in einem beträchtlichen Prozentsatz der Fälle zu exogenen Psychosen, besonders zu ängstlichen Delirien mit nachfolgendem Korsakow. Im Verlauf der Chorea gravidarum treten wie bei der infektiösen Chorea manchmal amentielle Psychosen auf, besonders dann, wenn die Krankheit stürmisch und ernst verläuft.

Eklampsie. Besonders die schweren Formen dieses Leidens führen zu exogenen Reaktionstypen, die Stunden, wenige Tage, aber auch mehrere Wochen dauern können und die oft eine Ähnlichkeit mit epileptischen Psychosen zeigen. Meist entstehen die Psychosen erst nach dem Sistieren der Anfälle aus dem posteklamptischen Koma heraus oder nach einem kurzen Intervall. Im ganzen sind sie nicht häufig (5-10\% der Fälle). Die meisten exogenen Reaktionstypen dieser Art kommen wegen ihrer kurzen Dauer überhaupt nicht in psychiatrische Beobachtung. Nach Abklingen der Psychosen bleiben nicht selten vorübergehende hyperästhetisch-emotionelle Schwächezustände zurück. Das amnestische Syndrom ist demgegenüber selten. Während der Geburt treten manchmal Ohnmachten ein. Vereinzelt sehen wir auch psychogene Erregungen und ängstliche hysterische Verwirrtheitszustände, in denen es auch einmal zu Angriffen auf das Leben des Kindes kommen kann. Man hüte sich aber, etwa bei jeder Kindstötung unter der Geburt oder unmittelbar nachher krankhafte Zustände anzunehmen, die im ganzen sehr selten sind.

Im Puerperium entstehen relativ am häufigsten geistige Störungen. In der Mehrzahl der Fälle handelt es sich um endogene Psychosen, die von den Umwälzungen des Puerperiums ausgelöst sind. Die schizophrenen Psychosen sind dann oft katatoner Natur und haben eine relativ gute Prognose, die Melancholien erscheinen ängstlich erregt, die Manien verworren. Vielleicht haben wir hier Einflüsse des Puerperiums vor uns. Im Zusammenhang mit den Infektionen im Puerperium, wohl auch mit autointoxikatorischen Zuständen, treten relativ häufig Amentiabilder auf, in denen oft katatone Symptome vorherrschen. Die Differentialdiagnose bleibt in solchen Fällen in der Regel lange Zeit hindurch sehr schwierig. Entsprechend dem Seltenerwerden der Wochenbettinfektionen sind auch die typischen amentiellen halluzinatorischen Verworrenheiten der Wöchnerinnen in starkem Rückgang.

Für die Lakt ation lassen sich bestimmte Angaben nicht machen. Immerhin scheinen endogene Psychosen eher im Beginn als am Ende der Laktationszeit auszubrechen. Daß stillende Frauen gelegentlich eifersüchtig werden, hat mit dem biologischen Vorgang der Laktation nichts zu tun. Es handelt sich hier um verständliche Reaktionen.

\section{k) Alkoholismus}

\section{Der akute Rausch. Pathologische Rauschustände}

Die Erscheinungen des gewöhnlichen Rausches dürfen im wesentlichen als bekannt vorausgesetzt werden: Wohlbehagen bei Verflachung und Erschwerung aller eigentlichen geistigen Tätigkeit und Steigerung der Erregbarkeit, weiterhin Beeinträchtigung der koordinatorischen Leistungen, insbesondere auch der Sprache, bei zunehmender geistiger Lähmung, in der lange 
Zeit noch Reizbarkeit und Erregbarkeit fortbestehen, bis schließlich auch hier die Narkose zur Lähmung und damit zum narkotischen Schlaf führt. Wer häufiger trinkt, weiß, daß er recht verschiedene Mengen Alkohol braucht, um berauscht zu werden, in Abhängigkeit wohl vom Allgemeinzustand, vom Grad der Ermüdung, von der Stimmung und der Witterung, sowie daß schon lange vor dem "gewohnten Maß" die Zunge schwer wird und die Gedanken nicht mehr gehorchen. Er weiß aber auch, daß einzelne Trinkkumpane regelmäßig schon nach sehr kleinen Mengen Alkohol schwer betrunken werden, alkoholintolerant sind, sei es, daß die den Geist lähmenden Wirkungen rasch hervortreten, sei es, daß die motorische Koordination schnell versagt. Endlich gibt es Menschen, die häufig, wenn auch nicht regelmäßig, bei mehr oder weniger großen Mengen schwer erregt und zugleich auch bewußtseinsgetrübt werden. Sie gelangen in Zustände, die den Erregungsstürmen mancher erregbarer Psychopathen gleichen und von epileptiformen oder hysterischen Erregungen nicht recht zu unterscheiden sind. Besonders die von Bonh oeffer sogenannten epile ptifor men Erregungen, die nur ganz kurze Zeit, aber auch einmal Stunden andauern können und volle Amnesie oder doch eine sehr lückenhafte Erinnerung hinterlassen und in tiefem Schlaf enden, sind deshalb bedeutungsvoll, weil aus ihnen heraus nicht selten Gewalttaten gegen Kumpane oder Schutzleute (Blaukoller) oder auch blindes Wüten gegen die sachliche Umgebung (Zertrümmern des Mobiliars in Arrestzelle oder Krankenzimmer) zustande kommen. Es handelt sich vielfach um alte Säufer (hier überwiegt die Bewußtseinstrübung und es kommt zur Verkennung der Umgebung, zum Orientierungsverlust, ja gelegentlich auch zu einzelnen halluzinatorischen Erlebnissen und zu Angst [deliranter Rausch]), um Hirngeschädigte (Traumatiker), Menschen mit leichter Arteriosklerose, um Epileptiker und vor allem um erregbare, hysterische Psychopathen, die solche krankhaften Räusche bekommen. In den letzteren Fällen überwiegt die sinnlose Erregung bei einfachem Orientierungsverlust und Enthemmung primitiver triebhafter Einstellungen (eigentlicher epileptoider Rausch). Bei solchen Menschen gibt es daneben aber auch „,normale“ Räusche, wie auf der anderen Seite bei Leuten, die für gewöhnlich Alkohol gut vertragen, unter besonderen Umständen (große Hitze, starke Überanstrengung, erregende Erlebnisse, Rekonvaleszenz) einmal ein solcher epileptiformer Rausch sich überraschend einstellen kann. Als krankhaft im Sinne des $§ 51$ StGB., Abs. 1, wird man solche Räusche ebenso wie den einfachen sehr schweren Rausch dann betrachten, wenn sie Amnesie hinterlassen. Man sei aber vorsichtig, weil mancher Rechtsanwalt seinen Klienten entsprechend berät. Wo man nicht Augenzeuge war oder Gelegenheit zur Befragung unmittelbar nach dem Rausch hatte, überlasse man das Gutachten dem Sachverständigen. Die Bestrafung eines wegen sinnloser Betrunkenheit Unzurechnungsfähigen erfolgt nach $\S 330$ a StGB. (vgl. hierzu Abschnitt D).

\section{Der chronische Alkoholismus}

Von Alkoholismus als Krankheit spricht man erst dann, wenn der gewohnheitsmäßige Alkoholgenuß zu körperlichen oder seelischen Schäden oder, meist, beiden geführt hat. Unter dem Einfluß unserer Trinksitten wurden in 
Vorkriegszeiten sehr zahlreiche Menschen zu Alkoholikern, viele aus besonderen Anlagen heraus, aus "Alkoholsucht ${ }^{66}$, aus chronischen mißmutigmorosen depressiven Verfassungen, die durch Alkohol gemildert werden, aus Haltlosigkeit, aus allgemeinem Reizhunger, viele aber auch aus dem berufsmäßigen Trinken selbst heraus (Wirte, Kellner, Brauer, Destillateure, Kutscher, Maurer) bei ursprünglich nicht psychopathischer Anlage, ja gerade Menschen, die bei heiterer, geselliger Veranlagung den Sorgenbrecher Alkohol und den Alkohol als Wegbereiter zu menschlichen Beziehungen eigentlich gar nicht brauchen. So gewiß also zahlreiche Trinker von jeher abnorme Persönlichkeiten sind, so gibt es doch auch solche, für die dies nicht gilt. Gerade jene Trinker, die dem Delirium tremens verfallen, sind häufig ursprünglich nicht psychopathische Menschen.

Der gewohnheitsmäßige Alkoholmißbrauch (auch hier gibt es natürlich erhebliche individuelle Verschiedenheiten) führt zunächst einmal mancherlei Organschäden herbei. Besonders der Kreislauf leidet (Herzhypertrophien und -erweiterungen, besonders bei Biertrinkern, Herzparenchymschädigungen bei Schnapstrinkern, Hautgefäßlähmungen [Weinfahne] bei Weintrinkern), nicht selten auch die Niere, sodann aber vor allem die Leber (Fettleber, Leberzirrhose). Immer besteht Magenkatarrh.

Fast immer kommt es bei Biertrinkern zur Fettsucht, bei Schnapstrinkern oft zu erheblicher Magerkeit, vielleicht in Abhängigkeit von der Schädigung vegetativer Zentren. Endlich leidet das periphere und zentrale Nervensystem Schaden: selten vermißt man leichtere oder schwerere Formen der Polyneuritis (Druckschmerzhaftigkeit der Nervenstämme und der Muskulatur, Sensibilitätsstörungen, Reflexdifferenzen), in den schweren Fällen auch Muskelatrophien, leichte Pupillenstörungen (allgemeine Trägheit, Entrundungen, Anisokorie, Erscheinungen, die bei Abstinenz sich weitgehend zurückbilden können). Die meisten Trinker haben, besonders nüchtern, einen auffallenden grobschlägigen Tremor, der, wenn sie sich Alkohol zuführen, feinschlägiger zu werden pflegt. Häufig sind Zungentremor und leichte Gleichgewichtsstörungen.

Auf seelischem Gebiete zeigen die Alkoholiker regelmäßig eine Einengung des Horizontes, Auffassungsstörungen, Unfähigkeit Neues zu erlernen, die Neigung zu flachem Denken, das sich in gewohnheitsmäßigen Bahnen bewegt, zu leeren Redensarten, zur Abrundung ihrer Erinnerungen, vor allem aber eine zunehmende Ermüdbarkeit, in den schweren Fällen eine ausgesprochene organische Demenz mit allgemeiner Urteilsschwäche, Merk- und Gedächtnisstörungen. Auf affektivem Gebiete ist der ,Trinkerhumor ${ }^{66}$ kennzeichnend, eine flache Euphorie, der nichts wirklich ernst ist, vor allem aber eine eigenartige haltlose Gefühlsduselei, die Fähigkeit, in Augenblicksstimmungen aufzugehen, die auf Nichterfahrene einen echten Eindruck macht. Selten aber haben diese Gemütsbewegungen Bestand; sie sind im Augenblick durch andere verdrängt; hohe Begeisterung für irgend ein edles Ziel kann im nächsten Augenblick weinerlicher Rührseligkeit um ${ }_{, H} \mathrm{Hekuba}^{66}$ oder zornmütiger Gereiztheit Platz machen, die ebenso rasch in heulenden Kummer oder zynische Bummelwitzigkeit sich auflöst. Immer scheint der Trinker in seinen Gemütsbewegungen ganz drin zu sein; ihre mangelnde Nachhaltigkeit aber läßt auch das Handeln der Trinker durch den Augenblick, vor allem aber durch die alles 
beherrschende Neigung zum Alkohol bestimmt werden. Der Trinker zeigt immer eine ausgesprochen ethische „Depravation“6. Um seinen Trinkbedürfnissen zu genügen, muß er zu Lügen, zu Ausreden greifen. Er kommt in seiner Trinkgesellschaft immer weiter herunter, verliert den Kontakt mit seinen Kollegen, wird nachlässig in seiner Arbeit und seinem Amt, versäumt die Arbeit, macht blauen Montag, wird unzuverlässig und ermüdet außerordentlich rasch. Im häuslichen Kreis fällt er durch seine Reizbarkeit, seine Rücksichtslosigkeit und die Roheit auf, mit der er Frau und Kinder darben läßt, um seinen Trinkgewohnheiten zu genügen, die ihn Frau und Kinder mißhandeln, der Frau den Spargroschen erpressen, die Wohnungseinrichtung verpfänden, alles Verkäufliche verkaufen läßt. Auch die sexuelle Scham leidet vielfach Schaden, wie überhaupt der Takt des Trinkers sehr früh verlorengeht. So kommt es, daß viele Alkoholiker mit dem Strafgesetz in Konflikt geraten, auf der sozialen Stufenleiter immer weiter herabsinken, im Gefängnis, im Zuchthaus, im Arbeitshaus oder der Heil- und Pflegeanstalt enden. werden.

Hartnäckige Trinker, die ihre Familien schädigen, können entmündigt

Die Behandlung hat immer volle Abstinenz anzustreben, da es nicht möglich ist, einen Alkoholiker zu mäßigem Alkoholgebrauch zu bringen. In der Regel ist die Verbringung in eine Trinkerheilanstalt nötig, und nach der Entlassung sollen die Kranken sich einem Abstinenzverein anschließen, der allein Gewähr für die endgültige Heilung geben kann.

Bei der Beratung von Trinkern und deren Angehörigen ist zu beachten, daß meist auf beiden Seiten gelogen, abgeleugnet und übertrieben wird. Am besten wird man auch Berichte Unbeteiligter einholen.

Schwerer Alkoholismus fällt unter das Gesetz zur Verhütung erbkranken Nachwuchses.

\section{Delirium tremens}

An Delirium tremens erkranken nur langjährige Säufer, und zwar ausschließlich oder doch ganz überwiegend Schnapsalkoholisten. Die körperlichen Erscheinungen des Alkoholismus sind bei ihnen schon vor dem Ausbruch des Delirs mehr oder weniger lange Zeit deutlich ausgeprägt. Auch auf psychischem Gebiete finden wir häufig Vorläufer, abendliche und nächtliche Angstzustände, Aufschrecken aus dem Schlaf mit lebhaftester Angst und Schweißen, einzelne Visionen (trunkfällige Sinnestäuschungen), die gern bei der Heimkehr vom Wirtshaus, aber auch in der Wohnung oder bei der Arbeit unheimlich auftauchen (flüchtige Schatten, ein laufender Mann, ein unheimliches Tier). Nicht ganz selten kommt es einige Tage vor dem Delir zu einem oder auch mehreren schweren epileptiformen Anfällen. Der Anfall kann auch den Auftakt zum Delir bilden oder in den ersten Tagen der Krankheit sich einstellen. Im übrigen finden wir in der Mehrzahl der Fälle Gelegenheitsursachen, die das schon lange vorbereitete Delir aufklinken, besonders oft Bronchitiden oder andere Lungenaffektionen, aber auch Traumen, etwa Knochenbrüche, und selbst gefängliche Internierung, d. h. Ereignisse, die den Organismus vor ungewohnte und schwere Aufgaben stellen. Wir haben anzunehmen, daß es nicht 
der Alkohol selbst ist, der zum Delir führt, vielmehr müssen wir ,ätiologische Zwischenglieder ${ }^{6}$ annehmen, und zwar Stoffwechselstörungen, unter denen Leberschädigungen sicherlich eine Rolle spielen. Diese Zwischenglieder entstammen freilich ihrerseits dem Alkoholismus.

Das Delir beginnt trotz aller Vorboten schließlich doch überraschend und erreicht meist sehr rasch seine volle Ausbildung. Vom Fieberdelir unterscheidet es sich wesentlich, rein äußerlich schon, durch den grobschlägigen Tremor der Hände, der Zunge, des Kopfes und die Bewegungsunruhe auf weitem Raum, die zugleich schwere Gleichgewichtsstörungen erkennen läßt, weiter durch die völlige oder fast völlige Schlaflosigkeit. Dabei ist das Bewußtsein nicht so getrübt wie durchschnittlich beim Fieberdelir. Der Kranke ist örtlich und zeitlich falsch orientiert, während er über die eigene Person sich keinerlei Täuschungen hingibt. Seine Aufmerksamkeit ist immer zu erregen und meist, wenigstens kurze Zeit, so lebhaft zu erhalten, daß man mit dem Deliranten kurze sinnvolle Gespräche führen kann. Doch ist die Ablenkbarkeit eine hochgradige, freilich nicht so sehr von außen her als vielmehr durch die deliranten Erlebnisse. Bei zu lang dauernder Inanspruchnahme oder aber in dem Augenblick, in dem die Zügel etwas lockerer gelassen werden, wird der Kranke durch seinen Sinnestrug und diesem entsprechende wahnhafte Erlebnisse gefangengenommen, in denen er ganz versinkt, sobald man ihn sich selbst überläßt. Zum Teil handelt es sich dabei um phantastische Erlebnisse, die dem Traumgeschehen gleichen und sich szenenhaft zusammenschließen; die sonderbarsten Fabelwesen erfüllen den Raum, drohen den Kranken zu verschlingen, entrücken alles Anwesende und verschwinden plötzlich im Nichts, um einer Gruppe musizierender Zechkumpane Platz zu machen, die nur alle keinen Kopf aufhaben. Oder aber die Umgebung gestaltet sich dem Deliranten um: der Schlafsaal wird zum Wirtshaus, die Betten zu Schanktischen, das Klosett zum Kutschersitz, das Bett zur Hobelbank, und an diesen Phantomen ist der Kranke im Sinne seiner Alltagsbeschäftigung tätig. Der Gastwirt empfängt jeden Eintretenden, weist ihm den Platz an, nimmt Bestellungen entgegen und gibt sie weiter. Offenbar gestattet die außerordentlich flüchtige und unvollkommene Auffassung dem Deliranten besonders gut illusionäre Anknüpfungen, die noch dazu durch seine hochgradige Suggestibilität gefördert werden. Einfaches Verhängen der Augen oder Druck auf die Augen genügt gelegentlich, den Deliranten alles sehen zu lassen, was man ihm sagt. Man kann ihn mit dem Hörrohr lange telephonische Gespräche führen lassen, ihm einreden, daß man ihm Gegenstände in die Hand gibt, die er dann fühlt, fallen läßt, wieder aufhebt und die ihm im Ohr klingen. Man kann ihn vom leeren Blatt Beliebiges ablesen lassen. Dabei kommt es meist zu sinnlosen Sätzen, zu seltsamen Wortverstümmelungen, die Paraphasien gleichen können. Auch die Schrift ist oft paragraphisch und zeigt groben Tremor. Der Sinnestrug der Deliranten ist meist von großer sinnlicher Deutlichkeit. Gesicht und Gefühl sind ganz besonders betroffen; doch kommt es in der Regel auch zu einzelnen akustischen Trugwahrnehmungen. Die Truggebilde sind meist in lebhafter Bewegung, auch inhaltlich rasch wechselnd. Schon der Raum, in dem sich der Delirante bewegt, ist vielfach selbst in Bewegung. Die Wände stürzen ein und verbiegen sich, die Decke fällt herab, der Boden schwankt wie ein Ozeandampfer. In allen diesen Bewegungseindrücken haben wir wohl die Folgen 
von Störungen des Gleichgewichtsorgans vor uns. Die eigenartige Flüchtigkeit und Beweglichkeit der deliranten Trugwahrnehmungen kennzeichnen besonders die kleinen huschenden Tiervisionen, die bekannten "weißen Mäuse" der Deliranten, in denen zugleich noch die nicht selten eigenartige Wahrnehmungsanomalie, die Mikropsie, zum Ausdruck kommt, dann aber auch Fäden, Haare, Drähte, Spinngewebe, die in Bewegung sind. Der Trug auf einem Sinnesgebiet regt solche auf den anderen an. Die Stimmung der Deliranten ist eine eigenartige Mischung von Angst und Euphorie, welch letztere an die Euphorie des alten Trinkers erinnert. Manchem Deliranten fehlt jedes Krankheitsgefühl; viele aber erkennen immer wieder, daß nicht alles mit rechten Dingen zugeht. Zum mindesten schimmert eine Ahnung für das Unwahrscheinliche der Situation oft genug durch.

Dabei finden sie aber doch in der Regel überraschend schnell Erklärungen für ihr Benehmen, ihre Fehlhandlungen usw. im Sinne der Trugerlebnisse, offenbar aus jenem eigenartigen Ergänzungsbedürfnis heraus, das dem Alkoholiker überhaupt eignet, und wohl auch jener Virtuosität der freilich immer fadenscheinigen Trinkerausreden.

Die Deliranten sind besonders gefährdet durch ihre Unruhe, die ihren ohnedies kranken Körper vor schwere Aufgaben stellt, sie aber vor allem im Zusammenhang mit den Gleichgewichtsstörungen Verletzungen aussetzt. Tritt nicht der Tod an Herzschwäche oder einem interkurrenten Leiden ein, dann heilt das Delir in 3-7 Tagen ab, selten auch rascher oder später. Die bis dahin schlaflosen Kranken verfallen in einen tiefen, oft lang dauernden Schlaf, aus dem sie klar, besonnen, ohne Trugwahrnehmungen, wenn auch noch müde, konzentrations- und merkschwach erwachen, um sich rasch zu erholen. Die Erinnerung an die Delirerlebnisse ist lückenhaft, das Erinnerte haftet aber im allgemeinen.

Außer Tremor und Gleichgewichtsstörungen findet man meist neuritische Störungen und leichtere Pupillenanomalien, dazu die Erscheinungen des Magenkatarrhs, sehr häufig Eiweiß, selten Zucker, immer Urobilinogen im Urin, ein stark verändertes Blutbild, häufig auch leichte, ja selbst hohê Temperatursteigerungen (Delirium tremens febrile, das besonders gefährlich ist, zerebrales Fieber), Herabsetzung der Urinausscheidung, raschen, weichen Puls und oft sehr starkes, gelegentlich anfallweises Schwitzen.

Bei tödlichen Delirien sehen wir meist Augenmuskelstörungen; die Unruhe ist geringer, mehr moussitierend; es besteht Schlafneigung, die schließlich zum Koma und zum Tode führt. Anatomisch stellen wir dann das Bild der Wernickeschen Polioenzephalitis haemorrhagica superior fest, d. h. um die zentralen Höhlen des Hirns verbreitete Gefäßveränderungen, und zwar im Sinne einer Proliferation aller Wandzellen, die zugleich mit einer Blutungsneigung einhergeht. Blutungen sind aber nicht immer vorhanden. Wo sie auftreten, läßt die Verbreitung der Blutpunkte im Grau um den Aquädukt und den dritten Ventrikel herum, also in Mittel- und Zwischenhirn schon makroskopisch die Diagnose stellen.

Das Delir hinterläßt immer eine erhöhte Bereitschaft, erneut an Delir zu erkranken. Manche Alkoholisten bekommen eine ganze Reihe von Delirien im Laufe des Lebens. Freilich wächst damit zugleich die Gefahr des ungünstigen Ausgangs, sei es in Tod, sei es in den Korsakowschen Schwächezustand. 
Die Behandlung des Deliriums hat vor allem das Herz und den Stoffwechsel ins Auge zu fassen. Man tut gut, jedem Deliranten von vornherein Herzmittel zu geben und um die Entgiftung des Organismus anzustreben Decholin und Traubenzuckerinjektionen. Schlaflosigkeit und Unruhe sind im Beginn des Deliriums außerordentlich schwer zu bekämpfen. Die üblichen Schlafmittel helfen nicht, Skopolamin bringt, wenn überhaupt, nur ganz vorübergehend Ruhe; am besten sind noch Paraldehydgaben, die meist aber auch erst am 2. oder 3. Tage den Kranken Schlaf bringen. Wegen der Herzschwäche vermeide man Chloralhydrat, ebenso Einwicklungen, um so mehr, als dadurch die Angst der Deliranten oft gesteigert wird. Durch Fortgabe von Alkohol kann man die Gefahren des Delirs nicht verringern.

\section{Trinkerhalluzinose}

Diese ist wesentlich seltener als das Delir. Sie bevorzugt ebenfalls Schnapsalkoholisten, doch setzt sie keinen so langjährigen Mißbrauch voraus. Auf der anderen Seite gehen der Halluzinose oft besonders schwere Exzesse unmittelbar voraus. Während beim Delir die Männer weit überwiegen, ist dies bei der Halluzinose nicht in dem Maße der Fall. All dies spricht dafür, daß eine endogene Bereitschaft von Bedeutung ist, während das Delir gerade widerstandsfähige, "gesunde" Trinker bevorzugt.

Bei den Halluzinanten ist das Bewußtsein nicht deutlich getrübt. Sie bleiben besonnen, orientiert und nach außen hin oft lange unauffällig. Unter Angst entwickelt sich bei den Kranken ein besonnener Verfolgungswahn mit lebhaften akustischen Sinnestäuschungen, anfangs oft elementaren Halluzinationen (Knacken, Rauschen, Glockenläuten), später Stimmen, die besonders oft auf die Trinkkumpane oder aber auf Gesetzesorgane bezogen werden und vielfach die Trinkgewohnheiten, daneben tatsächliche Verfehlungen, die dunkle Vergangenheit oder auch falsche schlimme Anschuldigungen und gelegentlich die Gedanken der Kranken selbst zum Inhalt haben. Häufig hören die Kranken Wechselreden ihrer Verfolger, während sie selbst sich selten angesprochen wähnen. Die Stimmen sind meist laut, deutlich, klar voneinander zu unterscheiden, vom Willen nicht beeinflußbar. Entsprechend der Besonnenheit und dem im übrigen ungestörten Denken der Kranken kommt es in der Regel zu einem den Sinnentrug verbindenden, zusammenhängenden, mehr oder weniger systematisierten Wahn, der freilich nicht so ganz fest bleibt. Vielfach suchen die Kranken sich den Verfolgern zu entziehen; sie verlassen die Wohnung, irren umher, suchen Schutz bei der Polizei, bei Bekannten oder aber sie verschließen sich ängstlich. Manche arbeiten, angstgequält, weiter, ohne sich der Umgebung anzuvertrauen. Selten kommt es zu brutalen Angriffen auf die vermeintlichen Verfolger, häufiger zu Selbstmord oder Selbstmordversuchen.

Gesichtstäuschungen treten ganz zurück, solche der niederen Sinne spielen eine bescheidene Rolle.

Manche Halluzinose klingt in wenigen Tagen ab. Meist dauert sie einige Wochen; sie kann aber auch Monate andauern. Gerade in solchen Fällen müssen wir wohl eine besonders starke endogene Bereitschaft voraussetzen. Dafür spricht auch der Umstand, daß die Rückfallsgefahr eine sehr große ist, 
daß nicht selten die Wahnideen nicht ganz berichtigt werden und immer wieder einmal auftauchen (Residualwahn), daß auch Halluzinationen vereinzelt wiederkehren oder bei fortgesetztem mäßigem Alkoholverbrauch überhaupt nicht ganz verschwinden (halluzinatorischer Schwachsinn der Trinker).

Bei chronischen Wahnerkrankungen von Trinkern, die lange Zeit der akuten Halluzinose symptomatisch gleichen können, handelt es sich wohl immer um durch den Alkoholmißbrauch gefärbte und ausgelöste Schizophrenien. Dafür spricht auch die kennzeichnende Erblichkeit.

Nicht ganz selten sind Mischungen und Durchdringungen alkoholdeliranter Erscheinungen mit solchen der Halluzinose. Je mehr die deliranten Erscheinungen hervortreten, um so kürzer pflegt die akute Psychose zu dauern.

Die körperlichen Erscheinungen der Halluzinose sind diejenigen des chronischen Alkoholismus; freilich sind sie meist längst nicht so ausgeprägt wie beim Delir.

Die Behandlung hat den Kranken vor allem vor sich selbst, daneben aber auch seine Umgebung zu schützen. Halluzinanten gehören dringend in die geschlossene Abteilung.

\section{Die Korsakowsche Krankheit}

Die Hauptursache ist auch hier langjähriger schwerer Schnapsalkoholismus. Das Durchschnittsalter der Korsakowkranken ist aber wesentlich höher als jenes der Deliranten, und neben den alkoholischen Zerstörungen mögen oft auch beginnende Involutionsvorgänge der Krankheit den Boden bereiten, die Frauen relativ weit häufiger befällt als Männer. Der alkoholische Korsakow entwickelt sich nicht selten schleichend aus der zunehmenden alkoholischen Vertrottelung heraus, häufig ist auch der Ausgang eines schweren Delirs in den Korsakow, und in anderen Fällen entwickelt er sich aus einem benommenen Stuporzustand oder einer Verwirrtheit mit deliranten Zügen heraus. Delirante Sinnestäuschungen können auch im Korsakow immer wieder einmal hervortreten.

Im übrigen ist das Bewußtsein der Kranken klar. Sie können unauffällig erscheinen, besonnen, rasch auffassen und sich in konventionellen Bahnen ungestört bewegen und unterhalten. Aber sie sind zeitlich und meist auch örtlich grob desorientiert, und zwar vorwiegend auf Grund einer hochgradigen Merkstörung und eines meist umfangreichen Gedächtnisausfalls. Die Kranken vergessen von einem Augenblick zum anderen und sind so oft auch im Tageslauf grob desorientiert. Sie behalten unter Umständen kein Gesicht, keinen Namen; auch eingreifende Ereignisse prägen sich ihnen nicht ein. Freilich läßt sich experimentell nachweisen, daß auch bei schweren Korsakowzuständen gelernt werden kann, daß Einzelheiten haften, daß also keine absolute Merkunfähigkeit besteht. Aber es versagt neben der Merkfähigkeit noch die Reproduktion; das Behaltene steht nicht im gegebenen Augenblick zur Verfügung. Und endlich ist vielfach alter Gedächtnisbesitz ganz ausgelöscht, mitunter viele Jahre, in der Regel doch längere Zeiträume vor dem Beginn des Korsakow. Die Gedächtnislücken und die Merkschwäche werden von den Kranken meist durch Konfabulationen verdeckt, die oft nur auf Anregung (Verlegenheitskonfabulationen) vorgebracht, manchmal aber auch spontan 
produziert werden und dann gern ihren phantastischen deliranten Ursprung verraten. Zu einem zusammenhängenden Wahn kommt es bei der Korsakowschen Krankheit nicht; doch sind dürftige Wahnideen nicht selten.

Die genauere Untersuchung zeigt, daß auch Aufmerksamkeit und Auffassung schwer gestört sind und daß das Urteil grob gelitten hat. Die unvereinbarsten Dinge werden unmittelbar nacheinander vorgebracht, offenbar nicht bloß, weil die Merkschwäche eine Korrektur verhindert.

Korsakowkranke sind meist inaktiv, initiativelos, stumpf, bald euphorisch leer, bald mehr moros-verdrossen, gelegentlich auch ängstlich. Doch fehlt ihnen vielfach das Bedürfnis, sich Rechenschaft über ihren Zustand zu geben.

Körperlich sind die Kranken, wo das Leiden akut entsteht, vielfach hinfällig und elend; nicht wenige von ihnen gehen an zunehmendem Kräfteverfall zugrunde. Andere werden fett und schwammig. Meist zeigen sich bei ihnen hartnäckige polyneuritische Störungen, die gelegentlich das Bild der Tabes dorsalis nachahmen.

Die Prognose ist durchschnittlich ungünstig. Gelegentlich kommt es freilich zu weitgehenden Besserungen, ja praktischen Heilungen; meist aber bleiben auch bei erheblicher Besserung deutliche Merkschwäche, Verlust an Initiative, Vertrottelung bestehen. Manche Korsakowzustände werden nach einer erheblichen körperlichen und einer sehr bescheidenen seelischen Besserung stationär. In solchen Fällen kommt es darauf an, den erhaltenen Rest der Leistungsfähigkeit bei einfachen Arbeiten in der Anstalt zu erhalten. Leicht vertrottelte gebesserte Korsakowkranke müssen vor allem vor jedem Alkoholgebrauch bewahrt werden, da sonst rasch Rückfälle und endgültiger Verfall drohen.

\section{Eifersuchtswahn der Trinker}

Chronische Alkoholiker sind nicht selten eifersüchtig. Anfänglich werden die Eifersuchtsideen meist nur im Rausch geäußert, im Katzenjammer abgebeten, in der Nüchternheit korrigiert. Allmählich aber dauern sie als Verdachtsregungen auch im nüchternen Zustand fort und schließlich ist der Trinker felsenfest von der Untreue der Frau überzeugt. Gute Freunde, Nachbarn, besonders gern aber Blutsverwandte, erwachsene Söhne, Väter, Brüder werden der ehebrecherischen Beziehungen beschuldigt. Der Kranke macht tausend Beobachtungen, fängt Blicke des Einverständnisses auf, bemerkt eine veränderte Haltung der Beschuldigten. Die Frau schließt sich ein, wenn er kommt, ordnet schnell ihre Kleider oder das Bett; im Bett finden sich verdächtige Flecke, die Frau ist unten naß, hat sich eben gewaschen; sie hat Ringe um die Augen, ist unempfindlich für den Geschlechtsverkehr, ja sie weist den Kranken zurück, verlacht ihn, wenn er versagt, und macht verdächtige Bemerkungen. Der Kranke belauscht Reden durch das Fenster, sieht jemand zum Fenster hinaushuschen, hört verdächtige Geräusche. Immer dringender werden die Beschuldigungen und die Drohungen; meist macht der Kranke den Versuch, von der Frau ein Geständnis zu erpressen. Nicht selten sind grobe Gewalthandlungen. Schließlich wird die Internierung unvermeidlich. Gelegentlich kommt es aus dem alkoholischen Eifersuchtswahn heraus zum Totschlag, um so eher, als der Patient zunehmend gereizt gegen seine gesamte Umgebung, besonders aber gegen die Frau wird. 
Sicherlich wirken bei der Entstehung des alkoholischen Eifersuchtswahns zahlreiche Momente zusammen, die tatsächliche Abkehr der Frau, das zerrüttete Familienleben, die begreifliche sexuelle Kälte der Partnerin, dann aber auch das schlechte Gewissen des Trinkers, das Entlastung in Verfehlungen der Frau sucht, weiter die anfänglich zunehmende Appetenz bei schon erloschener oder absinkender Potenz und schließlich auch die nachlassende Appetenz selbst, die dem Trinker deutlich macht, daß er zu allen anderen Vorwürfen hinzu auch noch jenen des sexuellen Versagens verdient. Dazu kommt aber wohl auch eine unmittelbare oder mittelbare Wirkung des Giftes. Ähnliches ist auch vom Kokain bekannt. Vielleicht ist es die Wahnbereitschaft, der durch die chronische Vergiftung der Boden bereitet wird.

Bei Internierung und Abstinenz wird der Eifersuchtswahn meist rasch abgebaut. Die Eifersucht spielt dann zum mindesten keine Rolle mehr, wenn die wahnhaften Gedankengänge auch nicht sogleich korrigiert werden. Oft geschieht aber auch dies. Bei neuem Mißbrauch kehrt der Eifersuchtswahn. aber vielfach rasch wieder.

\section{Alkoholepilepsie}

Wie bei allen schweren Stoffwechselvergiftungen, so können sich auch beim chronischen Alkoholismus typische epileptiforme Anfälle einstellen, die meist selten bleiben und denen gelegentliche Dämmerzustände folgen. Zu diesen Anfällen (Alkoholepilepsie) gehören die Krämpfe, die das Delirium tremens einleiten oder begleiten können. Wir haben es offenbar mit dem Ausdruck der schweren Stoffwechselstörung zu tun.

Der Alkohol steigert aber überhaupt die Krampfbereitschaft und verschlimmert daher die Erscheinungen der genuinen ebenso wie jene der traumatischen Epilepsie. Aus einer Oligoepilepsie kann also eine solche mit häufigen Anfällen werden.

Bei einer Gruppe erregbarer, unsteter, hysterischer Persönlichkeiten, die gelegentlich schon bei Affektstürmen auf dem Umwege über Hyperventilation und Tetanie einzelne epileptiforme Anfälle bekommen, kann der Alkohol diese Neigung steigern.

Endlich aber werden auch hysterische Anfallsleiden durch den Alkohol verschlimmert und mancher Alkoholiker erwirbt erst durch seinen Giftmißbrauch die Bereitschaft zu hysterischen Bewegungsstürmen und Anfällen. Hier haben wir es vielfach mit jugendlichen Menschen zu tun (sog. habituelle Epilepsie der Trinker). Alle diese Anfallsstörungen werden durch Abstinenz deutlich gebessert bzw. nicht selten praktisch geheilt.

\section{1) Suchten}

\section{Morphinismus}

Schon die erste Morphingabe kann über das Schicksal bestimmen. Bei der Mehrzahl der Menschen macht sich neben der schmerzstillenden auch eine euphorisierende Wirkung bemerkbar. Bei manchen überwiegen die unangenehmen Erscheinungen (Magendruck u. a.) so sehr, daß sie nicht in Gefahr 
sind. Aber auch nicht Prädisponierte können Morphinisten, Süchtige werden durch die Gewöhnung und die damit verbundenen Entziehungserscheinungen, die auch den Süchtigen schließlich zum eigentlich Kranken machen.

Die Süchtigen suchen die Euphorie. Vielfach handelt es sich um erschöpfbare oder chronisch erschöpfte Menschen, Nervöse, die für gewöhnlich von Mißempfindungen, innerer Unruhe, Neigung zu Verstimmung und Empfindlichkeit schon für die kleinen Nöte des Daseins nicht loskommen und die dann im Morphiumrausch eine Befreiung erleben, nun plötzlich sich behaglich, ruhig, ausgeglichen füblen und statt lauter Schatten auch einmal die rosigen Seiten des Daseins sehen. Viele Süchtige sind zudem träge und willensschwach, dysphorisch, zu anderen Genußgiften geneigt. Sie haben süchtige und andere psychopathische Verwandte und auffallend oft Selbstmorde im Familienumkreis. Die abklingende Morphinwirkung macht das alte Ungemach doppelt deutlich und fügt noch unangenehme Katzenjammererscheinungen, vielleicht auch spezielle peinliche Nachwirkungen hinzu. Neue Morphingaben beseitigen diese Niederlagen schlagartig. Es kommt so rasch zu ständigem Gebrauch, und nicht nur dazu, sondern auch zu immer steigenden Dosen.

Das Morphin hat Gewöhnungswirkungen. Der Körper verträgt und er braucht immer mehr von dem Gift, wenn die gleiche Wirkung erzielt werden soll. Er nimmt das Morphin wohl als notwendigen Bestandteil in dieses oder jenes Organ, besonders ins Hirn, auf. Vielleicht handelt es sich auch, wie Wuth annimmt, um eine spezifische Beeinflussung des vegetativen Gesantapparates: Steigerung des parasympathischen Tonus durch das Gift, der zu einer neuen Gleichgewichtslage durch Steigerung auch des sympathischen Tonus führt. Entfällt die parasympathische tonisierende Wirkung, so wird der Körper schutzlos dem Sturm des erhöhten Sympathikotonus preisgegeben. So entstehen die Entziehungserscheinungen: Gähnen, Niesen, Tränen, Magensaftproduktion; Muskelschwäche, starke innere Unruhe, verstärkte Darmbewegungen, Diarrhöen, Schweiße, Gliederschmerzen, hochgradige Schlaffheit, Müdigkeit bei gleichzeitiger Schlaflosigkeit, Blasenkrämpfe, Angst, Beklemmungen, Herzklopfen, Schwindel, Hitze und Frösteln. Die Entziehungserscheinungen erzwingen neue Gaben, auch bei jenen, die nicht usprünglich süchtig, aber durch chronischen Gebrauch infolge schmerzhaften Leidens nur morphingewöhnt sind.

Auf diese Weise kommt es rasch zu Gaben bis zu 1 und 2, ja $3 \mathrm{~g}$ am Tag. Schmerzhafte Leiden, ein Gallenanfall, eine Verwundung, gastrische Krisen, aber auch Neugier und vor allem Verführung sind Anlaß zu der ersten Spritze. Die skrupellose Verführung, die von morphinsüchtigen Ärzten ausgeht, ist besonders hervorzuheben. Ärzte und ärztliches Personal, Apotheker, Schwestern, Heilgehilfen, Tierärzte, Zahnärzte sind vor den anderen Berufen gefährdet, weil ihnen das Mittel am ehesten zugänglich ist. Nach dem Kriege freilich war der Morphinismus eine verbreitete Erscheinung, da zahllose Soldaten das Mittel kennengelernt hatten und die Demoralisierung der Nachkriegszeit die Verbreitung der Seuche erleichterte. Heute hat das Opiumgesetz der Sucht recht feste Riegel vorgeschoben.

Der chronische Morphiummißbrauch kann lange Zeit, Jahre, ohne ernste Folgen bleiben. Die Intelligenz leidet überhaupt nicht oder doch nur in besonders schweren chronischen Fällen. Dagegen werden Willensschwäche, 
Haltlosigkeit, Wehleidigkeit, Empfindlichkeit, Neigung zu Trägheit, zum Vergeuden der Zeit, zum Aufsuchen immer einfacherer Genüsse, zum Meiden stetiger Arbeit regelmäßig verstärkt und damit leidet die Leistungsfähigkeit der Morphinisten. Regelmäßig kommt es auch zu einer ethischen Depravation, wenigstens auf jenen Gebieten, die mit dem Morphin unmittelbar zusammenhängen. Die Beschaffung des Morphins steht im Mittelpunkt des Strebens; dazu wird aber jedes Mittel recht, auch Rezeptfälschungen, Diebstähle, Betrügereien; vor allem aber muß der Morphinist immerzu schwindeln, um seine Sucht zu verdecken, muß Familienangehörige und Mitarbeiter hintergehen, ist auf schiefe Wege angewiesen. Da Morphin teuer ist, muß mancher Morphinist auch sonst die Familie vernachlässigen; es kommt zu Zwist und zu brutalem Egoismus. Dann aber leidet vor allem auch der Körper. Trophische Störungen an Haaren, Nägeln, Zähnen und Haut treten ein. Die Haut wird fahl und trocken, zu Infektionen geneigt. Die Darmtätigkeit, der Appetit liegen darnieder. Die sexuelle Appetenz läßt nach und erlischt schließlich. Der Morphinist nimmt ab und wird immer elender und kachektischer auch dann, wenn er nicht Abszesse und Phlegmonen bekommt. Diese sind häufig, weil der Kranke es oft nicht genau mit der Spritze und der Lösung nimmt und auch durch die Kleider hindurchspritzt.

Schließlich entsteht ein unhaltbarer Zustand. Ohne Hilfe kommen nur wenige Morphinisten vom Gift frei. Die meisten landen eher oder später zur Entziehungskur in der Anstalt. Dann treten die Entziehungserscheinungen mit ihrer ganzen Gewalt hervor. Der Morphinist muß sich daher verpflichten, die Kur durchzuführen; sonst soll er nicht aufgenommen werden. Plötzliche Entziehung ist das Vorgehen der Wahl. Langsame kann überhaupt nur dort in Frage kommen, wo der körperliche Zustand des Kranken die nicht unerhebliche Belastung durch die plötzliche Entziehung nicht zuläßt. Die plötzliche Entziehung ist weitaus am wenigsten qualvoll, weil sie rasch geht und dem Kranken nicht Raum zur Entwicklung psychopathischer Abwehrmanöver läßt. Sie verhindert auch am ehesten, daß der Kranke seine Entlassung erzwingt.

Bei der Aufnahme, die immer in geschlossenen Anstalten erfolgen soll, bekommt der Kranke neue Kleider, neue Wäsche. Seine Habseligkeiten soll er nicht haben, es sei denn, sie werden sehr genau untersucht. Fast jeder Morphinist neigt dazu, Morphium mit einzuschmuggeln, in Taschen, Büchern, Büchsen, Toilettengegenständen, hohlen Zähnen, Körperöffnungen. Er muß also auch selbst ganz genau untersucht werden.

Man kann den ersten Sturm der Entziehungserscheinungen mit einem Dauerschlaf abfangen. Ich halte dies nicht für zweckmäßig. Der Kranke soll schon um der Zukunft willen den Sturm erleben; er soll das Bewußtsein erhalten, daß er allein mit dem Gift fertig wird. Man kann ihm dabei doch manches erleichtern, ihm für die Nacht Schlafmittel in größeren Dosen geben, ihm Eiweißpräparate einspritzen, alkalische Wasser gegen die saure Magensaftproduktion, Wickel gegen die Unruhe, warme protrahierte Bäder, kühle Abreibungen, Güsse, um ihn abzulenken, ihn zu beschäftigen, seiner Unruhe Raum zu geben. Meist ist in wenigen Tagen der große Sturm, der oft zu Selbstmorddrohungen, zu hysterischen Erregungen, zu Herumtorkeln und großem Wälzen führt, vorbei. Dann kommen noch wenig angenehme Tage. Aber bald meldet sich der Appetit, der Schlaf wird besser, die Müdigkeit nimmt ab, die 
Sexualtätigkeit regt sich erneut, der Hautturgor hebt sich, der Kranke wird ausgeglichener und freier, zuversichtlicher und heiterer. Er hat zudem das Bewußtsein, daß er es geschafft, daß er aus eigener Kraft so weit gelangt ist und daß die Zukunft sich aufhellt.

Bei der Entziehungskur verdienen Herz und Kreislauf alle ärztliche Sorgfalt. Am besten gibt man von allem Anfang an Herzmittel. Während der Kur, besonders an den ersten Tagen, selten auch noch dann, wenn die schweren Entziehungserscheinungen schon abgeklungen sind, kann es zu Kollapsen kommen. Kleine Morphingaben bringen meist sofortige Besserung. Wenn möglich wird man aber versuchen, mit den gewöhnlichen analeptischen Mitteln auszukommen.

Die Prognose des Morphinismus ist nicht gut. Süchtige Menschen bleiben ihr Leben lang süchtig, auch wenn sie vom Morphium frei sind. Mißgestimmte werden durch die Entziehung nicht froh. Von den Morphinisten der Vorkriegszeit blieben daher nur wenige Prozent vor Rückfällen verschont. Jene der Nachkriegszeit haben eine viel bessere Prognose; fast die Hälfte wurde geheilt, wohl deshalb, weil gerade unter ihnen Sü chtige so selten waren.

Morphinisten sollen weiter kontrolliert und immer wieder zu kurzdauernden Beobachtungen bestellt werden, bis sich erwarten läßt, daß erneuter Mißbrauch nicht mehr droht.

Wird der Morphinist rückfällig, dann steigt die Dosis in der Regel besonders rasch zu der alten Höhe. Die neuen Entziehungskuren bringen meist nicht so schwere Störungen mit sich wie die erste. Mit dem ersten Rückfall verschlechtert sich die Prognose weiter.

Es gibt manche Morphinisten, die nur zu gewissen Zeiten Morphium gebrauchen und immer wieder von selbst aufhören oder die Dosis doch sehr stark reduzieren können (Morphiumdipsomanen). Es handelt sich hier um besonders willensstarke Süchtige oder solche mit periodischen Verstimmungen oder immer erneuten exogenen Erschöpfungen, die mit dem Nachlassen des Druckes auch die Morphiumwirkungen nicht mehr brauchen. Selten sind jene Morphinisten, die durch Jahrzehnte bei den gleichen bescheidenen Dosen bleiben, ohne schwere Störungen zu bekommen.

Viele Morphinisten sterben durch Suizid, meist mit Morphin. Andere gehen an Sepsis infolge ihrer Abszesse und Phlegmonen zugrunde. Weitere sterben in der Kachexie an interkurrenten Erkrankungen.

Die Mehrzahl der Morphinisten brauchen nicht bloß Morphin. Sie nehmen auch Alkohol und Schlafmittel, Kokain und Morphinderivate; die meisten sind leidenschaftliche Raucher. Gerade darin verrät sich ihre süchtige Natur.

$\mathrm{Ob}$ der Morphinismus zur Inversion führen kann, ist ungewiß. Bei den meisten Morphinisten freilich erlischt die Appetenz mehr oder weniger rasch; aber die sexuelle Einstellung bleibt der Richtung nach doch wohl stets die gleiche. Manche Morphinisten sind aber ursprünglich homosexuell.

Eigentliche Psychosen gibt es im Zusammenhang mit dem Morphinismus allein oder in der Entziehung nicht. Wohl aber kommt es bei Morphinisten, die zugleich Kokainisten oder Alkoholisten sind oder chronisch Schlafmittel gebraucht haben, vereinzelt zu Delirien, auch zu Halluzinosen.

Die Schwierigkeit Morphium zu erhalten, veranlaßt viele Süchtige, sich das Mittel auf unrechtmäßigem Wege zu beschaffen (Rezeptfälschung, -Dieb- 
stahl usw.). Die Anwendung des $§ 51,1$ oder 2 kommt dabei in der Regel nicht in Betracht, zumal da die meisten Süchtigen gut vorsorgen und die diesbezüglichen Delikte nicht etwa unter Einwirkung starker Entziehungserscheinungen zu verüben pflegen.

\section{Heroinismus}

In Amerika, in Deutschland vor allem in Hamburg, wird das Heroin (Diazethylmorphin) als Genußmittel in Tabletten genommen oder gespritzt, anscheinend mit Wirkungen, die denen des Morphins sehr ähnlich sind. Ein euphorisches müdes „Heldengefühl ${ }^{6}$, das erlebt wird, hat doch keinen Widerhall im Handeln. Die Kranken, die rasch $1 \mathrm{~g}$ und mehr nehmen, kommen noch schneller herunter als die Morphinisten. Wegen der Herzkollapsgefahr - es kommen auch epileptische Anfälle bei der Entziehung vor -, soll man nicht plötzlich, sondern etwa in 8 Tagen entwöhnen. Die Schicht, aus der die Heroinisten stammen, ist wesentlich tiefer als die der Morphinisten. Die Prognose ist offenbar noch schlechter.

Wie Morphin können alle Morphinderivate, Eukodal, Dikodid, Dionin, Dilaudid, Paramorphin zur Sucht führen, ebenso Pantopon, das alle Alkaloide des Opiums enthält, Opium selbst, Laudanon, Holopon und das zur Entziehung empfohlene Eumekon. Am seltensten führt Kodein zum Mißbrauch. Symptomatologie, Entziehungserscheinungen und Gefährdungsbereich entsprechen im wesentlichen denen des Morphinismus. Die nur in Tablettenform verbreiteten Gifte sind im ganzen weniger gefährlich.

\section{Kokainismus}

Blätter der Erythroxylon Coca wurden schon von den Inka gekaut, als die Spanier Peru eroberten. Auch jetzt gibt es in Peru und Bolivien zahlreiche Coqueros unter den eingeborenen Arbeitern, die rasch an ihrer Giftsucht verfallen. In Europa fand das Kokain Eingang als Morphinentwöhnungsmittel, wurde dann bald, meist mit Morphin zugleich, als Genußmittel gebraucht, beschränkte sich aber auf jene Gesellschaftsschicht, in der auch der Morphinismus hauptsächlich zu Hause war. Eigentlich erst nach dem Kriege wurde in Deutschland Kokain auch geschnupft, hauptsächlich in Kreisen, die sich um Dirnen, Zuhälter und Kellner übler Gaststätten gruppierten. Die Kokainschnupfer bildeten ein seltsames Volk mit engen Zunftregeln, Jargon und Heimlichkeiten. Seit Jahren, besonders nach dem Opiumgesetz, scheint die Seuche allmählich zu erlöschen.

Die einmalige Kokaingabe führt rasch zur Euphorie, zu glückseliger Gehobenheit, dann zu einer Art Rausch, in dem alle Leistungen erleichtert erscheinen, die Kraftleistungen und die Koordinationssicherheit auch tatsächlich erhöht sind und auch geistige Leistungen sich rascher vollziehen, während die Qualität leidet. Gedanklich machen sich Ideenflucht und leichte Inkohärenz bemerkbar. Zugleich besteht Erregung, die in raschem Reden, lebhaften Gliederbewegungen, Neigung zum Tanzen zum Ausdruck kommt. Der Kokainist kann nicht still sein, er muß sich mitteilen und braucht daher Gesellschaft, zu der ihn auch die sexuelle Erregung hintreibt. Das Selbstbewußtsein 
ist immer gehoben. Der Berauschte traut sich alles zu und ist von dem Tiefsinn seiner Gedanken wie von seinen motorischen Heldenstücken überzeugt. Dem Rausch folgt ziemlich rasch Ernüchterung, Müdigkeit, Schlaffheit, Katzenjammer. Herztätigkeit, Blutdruck, Atmung sind beim Kokainisten erhöht. Das Gesicht ist blaß, die Pupillen sind weit. Oft sieht man auch vegetative Störungen. So werden oft Herzklopfen und Schwitzen peinlich; bei Überdosierung kommt es auch zu Herzangst.

Wiederholte Gaben, zu denen die Euphorie Anlaß gibt, steigern die Toleranz, so daß bald mehrere Gramm Kokain genommen werden können. Eigentliche Entziehungserscheinungen gibt es nicht. Zu Kokainisten werden also nur Rauschhungrige, d.h. in der Regel erheblich psychopathische Menschen, die oft von je großsprecherisch, unzuverlässig, unstet, ja unsozial und kriminell sind.

Schwerere Kokainräusche, zu denen es erst nach mehreren Gaben kommt, bringen neben der Euphorie und den bisher genannten Erscheinungen Sinnestäuschungen und im Abklingen ängstlich-paranoide Zustände mit sich, in denen der Berauschte sich verfolgt, gestellt, bedroht fühlt, mit halber Einsicht und so, daß er auch dieses Stadium als romantisches und spannendes Abenteuer fast sucht. Die Sinnestäuschungen sind vor allem optischer und haptischer Natur. In beiden Fällen sind es sehr kleine Objekte, besonders gern Insekten, Milben, Flöhe, Läuse, Bakterien, die gesehen und in der Haut gefühlt und dann gelegentlich mikroskopisch „,nachgewiesen ${ }^{66}$ werden. Gehörstäuschungen sind seltener.

Der Kokainist, der regelmäßig größere Mengen des Giftes nimmt, verkommt rasch, geistig, moralisch und körperlich. Häufig werden mangelnde Konzentration, Merk- und Gedächtnisstörungen, geistige Ermüdbarkeit, selbst Urteilsschwäche deutlich. Moralisch verfällt der Kokainist ganz wie der Alkoholiker, und er gleicht ihm um so eher, als auch er roh, gewalttätig, rücksichtslos, egoistisch, eifersüchtig und oft kriminell wird. Körperlich wird er elend, kachektisch; er sieht grau, verfallen aus, wird kraftlos und impotent. Beim Schnupfkokainisten kommt es oft zu Nasenschleimhautentzündungen und selbst Durchlöcherung der Nasenscheidewand, die diagnostisch wichtig ist. Der Spritzkokainist ist durch Abszesse und Phlegmonen wie der Morphinist sehr gefährdet. Der Spritzkokainist verkommt wesentlich rascher als der Schnupfer.

Bei längerem Gebrauch, der aber nur Wochen oder Monate zu dauern braucht, können sich eigentliche Psychosen einstellen, die eine Zeitlang fortbestehen, auch wenn Kokain nicht mehr genommen wird. In den Delirien ist das Bewußtsein lange nicht so tief getrübt wie beim Alkoholdelir. Sie sind bald von heiter-euphorischem Anstrich mit reichlichen Sinnestäuschungen kennzeichnender Art, bald ängstlich-paranoid gefärbt. In der Regel dauern sie nur kurz, wenn auch länger als das Alkoholdelir. Durchschnittlich von wesentlich längerer Dauer und ernster ist der Kokainwahnsinn. Ohne deutliche Trübung des Bewußtseins kommt es hier zu Angst und Unruhe, aus der sich bald ein ausgesprochener Verfolgungswahn mit Verkennungen, Illusionen, reichlichen Sinnestäuschungen, vor allem des Gesichts und des Körpergefühls, entwickelt. Dabei werden diese Täuschungen häufig im Sinne des physikalischen Verfolgungswahns gedeutet; Gedankenübertragung, Hypnose, elektrische Apparate spielen eine große Rolle. Gleichzeitig sind die Kranken 
selbstüberzeugt; sie halten sich für große Entdecker und Erfinder, die den Verfolgern auf die Schliche kommen und ihnen die Ränke absehen, oder auch selbständig große Entdeckungen machen. Die Stimmung schwankt zwischen Gehobenheit und mißtrauischer Angst; der Kontakt mit der Umwelt geht aber nicht verloren. Die Kranken bleiben mitteilsam, sind lebhaft und tätig, ja sie können ihre Umgebung von dem Inhalt ihres Wahns überzeugen. Bei Entziehung heilt der Kokainwahnsinn meist rasch, selten erst nach längerer Zeit, ab. Von schizophrenen Erkrankungen ist der Kokainwahnsinn oft schwer zu unterscheiden. Der bessere Kontakt mit der Umgebung, die Eigenart der Trugwahrnehmungen, die Betriebsamkeit, vor allem aber der körperliche Befund und die Abhängigkeit der Erscheinungen vom Gift machen aber in der Regel die Diagnose möglich.

Besonders schwere Formen des Kokainismus können auch zu amnestischen Symptomenkomplexen und paralyseähnlichen Zuständen führen.

Kokain kann und soll sofort entzogen werden, und dies muß in der Anstalt geschehen. Quälend ist meist nur die Schlaflosigkeit, die mit geeigneten Mitteln bekämpft werden kann. Neben der vollen Erholung gilt es vor allem der Klärung der Vorgeschichte und der nachgehenden Fürsorge auf Grund der genauen Kenntnis der Person und ihres Umkreises, die vor Rückfällen schützen soll, vielfach aber auch beim besten Willen der Beteiligten versagt. Delikte im Kokainwahnsinn sind nicht selten: Eigentumsdelikte und Betrügereien, die zur Beschaffung des Giftes ausgeführt werden, Gewalttätigkeit aus der Angst des Rausches, des Wahnsinns heraus, aber auch im Zusammenhang mit Erregungen in der meist eigenartigen Gesellschaft. Eine besondere Rolle spielt auch die spezifische Wirkung des Kokains auf das Geschlechtsleben. Anfänglich ist die Erregbarkeit besonders gesteigert. Frauen suchen hemmungslos Befriedigung. Häufig sind aber auch homosexuelle Neigungen und Handlungen, vielleicht deshalb, weil offenbar gerade Homosexuelle leicht zu diesem Genußmittel kommen.

Delikte, die in Kokainpsychosen und -räuschen begangen werden, fallen unter den Schutz des $\S 51$, nicht aber jene, die der oft kriminellen Wesensart der nüchternen Kokainisten entspringen, falls diese nicht durch den chronischen Giftmißbrauch schwer geschädigt und als Geisteskranke zu betrachten sind.

\section{m) Psychische Störungen bei anderen Vergiftungen}

\section{Gewerbliche Gifte}

Am häufigsten ist immer noch die Bleivergiftung, die nicht selten zu echten neurasthenischen Zuständen Anlaß gibt. Sodann kommt es im Zusammenhang mit epileptiformen Anfällen manchmal zu Delirien und anderen epileptiformen Psychosen. Delirante Zustände gibt es aber auch ohne Beziehung zu den Anfällen. Dabei ist nicht zu vergessen, daß das Blei in solchen Stadien immer auch schwere Organveränderungen hervorgerufen hat, besonders Nierenschädigungen und Veränderungen des Gefäßapparates, auch im Gehirn, so daß wir es bei den Psychosen nicht mehr mit unmittelbaren Bleiwirkungen zu tun haben. 
Bei der chronischen Quecksilbervergiftung entsteht der ,Erethismus

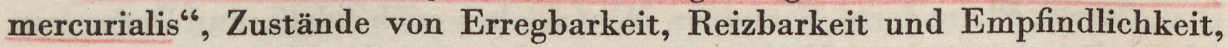
die mit den körperlichen Erscheinungen der Vergiftung, Zahnfleischentzündungen, Magen-Darmstörungen, Hinfälligkeit, Schwäche, Tremor, nicht selten auch Gedächtnisschwäche verbunden sind.

Endlich führt das Mangan zu ausgesprochen parkinsonistischen $\mathrm{Zu}$ ständen, in denen die Pulsionen und die Zwangsaffekte besonders hervortreten, dazu Mikrographie und ein seltsamer Zehengang. Seelisch besteht häufig eine euphorische Indolenz, mitunter auch eine paranoide Seelenhaltung. Wiederholt wurde Schlafsucht beobachtet. Die Prognose ist bei den sehr leichten Fällen gut; bei schweren ist eine Heilung wohl ausgeschlossen.

Benzin- und Schwefelkohlenst offvergiftungen führen, wenn sie nicht tödlich sind, zu Rauschzuständen, meist heiter-erregter Art, und zu Delirien. Seltener sind eigentliche exogene Psychosen bei chronischen Vergiftungen. Bei beiden Giften, besonders aber beim Schwefelkohlenstoff, kommt es dagegen häufig zu schweren Schäden am peripheren Nervensystem, besonders Neuritiden, auch solchen des Optikus.

Kohlenoxyd. Das CO, das in zahlreichen gewerblichen Betrieben (Bergwerk, Hochofen, Gaswerk; auch Rohrleger sind besonders gefährdet) ständig vorkommt, verdrängt im Blut den Sauerstoff aus dem Hb., das damit seine Rolle als Sauerstoffübertrager einbüßt. Bei chronischer Aufnahme kleiner Mengen entstehen so Anämien mit Kopfschmerzen und uncharakteristischen neurasthenischen Beschwerden, die bei Entfernung aus dem Betrieb abheilen.

Akute Vergiftungen, besonders häufig solche durch Leuchtgas, das in suizidaler Absicht eingeatmet wird, führen nach wenig kennzeichnenden Vorboten zu tiefer Bewußtlosigkeit und gelegentlich unter Krämpfen zum Tode. Zufuhr frischer Luft, $\mathrm{O}_{2}$-Atmung, Lobelin, Herzmittel können auch schlimm aussehende Vergiftungen rasch bessern. Das Erwachen aus der Bewußtlosigkeit kann plötzlich erfolgen oder auch über rauschartige und deliriöse Zustände hinweg. Damit sind aber die Gefahren noch nicht gebannt, die durch Lungenentzündung, vor allem aber durch zerebrale Allgemeinerscheinungen nach Intervallen von mehreren Tagen bis Wochen noch eintreten können, offenbar wesentlich unter dem Einfluß der Gefäßlähmung, die zu Hirnblutungen und -erweichungen führt. Nicht ganz selten sind paralyseähnliche Bilder, die oft einen amnestischen Symptomenkomplex hinterlassen und die prognostisch nicht ungünstig sind. Häufig kommt es auch zu parkinsonistischen Zuständen, gelegentlich zu reinen Stirnhirnsyndromen, zu Aphasien und wohl auch zu optisch-agnostischen Symptomen, die alle eine erhebliche Restitutionstendenz zeigen, aber doch immer ernste Komplikationen bleiben.

\section{Arzneimittel}

Äther und Paraldehyd führen bei gewohnheitsmäßigem übertriebenem Gebrauch zu Verfassungen, die jenen des chronischen Alkoholismus außerordentlich ähneln. Beim Paraldehydismus kommt es gelegentlich auch zu epileptiformen Anfällen und zu Delirien, die vom Delirium tremens kaum unterscheidbar sind. 
Die Schlafmittel der Barbiturs äurereihe, Veronal, Medinal, Luminal, Dial, Curral, Phanodorm, Somnifen, Noctal, aber auch Adalin und Dormalgin führen bei chronischem Mißbrauch zu paralyseähnlichen Bildern: Pupillenstörungen, Augenmuskelschäden, Nystagmus, VII-Parese, artikulatorischer Sprachstörung, zerebellaren Erscheinungen, mimischen Mitbewegungen, Tremor, ferner zu Störungen der Merkfähigkeit, des Gedächtnisses, Verlangsamung, Stumpfheit, gelegentlich auch Euphorie. Schließlich können, wie übrigens auch beim Chloral, Delirien und andere exogene Reaktionstypen entstehen, unter Umständen auch mit epileptiformen Anfällen. Verhältnismäßig oft wurden in der letzten Zeit Delirien mit epileptischen Anfällen nach länger dauerndem Phanodormmißbrauch beobachtet. Die Gefahr des Mißbrauches pflegt bei diesem sonst empfehlenswerten Schlafmittel in dem Augenblick zu beginnen, in dem es nicht mehr als Schlafmittel, sondern als Tagesberuhigungsmittel verwandt wird. Die Phanodormdelirien bedeuten immer eine ernste Gefahr; es wird empfohlen, in solchen Fällen das Mittel nicht abrupt zu entziehen; sonst ist die Prognose dieser Zustände nicht schlecht. Immerhin hinterläßt jeder chronische Mißbrauch eine Schädigungsbereitschaft im Sinne der Polioencephalitis haemorrhagica.

Brom. Bromismus entsteht besonders bei der Epilepsiebehandlung, leichtere Fälle aber auch dadurch, daß bei nervösen Störungen aller Art gerne Brom verordnet wird, das die Patienten, ohne sich beim Arzt wieder sehen zu lassen, lange Zeit weiternehmen. Herabstimmung, Schläfrigkeit, Apathie führen rasch zu einem ernsten Krankheitsbild: Kraftlosigkeit, Koordinationsstörungen, Doppelsehen, artikulatorische Sprachstörung, Schriftstörung, Steigerung bzw. Abschwächung der Reflexe. Dazu treten Herabsetzung und Verlangsamung aller geistigen Leistungen, gelegentliche Verwirrtheits- und Benommenheitszustände, Beeinträchtigungsvorstellungen, Veränderung der Stimmungslage nach der depressiven Seite, selten nach der euphorischen Seite hin. Körperlich finden wir Katarrhe der Schleimhäute, Foetor und Bromakne. Schließlich kann es zur Kachexie kommen. Gelegentlich sehen wir auch erst nach dem Aussetzen des übertriebenen Bromgebrauches Verwirrtheitszustände; das Brom verdrängt das Chlor und wird sehr langsam ausgeschieden. Kochsalz muß auch therapeutisch gegeben werden.

Skopolamin, Atropin. Vergiftungen mit Bilsenkraut, Tollkirsche und Stechapfel, die an der Akkommodationslähmung, der Trockenheit des Mundes und Heiserkeit kenntlich sind, führen zu lebhaften Delirien, die anfänglich mit Illusionen, dann mit Halluzinationen und Erregung, sonderbaren Handlungen und Stellungen, auch oft mit Heiterkeit und Faxen (es wird alles als komisch erlebt), dann mit Ängstlichkeit, Unruhe und Rededrang, zunehmender Schläfrigkeit und Koma einhergehen. Nach dem Erwachen finden sich Merk- und Gedächtnisstörung, Erschwerung aller geistigen Leistungen. Es besteht Amnesie oder verschwommene Erinnerung, Reizbarkeit, körperliche Schwäche, Alle diese Erscheinungen gleichen sich langsam aus. Die Vergiftungen mit der Pflanze selbst führen offenbar zu reichhaltigeren Bildern als jene mit den reinen Alkaloiden.

Auch Jod oform kann zu exogenen Psychosen führen, meningitisartigen Bildern und Verwirtheiten, in denen besonders Gesichterschneiden und stereotype Bewegungen vorkommen sollen. 
n) Die genuine Epilepsie und die symptomatischen Epilepsien

Allgemeines

Vom rein klinischen Standpunkt aus ist die Umgrenzung der genuinen Epilepsie heute noch eine vorwiegend negative. Als genuin faßt man jene Krampfkrankheiten zusammen, für die eine äußere Ursache nicht bekannt ist. Dabei ist das Symptom, an das sich die Klinik hält, der elementare tonisch-klonische Krampf, bei dessen Fehlen eine Epilepsie nicht diagnostiziert werden kann.

Dieser generalisierte, das heißt mit Beteiligung des ganzen Körpers und mit Bewußtseinsverlust einhergehende Krampfanfall kommt vor als Ausdruck der genuinen (erblichen) Epilepsie; er kann aber auch lediglich Symptom einer irgendwie gearteten Hirnschädigung oder Hirnerkrankung sein; in diesen Fällen sprechen wir von symptomatischer Epilepsie. In den meisten Fällen dieser Art macht sich die Hirnschädigung noch in anderen Erscheinungen bemerkbar, in erster Linie in der Gestalt von neurologischen Symptomen, die allerdings oft mühsam gesucht werden müssen (Augenhintergrund, Liquor, Röntgenaufnahme, Enzephalographie). Auch auf den Zustand der inneren Organe ist zu achten (Niere, Blutdruck, Vergiftungen usw.). Erst wenn alle entsprechenden Untersuchungen negativ ausgefallen sind, wird man eine genuine Epilepsie annehmen dürfen. Immerhin kann man der Diagnose wenigstens oft auch einige weitere positive Bestimmungsstücke hinzufügen, wenn man nur guten Willens ist. An der Tatsache, daß es erbliche Epilepsieformen gibt und daß damit ein großer Teil der genuinen Epilepsie erfaßt ist, läßt sich nicht zweifeln. Kinder aus Ehen, in denen ein Elternteil epileptisch ist, sind zu $11 \%$ wieder epileptisch. Dazu ist die Kleinkindersterblichkeit in diesen Familien eine sehr große, und von den Kleinkindern gehen viele an Krämpfen zugrunde. Häufig erkranken Geschwister von Epileptischen gleichfalls epileptisch $(4,1 \%)$ und die eineiigen Zwillingspaare verhalten sich der Epilepsie gegenüber ganz vorwiegend konkordant, die zweieiigen dagegen nicht häufiger, als der Häufigkeit der Geschwisterepilepsie entspricht. Für eine Sonderform der Epilepsie, die mit myoklonischen Zuckungen einhergehende Myoklonusepilepsie, hat Lundborg einen einfach rezessiven Erbgang nachgewiesen. Die gewöhnliche genuine Epilepsie hat wohl einen verwickelteren Erbgang. In den Familien finden wir neben den Krampfkranken selbst auffallend häufig athletische und dysplastische Körperbauformen und wohlgekennzeichnete Persönlichkeitstypen, nämlich einmal besonders erregbare, explosive, zornmütige Menschen, auf der anderen Seite langsambedächtige, sozial hochstehende Typen von starkem Familiensinn, konservativer Gesinnung, nachhaltigen Gemütsbewegungen, langsam, ein wenig umständlich und pedantisch. Endlich sind leichte Schwachsinnsformen im Umkreis der Epilepsie nicht selten. Man muß daran denken, daß wir es bei diesen Anomalien zum Teil mit Heterozygoten zu tun haben.

Die Möglichkeit, positive Kennzeichen für die genuine Epilepsie zu gewinnen, wurzelt also in dem Bestreben, einmal eine gleichartige erbliche Belastung festzustellen, und dann in dem Versuch, die Persönlichkeit des genuinen Epileptikers bzw. die Art seiner geistigen Veränderung als etwas 
Besonderes und für die genuine Epilepsie Spezifisches zu erkennen. Wieweit eine solche Möglichkeit heute schon gegeben ist, wird in einem späteren Abschnitt zu erörtern sein. Zunächst sei auf den Anfall selbst eingegangen.

\section{Der elementare Krampf}

ist das Leitsymptom der Epilepsie. Die folgende Beschreibung der Anfälle fußt im wesentlichen auf den Erfahrungen bei der genuinen Epilepsie; sie gilt aber auch für einen großen Teil der symptomatischen Epilepsien, soweit diese mit generalisierten Anfällen einhergehen. Unvermittelt oder nach verschiedenartigen Vorläufererscheinungen (Aura) setzt unter Bewußtseinsverlust und Hinstürzen ein tonischer Krampf der Körpermuskulatur, meist auch der Glottis (initialer ,Schrei“", oft auch nur Krächzen oder ein anderer gepreßter Laut) ein, der meist infolge des Überwiegens der Strecker zu einer allgemeinen Streckhaltung führt, aber einzelnen Gliedern auch langsame und steife andersartige Bewegungen geben kann und nach kurzer Zeit in klonische Zuckungen des Rumpfes, der Glieder, der Kau-, Zungen-, Gesichts- und Augenmuskulatur übergeht. Nach einer Gesamtdauer von 1-2 Minuten werden die Zuckungen seltener und die Zuckungsausschläge umfangreicher, bis, gelegentlich nach einem Stadium ,großer" Gliederbewegungen, das längere Zeit anhalten kann, Körperruhe eintritt. Die den Krampf begleitende Bewußtlosigkeit kann unmittelbar in Schlaf hinüberführen, aus dem die Kranken zerschlagen und müde erwachen. Nicht selten, oft unter dem Einfluß der Umgebung, wachen die Kranken bald nach dem Beginn der Bewegungsruhe, meist langsam, auf, um über einen dämmerigen Zustand mit allmählich sich aufhellender Auffassung hinweg klar zu werden. Auch dann schlafen sie in der Regel bald ein. Beim Anfall kommt es oft zu Urin-, selten zu Stuhlabgang, unmittelbar danach gelegentlich zu Erbrechen. Während des Anfalles sind die mydriatischen Pupillen starr. Meist läßt sich am Ende des Anfalles Babinski nachweisen, während die Sehnenreflexe fehlen, aber auch lebhaft sein können. Die Bauchdeckenreflexe fehlen oft, ebenso der Fingergrundgelenkreflex. Beim Sturz ziehen die Kranken sich unter Umständen schwere Verletzungen an Kopf und Gliedern zu. Nicht selten entstehen Zungenbisse dadurch, daß beim Beginn des Krampfes die Zunge sich zwischen den Zahnreihen befindet oder daß diese während der Klonismen verletzt wird. Der oft blutig gefärbte Speichel wird durch die Zungenbewegungen zu Schaum geschlagen und läuft aus dem Munde.

In manchen Fällen stellen sich neue Anfälle ein, bevor das Bewußtsein wiederkehrt. Es kann auch zu langen Serien von Anfällen bei ständig fortdauernder Bewußtlosigkeit kommen (Status epilepticus). Dabei ist häufig die Körpertemperatur erhöht. Viele Kranke sterben in diesem immer bedrohlichen Status.

Die Aura kann die denkbar verschiedenste Gestalt annehmen. Wir kennen sie als Herzangst, als „aufsteigendes" Gefühl, als Sensation des Angeblasenwerdens (diese hat der Erscheinung den Namen gegeben), als Sensationen in diesem oder jenem Glied, als elementare Halluzinationen auf einem Sinnesgebiet, besonders gern als Schwindel, auch als gestaltete Halluzinationen. Bei dem einzelnen Kranken bleibt die Aura meist gleich; es 


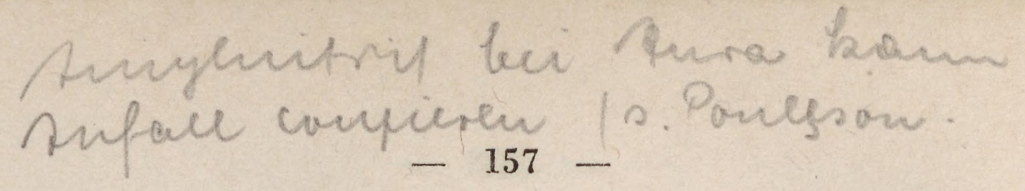

kommt also etwa regelmäßig zu der gleichen Halluzination eines immer größer werdenden Kopfes oder eines Tunnels oder einer Landschaft oder aber eines Anrufes, eines immer lauter werdenden Dröhnens (gelegentlich kann man hier Erlebnisbeziehungen nachweisen). Viele Kranke mit Aura sind imstande, sich durch rasches Niederlegen vor den Folgen des Sturzes zu bewahren. Solche ohne Aura sind stärker gefährdet. Die elementaren Anfälle stellen sich vielfach in der Nacht ein, besonders gegen Morgen. Es gibt Kranke, die vorher durch die Aura geweckt werden.

Nicht immer ist der Krampf voll ausgebildet. Bei manchen Kranken bleibt es beim tonischen Stadium, dem nur ganz vereinzelte Zuckungen folgen; bei anderen dauert das tonische Stadium nur kurz, und es kommt zu einer tonischen Bewegung eines Gliedes oder einer Körperhälfte oder eines Armes und des kontralateralen Beines. Dafür dauert das klonische Stadium dann länger, gelegentlich ist aber auch dies nur sehr kurz und unvollkommen. Vereinzelt sehen wir auch nur tiefe, kurzdauernde Ohnmachten, die mit einzelnen langsamen oder aber zuckenden Gliederbewegungen einhergehen.

Solche mehr rudimentäre Krämpfe führen zu dem Symptom des ,petit mal $^{66}$, der Absence, hinüber. Hier kommt es, oft zahlreiche Male am Tage, zu einer Bewußtseinsunterbrechung oder doch einer tiefgreifenden Trübung des Bewußtseins von wenigen Sekunden Dauer, in der die Kranken zusammensinken oder einige Augenbewegungen, schnappende Bewegungen mit dem Mund, die eine oder die andere hilflose Handbewegung machen oder sehr selten ganz ohne motorische Erscheinungen bleiben. Manche Kranke verlieren dabei, was sie in der Hand haben. Sprechen sie gerade, so kommt es zu einigen lallenden, schlecht artikulierten Worten oder unartikulierten Lauten. Nach der Absence geht, ohne daß die Kranken wissen was geschah, die Beschäftigung weiter, oder der Satz wird zu Ende geführt. Viele Kranke bemerken die Absence aber. Vom petit mal bis zum voll ausgebildeten elementaren Krampf gibt es Übergänge.

Ein - wenn man so will - in anderer Hinsicht rudimentärer Anfall ist der JacksonAnfall. Hier fehlt die Bewußtseinstrübung und es fehlt im allgemeinen auch die tonische Komponente des Krampfes. Es gerät auch nur ein Glied, etwa Hand oder Fuß oder das Fazialisgebiet, in Zuckungen. Der Anfall bleibt also auf eine Extremität, jedenfalls auf eine Körperhälfte beschränkt. Ursache ist stets eine Reizeinwirkung im Bereiche der gekreuzten motorischen Rinde. Der Jackson-Anfall ist also immer das Zeichen einer symptomatischen Epilepsie, während der generalisierte Anfall sowohl bei der genuinen wie auch bei symptomatischer Epilepsie vorkommt.

In der

\section{Genese des epileptischen Anfalles}

spielen vasomotorische und endokrine Vorgänge unzweifelhaft eine wesentliche Rolle. Vielleicht wirken beide auf dem Umwege über eine Verschiebung des Säure-Basengleichgewichts. Vor dem Anfall kommt es, wie bioptische Befunde zeigen, zu einer Vasokonstriktion im Gehirn, im Anfall aber zu einer üppigen Vasodilatation. Testes, Schilddrüse und Nebenschilddrüse sollen krampfhindernd, deren Ausfall krampffördernd wirken. Für die Testes scheint mir dies nicht ganz sicher. Unzweifelhaft ist dagegen die Bedeutung der Epithelkörper. Hypertrophie der Nebenniere wirkt, wie es scheint, krampffördernd; Ausschaltung einer Nebenniere hat eine vorübergehende krampf- 
mindernde Bedeutung. Übersäuerung, vor allem aber Alkalose wirken demgegenüber krampffördernd. Alkalose kann man etwa durch Hyperventilation erzeugen, die zur Prüfung der Krampfbereitschaft vor allem von Foerster in die Untersuchungsmethoden der Epilepsie eingeführt worden ist, aber leider nicht sehr häufig zum Ziele führt.

Bei all dem darf das Hirn selbst nicht vergessen werden, da es bei der Anfallsgenese offenbar eine sehr wesentliche Rolle spielt. Es scheint, als ob im Anfall in der Rinde selbst ein Giftkörper gebildet wird, der bei der Übertragung aufs Tier (Katze, Kaninchen) unweigerlich zu Anfällen führt.

Sehr häufig sind bei Epilepsie Störungen der Darmtätigkeit, besonders Verstopfung.

Am Nervensystem findet man grobe Veränderungen in der Regel nicht. Immerhin sind vorübergehende oder bleibende Reflexdifferenzen im späteren Krankheitsverlauf nicht selten. Sie beruhen zum Teil wohl auf Hirntraumen, die der Epileptiker sich beim Hinstürzen im Anfall zuzieht. Häufig begegnen uns auch Geruchsstörungen (Kontercoup bei Fall auf den Hinterkopf?).

Anfallsauslösend wirken besonders Alkohol, überhaupt reichliche Flüssigkeitsaufnahme, wohl auch Nikotin und unzweckmäßige, besonders fleischund kochsalzreiche Ernährung. Auch dauernde starke Muskelanstrengung und alle stärkeren körperlichen und gemütlichen Belastungen können die Häufigkeit der Anfälle steigern. Demgegenüber wirken chronische Krankheiten und Leiden, welche vorübergehend eine erhebliche Reduktion der Kräfte herbeiführen, auf das Anfallsgeschehen oft auffallend günstig.

\section{Dämmerzustände}

Der Zustand der Bewußtseinstrübung, der sich zwischen den elementaren Krampf und das Erwachen einschiebt, kann längere Zeit, Stunden, Tage, Wochen andauern und sich dann langsam oder auch rasch aufhellen. Wir sprechen dann von Dämmerzuständen, die auch als selbständige epileptische Erscheinungen ohne vorausgegangene Anfälle - als Äquivalente auftreten können. Nicht selten kommt es auch in solch einem Dämmerzustand erst zum Anfall oder zu einer Anfallsserie. Diese einfachen Dämmerzustände sind gekennzeichnet durch eine traumhafte Benommenheit. Die Kranken sind meist stark verlangsamt in Bewegung und Rede, fassen langsam und unvollkommen auf, sind örtlich und zeitlich desorientiert, örtlich oft auch falsch orientiert, verkennen einzelne Personen, die gesamte Umgebung, die Vorgänge in der Umgebung, soweit sie darauf achten. Sie begehen grobe Fehlhandlungen, trinken aus dem Spucknapf, urinieren ins Zimmer, steigen zum Fenster hinaus, ziehen sich verkehrt an usw. Ihr Denken ist wie ihr Handeln durch eine ganz außerordentliche Perseveration ausgezeichnet. Das Innenleben ist offenbar zähflüssig und arm. Es geht nichts oder wenig in den Kranken vor. Nicht selten ist eine gewisse Angst, die bei pflegerischen Maßnahmen plötzlich sehr heftig werden und zu wildester Abwehr führen kann. Gelegentlich kommt es aus der Verkennung der Situation heraus auch zu brutalen, sinnlosen Angriffen. Die Dämmerzustände hinterlassen volle Amnesie, wenn auch mit besonderen Methoden nachgewiesen werden kann, daß in ihnen die Merkfähigkeit nicht ganz aufgehoben ist. 


\section{Delirien}

An Stelle der Dämmerzustände, mit ihnen abwechselnd, bei manchen Kranken aber auch ausschließlich, kann es zu Delirien kommen, in denen lebhafte Erregung mit traumhaft phantastischen Visionen, aber auch mit Gehörs- und Gefühlstäuschungen einhergeht. Dabei besteht meist außerordentliche Angst, oder aber Angst wechselt mit gespannter Ekstase oder auch einer hochgradigen Zornmütigkeit, der Angst beigemischt ist. Die Inhalte der durch Sinnestäuschungen illustrierten Erlebnisse sind vielfach religiöser Natur (Gott, Himmel, himmlische Heerscharen, Teufel, Christi Leiden, Märtyrer), vielfach aber auch phantastische Quälereien und Bedrohungen. Die Visionen sind farbenreich; rot spielt eine besondere Rolle, besonders Blut und Flammen. Die Umwelt wird, soweit sie überhaupt für die Kranken eine Rolle spielt, im Sinne der Erlebnisse verkannt, meist wohl nur bruchstückweise, und dann auch noch unvollkommen verarbeitet. Dabei fehlt die Ansprechbarkeit oder sie ist gering. Bei aller Erregung sind die Bewegungen der Kranken oft langsam, ebenso auch die Reden, in denen wiederum Perseveration und eine unendliche Monotonie vorherrschen. Ganz vereinzelt sieht man auch ideenflüchtige Anknüpfungen. Perseveration, Langsamkeit und Schwerfälligkeit lassen aber auch dann die Komponenten der Benommenheit, die all diesen Zuständen eignet, immer durchscheinen. Bei nicht zu tiefer Bewußtseinstrübung kann es zu ausgeprägteren Wahnbildungen kommen (meist persekutorischer Art), die auch noch in die Zeit der Aufhellung des Bewußtseins als Residuärwahn hinübergenommen werden können. Recht selten sind die epileptischen Delirien ekstatisch-heiter gefärbt. Auch sie dauern Tage und Wochen. Die Delirien können Inhalte haben, die als solche erheblich an schizophrene Erlebnisse erinnern; die Benommenheitskomponente schützt meist vor Verwechslung. Auch für die Delirien besteht nachträglich Amnesie, abgesehen von den Residuärwahninhalten.

\section{Atypische Dämmerzustände und Delirien}

Die psychotischen Äquivalente sehen manchmal schizophrenen Schüben, ganz selten auch einmal zirkulären Phasen, insbesondere Mischzuständen, weitgehend ähnlich. Es handelt sich dann, wie es scheint, um Kranke, die entsprechendes Erbgut in sich tragen. Es gibt Krankheitsfälle, bei denen man Jahre hindurch nicht entscheiden kann, ob es sich um Epilepsien mit schizoformen Äquivalenten oder Schizophrenien mit Anfällen handelt. Hier kann klinisch nur die Art der Persönlichkeitsveränderung entscheiden.

\section{Besonnene Dämmerzustände}

Diese sind wohl in ausgeprägter Form recht selten. Epileptische in besonnenen Dämmerzuständen können sich geordnet und ganz unauffällig bewegen. Ihr Bewußtsein ist aber weitgehend eingeengt und die Gesamtsituation wird im Sinne wahnhafter Einstellungen einheitlich verkannt. In solchen Fällen kann es auch zur Veränderung des Persönlichkeitsbewußtseins, zu planlosem Wandern, zu unsinnigen Geschäften, zu Gewalttaten kommen. Eine nähere Untersuchung zeigt, daß Auffassung und Denken doch verlangsamt und unvollkommen sind im Gegensatz zu äußerlich vielleicht 
ähnlichen Zuständen hysterischer Art, bei denen Davonlaufen, Berufswechsel, Alternieren der Persönlichkeit usw. zweckhaft sind und einer Flucht in die Krankheit entsprechen. Amnesie oder doch lückenhafte Erinnerung gehört auch zu den besonnenen Dämmerzuständen.

Die besonnenen Dämmerzustände führen endlich hinüber zu den

\section{Verstimmungen}

der Epileptiker, die Stunden, Tage, Wochen anhalten und die verschiedenste Färbung annehmen können. Es gibt Zustände feierlicher Gehobenheit, in denen die Kranken sich unerhört glücklich, ekstatisch gehoben fühlen und eine feierlich-getragene Haltung zeigen. Ihre "Gottnomenklatur ${ }^{66}$ ist in solchen Fällen besonders ausgeprägt. Andere Epileptiker bekommen depressivgehemmte Verstimmungen, die von den melancholischen schwer zu unterscheiden sind. Besonders häufig aber sind die nervös-geladen-gereizt-explosiblen Verstimmungen, die oft ganz kurz dauern, aber auch lange Wochen fortbestehen können, Zustände, in denen die Kranken durch jede Kleinigkeit bis aufs Blut gereizt werden und sinnlos poltern, toben oder auch sich in zunehmend verbissene Wut hineinsteigern können. Oft finden sich dann paranoide Gedanken, unmotivierte verbissene Feindschaften mit entsprechenden Gewalttaten. Mitunter ist auch in diesen Zuständen das Bewußtsein ganz leicht getrübt. Die gereizten Verstimmungen können den großen Anfällen Tage vorausgehen oder ihnen nachfolgen, ebenso aber auch als einfache Äquivalente auftreten. Verstimmte dieser Art erwachen vielfach schon mit verbissener Geladenheit, die unter Umständen schon im Laufe des Vormittags verschwinden oder mit Schwankungen fortdauern kann.

\section{Wandertrieb (Poriomanie), Fugues, Dipsomanie}

In ihren Verstimmungen, vor allem in den gereizt-nervös-ablehnenden, treibt es manche Epileptiker davon, aus ihren Stellen, aus ihrer Arbeit, von ihrer Familie fort auf die Landstraße, an andere Plätze. Die Hauptsache ist dabei nicht das Ziel, nicht das Wandern und Umherirren als solches, sondern der Drang „fort", das Getriebenwerden, die innere ziellose Spannung. Tatsächlich finden sich viele Epileptiker dauernd auf der Landstraße. Oft ist bei ihnen zugleich das Bewußtsein ganz leicht getrübt, so daß gerade hier eine scharfe Trennung zwischen Dämmern und Verstimmung manchmal nicht möglich ist. Das Davonlaufen der Jugendlichen ist meist ganz anderer, psychopathischer Genese (Freiheitsdrang, reale Angst, Abenteuerlust, hysterische Sucht nach Ungewöhnlichem).

Selten sind jene Fälle, bei denen es in der Verstimmung zu Betäubungssucht kommt, so daß die Kranken dann mehr oder weniger regelmäßig dem Alkohol in die Arme getrieben werden. Die lösende und befreiende Alkoholwirkung sorgt dann dafür, daß der gleiche Ausweg immer erneut gefunden wird. Diese epileptischen Dipsomanen überfällt nach einer Periode der Nüchternheit und oft fleißigster, zäher Arbeit eines Tages plötzlich der nicht widerstehliche Drang zum Alkohol, oft zum Schnaps, der sie ins Wirtshaus führt und hier tagelang hängen bleiben läßt. Gelegentlich werden dann enorme Mengen Alkohol ohne deutlich sichtbare Trunkenheit vertragen. Der Drang 
zum Alkohol läßt dann unter Umständen ebenso plötzlich nach. Unter den sog. Dipsomanen sind die eigentlichen Epileptiker wohl verhältnismäßig seltene Erscheinungen. Die meisten von ihnen sind Psychopathen mit motivierten, selten auch unmotivierten Verstimmungen, manche auch Zirkuläre mit kurzdauernden Depressionen.

\section{Die Persönlichkeitseigenart und die Demenz des Epileptikers}

Bisher war, soweit von psychischen oder psychotischen Auffälligkeiten beim genuinen Epileptiker gesprochen wurde, nur von episodischen Störungen die Rede. Nun beobachten wir aber auch beim Epileptiker bleibende psychische Auffälligkeiten; ja, es steht auch fest, daß sich ein Teil dieser psychischen Erscheinungen im Laufe der Zeit so verstärkt, daß der Ausdruck „epileptische Demenz" berechtigt erscheint. Diese Entwicklung kann lange dauern; in anderen Fällen kann sie sich recht rasch entwickeln, auch dann, wenn große Anfälle nur selten eintreten. Im allgemeinen freilich scheint ein lockerer Parallelismus zwischen Anfallshäufigkeit und Einsatz sowie Tempo der Verblödung zu bestehen. Indes kommt man in manchen Fällen zu allzu ungünstigen Urteilen, weil man leichtere oder schwerere Ausnahmezustände, die im späteren Verlauf der Epilepsie lange andauern können, für den Ausdruck der Habitualpersönlichkeit hält.

Gewisse Persönlichkeitseigenarten finden wir bei vielen genuinen Epileptikern schon von vornherein, ja wir sehen sie auch bei ihren Verwandten, die nicht an Anfällen leiden. Man ist daher bestrebt, zu unterscheiden zwischen einer charakteristischen Persönlichkeitseigenart des genuinen Epileptikers und einer im Laufe des Leidens sich entwickelnden Demenz; für ihre Entstehung werden gerne die beim Anfall auftretenden Gefäßkrämpfe verantwortlich gemacht, die durch Ernährungsstörung im Laufe der Jahre zu Dauerschädigungen des funktionstragenden Nervengewebes führen können.

$\mathrm{Da}$, wie wir noch sehen werden, die charakteristische Persönlichkeitseigenart der genuinen Epileptiker ihrerseits dem Kranken den Gebrauch oder doch die Entäußerung seiner intellektuellen Fähigkeiten etwas erschwert, so ist es oft außerordentlich schwer möglich, die Persönlichkeitsveränderung und eine beginnende Demenz auseinanderzuhalten.

Wenn auch hier alles noch in Fluß ist, so wird sich doch der Begriff der iktaffinen Konstitution in irgendeiner Form durchsetzen. Mau z unterscheidet dabei zwei große Gruppen: Die eine, die sogenannte enechetische Konstitution ( $\dot{\varepsilon} \dot{\varepsilon} \chi \varepsilon \sigma \vartheta \propto \iota \iota=$ haftenbleiben) mit dem Kernsymptom des Haftens, entspricht etwa den Persönlichkeitseigenarten, die seit langem als kennzeichnend für die genuinen Epileptiker angesehen werden, während die anderen etwas uneinheitlicheren an das erinnern, was wir seit langem als epileptoid psychopathisch auszulegen versucht haben.

Im Vordergrund des enechetischen Persönlichkeitsbildes steht die Verlangsamung, die Mühseligkeit aller seelischen Vorgänge, von der Aufnahme des Materials bis zur eigentlichen Denkleistung. Dabei geht das Denken meist noch langsamer als das Sprechen. Der Epileptiker kommt nicht vom Fleck, braucht Flickworte, wiederholt sich und entwickelt jeden Gedankenfaden bis in die kleinste Einzelheit hinein; immer ist er unfähig, Wesentliches

11 Lange †-Bostroem, Psychiatrie, 3. Aufl. 
und Nebensächliches auseinanderzuhalten. Er ist umständlich, weitschweifig, unbestimmt, bewegt sich im allgemeinen und stellt die allergrößten Anforderungen an die Geduld der Hörer.

Die Grundstimmung der Epileptiker ist außerhalb der Ausnahmezustände vielfach euphorisch mit einer feierlichen Note, oft aber auch morosunfroh-gespannt; die Gemütsbewegungen, die sich auf dieser Grundstimmung entwickeln, sind eigenartig nachhaltig und zähflüssig wie das Denken, und deshalb so auffallend, weil es in der Regel Nichtigkeiten sind, an die sie sich knüpfen, das Wort eines Arztes oder Mitkranken, irgendeine "verbotene“ Handlung eines anderen, die Tatsache, daß der Alltag um eine Kleinigkeit anders verläuft als sonst. Vor allem ist der Epileptiker aber reizbar und empfindlich gegen kleinste „Kränkungen “. Eine Kränkung ist es schon, wenn der Arzt mit einem Nebenkranken ein Wort mehr spricht oder der Teller einen kleinen Sprung hat. Der Epileptiker kann darüber sehr erregt werden und vor allem endlos nachtragen. Er beachtet mit Nachdruck, daß es ,gerecht" zugeht, wobei er freilich im wesentlichen sein eigenes Recht sucht, gegen dessen Verletzung er sich zur Wehr setzt, während er anderen mit Mißgunst, Schadenfreude, Klatscherei, Verlogenheit, Gehässigkeit, die er gern in pathetisch-weltanschaulichen oder religiös-strafenden, innerlich verlogenen Reden verbirgt, in gröbster Weise Unrecht tut. In Epileptikerabteilungen herrscht oft Zank, immer Feindschaft und gegenseitiges Auf-die-Finger-Sehen. Der Epileptiker kann sich aber auch nachhaltig freuen und von strahlendem Glück über eine Kleinigkeit, über einen freundlichen Blick, über einen Händedruck sein. Er lobt Vater und Mutter, die er die liebsten und besten Menschen nennt, auch dann, wenn er oft in Streit und Unfrieden mit ihnen ist (Familienlobrednerei), ebenso wie den lieben Gott, den er gern im Munde führt. Bei aller Wichtigkeit, die Kleinigkeiten, auch ein graues Haar am Kopf oder ein Tropfen neben dem Teller, haben, ist die Krankheit selbst mit ihren elementaren Anfällen oft von nebensächlicher Bedeutung. Epileptiker, die nach jedem schweren Anfall behaupten, dies sei der letzte, und immer erneut zuversichtlich das gleiche behaupten, sind nicht selten. Andere freilich sind nach jedem Anfall gänzlich verzweifelt. Im ganzen aber überwiegt der Optimismus.

Im Handeln der Kranken herrscht Pedanterie, Umständlichkeit, Langsamkeit. Alles muß peinlich genau, der Ordnung nach getan werden, Anziehen und Waschen, Bettmachen und Säubern des Zimmers. In den großen Dingen herrscht dabei freilich oft Unordnung, weil der Kranke sie nicht mehr zu überblicken vermag.

In seinen langsamen, oft stockenden Reden fließt der Epileptiker gern vor Höflichkeit, Süßlichkeit und verlogenem Pathos über. Dabei sind die Gedanken arm und voll von Wiederholungen, die Wendungen oft umständlich und stereotyp. Nicht selten ist die Wortfindung leicht erschwert, und es kommt dann zu verschrobenen, schwülstigen Ausdrücken und Redewendungen, die den langsamen Ausführungen des Epileptikers etwas Gequältes und für den Hörer Anstrengendes geben. Die Schrift ist oft gestochen, klar und sauber, peinlich angeordnet und unterstrichen. Perseveration und Umständlichkeit finden sich in verstärktem Maße auch hier.

Stauder sieht diese Persönlichkeitseigenart als eine Besonderheit der genuinen Epilepsie an, während die Demenz nach seiner Meinung nur auf 
die Anfälle zurückzuführen ist und demgemäß also auch bei symptomatischer Epilepsie vorkommen kann, wenn nur die Anfälle zahlreich genug auftreten. Differentialdiagnostisch ist diese Auffassung deshalb schwer zu verwerten, weil Persönlichkeitsveränderung und Demenz praktisch oft schwer zu unterscheiden sind, wenn sie auch theoretisch getrennt werden müssen.

Richtig ist, daß man die Persönlichkeitsveränderung auch bei den Verwandten der genuinen Epileptiker oft antrifft und daß sie oft mit dem athletischen Körperbau vergesellschaftet ist (Kretschmer, Enke); dieser kommt neben den dysplastischen Körperbauformen am häufigsten bei der genuinen Epilepsie vor.

Sicher erscheint mir aber weiter, daß es auch andere Konstitutionsformen bei der genuinen Epilepsie gibt; diese sind weniger einheitlich und auch weniger klar zu präzisieren. Mauz hat sie einstweilen noch etwas unbefriedigend unter dem Ausdruck "kombinierte Defektkonstitutionen" zusammengefaßt und darunter bestimmte Minderwertigkeiten und Schwächen des zentralen und gesamten vegetativen Nervensystems, die mit erhöhter Krampfbereitschaft verknüpft sind, verstanden. Im einzelnen nennt er als komplexeren Typ die explosive Konstitution, die Beziehungen zu vasomotorischen Störungen, aber auch zu athletischem Habitus haben können. In diesen Bereichen finden sich auch Dysplasien und Zeichen endokriner Minderwertigkeit und auf psychischem Gebiet ein mürrisches, launenhaftes, oft brutales, widerspenstiges Wesen, das es im Zusammenhang mit geringer intellektueller Begabung erklärt, daß sich hier viele Asoziale finden.

Auch bei diesen Typen ist die zusätzlich entstehende Demenz nicht immer leicht abgrenzbar, zumal da hier oft von vornherein eine intellektuelle Minderveranlagung besteht. Man ist daher bei der Feststellung der eigentlichen Demenz praktisch meist auf die Beobachtung der Progredienz angewiesen.

Zunächst hat man dabei oft nur den Eindruck einer Verdichtung der schon vorhandenen Persönlichkeitseigenart. Aber je weiter die Veränderung fortschreitet, desto bescheidener werden die Zusammenhänge, die er überblickt. Zugleich lassen Merkfähigkeit und Gedächtnis, meist in gleichem Maße, nach, während die Reproduktionsfähigkeit als solche nicht Schaden leidet. Inhaltlich wird das Denken des Epileptikers zunehmend eng. Sehr bald sieht er nicht über seinen engsten Arbeitskreis, später über die Familie und schließlich über das allereigenste Wohl und Wehe hinaus. Nur die religiöse Welt ist ihm vielfach noch in einem allzu egozentrischen Ausschnitt zugänglich. Der liebe Gott und der gute Jesus (Gottnomenklatur) gehören. eigentlich ihm; er ist ihr liebes Kind. Im übrigen ist das nicht anders mit Vater, Mutter und Ehepartnern, von denen wenigstens geredet wird, während ernstlich nur die Vorgänge am eigenen Körper, Stuhlgang und Appetit, Schmerzen, Körperwärme, Puls und Schlaf Beachtung finden, dazu die kleinen und kleinsten Vorkommnisse des Alltags, die das Wohl des Kranken berühren. Neben dieser Einengung kommt es schließlich auch zu ausgemachter Urteilsschwäche, die meist das Kennzeichen der Verlangsamung und Zähflüssigkeit behält. 


\section{Verlauf}

Die genuine Epilepsie beginnt meist früh im Leben. Fast 20\% der Kranken haben ihre ersten Erscheinungen schon bis zum 10. Lebensjahr, weitere $50 \%$ bis zum 20. Lebensjahr, nicht ganz $15 \%$ erkranken erst jenseits des 30 . Lebensjahres. Männer werden wesentlich häufiger befallen als Frauen.

Die Krankheit kürzt das Leben durchschnittlich erheblich ab. Mehr als zwei Drittel sind beim Tode noch nicht 40 Jahre, $40 \%$ noch nicht 30 Jahre alt. Jene Epileptiker, die vor dem 10. Lebensjahr erkranken, leben bis zum Tode noch durchschnittlich 25 Jahre. Die Krankheitsdauer bis zum Tode wird bei den später Erkrankenden kürzer. Weniger als 15 Jahre vergehen bis zum Tode bei mehr als der Hälfte der Epileptiker, bis zu 20 Jahre bei fast drei Viertel der Fälle. Immerhin kennen wir besonders unter den leichteren Fällen auch ältere Epileptiker; bei entsprechender Schonung auch Patienten mit über 50 und über 60 Jahren. Unter den Todesursachen spielt die Epilepsie selbst, also vor allem der Status und der Tod im Anfall, die wichtigste Rolle. Häufig ist auch die Tuberkulose. Nicht selten aber sind es auch andere Krankheiten, die den Tod herbeiführen.

Eine einheitliche Schilderung des Verlaufs ist unmöglich, da es die allerverschiedensten Typen gibt. Immerhin ist es recht häufig, daß sich die allerersten Erscheinungen des Leidens in „Kinderkrämpfen “ äußern, solchen im Kleinkindesalter oder einzelnen Anfällen, die sich bei älteren Kindern gern gelegentlich der Infektionen einstellen. Dann tritt vielfach eine längere Pause ein, bis in der Pubertät, bald vorher oder bald nachher, die Anfälle erneut einsetzen. In vielen Fällen kommt es zunächst zu Absencen, die vereinzelt oder gleich anfangs gehäuft auftreten; dann kann lange Zeit vergehen, bis den Kranken der erste schwere Anfall überfällt. Manchmal geschieht dies aber sehr bald, und oft kommt es gleich anfangs zu schweren Anfällen. Bei manchen Kranken dauern gehäufte kleine Anfälle eine ganze Reihe von Jahren fort, ehe elementare Krämpfe die Natur der Krankheit anzeigen. Manchmal kommen die typischen Krämpfe gleich anfangs in längeren, zunächst gleichbleibenden Abständen von einem oder mehreren Monaten; es können aber zunächst auch Pausen von langen Jahren eintreten und die Krankheit kann geheilt erscheinen, bis nach 5 und 10, ja mehr Jahren das Anfallsspiel erneut, für dauernd oder abermals nur für eine gewisse Periode, beginnt. In zahlreichen Fällen werden die Pausen zwischen den einzelnen elementaren Anfällen rasch kürzer. Die Anfälle schließen sich zu Serien zusammen. Kam es erst nur zu nächtlichen Anfällen, so treten solche später auch am Tage auf; dazu gesellen sich kürzer dauernde Dämmerzustände und Verstimmungen, die in anderen Fällen auch schon früh hervortreten können. Der erste Status ist oft von besonders schlimmer Wirkung auch für den Habitualzustand. Die Demenz wird manchmal ziemlich früh deutlich; bald läßt sie aber lange Jahre auf sich warten. Sie kann schubweise Fortschritte machen. Im späteren Verlaufe mancher Epilepsien werden die Anfälle ihrer Schwere nach weniger alarmierend. Dafür bleiben Verstimmungen und leichte Dämmerzustände fast chronisch bestehen, so daß die Kranken, die in guten Zeiten noch recht ordentlich erscheinen können, in der Regel doch einen sehr schwer veränderten Eindruck machen. Man warte also mit seinem Urteil 
über einen alten Epileptiker immer längere Zeit, bis Gelegenheit gewesen ist, auch den bestmöglichen Zustand kennenzulernen.

Bei vielen Epileptikern ist das Ende eine sehr erhebliche Demenz, die sich in außerordentlicher Schwerfälligkeit, Langsamkeit, Einengung, Sprachschwierigkeiten und Charakterveränderungen kennzeichnender Art kundgibt und sich lange Jahre hinziehen kann.

Es gibt aber Epilepsien, die im Leben nur wenige Anfälle machen - Oligoepilepsien - und vielfach auch ohne tiefe Demenz verlaufen, während in anderen Fällen trotzdem, und obwohl vorwiegend nur Absenzen vorkommen, die Demenz ziemlich ausgeprägt werden kann. Endlich kennen wir seltene Fälle, in denen die Epilepsie auszuheilen scheint.

Etwa ein Drittel der Kranken wird bald nach der ersten Aufnahme, die oft schon durch Anfallshäufung herbeigeführt wird, für dauernd anstaltsbedürftig. Andere leben arbeitsunfähig daheim. Mehr als ein Drittel vorübergehend anstaltsbedürftiger Kranker aber lebt arbeitsfähig - meist in bescheidenen Berufen - in der Freiheit. Die Oligoepilepsien sind nicht so selten, wie man gern annimmt; sie halten sich vielfach auch in gehobenen Berufen. Bescheiden ist die Zahl der "geheilten“ oder bei ganz seltenen Anfällen stationären Fälle. Hier sind es dann oft Zusatzreize - Alkohol, Überanstrengung, Infektionen, Traumen -, die erneut zu einzelnen Anfällen führen.

\section{Soziale Beurteilung}

Bis 1934 ist in recht zahlreichen Fällen die Epilepsie kein Ehehindernis gewesen. Von den Münchener Klinikfällen waren etwa ein Drittel verheiratet und die meisten davon haben lebende Nachkommenschaft. Immer noch spielt dabei offenbar die verbreitete Volksmeinung, die Ehe könne die Anfälle beseitigen, eine wesentliche Rolle. Als Erbkrankheit fällt die genuine Epilepsie jetzt unter die Anzeigepflicht des Gesetzes zur Verhütung erbkranken Nachwuchses. Vor Durchführung des Verfahrens ist eine genaue Klärung der Frage, ob erbliche oder erworbene Fallsucht vorliegt, unbedingt erforderlich. Aber auch bei symptomatischer Epilepsie wird man unter Umständen an ein Eheverbot im Sinne des $\S 1$ c des Ehegesundheitsgesetzes zu denken haben, nämlich dann, wenn die Erkrankung mit psychischen Störungen einhergeht.

Die Unterbrechung der Schwangerschaft kann durch Häufung der Anfälle während der Gravidität indiziert sein.

Invalidisierung kommt in Betracht, wenn die Anfälle zu rasch aufeinanderfolgen; zu bedenken ist dabei, daß auf Zeiten mit Anfallshäufung auch solche mit weniger zahlreichen Anfällen folgen können. Auch eine erkennbare Demenz oder eine starke Schwerfälligkeit kann die Voraussetzungen für eine Invalidisierung sein.

Straftaten, die sicher im epileptischen Dämmerzustand erfolgt sind, fallen unter den $\S 51,1$ StGB. Die Frage der Zurechnungsfähigkeit außerhalb einer solchen episodischen Psychose hängt ab von dem Grade der vorhandenen Persönlichkeitsveränderung oder Demenz. Zu berücksichtigen sind unter Umständen auch zeitliche Beziehungen zum Anfall. Unter Umständen kommt bei leicht veränderten Persönlichkeiten auch der $\S 51,2$ in Betracht. 


\section{Der Leichenbefund}

Der Leichenbefund zeigt wenig kennzeichnende Veränderungen. Am meisten charakteristisch ist noch die Ammonshornsklerose und gewisse Veränderungen in der Molekularschicht der Kleinhirnrinde, die aber vielleicht Folgen der die Anfälle begleitenden (verursachenden?) Gefäßspasmen sind. Regelmäßig ist auch eine ausgesprochene sogenannte Randgliose (Chaslin), d. h. eine starke Gliafaserbildung an der Oberfläche der Rinde, die aber auch bei anderen chronischen Leiden vorkommt. In zahlreichen Epileptikerhirnen finden sich Zeichen von Entwicklungsstörungen, aber nicht nur bei diesen, ja selbst bei normalen. So sieht man häufig Cajalsche Zellen, d. h. große Nervenzellen in der ersten für gewöhnlich fast nervenzellfreien Rindenschicht, aber auch Nervenzellen im subkortikalen Mark. Häufig begegnen uns bei Epileptikern kuppenständige Herde an den Polen und der Oberfläche von Stirn- und Schläfenlappen, und zwar als Folgen von Stürzen im Krampf (Rindenprellungsherde).

\section{Die Behandlung}

hat vor allem alle jene Reize auszuschalten, welche die Anfallshäufigkeit steigern. Der Epileptiker soll also ohne Alkohol, ohne Nikotin, mit möglichster Regelmäßigkeit bei reichlichem Schlaf, ohne starke Muskelanstrengung und bei laktovegetabiler, fleisch-, kochsalz- und flüssigkeitsarmer Ernährung leben. Für regelmäßige Darmtätigkeit ist Sorge zu tragen.

Von den Mitteln zur Anfallsbekämpfung stehen Luminal und Brom im Vordergrund. Luminal oder Luphenil gibt man in Dosen von 0,05 bis 0,1 2 - 3 mal am Tage. Man beginne mit kleinen Dosen und steigere bis zur Anfallsfreiheit, gehe dann so lange zurück, bis der erste Anfall wiederkehrt, um dann ein wenig zuzulegen. Auch fortlaufende Gaben von 0,3 und 0,4 am Tage werden von vielen Epileptikern auffallend gut und ohne besondere Ermüdungserscheinungen vertragen. Luminal muß man ständig fortgeben und im Notfalle langsam ersetzen, da bei raschem Aussetzen stürmische Anfälle und Statuszustände eintreten können.

Brom gibt man in Gaben bis zu 4, 5, $6 \mathrm{~g}$ am Tage als Bromkalium-, Bromnatriumlösung oder in der Form von Sedobrolwürfeln (1 g pro Würfel) als angenehm schmeckende Suppe oder als Suppenzusatz. Notwendig ist bei jeder Brombehandlung eine Einschränkung der Kochsalzaufnahme. Zweckmäßig kann eine Kombination der Mittel sein. Man verwendet jetzt gern Lubrokal (1 Tablette 0,6 g Brom, 0,04 g Natr. phenylaethylbarbitur. bis zu 3 mal täglich 2 Tabletten). Beim Bromgebrauch ist stets auf den Bromismus zu achten, der sich meist in der Bromakne ankündigt und zu recht schweren Zuständen (Somnolenz mit Erregung, lallender Sprache usw.) führen kann. Auch Brom soll man nur langsam absetzen.

An Stelle von Luminal gibt man heute gern Prominal in Dosen von $0,1-0,4$, besser ist Lurasyl.

Zweckmäßig ist es, neben Luminal noch Ameisensäure (3 mal 10 Tropfen) zu geben. Vielleicht wirkt auch Luminal vor allem wegen seiner sauren Eigenschaften. An Fabrikpräparaten wird besonders Epilepsin und Epileptol gelobt. In neuerer Zeit setzt man dem Luminal gern Koffein zu; in der Form 
von Coffeminal kann man gleich ein Kombinationspräparat (Luminal 0,05 und Koffein 0,025) verwenden. Man kann auch eines der neueren Gefäßmittel, etwa Padutin mit Luminal, kombinieren. Vielversprechend ist der von St a uder erprobte sog. vierte körpereigene, blutdrucksenkende und gefäßerweiternde Stoff (neben Cholin, Histamin, Adenosin), der offenbar an die Arteriolen gebunden ist.

Der immer äußerst gefährliche Status wird mit großen Gaben narkotischer Mittel angegangen. Als zweckmäßig hat sich besonders das Amylenhydrat (6,0 in 30,0 Gumm. arab. als Klysma) unter Umständen mehrfach täglich erwiesen. Man kann auch Pernokton bis zu 4,0 und Endorm versuchen. Im Notfalle greife man zur Allgemeinnarkose (nicht Äther). Günstig hat sich mir oft ein großer Aderlaß (500-600 ccm) erwiesen, und in einzelnen Fällen wirkt die wiederholte Lumbalpunktion lebensrettend. Es ist auch vorgeschlagen worden, den Liquor durch Luft zu ersetzen. Luminal hilft hier im allgemeinen wenig.

Der Epileptiker soll in den Anfällen und besonders im Status vor Verletzungen geschützt werden. Zweckmäßig ist hier besonders das Polsterbett. Im übrigen wird man den Kranken nach genauem Studium der Auraerscheinungen beraten. Auf keinen Fall gehört der Epileptiker in Maschinenbetriebe, auf oder ans Wasser oder in die Nähe des Feuers und in die Höhe. Auch im Pferdestall ist er nicht am Platz. Einfache Feldhandarbeit, Gärtnerarbeit, Arbeit zu ebener Erde kommen in Betracht. Schwimmen muß untersagt werden.

Die Abgrenzung der symptomatischen Epilepsien

Der epileptiforme Anfall ist eine allgemein menschliche Reaktionsform, die bei den verschiedensten Leiden auftreten kann. Die wichtigste Frage ist daher die: Handelt es sich um eine genuine oder um eine symptomatische Epilepsie? Die Art des Anfalls kann hier nur selten eine Klärung bringen, denn sicher symptomatischer Natur sind lediglich die halbseitig oder eingliedrig auftretenden Jackson-Anfälle ohne Bewußtseinsverlust (Herd in der gekreuzten motorischen Rinde); wir wissen aber, daß die meisten symptomatischen Epilepsien mit generalisierten Anfällen einhergehen; ja auch das Auftreten von Dämmerzuständen kann, wenn auch sehr selten, bei symptomatischer Epilepsie vorkommen. Es ist als praktisch in jedem Fall von Epilepsie erforderlich, sich zu vergewissern, ob nicht eine äußere Ursache, eine erworbene Schädigung der Ausgangspunkt für die Anfälle sein kann. Von den Vergiftungen sind besonders Alkohol und Blei zu nennen. Die genaue körperliche Untersuchung (Polyneuritis hier, Bleisaum, Darmstörungen, Kolorit, unter Umständen Bleilähmung, Blutbefund dort) wird vor Verwechslungen schützen. Wichtig ist aber, daß Alkohol, wie erwähnt, auch die Erscheinungen der genuinen Epilepsie verschlimmern kann. Die Alkoholepilepsie ist aber ein Zeichen besonders schweren Alkoholismus und wird kaum fälschlich angenommen werden können, um so weniger, als die Anfälle mit der Abstinenz verschwinden. Wo dies nicht der Fall ist, wird meist Epilepsie vorliegen. $\mathrm{Daß}$ auch bei allen möglichen anderen Vergiftungen (Kohlenoxyd, Schlafmittel usw.) vereinzelt epileptische Anfälle vorkommen, sei erwähnt. 
Eine genaue körperliche Untersuchung wird in der Regel auch erkennen lassen, ob der epileptische Anfall Ausdruck einer Urämie, einer anderen Stoffwechselvergiftung, der Lues, der Paralyse ist. Die Arteriosklerose wird differentialdiagnostisch Schwierigkeiten nur selten machen.

Viel wichtiger ist die Tatsache, daß auch Hirntraumen zu generalisierten epileptiformen Anfällen führen können. Der Umstand, daß die Aura sich gelegentlich in dem Herdgebiet abspielt, kann zuweilen einen Hinweis geben. Das Wesentliche sind aber neurologische Herderscheinungen. Äquivalente sind bei der traumatischen Epilepsie wesentlich seltener als bei der genuinen. Die hirntraumatischen epileptischen Anfälle können zuweilen erst nach sehr langem Intervall auftreten, unter Umständen erst nach einem Jahrzehnt und nach noch längerer Zeit. In allen zweifelhaften Fällen ist neben einer genauen neurologischen Untersuchung eine Röntgenaufnahme des Schädels und eine Enzephalographie, die allerdings in der ersten Zeit nach dem Trauma vermieden werden muß, unerläßlich. Wichtig ist, daß nicht jede leichte Schädelverletzung etwa zur traumatischen Epilepsie führen kann; aber auch die unkomplizierte Gehirnerschütterung ist dazu nicht geeignet, wohl aber schwere Hirnschädigungen und vor allem penetrierende Schädelhirnverletzungen können als Ursache einer traumatischen Epilepsie in Betracht kommen.

Auch geburtstraumatische Gehirnschädigungen oder frühkindliche Enzephalitiden sind zuweilen Anlaß zur symptomatischen Epilepsie.

Weitaus am wichtigsten bei der Entstehung der symptomatischen Epilepsie ist der Hirntumor. Wir müssen wissen, daß der epileptische Krampfanfall (auch der generalisierte) oft das einzige Symptom eines Hirntumors sein kann und daß er auch oft lange die einzige Erscheinung bleibt. Man darf daher auch hier nichts unversucht Iassen (Enzephalographie), um zur Diagnose zu kommen. Die psychischen Erscheinungen des traumatischen Epileptikers können zuweilen denen des genuinen ähneln.

Eine absolut scharfe Trennung zwischen genuiner und symptomatischer Epilepsie ist allerdings praktisch nicht immer möglich. So muß es auffallen, daß zuweilen ein recht geringfügiger äußerer Schaden bei manchen zu epileptischen Anfällen führt, der bei anderen Personen keine Anfälle hervorruft. Das setzt voraus, daß bei den mit Anfällen reagierenden Menschen doch eine Anlage vorhanden gewesen sein muß, die aber so gering war, daß sie allein nicht zur Manifestation ausreichte. Solche Fälle, bei denen die epileptische Veranlagung zu ihrem Inerscheinungtreten noch irgendwelcher äußerer Hilfsfaktoren bedarf, nennt Stauder ,provozierte Epilepsien“; Mauz spricht bei diesen etwas ,milderen“ Anlagen von ,,iktaffinen Diathesen“.

Nun gibt es außerdem noch Anfallsleiden, die mit der Epilepsie nichts zu tun haben und von denen die gehäuften kleinen Anfälle im Kindesalter (Pyknolepsie) und die Narkolepsie zu nennen sind. Die gehäuften kleinen Anfälle gleichen weitgehend den Absenzen. Sie können zahllose Male (30 bis $40 \mathrm{mal}$ ) am Tage auftreten und sprechen nicht auf antiepileptische Mittel an. Die betroffenen Kinder sind meist geweckt, lebhaft und intelligent. Wo die Anfälle nach der Pubertät fortdauern, handelt es sich tatsächlich um Epilepsien.

Die Narkolepsie geht mit Anfällen unwiderstehlichen Schlafes und plötzlich auftretenden Zuständen von affektivem Tonusverlust einher, d. h. bei plötzlichen Gemütsbewegungen aller Art (auch Freude) sinken die Kranken 
in sich zusammen, um sich rasch zu erholen. Es finden sich bei ihnen auch nächtliche Wachanfälle, in denen sie bewußtseinsklar, aber bewegungsunfähig sind und unter Umständen lebhafte halluzinatorische Erlebnisse haben. Häufig ist die Narkolepsie eine Folge der Encephalitis epidemica; wir sehen sie aber auch bei endokrin Stigmatisierten, besonders bei Jugendlichen.

Tetanische Anfälle können in seltenen Fällen mit epileptischen verwechselt werden. Umgekehrt darf nicht jeder epileptische Anfall, der bei einem zur Tetanie Neigenden auftritt, als tetanischer Anfall aufgefaßt werden.

Die Spasmophilie (kindliche Tetanie), kenntlich an Laryngospasmus, mechanischer und elektrischer Übererregbarkeit, häufig bei deutlicher Rachitis, hat mit der Epilepsie nichts zu tun. Sie ist eine Erkrankung der ersten Lebensjahre. Sicher epileptische Krämpfe in den ersten Monaten nach der Geburt weisen auf Hirnschädigungen (Geburt) hin, ohne sie zu beweisen. Frühkindliche Hirnschädigungen, die auch noch spät im Leben Epilepsie verursachen können, sind meist an geringgradigen neurologischen Störungen und feineren oder gröberen einseitigen Wachstumsanomalien (Verbiegungen und abnorme Relationen der Fingerlängen) erkennbar. Die sogenannten kindlichen Gelegenheitskrämpfe sind vielfach Ausdruck symptomatischer Epilepsie. Besonders der Keuchhusten ist hier zu nennen (Blutungen).

Der hysterische Krampf kann, von seltenen Ausnahmen abgesehen, mit dem epileptischen schwer verwechselt werden, wo man auf die nicht nachzuahmenden Erscheinungen, Babinski, Pupillenstarre, achtet. Nur bei besonderer Dressur kann ein Psychopath einmal einen epileptischen Anfall geschickt vortäuschen. Im übrigen sind alle hysterischen Erscheinungen, auch die Dämmerzustände, von außen her beeinflußbar. Sie sind Demonstrationen für die Zuschauer und sprechen regelmäßig auf Nichtbeachtung an. Die epileptische Wesensveränderung, das Kleben und Haften, die Enge und Pedanterie lassen sich nicht nachahmen. Hysterische sind ganz andere Menschen. Zu beachten ist aber, daß gar nicht so selten auch Epileptische einmal hysterische Anfälle bekommen.

\section{o) Schizophrenie}

Die Schizophrenie ist die häufigste Geisteskrankeit. Bei der Untersuchung von verschiedenartig gewählten Gruppen der Durchschnittsbevölkerung in verschiedenen Teilen Deutschlands hat man eine Erkrankungswahrscheinlichkeit von 0,5 bis über 1 auf 100 (durchschnittlich 0,85\%) errechnet. Bei Berücksichtigung der Tatsache, daß die leichtesten Formen der Erkrankung dabei schwerlich erfaßt werden, wird man demnach damit rechnen müssen, daß ungefähr 1 von 100 Menschen, welche die Gefährdungszeit erleben, tatsächlich erkrankt. Freilich muß man mit erheblichen Häufigkeitsunterschieden bei den verschiedenen Rassen, aber auch in den verschiedenen Gegenden des deutschen Sprachgebietes rechnen. So ist etwa in Basel die Schizophrenie wesentlich häufiger als in Oberbayern.

Kraepelin hat die Zusammengehörigkeit der hier beschriebenen Krankheitsprozesse erkannt. Er wählte den Namen Dementia praecox. Die Bezeichnung Schizophrenie ist angemessener. Sie stammt von Bleuler, der sich 
entscheidende Verdienste um die Erforschung der schizophrenen Krankheitsvorgänge, besonders auch deren Psychopathologie, erworben hat.

Langsam progredient, häufig auch in einzelnen abgesetzten Schüben, verlaufend führt die Krankheit in der großen Mehrzahl der Fälle zu bleibenden Veränderungen und oft genug zu eigenartigen schweren Defektzuständen, die eine dauernde Absonderung der Kranken von der Gemeinschaft nötig machen.

Man hat wiederholt versucht, eine zentrale psychologische Veränderung als Ausdruck des schizophrenen Prozesses herauszustellen, aus der sich dann alle schizophrenen Einzelsymptome herleiten sollen. Diese Versuche sind nicht überzeugend gelungen. Sie eignen sich auch nicht zur kurzen Darstellung. Sicherlich ist aber jeweils das gesamte Seelenleben der Kranken verändert. Auf dem Gebiete des Denkens ist es ein eigenartiger Zerfall der Denkregeln und Begriffe, der in jedem Falle deutlich wird. Stets erscheint auch das Gemütsleben verändert. Die für den Gesunden verbindlichen gemütlichen Beziehungen machen einer allgemeinen Gemütsleere Platz, oder sie werden dauernd oder vorübergehend durch dem Gesunden uneinfühlbare Gemütsregungen und Gefühlsbeziehungen ersetzt. Im Handeln schwindet wie im Denken Folgerichtigkeit, Einheit und die Richtung auf die Verwirklichung allgemein verbindlicher Werte. Dabei passen weder die Denkinhalte zueinander noch führen sie zu verständlichem gemütlichem Widerhall oder entsprechendem Handeln. Gerade darin äußert sich die zuerst von Stransky so genannte ,intrapsychische Ataxie ${ }^{66}$, das eigentlich ${ }_{9}$ Schizophrene ${ }^{66}$, die Spaltung im Seelenleben der Kranken.

Im einzelnen sind besonders häufig die Störungen des Denkens, die immer noch am besten als Zerfahrenheit bezeichnet werden. Zwei besonders gute Beispiele Gruhles sollen dies deutlich machen: 1. Mit dem Hut in der Hand kommt man durchs ganze Land. Was heißt das? ,Was für ein Hut? Ich weiß nichts ${ }^{66}$ (?). ,Wenn man irgendwohin geht, dann setzt man anstandshalber einen Hut auf. Wenn es im Sommer heiß ist, dann laufen die Herren ohne Hut, dann hängen sie ihn an eine Schnalle“6 (?). „Wenn die Herren auf der Straße grüßen, dann nehmen sie ihn herunter. - Ich weiß nichts mehr. ${ }^{66}$ - 2. Neue Besen kehren gut. Was heißt das? „Sobald die Hausfrau einen neuen Besen hat, kehrt er gut, sie kann aber auch alte sehr lang ausnutzen und sich dadurch die neuen Besen zu erhalten suchen. Man hat auch oft altes Material, das verwendet werden kann. Es ist nicht gesagt, daß es immer neue Besen sein müssen“6 (?). „Es liegt sehr viel an der Hausfrau, wenn sie ordentlich angezogen ist. Man sagt auch, Kleider machen Leute, vor allem aber muß die Gesundheit da sein."6

Wir sehen hier, wie die beiden Kranken am Sinn der Aufgabe vorbeidenken, der ihnen entgleitet, wie sie an Einzelheiten kleben, immer neue an sich richtige Gedanken vorbringen, die nur mit dem Sinn der Aufgabe nichts und die zum Teil auch miteinander nichts oder nur wenig zu tun haben, um schließlich erneut auf andere Gedanken abzugleiten. Das Denken erscheint faselig. Die Denkergebnisse passen nicht zur Frage; es fehlt an der Ordnung, welche die Aufgabe in das normale Denken bringt.

In allen ausgesprocheneren Fällen wird es dem Kranken möglich, die absonderlichsten Inhalte gedanklich zusammenzubringen, etwa die home- 
rischen Griechen mit Schnellfeuerschützen auszustatten oder das Meer als Frau zu denken, weil es Meerbusen gibt. Überhaupt können gleiche oder ähnliche Bezeichnungen, Mehrdeutigkeiten, historische Nachbarschaft darüber bestimmen, daß ganz heterogene Begriffe füreinander unvermittelt eintreten. und den Gedankengang abbiegen oder völlig undurchsichtig machen. Symbolische Beziehungen, Analogien und Bilder werden plötzlich als tatsächlich genommen, im nächsten Augenblick aber wieder nicht. Dies alles ist ganz unberechenbar. Im schizophrenen Denken können schlechthin alle Gegenstände mit allen anderen zusammengebracht werden und alle Arten von Beziehungen: Grund und Folge, Ursache und Wirkung, Bedingungs- und zeitliche Zusammenhänge, äußere und innere Wirkung gegeneinander vertauscht werden. So kommt es zu Begriffsverschiebungen, zum Zerfall, zur Verdichtung einzelner Begriffe. Dabei ist besonders wichtig, daß häufig noch zahlreiche Gedanken normal erscheinen, ja daß der Kranke im ganzen unauffällig sein kann, ohne doch vor plötzlichen, ganz groben Entgleisungen seines Denkens geschützt zu sein. Die Schwere der schizophrenen Denkstörung ist nicht durch den Grad der einzelnen möglichen Entgleisung, sondern durch deren Häufigkeit bestimmt.

Die unvereinbaren Widersprüche im Denken der Schizophrenen erwecken oft den Eindruck, als ob manche, auch einfachste Begriffe aufgelöst seien. Der Schizophrene kann sich etwa mit seinem Vater völlig gleichsetzen, kann Vater und Mutter als ganz das gleiche denken und sich zugleich als tot und als lebendig, als Mann und als Frau, er kann den Regenbogen und Gott und den Teufel und irgendeine Pflanze oder ein leeres Wort völlig identifizieren. Aber im nächsten Augenblick, in anderem Zusammenhang, ist doch erkennbar, daß er die eben identifizierten Dinge auch im Denken scharf voneinander trennt, jedenfalls aber im praktischen Handeln. Der Schizophrene, der ganz oder zu $80 \%$ oder zu $20 \%$ tot ist, kann sich beschweren, daß er zu wenig Essen bekommt, und derjenige, der schon fünfmal ermordet, richtig ermordet worden und damit fünfmal tot ist, darüber, daß ihn der Arzt bei der Visite nur $3 \frac{1}{2}$ Minuten und nicht 4 , wie er erwartet hatte, gesprochen habe. Viele Gegenstände zeigen den Schizophrenen also ein doppeltes, ein vielfaches Gesicht, darunter auch das richtige, das beliebig gegen andere vertauscht werden kann.

In den leichteren Krankheitszuständen empfinden die Schizophrenen selbst ihre Zerfahrenheit. Vielfach erleben sie Gedankenlücken, das Entgleiten der Gedanken, Denkpausen, dabei oft mit dem Erlebnis des ${ }_{\text {"Ge- }}$ machten ${ }^{66}$ als Unterbrechung von außen her durch eine fremde Gewalt (Gedankenentzug). Auf der anderen Seite empfindet der Kranke viele Gedanken nicht als seine eigenen, sondern als ,gemacht ${ }^{66}$, als eingegeben, als fremd.

\section{Affektivität}

Bei der großen Mehrzahl der schweren schizophrenen Defektzustände kommat es zu gemütlicher Verödung. Vorkommnisse von objektiv einschneidender Bedeutung erwecken auch dann nicht mehr einen adäquaten gemütlichen Widerhall, wenn sie ihrem Inhalt nach nachweislich zur Kenntnis genommen werden. Der Kranke reagiert nicht sichtbar auf den Tod nächster Angehöriger, auf das Sterben im Bett nebenan, auf die widerlichsten Gewohn- 
heiten seiner Mitkranken, auf eine Ohrfeige, die er erhält, auf rohe Beleidigungen oder gar auf schmerzhafte Eingriffe, und in manchen Fällen wird auch auf Hunger und Kälte keinerlei affektiver Bezug genommen.

So ist es aber keineswegs immer. Kennzeichnender für die Schizophrenen ist schon, daß sie mit ihren vermeintlichen grausamen Verfolgern freundschaftlich verkehren können oder daß sie, geschwellt von üppigsten Größenideen, doch die Anstaltsinternierung ohne Widerspruch ertragen und maschinenmäßig die niedrigste Arbeit verrichten. Und noch eine Stufe deutlicher schizophren ist es, daß sie den gleichen Menschen gleichzeitig mit glühendem $\mathrm{Haß}$ und glühender Liebe zu begegnen vermögen (Ambivalenz).

Immer ist die Affektivität der Schizophrenen anders als die der Normalen. Im Beginn der Erkrankung bemerken sie das selbst sehr häufig. Sie spüren auf mancherlei Gebieten einen Nachlaß, ein Verblassen der gemütlichen Beziehungen: Eltern, Freunde, die bisher erstrebten Werte verlieren an Bedeutung, zugleich aber eine erhöhte Empfindlichkeit gegen mancherlei kleinliche Vorkommnisse, die für sie selbst unverständlich bleibt. Sehr häufig ist ferner eine Verkehrung der gemütlichen Beziehungen. Die geliebte Mutter wird nicht nur gleichgültig, sondern verhaßt; in die Familie kommt durch den Kranken die stacheligste, verbittertste Zwietracht nach dem Geiste Strindbergs. Die eigenen häßlichsten Regungen, eben noch bekämpft, werden gepflegt. Der Kranke kennt sich selbst nicht wieder in der Verschiebung und Zertrümmerung seiner Werttafeln.

Dazu tauchen qualitativ neue Stimmungs- und Gefühlsregungen auf, Regungen des Grauens, der Verzweiflung, der abgründigen Öde, des Fortgeworfen-, des Verlorenseins, des Hasses und der Scheidung von Lebendigem und Totem, aber auch solche der vollen Einigung, der Begnadigung, der Erleuchtung, ekstatische Glücksgefühle. Es gibt hier eine unendliche Mannigfaltigkeit zuständlicher (die gegenstandslosen gemütlichen Regungen abnormer Art sind besonders häufig) und gegenständlicher Gemütsregungen, die vielleicht am deutlichsten die abändernde Wirkung der Krankheit auf die Triebgrundlagen der Persönlichkeit anzeigen.

Von vielen Kranken kann man näheres über diese Erlebnisse nicht erfahren. Sie sind vermutlich überhaupt nicht oder im besten Falle analogisch mitteilbar. Faßbar nach außen wird dies Geschehen immer erst dann, wenn es sich in der Verkehrung der natürlichen gemütlichen Beziehungen und in der gemütlichen Verödung kundgibt. Dabei finden wir einzelne, besonders kennzeichnende Gestaltungen, die uns das Ergebnis jenerLösung der normalen Regungen, jener Verkehrungen und wohl selbständigen Abwandlung der Grundstimmung im Verein mit der Gesamtreaktion auf diese erlebten Veränderungen darstellen, nämlich die läppisch-leere, bizarre und heitere Wurstigkeit, in der jede Ernstwertung aufgehoben erscheint, die hochmütig überlegene Unberührbarkeit, hinter der wohl noch das Gefühl des Versagens und Anderswertens verborgen ist, und endlich die stumpf-depressiv-ratlose Gesamthaltung, der jede Resonanz für die Außenwerte abhanden gekommen ist. Diese besonders anfänglich klar ausgesprochenen Haltungen bleiben auch später meist noch erkennbar, wenn die Krankheit fortgeschritten und die ursprünglichen Inhalte überwuchert sind, oder wenn eine Remission und eine der natürlichen angenäherte Neuorientierung erfolgt ist. 


\section{Handeln}

Die Veränderungen der Affektivität und des Denkens, in denen unzweifelhaft jene der Affekte von erheblicher Bedeutung sind, bestimmen auch über das Handeln der Schizophrenen, das immer unberechenbar, bizarr, anders als vor der Erkrankung und als normal und auch im mildesten Falle ",verschroben ${ }^{66}$ erscheint.

Schon die Grundlagen der Exekutive freilich erscheinen vielfach abgeändert, besonders dann, wenn die Krankheit früh im Leben einsetzt. Ein „Verlust der Grazie" ${ }^{66}$ ist es, der bei vielen Hebephrenen und Katatonen deutlich ist; allen Bewegungen, dem Gang und dem Zupacken fehlt das Abgerundete, der natürlich fließende Ablauf, der dem Kinde und dem ausgereiften Erwachsenen eignet. Alles erscheint irgendwie eckig, unschön, abrupt wie bei Pubertierenden. Die Mimik ist vielfach unbelebt, steif. Sie ist arm oder hinkt nach oder widerspricht dem Gedankeninhalt (Paramimie). Ganz entsprechend sind die Veränderungen der Sprache, die vielfach unnatürlich, geziert erscheint, abgesehen von den Verschrobenheiten in Aussprache und Ausdruck, der Wahl besonderer Eigendialekte oder des Hochdeutschen statt des Dialekts.

Sehr häufig sind unnatürliche mimische Bewegungen, Grimassen oder doch Gesichtsverzerrungen, Zuckungen einzelner Gesichtsmuskeln, die gelegentlich choreiformen Charakter annehmen. Bekannt ist besonders die Schnutenbildung, der ,Schnauzkrampf ${ }^{66}$, den man bei vielen Schizophrenen findet. Den Grimassen entsprechen andere Bewegungs- ,Manieren ${ }^{66}$, sonderbare Bewegungsgewohnheiten, die etwa schon bei dem auffallend steifen und unnatürlichen Handgeben eindrucksvoll werden. Aber auch jede Alltagsverrichtung sonst, das Essen, das Schreiben und Schneuzen, das Hantieren mit dem Berufswerkzeug kann manieriert erfolgen. Der Löffel wird im Bogen oder in einzelnen scharfen Absätzen zum Munde geführt, von fünf Schritten ist einer hüpfend oder überkreuzend; der Hobel wird absonderlich gehalten oder der Federhalter ganz am Ende angepackt.

Manche von diesen Bewegungen erfolgen ganz „stereotyp ${ }^{66}$, werden „sinnlos ${ }^{66}$ wiederholt. Besonders aber sind die akuten Zustände von Stereotypien der Haltung, der Bewegung, der Sprache beherrscht. Im katatonen Stupor wird eine bestimmte, vielfach unbequeme Lage (mit abgehobenem Kopf, verquer im Bett, mit eigenartig ausgestrecktem oder angewinkeltem Arm, mit zusammengepreßten Beinen) stereotyp festgehalten. Oder der Kranke steht immer an einem Ort oder er kehrt stets dahin zurück, unbeirrbar auf dem gleichen Weg, wiederholt eine ,sinnlose ${ }^{66}$, oft manierierte Bewegung, reiht stereotyp ein Wort, einen Satz, eine Reihe von Sätzen aneinander, die inhaltlich nicht verständlich sind oder nur als verstümmelte, verdichtete Reste ehemals sinnvoller Äußerungen, die nicht mehr in die Lage passen (Verbigeration).

Bei den Stereotypien scheint der Exekutivapparat vielfach selbständig geworden, nicht mehr der Diener des seelischen Gesamtgeschehens zu sein, auf der anderen Seite aber von sich aus gelegentlich den seelischen Prozeß zu beeinflussen. Ganz Ähnliches sehen wir in den Geschehnissen, die man als ,Negativismus ${ }^{66}$ zusammenfaßt. Negativistisch nennt man alle solche Verhaltensweisen, mit denen das Gegenteil von dem erreicht wird, was die Situation 
oder die Anregung von außen verlangen. Der Kranke geht vorwärts, wo er ausweichen sollte, zieht die Hand weg, wenn es natürlich wäre sie zu geben, preßt den Mund zusammen, wo er ihn öffnen soll. Passiven Bewegungen setzt er einen federnden Widerstand entgegen. Ebenso aber ${ }_{\text {,redet er vorbei }}{ }^{66}$, sagt das Gegenteil des Erwarteten oder aber schweigt, wo er gefragt wird, und spricht in dem Augenblick, in dem man sich von ihm abwendet (Reaktion im letzten Augenblick). Hierher gehört auch das stereotype Schweigen, der Mutismus.

Dies ganze Verhalten macht einen ,triebhaften ${ }^{66}$ Eindruck um so mehr, als es oft unvermittelt abwechselt mit dem Gegenteil, der Befehlsautomatie, d. h. der übertriebenen Nachgiebigkeit gegen Außenanregungen. Die Befehlsautomatie wird besonders deutlich in den Echoerscheinungen, der Echopraxie, d. h. dem triebhaften Nachahmen von Bewegungen, die gesehen werden, und der Echolalie, dem Nachsprechen von zufällig gehörten Worten. Gleichzeitig hält der Kranke etwa Stellungen stereotyp fest, die man seinen Gliedern gibt. Er behält auch die unangenehmsten passiv gegebenen Lagen bei, bis sie von außen abgëändert werden. Gelegentlich trifft man in solchen Zuständen auch Flexibilitas cerea, wächserne Biegsamkeit, d. h. Muskelzustände, die man von dem leichten Rigor bei extrapyramidalen Erkrankungen zuweilen schwer unterscheiden kann.

In den katatonen Erregungszuständen kann man neben Stereotypien, neben wilden, ungeordneten Gliederbewegungen, übertriebenen und verzerrten Ausdrucksbewegungen, Jaktationen, die der stürmischen Bewegungsunruhe akuter Enzephalitisformen ähnlich sind, auch Bewegungsformen beobachten, die choreatischen, athetotischen, aber auch solche, die innervatorisch-apraktischen und gliedkinetischen oder motorisch-apraktischen so ähnlich sehen, daß eine Unterscheidung fast unmöglich wird. Auch manche Manieren wirken wie eingefrorene apraktische Entgleisungen.

Bei allen bisher genannten sogenannten katatonen Symptomen muß man an die Enthemmung von Mechanismen denken, die bei den organischen Hirnkrankheiten rein hervortreten. Typisch schizophren sind die gleichfalls zu den katatonen Symptomen zu rechnenden „impulsiven“" Akte, unvermittelte, offenbar ,triebhafte" Einzelhandlungen, die den Gedankensprüngen der Schizophrenen gleichen. Ein vollkommen besonnener Kranker etwa springt plötzlich in den Fluß, ohne dies sich selbst und anderen motivieren zu können, er erschießt jemanden, der ihm nichts getan hat, oder teilt in voller Ruhe Ohrfeigen aus, schlägt einen Hut oder eine Fensterscheibe ein.

Im übrigen entspricht das Handeln der Schizophrenen ihrem zerfahrenen, inhaltlich verschrobenen Denken und ihrem veränderten Triebleben. Wir sehen die Hebephrenen läppisch-spielerisch, ungeordnet und unberechenbar ihren Launen, Gedankenbruchstücken und zufälligen Anregungen von außen preisgegeben oder aber entsprechend ihrer überlegen-abweisenden Haltung mit Grandezza, wortlos oder manieriert paradieren, aber auf alles folgerichtige Handeln verzichtend, nichts zu Ende machend, kein Ziel verfolgend. Oder aber es werden irgendwelche sinnlosen, der Gesamtlage unangepaßten Ziele mit zäher Hartnäckigkeit verfolgt. Der Kranke drängt tage-, wochenlang aus der Tür, ohne sie doch zu verlassen, wenn sie geöffnet wird; er versucht selbstschädigende Handlungen, bohrt in den Augen usw., verschluckt alles, was 
ihm in die Finger kommt, bestreicht alles mit Speichel, macht ins Bett oder beschmiert sich selbst hartnäckig mit Kot.

Auf der gleichen Ebene liegt der plötzliche Wechsel zwischen Negativismus und Befehlsautomatie, von dem schon gesprochen wurde, und vor allem die Ambitendenz, eine Störung der Willenssphäre, die sich im gleich zeitigen Streben und Widerstreben dem gleichen Gegenstand gegenüber kundgibt. Der Kranke, aufgefordert, die Hand zu geben, streckt sie wohl aus, zieht aber gleichzeitig den Arm nach hinten. Er will einen Kuß geben und beißt den geliebten Menschen dabei.

Einheitlichere, aber als Ganzes schizophrene Gesamtzustände kennen wir im katatonen Stupor und in der katatonen Erregung. Im Stupor geschieht nichts oder doch nichts spontan, Bewegungsansätze werden sofort ,gesperrt", spontane wie auch von außen angeregte, es wird, ,gegengehalten ${ }^{66}$, negativistisch widerstrebt. Die Kranken sind dabei mutistisch, abstinieren vielfach, lassen ihre Ausscheidungen unter sich usw.

In der katatonen Erregung herrschen bald die ungeordneten Gliederbewegungen, bald Ausdrucksbewegungen ähnelnde Bewegungsformen, bald faxenhaft-spielerische, bald an choreatische und athetotische erinnernde Zwangsbewegungen vor, die alle meist eine stereotype Note haben.

\section{Trugwahrnehmungen}

Echte Halluzinationen, also Sinnestäuschungen von Leibhaftigkeitscharakter, die den Wahrnehmungen gleichen, ohne daß ihnen ein reales Vorkommnis der Außenwelt entspricht, sind bei der Schizophrenie besonders häufig, hartnäckig und vor allem den besonnenen Zuständen der Kranken eigen. Akustische Halluzinationen und solche des Gemeingefühls überwiegen; jene des Geruchs, Geschmacks sind seltener; die des Gesichts treten ganz zurück.

Von den akustischen Halluzinationen stehen im Vordergrund die ,Stimmen ${ }^{6}$. Die Kranken hören Worte, Sätze, oft abgerissen, nicht selten mit ganz bestimmten Merkmalen: weibliche oder männliche Stimme, gewöhnlicher Gesprächston oder besonders laut oder leise, aus der und jener Entfernung und aus einer ganz bestimmten Richtung, von einem ganz bestimmten Orte her. Es ist nur niemand zu sehen, der spricht. Nur dadurch kann mancher Kranke die Stimmen von der Rede anwesender Personen unterscheiden, durch andere Mittel aber nicht. Inhalte der Stimmen können ganz gleichgültige Dinge sein; oft sind es Beschimpfungen, oft auch Dinge, die den Kranken sonst angehen. Der Schizophrene kann auch alle seine Gedanken nachgesprochen (Gedankenecho) oder vorgesprochen (Gedankenlautwerden) oder Bemerkungen zu allen seinen Handlungen und Gedanken hören. Häufig aber haben die Stimmen mit dem augenblicklichen Gedankeninhalt gar nichts zu tun.

Nicht selten haben die ${ }_{\text {SStimmen }}^{66}$ zugleich den Charakter des, $\mathrm{Ge}-$ machten", des Aufgezwungenen, und hier handelt es sich, wie bei den Phänomenen des Gemachten überhaupt, um spezifisch Schizophrenes. Meist aber unterscheiden sich die Stimmen auch sonst von dem gewöhnlichen Reden Anwesender: sie sind besonders laut oder leise, flüsternd, krächzend, wie hohl; sie kommen aus der Wand oder von der Decke her, ganz laut zum Fenster herein oder aus dem Körper, aus dem Herzen, aus dem Magen, dem Fuß, aus dem Kopf selbst, und bleiben dabei doch leibhaftig. 
Neben diesen echten "Stimmen" gibt es auch sinnlich besonders lebhafte Vorstellungserlebnisse (Pseudohalluzinationen), die gewöhnlich zum Gedankeninhalt passen, und illusionäre Vorkommnisse. In akuten Zuständen kommen halluzinatorischer, pseudohalluzinatorischer und illusionärer Sinnentrug in unentwirrbarer Reichhaltigkeit nebeneinander vor, und zwar dann meist nicht bloß auf einem Sinnesgebiet, sondern auf mehreren nebeneinander, wobei szenenhafte Gesamterlebnisse, lang sich hinziehende, einheitlichere, wie bruchstückhaft abwechslungsvolle, entstehen können.

Reichhaltig sind die halluzinatorischen Erlebnisse im Gebiete der "Gemeinempfindungen"; meist sind sie unangenehmster Natur: die Kranken fühlen sich gestochen, gebrannt, aufgesägt, mit Nadeln gepickt, entzweigeschnitten, aufgebläht, sie fühlen einzelne Glieder, die Zunge aufschwellen, abgehackt, zur Schraube gedreht, spüren, wie der Kopf abgehoben, skalpiert, wie der Leib verstopft, der After zugenäht, der Penis verdreht und bewegt wird. Sie spüren die Speisen direkt in die Füße, in den Kopf gehen, im Leib unmittelbar zu Boden sinken, sich zu Tieren verwandeln und in den Adern umherkriechen. Die Fülle der absonderlichen halluzinatorischen Erlebnisse selbst hat vielfach schon eine wahnhafte Verarbeitung erfahren, wenn sie zur Mitteilung gelangen. Nicht selten fühlen die Kranken sich vergewaltigt, sie erleben zahllose Male den Orgasmus, spüren sich am Penis gezogen, masturbiert oder aber gleichzeitig von mehreren Männern im Genitale wie im Kopf oder Leib oder Magen koitiert.

Ärmlich, wenn auch recht verbreitet, sind einzelne Geruchshalluzinationen, häufiger noch Geschmackserlebnisse von halluzinatorischem Charakter. Freilich kann man hier wie auch bei den Gemeingefühlen nie mit Sicherheit illusionäre von halluzinatorischen Erlebnissen trennen.

Auf dem Gebiete des Gesichts treten die Erscheinungen, die halluzinatorischen Gestalten und Dinge zurück hinter den Wahrnehmungsanomalien. Die Gesichter in der Umgebung erscheinen verzerrt, verschoben, zu schmal oder zu breit, es werden Grimassen oder besondere Ausdrucksbewegungen in sie hineingesehen. Alle Bewegungen erscheinen eigenartig in der Form oder auch im Zeitmaß. Gleiches kann von der Sprechweise der Personen in der Umgebung erlebt werden.

Die Bedeutung der Stimmen für die Kranken ist verschieden. In der Regel zweifelt der Schizophrene eher an den wirklichen Erlebnissen seiner Sinne und seiner Überlegungen, als an der Tatsächlichkeit der Stimmen und des übrigen Sinnentrugs, der sein Denken und sein Handeln beherrscht. Da viele Stimmen ,imperative“ Inhalte haben, führen sie nach außen zu unverständlichen Handlungen, gelegentlich auch zu unvermittelten Gewaltakten gegen das eigene oder aber fremde Leben. Manche Kranken suchen sich gegen die Stimmen abzusperren durch Antiphone, durch Ohrzuhalten, durch irgendwelche anderen Manöver, gelegentlich mit Erfolg. Anfänglich reagieren die Schizophrenen auf die beschimpfenden Stimmen und die Quälereien oft mit lebhaften Affekten und Abwehrmaßregeln. In späteren Verläufen brauchen die Halluzinationen keineswegs an Eindringlichkeit und Häufigkeit abzunehmen. Sie führen aber keine lebhafte affektive Stellungnahme mehr herbei, werden neben der Wirklichkeit erlebt, abgekapselt, ja gelegentlich belächelt und ironisiert. Nicht selten geben aber auch im späteren Verlauf der Krankheit 
halluzinatorische Erlebnisse zu immer wiederholten Schimpfexzessen oder unvermuteten Angriffen auf die Umgebung Anlaß.

Die Halluzinationen führen meist zu wahnhaften Deutungen. Sie werden auf bestimmte Verfolger oder Banden von solchen, sodann auf irgendwelche dunklen, magischen Einwirkungen - telepathische, besondere Apparate, Drähte usw. - zurückgeführt. Das Gedankenlautwerden und das Hören fremder Gedanken wird als Ausdruck besonderer Fähigkeiten: „Hinterhörigkeit ${ }^{66}$ usw. gedeutet.

\section{Wahnideen}

Aus der unendlichen Fülle der Wahnvorgänge Schizophrener heben sich zwei Gestaltungsformen heraus, die für die Krankheit, und zwar besonders für die akuten Zustände, mehr oder weniger kennzeichnend sind, das in der Form der unvermittelten Gewißheit vor sich gehende, unmotivierte Erleben von Bedeutungen und die krankhafte Eigenbeziehung. Im ersteren Falle erfüllen sich dem Kranken Wahrnehmungen oft ganz belangloser Art, aber auch auftauchende Vorstellungen oder Gedanken, die als solche nichts Abnormes haben müssen, mit Bedeutungen, für die jedes erkennbare Motiv, jede Begründung fehlt. Der Kranke sieht auf der Straße einen Mann den Hut vom Kopf nehmen: dies bedeutet, wie er plötzlich bestimmt weiß, daß soeben die Braut einen Unglücksfall erlitten hat. Es fällt ihm ein, daß er seiner Schwester zum Geburtstag zu gratulieren vergessen hat, und dies bedeutet: die Schwester ist syphilitisch erkrankt, oder er denkt an die Unterschiede vom Spanischen und Portugiesischen und weiß zugleich, daß Krieg zwischen den beiden Staaten ausgebrochen ist. All dies ist für den Kranken unmittelbar gewiß. Er kann es nicht begründen. Er weiß es eben. Eine Diskussion darüber hat keinerlei Sinn.

Besonders häufig ist, vor allem im Beginn der Krankheit, der „Beziehungs$w{ }^{2 h n}{ }^{6}$, die krankhafte Eigenbeziehung. Alle Vorkommnisse oder aber irgendwelche Geschehnisse, die sich für den Gesunden in keiner Weise vor anderen auszeichnen, setzt der Kranke zu sich in Beziehung. Sie gehen ihn irgendwie an, sind auf ihn gemünzt und, im weiteren Fortgang, meist in bestimmter Weise auf ihn gemünzt. Auf der Straße hupen Autos: das geht den Kranken an. Zwei Schutzleute stehen zusammen: sie sprechen über ihn - er weiß dies, auch wenn er weit von ihnen entfernt steht. Ein Fenster klappt, wenn er vorbeigeht, die Leute grüßen einander und meinen ihn, ein Mann spuckt aus und zielt damit auf den Kranken ab. Er hört irgend jemanden das Wort „,meinetwegen äußern, der Betreffende spricht nichts zu ihm, er sieht ihn gar nicht an, er ist mit seinem Gesprächspartner in lebhafter Diskussion. Aber der Kranke weiß, daß ihn das Wort angeht, und zwar bedeutet es, daß er heute nacht ermordet werden soll.

Bei den letzten Beispielen durchdringen wahnhaftes Bedeutungsbewußtsein und abnorme Eigenbeziehung einander, wie dies vielfach im Beginne schizophrener Erkrankungen geschieht. In der Regel befinden sich die Kranken zugleich in einer eigenartigen gemütlichen Verfassung, einer, Wahnstimmung “6, in der Ratlosigkeit, Gefühl des Unheimlichen, des Verändertseins oder der Änderung der Welt und Angst sich in eigenartiger Weise mischen. Es ist nicht klar, in welcher Weise diese Stimmung und die Wahnbildung zusammengehören. Sie sind wohl am ehesten zwei Seiten einer Gesamtveränderung und 
nicht ursächlich aufeinander zu beziehen. Jedenfalls kann ein Kranker sich in Wahnstimmung befinden und doch nicht zu wirklichen ausgesprochenen Wahnideen kommen. Es ist dann nur alles anders, eigentümlich, sonderbar, ohne daß er angeben kann, wie und was dies bedeutet. Auf der anderen Seite kann lebhafte Eigenbeziehung vor sich gehen ohne eigentliche Wahnstimmung.

Besonders häufig führt die "Wahnstimmung“" zu den kosmischen Erlebnissen des "Weltunterganges", des „jüngsten Gerichts“" oder aber der Umwandlung der Person nach irgendeiner Richtung: Heiligung oder Verteufelung oder Verweiblichung. Oder aber die eigene Veränderung wird nach außen projiziert; alle anderen sind verrückt, abnorm, komisch, unverständlich (Transitivismus).

Primäres Bedeutungswahnerleben und krankhafte Eigenbeziehung sind auch außerhalb der akuteren Zustände immer wieder nachweisbar. Die einzelnen Inhalte können zurücktreten, ja sogar korrigiert werden, alle oder doch viele, während manche verharren (Residualwahn) und nachträglich den Gang des schizophrenen Denkens bestimmen, gedanklich verarbeitet werden, zu sekundären Wahnideen, zum Erklärungswahn führen.

Auch abnorme Sensationen, Trugwahrnehmungen, tatsächliche Erlebnisse werden im Sinne des Erklärungswahns verarbeitet und zwar besonders von Kranken, deren Denkstörung wenig ausgesprochen ist. Es kommt dann nicht ganz selten zu mehr oder weniger folgerichtigen "Wahnsystemen“. Bei schwerer Denkgestörten entwickeln sich aber meist nicht Wahngebilde, die noch den Namen System verdienen würden. Für sie ist vielmehr kennzeichnend, daß miteinander unvereinbare Wahninhalte barock nebeneinanderstehen und daß der Wahn ebenso zerfahren ist wie das gesamte Denken. Nichts paßt. dann mehr zusammen. Verfolgungs- und Größenideen können ganz ohne Beziehung nebeneinander entstehen wie bestehen bleiben oder nachträglich miteinander in lockere Beziehung gebracht werden. Besonders häufig ist freilich, daß im Beginne der Erkrankung dysphorisch gefärbte Wahnideen vorherrschen, während später expansive Inhalte sich breiter machen. Bei läppischheiterer Grundstimmung kann der Kranke doch grausamste Verfolgungsideen haben und umgekehrt. In der Regel macht sich aber doch die Grundstimmung: in der Richtung der Wahnideen mehr oder weniger bemerkbar.

Inhaltlich sind für akutere schizophrene Zustände kennzeichnend Erlebnisse des Weltunterganges und andere religiös gefärbte kosmische Erlebnisse, Leidenserlebnisse nach Art des Heilandsmartyriums, Erlebnisse der sexuellen Verwandlung. Alle diese Inhalte haben aber meist nur eine episodische Bedeutung. In den mehr chronischen Verläufen spielt der physikalische Verfolgungswahn (Beeinflussung durch Elektrizität, Magnetismus), spielen magische Gewalten (Hypnose, Eingebung, Telepathie), Willens- und Gedankenbeeinflussung, sexuelle Beeinflussung auf magischem Wege eine hervorragende Rolle. Besonders häufig werden die Verfolger durch ganze Banden dargestellt (Freimaurer, Hypnosebund). Der schizophrenen Gesamtveränderung, die meist qualvoll erlebt wird, entspricht es wohl, daß die Kranken sich selbst nicht so sehr für verwandelt, als vielmehr für andere Menschen, von anderen Eltern geboren, für Leute mit anderen Namen, aus einem fernen Erdteil oder einer eigenartigen herausgehobenen Sippe halten. 
Zu Quellen der Wahninhalte werden manchmal auch die Träume der Kranken, die sehr wohl darum wissen können, ohne doch in ihrer wahnhaften Bewußtheit schwankend zu werden. Ja einfache, zunächst unernste Phantasiespielereien können nachträglich wahnhaften Charakter gewinnen, Erinnerungen eine wahnhafte Verfälschung nicht bloß bedeutungsgemäß, sondern auch inhaltlich erfahren. Endlich sehen wir Wahnideen mit dem Charakter der Erinnerung auftauchen, als „Halluzinationen ${ }^{66}$ der Erinnerung. Die Kranken behaupten plötzlich, schon als Kinder gewußt zu haben, daß sie der Heiland, der König seien, und berichten zahllose Einzelheiten als völlig sichere Erinnerung. Bei manchen Schizophrenen fließt diese Quelle sehr ausdauernd, allmählich die gesamte Vergangenheit verfälschend oder doch verdoppelnd; denn die gewöhnlichen Erinnerungen bleiben unvereinbar neben den wahnhaften bestehen.

Sehr häufig spielen die Widersprüche zwischen der sehr wohl wahrgenommenen Wirklichkeit und der Welt des Wahns für das Handeln und das Erleben der Kranken keinerlei Rolle. Der Kranke verkehrt freundschaftlich mit dem gleichen Arzt, von dem er sich in grausamster Weise physikalisch verfolgt wähnt. Oder der „Heiland“6 macht Buchbinderarbeiten oder Feldarbeit, ohne je Konsequenzen aus seinem Wahn zu ziehen. In vielen Fällen wehrt der Kranke die unheimlichen Verfolgungen mit magischen Gegenwirkungen ab: er sucht durch Worte und Gesten, durch Einnahme von bestimmten Lagen oder Meiden von bestimmten Nahrungsmitteln den Verfolgern zu begegnen, oder er reagiert auch mit Schimpfen und Drohen und unter Umständen auch mit Gewalttaten. Manche von Größenideen beherrschte Kranke tragen ihre Wahninhalte auch in Kleidung und Haltung, in Bart-, Haartracht oder Redeweise zur Schau.

Ungestört sind bei den Schizophrenen häufig Wahrnehmung, Gedächtnis, Orientierung und Bewußtsein. Natürlich kann die Wahrnehmung durch Sinnestäuschungen gestört oder durch wahnhafte Vorgänge komplexmäßig verfälscht werden, und das gleiche gilt für die Orientierung in Raum und Zeit. Auch mangelndes Interesse kann vor allem die zeitliche Orientierung stören. In seltenen Fällen aus dem Bereiche der Katatonie, Stuporen sowohl als Erregungen, die den Anstrich der Amentia haben, scheint schon der Schwellenwert der Empfindungen erhöht, die Wahrnehmung, alles seelische Geschehen erschwert und dabei bruchstückhaft vor sich zu gehen; kurz, es gibt hier echte Bewußtseinstrübungen im Sinne jener bei Vergiftungen. Dann findet man nachträglich auch eine echte Erinnerungslücke (Amnesie). Aber häufig sind diese Zustände nicht.

Die A u fmerks a mkeit ist meist launenhaft und im wesentlichen von den Gesamtzuständen abhängig. Findet man bei den eben erwähnten akuten Psychosen auch erschwerte Einstellung, so in manchen anderen Erregungen Hypermetamorphose, d. h. triebhaftes Beachten aller neuen Eindrücke. In anderen scheint die Aufmerksamkeit von einzelnen Sinneseindrücken, Halluzinationen oder Denkinhalten ,gefesselt". Die der Schizophrenie eigentümliche „Aufmerksamkeitsstörung" läßt sich von der Denkstörung nicht trennen.

Die mnestischen Funktionen, also vor allem Gedächtnis und Merkfähigkeit, erleiden in der Regel keine Störung. Die Erinnerungen schwinden nicht rascher, das Zeitgitter scheint nicht weniger stabil als beim Normalen, 
und auch Neues eignen sich die Kranken an, wenn das Interesse dies möglich macht. Ja, viele Kranke merken sich zahlreiche unwesentliche Einzelheiten. Gestört ist häufig dieVerfügung über das Gedächtnismaterial, die Reproduktion, und zwar vor allem im Zusammenhang mit der Denkstörung, aber auch unter dem Einfluß von Komplexen, also vor allem der Wahnvorgänge. Auch Erinnerungslücken kommen, abgesehen von der echten seltenen Amnesie, auf diese Weise zustande, also durch nachträgliche „psychogene ${ }^{66}$ Ausschaltung. Zuweilen wird vor allem für die bei Schizophrenen nicht seltenen „Delirien ${ }^{66}$ Amnesie gefunden. (Über die Erinnerungshalluzinationen und Fehlerinnerungen s. oben.)

\section{Delirante Zustände}

Schizophrener entsprechen ihrer Genese nach, von seltenen organischen Vorkommnissen abgesehen, affektiv bedingten Bewußtseinsveränderungen mit Abwendung von der Außenwelt bei lebhaft bewegter Innenwelt, nur daß neben affektbetonten tatsächlichen Erlebnissen Wahn und Sinnestrug nicht selten eine auslösende Rolle spielen und die Grundstörungen der Schizophrenie den Bildern ihre Färbung geben. Nicht wenige Kranke sind in diesen Delirien „,doppelt ${ }^{66}$ orientiert; sie leben zugleich in ihrer deliranten und in der wirklichen Welt und können von der einen zur anderen plötzlich umstellen. Den Delirien der Fieberkranken und Vergifteten ähnliche Zustände gibt es bei der Schizophrenie selten und dann wohl nur im Zusammenhang mit groben äußeren Schäden. Auch oneiroide (s. d.) Episoden sind bei Schizophrenen Ausnahmen.

\section{Sprechen und Schreiben}

Im Sprechen der Schizophrenen kommt zunächst einmal die Denkstörung zum Ausdruck, die zur Zerfahrenheit, aber auch zu ungewöhnlichen Betonungen, zu grammatischen Fehlbildungen im Sinne der Entgleisung wie der Kontamination führt. Daneben erlebt der Kranke aber oft genug Ungewöhnliches, Neues und sucht dies auszudrücken. Er bildet dann gern neue Worte (Neologismen), sei es durch Zusammensetzung bekannter Worte und Wortteile, sei es durch neue Buchstabenzusammensetzungen. Manche Kranke sind sehr reich an solchen Neologismen.

Etwas anderes sind die neuen Sprachen, die "Geheimsprachen ${ }^{66}$, die einzelne Kranke erfinden, und zwar aus wahnhaften Gründen, um sich ihren Verfolgern zu entziehen oder aber mit den Menschen zu verständigen, die in „Stimmen ${ }^{66}$ zu ihnen sprechen. Der Kern mancher solchen Geheimsprache ist wohl nicht selten das Ergebnis von Halluzinationen.

Viele Kranke drücken sich sonderbar, verschroben aus, wählen seltene Worte, eigenartigen Satzbau, unnatürliche Betonungen. Schon dabei handelt es sich oft, wie es scheint, um den gewollten Ausdruck andersartigen Erlebens, eines neuen Lebensgefühls, das bewußt kenntlich gemacht wird. Aber daneben trifft man doch nicht selten eine Wortwahl, die an die Paraphasien der Aphasischen erinnert, um so mehr, als manche Schizophrene mühsam um die Wortfindung ringen, d. h. Störungen darbieten, die am ehesten jenen der amnestischen Aphasie gleichen. Einzelne Kranke bringen auch verstümmelte Worte heraus, die dann freilich bei auch sonstigem stereotypem Ver- 
halten aus Verschrobenheit, aus Spielerei wiederholt, als Stereotypien festgehalten werden können. Auch leichte sensorisch-aphasische Störungen sollen vorkommen; im ganzen aber sind solche an organische Sprachmängel erinnernde Gebilde bei Schizophrenen nicht häufig.

Nicht sicher läßt sich sagen, ob nicht in einer recht kennzeichnenden schizophrenen Sprachstörung, die bei vielen akut Kranken auftritt, im Wortsalat, der schizophrenen Sprachverworrenheit, auch solche Paraphasien und Paralogien enthalten sind. Im Wortsalat haben wir es offenbar nicht mit der Absicht der Kranken, etwas Bestimmtes kundzugeben, einen Sachverhalt darzustellen, zu tùn, sondern mit einem gestaltlosen Ausdrucksbedürfnis. Die Kranken wollen mit ihrem Gerede nichts Sachliches mitteilen, sondern sich mitteilen; sie genießen den Wortsalat, und viele von ihnen können beliebig von dem Wortsalat zu mehr oder weniger normalen Mitteilungsleistungen umschalten. Andere bringen den Wortsalat nur vor, wenn sie sich in ihren wahnhaften Gedankengängen bewegen, wieder andere nur in der Erregung, im Affekt. In der oft affektfreien oder -armen katatonen Erregung kommt es endlich gern zur Verbigeration, zur monotonen Aneinanderreihung von stereotypen Worten, kurzen Wort- und Satzbruchstücken oder auch bloß Lauten ohne jeden erkennbaren Sinn.

Die schriftlichen Äußerungen der Kranken können zunächst alle Eigentümlichkeiten der sprachlichen haben, also schriftlichen Wortsalat, schriftliche Verbigeration darstellen. Mancher Kranke, der nur Salat spricht, bringt es aber fertig, einmal einen vernünftigen Brief zu schreiben.

Daneben sind oft die Anordnung der Schriftstücke, die Form der Schriftzeichen, der Wechsel der Schriftarten und der Schreibgröße auffallend. Wir sehen Sonderbarkeiten der Interpunktion, der Unterstreichung, der Orthographie, Manierismen der Federführung, der Bildung einzelner oder auch aller Buchstaben, das Verwenden von Bilderschrift und Eigensymbolen. Manches Schriftstück von Schizophrenen läßt mit recht erheblicher Wahrscheinlichkeit die Diagnose stellen.

\section{Störungen der Persönlichkeit}

Versucht man das allen Schizophrenen, leichten und schweren Defektzuständen nach den verschiedensten Verlaufs- und Gestaltungsformen, Gemeinsame herauszuheben, so trifft man auf Persönlichkeitsveränderungen im Sinne der Gefühls-, Willens- und vor allem Wertstruktur. Der Kranke ist anders geworden, als er vor der Krankheit war. Er kann dem Anschein nach vor allem ärmer geworden sein. Ausgesprochener aber ist meist das Zurücktreten früherer, das Hervortreten neuer Triebregungen, Strebungen und Werte, etwa in einer Weise, daß eine einheitliche, geschlossene Person überhaupt nicht mehr besteht. Vom Kranken her gesehen ist dies so, daß er vielfach sich selbst nicht oder doch in einzelnen Regungen nicht wieder erkennt, daß er sich unberechenbaren Regungen aus seinem Innern preisgegeben sieht, auch dann, wenn er diese nicht als gemacht erlebt. Auch von außen her ist der Schizophrene anders; vor allem ist er uneinfühlbar, eben ,schizophren geworden. Der Betrachter sieht vereinzelt oder häufig Entäußerungen, für die ihm das Verstehen fehlt, ganz abgesehen von der so häufigen Unberechenbarkeit, die nur ein gröberes Symptom darstellt und den Schizophrenen rein 
quantitativ vom Mitmenschen überhaupt unterscheidet. Die Welt des Schizophrenen wandelt sich und er wird anders für die Welt, und damit einsam und unverstanden. Bekennt er sich zur neuen Welt, bejaht er sie, so wird er dies nach außen in Verschrobenheiten kundtun; spürt er den Verlust der alten Welt, leidet er unter der Einsamkeit, so ist dies ausdrucksgemäß meist am scheuen, stillen Sichzurückziehen, an dem, was man im engeren Sinne als Autismus bezeichnet, deutlich. Im weiteren Sinne sind beide Formen des Gesamtverhaltens autistisch, nur daß der eine seine Welt in die Wirklichkeit hineinlebt, der andere sie scheu in sich verbirgt und soviel von der alten Welt aufnimmt, als er im Vorbeigehen ihr entreißen kann.

In den akuteren Syndromen ist die schizophrene Persönlichkeitsänderung oft unter stürmischen Symptomen und Gesamtreaktionen verdeckt. Sie bleibt aber dem Kundigen doch meist deutlich und aus ihr allein gelingt nicht selten die Diagnose.

\section{Körperliche Störungen}

Wir kennen keine körperliche Störung, die bei allen oder doch der großen Mehrzahl der Schizophrenen nachweisbar wäre. Am häufigsten findet sich eine mehr oder weniger ausgesprochene Herabsetzung des Grundumsatzes, wenigstens nach dem in der Breslauer Klinik üblichen Vorgehen. Dieser Befund, der freilich von vielen Seiten bezweifelt wird, hat sich uns doch als so regelmäßig wiederkehrend erwiesen, daß wir ihm einen gewissen diagnostischen Wert nicht absprechen möchten. Die akuten Zustände gehen gern mit starken, oft sehr steilen Gewichtsschwankungen einher, die an Störungen im Wasserhaushalt denken lassen. Auch Störungen im Säurebasengleichgewicht, in der Stickstoffausscheidung usw. sind gefunden und als Ausdruck eines noch nicht erkennbaren Stoffwechselgeschehens angesehen worden. Bei tödlich verlaufenen Katatonien, die schon von vornherein zu Hautblutungen neigen, wurde bei der Sektion mehrfach eine rote Metaplasie des Fettmarks in den langen Röhrenknochen festgestellt, ein Befund, von dem man ebenfalls annimmt, daß er mit noch unbekannten körperlichen Ursachen der Schizophrenie in Verbindung steht.

Gelegentlich sieht man leichtere Pupillenstörungen, neben Anisokorie vor allem das Fehlen der Pupillenunruhe und der Pupillenerweiterung auf sensible, sensorische und psychische Reize, während am ehesten noch auf Schmerz und Schreck angesprochen wird. Ähnliches zeigt sich plethysmographisch in der sog. „relativen Volumstarre"6, d. h. von Reizen, auf die der Normale anspricht, bleibt bei vielen Schizophrenen die Volumkurve unbeeinflußt.

In akuten Zuständen vor allem jugendlicher Kranker fehlen vasomotorische Störungen selten. Besonders ausgesprochen ist oft die Akrozyanose. Manche Katatone zeigen starke Seborrhöe im Gesicht, so daß es zum „Salbengesicht $^{66}$ kommen kann.

Flüchtige neurologische Störungen, Stauungspapille, Reflexdifferenzen, Pyramidenzeichen begegnen uns in katatonen Erregungen offenbar besonders dann, wenn es zur ,Hirnschwellung"6 kommt. Bei dieser Erscheinung, die, vielfach der Rückbildung fähig, doch vereinzelt zum Tode führt, wird Wasser in die Hirnsubstanz in einer Weise aufgenommen, daß trotz der entstehenden, zum Hirndruck führenden Schwellung die Hirnsubstanz zum Unterschied vom Hirnödem eine eigenartig trockene Beschaffenheit behält. Auffallend 
häufig begegnen uns Zuckungen im Fazialisbereich, die freilich ohne scharfe Grenze in das einfache Grimassieren übergehen. In das gleiche Gebiet gehört die sehr häufige Einbuße an feinsten koordinatorischen Leistungen, die im ${ }_{9}$ Verlust der Grazie ${ }^{66}$ am deutlichsten zum Ausdruck kommt.

Die akuten Zustände der Frauen gehen in einem hohen Prozentsatz mit Ausbleiben oder doch Störungen der Menstruation einher.

Häufig ist ferner eine Herabsetzung der Permeabilität der Meningen, die sich besonders bei der Zufuhr von Brom feststellen läßt.

Engste Beziehungen zu Darminfektionen wie zur Tuberkulose, die behauptet worden sind, konnten nicht bestätigt werden, wenn auch viele Schizophrene gerade an den genannten Infektionen zugrunde gehen.

\section{Krankheitsbeginn}

Bei der großen Mehrzahl der Schizophrenen geht den akuteren Krankheitserscheinungen ein oft lange hingestrecktes Stadium voraus, das meist erst nachträglich als erstes Wetterleuchten der Krankheit erkannt werden kann. In vielen Fällen spielt sich der erste Schub ganz in solchen nicht erkannten verwaschenen Erscheinungen ab. Leichte Änderungen der Grundstimmung, besonders moros-depressive, gereizte Gemütslage, viel seltener allein eine dem Kranken selbst nicht verständliche, unheimliche Gehobenheit, weiter Mangel an Konzentration, Erschwerung der gewöhnlichen Aufgaben, leichte Faseligkeit, subjektive Uneindringlichkeit der Erlebnisse und Gedanken, dazu vor allem eine Änderung der Beziehungen zu den Menschen, Abkühlung, unverständliche, feindselige Regungen gegen die nächsten Angehörigen, Verlust des Kontaktes mit den Freunden, Hervortauchen neuer Regungen und Werte, Nachlassen des Interesses an anderen, erhöhte Empfindlichkeit in mancherlei Beziehung bei Abstumpfung anderen Dingen gegenüber, endlich häufig, nach außen am ehesten erkennbar, leise Änderungen und Versteifungen der Mimik, Verlust der Grazie, Hervortreten eigenartiger Gewohnheiten, dazu vielleicht körperliche Mißempfindungen, hypochondrische Gedanken, Neigung zur Beschäftigung mit wirklichkeitsfernen Dingen, das sind die Klagen, die man hört, die Tatsachen, die sich nachträglich feststellen lassen. Bei Mittelschülern in den höheren Klassen werden die Zustände gern deutlich dadurch, daß die Jungen plötzlich auffallend in den Leistungen nachlassen, ja sitzen bleiben, vielleicht um später wieder ganz gut voranzukommen. Die affektiven Veränderungen werden dann gern als Reaktion auf den Nachlaß, auf Tadel und Mahnungen, vielleicht auch als Folgen der Onanie gedeutet.

Diesem schleichenden Beginn kann eine gute Periode folgen, die dann über eine erneute Verschlechterung zu akuten Syndromen hinführt; es können sich die Störungen aber allmählich verstärken oder auch plötzlich akute Syndrome aus sich hervorgehen lassen.

Die Syndrome der ausgesprochenen Erkrankung pflegt man in Hebephrenien, Katatonien und paranoide Schizophrenien einzuteilen, ohne daß es zweckmäßig erscheint, diese Zustandsbilder scharf zu trennen.

Bei der

\section{Hebephrenie}

fehlen sowohl ausgesprochene Wahnbildungen und Halluzinationen wie schwere katatone Symptome und Episoden. Vielmehr sind es die Grund- 
störungen, jene des Denkens, der Affektivität und der höchsten Willensfunktionen, welche die Bilder beherrschen, wobei nicht selten eine seltsam leere, unwürdig heitere, läppische oder eine steife, depressiv leere Grundstimmung dauernd oder lange Zeit hindurch einen eigenartigen Hintergrund für die "Grundsymptome" bildet. Manchmal bleiben die Hebephrenien ganz ohne akutere Episoden und nehmen einen schleichend progredienten Verlauf (Dementia simplex); in der Regel kommt es aber zu wiederkehrenden schubartigen Verschlimmerungen mit etwas akuteren und störenden Symptomen und mit Remissionen, in denen die Persönlichkeitsveränderung immer deutlicher wird. Bei der

Katatonie

sind es Hyperkinese und Akinese, lebhafte Erregungen mit der ganzen Mannigfaltigkeit der "katatonen ${ }^{66}$ Symptome, und Stuporen, welche die Namengebung veranlassen. Hinter den zeitweise oder dauernd beherrschenden Symptomen fehlen aber Denk- und Gemütsstörungen nicht, und selten werden Wahnbildungen und Halluzinationen ganz vermißt. Die Katatonie verläuft besonders gern in voneinander wohl abgesetzten Schüben mit anfänglich guten Remissionen, die freilich später der Dauer und dem Ausmaß nach sich ungünstig verändern. Es gibt aber auch chronische Katatonien, die bald zum Endzustand hinführen.

Endlich bleibt bei der

paranoiden Demenz

die allgemeine Denkstörung oft lange Zeit hindurch in bescheidenen Grenzen, ebenso die Veränderung der Affektivität, und Willensstörungen im Sinne der Katatonie fehlen bis auf Andeutungen. Die Bilder werden beherrscht vom Wahn, der meist von lebhaften Halluzinationen begleitet ist.

Es folgen hier einzelne kennzeichnende Krankengeschichten:

\section{Katatonie}

Arthur R., Student, geb. 1906. Patient war ein verschlossenes Kind, immer sehr ruhig und scheu, gar nicht aufgeregt. Von seinen Erlebnissen in der Schule und mit seinen Kameraden erzählte er den Eltern nie etwas. Er lernte ordentlich, wurde auf dem Gymnasium immer versetzt, versagte aber in der letzten Klasse, da er in Mathematik schwach war, und wurde ein halbes Jahr von der Abschlußprüfung zurückgestellt. Zu seinen Kameraden hatte er keine rechte Beziehung. Schon vor der Prüfung suchte er einmal den Nervenarzt wegen Beklemmungen auf, ohne seinen Eltern etwas davon zu sagen, die durch die ärztliche Liquidation überrascht wurden. Auffällig wurde er zuerst dadurch, daß er eines Tages nicht nach Hause kam, sondern sich mehrere Nächte lang in Schrebergärten umhertrieb, wo er durch Zufall gefunden wurde. Schon vorher fühlte der Kranke sich verändert, nicht mehr so tatkräftig wie früher, schüchterner, scheuer. Er schloß sich zunehmend ab. Das Lernen fiel ihm schwerer; er konnte zuweilen die Gedanken nicht mehr recht zusammennehmen. Wohl hatte er noch Interesse am Studium, aber er konnte im Kolleg nicht mehr recht folgen; die Anwesenheit anderer Menschen machte ihn unruhig; im Umgang mit Mädchen kam er sich lächerlich vor. Er litt unter dem Gedanken, anders zu sein als die andern Menschen, war schwerfälliger in allem, auch im Sprechen, spürte eine dauernde innere Unruhe und dazu Mißempfindungen im Gesicht.

Vom Studium beurlaubt, machte er eine Skitour. Unterwegs fühlt er sich plötzlich verfolgt, steigt aus der Bahn, schickt widerspruchsvolle Nachrichten nach Hause, geht mit Selbstmordabsichten um und wird nach einigen Tagen völlig abgerissen aufgefunden. Im Sanatorium und zu Hause ist er geordnet, aber scheu, niedergeschlagen und nicht unter die Leute zu bringen. Er meint, man sehe ihm seine Onanie an, rede über ihn, mache sich ,fürchter- 
liche" Vorstellungen von ihm. Auch im Rundfunk kommen Andeutungen. Zwischen die Reden anderer schieben sich Bemerkungen: ,Tier", „Vieh", ,Schwein" ein. Man meint, er tue homosexuelle Dinge, will ihn überführen, belästigt ihn mit zweideutigen Reden. Als er aus dem Sanatorium kam, war er erstaunt, was die Leute alles von ihm wußten. Man hielt ihn für völlig geistesgestört. Auch in Briefen an ihn selbst wie an den Vater stand dies zwischen den Zeilen zu lesen. Selbst das Verhältnis zu den Angestellten des Vaters war verändert; er fühlte sich überall bloßgestellt und isoliert. „Es ist nicht mehr das richtige Leben, kein richtiges Lebensinteresse mehr in mir: Es kommt mir vor, als wenn ich aus der ganzen Umgebung herausfiele. Ich mußte mich bemühen, Fühlung mit früheren Bekannten zu bekommen. Aber die anderen ,drücken sich weg6." Die Leute verstehen es, auch seinen Vater zu beeinflussen. "Ich bin ganz abgestumpft."

1928 in die Klinik gebracht, ist er anfänglich ängstlich-unruhig, dabei leicht abgelenkt, zerfahren und schwer zu fixieren, da er murmelnde Monologe hält. Bei jeder seiner Fragen und Antworten nimmt er in eigenartiger Weise die rechte Hand an die Stirn. Er kommt immer erneut aus dem Bett, läuft planlos im Saal umher und stellt an seine Umgebung ,törichte ${ }^{6 *}$ Fragen, flüstert unverständliche Worte vor sich hin, macht gelegentlich den Eindruck, als ob er halluziniere. Bald ist er vorwiegend mutistisch; seine Antworten kommen stockend oder hören plötzlich auf. Im Bett spuckt er im Kreise um sich, im Garten reißt er Früchte und Blüten von den Bäumen. Ansprechbar ist er gar nicht. In den nächsten Wochen ist er zeitweise erregt, läuft ruhelos umher, spuckt, hält Selbstgespräche oder ist ganz mutistisch. Schließlich vergräbt er sich ins Bett, ist ganz zugesperrt, stumm, unsauber, widerstrebt allen Einwirkungen. Dieser Wechsel zwischen vollkommener negativistischer Sperrung mit Zeiten zerfahrener Erregung dauert bis zum März 1930 fort. Nur gelegentlich ist er etwas ansprechbarer: ,Jetzt läuft man hier herum und wird immer harmloser ... Die Zeiten sind so mager geworden." (Wie geht es?) „Ach, es wird so langsam, aber es ist am besten, man ist weg." Nach Stimmen befragt: ,Ach, es ist wirklich nicht so wesentlich." Beim Reden runzelt er die Stirn, dreht die Augen im Kreis herum, kneift bald das eine, bald das andere Auge zu, bald läßt er den Kopf zwischen den Knien herabhängen oder beugt ihn nach hinten zurück. Mit den gespreizten Fingern werden mitunter vor dem Gesicht kreisende Bewegungen ausgeführt. Plötzlich summt und pfeift er vor sich hin, um im nächsten Augenblick zu stöhnen und zu schnaufen, alles ohne ersichtlichen Affekt. Die Antworten werden nachlässig gegeben, wobei er dem Arzt den Rücken zudreht. Einzelne Sätze werden mehrfach wiederholt, leise, tonlos.

Gelegentlich hält er Gespräche mit Personen in der Wand. Dabei kommen auch richtige technische Bemerkungen heraus. Ein anderes Mal äußert er, er habe vor wenigen Minuten gesehen, daß die Jahreszeiten sich ändern würden, denn das Fensterkreuz sei verbogen. Die Tatsache, daß ein Mitkranker das Bett gewechselt habe, beweise, daß dessen Mutter im Sterben liege. Auf eine Frage nach seinem Befinden: „Etwas besser, alles zu breit und zu groß hier, aber man ist immerhin zufrieden. Ich tue ja nicht allzuviel dabei. Die Räumlichkeiten, das Bildwerk sind groß aufgezogen. Es bricht vielleicht ein Eisenpferd; Schlitten kommen, es ist ja so harmlos. Er hat halt grade so seine Hemmungen hin und wieder." (Hemmungen?) ,Ja, die Möglichkeit besteht. Aber es ist immerhin was wert. Über die Blutdehnung weiß man ja Bescheid.“ (Blutdehnung?) „Dichtung und Familie. Man ist ja so allein." - Im Jahre 1929 kommen verständliche Bemerkungen kaum mehr. Der Kranke liegt in irgendeiner verschrobenen Haltung, die Knie hochgezogen, den Kopf erhoben im Bett, starrt vor sich hin, macht unverständliche Handbewegungen, ist stumm oder äußert abgerissene Worte. „Er ging einige Wege auf und ab und verschanzte sich ganz genau.“" Oder aber er ist erregt, lebhaft, gereizt, pfeift, klatscht in die Hände, kommt aus dem Bett, schlägt andere Kranke, wandert mit umgehängter Decke umher, redet unzusammenhängend, spuckt, läßt sich aus dem Bett fallen, schlägt mit dem Kopf gegen die Wand oder an die Tür, wehrt jede Einwirkung heftig ab, wirft sich auf andere Betten, stößt gegen das Bettbrett, hält die Decke zwischen den Zähnen, lacht laut auf. Seinem Besuch bringt er in keinem seiner Zustände Interesse entgegen. Er beachtet ihn gar nicht.

Im März 1930 nach Hause genommen, hielt der Kranke sich ruhig; ja, er besorgte sich selbst, begann auch, Aufträge auszuführen, setzte aber die angefangenen Tätigkeiten nicht fort. Ab und zu war er ohne erkennbaren Grund erregt. Im Juni machte er plötzlich Anstalten, sich zu erhängen und wurde in die Klinik zurückgebracht. In der Klinik ist er bald wieder in seinem katatonen Zustand: er liegt meist in verschrobener Lage im Bett und spuckt fortgesetzt, und zwar unter das Bettlaken, das er vorher aufhebt. Gelegentlich redet er un- 
verständlich. Er geht auf Fragen nicht ein, legt nur wie militärisch grüßend die Hand an die Stirn, macht gelegentlich Ausrufe : ,Weg, alles weg, Luft! Theater! Unglaubliche Schweinerei!"6 Gelegentlich etwas ansprechbarer, äußert er doch selten Verständliches und Zusammenhängendes. Vereinzelt kommen Wortneubildungen heraus: „Etzmobilien“. Im November ist er etwas erregter; er hat die Neigung, aus dem Bett zu kommen und in starrer Haltung herumzustehen, grimassiert stark, kratzt an einem pustulösen Ausschlag. Gelegentlich ist er triebhaft erregt: er springt dann aus dem Bett, legt sich auf den Boden und schreit unverständliche Worte, oder er setzt sich plötzlich auf die Heizung, das Waschbecken, lacht laut auf. Er bezeichnet sich als Psychiater, er leide an paralytischer Gehirnatrophie. Oft brummt er unter manierierten Gesten vor sich hin. Längere Reden sind ganz zerfahren. Anfang 1931 beginnt er überall herumzuklettern und dann herabzuspringen. Behindert, wird er aggressiv und äußert Schimpfreden. Einmal versucht er sich in plötzlicher Erregung die Genitalien auszureißen. Im Juni etwas ruhiger, wird er bald wieder erregter, macht auch plötzliche Angriffe auf die Umgebung, läßt sich aber stets rasch ohne Widerstreben ins Bett führen. Die Nahrung muß ihm immer eingegeben werden. Mitunter läßt er Urin ins Bett, obwohl er eine große Vorliebe für das Klosett hat, das er oft aufsucht. Es kommen nur seltene zusammenhanglose Äußerungen, meist Summen. Auf die Frage nach seinem Befinden äußert er stereotyp: „Fortschritte $^{66}$. Im Oktober schreibt er plötzlich ganz geordnet einige Worte und liefert eine allerdings unvollkommene Lösung des Pythagoräischen Lehrsatzes, löst auch ein paar Rechenaufgaben.

Wenige Monate darauf stirbt er ohne wesentliche Änderun ̧̧̧ seines Verhaltens in der Heil- und Pflegeanstalt.

\section{Paranoide Demenz}

Der Kaufmann Karl F., geb. 1898, soll als Kind folgsam, aber lebhaft und temperamentvoll, dabei wohl immer etwas schwierig gewesen sein und gern gelesen haben. Er hatte wenig Umgang mit anderen, später gern mit Mädchen, sonderte sich aber sonst ab. Erst Lehrling in einem Vermessungsinstitut, wurde er dann Volontär in der Textilbranche und hatte, vor allem auch nach dem Kriege, gute Erfolge als reisender Kaufmann. Im Kriege erlitt er eine Verwundung und angeblich eine Gasvergiftung mit Lungenentzündung. Damals soll er elend, „gebrochen“", gedrückt auf Urlaub gekommen sein. 1920 oder 1921 stellte er Versorgungsansprüche wegen Schlaflosigkeit und Angstzuständen. Schon damals soll er sich gelegentlich auf seinen Reisen beobachtet und verfolgt geglaubt haben. Erst im Jahre 1927 fiel eine seelische Störung auf. Er trug plötzlich einen sehr auffälligen und kostspieligen Anzug und äußerte bald darauf Verfolgungsideen. Er hörte Stimmen, fühlte sich von der Kriminalpolizei verfolgt und verdächtigt, einen Feldwebel erschossen zu haben. Schließlich meinte er, er werde verdächtigt, an 5 oder 6 Morden beteiligt zu sein. Er arbeitete nicht mehr, saß untätig und mißtrauisch zu Hause herum, war gereizt, bedrohte die Geschwister, sprach oft leise vor sich hin, führte auch erregte Selbstgespräche, beschimpfte die Kriminalpolizei und meinte, man habe vorläufig noch Angst, ihn zu verhaften. Er wurde auch bei der Kriminalpolizei vorstellig, bewaffnete sich mit einem Rasiermesser und anderen scharfen Gegenständen, äußerte Suizidgedanken. Wiederholt suchte er sich den Verfolgern durch weite Fußwanderungen bis nach Oberschlesien und der Lausitz zu entziehen. Nach Hause zurückgekehrt, war er läppisch, belästigte Passanten, kam in Konflikt mit den Hausbewohnern und faselte oft davon, er müsse einen Mord begehen. Eines Abends verlangte er ein langes Messer, und als er es nicht bekam, verließ er, mit einer Hantel bewaffnet, die Wohnung.

Deshalb wurde er 1928 in die Heilanstalt aufgenommen. Er protestierte gegen die Aufnahme. Er habe wohl mal an Neurasthenie gelitten und in der letzten Zeit an ,Kopfdepressionen“. Deshalb sei er aber noch nicht verrückt. Zu arbeiten werde ihm durch, ,äußere Einflüsse", nämlich die Kriminalpolizei, unmöglich gemacht, von der er wie von anderen Leuten mit mehreren unaufgeklärten Morden in Beziehung gebracht werde. Trotz seines Drängens sei man aber nicht auf eine nähere Untersuchung eingegangen und habe ihn ausgelacht. Darum sei er Zyniker geworden.

Wenn er zwei fremde Frauen sich unterhalten höre: „Heute ist es warm“, dann wisse er schon, was das zu bedeuten habe. Man könne sich nicht denken, auf welch verschiedene Art ibm gezeigt werde, daß er nicht normal veranlagt sei. Wo er nur gehe, überall strecke man ihm die Zunge heraus. Oft scheine es freilich nur, als wolle man sich die Zunge befeuchten; aber er verstehe das schon. Überall finde er ,gemachte Situationen ${ }^{6}$ vor. 
In der Abteilung ist er zunächst geordnet, zuvorkommend, aber mißtrauisch und hält mehr und mehr zurück. Er grimassiert leicht. Halluzinationen lehnt er ab, läßt sich überhaupt nicht auf krankhafte Erlebnisse festlegen. Anschluß sucht er nicht, beschäftigen kann er sich nicht recht. Er äußert immer wieder, es werde ihm nichts übrig bleiben, als jemand zu ermorden. Bald zeigt sich seine Streitsucht; er fühlt sich beobachtet, faßt Bemerkungen anderer als auf sich gemünzt auf, geht gespannt umher. Ein Beurlaubungsversuch scheitert. Er fühlt sich auf der Straße beobachtet, dann auch in der Abteilung fortgesetzt beeinträchtigt. Er halluziniert viel, hört „Mörder" rufen, bekommt Konflikte, droht mit Gewalttätigkeiten. Vorübergehend nach Hause beurlaubt, fühlte er sich fortgesetzt beleidigt, hypnotisch beeinflußt, hörte Stimmen, hatte wohl auch Vergiftungsideen und wurde erneut in die Heilanstalt zurückgebracht. Hier klagte er über Beeinflussung durch Hypnose. Er müsse zwangsmäßig Worte aussprechen, die er nicht als sein geistiges Eigentum empfinde. Stimmen beschimpfen, beleidigen ihn, beschuldigen ihn eines Mordes; Visionen beschuldigen ihn, eine Frau geschlechtlich infiziert zu haben. Anfang 1929 wird er in die Heil- und Pflegeanstalt übergeführt.

Hier ist er klar, besonnen, gibt geordnet über die Vorgeschichte Auskunft. Schon die ersten Verfolgungen führt er nun auf Hypnose zurück, aber auch den Umstand, daß er ohne Widerspruch mit in die Anstalt gegangen sei..Die Hypnotiseure kenne er nicht. Es handle sich um Fernhypnose. Man zwinge ihn durch Zungenbewegungen, gegen seinen Willen Worte auszusprechen; er nennt dies „Sprachhypnose“6 oder „Hypnose mit Zungenbewegung". Es gebe aber auch noch eine andere Art von Hypnose, bei der man die Worte nicht laut aussprechen müsse, bei der die Worte vielmehr auf das Hirnzentrum übergehen: ,stille Hypnose ${ }^{66}$. Krank sei er nicht. Er habe prachtvolle Nerven. Selbstverständlich müsse er sofort entlassen werden. Er geht aber ohne Schwierigkeit auf die Abteilung. Sein Auftreten ist selbstbewußt, sicher; seine Stimmung ist euphorisch. In der Folgezeit fordert er immer erneut, zornig oder weinend, seine Entlassung, schreibt viel an die Kriminalpolizei, sucht einmal auch zu entweichen. Immer neue krankhafte Erscheinungen tauchen auf. Auf einem EBlöffel wird ihm der Name Hulda suggeriert; es erscheinen ihm Städtebilder. Man wolle mit ihm einen zweiten Fall Jakubowski schaffen. In der zweiten Hälfte 1928 wird er ruhiger, arbeitet auch etwas; an die Geschwister schreibt er nette, natürliche Briefe, an den Landgerichtsdirektor zuma Teil ganz verzwickte und schließlich verunglückte Satzkonstruktionen mit wahnhaftem Inhalt. Oft schimpft er zum Fenster hinaus, daß er fortgesetzt hypnotisiert und befunkt und daß seine Schulter „bepunktiert“" werde. Im Oktober gelingt es ihm, zù entweichen.

Im November erschien er mit einem Brotmesser in der Manteltasche bei der Staatsanwaltschaft und wurde nach der städtischen Heilanstalt zurückgebracht. Angeblich hatte er bei der Staatsanwaltschaft nur Hilfe haben wollen. Als Hypnotiseur taucht in seinen Reden jetzt zum ersten Mal Professor F. auf, der die Sache zwar nicht selbst mache, aber von , seinen Leuten" machen lasse. Wenige Monate darauf ist der Hypnotiseur Professor F. selbst, auf den er fortgesetzt schimpft. Auf den Arzt redet er lebhaft und eindringlich ein, ohne ihn zu betrachten. Geht dieser nicht auf ihn ein, dann äußert F. verächtliche Bemerkungen, wird manchmal auch zudringlich, aber nicht eigentlich drohend. Man findet bei ihm eine Feile. Januar 1930 taucht das Wort ,schlechte Körperfernhypnose ${ }^{66}$ auf, Hören durch Fernhypnose. Er spricht von Brustschmerzen, die ihm verursacht werden. Bald hat er ,Körperfernhypnose für fremde Täterschaft ${ }^{6}, d . h$. er erlebt dauernd durch verbrecherische Hypnotisierung aus der Hypnosestation Breslau an seinem Körper, und zwar an der rechten Brustseite, unangenehme Beeinflussungen: Kribbeln und Schmerzen, mit denen ihm angedeutet werde, an welchem Körperteil sich vielleicht Verletzungen am Opfer eines fremden Täters finden werden.

Vom März 1930 ab läßt er den Arzt links liegen; er macht nur ironische, spöttische Bemerkungen: „Guten Abend, Herr Geheimrat", ist sehr unruhig, schläft wenig, läuft umher, schreit vor sich hin, lacht laut auf, macht eigenartige Bewegungen mit den Armen, setzt sich auf den Fußboden, trinkt Wasser aus einem Teller, läßt sich nicht scheren, so daß er wild aussieht, verschafft sich Sattlerahle und Taschenmesser, wird zudringlich, gestikuliert wild, erscheint aber doch nicht bedrohlich. Nach einigen Wochen wird er ruhiger, sitzt sinnend im Bett, den Blick ins Leere gerichtet. In seinen sprachlichen Äußerungen ist er formal geordnet, inhaltlich zunehmend zerfahren. Allmählich beschäftigt ex sich etwas, zeigt aber zugleich einen ausgesprochenen zerfahrenen Rededrang, der so laut ist, daß er seine Mitkranken oft stört. 1931 tauchen immer neue Wortzusammensetzungen auf: „Hypnobrutalmörder", womit er Professor F. und Primärarzt Ch. meint. 
In den folgenden Monaten dauert der zerfahrene Rededrang fort: F. zeigt dabei immer eine sehr laute, forcierte Sprechweise, aber keinen tiefen Affekt. Immer neue wilde Wortzusammenstellungen mit Beschuldigungen gegen Professor F. stellen sich ein. Dabei hilft er weiter bei der Hausarbeit. In gleicher Weise geht es 1932 fort. Im März 1933 entweicht er erneut bei einem Ausgang mit der Schwester und läuft $50 \mathrm{~km}$ zu Fuß nach Hause.

Hier fährt er wenige Tage darauf mit dem Wagen bei dem Oberarzt der Klinik vor, den er mitnehmen will, um Professor F. zu verhaften. Diesen will er ,genikulieren“, d. h. seinen Schädel auf- und zuklappen und dann hinrichten oder ins Zuchthaus bringen. Rasch wird er unter einem Vorwand in die Klinik gebracht und hier verlangt er vom Direktor ein Gesundheitszeugnis. Gegen die Aufnahme setzt er sich stark zur Wehr, um dann plötzlich nachzugeben. Er bewegt sich mit Grandezza, hält den bedeutenden Kopf hoch, ein wenig in den Nacken zurückgelegt, hat gemessene Bewegungen und ist herablassend gegen das Pflegepersonal und die Ärzte, gegen den Direktor bald sehr gereizt, ja bedrohlich, als er zurückgehalten wird und das Zeugnis nicht erhält, meist aber höhnend, ironisch, schneidend. Er wisse nicht, worauf der Direktor so eingebildet sei, vermutlich auf das preußische Gehalt, er, der zu jugendliche, kümmerliche Theoretiker, der offenbar auch gar nichts von der Hypnose verstehe und seinen Titel schon längst verloren habe. Er geht untätig und Selbstgespräche führend mit hoheitsvollen Gebärden einher, schimpft oft zum Fenster hinaus, grimassiert etwas, erscheint oft gespannt, gereizt; meist aber hat er nicht den seinen wahnhaften Gedanken angemessenen Affekt, sondern spricht von seinen angeblichen qualvollen Erlebnissen sachlich, fast euphorisch.

Er drängt unablässig hinaus, sobald er einen Arzt erblickt, wird aber doch nie energisch und läßt sich von seinen Geschwistern immer erneut Sand in die Augen streuen.

Seine Reden sind geordnet, sobald man ihn über einfache Sachverhalte zu sprechen bringt. Er faßt ausgezeichnet auf, hat ein erstaunliches Gedächtnis und weiß bald über tausend Einzelheiten Bescheid. Gelegentlich haut er einem anderen Kranken eine herunter. Sonst hält er sich von ihnen fern. Nach wie vor fühlt er sich von Professor F. hypnotisiert, der ihn beseitigen will, um sich seiner Erbschaft zu bemächtigen, wie er schon seine Mutter beseitigt hat, und zwar auch aus Rasseneid. Denn F. ist Ostgalizier; übrigens hat er F. noch nie gesehen. Professor F. sei in einer internationalen Geheimverbindung, die überall, wo sie Vermögen wittere, die Erben beseitige durch „Erbschleichhypnose“. Er selbst sei ein „Kriminalbegriff im Studium". Es gehe nicht an, daß er als hochangesehener Bürger einfach durch „Kopfschleichgesangsmeuchelmorde“ durch die Benutzung des Rasseneides 4 Jahre ausgeschaltet, in die Anstalt „beseitigt" werde. Es sei bei ihm durch die fortwährende Hypnose zu einem „Innenausbruch des Nervrerumgestänges“ gekommen. Der „Dynamieabstrom“ fehle ihm. Professor F., ein „Innenflieher mit nervösem Auge“ - er sehe dies am Querschnitt der Tränendrüse - könne ihm nicht helfen. Er spricht von "Schwermeuchelmordversuchsermordung“", „Innenschleichmeuchelgestängemord“", der mit „Überhandgesang" begonnen, dann den „Oberdeckel", das "Gewicht" und schließlich das „Murr" befallen habe. So sei ein „Nervrerumvorfall" entstanden, in dem die Kabel des Professors F. nach dem Kopf explodiert seien. Als Privatbürger wolle er die Klinik nur im "Sinne eines Attestes" in Anspruch nehmen und sei darum in ,eigener Autoaufwendung“ gekommen. Er gehöre der ältesten preußischen Militärstammrolle an und habe große Schlachten im Kriege durch seine Person gewonnen. - Er spricht wieder von „Schweremord“", „Durchdruck“, „Fikatimpunkt", „Bikschule“, „Intellektbürger", „Schmart", „Asikaschoch“, „Gemilare“. Abends verlangt er immer ein Dauerbad, das ihm angeblich die Blutadern aufreißt und ihn für die Nacht stärkt. Er ist ja schon zu $90 \%$ ermordet: der „Exitus" steht unmittelbar bevor. Daran sind die „südgalizianischen Blutschandjuden, die Lastträger, Ziegelarbeiter, Bordelljudenfamilien usw." schuld. - „Die Beseitigung von dem Ostjuden F. in der Anstiftung war die Erbbeseitigung, die Großlodzer Blutsverwandten und Erbhinterlasser. Außerdem hat der Ostjude F. bereits unsere alte Dame ermordet durch hypnotischen Meuchelmord in unserer Familie. Es liegen aber noch andere Familien vor. Er hat es gemacht über den Dr. J. durch Mastdarmverblutung, durch Hypnose. Bei mir hat er 1926 am Kopf angefangen. Er ist außer Erbenmörder auch noch reiner Kopfmörder. Der Ostjude F. treibt außer dem Erbschleichmord durch Hypnose auch noch einen Rassekopfmord. Das hat bei mir noch den Zusammenhang meiner alten Kopfrasse ,Asikanschoch', als asiatische Malagarasse. Die Bevölkerung ist überwiegend asiatischen Ursprungs. Wir sind ein altes, reinrassiges Geschlecht von der Ostsee in Pommern. Wir waren außerdem noch Offiziersstammrolle. Der Ostjude F. betreibt für K. 
die berüchtigten hypnotischen Soldatenmorde, die Umwandlung der vielseitigen Erbschleichmorde als Rassenmord des berühmten Soldaten Riga-Wenden und Tarnopol an der Westfront durch den Eingriff meiner Person im ersten Garde zu Fuß, von dem die letzten beiden entscheidenden Offensiven gegen Rußland zuwege gebracht... Durch Hypnoseeinlegung hat es der Ostjude F. erreicht, daß sein Genosse und Jude Ch. erledigt ist in der Jungmännerbedeutung, in der Einstellung zur Frau, das heißt, daß er heiratete. F. treibt an 50jährigen Männern seine ,Sichselbstverjüngungsmethode', da er ein kreuzförmiges Moment des Rerums über Rücken und Hüfte hat. Aus diesem Rücken-Rassen-Moment drückt er sich in seinem Körper das Rerum, um sich seine Vitalität zu sichern. F. macht also Erbschleichmorde, Soldatenmorde und Verjüngungsmorde. Aber außerdem verfolgen noch 17 Professoren an seinem Körper letztmalig das Strafmaß. Mit ihnen steht er durch unsichtbare Stromkabel in Verbindung."

\section{Milde paranoide Demenz}

Dora K. ist ein 33 Jahre altes Mädchen ohne Beruf, das seit einem Jahre in der Hauptstadt lebt und eine Musikstunde in der Woche nimmt, im übrigen Klavier übt, sonst aber nichts tut. Sie leidet darunter, daß sie nachts immer durch Gas und Gerüche belästigt wird, so daß sie schon wiederholt unter Krach die Wohnung hat wechseln müssen. Deshalb schläft sie nachts unter dem offenen Fenster, nicht im Bett, sondern auf dem Sofa, und sie schiebt immer das Taschentuch zwischen die Zähne, damit sie genug Luft bekommt und nicht erstickt. Das Gas wird offenbar in die Wohnung gelassen, sie weiß nicht, von wem. Vielleicht steht sie bei irgendeinem Bund auf der schwarzen Liste. Sie ist ein wenig steif, ein wenig eckig, ein wenig manieriert, leicht verschroben, sehr höflich und sehr zurückhaltend. In der Klinik geht es ihr ausgezeichnet; nichts von Gerüchen; nur hat sie mit dem Magen zu tun und stößt oft auf.

Die Geruchsbelästigungen gehen schon lange zurück. Von jeher war sie zurückhaltend und ohne Schwung. Das „lag in ihrer Natur". Freundinnen hatte sie nicht. Thr Tanzstundenherr war ihr unsympathisch. Doch tanzte sie ganz gern, aber nur in geschlossener Gesellschaft, am liebsten mit dem Bruder. Als sie mit 21 Jahren aus der Pension zurück kam, hatte sie einen "Erschöpfungszustand". Sie war niedergeschlagen, weinte leicht, tat nichts, hatte keinen Antrieb, litt an Kreuz- und Gelenkschmerzen. Damals war sie ein halbes Jahr lang in ärztlicher Behandlung. Sie ließ sich die Mandeln entfernen. Magenschmerzen von den vielen Medikamenten her beseitigte das Rezept eines Schäfers. Sie half nun durch Jahre im Haushalt der Eltern, in einem einsamen Forsthaus. Dann ging sie zum Bruder, um da die Wirtschaft zu führen. Er lebte in einer Gastwirtschaft, in der bald das Leben unerträglich wurde. Nachts gab es laute Geräusche: Türen schlugen, Katzen, Hunde machten Geräusche. Eine Beschwerde führte zu bitterer Feindschaft mit den Wirtsleuten, die Patientin nun schikanierten. Auf dem Klosett wurde eine Postkarte angebracht, die Patientin verhöhnen sollte, wenn Patientin auch nicht genannt war. Nachts wurde an den Wänden geklopft; sie mußte Ohropax nehmen, wurde aber trotzdem schlaflos, und zwar, wie sie meint, durch geruchlose Giftgase. Der Bruder schlief freilich gut. Als sie nachts wieder einmal Geräusche hörte und an die Wand klopfte, gab es eine große Auseinandersetzung. - Patientin hatte damals immer einen Revolver zum Schutz im Nachtkasten - und die Geschwister zogen aus. Aber auch in dem neuen Wohnort kam bald wieder die Schlaflosigkeit; heute erinnert sich die Patientin, daß auch damals süßlicher Gasgeruch sie störte.

Im Elternhaus hatte sie nun ein halbes Jahr lang Ruhe. Aber in Breslau begannen die Gerüche bald erneut, in welche Wohnung die Patientin auch zog. Bald roch es nach süßlichem Rauch, bald nach Schwefel. Sie hatte dann „Kopfdruck zum Zerspringen“, Mattigkeit, Schwitzen, schreckliche Blähungen. Sie fühlte sich krank und erinnert sich, daß alles mit einem Zucken in der Nase begonnen hatte. Zu Hause hatte sie dann Ruhe, aber sie war matt und lag ein Vierteljahr lang im Bett, war ein Jahr lang matt und elend, hatte Kopfschmerzen, Schlafstörungen, Blähungen. Dann kamen auch daheim Geräusche: Ruten schlugen ans Fenster, Steine flogen, Ziegel fielen vom Dach, draußen war Krach, der Hund heulte. Die Geräusche schwanden, um einem Geruch Platz zu machen: Nebelgeruch, der den Schlaf raubte. Einmal beim Backen begann plötzlich der Ofen zu glühen; Patientin dachte an einen unterirdischen Anschlag. Einmal bemerkte sie zwei Männer, die über sie sprachen. Einer von ihnen sah sich später immer eigenartig nach ihr um. Patientin war all dies unheimlich: „Ob ein Verbrechen vorliegt?“" „Es kann bald nichts anderes sein.“ Die Angehörigen lachten sie freilich aus. Aber sie siedelte nach Breslau über und hier geht es nun schon in der dritten Wohnung in der gleichen Weise fort, so daß sie nun kommt, Schutz zu suchen. 
All dies wird höflich, in korrekter, wohlgesetzter Rede konventionell, etwas starr, geziert vorgebracht. Einwände werden überlegen abgewehrt. Wenn jemand Stimmen hört, ja, das ist krankhaft. Aber an den Geräuschen und den Gerüchen, an den schädlichen Wirkungen und daran, daß alles sich auf sie bezieht und ihr zum Schaden gemacht wird, daran ist für sie nicht der leiseste $Z$ weifel, auch wenn sie nicht weiß, wer ihr all das antut.

\section{Prämorbide Persönlichkeit}

Es gibt sicherlich Schizophrene, die vor dem Beginn ihrer Erkrankung normal sind; doch werden außerordentlich häufig von jeher bestehende Wesenseigentümlichkeiten beschrieben, unter denen Kretschmer drei Gruppen hervorgehoben hat:

1. Ungesellig, still, zurückhaltend, ernsthaft (humorlos), eigenartig (Sonderling).

2. Schüchtern, scheu, feinfühlig, überempfindlich, nervös, aufgeregt, Naturund Bücherfreund.

3. Lenksam, gutmütig, brav, gleichmütig, stumpf, dumm.

Dabei finden sich die Merkmale der ersten Gruppe überall, auch dort, wo die der zweiten und dritten überwiegen, vor allem aber sind die Merkmale zu 2 und 3 nie rein; vielmehr sind diese Menschen, die Kretschmer in deutlichen psychopathischen Ausprägungen als Schizoide, in ihren der Norm angenäherten Gestaltungen als Schizothyme bezeichnet, immer zugleich überempfindlich und unterempfindlich; es kommt auf das Mischungsverhältnis an, das Kretschmer als "psychästhetische Proportion" bezeichnet. Von der Seite ihres seelischen Tempos sind die Schizoiden zäh oder aber sprunghaft, energisch, eigensinnig, störrisch, pedantisch oder aber haltlos, träumerisch, fahrig, unberechenbar, in ihrem Ausdruck affektlahm, schüchtern, in ihrer Psychomotorik eigenartig steif, stilisiert, verhalten, eckig, gespreizt, förmlich, feierlich, kurz unnatürlich, oder aber hastig, fahrig, zappelig. Es fehlt die Ausgeglichenheit, die Abrundung des Natürlichen, der sich zwischen Menschen und Dingen zu Hause fühlt. Alles

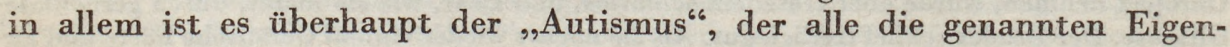
schaften der Schizoiden zusammenhält, die Kluft, die zwischen ihm und der Welt, vor allem den Menschen, besteht, im Sinne einer Abwehr bei starker Überempfindlichkeit, einer mehr affektiven Ablehnung oder einer stumpfen Unberührtheit. In Ängstlichkeit und Feindseligkeit, feinfühliger Scheu und aktiver Menschenfeindschaft, mißtrauischer Sicherung und kalter Aggression, aristokratischer Distanz und ironisch-stacheliger Abwehr und mancherlei anderen Formen kann sich der Autismus kundgeben. Im psychologischen Versuch erscheint der Schizoide mehr intensiv, abstraktiv, analytisch, zäh, beharrend, mit einzelnen barocken Gedankensprüngen, subjektivierend, gefühlsverhalten im Gegensatz zum Syntonen (s. unten), der mehr extensiv, gegenständlich, synthetisch, leicht ansprechbar und umstellbar, objektivierend, naiv-gefühlsmäßig ist.

Bei mancherlei Einwänden, die gegen die Lehren Kretschmers gemacht worden sind, ist deren Wirklichkeitsgehalt doch unbestritten. Insbesondere ist kennzeichnend der Autismus: einsame, reizbare, launenhafte, absonderliche und langsame, schüchterne, einsam trübselige Typen sind 
unter den prämorbiden Persönlichkeiten der Schizophrenen nicht nur absolut häufig, sondern bestimmt auch wesentlich häufiger als beim Durchschnitt der Menschen. An geschlosseneren Menschentypen, die häufiger hervortreten, nenne ich ferner: eigensinnige Querköpfe, jähzornige Gemütsstumpfe, gemütskalte Ethisch-Defekte, menschenscheue Zurückgezogene, Verschlossene, eigenartig Verschrobene, hypochondrisch Nervöse, Paranoide. Auffallend häufig sind ferner die ,Musterkinder ${ }^{66}$, die auch später eine eigenartig unlebendige, trockene, nüchterne Gewissenhaftigkeit und Schwunglosigkeit beibehalten. Die gleichen Menschentypen begegnen uns im familiären Umkreise der späteren Kranken als bleibende psychopathische Dauerverfassungen.

\section{Körperbau}

Im Gegensatz zu den Zirkulären, für die unzweifelhaft eine Korrelation zum pyknischen Körperbau besteht, sind unter den Schizophrenen pyknische Typen selten, leptosome, schlanke Menschen, insbesondere auffallend asthenische, nächstdem dysplastische und endlich muskulär-athletische Körperbauformen aber häufig. Es kann noch nicht als gesichert gelten, daß die Verteilung dieser Typen bei den Schizophrenen eine wesentlich andere ist als in der Durchschnittsbevölkerung. Ich halte es aber nicht für zweifelhaft, daß extreme asthenische und dysplastische Typen, die letzteren besonders in der Form des eunuchoiden Hochwuchses und des dysplastischen Fettwuchses, bei Schizophrenen häufiger sind als in einer durchschnittlichen Population. Dem relativen Überwiegen der asthenischen Typen entspricht auch die Tatsache, daß bei den Schizophrenen selbst wie in ihrem familiären Umkreis die Tuberkulosebereitschaft eine erhöhte ist, wie Luxenburger festgestellt hat. Auch daran ist schwerlich zu zweifeln, daß gerade bei den ungünstig verlaufenden Schizophrenien abnorme Körperbautypen vorwiegen, so bei den ungünstigen Hebephrenien extreme asthenische Typen, bei den Katatonien besonders dysplastische Körperbauformen. Andererseits sind viele Katatone muskuläre Typen. Endlich zeigen viele paranoide Schizophrene pyknische Merkmale, ja, bei den mildesten paranoiden Verlaufsformen mit weitgehender Erhaltung der Persönlichkeit, den sog. Paraphrenien, sehen wir vielfach überwiegend pyknischen Körperbau. Es ist wohl auch richtig, daß, je deutlichere pyknische Merkmale ein Kranker hat, um so günstiger durchschnittlich seine Prognose ist.

\section{Verlauf und Prognose}

Der Krankheitsbeginn läßt sich in vielen Fällen, da die Veränderung ganz schleichend vor sich geht, nicht mit hinreichender Genauigkeit festlegen. In mehr als $50 \%$ der Fälle läßt er sich aber vor das 25. Lebensjahr, in etwa 70 bis $75 \%$ der Fälle vor das Ende des dritten Lebensjahrzehntes ansetzen. Erkrankungen, die später beginnen, haben einen zunehmend paranoiden Anstrich. Hierher gehören die häufigsten Formen der eigentlichen paranoiden Demenz. Noch später beginnen in der Regel die mit weitgehender Erhaltung der Persönlichkeit einhergehenden sog. Paraphrenien, von denen unten noch kurz gesprochen werden soll. Früh setzen meist die Hebephrenien und der Hauptteil der Katatonien ein. Die Schizophrenien 
wurden von Kraepelin unter dem Namen Dementia praecox zusammengefaßt, einer Bezeichnung, welche die Annahme einer früh einsetzenden gesetzmäßigen Verblödung nahelegte. Tatsächlich trifft es ja zu, daß die Erkrankung in der Regel früh beginnt, und es ist nicht minder richtig, daß sie in der übergroßen Mehrzahl der Fälle zur bleibenden Persönlichkeitsveränderung und sehr häufig zur - schizophrenen - Demenz führt. Eine Demenz im Sinne der organischen Psychosen tritt aber nicht ein, da ja die Grundfunktionen auffallend gut erhalten bleiben. Der entstandene Defekt trägt vielmehr die kennzeichnenden Züge der Schizophrenie, die eigenartige Denkstörung und die Wandlung und Verödung der Affektivität. Er kann aber ganz verschiedene Grade erreichen. Die schwersten Formen führen zu einem völligen Zerfall des Denkens und zur tiefen affektiven Verödung, wobei man häufig noch aus dem Überwiegen der katatonen, der hebephrenen, der paranoiden Züge die Verlaufsgeschichte erraten kann. In sehr zahlreichen Fällen aber ist die Veränderung eine weniger tiefe, so daß auch im „Endzustand $^{66}$, der wesentliche Umbildungen nicht mehr erfährt, noch recht gute Leistungen, auch im Beruf, möglich sein können, daneben allerdings immer erneute überraschende Entgleisungen schizophrener Art vorkommen. Den Grad solcher Defekte wird man nach der Häufigkeit solcher Entgleisungen bemessen müssen.

Durchaus nicht alle Psychosen schizophrenen Gepräges führen zu schweren Defekten, ja bei einem nicht ganz kleinen Prozentsatz (10 bis höchstens 20\%) vermissen wir nach dem Ablauf des akuten Krankheitsvorganges sichere Persönlichkeitsveränderungen. Besonders nach einmaligen akuten katatonen Schüben, vor allem Stuporen, aber auch Erregungen, kommt dieser Ausgang vor.

Die Krankheit verläuft überhaupt nur in einem kleineren Teil der Fälle in einem einheitlichen, wenn auch unter Schwankungen vor sich gehenden Verlauf zum Endzustand, der dann nach ein paar Jahren erreicht wird. Meist geht die Veränderung in einzelnen durch mehr oder weniger leichte Besserungen (Remissionen) unterbrochenen Schüben vor sich. Besonders die katatonen Verlaufsformen zeigen sehr häufig solche klar abgesetzten Schübe und Remissionen, die anfangs sehr weitgehend und langdauernd sein können. Manchmal bringt auch der zweite und dritte Schub noch keine deutliche Veränderung mit sich, die dann erst in den späteren Remissionen immer gröber erkennbar wird. Die späteren Remissionen pflegen von immer kürzerer Dauer zu sein, die ersten können 3, 6, ja 10 Jahre und noch länger anhalten.

Am ungünstigsten sind die eigentlich hebephrenen Verläufe, die zwar leichte Besserungen, aber kaum je an Heilung grenzende Remissionen erfahren. Aber auch viele Katatonien verlaufen katastrophal in einem einheitlichen Zuge zur tiefen Veränderung. Es scheint, als ob besonders die Kranken mit ausgesprochen dysplastischen und extrem asthenischen Körperbauformen zu solch raschem Zerfall geneigt sind.

Demgegenüber führen die eigentlich paranoiden Formen, denen katatone Züge fehlen, kaum je zu ganz schweren Persönlichkeitsveränderungen. Andererseits kommt es hier zu eigentlichen Heilungen so gut wie nie, wenn auch manche Kranke eine „doppelte Buchführung ${ }^{66}$ lernen, d. h. ihre Wahnideen zwar nicht korrigieren, aber sich doch in leidlich brauchbarer Weise 
wieder in die Umwelt einordnen, ohne daß sie sich dabei von ihren Wahninhalten beeinflussen lassen.

Es wurde schon darauf hingewiesen, daß die Schizophrenie gleichzeitige manisch-depressive Anlagen nicht ausschließt. Diese sind sogar häufig und, was wichtiger ist, sie verbessern im allgemeinen die Prognose. Dies gilt sowohl für den pyknischen Körperbau als für ursprünglich syntone Wesenszüge als endlich für entsprechende Färbungen der akuten Krankheitsbilder. Je mehr in diesen manische oder aber eigentlich melancholische Züge hervortreten, um so besser ist durchschnittlich die Prognose des Schubes. Vielfach sehen wir allerdings im späteren Verlauf die zirkuläre Färbung immer mehr verblassen und damit auch die Prognose des Schubes ungünstiger werden.

Im Beginn der schizophrenen Verläufe sind hysterische Überlagerungen und Symptome sehr häufig; eine prognostische Bedeutung kommt ihnen im allgemeinen nicht zu. Immerhin können auf dem Boden schizophrener Persönlichkeitsveränderungen reaktive Psychosen hysterischer Färbung auftreten, welche als solche den Verlauf der reaktiven Psychosen überhaupt zeigen.

Die Unterformen der Schizophrenie, Hebephrenie, Katatonie und das „Paranoid", lassen sich nicht scharf voneinander abgrenzen. Die Hebephrenie kann mit katatonen Zügen einhergehen, ebenso die Erkrankungen, die man ihren Haupterscheinungen nach der paranoiden Demenz einordnen wird. Vor allem aber kann eine Schizophrenie auch einmal als Hebephrenie beginnen, späterhin katatone Episoden zeigen und in einem paranoiden Restzustand enden. Wir finden auch sonst vereinzelt alle erdenklichen sonstigen Kombinationen verwirklicht.

\section{Paraphrenien}

Von der damals sogenannten Dementia paranoides (Paranoid) hat Kraepelin als sog. paranoide Prozesse oder Paraphrenien eine Reihe von Krankheitsbildern abgegrenzt, die sich insgesamt dadurch auszeichnen, daß die Wahnbildung ganz im Vordergrund steht, während es zu der kennzeichnenden schizophrenen Persönlichkeitsveränderung, also zur affektiven Verblödung und zu Willensstörungen gar nicht oder doch sehr spät kommt. Außerhalb ihres Wahns wirken die Paraphrenen also nicht schizophren, während die Wahnideen ihrem Aufbau und ihrem Inhalt nach durchaus schizophrenes Gepräge tragen. Den Paraphrenien ist weiter gemein, daß sie durchschnittlich wesentlich später beginnen als die anderen Formen von Schizophrenie. Auffallend häufig ist ferner pyknischer Körperbau und das Hervortreten hypomanischer bzw. ursprünglich paranoischer Wesenszüge.

Von den Sonderformen der Paraphrenie sei die Paraphrenia systematica genannt, in deren Beginn ein zunächst systematisierter, bald mit lebhaften Gehörstäuschungen einhergehender Verfolgungswahn sich entwickelt, der unter lebhaftem Affekt unter Umständen zu sehr erheblichen Abwehrmaßnahmen führt. Allmählich pflegt aber die Systematisierung einem zunehmenden Zerfall und oft auch der Entwicklung schizophrener Größenideen Platz zu machen. In vielen Fällen dieser Art kommt es schließlich doch zu einer gewissen affektiven Verödung. 
Bei der Paraphrenia expansiva beherrscht ein üppiger Größenwahn, der von einem expansiven, meist manischen Affekt getragen wird, das Bild. Gerade diese Kranken zeigen lange Jahre hindurch eine auffallend frische, natürliche Persönlichkeit.

In geringerem Maße gilt dies für die konfabulatorischen und phantastischen Formen der Paraphrenie, bei denen in üppiger Fülle sich einstellende Erinnerungstäuschungen bzw. einfache spielerische und oft rasch wechselnde Erfindungen die Inhalte des Wahns bestimmen. Auch in diesen Fällen ist eine manische Färbung nicht selten.

Rein paraphrener Verlauf, d. h. Ausbleiben jeder kennzeichnenden schizophrenen Persönlichkeitsveränderung, läßt sich nur in seltenen Fällen feststellen. Anscheinend handelt es sich bei den Paraphrenien um schizophrene Prozesse bei konstitutionell eigenartigen (zirkuläres Erbgut), besonders widerstandsfähigen Persönlichkeiten, die deshalb auch spät erkranken.

\section{Tod und Leichenbefund}

Ein kleiner Bruchteil der Schizophrenen geht, wie es scheint, an dem schizophrenen Prozeß selbst zugrunde, und zwar in den schon genannten Hirnschwellungszuständen, in denen, selten, auch einmal ein epileptiformer Anfall auftreten kann. Bei einzelnen Fällen sogenannter tödlicher Katatonie, die mit roter Metaplasie des Fettmarks der langen Röhrenknochen einhergehen, kommt es zu schweren Gefäßkollapsen. Andere werden in der katatonen Erregung entkräftet und erliegen septischen Infektionen infolge von Verletzungen und Dekubitus. Manche gehen auch an schweren Parotitiden und Pneumonien während der akuten Schübe zugrunde. Auch der Selbstmord, der oft in absonderlicher Weise ausgeführt wird, beendet das Leben zahlreicher Schizophrener.

Im späteren Verlauf treten unter den „natürlichen“ Todesursachen besonders die Tuberkulose und infektiöse Darmerkrankungen in den Vordergrund. Nicht wenige Schizophrene erfahren einen senilen Verfall und manche gehen auch an Schlaganfällen auf arteriosklerotischer Basis zugrunde.

Der Leichenbefund zeigt zwar nach längerer Krankheitsdauer am Hirn jedes Schizophrenen Veränderungen, doch sind diese nicht kennzeichnend, da wir gleichartigen morphologischen Störungen auch bei anderen Leiden begegnen. Insbesondere finden sich diffuser, mehr oder weniger hochgradiger Schwund der Ganglienzellen in der Rinde, besonders deren dritter Schicht, nicht selten wirkliche Lichtungen von geringem Umfang, ohne jedes Zeichen einer entzündlichen Reaktion und selbst ohne deutlichere begleitende Gliaveränderungen. $\mathrm{Ob}$ die Verteilung dieser Lichtungen auf die Rindenterritorien kennzeichnend ist, wissen wir noch nicht.

Bei der "Hirnschwellung", von der schon gesprochen wurde, und die sich makroskopisch in der Volumvergrößerung des Hirns, im Verstreichen der Furchen, in der Abplattung der Windungen und der trockenen Beschaffenheit des Hirngewebes äußert, finden wir schwere Ganglienzellveränderungen und auch eine schwere Schädigung der Glia (amöboide Umwandlung der Astrozyten). 


\section{Behandlung}

Eine kausale Behandlung der Schizophrenie gibt es nicht. Das Gesetz zur Verhütung erbkranken Nachwuchses wird dazu führen, daß allmählich weniger Schizophrene geboren werden. Darüber hinaus sollten Schizoide auf keinen Fall untereinander heiraten. Manchen gequälten Menschen aus diesem Kreis wird man überhaupt von der Ehe abraten. Unter Umständen wird ein Eheverbot gemäß $\S 1 c$ des Ehegesundheitsgesetzes möglich sein. Eigens bemerkt sei, daß nicht bloß Schizophrenien im engeren Sinne, sondern auch Paraphrenien, paranoische Entwicklungen, soweit sie auf dem Boden von Defekten zustande kommen, vom Gesetz betroffen werden.

Jeder akutere schizophrene Schub macht wegen der damit verbundenen Gefahren (Erregung, Suizid, Nahrungsverweigerung, Gefährdung der Umgebung) Anstaltsunterbringung nötig. In der Anstalt sind wir auf die symptomatische Behandlung (Schlaf- und Beruhigungsmittel, künstliche Ernährung usw.) angewiesen. Bei Fällen, die rasch in stationäre Zustände übergehen, wird man unter Umständen den Versuch einer Fieberbehandlung (Pyrifer) machen. Bei akuteren Erregungen ist manchmal Dauerschlaf angezeigt. In letzter Zeit hat man recht heroische Behandlungsmethoden ausgearbeitet, und zwar steht jetzt im Vordergrund des Interesses die Insulinbehandlung (Sakel); dabei werden durch allmählich gesteigerte Insulindosen hypoglykämische Bilder, Schocks und Komazustände erzeugt, die nach verschieden langer Dauer durch Kohlehydratzufuhr vermittels Nasensonde bzw. intravenös unterbrochen werden. Gerade diese manchmal recht bedrohlichen Zustände bilden wohl den therapeutischen Faktor. Eine abschließende Beurteilung ist noch nicht möglich, wenn auch vielfach günstige Erfolge berichtet werden. Wegen der großen technischen Schwierigkeiten ist die Durchführung nur in dazu eingerichteten Anstalten möglich. Ähnliches gilt auch für die von Meduna angegebene Konvulsionstherapie, bei der durch intravenöse Cardiazoleinspritzungen Krämpfe erzeugt werden.

Schizophrene sollen möglichst nicht isoliert werden, da diese Maßnahme der Entwicklung des Autismus, der Stereotypien und Manieren und aller erdenklichen unangenehmen katatonen Symptome Vorschub leistet. Zunehmend ist man dazu übergegangen, die Schizophrenen rasch an die Arbeit zu bringen. Auch wenn es sich bei Schwerkranken um ganz mechanische und leere Beschäftigungsarten handeln muß (Wollezupfen), wird damit dem Verfall vorgebeugt. Am besten halten sich Schizophrene in der Familie, in die sie so rasch als irgend angängig zurückgebracht werden sollten (Frühentlassungen). Gemeingefährliche gehören aber bleibend in die Anstalt. Katatone Stuporen werden manchmal durch Milieuänderung (Verbringung in eine andere Anstalt, in die Familie) schlagartig gebessert. Hier müssen wir psychogene Zutaten annehmen, die auch sonst im Bereiche der schizophrenen Zustände eine nicht unwesentliche Rolle spielen.

Insbesondere bei leichteren Defektzuständen sehen wir abnorme Reaktionen nach Art der psychopathischen Syndrome. Hier sind psychotherapeutische Einwirkungen angezeigt. Überhaupt erfordern leichtere Defekte oft die Führung durch einen sachverständigen Arzt.

Forensisch wird jeder schwere Defekt wie jede akute Psychose schizophrenen Gepräges zur Anwendung des $\S 51$ führen; leichtere Defekte können 
zur Anwendung des $\S 51$ Abs. 2 Veranlassung geben. Der praktische Arzt ziehe aber in jedem Falle den Sachverständigen zu Rate.

Für die Unfallsbegutachtung muß man wissen, daß der Weltkrieg eine Zunahme der Schizophrenie nicht mit sich gebracht hat. Ursächliche $\mathrm{Zu}$ sammenhänge im Sinne einer Auslösung wird man höchstens bei unmittelbarem zeitlichem Zusammenhang des ersten Schubes mit einer sehr schwerwiegenden äußeren Einwirkung annehmen können (schweres Schädeltrauma, schwere Allgemeininfektion), da wir wissen, daß etwa die kombinierten Wirkungen des komplizierten Wochenbettes nicht ganz selten katatone Schübe heraufführen.

\section{Erkennung}

Von den bei der Schizophrenie vorkommenden Symptomen geben die sichersten diagnostischen Anhaltspunkte die spezifische Denkstörung, die Veränderung des Gemütslebens sowie alle jene Erscheinungen, welche die „intrapsychische Ataxie ${ }^{6}$ deutlich machen, die Ambivalenz und Ambitendenz, die Paramimie, die doppelte Orientierung usw. Recht kennzeichnend sind ferner die Erlebnisse des Gemachten, des Gedankenentzugs und der Beeinflussung der Sexualsphäre.

Demgegenüber ist die diagnostische Bedeutung der katatonen Symptome gering. Katatone Zustandsbilder können zumal bei allen organischen Hirnerkrankungen, bei symptomatischen Psychosen auftreten. Man muß nur daran denken und eingehend untersuchen, um eine Paralyse nach den kennzeichnenden neurologischen Erscheinungen und damit serologisch sicherzustellen. Immerhin kann auch eine Paralyse neben katatonen Symptomen auch einmal ein schizophrenes Bild hervorrufen. Die Lues cerebri läßt sich meist leicht erkennen, mit Ausnahme der seltenen halluzinatorischparanoiden Zustandsbilder, die, abgesehen von den serologischen Befunden, durch das Fehlen der schizophrenen Symptome im engeren Sinne charakterisiert sind. Bei aller äußeren Ähnlichkeit wird die Unterscheidung eines katatonen von einem enzephalitischen Folgezustand meist keine Schwierigkeiten machen, wenn man nur das Syndrom des Parkinsonismus wirklich kennt. Auch die seltenen paranoid-halluzinatorischen Zustände der Enzephalitiker gehen doch zugleich mit Rigor und Salbengesicht einher. Im übrigen wird die Vorgeschichte meist Klarheit bringen.

Symptomatische Psychosen, besonders kataton gefärbte amentielle Zustände, lassen sich dagegen manchmal nicht von akuten schizophrenen Psychosen unterscheiden, da auch bei ihnen, wenn auch selten, eine deutliche Bewußtseinsstörung vorkommt und da auch schizophrene Schübe von schweren organischen Schäden ausgelöst werden können. Jeder Sachverständige wird etwa bei Grippeepidemien oder bei kataton gefärbten Psychosen im Wochenbett Überraschungen nach der einen oder anderen Seite erleben. Vorsichtige Prognosestellung ist also immer nötig. Im allgemeinen läßt sich aber sagen, daß symptomatische Psychosen um so wahrscheinlicher werden, je enger der Zusammenhang mit den äußeren Schäden und je deutlicher die Bewußtseinstrübung ist, vor allem je mehr das Syndrom sich dem eigenartig schwankenden Verlauf der deliranten Störungen annähert. Fortdauer der Erscheinungen bei nicht nachweislich getrübtem Bewußtsein macht die Diagnose Schizophrenie zunehmend wahrscheinlich. 
In epileptischen Ausnahmezuständen können alle schizophrenen Symptome und Syndrome episodisch hervortreten. In der Regel aber machen die durchscheinenden Züge der epileptischen Schwerfälligkeit, Umständlichkeit und Unbesinnlichkeit die wahre Natur der Störungen kenntlich. Auch die genaue körperliche Untersuchung (Zungenbisse) und natürlich die Vorgeschichte bringen meist Klarheit.

Typische Manien und Melancholien können mit schizophrenen Syndromen nicht verwechselt werden, wenn man sich an den echten Affekt, die einfühlbare Traurigkeit, die ansteckende Heiterkeit, an den Unterschied von Hemmung und Sperrung, jenen von katatoner, gewissermaßen im leeren Raum sich abspielender Erregung und manischer Geschäftigkeit hält. In manchen Fällen aber versagen diese Unterschiede, vor allem dort, wo der Schizophrene gleichzeitig zirkuläre Anlagen hat. Hier bringt erst der spätere Verlauf eine endgültige Klärung. Dem depressiven Stupor fehlt die Sperrung der Katatonen; meist wird sich doch ein gemütlicher Kontakt, eine affektive Reaktion erreichen lassen. Demgegenüber können gewisse ängstliche Erregungen im Verlaufe zirkulärer Erkrankungen schizophrenen Angstzuständen sehr ähnlich sehen. Monotonie und Steifheit der affektiven Haltung sprechen eher für die schizophrene Natur der Syndrome. Im manischen Stupor ist fast immer der Affekt ein echt manischer, wenn dies auch nicht zu allen Zeiten erkennbar ist. Bei manchen Mischzuständen des manisch-depressiven Irreseins dagegen kann eine Unterscheidung von schizophrenen Syndromen unmöglich werden. Allenthalben wird man den Körperbau, die prämorbide Persönlichkeit und den bisherigen Verlauf berücksichtigen müssen; denn zirkuläre Erkrankungen, die ausschließlich unter dem Bilde von schwer durchsichtigen Mischzuständen verlaufen, gehören zu den großen Seltenheiten.

Wenn in schizophrenen Verläufen Reaktionen nach Art der psychopathischen vorkommen und hysterische Symptome nicht selten sind, so schimmert doch meist die Grundpersönlichkeit deutlich durch, so daß ernstliche Schwierigkeiten meist nicht entstehen. Rein hysterische Psychosen behalten immer eine besondere Beeinflußbarkeit und eine so starke Abhängigkeit von der jeweiligen Lage, wie sie bei den abnormen Reaktionen der Schizophrenen in dieser Weise nicht besteht. Nur gewisse, im Gefängnis auftretende reaktive Psychosen können schizophrenen Prozessen zum Verwechseln ähnlich sein. Hier helfen mitunter die lebhaften Psychoreflexe der Pupillen.

Große Schwierigkeiten bestehen manchmal, wenn es gilt, leichtere schizophrene Persönlichkeitsveränderungen von schizoiden Dauerverfassungen zu unterscheiden. Hier hilft nur eine sehr eingehende Erforschung der Vorgeschichte, die bei den Prozessen immer eine schubartige Veränderung, einen Knick in der Entwicklung, meist erst in den Jahren nach der Pubertät, ergibt. Wandlungen in der Pubertät selbst sind dagegen ganz allgemein so häufig, daß ihnen eine kennzeichnende Bedeutung nicht zukommt.

Endlich gibt es abnorme seelische Reaktionen (s. d.), die ein ganz schizophrenes Gepräge annehmen können und sich nach dem Erscheinungsbild unter Umständen nicht von Syndromen im Rahmen schizophrener Prozesse unterscheiden lassen. Es handelt sich dabei um schizoide Persönlichkeiten, die unter dem Einfluß schwerwiegender einmaliger Erlebnisse oder allmählich untragbar gewordener chronischer Konfliktslagen krank werden. Voraus- 
setzung dafür ist aber wohl, daß auch sonst ihre Widerstandskraft lahm gelegt wird. Wo durch den weiteren Verlauf die Annahme einer solchen schizoiden Reaktion wahrscheinlich gemacht wird, da finden wir in der unmittelbaren Vorgeschichte der Psychose nämlich erschöpfende und vielfach zugleich leichtere toxische (Schlafmittel, Alkohol) oder infektiöse Schäden. Es kommt besonders zu schizophren-gefärbten Verwirrtheiten, aber auch zu negativistisch-stuporösen und manchmal zu paranoid-halluzinatorischen Bildern. Solche Reaktionen dauern meist nur kurze Zeit und sprechen, wie die abnormen Reaktionen überhaupt, auf die Bereinigung der Konfliktslage an, wenn zugleich der körperliche Zustand sich hebt, was meist rasch der Fall ist. Besonders schwierig kann es sein, entsprechende Reaktionen, die auf dem Boden leichterer schizophrener Defekte zustande kommen, von den echten schizoiden Reaktionen zu trennen. Hier kann nur die eingehendste Erhellung der Vorgeschichte helfen. Eine Klärung der Sachlage ist vor allem wegen der Forderungen des Erbgesundheitsgesetzes nötig, von denen schizoide Reaktionen nicht betroffen werden.

\section{Ursachen}

Schizoide Psychopathie und extreme ,,schizaffine ${ }^{66}$ Körperbautypen finden sich nicht nur bei den späteren Kranken selbst, sondern gehäuft auch in ihrem nächsten familiären Umkreis als bleibende Eigentümlichkeiten. Schon dies spricht für erbliche Beziehungen. Aber auch die Familienund die Zwillingsuntersuchungen ergeben unzweifelhaft, daß der Kern der Schizophrenie erblich ist.

Erbgleiche Zwillinge verhalten sich gegenüber der Schizophrenie ganz überwiegend konkordant, $d . h$. wenn der eine erkrankt, so erkrankt in der Regel auch der andere Zwilling (etwa in $70 \%$ der Fälle). Ferner finden sich unter den Geschwistern Schizophrener, die von ,gesunden ${ }^{66}$ Eltern abstammen, etwa 7,5\% Schizophrene. Ist ein Elternteil schizophren, so ist der Prozentsatz schizophrener Kinder $16,4 \%$, sind beide Eltern schizophren, so ist mehr als die Hälfte der Kinder $(63,4 \%$ ) wiederum schizophren. Schizophrene finden sich endlich mit abnehmendem Grad der Blutsverwandtschaft im Umkreis der Schizophrenien in abfallender Häufigkeit.

Neben den schizophrenen Psychosen finden sich in den Geschwisterschaften der Kranken bei gesunden Eltern etwa 10\% schizoide Psychopathen und noch mehr als $10 \%$ andere abnorme Typen.

Über den speziellen Erbgang der Schizophrenie wissen wir freilich noch nichts Bestimmtes. Eine gewisse Wahrscheinlichkeit hatte die Annahme für sich, daß wir es mit einer dihybriden rezessiven Anomalie zu tun haben, d. h. daß die Krankheit auf zwei verschiedene Erbfaktoren beruht, die beide homozygot vorhanden sein müssen, damit es zur Krankheit kommt. Neuerdings wird aber auch an die Möglichkeit einer einfachen Rezessivität, ja auch an Dominanz gedacht. Es ist nicht unwahrscheinlich, daß die ausgeprägten Schizoiden Heterozygoten entsprechen.

Insbesondere nach den Zwillingsuntersuchungen steht jedoch fest, daß die Anlage zur Schizophrenie allein nicht in jedem Fall mit Sicherheit den Ausbruch der Krankheit mit sich bringt, d. h. die Manifestationswahrscheinlichkeit ist keine absolute (nach neuen Untersuchungen 70 bis 
$80 \%$ ). Wir haben also anzunehmen, daß äußere Momente beim Ausbruch der Krankheit eine gewisse Rolle spielen. Wahrscheinlich ist die „Expressivität ${ }^{66}$ der Anlage aber in nicht wenigen Fällen so groß, daß sie sich im Laufe des Lebens mit Sicherheit durchsetzt, also ohne jede Rücksicht auf die besondere Lebensgestaltung. In anderen Fällen ist diese Expressivität geringer. Wir wissen aber noch nichts darüber, welche äußeren Faktoren es sind, welche dann schließlich die erbliche Bereitschaft manifest machen.

Immerhin sehen wir nicht ganz selten den Ausbruch der Krankheit im Zusammenhang mit schweren Infektionen, mit dem Wochenbett, manchmal auch mit schweren Schädeltraumen, mit Erschöpfungszuständen, so daß wir in diesen körperlichen Belastungen vielleicht Momente zu sehen haben, welche geeignet sind, weniger ausgesprochene Anlagen aus ihrer Latenz hervorzuholen. Sehr zweifelhaft ist demgegenüber die Rolle der häufig als Krankheitsursache angeschuldigten schwerwiegenden Erlebnisse. Diese sind vielmehr in der Regel schon Ausdruck der beginnenden Krankheit selbst.

Eine nur einigermaßen hinreichende Wahrscheinlichkeit dafür, daß schwerere körperliche Belastungen im Laufe des späteren Individuallebens die manchmal notwendigen Zusatzursachen darstellen, haben wir nicht. Der Krieg mit seinen ungeheueren Belastungen körperlicher und seelischer Natur hat keinerlei Häufung der Schizophrenien mit sich gebracht. Es ist möglich, daß frühkindliche Vorgänge oder Einwirkungen schon vor der Geburt darüber bestimmen, ob die krankhafte Anlage sich einmal manifestieren wird oder nicht.

Die Schizophrenie ist eine Erbkrankheit im Sinne des Gesetzes zur Verhütung erbkranken Nachwuchses, also anzeigepflichtig.

\section{p) Das manisch-depressive (zirkuläre) Irresein}

Das manisch-depressive Irresein ist eine Erbkrankheit, die in ihren schweren Formen bei 3 bis 4 von 1000 Menschen vorkommt, tatsächlich aber wohl wesentlich häufiger ist, wenn man auch die leichtesten Gestaltungsformen berücksichtigt. Im Süden Deutschlands ist die Krankheit offenbar verbreiteter als im Norden. Sicherlich erkranken Juden zahlreicher als Nichtjuden, und auch in den wirtschaftlich höheren Schichten ist die Krankheit mehr zu Hause als in der Breite des Volkes.

Die Krankheit verläuft in einzelnen voneinander abgetrennten $\mathrm{Phasen}$ von recht verschieden langer Dauer, die als solche abheilen und dem Zustand durchschnittlicher Gesundheit Platz machen. Insofern ist die Prognose eine günstige. Sie wird aber getrübt dadurch, daß, wenn auch nur bei einem Teil der Betroffenen, immer neue Krankheitsphasen eintreten und daß diese sich in den schwersten Fällen fast oder völlig pausenlos aneinander reihen können. In solchen Fällen pflegen Phasen von Erregung und solche von Hemmung einander abzuwechseln. Bei anderen, prognostisch ungünstigeren Gestaltungsformen kommt es, besonders im höheren Lebensalter, zu lange Jahre sich hinziehenden Krankheitszuständen, die nicht mehr völlig abheilen und allmählich die Zeichen der Hirninvolution in sich aufnehmen.

Die Haupterscheinungsformen des manisch-depressiven Irreseins sind die Melancholie und die Manie. 
Im Vordergrund der melancholischen Symptomenbilder stehen die unmotivierte Traurigkeit, der sich oft Angst beimischt, und die Hemmung aller seelischen Lebensäußerungen, besonders des Denkens und des Handelns. Die gemütliche Herabstimmung kann eine recht verschiedene Färbung annehmen. In den leichteren Fällen ist es nicht so sehr eigentliche Trauer als vielmehr das Fehlen jeder freudigen, jeder leichteren Regung, was erlebt wird. Auch solche Lebenswerte, die das gesunde Leben der Erkrankten beherrschen, erwecken keinen seelischen Widerhall mehr. Die Liebe, zu Ehegatten und Kindern, Eltern und Verlobten scheint zu verblassen, Beruf und Liebhabereien werden gleichgültig. Dieses Schwinden des affektiven Widerhalls, eine Form der Depersonalisation, wird von den Kranken als quälend erlebt. Bei Selbstanklagen, die sich auf dieses gemütliche Erkalten beziehen, bringen sie lebhaften depressiven Affekt auf. In schweren Formen der Melancholie ist es aber wirkliche Trauer, welche den Kranken erfüllt und auch in seinem Ausdruck vielfach unverkennbar deutlich wird. Der Trauer eignet immer ein Zug der Tiefe, der unabwälzbaren Schwere und in der großen Mehrzahl der Fälle gesellt sich zu ihr mehr oder weniger ausgeprägte Angst, die auch körperlich bald als ständiger ängstlicher Druck auf der Brust, bald mehr in einer Weise erlebt wird, als erfüllte sie den ganzen Körper. Der Herabstimmung des Melancholischen eignet überhaupt etwas „Vitales“6. Sie erfüllt auch den Gesamtraum des zugleich als gehemmt, als seltsam schwer erlebten Leibes.

In dieser eigenartigen Beziehung zum Leibe ist die Depression von der Hemmung kaum zu trennen. Auch die Hemmung macht sich im Gesamt des Organismus spürbar. Die Mimik ist depressiv erstarrt, die Bewegungen erscheinen langsam und müde, wie gegen einen vermehrten Widerstand erfolgend. Die Sprache ist leise und oft langsam. Vor allem aber ist der Kranke in seinen höheren Willensleistungen gehemmt. Er kann sich zu nichts entschließen, alles erscheint ihm zu schwer und unausführbar. Schon für den Beginn und die Durchführung der einfachsten Verrichtungen braucht er lange Zeit, zum Aufstehen, zum Essen, zum Ankleiden. Zur Tagesarbeit kann er sich nicht oder nur unter großen Mühsalen aufraffen.

Zugleich ist sein Denken gehemmt. Es fällt ihm nichts ein, er kann dem Gespräch oft nur mühsam folgen, von sich aus den Gedanken und das Gespräch nicht fortspinnen; er erscheint sich selbst leer und oft wie blöde. Seine Vorstellungen sind dabei blaß und farblos. Auch in den leichtesten Fällen fehlt dem Denken die Frische, der Schwung, die Farbe wirklichen Lebens.

In den schwersten Formen der Erkrankung erlischt tatsächlich jede willkürliche Lebensregung. Die Kranken sind wie in ihrer Depression erstarrt, bewegungslos, ohne doch Anregungen von außen Widerstand entgegenzusetzen. Die depressive Stimmung bleibt dabei immer deutlich (depres siver Stupor). Die ganz leicht Kranken vermögen mit Mühe noch den Verpflichtungen des Alltags zu genügen. Aber sie selbst und alle, die sie näher kennen, spüren doch die Hemmung, die Entschlußlosigkeit, die Unlust.

So unmotiviert die Verstimmung tatsächlich ist, so suchen doch sehr viele Kranke die Anlässe in sich und in ihrem Erleben. Insbesondere die alltäglichen Sorgen wachsen an. Die Furcht vor Verarmung, vor Verlust 
anderer materieller Güter, die Sorge um Amt, um Beruf und Auskommen können wahnhafte Formen annehmen. Anfängliche ängstliche Befürchtungen werden in gewissen Zuständen bald als felsenfeste Tatsachen genommen, bald als bloße Befürchtungen erkannt (mobile Wahnideen), schließlich aber kommt es zu unbeirrbaren Wahnideen (affektive Wahnideen). In der gleichen Weise dreht sich die Sorge der Kranken in hypochondrischen Befürchtungen und Wahnideen um die Zustände des eigenen Körpers. Der träge Darm und der Schlaf spielen dabei die Hauptrolle. Der Melancholische kann aber auch überzeugt sein, an allen erdenklichen anderen schrecklichen Krankheiten zu leiden, insbesondere an Krebs und unheilbaren Herzstörungen. Sehr selten werden bei ausgesprochenen Melancholien Versündigungsideen vermißt, die sich gern an diese oder jene kleine tatsächliche Verfehlung (eine Lüge, Naschen in der Kindheit, Onanie) anknüpfen, sehr bald aber recht grobe Formen annehmen (am eigenen und am Untergang der Familie, am Tode der Eltern, am Unglück aller anderen Kranken, des Volkes, der Menschheit schuld zu sein). Solche sehr weitgehende, in ihrem Ausmaß an Größenideen erinnernde Versündigungsideen und entsprechend großartige hypochondrische Wahnvorstellungen (ganz klein, schon tot, ganz weg, ohne Darm und Magen zu sein) finden sich besonders in den melancholischen Erkrankungen des Rückbildungsalters. Ihre prognostische Bedeutung ist an sich nicht ungünstig, wenn auch Erkrankungen dieser Altersstufe gern besonders lange andauern. Wie für sich selbst, so fürchtet der Melancholische auch für seinen nächsten Umkreis, seine Familie und überhaupt die Menschen, denen er sich nahe fühlt. Oft genug aber meint er mit seiner Schlechtigkeit ebenso wie mit seiner vermeintlichen schweren körperlichen Erkrankung alle anzustecken, die mit ihm in Berührung kommen.

Selbstvorwürfe und andere ängstliche Befürchtungen hört der $\mathrm{Me}$ lancholische gern auch illusionär in die Gespräche und Geräusche seiner Umgebung hinein und aus der Umgebung widerhallen. Er hört etwa Schimpfworte oder vermeint, daß andere mit Recht vorwurfsvoll von ihm reden. Er kann aber auch Schreie in der Umgebung auf seine vermeintlich der eigenen Schuld wegen gequälten Lieben beziehen u. a. m. Sinnestrug, der in das Bereich der Halluzinationen zu rechnen wäre, ist schweren Melancholien nicht völlig fremd, aber im ganzen doch recht selten.

Das körperliche Befinden der Melancholischen ist immer beeinträchtigt. In der Regel ist der Schlaf schlecht. Die Kranken schlafen spät ein und der Schlaf ist dann auch noch unruhig, zerhackt und vor allem gar nicht erfrischend. Morgens nach dem Erwachen sind sie oft besonders gehemmt und zerschlagen, um dann im Laufe des Tages ein wenig freier zu werden und vom Mittag, oft auch erst vom späten Nachmittag, ab die besten Stunden des Tages zu haben (Tagesschwankungen, die fast in keinem melancholischen Krankheitsverlauf ganz fehlen). Manche Kranke schlafen traumlos, andere haben quälende Träume. Im Halbschlaf werden sie ihre Sorgen nicht los (einer meiner Kranken sprach von "Grübeldämmern"6). Erfreuliche Träume sind nicht selten ein Zeichen der sich anbahnenden Besserung.

Der Appetit der Kranken liegt darnieder. Viele muß man zur Nahrungsaufnahme nötigen. Nicht selten besteht Widerwille gegen bestimmte Speisen, 
besonders Fleisch. Das Körpergewicht sinkt so in allen typischen Fällen Melancholie, von oft sehr rasch und tief, ab. Gewichtsanstieg ist vielfach ein Zeichen der Besserung, auch dann, wenn sich diese seelisch noch nicht bemerkbar macht.

Die Verdauung ist träge. Viele Kranke sind ausgesprochen obstipiert. Bei der typischen Melancholie liegt schlaffe Obstipation vor, doch ist auch die spastische Form nicht selten. Dort, wo es nicht zu eigentlicher Verstopfung kommt, ist doch die Verweildauer der Ingesta im Darm eine verlängerte.

Gleich der Speichelsekretion ist auch die Tränensekretion nicht selten vermindert. Mancher Kranke klagt, daß er keine Tränen mehr habe.

Die Gesichtsfarbe der Melancholischen ist vielfach unfrisch. Nur am Abend (Tagesschwankungen) und beim Beginn der Besserung kehren die natürlichen, dann vielfach rosigen Farben wieder. Gern gehen in der Melancholie die Haare mehr aus als sonst. Die Menstruation nimmt bei vielen Frauen an Stärke ab oder erlischt ganz, ohne daß dies prognostisch ungünstig zu werten wäre.

Auch bei der feineren Untersuchung des Stoffwechsels finden wir Störungen, die freilich noch nicht genügend geklärt sind. So hat man verzögerte Wasserausscheidung gefunden. Anfangs wird manchmal Zucker ausgeschieden. Der Blutzucker ist vielfach hoch, und Zuckerbelastung bringt eine langhingezogene Steigerung des Zuckerspiegels im Blut mit sich. Ganz Ähnliches gilt für das Cholesterin, und nach früheren Untersuchungen ist dies wohl auch bei der Eiweißverarbeitung nicht anders. Auch Kaliumund Kalziumstoffwechsel scheinen Veränderungen zu unterliegen. Auf jeden Fall gehen mit den melancholischen Erkrankungen Verschiebungen im Körperhaushalt einher, deren Deutung freilich noch nicht ganz sicher ist und die auch nicht spezifisch sind. Grundumsatz und spezifisch-dynamische Wirkung entsprechen übrigens bei der typischen Melancholie der Norm.

Daß die Mehrzahl dieser Veränderungen nicht so sehr ein Korrelat der Melancholie als solcher, als vielmehr der Krankheit manisch-depressives Irresein ist, geht schon aus der Tatsache hervor, daß gleichartige Störungen auch bei der Manie festgestellt werden können, die sonst freilich als das gerade Gegenteil der Melancholie erscheint.

Bei der Manie beherrschen heitere oder doch irgendwie expansive Stimmung und Erregung das Krankheitsbild. Die Stimmung ist in den typischen Fällen eine ansteckende, natürliche Heiterkeit bei starker affektiver Erregbarkeit auch nach anderen Richtungen hin. Alle Erlebnisse, die nicht zu der heiteren Grundstimmung passen, beantwortet der Kranke dabei qualitativ in natürlicher Weise; er kann also etwa sehr gerührt werden, wenn er vom Tod eines Lieben spricht, oder außerordentlich gereizt, wenn man ihm entgegentreten muß; aber im nächsten Augenblick ist die heitere Grundstimmung wieder da. In anderen Fällen hat die Grundstimmung freilich immer eine gereizte Note oder der Übermut schlägt doch besonders leicht in Gereiztheit oder auch in eine eigentlich erregte Stimmung um, in der nur das gehobene Selbstbewußtsein die positive Note der Grundstimmung verrät.

Das Denken der Manischen ist in allen ausgeprägten Fällen gekennzeichnet durch Ideenflucht. Die Inhalte des Denkens und Redens ordnen sich nicht einem umfassenderen Gedanken unter. Sie erfüllen nicht die 
Aufgabe, die etwa eine Frage stellt; vielmehr kommt der Kranke immer wieder vom Thema ab. Die einzelnen Inhalte haben zwar assoziative Beziehungen zueinander, die immer deutlich sind, aber der erste und schon der übernächste Inhalt haben sachlich nichts mehr miteinander zu tun; sie sind nicht mehr Glieder eines umfassenden Gedankens. In leichteren Fällen kommt es gelegentlich dazu, daß der Kranke nicht eigentlich den Faden verliert, aber er ist weitschweifig, denkt und spricht zahlreiche unwesentliche Einzelheiten aus, wird durch äußere Reize leicht abgelenkt, unterliegt der Neigung zu Witzen und jeder Gelegenheit, das Denken seiner Stimmung anzupassen, die rosigen und angenehmen Seiten besonders zu entwickeln. Oft sind es auch nur Gleichklänge, Reime, Redensarten, die den Fortgang des Denkens bestimmen. Der Affekt entspricht dabei immer den Inhalten. Der Manische ist gewissermaßen in jedem Augenblick ganz, nur von Augenblick zu Augenblick anders gerichtet. Dem Fehlen leitender, umfassender Gedanken entspricht die Ablenkbarkeit des Manischen. Sie ist nur eine Seite der Ideenflucht und bald mehr als äußere, bald mehr als innere Ablenkbarkeit ausgeprägt. Manische mit besonders starker innerer Ablenkbarkeit (oft handelt es sich um Kranke ohne wesentliche motorische Erregung, die auch wenig sprechen) können, ziemlich langsam, Reden vorbringen, die ganz unzusammenhängend, inkohärent wirken, da gedankliche Zwischenglieder in der Rede ausfallen. Gleiches gilt für die hochgradigen Erregungszustände, in denen das Sprechen dem Denken nicht nachkommt.

Bewegt wie Denken und Reden des Manischen ist immer auch das Handeln. Der Manische hat immer etwas zu tun, freilich in jedem Augenblick etwas anderes. Immer macht er Betrieb. Im Krankenhaus wird er mit allen Mitkranken schon am ersten Tage bekannt, schließt sofort Freundschaften, erwirbt Feinde und mischt sich in alles, vielfach auch in ärztliche Angelegenheiten, ein. So lange er daheim ist, wird er von seiner gewohnten Tätigkeit immer wieder abgelenkt; er ist immer unterwegs, fängt neue Sachen an, um sie sogleich wieder mit anderen Beschäftigungen zu vertauschen. Rosige Stimmung und Optimimus sowie die Denkstörung, die ihm nicht gestattet, die Dinge zu Ende zu denken, lassen ihn leicht in gewagte und leichtsinnige Unternehmungen hineingeraten. Sie treiben ihn zu Alkohol und Weibern, junge Mädchen nicht selten zu unerwarteten sexuellen Entgleisungen in Rede und Tun. Es kommt zu unsinnigen Geldausgaben, zu leichtfertigen Spekulationen und unerfüllbaren Verpflichtungen, die den Kranken in die größten Schwierigkeiten bringen können. Übertriebene Selbstüberzeugung und Reizbarkeit führen zu zahlreichen Konflikten mit. der näheren und weiteren Umgebung, so daß in jedem ausgeprägten manischen Zustand schließlich Internierung nötig wird. Sperrt man einen stärker Erregten in einen engen Raum, so ist in diesem bald kein Gegenstand mehr an seiner alten Stelle. Alles wird zum Werkzeug, mit dem sich irgendeine manische Laune erfüllen läßt.

Eigentliche Wahnideen sind der Manie fremd. Das Selbstbewußtsein der Kranken ist aberimmer unangemessen. Sie renommieren gern, und es kommt vor, daß sie sich in ihrer übermütigen Laune spielerisch Würden und Titel beilegen, daß sie sich aufspielen, als wären sie der Kaiser oder große Herren, und daß sie gelegentlich auch längere Zeit an solchen wohl immer unernsten Darstellungen 
festhalten. Aus ähnlichen Launen heraus, ,verkennen“ sie auch die Umgebung, besonders die Personen, oder geben ihnen doch falsche Namen. Mitunter mag dabei auch die Flüchtigkeit und Ungenauigkeit der Auffassung eine Rolle spielen.

Anders ist dies im stürmischen Beginn mancher Manien, in dem es zu traumhafter Bewußtseinstrübung, zu flüchtigen, wahnhaften Ideen, zu Trugwahrnehmungen deliranter Art kommen kann. Nach einem oder nach wenigen Tagen ist das reine manische Syndrom meist deutlich. Bei seltenen schweren, sog. verworrenen Manien bleibt eine leichtere oder schwerere Bewußtseinstrübung aber auch längere Zeit hindurch bestehen. Diese Bilder sind schwer von gewissen Formen der Schizophrenie, aber auch von exogenen Erregungen zu unterscheiden. Häufig sind in der Entwicklungsgeschichte dieser schweren Manien äußere Krankheitsursachen, fieberhafte Erkrankungen, Stoffwechselleiden, etwa Basedow, Vergiftungen nachweisbar.

Manische haben in der Regel ein außerordentliches Kraftbewußtsein. Sie fühlen sich körperlich gesünder als je, und sie sind auch tatsächlich „unermüdlich". Meist schlafen sie nur kurze Zeit, aber sehr tief, und von aller Morgenfrühe an sind sie in Bewegung. Ist die Erregung nicht zu groß, dann essen sie auch gern und reichlich. Bei starker Erregung haben sie aber selbst zur Nahrungsaufnahme keine Zeit. Sie spielen und schmieren mit den Speisen herum oder haben so viel zu tun und zu reden, daß sie vom Essen immer wieder abgelenkt werden. Das Aussehen der Manischen ist in der Regel frisch und lebhaft.

Manische und Melancholische zeigen gemeinsam starke Anregbarkeit. Jedes Tun bedeutet eine Erleichterung für alles folgende Handeln. Bringt man den Melancholischen einmal zum Sprechen, so geht es bei Geduld dann immer leichter. Auf der Anregbarkeit beruhen offenbar zum Teil die Tagesschwankungen. Aber auch der Manische wird im Laufe des Tages zunehmend lebhaft und unbeherrscht. Beim Abebben der Krankheit ist oft nur noch abends das Bild deutlich manisch, während der Kranke am Morgen schon wieder ziemlich ausgeglichen oder sogar schon leicht depressiv erscheinen kann.

\section{Krankheitsbeginn}

Melancholie und Manie können unvermittelt, über Nacht, einsetzen und rasch ihre größte Tiefe erreichen. Häufiger aber entwickeln sie sich aus schleichenden Anfängen. Bei der Manie kann, wie erwähnt, ein kurzer rauschartiger Zustand den Anfang bilden. Der Melancholische spürt eines Tages eine Unfrische; der Schlaf wird schlecht; alles geht ein wenig mühsamer; erst allmählich beginnen die anderen Störungen. Zunächst wehrt sich der Kranke noch gegen die Hemmung, bis er allmählich immer mehr erliegt. Es dauert dann unter Umständen Wochen, ja manchmal Monate, bis die Melancholie auf ihrem Tiefpunkt angelangt ist. Ebenso allmählich geht dann die Besserung vor sich, die mit deutlichen Tagesschwankungen, mit heiteren Träumen, mit Gewichtsanstieg sich einleiten kann.

\section{Phasendauer}

Die typische Melancholie dauert immer Monate, durchschnittlich 5-6 bei jugendlichen Menschen, 9 Monate, ja über ein Jahr lang im Beginn des 
Rückbildungsalters. Nicht ganz selten ist die Dauer eine kürzere; die Krankheit kann aber auch viel länger währen. Es gibt Melancholien, vor allem im höheren Lebensalter, die viele Jahre anhalten können.

Für Manien gilt das gleiche. Im jugendlichen Alter freilich gibt es Erregungen von wenigen Wochen Dauer, die sich aber rasch wiederholen, um später einer längeren Pause Platz zu machen. Ähnliches finden wir im höheren Lebensalter. Längerdauernde jugendliche Manien bleiben vielfach isoliert, oder es folgt doch erst nach langen Jahren eine neue manische oder depressive Phase.

Neben den bisher geschilderten typischen Bildern kennen wir andere, die unzweifelhaft dem manisch-depressiven Irresein angehören, aber von der klassischen Symptomatologie sich sehr erheblich unterscheiden.

\section{Klinische Sonderformen}

Zunächst einmal gibt es leichtere und leichteste Gestaltungsformen der Erkrankung. Die Symptome der voll ausgebildeten Erkrankung sind in diesen Fällen zwar alle vorhanden, aber nur in Andeutungen. In solch subdepressiven Zuständen ist der Kranke weniger frisch als sonst, alles geht ihm schwerer von der Hand, er vermag keine Berufsfreude, überhaupt keine Freude aufzubringen, zieht sich von der gewohnten Geselligkeit zurück, vertrödelt seine Zeit, verfolgt seine Liebhabereien nicht mehr, ist leicht herabgestimmt, schläft schlecht, ist leicht gereizt, weil seine Umgebung unzufrieden mit ihm ist, empfindet körperliche Beschwerden besonders lästig, macht sich unnötige Sorgen und ist für seine Umgebung schwierig. Kennt er aus früherer Erfahrung den Zustand, dann weiß er ihn zu verbergen und richtet sich seine Tätigkeit darnach ein; er beschränkt sich etwa darauf, nur das Nötigste zu tun, und zieht sich im übrigen zurück, bald hoffnungslos verzweifelt, bald in geduldiger Erwartung der besseren Zeit, die, wie er weiß, wieder kommen wird. Erste Zustände dieser Art werden vom Kranken selbst wie vom Arzt meist als Ausdruck körperlicher Erkrankungen gedeutet. Irgendeine körperliche Störung am Magen oder Darm, an den Nebenhöhlen, eine „Herzneurose“6, unklare Kopfschmerzen und Rheumatismen, Uterinleiden, finden sich ja in jedem Fall oder es wird doch darnach gefahndet, und meist wird auch an einem Organ herumbehandelt. Es kommt hinzu, daß in den biologischen Katastrophen, die der Melancholie zugrunde liegen, Organbeschwerden aller Art gern deutlicher werden, ja daß sie sogar allein um diese Zeiten in Erscheinung treten, etwa Magengeschwüre. Erst die Wiederholung ähnlicher Phasen zeigt dem Arzt die wahre Natur des Leidens und dann weiß sehr bald auch der Kranke selbst, was mit ihm los ist, wenn er nicht in der Abwehr gegen den Gedanken, seelisch abnormisiert zu sein, sich immer wieder hinter einer angeblichen körperlichen Erkrankung, hinter vermeintlicher Überarbeitung u. a. versteckt. Sehr viele leichte Depressionen gehen als "Neurasthenie ${ }^{6 .}$. Neurasthenische Erscheinungen, Ermüdbarkeit und Empfindlichkeit, verdecken in der Tat oft genug Hemmung und vitale Depression, um so eher als viele der hierher gehörenden Kranken tatsächlich nervöse, ,neurasthenische" Menschen sind. In seltenen Fällen machen sich die subdepressiven Zustände nur in periodischer Schlafstörung und der darauf bezogenen einige Wochen und Monate anhaltenden Arbeitserschwerung und Ermüdbarkeit geltend. 
Nur die periodische Wiederkehr und die Familiengeschichte oder aber eine plötzlich auftretende manische oder hypomanische Erregung oder schwerere Melancholien machen in manchem dieser Fälle die wahre Natur der Störungen deutlich.

Die entsprechende Erregungsphase kann sich im Gewande der klassischen Hypomanie mit heiterer Stimmung, erhöhter Geschäftigkeit und Plänemacherei, Gedankenreichtum und Einfallsfülle, unter Umständen auch unerhörter Arbeitskraft und unverwüstlicher Genußfreude äußern. Manche Kranke fühlen sich nur in den Erregungsphasen wirklich gesund. Diese erleben sie als Höhepunkte ihres Daseins, und in manchem Falle mit Recht. Ein wenig mehr an Enthemmung führt freilich über die Grenze hinaus, bringt übertriebene Geldausgaben und andere leichtsinnige Handlungen, besonders auch sexuelle Exzesse, mit sich. Oft genug aber haben diese Erregungen auch eine Note von Gereiztheit und Unrast. Die eigentlich manische Stimmung fehlt. Der Kranke spürt selbst den Mangel an Disziplin und Folgerichtigkeit und leidet unter dem Dämon, der ihn beherrscht, um so mehr als er sich Streitigkeiten nicht zu entziehen vermag und sich bald in der Fülle seiner Händel nicht mehr auskennt, ohne doch nach außen als krank erkannt zu werden und sich selbst die Krankheit zuzugestehen.

Bei vielen Patienten dieser Art gibt es keine eigentlich gesunden Zwischenzeiten; die subdepressive Phase mündet meist rasch in hypomanische Erregung aus oder umgekehrt Bei diesen Persönlichkeiten sprechen wir von Zyklothymen; charakteristisch für sie ist der rasche Wechsel der Verstimmungen, ohne daß es zu schweren Manien oder Depressionen zu kommen braucht. Dabei kann es auch zu einer Überschichtung der Symptome kommen, die teils der manischen Erregung, teils der melancholischen Hemmung angehören. In solchen Zeiten sehen wir gern auch paranoide Gedankengänge, manchmal auch Zwangserscheinungen. Diese Bilder geben den Schlüssel zu den sog. Mischzuständen schwerer Art, denen wir auch bei dem Grad nach ernsteren Gestaltungsformen des manisch-depressiven Irreseins nicht allzu selten begegnen.

Besonders häufig sind die erregte Depression und der manische Stupor. Bei der erregten Depression, welche die Rückbildungszeit bevorzugt, ist die motorische Hemmung der Melancholischen ersetzt durch Erregung, insbesondere des Ausdrucksgeschehens. Die Kranken sind unstet, ruhelos, jammern und klagen, weinen und ringen die Hände, sind nicht im Bett zu. halten. Dabei sind sie aber gedankenarm, bringen monoton ihre depressiven Inhalte vor und zeigen meist eine verzweifelte, ängstlich-hoffnungslose Stimmung. Vorübergehend, auch längerdauernd, kann Ideenflucht auftreten.

Im manischen Stupor sind Ideenflucht und Erregung ersetzt durch Denkhemmung und stuporöses Verhalten. Die Kranken liegen in ausgesprochen heiterer Stimmung, offenbar gedankenlos, unbeweglich im Bett. Oft aber wird doch eine ,ideenflüchtige Denkhemmung ${ }^{66}$ an den spärlichen, aber inkohärenten sprachlichen Äußerungen deutlich. Wenn sie der Genesung zugehen, schildern die Kranken, wie sie ihre spärlichen Gedanken nicht festzuhalten vermochten. Andere nach außen als manisch-stuporös wirkende Kranke haben aber ein reiches, wogendes, oft optisch illustriertes Gedankenleben von großer Anschaulichkeit und oft köstlichen Inhalten, offenbar bei 
gleichzeitiger traumhafter Befangenheit, die ihnen aber doch einen gewissen Kontakt mit der Außenwelt - Lächeln bei Anrede, flüchtiges Notiznehmen von Außenanregungen - gestattet.

Diese und andere Mischzustände treten gern als Übergangsphasen zwischen Melancholie und Manie auf und sind dann leicht als Zustandsbilder des manisch-depressiven Irreseins zu deuten. Sie können aber auch als selbständige Krankheitsphasen vorkommen, allerdings auch dann nicht selten mit einer deutlichen manischen oder melancholischen Eingangsphase oder einem entsprechenden Endstadium. Es gibt aber Kranke, die allein immer neue erregte Depressionen, ebenso immer oder doch fast immer neue manische Stuporen oder gehemmte Manien durchmachen.

\section{Atypische manisch-depressive Phasen}

Ist schon bei den isolierten Mischzuständen die klinische Deutung oft eine schwierige, so noch viel mehr bei Phasen, die einen stark paranoiden oder katatonen Anstrich haben, und solchen, in denen es zum ausgesprochenen Halluzinieren, insbesondere zu Sprachhalluzinationen, kommt. Solche Phasen sind unzweifelhaft nicht ganz selten. Sicher erkennbar werden sie nur, wenn die melancholischen oder manischen Grundsymptome zugleich deutlich ausgeprägt sind oder doch zu Zeiten unverkennbar hervortreten. Man nimmt an, daß Kranke dieser Art auch schizophrene Teilanlagen in sich haben, die, von der zirkulären Phase vorübergehend flottgemacht, pathoplastisch die Krankheitsbilder färben. Bei eingehenden Familienforschungen hat man in der Tat zeigen können, daß solche Kranke neben zirkulären auch schizophrene Verwandte haben, daß bei ihnen also eine sog. „Konstitutionslegierung ${ }^{66}$ vorliegen kann, in der zirkuläre und schizophrene Anlagen sich vergesellschaften. Nicht wenige Kranke dieser Gruppen tragen in ihren häufigen Phasen dann schließlich doch Defekte davon, die schizophrenen Persönlichkeitsveränderungen ähneln, ganz abgesehen davon, daß auch die Prognose der Einzelphasen sich in zeitlicher Hinsicht verschlechtert. Atypische Phasen dauern gern, nicht immer, besonders lang. Überhaupt sind atypische Bilder prognostisch weniger günstig als typische.

\section{Degenerationspsychosen}

Als Degenerationspsychosen faßt man heute dem häufigsten Sprachgebrauch nach alle jene endogenen Seelenstörungen zusammen, denen mit dem typischen manisch-depressiven Irresein der periodische Verlauf und die grundsätzliche Heilbarkeit der Phasen gemeinsam ist, die aber eine andersartige Symptomatologie zeigen. Zum weiteren Begriff der Degenerationspsychosen gehören die zirkulären Erkrankungen selbst, zum engeren Begriff die bisher geschilderten atypischen Gestaltungen. Es gibt aber auch andere Bilder, die so verlaufen, vor allem hyperkinetische Motilitätspsychosen (s. Syndrome), Halluzinosen, Verwirrtheitszustände, Zwangszustände, reine Angstpsychosen, paranoide Formen, Depersonalisationszustände $u$. a. m. Besonders Kleist hat sich um die Abgrenzung dieser von ihm autochthone Degenerationspsychosen genannten seltenen klinischen Formen bemüht. Viele von diesen Fällen verraten ihre Zugehörigkeit zum manisch-depressiven Irresein durch das Vorkommen einzelner typischer Melancholien und Manien zwischen den atypischen Phasen. In anderen Fällen wechseln mannigfache atypische Gestaltungen einander ab, und vielfach findet man dann auch ausgesprochen hysterische Episoden. Bei anderen Fällen kehren aber bestimmte atypische Gestaltungen immer wieder und manchmal kann man dann auch sehr ähnliche Psychosen in der Familie auffinden. Es handelt sich also wohl zum Teil um besondere Erbanlagen (vielleicht eigenartige Hirnbeschaffenheiten), die vermutlich unter 
dem Einfluß von biologischen Umwälzungen, nach Art der im manisch-depressiven Irresein wirksamen, die ungewöhnlichen Bilder der Degenerationspsychosen hervorrufen. Auch Kleist nimmt übrigens für die autochthonen Degenerationspsychosen enge Beziehungen zum manisch-depressiven Irresein an.

\section{Verlauf und Ausgänge}

Der Verlauf des manisch-depressiven Irreseins kann die denkbar verschiedensten Gestaltungen annehmen, von einmaligen kurzdauernden Phasen bis zu dem chronischen, das ganze Leben füllenden, dauernden Wechsel manischer und depressiver Schwankungen. Die große Mehrzahl der Erkrankungen hält sich zwischen diesen Extremen. In einem großen Material wurden 14\% chronische zirkuläre, $12 \%$ einmalige Erkrankungen gefunden, während mehr als drei Phasen, abgesehen von den chronischen Fällen, nur $17 \%$ durchmachten. Dabei sind aber leichteste Schwankungen nicht mitgerechnet.

Der Krankheitsbeginn liegt durchschnittlich etwas später als für die Schizophrenie. Immerhin erkrankt mehr als die Hälfte der Manisch-Depressiven bis zum 30. Lebensjahr erstmalig, nach dem 40. Lebensjahr aber immer noch ein Viertel. Auch nach dem 60. Lebensjahr kommen noch Neuerkrankungen vor, die alle Kennzeichen des zirkulären Irreseins haben.

Manche Kranke erleben ausschließlich depressive, andere ausschließlich manische Phasen. Die Mehrzahl hat aber doch wenigstens entgegengerichtete Nachschwankungen, und viele zeigen neben typischen Melancholien auch typische Manien und Mischzustände aller Art. Nicht selten sind rein periodische Depressionen mit langen Intervallen, die freilich im Laufe des Lebens kürzer zu werden pflegen (durchschnittlich von etwa 10 auf 4 und weniger Jahre sich verkürzen), nicht sehr häufig periodische Manien, für die kennzeichnend die kurze Dauer des Einzelanfalls und des Intervalls ist, so daß sich lange Perioden manischer Erregungen aneinander schließen, die vereinzelt Jahrzehnte anhalten, häufiger aber doch abbrechen und einem längeren Intervall Platz machen.

Isoliert stehende Melancholien und isoliert stehende Manien zeigen meist schwere, eindrucksvolle Bilder und ziemlich lange Dauer, dafür aber lange Intervalle, während sog. alternierende Formen, d. h. solche, bei denen die Manie unmittelbar einer Melancholie folgt oder umgekehrt, leichtere Krankheitserscheinungen, dafür aber kürzer dauernde Intervalle und insgesamt eine schlechte Prognose haben. Die ganz chronischen Erkrankungen, denen eigentliche freie Intervalle fehlen, sind entweder ihren Erscheinungen nach sehr schwer - bei ihnen beginnen früh Mischzustände - oder aber ganz leicht; gerade die Zyklothymien verlaufen gern chronisch, ohne deutliche freie Intervalle.

Ganz allgemein verschlechtert jede neue Phase die weitere Prognose; die Intervalle werden kürzer; die Erkrankungsbereitschaft und zugleich die Neigung zur Entwicklung von Mischzuständen nimmt zu. Manche periodisch manische Formen enden in chronischen, lange Jahre bis zum Tode anhaltenden Manien, die freilich dem Grade nach meist nicht sehr schwere Symptome darbieten, aber doch dauernd anstaltsbedürftig machen. Ganz entsprechend kennen wir chronische depressive Ausgänge. Diese Kranken erholen sich nach einer Melancholie nicht ganz; sie bleiben dauernd leicht ängstlich, entschlußlos und in Abhängigkeit von ihrer Lage zu tiefer Verstimmung 
bereit, halten auch diese oder jene melancholische Idee fest. Diese Kranken trifft man häufiger in der Freiheit oder im Spital. Eine eigentliche Verblödung tritt auch bei ihnen nicht ein, soweit sie nicht arteriosklerotisch werden. Dies kommt allerdings nicht ganz selten vor.

Typische Melancholien im mittleren Lebensalter dauern durchschnittlich 5 Monate, typische Manien wenig kürzer. Mit dem Lebensalter nimmt die Dauer durchschnittlich zu; aber es gibt auch Ausnahmen. Ebenso verschlechtern atypische Züge, abnormer Körperbau, die Entstehung von Mischzuständen die zeitliche Prognose der Einzelphase. Im hohen Lebensalter kommen Phasen vor, die über Jahre, auch ein Jahrzehnt dauern können, ohne daß doch eine Heilung ausgeschlossen wäre. Die Phasen des manischdepressiven Irreseins sind eben grundsätzlich heilbar.

Kurz sei noch einer sehr häufigen Verlaufsform gedacht, die mit besonders langem Intervall einhergeht. Wir finden bei diesen Kranken meist zwei Phasen, eine um das 20. Lebensjahr herum, gelegentlich schon kurz nach der Pubertät oder im Zusammenhang mit dem ersten Wochenbett bei Frauen, eine im Beginn der Involution.

Ganz allgemein überwiegen die depressiven Phasen weitaus, für den ersten Anfall noch mehr als für die späteren Verläufe. Allerdings gibt es hier regionäre Unterschiede. So finden wir weit mehr Manien in Baden als in Württemberg, wo die Depressionen in ungewöhnlichem Maße vorherrschen.

\section{Ursachen}

Das manisch-depressive Irresein ist eine Erbkrankheit. Der spezielle Erbgang ist aber noch nicht geklärt. Doch darf man mit einer Polymerie rechnen, d.h. zum Zustandekommen der Krankheit gehören mehrere abnorme Teilanlagen, von denen eine vermutlich dominant, andere rezessiv vererbt werden. $10 \%$ der Geschwister der Manisch-Depressiven, die von gesunden Eltern abstammen, sind gleichfalls manisch-depressiv. Kinder, die einen manisch-depressiven Elternteil haben, sind zu einem Drittel wieder manisch-depressiv. Unter den Nachkommen zweier manisch-depressiver Eltern sind zwei Drittel gleichfalls manisch-depressiv, und der Rest ist im Sinne der psychopathischen Anomalien, die im manisch-depressiven Kreise vorkommen, abnorm.

Wahrscheinlich bestehen erbliche Beziehungen zu den gleichfalls erblichen Stoffwechselleiden, Diabetes, Gicht, bestimmten Formen der Leibesfülle. Solche zur Arteriosklerose hat man angenommen, ohne daß bisher ein Beweis gelungen wäre. Tuherkulose ist demgegenüber in manisch-depressiven Sippen nicht häufiger, vielleicht sogar seltener, als im Bevölkerungsdurchschnitt.

Die meisten manisch-depressiven Kranken zeigen auch in ihren gesunden Zeiten Eigentümlichkeiten auf körperlichem und seelischem Gebiete. Unzweifelhaft ist der sog. pyknische Körperbau bei ihnen häufiger als in der Durchschnittsbevölkerung und besonders im schizophrenen Formenkreise. Zum pyknischen Körperbau gehört große Umfangsentwicklung der Leibeshöhlen mit Neigung zum Fettansatz am Rumpf, besonders zum Fettbauch, bei relativ zierlichen Gliedmaßen. Der Schädel ist lang und nicht hoch, das Gesicht breit (breite Schildform, Fünfeckform). Dysplasien fehlen in der Regel, insbesondere solche der Behaarung. Nur glatte, große Glatzen sind häufig. 
Seelisch sind die Manisch-Depressiven in ihren gesunden Zeiten häufig Stimmungsmenschen. Sie sprechen in ihrer Stimmung besonders leicht und besonders intensiv auf Erlebnisse an, und zwar in natürlicher Weise. Kretschmer kennzeichnet diese zykloiden Typen als gesellig, gutmütig, freundlich, gemütlich, und zwar bald mehr als heiter, humoristisch, lebhaft, hitzig, bald mehr als still, ruhig, schwernehmend, weich. Die Gestaltungen, die in der Breite der Norm verschwinden, nennt Krets ch mer Zyklothyme ${ }^{1}$ ), die ausgesprocheneren hypomanischen bzw. hypomelancholischen Menschen aber Zykloide. Gemüt, realistische Lebenseinstellung, Anpassungsfähigkeit, praktische Energie, Beweglichkeit und Behäbigkeit, dabei immer natürliches, schlichtes, abgerundetes Wesen, all dies eignet tatsächlich den typischen Vertretern des manisch-depressiven Formenkreises, und zwar den Kranken in ihren gesunden Zeiten ebenso wie vielen ihrer Verwandten dauernd. Ja, wir finden neben den Kranken häufig ausgeprägte hypomanische und schwerblütige Temperamente, die offenbar Vorstufen der Krankheit, Manifestierungen von Teilanlagen, bedeuten.

Was zu diesen Temperamenten hinzukommen muß, damit Krankheitsphasen zustande kommen, wissen wir nicht im einzelnen. In zahlreichen Fällen genügen offenbar die alltäglichen Lebensreize, um die Krankheitsanlage manifest zu machen. Nach Zwillingsuntersuchungen dürfen wir aber annehmen, daß nur etwa bei $60-80 \%$ der Anlageträger die Krankheit wirklich manifest wird. Bei erbgleichen Zwillingen tritt die Krankheit in etwa zwei Drittel der Fälle konkordant auf. Da die Konkordanz keine vollkommene ist, müssen wir mitwirkende äußere Ursachen annehmen, die zum Ausbruch der Krankheit überhaupt wie vielleicht auch der einzelnen Phasen beitragen. In der Tat wissen wir, daß nicht ganz selten die Phasen sich an schwere Infektionen, daß sie sich an die weiblichen Fortpflanzungsperioden anknüpfen, daß oft genug auch erst die beginnende Involution oder ein Schlaganfall die Krankheit aus der Latenz weckt. Ebenso aber kann eine Phase plötzlich mit einer schweren körperlichen Erkrankung oder einer Gravidität oder dem Wochenbett zum Abschluß kommen.

Eine gewisse Ausnahmestellung scheinen manche in der Zeit des Klimakteriums vorkommende Depressionen einzunehmen, in denen die Hemmung durch Erregung ersetzt ist und die zugleich gern hysterische und paranoide Züge darbieten. Sie schließen sich häufig an eindrucksvolle Erlebnisse so

1) Kretschmer gebraucht den Ausdruck in etwas anderem Sinne. Es erscheint daher zweckmäßig, die mannigfache Bedeutung des Ausdrucks „zyklothym“ kurz zu erläutern. Der Begriff wird von mir in gleichem Sinne wie von Kraepelin und Bumke verwandt, nämlich zur Bezeichnung jener Persönlichkeiten, bei denen leichte, $d . h$. noch nicht eigentlich kranke depressive und manische Schwankungen in raschem Wechsel das ganze Leben oder doch lange Strecken durchsetzen. Im Gegensatz dazu hat Kretschmer diesen Ausdruck für die noch normalen Temperamentseigenarten dieses Konstitutionskreises gebraucht, wofür man besser den von Bleuler geprägten Ausdruck „synton“" verwendet. Neuerdings hat Kurt Schneider das Wort „zyklothym“ wiederum in anderer Bedeutung für den gesamten Konstitutionskreis anwenden wollen ( $\mathrm{Lux}$ enburg er neigt ebenfalls dazu). Gerade um diese Vielseitigkeit zu vermeiden, hat Bumke als Ausdruck für alle diese Fälle ,Thymopathien“" oder "pyknisch-thymopathische Konstitution" vorgeschlagen, der sich aber noch nicht eingebürgert hat. Es erscheint mir aber wünschenswert, diese Bezeichnung zu verwenden, um den Begriff, ,zyklothym“ auf seine alte Bedeutung im Sinne von Kretschmer und Bumke zu beschränken, wie es auch hier getan ist. 
unmittelbar an, daß diesen eine provozierende Bedeutung kaum abgesprochen werden kann. Der Verlauf dieser Erkrankungen ist aber von dem auslösenden Erlebnis und seinen Folgen ganz unabhängig; er folgt vielmehr inneren Gesetzen wie jener der gewöhnlichen Melancholien. Früher faßte man diese Bilder als „Involutionsmelancholien ${ }^{6}$ in einer eigenen Krankheitsgruppe zusammen. Übrigens gibt es auch außerhalb der Involution seltene Melancholien, die durch Erlebnisse aufgeklinkt zu werden scheinen.

Die wesentliche Ursache bleibt aber immer die Erbanlage, ohne die es zum manisch-depressiven Irresein nicht kommen kann. Die Frage der Krankheitsverhütung ist also vornehmlich eine eugenische. Das Leiden gehört zu den Erbkrankheiten im Sinne des Erbgesundheitsgesetzes, erfordert also Unfruchtbarmachung. Diese ist im Falle des manisch-depressiven Irreseins deshalb manchmal eine bittere Maßnahme, weil viele Manisch-Depressive sozial sehr wertvolle, zugleich intelligente Menschen sind und manischdepressives Irresein, wie erwähnt, besonders häufig in sozial und kulturell hochwertigen Sippen sich findet.

Aber es sind durchaus nicht alle Manisch-Depressive sozial hochwertig, wie sie auch keineswegs alle die Merkmale des hierher gehörenden Temperaments darbieten, ebensowenig wie die Kennzeichen des pyknischen Körperbaues. Umgekehrt erkranken nur wenig Pyknische und keineswegs die Mehrzahl der Hypomanischen und Schwerblütigen an ausgesprochenen Phasen. Der Sterilisierung zu unterwerfen sind aber nur die an ausgemacht krankhaften Zuständen des manisch-depressiven "Irreseins ${ }^{66}$ leidenden Menschen, nicht etwa auch die mit leichten Verstimmungen behafteten Persönlichkeiten. Wir vermuten nur, daß dort, wo wir solche Menschen finden, wohl Teilanlagen des zirkulären Irreseins vorliegen dürften und wahrscheinlich zirkuläre Psychosen sich nicht allzuweit im erblichen Umkreis finden werden.

\section{Behandlung}

Die größte Gefahr, welche die Melancholie mit sich bringt, ist die Selbstmordneigung. Viele Melancholische gehen durch Suizid zugrunde, noch ehe die Krankheit erkannt ist. Die nächstgefährliche Zeit ist jene der nachlassenden Hemmung, wenn die Verstimmung noch andauert. Melancholische gehören also in die geschlossene Krankenabteilung und unter ständige Aufsicht. Im häuslichen Milieu genügt eine Pflegeperson nicht. Es ist überhaupt nicht zweckmäßig, den Kranken in seiner gewohnten Umgebung zu belassen. Gerade hier, wo er infolge seiner Hemmung die selbstverständlichen Pflichten versäumt, leidet er unter seiner Krankheit am meisten. Demgegenüber fügt er sich meist in das Milieu der geschlossenen Abteilung ohne Mühe ein.

Die ärztliche Hauptsorge hat dem Schlaf, der Angst, der Nahrungsaufnahme und der Verdauung zu gelten. Schlaf suche man mit möglichst milden Schlafmitteln herbeizuführen. Man scheue sich aber in hartnäckigen Fällen nicht, auch größere Dosen und stärkere Mittel zu geben. In der Regel reichen aber Gaben von etwa 0,5 Veronal, 0,2-0,3 Luminal, zusammen mit einem Einschlafmittel (z. B. Evipan $0,25 \mathrm{~g}$ ) aus.

Das Mittel zur Bekämpfung der Angst ist das Opium, das am besten als Tinct. simplex in Dosen von $3 \mathrm{mal} \mathrm{5,3}$ mal 10 bis 3 mal 40 Tropfen gegeben 
wird. Man steigere die Gabe nach Bedarf, unter Umständen rasch, versuche immer wieder zurückzugehen (langsam), steigere nach Bedarf erneut und schleiche sich bei abklingender Angst nur langsam hinaus. An Stelle des Opiums kann man Neurophillin, das auch Abführmittel enthält, oder Opium mit Rhabarber oder eines der Ersatzpräparate des Opiums, Eukodal, Dicodid, in entsprechenden Dosen anwenden. Die Ersatzmittel haben den Vorteil, daß sie nicht oder doch nicht so obstipierend wirken wie das Opium selbst. Im ganzen scheint mir aber Opium immer noch am besten zu wirken und am leichtesten entwöhnt zu werden.

Auf alle Weise suche man den Kranken Nahrung beizubringen, durch häufiges Anbieten, durch freundliche Nachhilfe usw. Unter Umständen muß man bei depressiven Stuporen aber auch zu künstlicher Ernährung schreiten.

Die Obstipation muß, je nachdem sie spastisch oder schlaff ist, mit den geeigneten abführenden Mitteln bekämpft werden. Es empfiehlt sich jedoch nicht, den Kranken allzusehr zu verwöhnen.

Bei alleinstehenden Kranken, aber auch bei Melancholischen mit schwierigeren Aufgaben muß die Sorge des Arztes immer auch den „Angelegenheiten " des Kranken gelten. Der Melancholische darf keine geschäftlichen Maßnahmen treffen, weil er in Gefahr ist, aus seiner Verzweiflung, seiner Sorge und aus pessimistischer Beurteilung der Sachlage heraus sich ungünstig zu entscheiden, seine Stellung zu kündigen, das Pensionierungsgesuch einzureichen, Verkäufe einzuleiten, auf Erbschaften zu verzichten usw. Entmündigung kann aber fast immer umgangen werden durch die rasch zu. erreichende Pflegschaft.

Melancholische dürfen nicht zu früh entlassen werden, nicht bloß der Selbstmordgefahr wegen. Bei subjektiv noch deutlicher Hemmung und dennoch bestehendem Bestreben, möglichst bald die Pflichten wieder aufzunehmen, geraten die Kranken im Falle des Versagens oft ganz in Verzweiflung und in eine nun vollends hoffnungslose, wenn auch nicht mehr rein melancholische Verfassung, die nun von sich aus suizidale Tendenzen nährt.

Manische gehören in die Anstalt, sobald ihre Enthemmung sie in soziale Konflikte zu bringen droht. So gewaltig mancher Manische sich zunächst auch zur Wehr setzt, er findet doch in der Anstalt rasch ein geeignetes und ungefährliches Betätigungsfeld, und die meisten Manischen fühlen sich schließlich ganz wohl. Auch hier aber wird man von Fall zu Fall entscheiden müssen, wann und ob Anstaltsinternierung nötig ist. Sexuell enthemmte junge Mädchen können sich durch eine Schwängerung oder durch eine luische Infektion die ganze Zukunft verderben, und Gleiches gilt für Männer, die manchmal noch dazu durch Leichtsinn, übertriebene Geldausgaben und geschäftlich unsinnige Spekulationen ihre wirtschaftliche Basis zerstören. Auch Streit und Kampf können die Internierung nahelegen, ehe der Kranke es mit seiner gesamten Umgebung verdirbt und sich beruflich unmöglich macht.

Beim Manischen muß man gleichfalls für Schlaf sorgen, in schweren Zuständen auch für Beruhigung und Ernährung. Im übrigen aber nimmt der Manische seine Interessen meist hinreichend selbst wahr. Oft ist es gut, ihn durch kleine Vergünstigungen von seinen übertriebenen Forderungen abzulenken. 
Weder bei Melancholischen noch bei Manischen ist es zweckmäßig, auf die krankhaften Ideen näher einzugehen. Die Anregbarkeit der Kranken steigert allzugern das Festhalten an den Inhalten. Man suche mit einigen freundlichen Worten und kurzen Hinweisen auf die Krankhaftigkeit des Geschehens von der immer erneuten Erörterung der Wahninhalte abzulenken.

Bei manchen leichter Kranken kann es freilich nötig werden, auch in eine eingehende Prüfung der vorgebrachten Sorgen einzutreten, um nach Möglichkeit die sachlich bedeutsamen Erschwernisse aus der Welt zu schaffen. Auf jeden Fall muß der Arzt immer wissen, was auf dem Spiele steht. Er kann sonst in Gefahr geraten, ernstliche Versäumnisse mitzuverschulden.

Endlich gibt es melancholische Phasen leichterer Art, die von psychogenen Erscheinungen überwuchert oder doch nachhaltig in ihrer Symptomatologie mitbestimmt sind. In diesen Fällen, die vor allem außerhalb der Anstalten, in der Sprechstunde, nicht selten sind, ist planmäßiges psychotherapeutisches Vorgehen angezeigt. Wenn damit auch die Phase selbst nicht geheilt wird, so kann man dem Kranken doch große Erleichterung bringen. Besonders Depressionen unter dem Bilde von Organneurosen können durch psychotherapeutisches Vorgehen berufsfähig gehalten werden.

\section{Erkennung}

Die Erkennung typischer Melancholien und Manien ist leicht, wenn man sich nicht bloß an die Stimmung, sondern an die Gesamtsyndrome hält. Allerdings müssen in jedem einzelnen Falle exogene Ursachen eigens ausgeschlossen werden. Typische Bilder können Ausdruck jeder Art von ernster Hirnerkrankung sein, zumal der Paralyse, an die man nur zu denken hat, um sie auszuschließen. Jedes neurologische Symptom muß den Verdacht wachhalten, daß manisches oder melancholisches Syndrom nur die pathoplastische Gestaltung eines organischen Hirnvorganges, unter Umständen selbst eines Tumors, sein könnte.

Wird im Hinblick auf die organischen Hirnveränderungen die nötige, auf den Körper gerichtete Sorgfalt in der Regel ohne Mühe eine diagnostische Klärung zulassen, so kann die Unterscheidung zirkulärer Zustandsbilder von Gestaltungsformen der Schizophrenie lange Zeit unmöglich sein. Wir wissen nicht nur, daß die Schizophrenien lange Jahre hindurch unter zirkulären Bildern verlaufen können, ehe der schizophrene Verfall eintritt; auch manischdepressive Phasen können mit katatonem Beiwerk einhergehen. Insbesondere machen manche Mischzustände die Diagnose unmöglich. Hält man sich an die Grundpersönlichkeit, an die Erblage, an den vorangehenden Verlauf, an meist doch episodisch hervortretende typisch manische und melancholische Einsprengungen, dann wird man meist richtige Vermutungsdiagnosen stellen können. Ganz allgemein gehören Sperrung und Negativismus auch in milden Formen nicht zum manisch-depressiven Irresein, ebensowenig wie Zerfahrenheit bei klarem Bewußtsein und nur geringer Erregung. Den manisch-depressiven Verläufen fehlen, "gemachte ${ }^{66}$ Phänomene und der Wahn sexueller Beeinflussung. Wohl aber können Manien dann einen läppischen Anstrich annehmen, wenn die Kranken debil oder wenn sie gedanklich gehemmt sind. In den ängstlichen Erregungen der Zirkulären pflegt doch meist eine gewisse Beeinflußbarkeit zu bestehen und die Starre der Schizophrenen zu fehlen. 
Echte Halluzinationen sind bei Manisch-Depressiven sehr selten. Schizoforme Züge finden sich meist nur in sehr schweren Formen und bei Mitwirkung exogener Faktoren, wie in den verworrenen Manien, die gern an exogene Schäden anschließen. (Im übrigen s. Schizophrenie.)

Auch symptomatische Psychosen können eine ausgesprochen manische Färbung annehmen. Meist ist die Bewußtseinstrübung aber doch tiefer, die Auffassung erschwert, und der Ideenflucht mischen sich deutlich inkohärente Züge bei. Doch können auch zirkuläre Phasen bei entsprechenden Vorbedingungen exogen gefärbt werden. Dann kann eine genaue Klärung der Vorgeschichte vielfach die Entscheidung herbeiführen.

Epileptisch-dämmerige Erregungen werden kaum je den Verdacht einer Manie nahelegen. Die Verstimmungen der Epileptiker zeigen meist eine mißmutig-gereizt-geladene Note, beginnen jäh und enden meist ebenso. Auch hier wird man Gesamtpersönlichkeit, Vorgeschichte und die bei Epileptikern so häufigen Dysplasien zu beachten haben.

Depressive Reaktionen der Psychopathen, sog. psychogene Depressionen, können echten melancholischen Erkrankungen dann sehr ähnlich sehen, wenn eine manisch-depressive Veranlagung vorliegt. Meist kommen sie bei ganz andersartigen, hysterischen oder schizoid-nervösen Personen zustande. Immer bleibt die Konfliktslage deutlich, und dem depressiven Affekt fehlt meist eine demonstrative, ja vielfach eine aggressive Note nicht, während die eigentliche Hemmung fehlt. Abnorme seelische Reaktionen haben immer einen Sinn; sie bleiben in Abhängigkeit von den auslösenden Ereignissen und Konfliktslagen und von hier aus beeinflußbar.

Allerdings können auch Melancholien psychisch provoziert werden. Sie verlieren dann sehr bald den Zusammenhang mit dem auslösenden Ereignis, nehmen typische Formen an und sind von außen nicht mehr beeinflußbar.

Große Schwierigkeiten können aber hysterisch gefärbte Melancholien machen, wie sie besonders in der Involution vorkommen. Bei allem hysterischen Beiwerk bleibt der vitale Hintergrund und der Widerhall der seelischen Erkrankung im Körperlichen doch so deutlich, daß die Diagnose möglich ist. Durch geeignete seelische Maßnahmen kann man gelegentlich wohl die hysterischen Züge, nicht aber die Depression und die Hemmung beseitigen.

Große Schwierigkeiten machen oft die ersten manisch-depressiven $\mathrm{Zu}$ stände, wenn sie zunächst ganz leicht oder unter ausgesprochen neurasthenischen Bildern verlaufen; bzw. wenn sie mit somatischen Klagen oder mit andersartigen psychopathischen Manifestationen (Zwangserscheinungen, paranoide Züge) einhergehen. Hier wird oft eine Diagnose nicht gelingen, bis das unerwartete Abklingen der Erscheinungen und die unvermutete Wiederkehr gleicher oder ähnlicher Syndrome die Zusammenhänge klären. Leicht wird die Erkennung überall dort, wo neben den Depressionen auch manische Zeiten deutlich werden.

\section{q) Die psychopathischen Persönlichkeiten}

Jeder Lebende unterscheidet sich in dem einen oder anderen Wesenszuge von der Durchschnittsnorm, und auch die hochbegabte, harmonische Persönlichkeit bleibt weit hinter der Idealnorm ihrer Gruppe zurück. Wir sind also 
alle, wenn wir strenge Maßstäbe anlegen, nach irgendeiner Richtung hin abnorm. Psychopathien nennen wir abnorme Dauerverfassungen, wenn die abnormen Wesenszüge ausschließlich das Gefühls- und Willensleben betreffen und dabei so hochgradig sind, daß sie die Erreichung der normalen Lebensziele (Beruf, Ehe, Stetigkeit, volle soziale Eingliederung, Fähigkeit, auch größeren Forderungen der Gemeinschaft, etwa im Kriege, zu genügen) verhindern oder doch in erheblichem Maße erschweren. Psychopathen sind Menschen mit abnormen Dauerverfassungen, die unter ihrer Abnormität leiden (Versager) oder unter deren Abnormität die Gemeinschaft leidet (Störer).

Über die Verbreitung der Psychopathien läßt sich in der Klinik selbst kein zureichendes Bild gewinnen. In die Krankenanstalt kommen die Psychopathen meist erst infolge abnormer seelischer Reaktionen, an denen sie freilich besonders leicht erkranken, oder nach groben sozialen Entgleisungen, um begutachtet zu werden. In der ärztlichen Sprechstunde stellen sie aber sehr erhebliche Prozentsätze der Ratsuchenden. Unter den Selbstmördern, unter jenen, deren Ehe geschieden wird oder die überhaupt nicht zur Eheschließung gelangen, wie den Soldaten, die im Kriege ihrer , $N e r v e n$ “6 wegen in die Lazarette kamen, und jenen, die nach geringfügigen Unfällen ,neurotisch $^{66}$ reagieren, machen sie die Hauptmasse aus, aber auch unter den Kriminellen, den Alkoholikern und den anderen Süchtigen. Ein Überschlag über die Zahlen dieser Versager und Störer ergibt, daß wir mit 5-10\% psychopathischer Menschen in der Gemeinschaft zu rechnen haben.

Anomalien des Gemüts- und Willenslebens sind es, die den Psychopathen kennzeichnen. Schwachsinn hat mit Psychopathie unmittelbar nichts zu tun. Wohl aber finden sich Unzulängliche aller Art zur Eheschließung gern zusammen, und daher kommt es, daß viele Debile und Imbezille a u ch psychopathisch, viele Psychopathen daneben beschränkt oder selbst debil sind. So zählen wir in den Gefängnissen und Fürsorgeanstalten besonders zahlreiche psychopathisch und zugleich geistig unzulänglich Veranlagte.

Psychopathien sind abnorme Dauerverfassungen, die wir uns meist als angeboren denken. In der Tat treten abnorme Verhaltensweisen, besonders ausgeprägte Trotzperioden, Tics und auffallende Gewohnheiten, Enuresis usw., in der Vorgeschichte vieler Psychopathen hervor. Auf der anderen Seite ist kein Zweifel, daß viele dieser kindlichen Neurosen schon durch Milieuänderung oder doch durch einfachste ärztliche Maßnahmen günstig beeinflußt, ja geheilt werden können. Diese Neurosen entstehen also sicher zum Teil unter dem Einfluß der Umgebung, und es gibt psychotherapeutische Schulen, die für die Entstehung der Psychopathien den Hauptnachdruck auf eben die äußeren Einflüsse und Erlebnisse legen. Demgegenüber muß betont werden, daß manche Formen der Psychopathie mit Bestimmtheit erblich sind oder doch als erbliche Anomalien vorkommen. Dies gilt insbesondere für gewisse Gruppen der „hysterischen“" Persönlichkeiten, für Erregbare, Willenlose und Gemütslose, aber auch für die Psychopathien, die sich durch grobe Abweichungen des Temperaments auszeichnen, und für die schizoiden Psychopathien, von denen schon die Rede war. Näheres über die Erbgänge wissen wir aber noch nicht, da die Forschungen auf dem ganzen Gebiete mit außergewöhnlichen Schwierigkeiten zu kämpfen haben. Wir müssen zudem annehmen, daß zwar manche psychopathische Dauerverfassungen als solche 
und ganze im Erbgang weitergegeben werden, wenn sie auch je nach dem übrigen Anlagegut phänotypisch recht verschieden aussehen können, daß aber im übrigen Psychopathien im Erbgang immer neu aufgebaut werden durch das unglückselige Zusammentreffen an sich nicht ungünstiger, aber miteinander unvereinbarer Anlagen.

Dazu kommt, daß wir den angeborenen Psychopathien ähnliche Dauerverfassungen gelegentlich unter unseren Augen entstehen sehen, und zwar als Folgen schwerer äußerer Schäden. Ich-erinnere an die psychopathieähnlichen Abnormisierungen der Kinder nach Encephalitis epidemica, an die nach schweren Schädeltraumen zurückbleibende abnorme Erregbarkeit, an die Persönlichkeitsveränderungen nach ,geheilter" Paralyse, an die Dauerschäden nach chronischem Giftmißbrauch. Dennoch bezieht die große Mehrzahl der hierhergehörigen Persönlichkeiten ihre abnormen Züge sicherlich aus Anlagemängeln.

Grenzt man die psychopathischen Persönlichkeiten allgemein nach den Anomalien ihres Gemüts- und Willenslebens ab, so könnte man doch auch den Versuch machen, Zugang zu dem ganzen Gebiete von Anomalien im körperlichen Geschehen her zu gewinnen. So hat man in jüngster Zeit tatsächlich gewisse Stoffwechseleigentümlichkeiten bei , asthenischen ${ }^{6}$ Psychopathen aufgedeckt. Im übrigen wissen wir, seit das Gebiet überhaupt für die Psychiatrie erschlossen wurde, daß körperliche Anomalien der verschiedensten Art auch sonst unter den psychopathischen Persönlichkeiten weit verbreitet sind. Vor allem vegetative Störungen sind hier zu nennen, ausgesprochene Formen des Vasomotorismus, die sich äußerlich in Neigung zu Erröten und Erblassen, ja zu Schwindel und Ohnmachten, in Pulsarhythmien, Akrozyanose, Neigung zu Hautblutungen, in ,rosigem ${ }^{66}$ Teint oder ständiger Blässe zu erkennen geben. Weit verbreitet finden wir ferner leichtere und gröbere endokrine Anomalien, Hyper- und Hypothyreoidismus, tetanische Bereitschaften, Störungen der Geschlechtsfunktionen, leichte Hypophysenstörungen. Daher sehen wir gern Anomalien der Körperfülle, abnorme Beschaffenheit der Haut, Störungen im Haarkleid, besondere Hitze- und Kälteempfindlichkeit, abnorme Pulsfrequenz, Neigung zu Tremor und gesteigerte elektrische und mechanische Erregbarkeit der Muskulatur, Menstruationsund Potenzstörungen, herabgesetzte oder gesteigerte Libido, Neigung zum Schwitzen, Störungen der Darmtätigkeit im Sinne der schlaffen wie der spastischen Obstipation oder der Neigung zu Durchfällen, Anomalien der Magenmotilität, besonders erleichtertes, oft virtuoses Erbrechen, und solche der Magensekretion, besonders Hyperazidität. Auch der Schlaf wird vegetativ gesteuert; Schlafstörungen sind also an der Tagesordnung, ebenso wie Anomalien der Erholungsfähigkeit und erhöhte Ermüdbarkeit. Es ist ferner verständlich, daß diese Mängel mannigfache subjektive Beschwerden herbeiführen, vor allem gern Kopfschmerzen, Atembeschwerden, Angstgefühle, die vom Herzen ausgehen, Darmempfindungen, Störungen der Miktion. Wir wissen, daß tetanische und basedowoide Stigmatisierung mit der Neigung zu eidetischen Erscheinungen (lebhaften optischen Anschanungsbildern) verschiedener Art einhergeht. Häufig sind ferner Überempfindlichkeiten aller Art. Kurz, wir finden eine Fülle von Anomalien auf den verschiedensten Gebieten so verbreitet, daß manche bei den Psychopathen besonders hervor- 
tretende Neigungen, so jene zur Hypochondrie, zu funktionellen Störungen der verschiedensten Organe und Organsysteme, zu optischem Sinnestrug, zu Angst und zu Erschöpfung ohne weiteres verständlich werden.

Doch ist es heute noch, und wahrscheinlich grundsätzlich, unmöglich, das hier in Frage kommende Gebiet nach solchen vegetativen Gesichtspunkten aufzuteilen. Keine Störungsgruppe schließt die andere aus. Die vegetativen Mängel sind nur ein eindrucksvolles körperliches Korrelat der Anomalien des Gemüts- und Willenslebens. Wir dürfen annehmen, daß den Gesamtsyndromen vielfach Anlagefehler im vegetativen Grau zugrunde liegen, die sich körperlich und seelisch zugleich äußern. Im Organismus schon, besonders aber in der Persönlichkeit hängt alles mit allem zusammen, und nicht bloß in der fertigen, sondern schon in der sich entwickelnden Persönlichkeit. Wo immer der Eingriff geschehen mag, immer antwortet darauf das Gesamt der vorhandenen Möglichkeiten.

Wenn es nicht gelingt, von den vegetativen Störungsgruppen her einheitliche Typen psychopathischer Persönlichkeiten zu entwickeln, so ist dies grundsätzlich nicht anders von der seelischen Seite her. Alle systematischen Bemühungen, die in dieser Hinsicht erfolgt sind, erscheinen gezwungen und werden der Fülle psychopathischer Persönlichkeiten ebensowenig gerecht wie der unendlichen Mannigfaltigkeit des durchschnittlichen menschlichen Wesens. Die Klinik hält sich daher an besonders häufige Typen, die ein mehroder weniger einheitliches Gepräge zeigen und zum Teil durch soziale Gesichtspunkte zusammengehalten sind. Dabei bleibt sie sich bewußt, daß hier Grenzen in eine fließende Formenfülle hineingetragen werden, die tatsächlich nicht bestehen. Die Typen dieneu nur der Beschreibung und der Vorbereitung genetischer Bemühungen. Vereinzelt betreffen sie wohl schon heute genetisch einheitliche Gruppen.

Dies gilt vor allem für einen großen Teil der hyperthymen und der depressiven Psychopathen, die nichts anderes darstellen als die hypomanischen und hypomelancholischen Dauerverfassungen, denen wir schon beim manisch-depressiven Irresein begegnet sind. Die Hyperthymen, also die Menschen mit heiterem, sanguinischem Temperament und der Bereitschaft zu raschem Handeln können freilich nur in ihren extremen Varianten oder dann als psychopathisch angesehen werden, wenn sich zu der Hyperthymie andere psychopathische Wesenszüge hinzugesellen. So gibt es besonders streitsüchtige, reizbare Persönlichkeiten, deren hypomanische Beweglichkeit sie nicht zu echten Querulanten werden läßt, sondern nur zu Pseudoquerulanten, die sich immer erneut bei den verschiedensten Gelegenheiten in Streit und Kampf verwickeln, sich aber nicht in eine Sache progressiv verbohren (lästige Krakehler nach Kretschmer). Bei ihrem starken Selbstbewußtsein kommen Hypomanische gern zur Aufschneiderei. Ist diese Seite stärker entwickelt, so entstehen gewisse hypomanische Schwindler und Pseudologisten. Häufig ist beim Geselligkeitsdrang der Hypomanischen die Neigung zum Alkohol, der sie dann unter Umständen haltlos werden läßt. Auch andere Formen der Psychopathie (Erregbare, Fanatische, Haltlose, Geltungssüchtige) zeigen kennzeichnende Eigentümlichkeiten, wenn die Betroffenen zugleich hyperthyme Züge haben.

Die depressiven Persönlichkeiten, die Mühseligen, die, zu unbeschwertem Frohsinn unfähig, nur trübe Lebenserfahrungen machen, leiden aus- 
nahmslos unter ihrer Art. Als schwerblütige, unentschlossene, weiche und gütige Menschen können sie nur bei Strenge und großem Pflichtgefühl zu bedeutenden äußeren Leistungen kommen. Innerlich sind sie oft besonders differenziert und häufig tief religiös. Mit asthenischen Zügen versagen sie im Leben. Nur die eigentlich schwerblütigen Typen haben wohl engere Beziehungen zum manisch-depressiven Irresein. Häufiger in der Klinik sind die mißmutig-depressiven Menschen, deren gemütliche Dauerverfassung Züge der Verbissenheit und Feindschaft, gegen die eigene Person wie gegen alle anderen Menschen, an sich hat. Sie sind oft mürrische, egoistische, kalte, boshafte Einzelgänger, die ihrer Umgebung durch ihre gern zur Schau getragene, vor allem am falschen Platze proklamierte, wertverneinende Art alle Freude und allen Genuß vergiften können. Selbstmordversuche mit aggressiven Absichten (die anderen sind schuld) sind bei diesen Typen, die offenbar schizoide Wesenszüge haben, besonders häufig.

Gleichfalls leidend und störend in einem sind die mißtrauisch (paranoisch) Depressiven, die aus ihrer depressiven Verstimmung und ihrem unangemessenen, empfindlichen Selbstbewußtsein heraus zu falschen Deutungen und Eigenbeziehungen neigen und damit auch ihre nächsten Freunde und Verwandten quälen, wenn sie nur, wie so oft, zur Entäußerung ihrer Gedanken kommen. Auch hier sind es wohl schizothyme Züge, welche der Grundhaltung die kennzeichnende Farbe verleihen. Nicht selten suchen depressive Menschen aller Art Kompensationen auf irgendeinem Wertgebiet (Ästheten, Religiöse). Unter dem Einfluß schwerer Lebensschicksale erkranken sie gern an mehr oder weniger lang hingezogenen depressiven Reaktionen. Wo sie mitleiden machen, da ist nicht die große Gemeinschaft, sondern in der Regel nur der engste Umkreis betroffen.

\section{Selbstunsichere}

Bei diesen "Gewissensmenschen" finden wir das Leben überdauernd oder doch bis in späte Jahrzehnte hinein eine ständige innere Unsicherheit und Ängstlichkeit bei großer Gewissenhaftigkeit, Ordnungsliebe, oft Pedanterie, ferner erhöhte Eindrucksfähigkeit und verhaltende Verarbeitung aller Lebensreize, also tiefe Aufwühlbarkeit ohne die entsprechende Bereitschaft, die anhaltenden und tiefen Affekte nach außen zu entladen. Die ,sensitive ${ }^{66}$ Gruppe dieser Persönlichkeiten sucht die Schuld für das Versagen immer bei sich selbst und leidet um so tiefer, weil zugleich ein besonderer Ehrgeiz, gerade auch auf ethischem Gebiete, besteht. Geringe objektive eigene Verfehlungen, ja Handlungen, die nach außen hin nur wie Entgleisungen aussehen könnten, führen zu tiefen, lang anhaltenden inneren Konflikten, zu Verstimmungen und unter Umständen zum „,sensitiven Beziehungswahn“, den Kretschmer beschrieben hat (s. dort). Mitunter sind es nur mit der ethischen Grundhaltung unvereinbare Gedanken oder Wünsche, die zu solchen sensitiven Reaktionen führen, besonders solche auf geschlechtlichem Gebiete.

Sensitive dieser Art haben schon nahe Beziehungen zu der zweiten Gruppe der Selbstunsicheren, den Zwangsmenschen, den Anankasten, wie sie K. Schneider nach dem Vorgang von Donath bezeichnet. Bei ihnen finden wir unter untadeligem, ja oft besonders strengem ethischen Oberbau mit diesem unvereinbare, meist geschlechtliche, und zwar pervers- 
sadistisch-masochistische Regungen. Diese führen freilich nie zum Handeln, drängen sich aber immer wieder, manchmal als solche, unter Angst ins Bewußtsein, und zwar als Zwangsvorstellungen, die zugleich innerlich abgelehnt werden. Bald aber bleiben die verpönten Regungen hinter tausenderlei Symbolen und Ersatzvorstellungen völlig oder doch nur annähernd kenntlich verborgen. Zwangsvorgänge sind Bewußtseinsinhalte, die mit dem Erlebnis des subjektiven Zwangs auftreten und sich nicht verdrängen lassen, obschon sie in der Ruhe als unsinnig oder als ohne Grund dominierend erkannt werden. Bei mancherlei Inhalten von $\mathrm{Z}$ wangsvorstellungen, Zwangshandlungen und Unterlassungen (Phobien) ist die angedeutete Genese noch sehr deutlich. Es sind gerade geschlechtliche Gedanken, die sich an geheiligte Dinge (Jungfrau Maria, Jesus) und Menschen (nahe Verwandte), an den Gottesdienst, an feierliche Zeremonien anknüpfen, „Kontrastideen ${ }^{66}$ bei den gleichen Gelegenheiten (Fluchen in der Kirche, häßliche Verstümmelungen von Grußformen). Auch der Waschzwang und die Beschmutzungsfurcht, die Angst, wichtige Dinge zu beschmutzen, mit häßlichen Worten vollzuschreiben, verraten noch ihren Ursprung. Bei vielen anderen Zwangsinhalten ist die Genese nicht mehr so deutlich (Angst vor Nadeln, spitzen Gegenständen, Röhren, Öffnungen, Höhenangst, Brückenangst), aber doch meist noch leicht aufklärbar. Nicht ohne weiteres gelingt dies bei der Platzangst, bei der Budenangst, bei der Angst, still zu sitzen usw. Vielfach aber sind es nach der Art des Tabu entstandene Handlungen und Unterlassungen, die uns als Zwangserscheinungen entgegentreten und der Abwehr der eigentlichen Zwangsinhalte dienen.

Neben geschlechtlichen Regungen können auch sonstige verpönte Wünsche den Inhalt der Zwangserscheinungen bestimmen ( „Angst ${ }^{66}$, die nächsten Angehörigen könnten sterben, es könnte ihnen ein Unglück widerfahren, feindselige Gedanken gegen Gott und Kirche, einfache aggressive Regungen gegen andere usw.).

Es gibt endlich Vorstellungen nach Art der Zwangserscheinungen, die nicht hierher gehören, sondern bei jedem Menschen in der Ermüdung auftreten können, ohne eigentlichen Zwangscharakter, d.h. ohne das von Angst begleitete Erlebnis des subjektiven Zwangs (Nichtloswerdenkönnen von Melodien, Anknüpfen von Rechenexempeln an jede Zahl, Zählenmüssen usw.).

Zwangsneurosen begegnen uns nur bei Menschen, die in diesen Kreis gehören, also stark kontrastierten Persönlichkeiten, die nach außen pedantisch, sorgsam, korrekt, peinlich, gewissenhaft, oft streng, gern auch geizig, humorlos erscheinen, ohne doch die innere Unsicherheit, die Angstbereitschaft und die Lebensschwäche zu verbergen. Sie sind meist begabt und differenziert. Viele von ihnen sind zugleich geistig hochmütig und im Gegensatz zu den Sensitiven auch streng und lieblos gegen die Umgebung. Die äußere Verwundbarkeit, die Aufwühlbarkeit durch Erlebnisse ist geringer. Der Kampf wird lediglich von innen her genährt. Es sind diese ganz bestimmten Persönlichkeiten, die ihr Leben lang gewisse Zwangserscheinungen nicht los werden. Solche treten aber auch bei Nervösen anderer Art in Zeiten der Niederlage und Abgeschlagenheit häufig in Andeutungen hervor, und manche zirkuläre Depressionen oder beginnende Schizophrenien gehen mit 
ausgeprägten Zwangssyndromen einher. „Progressive Zwangsvorstellungsneurosen 6 , in denen die Betroffenen immer tiefer sich in Zwang, Zeremonien und Verschrobenheiten verstricken, sind wohl meist Prozeßschizophrenien.

Die hier entwickelte Auffassung der Zwangserscheinungen ist durch Freuds genetische Betrachtungsweise nahegelegt. Freud geht überall auf die entwicklungsgeschichtlichen Grundlagen der neurotischen Störungen zurück. Unzweifelhaft verdienen viele Zwangserscheinungen aber, unter Adlers finalem Gesichtspunkt betrachtet zu werden oder doch auch von hier aus. Manche Nervöse flüchten sich in die Zwangskrankheit, die ein „Arrangement" in ihrem „Kampf um die Macht ${ }^{66}$ darstellt. Es braucht nicht näher ausgeführt zu werden, daß sich beide Gesichtspunkte vereinen lassen, daß sie aber auch gemeinsam wohl nicht jedem Fall von Zwangsneurose gerecht werden.

Alle ausgesprocheneren Zwangserscheinungen schränken die Bewegungsfreiheit und die Leistungsfähigkeit der Betroffenen in erheblichem Maße ein. Nur mit leichteren Zwängen setzen sich manche Anankasten in ein leidliches Gleichgewicht. So aggressiv und schlimm Zwangsvorstellungen und -antriebe erscheinen, sie führen doch nicht zu kriminellen Entgleisungen. Forensische Verwicklungen sind diesem Kreis von Menschen fremd. Ihren nächsten Umkreis können sie aber tyrannisieren und quälen, wie sonst nur Psychopathen dies fertig bringen.

\section{Fanatische Psychopathen}

Gemeint sind jene Menschen, die überwertige Ideen, Gedanken oder Gedankengruppen, die infolge ihres Gefühlswertes ein U̇bergewicht über alle anderen Gedanken erlangt haben, nach außen mit Zähigkeit, Verbissenheit und Unbelehrbarkeit vertreten, sei es in heftigem, mutvollem und rücksichtslosem Kampf nach Art vieler echter Querulanten, sei es im Sinne des Bekenners, der trotz aller äußeren Widerstände, trotz Gefahr und Not sich zu seiner überwertigen Idee bekennt und unter Umständen daran zugrunde geht wie mancher Märtyrer. Zu dieser letzteren Gruppe gehören etwa die im Anfang des Krieges so häufigen Dienstverweigerer, die aus religiösen oder weltanschaulichen Gründen das Gewehr nicht zur Hand nehmen wollten, aber auch viele Sektierer und Schwärmer, die wenigstens im Ausdruck, in Haartracht und Kleidung, in der äußeren Haltung oder in der verschrobenen Lebensführung die Herrschaft der überwertigen Idee zur Schau tragen. Hier sind die Apostel der Nacktkultur, der ,natürlichen “ Lebensweise, die „wahren" Christen, die Rohkostler und manche Impfgegner, manche Frauenrechtler und -rechtlerinnen u. a. zu nennen. Ist dieser matte Flügel der Fanatiker ungefährlich und dem humorvollen Mitmenschen meist ein wenig lächerlich, so ist dies anders bei den starren und aggressiven, verbissenen und menschenfeindlichen Fanatikern im Sinne der Querulanten, die in Vertretung ihrer Ideen immer auf Widerstände stoßen, sich dann rücksichtslos durchzusetzen versuchen und gern zur ,Selbsthilfe", auch zur Gewalttat kommen, besonders häufig aber zu wörtlichen und tätlichen Beleidigungen und meist auch zu gerichtlichen Verwicklungen. Gerade durch die Freude am Kampf werden diese Fanatiker für die Umgebung lästig und unter Umständen gefährlich, wie der matte Fanatiker durch seine Dulderleidenschaft sich selbst. 
So sehr die extremen Flügel der Fanatiker sich sozial unterscheiden, das Bestimmtwerden durch dominierende Inhalte und das zähe, unbeirrbare Festhalten daran ist ihnen gemein und daneben die Tatsache, daß es sich letzten Endes immer um egozentrische, ganz persönliche Dinge handelt, die verfochten werden. Selbst hinter dem zähesten und aggressivsten Kampf des querulierenden Fanatikers um vermeintlich allgemeinste Werte lauert die Verwundbarkeit und die ganz persönliche Niederlage, und das bekennerhafte Märtyrertum ist nichts als die Überkompensation tatsächlicher innerer Schwäche. Wir werden diesen Menschen bei den paranoischen Reaktionen und Entwicklungen wieder begegnen. Sie haben genetisch, wie es scheint, Beziehungen zum schizophrenen Formenkreise, dazu in ihren aktiven, unermüdlich tätigen Vertretern zugleich solche zum hypomanischen, in ihren weichen, dulderischen aber zum depressiven Flügel des zirkulären Irreseins.

\section{Stimmungslabile Psychopathen}

Der Stimmungshintergrund des Seelenlebens, in dem alle gemütlichen Regungen widerhallen, von dem aber auf der anderen Seite alle Gefühle und Affekte schon in ihrer Entstehung, sodann aber in ihrem Ablauf und ihrer Intensität beeinflußt werden, ist in seiner Stetigkeit und Farbe ein wesentliches Kennzeichen der gereiften Persönlichkeit. Zwar unterliegt der Stimmungshintergrund je nach dem Erleben gewissen Schwankungen. Für alle gereiften Menschen gilt aber, daß, abgesehen von ganz schwerwiegenden Vorkommnissen und Konfliktslagen, zu einem bestimmt temperierten Stimmungshintergrund immer wieder zurückgefunden wird. Die meisten Menschen haben freilich „Launen“ meist von kurzer Dauer, d. h. jähe Abänderungen des Stimmungshintergrundes, für welche die Motive nicht ohne weiteres aufzeigbar sind. Bei den stimmungslabilen Psychopathen aber unterliegt der Stimmungshintergrund tieferen und vor allem nicht berechenbaren Schwankungen, und diese Schwankungen wirken sich auch in viel stärkerem Maße im gesamten Handeln selbst und der Gestaltung der sozialen Lebensführung aus als bei noch so launenhaften Durchschnittsmenschen. In der Regel sind es dysphorische, irgendwie von einer Note der Unrast, der Unstetheit, des Dranges, des Heimwehs, der Sucht nach anderem gefärbte Verfassungen, die mehr oder weniger periodisch, unberechenbar oder auch tatsächlich oder scheinbar motiviert, wiederkehren, zu vorübergeh en dem Trinken (Dipsomanie), zum Davonlaufen (Fugues), zur Aufgabe der Stellung, zum Abbrechen von menschlichen Beziehungen, zum Desertieren, zu Reisen, zu übertriebenen Geldausgaben führen. Der Lebenslauf solcher Stimmungslabiler wird dadurch unstet, zerrissen, und das soziale Verhalten kann zu verschiedenen Zeiten ein ganz verschiedenes Gesicht haben. Hierher gehören die "Orientkunden“, die an keinem Platz lange aushalten und die es von einem Ort zum anderen in die ferne Welt treibt, immer wieder fort, sooft sie auch Heimweh und Sehnsucht nach Hause treiben, hierher manche periodische Trinker, die ihre unlustvollen Spannungen im Alkohol ertränken, hierher manche Männer, die immer wieder ihre Familie verlassen, um dann doch zurückzukehren. Kraepelin hat einen Teil der Fugues, dazu das triebartige Brandstiften, triebhafte Tötungen kleiner Kinder durch Dienstboten, die damit von ihren Stellen loskommen wollen, triebartige Kauf- 
sucht, Schuldenmacherei und Diebstähle wertloser Gegenstände(Kleptomanie), auch die gewohnheitsmäßige Giftmischerei als, ,impulsives Irresein ${ }^{66}$ zusammengefaßt, ohne damit sagen zu wollen, daß es sich dabei etwa um Geisteskranke im eigentlichen Sinne handle, die man für ihr Tun nicht zur Verantwortung ziehen könne. Jedenfalls handelt es sich hier immer um Psychopathen, freilich nicht einheitlicher Natur, die oft im Zusammenhang mit unklaren (verdrängten) geschlechtlichen Regungen zu ihren impulsiven Handlungen kommen. Ein nicht unerheblicher Teil dieser Abnormen gehört zu den Stimmungslabilen.

Nicht alle Wanderzustände sind freilich Reaktionen solcher Stimmungslabiler. In der Pubertät führt Abenteuerlust, Angst, Druck des häuslichen Milieus hinaus. Trinkexzesse können unter dem Einfluß epileptischer Verstimmungen, aber auch periodischer Lohnzahlungen oder immer erneut sich anspannender familiärer Schwierigkeiten, oder auch als Ausdruck manischdepressiver Verstimmungen zustande kommen. Unzweifelhaft gibt es aber eine Gruppe von Menschen, die ausschließlich oder doch vorwiegend durch die Stimmungslabilität gekennzeichnet ist. Kraepelin sah auch hierin wohl mit Recht ein Fortbestehen kindlicher Wesenszüge. Gerade Jugendliche zeichnen sich ja durch ihre erhöhte Stimmungslabilität aus.

\section{Geltungsbedürftige Psychopathen (hysterische Charaktere)}

"Will man den Typus etwas schärfer fassen, so kommt man immer wieder auf einen Grundzug: anstatt sich mit den ihr gegebenen Anlagen und Lebensmöglichkeiten zu bescheiden, hat die hysterische Persönlichkeit das Bedürfnis, vor sich und anderen mehr zu scheinen, als sie ist, mehr zu erleben, als sie erlebensfähig ist. An Stelle des ursprünglichen echten Erlebens mit seinem natürlichen Ausdruck tritt ein gemachtes, geschauspielertes, erzwungenes Erleben, aber nicht bewußt, gemacht ${ }^{6}$, sondern mit der Fähigkeit (der eigentlichen hysterischen Begabung), ganz im eigenen Theater zu leben, im Augenblick ganz dabei zu sein, daher mit dem Schein des Echten. Daraus leiten sich verständlich alle weiteren Züge ab. Der hysterischen Persönlichkeit ist schließlich gleichsam der Kern ganz verlorengegangen; sie besteht nur noch aus wechselnden Schalen. Ein Schauspiel löst das andere ab. Da sie in sich nichts mehr findet, sucht sie alles außer sich. Sich selbst und anderen macht sie das Dasein von intensiverem Erleben durch übertriebene Ausdrucksbewegungen, denen die adäquate seelische Grundlage fehlt, glaubhaft. Alles, was einen starken Reiz von außen bedeutet, zieht sie an: Skandal, Klatsch, berühmte Persönlichkeiten, alles Wirkungsvolle, Maßlose, Extreme in Kunst und Weltanschauung. ${ }^{6}$..., ,S Sie spielen immer eine Rolle, machen sich interessant, selbst auf Kosten ihres Rufes und ihrer Ehre. Sie können nicht unbeachtet sein, sind daher maßlos eifersüchtig. Gelingt es durch keine andere Weise, so ziehen sie durch Krankheit die Aufmerksamkeit auf sich und führen das Theater des Märtyrers, des Leidenden auf. Dabei sind sie unter Umständen rücksichtslos gegen sich selber in der Zufügung von Leiden (Verletzungen), sie haben geradezu einen Willen zur Krankheit, falls ihnen nur eine entsprechende Wirkung auf andere verbürgt erscheint. Um das Erleben hinaufzuschrauben und neue Wirkungsmöglichkeiten zu finden, wird schließlich zur anfangs bewußten Lüge gegriffen, die bald zur völlig un- 
bewußten und selbst geglaubten "Pseudologia phantastica' sich entwickelt. Selbstanklagen, Bezichtigung anderer wegen erfundener sexueller Attentate, Auftreten und Benehmen in fremder Umgebung, als ob sie eine bedeutende Persönlichkeit, reich, adlig seien. Hierbei täuschen die Kranken nicht nur die anderen, sondern sich selbst. Sie verlieren das Bewußtsein der eigentlichen Realität, ihre Phantasie wird ihnen zur Wirklichkeit. Jedoch gibt es auch hier Unterschiede. In einem Falle besteht völlige Unwissenheit über die Unwahrheit: ,Ich wußte nicht, daß ich log. ${ }^{6}$ Im anderen Falle ging ein Wissen nebenher: ,Ich log, aber ich konnte nicht anders. Je mehr das Theatralische sich entwickelt, desto mehr geht diesen Persönlichkeiten jede echte, eigene Gemütsbewegung ab, sie sind unzuverlässig, keiner dauernden Gefühlsbeziehung mehr fähig, nirgends wirklich tief. Nur noch ein Schauplatz nachgemachter und theatralischer Erlebnisse..."

Dieser meisterhaften Kennzeichnung durch Jaspers ist wenig hinzuzufügen. In jedem Menschenkreis sind diese geltungssüchtigen Personen bekannt, die um jeden Preis, mit Verlogenheit, Theater, Renommistereien, Geheimniskrämerei, Heuchelei und Aufwand ebenso lauter wie unechter Gefühle eine Rolle zu spielen suchen. In der Ehe werden sie bald dem Partner und den Kindern zu namenloser Qual, vor allem wenn sich ihrem Aufwand unechter Gefühle, wie so oft, Gemütskälte paart und Szenen aller Art dazu dienen müssen, auf jeden Fall in den Mittelpunkt zu rücken. Krankheitsdarstellungen, Selbstbeschädigungen, Selbstmordversuche, kurz, all das, was mit dem Arzt in Berührung bringt, sind bei jungen und alternden hysterischen Charakteren, zumal bei den letzteren, deshalb fast unausweichlich, weil auf die Dauer auch der geduldigste Angehörige und Fremde die Unechtheit aller anderen Demonstrationen durchschaut, abgekühlt und ernüchtert wird und die Krankheit nun die letzte Ausflucht bleibt, die Beachtung erzwingt, unter Umständen erst bei recht nachdrücklicher, selbstschädigender Nachhilfe. Die Krankheitsdarstellung ist aber eben nur eines der schauspielerischen Hilfsmittel der Geltungsbedürftigen.

Eine weitere herausgehobene Gruppe der hysterischen Charaktere sind die von Jaspers oben gekennzeichneten Vertreter der „Pseudologia phant a stic a", die freilich mit fließenden Grenzen in die einfachen Schwindler und Betrüger übergehen. Es können bei den Pseudologen die sozial schädlichsten, wenn auch vielfach amüsanten Lebensläufe zustande kommen. Ich habe einen Schlosser gesehen, der damit begann, bei seinen Wanderungen durch ganz Deutschland durch vorgetäuschte, glänzend nachgeahmte epileptische Anfälle zahllose Male Krankenhausaufnahmen durchzusetzen, im Krankenhaus alle möglichen anderen Krankheitszustände studierte und dann schließlich als Arzt auftrat. Als solcher leitete er vertretungsweise ein Krankenhaus, schwängerte eine Schwester, ließ sich dann in einer Mittelstadt nieder, $\mathrm{saß}$ mit dem Kreisarzt und den Ärzten der Heil- und Pflegeanstalt monatelang am Stammtisch, ja wurde selbst, als er morphinistisch in eine psychiatrische Klinik aufgenommen wurde, zwar verdächtigt, aber nicht erkannt, bis ihn schließlich sein Schicksal ereilte. Der Pseudologist dieser Art betrügt also nicht sich selbst, sondern die Umwelt, und meist nicht bloß aus Geltungssucht und Eitelkeit, sondern auch um Gewinn materieller Art. Gemeinsam ist dieser Haltung der extreme Egoismus und die Fähigkeit, ganz Theater zu spielen. 
Hysterische Störungen im engeren Sinne, seelisch entstandene und seelisch festgehaltene körperliche Funktionsstörungen sind im Rahmen des allgemeinen Theaters Menschen dieser Art besonders leicht zugänglich und auch deshalb so häufig, weil dem fehlenden ethischen Gewissen auch ein fehlendes vegetatives Gewissen entspricht. Auch vegetativ sind die Geltungsbedürftigen meist irgendwie disreguliert, so besonders auch in ihrem Sexualleben. Hier gibt es, wie überall, keine echten Bindungen und keine durchgehende Befriedigung. Geltungsbedürftige Frauen sind häufig frigide. Aber auch im Vasomotorium finden wir in der Regel Störungen mannigfacher Art.

\section{Gemütlose Psychopathen}

Die Gemütlosen nannte Kraepelin Gesellschaftsfeinde, und früher faßte man sie mit anderen sozial schädlichen Psychopathen unter dem Begriff der Moral Insanity zusammen. Zweckmäßig ist es aber, die Gemütlosigkeit in den Mittelpunkt zu stellen, also das Fehlen von Mitleid und Bestimmbarkeit durch Gemütsregungen anderer und die Forderungen des Gewissens. Diese Gemütlosen können intellektuell gut begabt sein und verstandesmäßig alle moralischen Forderungen kennen. Die Mehrzahl ist freilich zugleich auch intellektuell nur wenig oder sogar schwach begabt und kommt gerade deshalb besonders leicht unter die Räder.

Den Gemütlosen fehlt nicht nur Mitleid und Mitfreude, sie werden auch durch Ehre und Schande, Ansehen und Verachtung, diesseitige und jenseitige Werte nicht berührt. Sie sind unfähig echter Zuneigung, erwerben niemals dauerhafte menschliche Bindungen, abgesehen davon, daß eine infantile $\mathrm{Zu}$ neigung zur Mutter auffallend oft bestehen bleibt. Beim Fehlen aller höheren Gemütsregungen, ein Spielball seiner niederen, aus dem Augenblick geborenen Wünsche, ist der Gemütlose meist unstet, kommt gerade noch durch die Schule, aber meist nicht mehr durch die Lehre, fügt sich nicht der militärischen Disziplin, bringt es nicht zur Gründung einer allen Stürmen standhaltenden Familie, kennt nicht die Segnungen einer geordneten und warmen Häuslichkeit, ja ihm fehlt selbst unter seinesgleichen das Gruppenbewußtsein, so sehr seine Reden auch danach klingen mögen. Kalt und unberührt gehen die Gemütlosen an den Menschen, die es gut mit ihnen meinen, vorbei, widerstehen sie den stärksten, aufwühlendsten Ereignissen, setzen sie sich über die Einflüsse von Strafhaft, Entehrung und Ächtung hinweg.

Meist fallen sie schon in der Kindheit durch Neigung zur Tierquälerei, durch Streunen und Mangel kindlicher Regungen, durch die Unfähigkeit, sich selbst im Familienkreis Liebe zu erwerben und Liebe zu geben, auf.

Bei den so häufig unzureichenden anderen Anlagen, vor allem auch des Verstandes, werden sie meist Verbrecher. Sind sie aktiv und roh, dann entstehen aus ihnen die schweren Jungen, deren Weg durch Einbruch und Tätlichkeitsdelikte gekennzeichnet ist. Die weniger aktiven Naturen werden Diebe und, wenn sie geschickt und phantasiebegabt sind, Schwindler und Betrüger. Viele gehen durch die Fürsorgeerziehungsanstalten hindurch.

Unzweifelhaft gibt es Gemütlose, die mit ihrem Gemütsdefekt geboren werden. Daneben kennen wir eine Gruppe von sozialen Schädlingen, die offenbar nicht so geboren werden, sondern erst, meist um die Pubertät herum oder kurz nachher, gemütlos werden und die genealogisch Beziehungen zur 
Schizophrenie haben. Kahlbaum hat sie Heboide genannt. Auch sie sind nicht durch Werte und gemütliche Bindungen bestimmbar, aber eindrucksgemäß erscheinen sie eher gemütsfalsch als gemütlos. Vor ihrem seelischen Abgleiten sind sie nicht selten Musterkinder, die höchstens durch die Neigung zur Unwahrhaftigkeit auffallen. Später ist ihre Unwahrhaftigkeit und Lügenhaftigkeit abgrundtief, nicht bloß hinsichtlich ihrer Worte und Handlungen, sondern auch der zur Schau getragenen Gefühle. Hinter ihren Tränen und Beteuerungen, ihren schönen Reden und edlen Gesten steckt nichts als Verlogenheit und kalter Egoismus. Gerade das Erkalten aller früheren Gemütsbeziehungen, die in Gesten und leeren Formen noch fortbestehen können, kennzeichnet die Persönlichkeitsveränderung. Der Knick ist meist auch in der Lebenskurve nachweisbar. Die Mehrzahl ist feige; aktive Verbrechen sind ihnen daher fremd. Viele enden auf der Landstraße. Näherem Zusehen ergeben sich manchmal unverkennbare Züge der Hebephrenie; ja, es gibt ausgesprochen Hebephrene, die mit solchen antisozialen Persönlichkeitswandlungen beginnen.

\section{Haltlose (Willenlose)}

Das Wesen dieser Psychopathen ist gekennzeichnet durch ihre Willensbeeinflußbarkeit. "Wechselwarme Milieumenschen" nennt sie Bleuler. In der Tat sind sie die angenehmsten Gefangenenanstaltsinsassen wie die besten Kameraden, wo keine besonderen Anforderungen an sie gestellt werden, die bequemsten Ehemänner für willensstarke Frauen und die beflissensten Untergebenen in windstillen Betrieben. Aber sie geben ebenso leicht, ja leichter ungünstigen wie günstigen Einflüssen nach. Denn sie bohren das Brett immer an der dünnsten Stelle. Zähe und stetige Arbeit, Anstrengung und Überwindung von Widerständen liegen ihnen nicht. Alle leichten Dinge sind ihnen anziehender als alles Schwere. Leichte Geselligkeit, bequemes Genießen, schöne Kleider, gedankenloses Dahinleben locken sie mehr als die Freude der Pflichterfüllung und die Überwindung auch nur der geringsten Widerstände.

Sie sind also besonders leicht verführbar, die typischen Mittäter, leichtsinnig und unernst. Alkohol, Spiel, Frauen sind ihr Verhängnis und im Gefolge davon Eigentumsdelikte, leichte Diebstähle, Unterschlagungen, Betrug, Vergehen, die durch die „wirtschaftliche Unfähigkeit" bestimmt sind.

Viele von ihnen haben liebenswürdige Eigenschaften, können gute Freunde, ja unter Umständen aufopfernd sein, oft sind sie gewinnende und freundliche Gesellschafter. Eignen ihnen hyperthyme Züge, so zeigen sie einen Zug von Flottheit und Frische.

Ihre Willenlosigkeit führt sie allenthalben bald zum Versagen und damit zur Ausrede und Lüge, zur Flucht in die Krankheit und oft auch zu schwächlichen Suizidversuchen. Sind die Lügen meist nicht mehr als das Abwehrmittel aller Schwachen, so kann eine stärkere Bereitschaft nach dieser Richtung pseudologistische Züge und damit aktivere Schwindeleien mit sich bringen.

$$
\text { Explosible (Erregbare) }
$$

Hier handelt es sich um die Menschen, die nicht nur besonders leicht in Unmut, Zorn und innere Erregung geraten, sondern auch unfähig sind, diese negativen Gemütsbewegungen in sich zu verschließen. Sie machen also 
ihrem Unmut Luft, mit Schimpfen und Poltern, mit Türschlagen und Zertrümmern der Gegenstände, die zur Hand sind, mit Beleidigung und Angriffen, Losschlagen und Messerstechereien. Der Blaukoller und der Zuchthausknall gehören hierher. Jeder Schutzmann reizt den Blaukollerigen, d.h. den Erregbaren, wenn er etwas getrunken hat, und die in der schlimmen Disziplin des Zuchthauses mühselig zurückgedämmte Erregung macht sich schließlich einmal unhemmbar Luft. Es kommt dann meist zugleich zu einer Art Bewußtseinstrübung und zu sinnlosem Wüten gegen die gesamte tote und lebendige Umgebung. In solchen Affektstürmen kann es auch zu hysterischen Entladungen und bei Disponierten selbst zu Anfällen kommen, die epileptiformen gleichen.

Als Mitarbeiter und Ehepartner, als Kameraden und besonders als Feinde müssen die Explosiblen mit besonderer Vorsicht angepackt werden. Ihr größter Feind ist der Alkohol, der die Erregbarkeit steigert, die noch vorhandenen Hemmungen mindert. Unter Alkoholeinfluß kommen daher die Wirtshausschlägereien, die Messerstechereien, Beleidigung, Widerstand, Ruhestörung, Sachbeschädigung, Körperverletzungen aller Art besonders leicht zustande. Viele von den Explosiblen begehen in ihrem Unmut auch ernste, selbstschädigende Handlungen. Nicht wenige gehen durch Selbstmord zugrunde, auch wiederum im Rausch. Der Unmut ist es, der zum Alkohol treibt.

Außerhalb ihrer mitunter lang sich hinziehenden explosiblen Erregungen können diese Psychopathen gutmütig und weich, freundlich und lenksam sein, gute Ehemänner und vortreffliche Kameraden. Ähnliche Persönlichkeiten sieht man unter Umständen nach Hirntraumen oder andersartigen Hirnschädigungen erst entstehen. Im epileptischen Formenkreis scheinen sie nicht ganz selten zu sein. Es gibt aber sicherlich von der Epilepsie unabhängige, erbliche Formen der explosiblen Psychopathie.

\section{Asthenische}

Das Kennzeichen der "konstitutionell Nervösen" ist die Erschöpfbarkeit und Ermüdbarkeit in körperlicher und seelischer Hinsicht, gepaart mit Empfindlichkeit, Reizbarkeit und der Neigung zu mannigfachen körper lichen und seelischen Funktionsstörungen. Hier gehen körperliche und seelische Unzulänglichkeit so innig ineinander über, daß es fraglich sein kann, ob man die Asthenischen überhaupt zu den Psychopathen rechnen soll. In der Tat hat Jahn bestimmte Eigentümlichkeiten des Arbeitsstoffwechsels aufgezeigt, die dartun, daß der Schaden ganz zentral sitzt und durch alle Lebensäußerungen hindurchgeht. Manche Asthenische zeigen von früher Jugend an ihre körperliche und seelische Verwundbarkeit und Zartheit. Sie können nichts Lautes, nichts Grausames, nichts Anstrengendes vertragen, aber zeigen auch Überempfindlichkeiten gegen mancherlei Nahrungsmittel, gegen Geräusche, gegen das Dunkel. Sie können kein Blut sehen, keine Hitze vertragen oder keine Kälte. Bei anderen zeigt sich die erhöhte Verwundbarkeit erst bei etwas stärkeren Belastungen und damit ist der Kreis geschlossen zum Normalen, der erst in der Rekonvaleszenz von schweren Infektionen, nach unsinnigen, unter Gemütsdruck vor sich gehenden Belastungen „neurasthenisch" wird.

Bei den Asthenischen macht also auch der Körper nicht recht mit. Von Schlafstörungen bis zu Organstörungen aller Art finden wir eine unendliche Fülle subjektiver Beschwerden, die bei der Zartheit, der Ängstlichkeit und 
dem Mangel an Widerstandskraft besonders leicht zu hypochondrischen Befürchtungen und Sicherungsmaßnahmen nach dieser Richtung, Vermeidung von Nahrungsmitteln und Anstrengungen aller Art usw., führen. Die hypochondrische Angst bringt ihrerseits „erwartungsneurotische ${ }^{66}$ Funktionsstörungen (Herzklopfen, Impotenz usw.) mit sich.

Neben den hypochondrischen Befürchtungen sehen wir nicht selten Andeutungen von Zwangserscheinungen, die freilich oft nicht zurückgedrängte sexuelle Regungen als vielmehr einfache, reale, natürliche Bedürfnisse mit dem Tabu belegen. Hier schließen sich die Depersonalisationserscheinungen an, die Entfremdung der Wahrnehmungswelt und vor allem der eigenen Regungen und des eigenen Wollens, das Gefühl, automatisch, gemütsleer usw. zu sein, in einer fremden, fernen Welt, wie in einem Nebel, durch eine Glasscheibe hindurch zu leben. Daneben kommt es gern zu den Erlebnissen des Déjà vu, des Anrufs mit dem eigenen Namen, zu Wachträumereien und Beschäftigung mit der eigenen Seele.

Es fehlt des Gedankens und des Handelns Frische, der Mut zum lebenserfüllten Dasein, die Freude am Widerstand. Wir begegnen daher bei den differenzierten Menschen aus diesem Kreis gern ästhetischen und philosophischen Neigungen, Stil und Form. Bei den primitiveren Asthenischen ist Flucht in die Krankheit, in Organneurosen, in erwartungshysterische Störungen, in schlaffe, müde Depressionen, rasches Niederlegen der Waffen die Regel.

Asthenische Züge begegnen uns überhaupt bei vielen Psychopathen, den depressiven, stimmungslabilen, selbstunsicheren, unter Umständen auch bei den Haltlosen.

\section{r) Abnorme seelische Reaktionen}

Wenn wir uns lächerlich gemacht haben und im Anschluß daran Spott, Bedauern, Schadenfreude in den Mienen der Augenzeugen sehen und ängstlich weiter danach suchen, auch wenn die anderen den Vorfall vielleicht längst vergessen haben, oder wenn wir nach einem schmerzlichen Verlust in lang anhaltende, tiefe Traurigkeit verfallen, die uns auch in der Arbeitsfähigkeit nachhaltig beeinflußt, so handelt es sich dabei um normale verständliche Reaktionen, die uns in ähnlicher Weise allenthalben begegnen, wo nur affektiv Bedeutsames geschieht. Abnorme seelische Reaktionen nennen wir solche, „deren Inhalt in verständlichem Zusammenhang mit dem Erlebnis steht, die nicht aufgetreten wären, ohne das Erlebnis und die in ihrem Verlauf von dem Erlebnis und seinen Zusammenhängen abhängig sind“"(Jaspers), dann, wenn sie nach ihrer Intensität, ihrer Dauer oder auch qualitativ von der durchschnittlichen Breite abweichen. Wie es im Bereiche der Psychopathien keine scharfen Grenzen gegenüber den durchschnittlichen Persönlichkeitsvarianten gibt, so auch auf dem Gebiete der seelischen Reaktionen. Schon manche normale seelische Reaktion führt zum Arzt, etwa ein nach Ausmaß und Dauer verständlicher Kummer, wenn er den Schlaf stört, eine völlig nacherlebbare innere Erregung über ein angetanes Unrecht, wenn der Betroffene Erleichterung von einer Aussprache erhofft. Daß die Steigerung von Trauer und Erregung fließend in das Gebiet des Abnormen hinüber führt, ist verständlich, und ebenso, daß es ganz vorwiegend psychopathische Per- 
sönlichkeiten sind, die an solchen abnormen Reaktionen erkranken. Deren Wesen entsprechen ja ungewöhnliche Reaktionen, ja, man kann sie nur nach ihren besonderen Reaktionen kennzeichnen. Die einzelnen Psychopathengruppen sind zu jeweils besonderen Formen abnormer seelischer Reaktionen ganz vorwiegend geneigt. Auf der anderen Seite kann auch einmal ein „Normaler $^{66}$ unter besonderen Bedingungen an einer abnormen seelischen Reaktion erkranken und ein bestimmter Psychopathentyp wird etwa nicht ausschließlich ganz bestimmte abnorme Reaktionen erleben und gegen andere geschützt sein. Hier gibt es keine gesetzmäßigen, wenn auch gewisse Häufigkeitsbeziehungen. Die von uns abgegrenzten Psychopathentypen sind ja Abstraktionen. Haben wir alle das Zeug zu Ansätzen aller Art abnormer Reaktionen in uns, so in besonderem Maße die in ihrem Gemüts- und Willensleben abnormen Psychopathen, die jeweils nach den verschiedensten Richtungen hin auffällig zu sein pflegen.

\section{Psychogene Depression}

Depressive Psychopathen pflegen auf bekümmernde Erlebnisse entsprechend ihrer Eigenart mit Verstimmungen zu antworten, die nach Tiefe und Dauer über das gewöhnliche Maß hinausgehen. Ja, das Leben mancher solcher Psychopathen ist eine Kette ineinander übergehender oder doch nur durch relativ freie Zeiten getrennter Verstimmungen, so daß kaum mehr von einzelnen abnormen seelischen Reaktionen gesprochen werden kann.

Aber auch bei anderen Psychopathen begegnen wir lang hingezogenen Depressionszuständen, die sich an einmalige schwere Schicksalsschläge anschließen, noch häufiger aber im Zusammenhang mit chronischen Konfliktslagen auftreten. Besonders Enttäuschungen in der Ehe, im Rahmen der Familie und im Beruf sind es, die zu solchen Zuständen führen. Die Persönlichkeiten, die in dieser Weise erkranken, haben vielfach geltungsbedürftige Wesenszüge. Es handelt sich nicht um warme, syntone, sondern eher um kühle, egoistische Menschen. Wir sehen auch nicht eigentlich Trauer, sondern eher Ablehnung und Mißstimmung, Reizbarkeit und Empfindlichkeit. Die Verstimmung hat demonstrativen oder gar aggressiven Charakter. Werden Selbstvorwürfe vorgebracht, dann sind sie wenigstens teilweise nicht echt, sondern fordern durch Übertreibung zu Widerspruch heraus. Viele von diesen Depressiven jammern und klagen, können aber außerhalb des gewohnten Kreises auch einmal ganz heiter sein. Sie legen die Hände in den Schoß, es fehlt ihnen aber die wirkliche Hemmung, wie denn überhaupt eine Veränderung des vitalen Hintergrundes nicht feststellbar ist, oder doch erst dann zustande kommt, wenn die Kranken auch die Nahrung verweigern, schlecht schlafen und viel Schlafmittel verwenden. Paranoide Ideen, von oft unechtem Anstrich, sind häufig.

Ähnliche Depressionen sehen wir auch bei Schwangeren, die ihr Kind nicht austragen wollen und die zugleich mit allen möglichen körperlichen Demonstrationen hysterischer Natur reagieren. Solche sind übrigens auch bei anderen psychogenen Depressionen an der Tagesordnung.

Aus der Schilderung ergibt sich ohne weiteres die Differentialdiagnose gegenüber der gewöhnlichen Melancholie. Freilich zeigen auch manche melancholische Erkrankungen ausgesprochen demonstrativeZüge. Der vitale Hinter- 
grund pflegt aber dann doch deutlich zu sein. Eine echte Melancholie kann auch einmal psychisch provoziert werden; in solchen Fällen entfernen sich die Inhalte der Depression aber meist rasch von dem auslösenden Erlebnis oder der anfangs gegebenen Konfliktslage, und die Beseitigung der objektiven Nöte bringt keine Besserung mit sich, während psychogene Depressionen auf äußere Einwirkungen geeigneter Art, vor allem aber auf die Erreichung des in der zweckhaften Depression erstrebten Erfolges rasch anzusprechen pflegen. Gerade die weitgehende Beeinflußbarkeit gibt differentialdiagnostisch oft den Ausschlag.

In psychogenen Depressionen sind Selbstmordversuche meist unernster, demonstrativer Art sehr häufig. Gerade sie führen vielfach in ärztliche Behandlung. Manchmal sind sie es zugleich, die eine Entspannung der Lage und mit der Aussprache eine entscheidende Besserung einleiten.

\section{Angstreaktionen und Angstneurose}

Angst entsteht häufig auf rein körperlichem Wege. Am eindrucksvollsten sind die stenokardischen Anfälle mit ihrer gestaltlosen Angst und mit dem Gefühl unmittelbarer Todesbedrohung. Auch bei Behinderung der Atmung, bei falschem Atemtypus entsteht Angst, meist mehr protrahierter Art. Ängstliche oder besser gestaltarme Furchtregungen können andererseits zur Veränderung des Atemtypus und damit zu somatisch verstärkter Angst Anlaß geben. Auch außerhalb des körperlichen Geschehens sehen wir Angst dann eintreten, wenn der Bestand der Person bedroht ist, und zwar, abgesehen von den Psychosen (Melancholien, Schizophrenien und Paralysen), meist in langgestreckten neurotischen Reaktionen, die der Abwehr mit dem ethischen Oberbau unvereinbarer triebhafter Regungen dienen. Bei den Anankasten ist uns dieser Sachverhalt schon begegnet. Auch sonst sind es häufig genug nicht abfuhrfähige sexuelle Spannungen (unbefriedigtes Eheleben), die den Frieden stören, aber nicht in ihrer eigenen Gestalt, sondern als Angst oder fortdauernde Ängstlichkeit in Erscheinung treten. Der Coitus interruptus scheint geeignet, solche Angstneurosen zu unterhalten. Auch aggressive Regungen gegen nahe Angehörige, gegen zugleich verehrte Vorgesetzte, die ohnmächtige Abwehr untragbarer sozialer Lagen kann sich angstneurotisch äußern. Vielfach ist den Psychopathen, die so erkranken, die letzte Quelle ihrer Angst im Grunde wohl bekannt, und zwar um so besser, je mehr Zweckhaftes in der Neurose enthalten ist. Aber auch in den nicht so durchsichtigen Fällen gelingt es meist leicht, die seelischen Hintergründe aufzudecken und damit eine Besserung anzubahnen. Bei den akuteren Zuständen dieser Art, die sich an einmalige adäquate Erlebnisse anschließen, sehen wir die körperlichen Symptome der Angst deutlich hervortreten. Schwerste, lang anhaltende Angstzustände ohne demonstrativen Charakter gehören meist eigentlichen Psychosen an.

\section{Schreckreaktionen}

Schreck ist die Antwort auf plötzlich eintretende gefahrdrohende oder doch vermeintlich gefahrdrohende Ereignisse und, so sehr alles Schreckhafte seelisch vermittelt ist, zunächst einmal eine im gesamten vegetativen System widerhallende körperliche Reaktion, welche Vasomotoren, glatte Muskulatur, 
endokrine Drüsen, aber auch den Tonus der quergestreiften Muskulatur abändert. Daß es einen wirklichen Schrecktod, außer bei Menschen mit krankem Gefäßsystem und krankem Herzen, gibt, halte ich für unwahrscheinlich. Bei solchen gefäßkranken Menschen kann der Schreck zudem zu Dämmerzuständen organischer Art führen.

In Katastrophen (Erdbeben) sehen wir im übrigen immer wiederkehrend an das Abebben der körperlichen Schreckreaktion anschließende Bewußtseinsveränderungen hysterischen Gepräges, von denen noch gesprochen werden soll, sodann heftigste Angstreaktionen im Sinne wildesten, besinnungslosen Fluchtdranges, in denen zugleich mindestens eine Bewußtseinseinengung besteht, endlich Zustände von „Emotionsstupor ${ }^{66}$, von „Affektabschaltung In diesen Zuständen werden Gemütsbewegungen, insbesondere Angst, Grauen, Furcht gar nicht erlebt, während doch das Bewußtsein völlig klar erscheint, sachlich alles registriert und auch zweckmäßiges Handeln zuläßt. Wir haben hier wohl den besonders deutlichen Ausdruck eines Geschehens vor uns, das in uns allen gelegentlich zur Wirkung kommt. Alle unzweckmäßigen Gemütsbewegungen, Unruhe, Angst, peinliche Erwartungsaffekte, schweigen in dem Augenblick, in dem wir in unangenehmen Lagen plötzlich handeln können oder müssen (Lampenfieber).

Bei manchen vegetativ labilen Menschen dauern die körperlichen Schreckfolgen, besonders Tremor, Adrenalinausschüttung, Stürme der glatten Muskulatur abnorm lange an, und die Erinnerung an das schreckhafte Erlebnis kann jeweils das ursprüngliche körperliche Syndrom, meist mit Angst begleitet, wieder heraufbringen. Auch im normalen Seelenleben gibt es Analoga, freilich nur im Traum. Wir alle kennen den wiederkehrenden und immer qualvollen Examenstraum. Von manchen Psychopathen wird die Wiederbelebung der ursprünglichen Angst und der Schrecklichkeiten virtuos vollzogen, freilich nicht, ohne daß zunehmend demonstrative Züge die Mitwirkung willentlicher Einstellungen verraten. Auch hier nähern wir uns dem hysterischen Geschehen.

\section{Paranoische Reaktionen und Entwicklungen}

Schon in der Einleitung zu diesem Kapitel wurde darauf hingewiesen, daß jeder Mensch geneigt ist, bei öffentlichen Blamagen die Bestätigung seiner Scham aus Schadenfreude, Spott und Hohn seiner Umgebung herauszulesen und sich länger im Mittelpunkt des allgemeinen spöttischen oder mitleidigen Interesses zu sehen, als dies bei der Egozentrizität und der Raschlebigkeit der Mitmenschen berechtigt ist. Es werden dann leicht die Mienen falsch gedeutet und aus harmlosen Bemerkungen Anspielungen herausgehört, kurz, es kommt zu Beziehungsideen, die sich freilich beim Durchschnitt der Menschen leicht berichtigen lassen. Diese normalen Reaktionen führen ohne scharfe Grenze hinüber zu dem, was Kretschmer unter der Bezeichnung

$$
\text { sensitiver Beziehungswahn }
$$

beschrieben hat. Es handelt sich um wahnhafte Reaktionen auf das Erlebnis beschämender Insuffizienz, die vor allem bei sensitiven Psychopathen auftreten. Lassen sich solche weichen, skrupulösen, schwerlebigen, verhaltenden Menschen, die gerade auf ethischem Gebiete einen gewissen selbstbewußten 
Ehrgeiz haben (Asthenische mit einem gewissen sthenischen Stachel), eine wenn auch noch so harmlose ethische Verfehlung zuschulden kommen, so werden sie damit nicht fertig. Ihre Selbstvorwürfe projizieren sie nach außen. Sie glauben sich belächelt, sehen sich als Mittelpunkt der allgemeinen Neugier und Aufmerksamkeit, fühlen sich verspottet und verachtet. Die innere Gegenwehr gegen diese wahnhaften Beeinträchtigungen, die zur Selbstbesinnung auf den eigenen Wert führt, steigert die wahnhaften Eigenbeziehungen weiter, die nun zu wirklichen Verfolgungsvorstellungen werden. So kommt es zu unter Umständen lange Monate anhaltendenWahnbildungen, die um so quälender werden, als die Erkrankten lange Zeit nach außen nichts davon ahnen lassen, bis dann schließlich ein verzweifelter Ausbruch des gestauten Affektes der Umgebung die Augen öffnet. Dies wird zugleich Anlaß zur Aussprache und zu ärztlichen Maßnahmen, welche die Konfliktslage klären und unter Umständen eine rasche Heilung herbeiführen. Oder es kommt doch wenigstens zu einem Zustand, in dem zwar eine gewisse, langsam abebbende Beziehungsneigung noch fortbesteht, aber doch nicht mehr die Qual der akuten Psychose.

Von den wahnhaften Reaktionen, die hierher gehören, ist wohl am häufigsten der "Masturbantenwahn"6. Onanisten, die sich mit ihrem "Laster ${ }^{66}$ umsonst abquälen und die weitverbreitete Meinung haben, man sähe ihnen die Onanie an, kommen bei sensitiver Veranlagung zu eigentlich wahnhaften Reaktionen nicht ganz selten. Kretschmer hat in den Mittelpunkt seiner Darstellung den Beziehungswahn alternder Mädchen gerückt, der sich an verpönte erotische Wünsche und harmlose Entgleisungen anschließt. Es kann aber auch jede andere Verfehlung, ein dienstliches Versehen etwa, eine Ehrenkränkung, die aus irgendeinem Grunde nicht gutgemacht werden kann, zu solchen Beziehungswahnsystëmen führen. Mancher Mensch trägt eine solche Wunde sein ganzes Leben lang mit sich herum, bleibt immer zu Eigenbeziehung geneigt und erlebt immer neue wahnhafte Episoden, wenn es ihm schlecht geht, wenn er abgespannt ist oder vom Schicksal mißhandelt wurde. Diese leichteren, aber chronischen Formen sind nicht selten dankbare Gegenstände beruhigender ärztlicher Maßnahmen.

Reaktionen sensitiver Art sind im übrigen nicht streng an sensitive Charaktere gebunden, wenn sie auch bei ihnen besonders häufig vorzukommen scheinen. Auch andere eindrucksfähige und nicht zu oberflächliche Menschen können bei geeigneter Gelegenheit erkranken.

\section{Querulatorische Reaktionen und Entwicklungen}

Das Erlebnis, das zu querulatorischen Reaktionen führt, ist die tatsächliche oder vermeintliche Kränkung des Rechtsbewußtseins. Zur Erkrankung neigen in besonderem Maße ganz andere als sensitive Menschen, nämlich selbstbewußte, starre, querköpfige, humorlose, reizbare und empfindliche Leute, die doch zugleich den Stachel irgendeiner inneren Unzulänglichkeit oder nicht erreichter Lebensziele dauernd in sich spüren. Je ausgeprägter diese Eigenart, um so harmloser wird die Rechtskränkung sein müssen, um zur Erkrankung zu führen. Leichtere querulatorische Reaktionen sehen wir aber weit verbreitet und bei recht verschiedenartigen Menschen, soweit sie sich nicht, allzu weich und verwundbar, allenthalben einfach zurückziehen. Neben dem Unterliegen im eigentlichen Rechtsverfahren kann auch der 
Rentenkampf, ein Unrecht im Dienst, eine Maßregelung im Gefängnis usw. Anlaß zum Querulieren werden, kurz, jeder äußere Konflikt des machtlosen Einzelnen mit den allmächtigen festen Ordnungen der Gesellschaft.

Beim wahnhaften Querulanten entwickelt sich sehr rasch die unerschütterliche Überzeugung, im Recht zu sein, welche die eigentliche Quelle der wahnhaften Reaktion oder Entwicklung wird. Zugleich ist bei Menschen dieser Art die Fähigkeit, das Recht anderer auch nur zu sehen, und das Verständnis für die Notwendigkeit der Gemeinschaftsforderungen von vornherein meist gering ausgebildet, und es entwickelt sich auf diesem Gebiete bald eine völlige Blindheit. Nach der ersten Rechtskränkung wird Berufung bis zu den obersten Instanzen eingelegt und das Wiederaufnahmeverfahren angestrebt. Eine Änderung der Rechtslage kommt dadurch nicht zustande, und meist ist das letzte Rechtsmittel noch nicht erschöpft, ehe sich der Qu neuen Verwicklungen sieht. Wenn er immer Unrecht bekommt, so muß dies an den Richtern, am Staatsanwalt, am eigenen Anwalt liegen, die mißgünstig, feindselig, bestochen sind und aus diesem oder jenem Anlaß alles tun, den Kranken zu schädigen. Der Querulant meint dies nicht nur, sondern spricht es auch aus und macht sich dadurch straffällig. Er beschuldigt Zeugen, die nicht in seinem Sinne aussagen, des Meineides oder beleidigt sie in anderer Weise. Schließlich ist jeder, der nicht unbedingt Partei für die Sache des Kranken ergreift, sein bitterer Feind. Der Querulant sieht sich einem Komplott gegenüber, in dem vom Erstrichter bis zum Minister, vom nächsten Familienangehörigen bis zum harmlosesten Zeugen alles beteiligt ist, einem Komplott, das ihn vernichten will. Die eigene kleine Sache ist mittlerweile zur Sache des Rechts überhaupt geworden, das nun gern in der Öffentlichkeit, in Flugschriften und Reden mit Nachdruck vertreten wird. Die ganze Justiz ist zum Sumpf, die ganze Menschheit zum elenden Gewürm, der Querulant zum allein Gerechten geworden. Zu dieser Entwicklung tragen die starren Gesetzesbestimmungen ebenso bei wie die unelastische Behandlung dieser Bestimmungen. Es kann zudem nicht ausbleiben, daß der Querulant manches tatsächliche Unrecht erfährt. Er wird kurz, unfreundlich behandelt, seine Eingaben werden nicht oder nicht rechtzeitig beschieden, es kommen Irrtümer in den Akten vor, und da meist ein ganzer Rattenkönig von Einzelprozessen entsteht, in dem niemand sich mehr ganz auskennt, da man den Querulanten zunehmend wenig ernst nimmt, da er selbst Erinnerungstäuschungen unterliegt und bei all seinem Gesetzesstudium doch vieles falsch versteht und anwendet, ist die Entwicklung nur allzu verständlich, wenn man nur die starre Ausgangspersönlichkeit voraussetzt. Dazu kommt aber auch, daß der Querulant vielfach Gleichgesinnte findet. Die Unzufriedenheit mit der Justiz ist ja recht verbreitet. Außerhalb seiner Reaktion bleibt der Querulant aber vor allem vielfach unauffällig, geordnet, fleißig, tüchtig, und da er seine Sache mit Nachdruck und Geschick vertritt, überzeugt er nicht ganz urteilsfähige Menschen nur allzu leicht. Ja, oft werden Familienangehörige und Freunde vom Wahn der Querulanten ,induziert".

Wahnhafte Gedanken lassen sich beim Querulanten fast nie sauber von einfachen Irrtümern und korrigierbaren Mißdeutungen trennen. Das Entscheidende der Entwicklung ist schon die Ausgangshaltung, die unkorrigierbare Überzeugung vom eigenen Recht, aus der alles andere verständlich hervorgeht. 
Meist entwickeln die Querulanten ihren eigenen Stil. Sie erwerben neben mancherlei Gesetzeskenntnis auch eine gewandtere Schrift, neigen zu besonderen Anordnungen der Schriftstücke, zu Unterstreichungen und andersartigen Hervorhebungen, zu vermeintlich klarer Gliederung nach einzelnen Punkten usw. Vielfach kann man schon dem einzelnen Schriftsatz rein formal ansehen, daß er von einem Querulanten stammt.

Der Querulantenwahn wurde früher als unheilbar angesehen. Tatsächlich finden wir weit mehr vorübergehende querulatorische Reaktionen als unheilbare querulatorische Entwicklungen. Die günstige Gestaltung der sonstigen Lebenslage, die Tatsache, daß der Querulant in irgendeinem, ihm besonders wichtig scheinenden Punkte Recht bekommt, gelegentlich auch die Entmündigung und eine vorübergehende Anstaltsinternierung bringen Beruhigung und damit teilweise Korrektur, jedenfalls das Aufhören des Querulierens mit sich.

Bei weitem nicht jedes Querulieren ist wahnhaft, und in manchen Fällen handelt es sich bei querulatorischen Wahnbildungen nicht um den Ausdruck abnormer Reaktionen, sondern um das Symptom eines andersartigen Krankheitsvorganges, gelegentlich eines schizophrenen Schubes, nicht selten auch eines zirkulären Mischzustandes. Auch auf dem Boden der traumatischen Hirnveränderung kann es zur querulatorischen Wahnbildung kommen. Hier allenthalben sprechen wir von symptomatischem Querulantenwahn.

\section{Die Paranoia Kraepelins}

Unter Paranoia verstand Kraepelin , die aus inneren Ursachen erfolgende, schleichende Entwicklung eines dauernden unerschütterlichen Wahnsystems ..., das mit vollkommener Erhaltung der Klarheit und Ordnung im Denken, Wollen und Handeln einhergeht ${ }^{66}$. „Hierbei pflegt sich eine tiefgreifende Umwandlung der gesamten Lebensanschauungen, jene ,Verrückung des Standpunktes gegenüber der Umwelt zu vullziehen "6, die als Verrücktheit zu bezeichnen ist. Bei den so zusammengefaßten Krankheitsbildern fehlen Sinnestäuschungen und Willensstörungen, unverständliche Veränderungen der Affektivität und des Stimmungshintergrundes usw., kurz, alle Erscheinungen, die kennzeichnend etwa für schizophrene Prozesse oder zirkuläre Phasen wären. Die Wahnbildung ist eine rein kombinatorische, sie ist geistig verarbeitet, in sich geschlossen und bei der Einnahme des Ausgangspunktes des Paranoischen, die meist eine unerschütterliche, unangemessene Selbstüberzeugung bestimmter Art ist, verständlich. Gesetzmäßig sind Erinnerungsfälschungen. Gegenüber dem Querulantenwahn und dem sensitiven Beziehungswahn würde die Paranoia dadurch ausgezeichnet sein, daß ein entscheidendes Ausgangserlebnis fehlen und grundsätzliche Unheilbarkeit bestehen soll. Die Wahnbildung soll ja aus ,inneren Ursachen“6 zustande kommen.

Kraepelin beschreibt im einzelnen den Verfolgungswahn, den Eifersuchtswahn, den Erfinderwahn, den Abstammungswahn, den Prophetenwahn, den Liebeswahn. Unzweifelhaft gibt es Krankheitsbilder, die diesem von Kraepelin gekennzeichneten Bild entsprechen. Sie sind aber außerordentlich selten. Kolle hat in allen deutschen Anstalten kaum ein halbes Hundert Fälle gefunden und zudem erbliche Beziehungen zum schizophrenen Formen- 
kreise wahrscheinlich gemacht. Tatsächlich scheint die fortschreitende Wahnbildung paranoischer Prägung nicht ganz selten auf dem Boden eines leichten schizophrenen Defekts zustande zu kommen, welcher die Persönlichkeit zu einer paranoischen erst gemacht hat. In anderen Fällen mag die Ausgangspersönlichkeit von je die Voraussetzungen zur paranoischen Verkrampfung in sich haben, wie der Querulant jene zur querulatorischen Entwicklung. Viele Paranoische zeigen neben pyknischem Körperbau auch noch ausgesprochene Temperamentseigentümlichkeiten im Sinne zykloider Psychopathien, ja, die Wahnbildung kann in engem Zusammenhang mit einer endogenen affektiven Schwankung in Erscheinung treten.

Dazu kommt, daß manche Erkrankungen, die zunächst völlig paranoischen Entwicklungen gleichen, sich doch als paranoische heilbare Reaktionen herausstellen oder als abnorme Entwicklungen unter dem Einfluß unbehebbarer Konflikte, oder endlich als Ausdruck von verwaschenen Phasen des manischdepressiven Irreseins. Der Krankheitsbegriff Kraepelins umschließt also Uneinheitliches. Die Reaktionsform der paranoischen, rein kombinatorischen Wahnbildung und Entwicklung muß man aber kennen und, wo man sie antrifft, den Versuch einer klinischen Einordnung nach jenen Symptomen machen, die neben dem Wahn bestehen oder vor seiner Entwicklung vorhanden waren. Den praktischen Arzt wird die Paranoia im engeren Sinne bei ihrer großen Seltenheit kaum je beschäftigen.

\section{Der Verfolgungswahn der Schwerhörigen}

Schwerhörige gelten ganz allgemein als mißtrauisch, zu Unrecht, wie die Untersuchung einer lückenlosen Reihe von Schwerhörigen uns ergeben hat. Immerhin begegnet uns Mißtrauen bei Schwerhörigen aus verständlichen Gründen häufig und wegen der Verständnisschwierigkeiten in kennzeichnender und vor allem schwer behebbarer Form. Vereinzelt kommt es zu wahnhaften Reaktionen, die kombinatorischen Charakter haben, aber durch Mißdeutungen von Ohrgeräuschen gern illusionär bereichert werden. Außer der Schwerhörigkeit selbst sehen wir dann auch eigenartige Persönlichkeiten und besondere Konfliktslagen, welche das Mißtrauen verstärken.

\section{Gefangenenwahnsinn}

Auch im Gefängnis kann es bei geeigneter Veranlagung als Reaktion auf die besonderen Bedingungen der Haft zu einem kombinatorischen Verfolgungswahn spezifischen Gepräges kommen, der feindselige Einstellungen des Beamtenpersonals, des Anstaltsvorstehers, des Staatsanwaltes usw. zum Inhalt hat. Die Einzelhaft, die hoffnungslose Lage, die Veränderung der gesamten Lebensbedingungen, die Stille und die Dunkelheit, Angst und Reue, Bitterkeit und Heimweh, der unnachsichtige Zwang, die Schlafarmut wirken zusammen, eine gespannte und gequälte, mißtrauische Gemütslage herbeizuführen, aus der zunächst verständliche Mißdeutungen und schließlich Wahnbildungen erwachsen. Oft sind dabei noch einzelne Gehörstäuschungen, vielfach nur illusionärer oder hypnagoger Art, wirksam. Dazu kommt in der Regel eine ausgesprochene schizoide Veranlagung, welche die Differentialdiagnose gegenüber schizophrenen Schüben sehr erschweren oder überhaupt unmöglich machen 
kann. BeiÄnderung der Lage klingen diese wahnhaften Reaktionen, die übrigens mit einer erheblichen Selbstmordgefahr einhergehen, erst allmählich ab.

Bei zu lebenslänglichem Zuchthaus Verurteilten sieht man im Präsenium vereinzelt Erkrankungen an Begnadigungswahn auftreten, die nicht rein reaktiver Natur sein dürften. Vielmehr spielt die beginnende Involution dabei eine entscheidende Rolle.

Psychogene Bewußtseinsveränderungen, hysterische Seelenstörungen

Die eindrucksvollste und zugleich vorwiegend auf physiologischem Wege ablaufende psychogene Bewußtseinsstörung ist die unter dem Einfluß heftiger Gemütsbewegungen eintretende Ohnmacht, der Bewußtseinsverlust, der zugleich mit lebhaften vegetativen Erscheinungen einhergeht: Erbrechen, Schweißausbruch, Pulsveränderungen. Wo die vegetativen Störungen zurücktreten, ist das Bewußtsein meist weniger verändert, und diese letzteren Zustände gehen ohne scharfe Grenze über in das zweckhafte „Sichtotstellen “6, die Abwendung von der Außenwelt unter Einstellung des motorischen Betriebes. Wir haben es dann zu tun mit psychogenen (hysterischen) Stuporzuständen, in denen bei voller Bewegungslosigkeit von der Umgebung keine Notiz genommen wird. Der Bewußtseinszustand kann dabei tief getrübt, aber auch vom Wachbewußtsein nicht sehr weit entfernt sein. Solche hysterischen Stuporzustände sehen wir besonders häufig bei Strafgefangenen, die sich damit der unangenehmen Berührung durch die Wirklichkeit entziehen. Auch in anderen peinlichen Lagen (Furcht vor Auseinandersetzungen aller Art) können hysterische Stuporen auftreten. Von den katatonen lassen sie sich meist ohne große Mühe unterscheiden. Schon die besondere Situation, in der sie einsetzen, weckt den Verdacht der hysterischen Natur. Die Kranken zeigen in der Regel keine Spannungsveränderungen der Muskulatur, keine Haltungsstereotypien quälender Art. Es kommt nicht zu extremer Nahrungsverweigerung, nicht, außer vielleicht bei Schwerkriminellen mit Angst vor dem Schafott, zur Inkontinenz mit Kot. Vor allem aber sieht man mindestens vasomotorische Reaktionen und mimische Veränderungen, wenn man vor den Kranken nachhaltig die Ausgangssituation bespricht. Eine entscheidende Änderung der Gesamtlage läßt die Stuporen rasch dem gewöhnlichen Verhalten Platz machen.

Wo die affektiv bedingte Bewußtseinstrübung mit mehr oder weniger lebhaften motorischen Entäußerungen einhergeht, sprechen wir von hysterischen Anfällen. Selten ahmen besonders Erfahrene tonisch-klonische Krämpfe nach Art der epileptiformen nach. Aber dann fehlen Pupillenstarre und Babinski, meist auch Einnässen und Zungenbiß und die den epileptischen Krämpfen zugehörigen schweren vasomotorischen Krisen. In der Regel ist das Bewegungsspiel viel gröber. Es kommt zu arhythmischen schlagenden und strampelnden Bewegungen, denen man das Gewollte und Zweckhafte ansieht. Häufig ist der, ,arc de cercle ${ }^{66}$, das Sichaufbäumen des Leibes, der nur noch auf Hinterhaupt bzw. Nacken und Füßen ruht. Manchmal sehen wir rhythmische Rumpfbewegungen, die an Koitusbewegungen denken lassen, und gelegentlich auch eine entsprechende Mimik. Hysterische Bewegungsstürme können ganze Szenen darstellen (Sturmangriffe, Handgranatenwerfen usw. oder aber stürmische Abwehr einer sexuellen Annäherung usw.). 
Diese Formen gehen ohne scharfe Grenze in die hysterischen Delirien und Dämmerzustände über. Hysterische Anfälle können Stunden und Tage anhalten, aber nur dann, wenn man sie durch besondere Beachtung unterhält. Meist lassen sie sich durch Nichtbeachtung oder auch unangenehme Eingriffe (Übergießen mit kaltem Wasser) oder selbst einfache Isolierung rasch unterbrechen. Man kann sie aber auch durch geeignete Suggestionen in ihrer Erscheinungsweise abändern. Das Bewußtsein ist nie ganz aufgehoben. Mancher „hysterische Anfall“" entfernt sich nicht von reinem Theater.

Hysterische Delirien und Dämmerzustände sind mit dem zunehmenden allgemeinen Wissen um die Bedeutung hysterischer Störungen immer seltener geworden. In ihnen besteht meist eine traumhafte Bewußtseinsveränderung, in der bestimmte affektbetonte Situationen unter Abwendung von, unter Umständen auch entsprechender Verkennung der Außenwelt wieder erlebt werden. Besonders Unglücksfälle, erotische Szenen beglückender oder peinlicher Natur kommen in Frage. Meist ist das Verhalten dabei theatralisch, pathetisch, unecht. Auch die Trugwahrnehmungen haben einen theatralischen Charakter. Wichtig ist, daß ganz ähnliche Dämmerzustände und Delirien auch auf dem Boden schizophrener Defekte, ja selbst organischer Hirnveränderungen auftreten können. Die Schizophrenie wird sich aber meist in irgendwelchen uneinfühlbaren Erscheinungen, in Sperrungen und unter Umständen einer kennzeichnenden Denkstörung verraten. Auch das Demonstrative, die Einbeziehung der Umgebung in das Delir, die Beeinflußbarkeit durch Suggestion bzw. Nichtbeachtung wird bei den schizophrenen katathymen Delirien dieser Art nicht so deutlich sein.

Gern nehmen Dämmerzustände und Delirien hysterischer Art eine puerilistische Färbung an. Die Kranken ahmen kindliches Gebaren nach, sprechen agrammatisch, Kleinkindleinsprache, schmiegen sich an, lassen sich füttern, machen kindliche Faxen und Späße usw. Auch diese Zustände pflegen bei Behebung der Konfliktslage, bei Erreichung des Zweckes, unter Umständen auch bei autoritativem Vorgehen rasch zu verschwinden. Eine echte Amnestie besteht danach nicht.

Keine nennenswerte Bewußtseinstrübung, oft gar keine, sehen wir in den von $G$ anser beschriebenen Zuständen von Scheinblödsinn (Pseudodemenz), wie sie besonders bei Untersuchungshäftlingen, jedenfalls bei Angeklagten, und in zunehmender Häufigkeit auch bei Rentenneurotikern vorkommen. Die Betroffenen verhalten sich so, wie sie sich einen Blödsinnigen vorstellen. Sie wissen vielfach nicht einmal über ihre Generalien Bescheid, scheinen grob desorientiert und beantworten auch die allereinfachsten Fragen nicht oder falsch. Dabei geht aus ihren Antworten doch hervor, daß sie die Fragen erfaßt haben und meist auch die richtige Lösung kennen müssen. Typisch ist bei einfachen Rechenaufgaben, daß immer eins zuviel oder zuwenig herauskommt, daß die Farbe von bekannten Dingen falsch genannt wird usw. Überall wird das Zweckhafte, das gewollt Blöde unverkennbar. Ähnliches „Vorbeireden" kommt auch bei Schizophrenen und anderen Seelenstörungen in entsprechenden Situationen oder aber als Form läppisch-negativistischen Verhaltens vor. Meist werden dann kennzeichnende Symptome die wahre Natur des Gesamtbildes erkennen lassen. Die Ganser-Zustände verschwinden vielfach schlagartig, wo sie nicht mehr nötig erscheinen, bei 
Untersuchungsgefangenen mit dem Aufhören der Haft, bei Rentenneurotikern mit dem Verlassen der Klinik oder des ärztlichen Sprechzimmers usw., bei Strafgefangenen mit der Entweichung.

Das gleiche gilt endlich für die sog. „wahnhaften Einbildungen", die meist in der Haft auftreten. Diese Gefangenen entrücken sich der quälenden Wirklichkeit durch steigerungsfähige, nach Art von Tagträumen rassch wechselnde, meist abenteuerliche Phantasiespielereien im Sinne üppiger Größen- oder wilder Verfolgungsideen, unter Umständen bei theatralischem Gebaren in diesem Sinne. Diese abnormen Zustände, die sich, solange man sie ernst nahm und solange sie zur Unterbringung in psychiatrischen Anstalten führten, immer mehr häuften, sind sehr viel seltener geworden, seitdem sie nicht mehr zu Begünstigungen führen.

Das Wesen all dieser Zustände ist also einmal die Entstehung im unmittelbaren Zusammenhang mit eindrucksvollen Erlebnissen - man nennt sie daher katathym - und das Zweckhafte, das aus ihrer Entstehungsgeschichte nicht fortgedacht werden kann. Die Einstellung auf Krankheitsgewinn, sei es auch nur die Verhüllung der nüchternen, kalten und feindlichen Wirklichkeit, stempelt sie zu hysterischen Erscheinungen. Meist geht es zudem auf mehr hinaus, als auf die bloße Verschleierung der Wirklichkeit, vielmehr werden greifbare Werte angestrebt, Haftentlassung, Rente, andersartige Behandlung, Mitleid der Umgebung, Aufsehen um jeden Preis usw. Allerdings gibt es, besonders bei Katastrophen, auch ähnliche Bewußtseinsveränderungen, Delirien und Dämmerzustände, die rein symptomatologisch den hysterischen gleichen, tatsächlich ja auch die grauenerregende Situation verhüllen, aber meist in wenigen Stunden abklingen. Wenn sie länger anhalten, wird der Verdacht dringend, daß ein mehr oder minder bewußtes Zweckwollen hinzugekommen ist und die krankhaften Erscheinungen unterhält. Wir haben dies besonders im Kriege gesehen, aus Motivlagen heraus, die ohne weiteres verständlich sind.

\section{Psychogene körperliche Symptome (hysterische Störungen im engeren Sinne)}

Wo es zu hysterischen Seelenstörungen kommt, da fehlen auch entsprechende ,,seelisch entstandene und seelisch festgehaltene körperliche Funktionsstörungen" nicht, für die von einzelnen Forschern der Namen ,hyste-

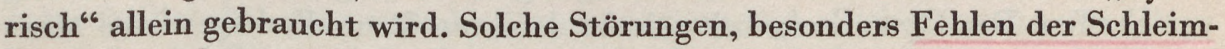
hautreflexe, konzentrische Einengung des Gesichtsfeldes, Störungen der Hautempfindung, Analgesie und Hypalgesie, kann man, wenn man danach fahndet, fast bei jedem psychopathischen Menschen, wenn es ihm darauf ankommt, krank zu scheinen, hervorzaubern. Man pflegt daher meist gar nicht mehr danach zu suchen. Hier wirken Untersuchungsvorgehen und autosuggestive Erwartung zusammen, um das Symptom zu erzeugen. Andere hysterische Störungen entstehen reflexmäßig und werden dann seelisch festgehalten. Das Kind etwa, das auf den Arm fällt und ihn wegen Schmerzen zunächst nicht bewegt, ,kann ${ }^{66}$ ihn, wenn die Schmerzen längst verschwunden sind, plötzlich nicht mehr bewegen. Angst vor dem Schmerz, der Wunsch, weiter im Mittelpunkt der Aufmerksamkeit zu stehen, die Vorteile eines nicht gebrauchsfähigen Armes (Klassenarbeiten) und ähnliche Tendenzen wirken zusammen, 
um solche Erscheinungen hervorzurufen und zu unterhalten, die, bei Kindern, meist mit einem autoritären Wort, mit der faradischen Rolle oder irgendwie anders suggestiv sofort zu beseitigen sind. In ähnlicher Weise werden im Schreck entstandene Zittererscheinungen oder falsche Funktionen (Hinken im Anschluß an Kontusionen oder längst geheilte Beinbrüche) festgehalten. Aber auch Störungen der Sinnesfunktionen (Taubheit nach Explosionen, Blindheit nach Konjunktivitis, nach starker Bestrahlung usw.) könnęn hysterisch konserviert werden, wobei die Sinneseindrücke nicht bewußt wahrgenommen, wohl aber verwertet werden, wie man durch , Simulations ${ }^{66}$ proben feststellen kann. Modern sind einseitige oder doppelseitige Geruchs- und Geschmacksstörungen im Anschluß an tatsächliche oder angebliche Schädeltraumen, offenbar weil es hier geeignete Simulationsproben noch nicht gibt. In ähnlicher Weise werden zufällig entstandene Funktionsstörungen aller Art (Blinzeln nach Bindehautkatarrh, Gesichtszucken, Tics, Schiefhaltungen des Körpers, Blasenstörungen, Darmentleerungsstörungen, Erbrechen, Aufstoßen, Singultus usw.) verewigt.

In vielen anderen Fällen haben die hysterischen Funktionsstörungen „Ausdruckscharakter" ${ }^{6}$. Der innerlich hilflose Mensch kann nicht mehr stehen und gehen (Astasie, Abasie), der in seinem Gleichgewicht Erschütterte leidet an Schwindelerscheinungen u. a.m., kurz, die Demonstrationen drücken symbolisch die innere Lage aus.

Alle diese Störungen können auch bewußt vorgetäuscht, simuliert werden, und es ist kein Zweifel, daß dies häufiger der Fall ist, als im allgemeinen angenommen wird. Die ärztliche Haltung geht nicht gern von moralischen Beurteilungen aus. Vielfach ist es aber so, daß zwar der Wille an der Konservierung der Symptome nicht unbeteiligt, aber doch nicht mehr für ihr Fortbestehen unmittelbar und allein verantwortlich ist. Wir können uns dies klarmachen, wenn wir etwa in der Kälte auf unser Zähneklappern achten. Jeder weiß, daß wir dies meist überwinden, aber auch verstärken können (willkürliche Reflexverstärkung). Der Hysterische tut mit seinen Funktionsstörungen meist das letztere. Man kann sich zu häufiger Urinentleerung erziehen und damit eine erhöhte Empfindlichkeit gegen die beginnende Füllung der Blase hervorrufen. Gewöhnt man sich absichtlich irgendeine vertrackte Handbewegung, eine Grimasse an, so bewirkt die Übung, daß die falschen Mechanismen leicht auch bei ungeeigneten Gelegenheiten sich Geltung verschaffen. Der Hysterische mit seinem defekten Gesundheitsgewissen überläßt sich gerade diesen Falscheinstellungen, ja er unterdrückt die bei ihm wie beim Gesunden vorhandenen Ansätze zur normalen Funktion, wo er eine ausgesprochene Tendenz zum Krankheitsgewinn hat. Was diese Tendenz bewirkt, kann unter Umständen auch die ängstliche Erwartung fertigbringen.

Am ehesten sehen hysterische Funktionsstörungen organischen ähnlich, wo auch ein defektes ,vegetatives Gewissen“ besteht und Krankheitswunsch, Befürchtung und Erwartung den für gewöhnlich dem bewußten Willen verschlossenen Zugang zu den vegetativen Apparaten eröffnet. Alle unsere Affekte und Gemütsbewegungen gehen mit vasomotorischen Reaktionen, Veränderung der Schweißsekretion, der Darmmotilität usw. einher. Beim vegetativ grob Stigmatisierten können solche vegetativen Reflexvorgänge groteske Ausmaße annehmen; es können Ödeme an den verschiedensten 
Körperstellen, grobe vasomotorische Störungen (Blässe, Zyanose) im angeblich gelähmten Bereich, ja selbst Hautblutungen zustande kommen.

Alle diese Erscheinungen können zum Verschwinden gebracht werden, wie sie entstanden sind, d. h. auf dem Wege über das Seelenleben, bei primitiven Menschen meist schon durch einfache, aber eindrucksvolle suggestive Maßnahmen, bei Differenzierteren durch Änderung der Gesamteinstellung zu den ursächlichen Schwierigkeiten. Ohnmächtig ist die Behandlung immer dann, wenn der Krankheitsgewinn gegenüber den Gefahren der Gesundheit zu groß ist (Kriegshysterien, die nur abheilten, wenn Felddienstfähigkeit ausgeschlossen wurde - oder am Ende des Krieges).

\section{Traumatische Neurose (Hysterie). Rentenneurose}

Unter diesen Bezeichnungen werden abnorme seelische Reaktionen zusammengefaßt, die sich an entschädigungspflichtige Unfälle und Kriegsschäden anschließen. Es handelt sich keineswegs um einheitliche Bilder; vielmehr sind die Neurosen in ihrer Motivlage so verschieden wie die Menschen, die von den Schäden betroffen werden. In der Regel freilich sind es unzulängliche, willensschwache, weiche Persönlichkeiten, die, seit jeher von nicht ganz zureichender Widerstandsfähigkeit, schwerere oder harmlose Unfälle zum Ausgangspunkt mannigfacher Beschwerden und Funktionsbehinderungen machen, die ihnen irgendwelchen Krankheitsgewinn verschaffen. Einzelne ängstliche, von je hypochondrische Menschen freilich finden aus ihren hypochondrischen Befürchtungen, die sich an die anfänglichen, objektiv begründeten Beschwerden anschließen, nicht mehr heraus, bleiben also aus ihrer Ängstlichkeit und Hypochondrie heraus krank, vielfach unter Mitwirkung unzweckmäßiger ärztlicher Maßnahmen und Worte und einer gleichfalls ängstlichen Umgebung. Reine Fälle dieser Art sind freilich selten. Hypochondrische Befürchtungen und Beschwerden gehen aber auch in viele grundsätzlich anders gelagerte Neurosen mit ein.

Wir finden einmal querulatorische Menschen, die aus dem Bewußtsein, einen Unfall erlitten zu haben, zunächst einmal das Recht zur Entschädigung ableiten und nun ihrer Art nach querulatorisch reagieren, oft genug auch ohne daß sie noch nennenswerte Beschwerden klagen. Viel häufiger ist es die Sicherung durch die Rente, welche im Mittelpunkt der Krankheitstendenzen steht, freilich bei ganz verschiedener Ausgangslage. Bisher spielte vor allem die allgemeine Not und die Schwierigkeit, Arbeit zu finden, eine große Rolle. Früher waren es vor allem die anlagegemäße oder erworbene (Alkohol, Arteriosklerose) Unzulänglichkeit und die dadurch herbeigeführte Konkurrenzunfähigkeit, welche in der Rente eine wirtschaftliche Sicherung erstreben ließen. Bei anderen muß die vermeintliche Unfallsschädigung als Deckmantel für sonstiges Versagen (Impotenz, Unfähigkeit, sich in einen Arbeitskreis reibungslos einzupassen, andere zum Versagen führende, vom Unfall unabhängige Konfliktslagen) herhalten. Die Rente wird dann nicht so sehr als solche, vielmehr als von dem schuldhaften Versagen freimachend erstrebt. Im Kriege war es natürlich vor allem die Angst vor der Front, im Frieden ist es manchmal die Angst vor der Arbeit unter Tage oder in einem anderen gefährlichen Betrieb, die bei der Unterhaltung der neurotischen Erscheinungen mitwirkt. 
Dazu kommen die Wirkungen der Gesetzesbestimmungen, die immer wiederholten Untersuchungen, kommen die Beispiele anderer Unfallsgeschädigter, die Einflüsse von Rechtsberatern und Organisationen, die eine von Fall zu Fall verschiedene Rolle spielen.

Endlich darf nicht vergessen werden, daß jede erzwungene längere Unterbrechung der Arbeit das Wiederanfangen erschwert, daß fortdauernde, wenn auch leichte Beschwerden den Klagen und Krankheitsdemonstrationen einen geeigneten Nährboden abgeben, und daß meist die eintönige und ermüdende unpersönliche Fabrikarbeit und andere mechanische Tätigkeiten, die unter dem Druck der allgemeinen Tempobeschleunigung vollbracht werden müssen, von je als Last, nicht aber unter dem Zeichen des Wertschaffens erlebt werden.

Die Bilder, die wir zu sehen bekommen, haben bei dieser Verschiedenheit der Entstehungsgeschichte doch meist sehr viel Gemeinsames, wohl unter dem Einfluß der gleichartigen äußeren Bedingungen, denen alle diese Geschädigten im Verlaufe des Rentenkampfes unterliegen. Neurotisch-depressive, oft gereizte, aggressive Stimmung, hypochondrisches Wesen, Wehleidigkeit, große Empfindlichkeit, Willensschwäche, Ermüdbarkeit, Schlafstörungen, Mißempfindungen aller Art und hysterische Symptomdemonstrationen, die von der Art der ursprünglichen Schädigung unabhängig sind, kehren immer wieder. Sehr häufig sind auch seelische Störungen, Auffassungs- und Denkerschwerung, echte oder unechte paranoide Einstellungen gegen Ärzte und Versicherungsträger, und bei Kopfverletzungen vor allem pseudodemente Verhaltensweisen, hochgradige Gedächtnis- und Merkschwäche. Meist kann man den ,Rentenmann ${ }^{66}$ schon an seinem wehleidigen, mißtrauischen Ausdruck und seinen demonstrativen müden Bewegungen auf den ersten Blick erkennen.

Für die Behandlung dieser Neurosen ist von entscheidender Bedeutung geworden die grundsätzliche Entscheidung des Reichsversicherungsamtes vom 24. September 1926:

„Hat die Erwerbsunfähigkeit eines Versicherten ihren Grund lediglich in seiner Vorstellung, krank zu sein oder in mehr oder minder bewußten Wünschen, so ist ein vorangegangener Unfall auch dann nicht eine wesentliche Ursache der Erwerbsunfähigkeit, wenn der Versicherte sich aus Anlaß des Unfalls in den Gedanken, krank zu sein, hineingelebt hat, oder wenn die sein Vorstellungsleben beherrschenden Wünsche auf eine Unfallsentschädigung abzielen oder die schädigenden Vorstellungen durch ungünstige Einflüsse des Entschädigungsverfahrens verstärkt worden sind.“"

Damit ist in vielen Fällen die Möglichkeit gegeben, die Rente zu entziehen, eine Tatsache, die vielfach eine rasche Wiederkehr der Arbeitsfähigkeit auch bei sehr ausgesprochenen traumatischen Neurosen mit sich bringt.

Wichtiger ist freilich, der Entstehung der traumatischen Neurose vorzubeugen, die Verunfallten von vornherein ermutigend zu behandeln und sie auf die rasche Wiederkehr der Arbeitsfähigkeit einzustellen. Unbedachte ärztliche Meinungsäußerungen können groben Schaden stiften (iatrogene Schäden). Bei wertvolleren Menschen, die aus andersartigen Konfliktslagen heraus ,unfalls"neurotisch werden, hilft nicht selten die Bereinigung der ursächlichen Konfliktslage, auch die Unfallsneurose zu heilen. Debile und besonders willensschwache, unzulängliche Menschen können aber oft genug durch keine gesetzliche Bestimmung und keine ärztliche Maßnahme zur „Genesung ${ }^{66}$ gebracht werden. 


\section{Induziertes Irresein}

Manche besonnene und aktive Geisteskranke, vor allem Querulanten, auch andere Paranoische, gelegentlich selbst Paraphrene und paranoide Schizophrene üben einen so nachhaltigen Einfluß auf ihre nächste Umgebung aus, daß Ehefrau, Kinder, Geschwister, aber auch andere, meist einfache, debile oder hysterische Menschen von dem Kranken ,induziert" werden. Die Umgebung übernimmt also die überwertige Idee oder die Wahninhalte, ja unter Umständen werden auch die Sinnestäuschungen miterlebt. Paranoische Propheten können eine ganze Gemeinde urteilsschwacher Menschen um sich sammeln, Familienväter oder Mütter alle ihre Angehörigen so beeinflussen, daß sie in der gleichen Weise krank erscheinen. Zumal bei Blutsverwandten muß man in solchen Fällen oft genug geeignete Teilanlagen annehmen, die den induzierten Krankheitsbildern die Echtheit verleihen. In solchen Fällen kann unter Umständen zunächst nicht entschieden werden, welches Familienmitglied das induzierende ist, welche anderen induziert sind. Erst die Trennung bringt, meist rasch, Klarheit, da die induzierten Seelenstörungen durch ärztliche Einflußnahme in der Regel eine rasche Heilung erfahren.

\section{Geschlechtliche Verirrungen (Perversität)}

Abnorme geschlechtliche Regungen sind im gesamten Bereiche der Seelenstörungen verbreitet. Bei den organischen und endogenen Seelenstörungen gehen sie meist in der Gesamtsymptomatologie unter, wenn sie auch gelegentlich, wie die sexuelle Enthemmung in der Manie, in der beginnenden Paralyse oder im Greisenblödsinn, die Kranken zuerst auffällig machen und zur Internierung Anlaß geben. Von großer Bedeutung sind die Perversitäten aber vielfach für die psychopathischen Persönlichkeiten, bei denen sie zugleich sehr häufig sind.

\section{Onanie (Masturbation)}

Onanie begegnet uns nicht selten schon bei kleinen Kindern als vorübergehende Unart. Bei manchen psychopathischen Persönlichkeiten bleibt sie von da ab dauernd bestehen. Länger dauerndes Onanieren ist bei männlichen Jugendlichen in der Entwicklungszeit und kurz nachher fast die Regel. Nur wo die Onanie über die Entwicklungszeit hinaus, ja bis in die Ehe hinein andauert, ist sie als psychopathisches Symptom anzusehen. Sie nimmt dann in der Regel auch einen erheblichen Umfang an. Bedenklich wird sie nur dadurch, daß sie keinerlei äußerem Widerstand begegnet und die Phantasie auf Abwege führt, die der Erreichung des natürlichen Sexualziels hinderlich sind. Für willensschwache, hypochondrische Psychopathen bedeutet sie einen fortgesetzten Kampf mit immer neuen Niederlagen, die der Entwicklung eines angemessenen, klaren Selbstbewußtseins hinderlich sind. Oft genug führt sie zu flüchtigen oder lang andauernden paranoischen Reaktionen. In masturbatorischen Phantasien tauchen vielfach zuerst auch die perversen Regungen auf, die später zu entsprechender Betätigung hindrängen.

\section{Exhibitionismus}

Das Zurschaustellen der Genitalien ist in psychotischen Zuständen aller Art nicht selten. In abgeschwächter Form gehörte es beim Manne in früheren Jahrhunderten zur modischen Regel, bei der Frau wechselt noch heute mit 
der Mode die Betonung des Busens. In der normalen Sexualbetätigung ist die Entblößung immerhin eine entscheidende Zwischenstufe. Abnorm wird das Zurschaustellen der Genitalien dort, wo dadurch bzw. bei gleichzeitiger Onanie die sexuelle Befriedigung erstrebt und erreicht wird. Besonders willensschwache, vielfach leicht debile Männer, die nicht den Mut zur natürlichen Annäherung an das andere Geschlecht finden, kommen, meist auf dem Umwege über die Masturbation, zum Exhibieren vor Frauen und Kindern. Bei der häufig zugleich bestehenden starken sexuellen Erregbarkeit geschieht dies bei den einzelnen Exhibitionisten zahllose Male, bis es meist zur polizeilichen. Feststellung kommt. Bei vielen Perversen dieser Art führt das bloße Vorzeigen zur Befriedigung, andere nehmen, wie erwähnt, dabei masturbatorische Handlungen vor.

\section{Fetischismus}

Neben dem natürlichen Sexualziel führen Körperpartien außerhalb der Genitalsphäre und unter Umständen auch Gegenstände, die mit dem Liebesobjekt zusammenhängen, zu geschlechtlich betonten Regungen schon bei der Sexualbetätigung des Normalen. Solche Nebenziele wirken beim Fetischisten an der Stelle des natürlichen Sexualziels. Meist handelt es sich bei den „Fetischen $^{66}$ um Dinge, an die sich die erste sexuelle Entspannung im Leben überhaupt anknüpfte. Häufig spielt das Haar eine solche Rolle (beim Zopfabschneider daneben wohl sadistische Regungen); bekannt sind als Fetische Schuhe und Kleider, besonders Hemden, bestimmte Stoffe, unter Umständen aber auch körperliche Mißbildungen (Kyphose). Manche Fetischisten legen sich ganze Sammlungen von gebrauchten Schnupftüchern, Zöpfen, Schuhen usw. an.

\section{Masochismus, Sadismus}

Der Weg zur sexuellen Befriedigung führt beim Manne über das Bewältigen, bei der Frau über das Bewältigtwerden. Schon im normalen Sexualleben kann das feste Zupacken, das Saugen und Beißen eine lusterhöhende Bedeutung haben. Masochistische Regungen bescheidener Art sind daher bei der normalen Frau ebenso verbreitet wie beim Manne solche, die im weiteren Sinne in das Gebiet der Schmerzzufügung gehören. Von Masochismus und Sadismus sprechen wir erst dort, wo das Schmerzerdulden und das Schmerzzufügen zur Voraussetzung der sexuellen Befriedigung wird. An Stelle des Schmerzes können passive und aktive Demütigungen und Schmutzereien aller Art treten. Besonders Kot und Urin spielen eine wesentliche Rolle. Bei den schlimmsten Formen kommt es zum Stechen und Schneiden, zum Brennen und Peitschen. Auch für Notzuchtsverbrechen sind oft sadistische Regungen entscheidend; vor allem aber ist der Lustmord ein Ausfluß sadistischerEntartung. Gefährlich sind sadistische Pädagogen (Prügel, Quälereien).

In das Gebiet des Sadismus und des Masochismus zugleich gehört die sexuelle Leichenschändung (Nekrophilie).

\section{Sodomie}

Geschlechtliche Betätigung an Tieren finden wir ganz vorwiegend bei Schwachsinnigen aller Art. Im Verein mit sadistischen Regungen kann es dabei auch zu schlimmsten Tierquälereien kommen. 


\section{Homosexualität}

In der Entwicklung der normalen Sexualität finden wir um die Pubertätszeit herum häufig schwärmerische, gleichgeschlechtliche Freundschaften, die einen unverkennbar sexuellen Anstrich haben. Gleichgeschlechtliche Regungen sind aber in Andeutungen und hinter mancherlei Verschleierungen auch bei vielen Erwachsenen (Stammtischfreundschaften) vorhanden. Die Entwicklung der Sexualität geht wohl von einer bisexuellen Anlage aus. Wenn wir aus Erfahrungen im Tierreich mit Vorsicht Schlüsse ziehen, ließe sich die Hypothese vertreten, daß es eine Frage der Quantität der beiden sexuellen Anlagen ist, nach welcher Richtung hin die körperliche und schließlich die seelische sexuelle Ausreifung erfolgt. Es gibt unzweifelhaft anlagegemäße, gleichgeschlechtlich eingestellte Menschen. Dem entspricht die Tatsache, daß in manchen Familien Homosexualität gehäuft vorkommt, und zwar unzweifelhaft auf erblicher Grundlage. Bei dieser Art Homosexueller (Invertierter) finden wir vielfach schon im Körperbau Merkmale, die dem anderen Geschlecht angehören (beim Manne etwa Gynäkomastie, breite Hüften, hohe Stimme, Anomalien der Behaarung), dazu ein weichliches, vielfach schöngeistiges Wesen mit mancherlei weiblichen Neigungen. Es hängt von der übrigen Persönlichkeit ab, ob es wirklich zu gleichgeschlechtlichen Handlungen und zu welchen Handlungen es kommt. Strafbar waren früher nur beischlafsähnliche Handlungen. Nach den jetzt geltenden Bestimmungen sind aber überhaupt alle gleichgeschlechtlichen Betätigungen unter Männern mit Strafe bedroht. Da weiter die Verführung Jugendlicher als die ernsteste Gefahr, die von den Homosexuellen ausgeht, angesehen werden muß, stehen hierauf besonders strenge Strafen, und als Jugendlicher gilt ein junger Mensch nach den neuen Erlassen (§ 175a) bis zum 21. Lebensjahr! Dieser besondere Schutz erscheint deshalb gerechtfertigt, weil gerade die Jugendlichen in dieser Periode ihres Lebens in der Regel nicht ganz zielklar ausreguliert sind. Sie unterliegen daher der Verführung besonders leicht, und sie bleiben dann unter Umständen in der Homosexualität stecken, da überhaupt die frühesten sexuellen Erfahrungen bei sehr vielen, besonders psychopathischen Menschen die spätere Entwicklung der Sexualität festlegen.

In homosexuellen Kreisen spielt die gegenseitige, durch die Erotik bestimmte Anhimmelung und schwärmerische Verehrung eine große Rolle. Vielfach findet man zugleich Neigung zum Mißbrauch von Rauschmitteln. Für manchen homosexuellen Verführer wird die Erpressung zum Schicksal, das sein Leben zerstört. Die Homosexualität bringt eine besondere Form der Prostitution (Strichjungen) mit sich, die sich aus den unerfreulichsten menschlichen Elementen rekrutiert.

Die Bekämpfung der Homosexualität ist zunächst eine vorbeugende; besonders muß die Verführung Jugendlicher mit allen Mitteln bekämpft werden. Nächst dem ist den onanistischen Neigungen zielunklarer Psychopathen zu steuern, weil gerade in den masturbatorischen Phantasien alle Arten von abnormen Regungen sich einnisten können. Manchen Homosexuellen, die unter ihren Neigungen schwer leiden, kann man durch eingehende seelische Maßnahmen erhebliche Erleichterung schaffen. Menschen mit ausgesprochenen homosexuellen Tendenzen, die aber doch noch potent gegenüber dem anderen Geschlecht sind, sollten nicht heiraten. 
Geschlechtliche Perversionen erfüllen, auch wenn sie auf angeborener Veranlagung beruhen, nicht die Voraussetzungen des $\S 51,1$ oder 2 des Strafgesetzbuches; dieser kann nur dann zur Anwendung kommen, wenn das Sexualvergehen von einem Geisteskranken verübt ist.

Wird jemand wegen bestimmter Sexualverbrechen verurteilt, so kann, wenn er älter als 21 Jahre ist, unter bestimmten Voraussetzungen neben der Strafe auch auf Entmannung erkannt werden. Eine Kastration der Homosexuellen war ursprünglich bei einer Verurteilung nach $\S 175$ nicht vorgesehen. Neuerdings gibt aber der $\S 14$ des Gesetzes zur Verhütung erbkranken Nachwuchses die Möglichkeit, einen Homosexuellen oder auch andere Perverse mit seiner Einwilligung zu entmannen, wenn diese Operation nach einem amtsärztlichen Gutachten erforderlich ist, um ihn von seinem entarteten Geschlechtstrieb zu befreien. Diese Maßnahme setzt eine Bestrafung nicht voraus. Sonst darf eine Entfernung der Keimdrüsen nur erfolgen, wenn sie zur Abwendung einer ernsten Gefahr für Leben und Gesundheit mit Einwilligung des Betroffenen vollzogen wird. 


\section{Behandlung}

Das ideale Ziel des Arztes ist nicht, Krankheiten zu heilen, sondern ihrer Entstehung vorzubeugen. Aus solchen Bemühungen der psychiatrischen Erbforschung sind die Grundlagen des Gesetzes zur Verhütung erbkranken Nachwuchses entstanden, dessen $\S 1$ wie folgt lautet:

„Wer erbkrank ist, kann durch chirurgischen Eingriff unfruchtbar gemacht (sterilisiert) werden, wenn nach den Erfahrungen der ärztlichen Wissenschaft mit großer Wahrscheinlichkeit zu erwarten ist, daß seine Nachkommen an schweren körperlichen oder geistigen Erbschäden leiden werden.

Erbkrank im Sinne dieses Gesetzes ist, wer an einer der folgenden Krankheiten leidet:

1. Angeborenem Schwachsinn,

2. Schizophrenie,

3. zirkulärem (manisch-depressivem) Irresein,

4. erblicher Fallsucht,

5. erblichem Veitstanz,

6. erblicher Blindheit,

7. erblicher Taubheit,

8. schwerer erblicher Mißbildung.

Ferner kann unfruchtbar gemacht werden, wer an schwerem Alkoholismus leidet.“

Eine straffe Durchführung des Gesetzes wird unzweifelhaft, wenn auch erst nach langen Jahrzehnten spürbar, die Erkrankungshäufigkeit herabsetzen. Freilich werden die endogenen Psychosen nicht verschwinden, da die Mehrzahl rezessiven Erbgängen folgt und die Heterozygoten vom Gesetz nicht betroffen werden. Für den Arzt wichtig ist die Anzeigepflicht, die nach den folgenden Paragraphen geregelt ist:

„Wird einem approbierten Arzt in seiner Berufstätigkeit eine Person bekannt, die an einer Erbkrankheit ... oder an schwerem Alkoholismus leidet, so hat er dem zuständigen Amtsarzt hierüber... unverzüglich Anzeige zu erstatten. Die gleiche Verpflichtung haben sonstige Personen, die sich mit der Heilbehandlung, Untersuchung oder Beratung von Kranken befassen. Bei Insassen von Anstalten trifft die Anstaltsleiter die Anzeigepflicht."

„Wer vorsätzlich oder fahrlässig der ihm ... auferlegten Anzeigepflicht zuwiderhandelt, wird mit Geldstrafe bis zu 150 Reichsmark bestraft."

Eine Ergänzung des Gesetzes zur Verhütung erbkranken Nachwuchses ist das

Gesetz zum Schutze der Erbgesundheit des deutschen Volkes (Ehegesundheitsgesetz)

vom 18. Oktober 1935 (RGBl. I S. 1246).

$\S 1$. (1) Eine Ehe darf nicht geschlossen werden

a) wenn einer der Verlobten an einer mit Ansteckungsgefahr verbundenen Krankheit leidet, die eine erhebliche Schädigung der Gesundheit des anderen Teiles oder der Nachkommen befürchten läßt,

b) wenn einer der Verlobten entmündigt ist oder unter vorläufiger Vormundschaft steht,

c) wenn einer der Verlobten, ohne entmündigt zu sein, an einer geistigen Störung leidet, die die Ehe für die Volksgemeinschaft unerwünscht erscheinen läßt,

d) wenn einer der Verlobten an einer Erbkrankheit im Sinne des Gesetzes zur Verhütung erbkranken Nachwuchses leidet. 
(2) Die Bestimmung des Absatzes 1 Buchstabe d steht der Eheschließung nicht entgegen, wenn der andere Verlobte unfruchtbar ist.

$\S 2$. Vor der Eheschließung haben die Verlobten durch ein Zeugnis des Gesundheitsamtes (Ehetauglichkeitszeugnis) nachzuweisen, daß ein Ehehindernis nach $\S 1$ nicht vorliegt.

$\S$ 8. (1) Das Gesetz tritt am Tage nach der Verkündung in Kraft.

(2) Den Zeitpunkt des Inkrafttretens des $§ 2$ bestimmt der Reichsminister des Innern. Bis zu diesem Zeitpunkt ist ein Ehetauglichkeitszeugnis nur in Zweifelsfällen vorzulegen.

Wichtig ist vor allem der $\S 1 c$; der hier als Ehehindernis genannte Begriff ,geistige Störung ${ }^{66}$ umfaßt auch nichterblicheZustände; auch schwerere Formen der Psychopathie wird man dazu rechnen können.

Über diese Bestimmungen des Gesetzes hinaus ist es wünschenswert, auch manchen vom Gesetz nicht betroffenen Menschen von der Eheschließung überhaupt oder doch von der Heirat mit bestimmten Partnern abzuraten. So wird man zu verhindern suchen, daß zwei Menschen aus schizophrenen Erbkreisen die Ehe schließen, wenn sie selbst schizoide Merkmale zeigen. Das gleiche gilt für ausgesprochen zykloide Temperamente. Freilich soll der Arzt sich nur dann auf die Eheberatung einlassen, wenn er als Hausarzt den ganzen Familienkreis sehr gut kennt oder aber Zeit hat, sich einen vollen Überblick über die Verhältnisse zu verschaffen. Am besten überläßt er diese schwierige Aufgabe Ärzten mit besonderem Sachverständnis.

Mit der Einführung der Gesundheitszeugnisse, die künftig von den Eheanwärtern vorgelegt werden müssen, wird sich vermutlich bald eine Eheberatung verbinden, die sich auf immer tiefere Erfahrung wird stützen können.

Nächst dem Kampf gegen die Entstehung von Erbleiden ist fruchtbar die Beseitigung der häufigsten exogenen Ursachen des Irreseins. Voran steht die Bekämpfung des Alkoholismus und der Syphilis, die von der Gemeinschaft mit allen Mitteln in Angriff genommen worden ist. Bei willensschwachen Menschen soll der Arzt auf keinen Fall durch Verordnung „einer Flasche dunklen Biers" als Schlafmittel oder ,eines Glases Wein ${ }^{66}$ als Anregungsmittel die Entstehung alkoholischer Gewohnheiten fördern. Daß Morphin nur bei strengster Indikation und immer nur vom Arzt, nie von einer Pflegeperson, nie vom Kranken selbst, gegeben werden darf, ist eine unbedingte Forderung, deren Verletzung zu den groben Kunstfehlern zu rechnen ist. Auch mit der Verordnung von Schlafmitteln übe man strenge Zurückhaltung, zumal bei psychopathischen Persönlichkeiten, um so mehr als im Laufe der letzten Jahrzehnte die Schlafmittelsuchten mit ihren schweren Folgen eine zunehmende Verbreitung erfahren haben.

Überall, wo der Arzt die Genugtuung hat, wirklich als Hausarzt tätig zu sein, wird er auch bei erzieherischen Fragen ein Wort mitzusprechen haben. Einordnung in die Gemeinschaft und Leistung für die Gemeinschaft sind die Ziele jeder Erziehung. Auf die Art der Leistung kommt es dort nicht an, wo nicht enge Tradition, falscher Ehrgeiz, Egoismus und Anmaßung den Blick trüben. Blinder Ehrgeiz der Eltern aber führt nicht selten zu Fehlentwicklungen, zur Flucht in die Krankheit, zu abnormen Gewohnheiten, die leichter entstehen, als beseitigt werden können. Nervösen Störungen in der Kindheit, lange anhaltenden Trotzreaktionen, hysterischen Demonstrationen, hypochondrischen Einstellungen, Verstimmungen muß der Arzt also die größte Aufmerksamkeit zuwenden. In der Regel werden unangemessene Anforderungen oder falsche Behandlung es sein, welche solchen nervösen Demonstrationen 
zugrunde liegen. Hier gilt es, einen angemessenen Ausgleich zwischen Fähigkeiten und Anforderungen zu finden. Kinder mit unzureichender Begabung gehören nicht auf die höhere Schule. Im übrigen knüpfe man bei Jugendlichen, die nervös auffällig werden, erzieherisch stets an die engsten menschlichen Bindungen und an die Werte an, die sie verstehen und bejahen. Häufig ist es allerdings richtiger, falsche Einstellungen der Eltern zu beseitigen (Verzärtelung, übertriebene Angst, Ungleichmäßigkeit, Affenliebe oder demonstrative Lieblosigkeit), als eine Behandlung der Jugendlichen selbst zu beginnen.

Besondere Aufmerksamkeit verdient die geschlechtliche Entwicklung, zumal die Beseitigung masturbatorischer Neigungen, welche die Quellen vieler sexueller Perversionen sind. Geduld und Güte sind hier meist wirksamer als Strenge und Liebesentzug. Dem Umgang schenke man stets sorgfältige Beachtung.

Die Behandlung der abnormen seelischen Reaktionen und neurotischen Fehlentwicklungen ist Sache der Psychotherapie, die heute noch nicht nach einheitlichen, allgemein anerkannten Gesichtspunkten lehrbar ist. Viele neurotische Gewohnheiten und hysterische Einzelsymptome lassen sich bei primitiven Menschen durch energische suggestive Maßnahmen, etwa durch den faradischen Strom, unterstützt durch Verbalsuggestion, rasch beseitigen. Auch die Hypnose hat hier, zumal bei beeindruckbaren Menschen, ihr geeignetes Feld. Das gleiche Verfahren kann bei der Bekämpfung der Perversionen, leichterer Zwangserscheinungen, mancher Formen von Schlaflosigkeit mit Erfolg herangezogen werden. Die Hypnose ist aber kein ,gerader" Weg. Man kann mit ihr wohl Symptome beseitigen, nicht aber die den Symptomen zugrunde liegenden Fehleinstellungen heilen. Daher sind alle Verfahren, welche sich an die Einsicht wenden und letzten Endes die Beseitigung der abnormen Erscheinungen bewußten, willentlichen Haltungen des Kranken selbst überlassen, vorzuziehen. Hier handelt es sich um ausgesprochen erzieherische Aufgaben. In vielen Fällen schafft schon eine vertrauensvolle Aussprache dem Leidenden große Erleichterung, weil sie ihn bisher verborgene Zusammenhänge selbst erkennen oder doch unter Mithilfe des Arztes sehen läßt. Die Erkenntnis der Zusammenhänge ist es, die den Weg für die Überwindung der Symptome freimacht.

Im Grunde gehen auch die großen psychotherapeutischen Schulen auf dieses Ziel aus, wenn auch von verschiedenen Ausgangspunkten her, mit verschiedenen theoretischen Einstellungen und verschiedenen Verfahren. Die Psychoanalyse Freuds führt letzten Endes alle neurotischen Störungen und Entwicklungen sowie alle Perversionen auf die fehlgeratene Libidoentwicklung zurück, wobei Libido bei Freud selbst wie seinen engsten Schülern einen ausgesprochen sexuellen Anstrich hat. Vom Idealich verworfene sexuelle Regungên der verschiedensten Art, die nicht ganz verdrängt und die nicht sublimiert, d. h. der Verwendung auf vom Idealich anerkannten Gebieten zugeführt werden können, machen sich in den abnormen Symptomen auf allen möglichen Umwegen deutlich, sei es in körperlichen Funktionsstörungen (Konversionsneurose, Hysterie), sei es in Angst und Zwang und Wahn. Die Symptome haben vielfach Symbolwert. Die Neurose arbeitet mit den Mitteln, mit denen auch der Traum die tatsächlich gemeinten Inhalte verhüllt. Traumdeutung und freie Assoziation bei entspannter Aufmerksamkeit, wobei den 
Pausen als Ausdruck des ,Widerstandes" besondere Bedeutung zukommt, sind die Mittel, welche die Psychoanalyse verwendet.

Eine ganze Reihe der von Freud und seinen Schülern geschaffenen Begriffe (Verdrängung, Komplex) ist ebenso Gemeingut der Wissenschaft geworden wie die Erkenntnis des außerordentlich verwickelten Aufbaues unseres Trieblebens, zumal der Sexualität. Sicherlich ist auch das Verfahren der Psychoanalyse ein sehr eindringliches und macht dem Kranken Regungen bewußt, die, für gewöhnlich am Rande seines Bewußtseins und von ihm nicht anerkannt, dennoch eine große Bedeutung für sein Wohlbefinden und sein Verhalten haben. Der Leidende wird sich also, ganz unabhängig von den Deutungen durch den Psychoanalytiker, durchsichtig. Er lernt seine Möglichkeiten, seine Fehleinstellungen, seine tatsächlichen Wünsche und unerfüllbaren Hoffnungen kennen. Aber alles Entscheidende bleibt ihm dann selbst überlassen. Verderblich können die oft gewaltsamen und peinlichen Deutungen der Analytiker für weiche und ethisch skrupulöse Menschen sein, die in der Psychoanalyse nichts gewinnen, sondern nur verlieren.

Gegenüber Freud, welcher der Kausalität der Symptome wie des Persönlichkeitsaufbaues nachgeht, sieht Adler in seiner "Individalpsychologie ${ }^{66}$ die Neurosen unter finalen Gesichtspunkten. Sie sind für ihn alle zweckhaft, und zwar Ausdruck des fehlgeleiteten „Machtstrebens ${ }^{6}$ bei Menschen, die mit ihren Minderwertigkeitsgefühlen nicht fertig werden und sich die Umgebung auf dem Umwege über die Krankheit dienstbar machen, sich selbst aber vor der Leistung und der vollen Einordnung in die Gemeinschaft „drücken ${ }^{66}$. Es handelt sich also um falsche „Kompensationen ${ }^{66}$ um Ausweichreaktionen aus Angst vor der Niederlage. Der Kranke „,sichert" sich durch seine Neurose. Dies „neurotische Arrangement ${ }^{66}$ muß ihm durchsichtig gemacht werden, was auf den von Freud eröffneten Wegen gelingt. Der falsche Lebensplan muß dann unter ermutigenden Einwirkungen des Arztes abgeändert werden. Wer psychotherapeutisch tätig sein will, der hat sich mit Freuds und Adlers Schriften sowie mit denen von Jung vertraut zu machen.

Die Psychotherapeuten der einzelnen Richtungen sind zu engen und strengen Zirkeln zusammengeschlossen, die jeden Abtrünnigen unerbittlich ausstoßen. Die Mehrzahl der Psychotherapeuten gehört aber heute zu den Abtrünnigen, den nicht schulmäßig Eingeschworenen. Die große Psychotherapie, besonders diejenige der Zwangsneurose und der Perversionen, ist Sache der eigentlichen Psychotherapeuten. Aber auch der praktische Arzt steht vielfach vor der Notwendigkeit, nervöse Menschen zu beraten und psychotherapeutisch zu beeinflussen. Voraussetzung für jede sinnvolle Einflußnahme ist die genaue Kenntnis der Umstände und persönlichen Bedingungen, unter denen die Symptome entstanden sind. Wer psychotherapeutisch tätig sein will, muß also Zeit haben. Der Kranke selbst muß sprechen; er soll nicht viel gefragt werden. Kennt man die Bedingungen, aus denen heraus er lebt, die Werte, die er bedingungslos anerkennt, dann wird man nach Möglichkeit die störenden äußeren und inneren Umstände beseitigen oder doch dem Kranken in ihrer wahren Bedeutung erkennbar machen, im übrigen aber therapeutisch an die Werthaltungen anknüpfen, und auf dem Umwege über ermutigende, steigerungsfähige Leistungen rasch Boden gewinnen. Dabei ist es heute unter dem Zeichen der Gemeinschaft und der allgemein anerkannten Werte leichter 
als früher, den Lebens- und Heilungsplan an den großen allgemeinen Zielen zu orientieren. Voraussetzung für jeden psychotherapeutischen Erfolg ist das unbedingte Vertrauen des Kranken zum Arzt, die "Übertragung“6 auf den Arzt, wie Freud das genannt hat. Wie in der Kindheit, kommen wir auch im späteren Lebensalter zu neuen Werten und Zielen meist nur auf dem Umwege über starke persönliche Bindungen. Die „Übertragung“" muß freilich allmählich immer mehr gelöst, d. h. es müssen vom Kranken anerkannte und realisierungsfähige Werte und Bindungen außerhalb der psychotherapeutischen Situation an die Stelle der Verhaftung an den Arzt rücken. Aus seinem Streben nach Wertverwirklichung heraus muß der Kranke selbständig gemacht werden.

Nicht bloß im Rahmen abnormer seelischer Reaktionen und Entwicklungen stehen wir vor psychotherapeutischen Aufgaben. Auch zahlreiche Symptome und Aufpfropfungen bei endogenen Psychosen, ja selbst organischen Hirnerkrankungen sind neurotischer Natur und psychotherapeutischen Maßnahmen zugänglich. Zumal für die Schizophrenen hat die strenge Durchführung der Arbeitstherapie gezeigt, welche außerordentliche Bedeutung solchen sekundären, psychisch beeinflußbaren Erscheinungen zukommt. Stereotypien und Manieren, lästige Gewohnheiten, Erregungen und unsoziale Verhaltensweisen der Schizophrenen sind der planvollen seelischen Einwirkung zugänglich und daher nicht als Ausdruck des Prozesses selbst anzusehen. Wahrscheinlich reicht die Bedeutung solcher abnormer Reaktionen auf dem Boden prozeßhafter Abläufe noch wesentlich weiter, als wir dies heute annehmen. Jedenfalls hat sich das Gesicht der Anstalten unter planvollen erzieherischen Einwirkungen entscheidend gewandelt, freilich ohne daß deshalb die Krankheiten selbst geheilt und die Anstaltsbedürftigkeit wesentlich eingeschränkt worden wären.

Im übrigen handelt es sich hier um Aufgaben des Psychiaters, nicht so sehr des praktischen Arztes. Dieser muß aber wissen, daß die geeignetste Unterbringung auch für den seelisch Kranken, wenn er nicht grob störende oder gefährliche Symptome hat, die Familie oder doch jedenfalls die Freiheit und $\mathrm{da} \beta$ das beste Heilmittel die nutzbringende Tätigkeit ist. Die Anstalten streben daher nach Möglichkeit Frühentlassungen an. Auf der anderen Seite läßt es sich natürlich nicht verantworten, eine ganze Familie unablässig unter störenden und ekelerregenden, antisozialen Verhaltensweisen eines einzelnen Kranken leiden zu lassen, auch wenn keine eigentliche Gemeingefährlichkeit besteht. Das Schicksal der Gesunden darf nicht über das erträgliche Maß hinaus belastet werden. In jedem einzelnen Falle sollte im übrigen sachverständige Beobachtung angestrebt werden, auch wenn sie nur von kurzer Dauer sein kann. Um Gemeingefährlichkeit auszuschließen, ist dies der einzige sichere Weg.

Ferner soll sich der Arzt allenthalben, wo er mit seelisch Kranken zu tun hat, die Frage der Selbstmord gefahr vorlegen. Sie ist, zumal bei allen depressiven Symptomenkomplexen und bei Angst, stets als dringend zu betrachten und unter Umständen nur bei Anstaltsunterbringung nach Möglichkeit zu beschränken. Schon wenn der Arzt zum Kranken gerufen wird, soll er sein Verhalten so einrichten, daß er im Notfalle Schaden verhüten kann. Ein Geisteskranker darf, solange keine volle Sicherheit über seinen Zustand besteht, grundsätzlich nicht ohne Aufsicht bleiben. 
Wahrhaftigkeit ist bei der Behandlung Geisteskranker, wie überhaupt für den Arzt, höchste Pflicht. Es gibt nur wenige Ausnahmefälle, in denen Umwege berechtigt sind. Auch die Wahrheit kann immer in einer Form an den Kranken herangebracht werden, die unmittelbaren Schaden ausschließt. Vielfach ist es möglich, durch Schweigen, durch Nichtantworten an geeigneter Stelle den Kranken die Wahrheit selbst finden und sagen zu lassen. Da sie dann meist in krassester Form ausgesprochen zu werden pflegt, kann der Arzt mit beruhigenden und beschränkenden Worten viel mehr ausrichten als durch Unwahrhaftigkeit und Verschleierung des Sachverhalts.

Auch bei der Verbringung der Kranken in die geschlossene Anstalt ist der gerade Weg in der Regel der beste, außer wenn es sich um erhebliche Demenzzustände mit großer Beeinflußbarkeit und deren natürlichem Begleiter, dem Eigensinn, handelt. Hier hat es keinen Sinn, erst den Eigensinn wachzurufen. Einem Paralytiker etwa wird man also nicht sagen, er müsse jetzt sofort in eine geschlossene Anstalt gebracht werden, sondern es solle noch ein Nervenarzt befragt werden, der dann weiter über die Behandlung entscheiden müsse. Bei Mißtrauen und Widerstreben, bei erheblicher Angst und Abwehr ist die Täuschung im übrigen besonnener Kranker ein Kunstfehler. Der Kranke wird seine Abwehrstellung gegen nächste Angehörige und Hausarzt nie mehr los werden, nachdem er einmal getäuscht worden ist. Hier bleibe man also bei autoritativem Vorgehen und wende im Notfalle auch chemische Zwangsmittel an. Kommt der Kranke nach Abheilen des akuten Leidens zur Einsicht, so billigt er das Vorgehen nachträglich selbst und hat an Vertrauen gegen seine nächste Umgebung nichts eingebüßt. Irreführungen aber sind höchstens für den Augenblick bequem; sie sind besonders schlimm, wenn der Kranke sie durchschaut und sich nun gegen jede weitere vernünftige ärztliche Maßnahme sperrt.

Jeder Arzt soll über die Aufnahmeformalitäten der psychiatrischen Anstalten und Abteilungen, die für seinen Wohnbezirk in Frage kommen, genau Bescheid wissen, damit in dringenden Fällen keine Verzögerungen entstehen. Bei Gefahr im Verzug muß Gemeingefährlichkeit bescheinigt werden, bei deren Vorliegen wohl jede Anstalt den Kranken als Notfall aufnehmen kann. Die Formalitäten können dann nachgeholt werden.

Wo Zwang nötig wird, bleibe man nicht bei halben Maßnahmen, die doch nichts helfen. Die Injektion von Skopolamin-Morphin in geeigneter Dosis (1 mg Skopolamin und 0,02 Morphin) bei im übrigen gesunden Menschen bringt keinen Schaden mit sich, hebt aber den sonst nicht überwindbaren Widerstand auf.

Fortgesetzte Nahrungsverweigerung, grobe Unreinlichkeit aus nichtneurologischen Anlässen, schwere Erregung machen auf jeden Fall Anstaltsbehandlung nötig, da sie nur hier in geeigneter Weise bekämpfbar sind. Das gleiche gilt für Kranke mit ernst zu nehmender Selbstmordneigung. Auch eine erfahrene Pflegeperson genügt im Haushalt nicht, die Gefahr zu beseitigen, und in der Regel läßt sich auch die ständige Pflege durch mehrere Personen im Haushalt nicht so lückenlos durchführen, daß damit die Gefahr auf das möglichste $\mathrm{Maß}$ eingeschränkt wäre.

In der Anstalt wird die Nahrungsverweigerung durch regelmäßige Sondenfütterung, unter Umständen auch durch geeignete Nährklystiere, 
usw. bekämpft, die Erregung notfalls im Dauerbad, durch Einwicklungen in feuchte Tücher (Beachtung des Herzens, Gefahr der Überhitzung), durch Hineinstellen des Erregten in einen angemessenen Arbeitskreis (Manische toben ihren Tätigkeitsdrang am Waschfaß aus), unter Umständen auch durch chemische Mittel behandelt.

Der Unreinlichkeit wird man, je nachdem sie neurologischer oder psychopathologischer Entstehung ist, in verschiedener Weise begegnen. Bei allen organischen Krankheitszuständen und allen Stuporen ist ständig auf regelmäßige Entleerungen zu achten und die Blasenfüllung immer erneut zu kontrollieren, da sonst Infektionen der Harnwege unvermeidlich sind. Nach Möglichkeit suche man ohne den Katheter auszukommen; doch soll er auch nicht zu spät angewendet werden.

Bei Bettlägerigen (Paralyse, Stuporen) darf nie die Gefahr des Dekubitus vergessen werden, der durch Umlagerung, Polsterung, Hautpflege vorgebeugt werden muß. Ist einmal ein ausgedehnter Dekubitus eingetreten, der in seltenen Fällen nicht vermeidbar ist, so gehört der Kranke auf das gespannte Netz im Dauerbad.

Mechanische $Z_{w}$ angsmittel, die früher zu den notwendigen Einrichtungen gehörten, sind heute praktisch aus allen Irrenanstalten verschwunden. Die No-restraint-Bewegung, die dazu führte und großen Segen bewirkte, hat es mit sich gebracht, daß heute vor dem Gebrauch irgendeines Zwangsmittels (feste Handschuhe, Netze über dem Bett) alle anderen Mittel erschöpft werden, so daß die Zwangsmittel bei ihrer Anwendung, die nur dem Arzt vorbehalten bleiben soll, immer das kleinere Übel darstellen. Hierher gehört auch die ,Zelle“6, die bei dauerndem Aufenthalt jeden Kranken zu lästigen Gewohnheiten führt, aber bei ganz kurz dauernder Isolierung schlagartig viele Erregungen beseitigt und damit auf seelischem Wege erreicht, was sonst unter Umständen nur mit grobem chemischen Geschütz sich durchsetzen läßt.

Neben dem Kranken selbst hat der Arzt immer auch das Schicksal seiner nächsten, unter Umständen von ihm abhängigen Angehörigen im Auge zu behalten. Geistige Krankheit bedeutet ja meist wirtschaftlich und sozial sehr viel mehr als nichttödliche körperliche Leiden. Schon das Gesetz zur Verhütung erbkranken Nachwuchses wirft Schatten in die Herkunftsfamilien. Langdauernder Krankenhausaufenthalt verursacht außerordentliche Kosten. Es ist daher von vornherein bei der Wahl der Anstalt die wirtschaftliche Lage der Familie zu überdenken und, soweit dies möglich ist, den Angehörigen klarzumachen, mit welcher Krankheitsdauer zu rechnen ist, damit besonders kostspielige Anstalten im gegebenen Falle vermieden werden. Es ist für hilflose Ehefrauen und Kinder Fürsorge zu treffen, im Bedarfsfalle Pflegschaft oder Vormundschaft anzuregen und, bei genauer Kenntnisder Sachlage, unterUmständen auch Wiederaufnahme von Gerichtsverfahren, die durch die beginnende, aber noch nicht erkennbare geistige Erkrankung verursacht wurden oder verloren gingen. Beläßt man den Kranken in der Familie, so vergesse man nicht, daß Gewalttaten, die vom Kranken begangen werden können, soziale Entgleisungen entehrender oder beschämender Art zwar dem Psychotischen von Einsichtigen nicht zugerechnet werden, daß die sensationslüsterne Umgebung solche Dinge aber doch nicht vergißt. Dies sage man den Angehörigen, die aus ähnlichen Gründen eine Anstaltsaufnahme gerade vermeiden wollen. 
Bei allen Entscheidungen sozialer Art, die aus Anlaß geistiger Er,krankung nötig werden, soll man also nicht bloß den Kranken selbst ins Auge fassen. Geistige Erkrankung geht immer auch die Gemeinschaft, immer auch die gesunden Angehörigen an. Alle drei müssen berücksichtigt werden; denAusschlag hat immer der höchste Wert zu geben, die Gemeinschaft vor dem einzelnen, das Gesunde vor dem Kranken. Die von der Gemeinschaft geschaffenen Einrichtungen sorgen ja ohnedies dafür, daß auch bei strenger Befolgung dieser Richtschnur dem einzelnen Kranken nach Möglichkeit am besten geholfen wird.

Von den bei der Behandlung Geisteskranker gebräuchlichen Mitteln ist jeweils schon im Zusammenhang der Darstellung der einzelnen Krankheitsgruppen gesprochen worden, so etwa von der Malariakur, von der Behandlung des Morphinismus usw. Hier sei noch kurz auf die allenthalben gebräuchlichen Schlaf- und Beruhigungsmittel eingegangen. Ganz allgemein darf vorausgeschickt werden, daß man nach Möglichkeit ohne diese Mittel auszukommen versuchen soll. Geeignete Beschäftigung, Fortschaffen von chronischen Schäden(Kaffee, Nikotin, Alkoholismus, überhitztes Schlafzimmer, falsche Tageseinteilung), physikalische Maßnahmen (halbstündige Bäder bei $35^{\circ} \mathrm{C}$, heiße Fußbäder, Abreibungen), Einschiebung einer Nachmittagsruhepause u. a. können auch in hartnäckigen Fällen bei Geduld und geeigneten suggestiven Einwirkungen plötzlich oder allmählich Schlaf machen; unter Umständen tut dies auch ein indifferentes Mittel (Natrium bicarbonicum, Milchzucker). Gelingt dies nicht, so soll man die leichteren Mittel vor den schweren bevorzugen, schwere Mittel aber nie längere Zeit fortsetzen, sondern nach wenigen Tagen mit einem einer anderen chemischen Gruppe angehörenden Mittel abwechseln lassen. Von Beruhigungsmitteln, die bei leichten Erregungen auch am Tage angebracht sein können, steht das Brom obenan, das gegen Unlustreize unempfindlicher macht und allgemein beruhigt. Die billigste Verordnung ist die Lösung von Bromsalzen (5,0-10,0 auf 150,0, $3 \mathrm{mal}$ täglich 1 Eßlöffel, so daß also $3 \mathrm{mal} 0,5-1,0$ gegeben werden). Diese Dosis schadet bei den hierzulande üblichen Kochsalzdosen schwerlich, wenn sie nur kurze Zeit genommen wird (1-2 Wochen); die Gefahr des Bromismus (Akne) behalte man aber immer im Auge. Angenehmer als die Lösungen sind die zahlreichen Handelspräparate Bromnervacit, Brosedan, Sedobrol usw. Wegen der kumulierenden Wirkung des Broms verwende man es (außer bei Epilepsie) stets nur kurz, da sonst Müdigkeit, Unlust und Unregsamkeit die Folgen dieser ,beruhigenden" Medikation sind.

Gern gegeben werden heute auch Luminaletten (Luminal 0,015) 3-6mal am Tage, denen bei geeigneter Dosierung die müdemachende Wirkung fehlt, und Hovaletten, die Hopfen enthalten und die bei manchen Nervösen vorhandene sexuelle Übererregbarkeit bekämpfen.

Von den Einschlafmitteln ist vor allem das Paraldehyd zu nennen, das, in Dosen von 4,0-6,0 in Fruchtschleimen gegeben, recht sicher Schlaf herbeiführt, freilich schlecht schmeckt und noch am nächsten Tage am Atemgeruch erkennbar ist. Manche Kranke nehmen es daher ungern. Andere gewöhnen sich aber daran, ja es gibt Paraldehydisten und im Gefolge davon Delirien, die dem Delirium tremens gleichen.

Auch Evipan ist ein mildes Einschlafmittel (0,5-1,0). Das gleiche gilt für Adalin (0,5-1,0). Beide sind ziemlich harmlos. Das Endorm (Evipan- 
natrium) kann man intravenös in Gaben von etwa $1 \mathrm{ccm}$ der Lösung für $10 \mathrm{~kg}$ Körpergewicht zur Erzielung einer ganz kurzdauernden Narkose für die Durchführung von Eingriffen (Lumbalpunktion, Enzephalographie), ja auch zur Einleitung einer Hypnose verwenden.

Von den eigentlichen Schlafmitteln, die den Schlaf vertiefen und verlängern, ist verhältnismäßig milde und ohne erhebliche Nachwirkungen das Phanodorm, das unbedenklich wäre, wenn es nur auf ärztliche Verordnung genommen werden dürfte, aber viel Schaden angerichtet hat, weil es frei erhältlich ist und häufig auch bei Tage als „Beruhigungsmittel ${ }^{66}$ gebraucht wird. Man gibt $0,2-0,4$, unter Umständen auch 0,6 (Morphinentziehung). Ein sehr gutes Schlafmittel ist das Veronal $(0,5$, bei Erregungen unter Umständen 1,0!, Höchstdosis 0,75), das freilich häufig auch nach dem Erwachen noch Müdigkeit hinterläßt, dafür aber auch unter Umständen den Schlaf am folgenden Abend so leicht herbeiführt, daß man dann ohne oder doch mit einem leichteren Schlafmittel auskommt. Man wird es als Acid. diaethylbarbit. verschreiben, um Kosten zu sparen. Manche Kranke ziehen das Medinal (Veronalnatrium - gleiche Dosen) vor.

Auch das Luminal $(0,2-0,3)$ ist ein recht sicher wirkendes Schlafmittel, das freilich lange im Körper verbleibt und gern kumulative Wirkungen entfaltet (Nystagmus, artikulatorische Sprachstörungen, Gleichgewichtsstörungen). Man verwendet Luminal daher am besten immer nur für einen oder zwei Tage, um es dann durch andere Mittel zu ersetzen. Als Luminalnatrium kann man es $(0,22)$ auch intravenös geben.

An Barbitursäureabkömmlingen sind noch Somnifen und Curral zu nennen. Von gut wirkenden Mitteln anderer chemischer Herkunft sind immer noch Sulfonal $(1,0-2,0)$ und Trional $(0,5-2,0$ in heißer Milch) zu empfehlen, die freilich wegen der Gefahr der Hämatoporphyrinurie nicht längere Zeit fortgegeben werden dürfen.

Auch das Chloralhydrat $(1,0-2,0 \mathrm{~g}$ in Wasser innerlich, 3,0-5,0 als Klysma bei Status epilepticus oder paralyticus) ist unter Umständen gut zu gebrauchen, bei Herzkranken aber zu vermeiden. Als Klysma (6,0 in schleimiger Lösung) gibt man in den Statuszuständen auch gern Amylenhydrat.

Von Kombinationspräparaten sind Allional und Somnacetin zu nennen, die beide in den üblichen Dosen milde wirken. Kombinationen nach Art des Somnacetins (etwa Acid. diaethylbarbitur. 0,5, Pyramidon 0,2, Codein phosph. 0,03 ) haben auch sonst manchmal Vorteile, insbesondere bei Zuständen von Ängstlichkeit.

Bei seltenen periodischen Schlaflosigkeiten, die tatsächlich den leichten Formen der manisch-depressiven Erkrankungen angehören, kann Tinct. opii simplex überraschende Erfolge haben (10-20 Tropfen) oder das mit einem Abführmittel versetzte Neurophillin ( $1-2$ Pillen). Aber nur hier ist Opium als Schlafmittel verwendbar. Im übrigen muß Opium wie jedes Morphinpräparat streng vermieden werden.

Schwere Erregungen wird man mit Skopolamin. hydrobrom. (0,0005 bis 0,001 , auch mehr) bekämpfen, unter Umständen mit einem Zusatz von Pantopon (0,02). Auch Pernocton (intravenös 2-4 ccm) kann mit Erfolg verwendet werden. 
Die Dauerschlafbehandlung, die in manchen Fällen, zumal bei schweren Erregungen, Gutes leistet, gehört nicht ins Privathaus. Bisher war am gebräuchlichsten das Dial als Dauerschlafmittel. Neuerdings wird eine verwickelte Kombination von Arzneien empfohlen (Cloettan).

Bei chronischen Psychosen wird man unter Umständen eine Fieberkur versuchen, etwa mit Tuberkulin, Typhusvakzine, am besten aber mit Pyrifer.

Sind bei einem Geisteskranken Operationen nötig, so werden sie, wenn es sich um einfachere Eingriffe handelt, in der Anstalt selbst durchzuführen sein. Nach größeren Eingriffen, die nur im chirurgischen Operationssaal gemacht werden können, sollen Erregte nach Möglichkeit in die Irrenanstalt zurückgebracht werden, wenn die Gefahr der Erregung voransteht. Im übrigen wird man in jedem einzelnen Falle nach der Sachlage (besondere chirurgische Nachbehandlung - Gefahr der Selbstbeschädigung) entscheiden müssen.

Schwangerschaftsunterbrechung kommt aus psychiatrischer Indikation, abgesehen von ganz seltenen, das Leben bedrohenden endogenen Depressionszuständen und bei bedrohlicher Häufung epileptischer Anfälle, so gut wie überhaupt nicht in Frage. Der praktische Arzt soll sich hier grundsätzlich einer gutachtlichen Stellungnahme enthalten. Daß Mißbräuche vermieden werden, dafür sorgen heute die Gutachterstellen, die in jedem Falle die Entscheidung haben. 


\section{Untersuchung, Krankengeschichte, Diagnose, Begutachtung}

Meist sucht der Geisteskranke nicht von selbst den Arzt auf, sondern wird von seinen Angehörigen gebracht oder der Arzt wird vorher von dem nächsten Umkreis ins Vertrauen gezogen. Bei dieser Gelegenheit soll eine möglichst eingehende objektive Anamnese erhoben werden, die sich nicht bloß auf die in Frage stehende Krankheit selbst, sondern auf die gesamte Vorgeschichte des Kranken, besonders auch auf seine Familiengeschichte, erstreckt. Auf jeden Fall muß der Versuch gemacht werden, über die Eltern und Elterngeschwister, die Geschwister, die Vettern und Basen und die Kinder alles Wichtige in Erfahrung zu bringen. Man darf sich nicht damit begnügen, ganz allgemein nach dem Vorkommen von Geisteskrankheit, Anfällen, Trunksucht, Kriminalität, Selbstmord im Verwandtschaftskreise zu fragen, sondern wird nach Möglichkeit von jedem einzelnen der genannten Verwandten das mitteilen lassen, was bekannt ist. Zweckmäßig ist es, jeweils besonders nach dem Lebenserfolg zu fragen. Für den praktischen Arzt wird eine solche außerordentlich zeitraubende Familienanamnese freilich vielfach nicht durchführbar sein. Er sollte aber anstreben, den Forderungen sich nach Möglichkeit anzunähern, da es ja in so vielen Fällen geistiger Krankheit nicht um den Kranken allein, sondern um die Volksgesundheit geht. Bei Überweisungen in die Anstalt sollte der Hausarzt alles Auffällige aus dem ihm bekannten Familienkreise mitteilen.

Die persönliche Vorgeschichte soll peinlich genau durchforscht werden. Am besten beginnt man mit dem, was von der Geburt und der ersten Kindheitsentwicklung bekannt ist (Krämpfe, Laufen-, Sprechenlernen), verfolgt dann den Werdegang in der Schule (Zeit der Einschulung, Zurückbleiben, Abgangszensur, gute und schlechte Fächer), um die Klärung des sozialen Entwicklungsganges anzuschließen (Lehre, Militärdienst usw.). Man frage insbesondere nach sozialen Entgleisungen und gefährlichen Gewohnheiten (Strafen, Prozesse, Alkohol, Nikotin). Man verschaffe sich Klarheit über die Entwicklung der Sexualität (Masturbation, Perversionen, Eheschließung, Kinder) und gehe dann auf die im Leben durchgemachten körperlichen Krankheiten und Zeiten minderer Leistungsfähigkeit ein (Krankenhaus-, Anstaltsaufenthalte). Sodann gewinne man ein Bild von den Neigungen, den Liebhabereien, den Beziehungen des Kranken zu seiner nächsten Umgebung. Endlich folgt die Klärung der unmittelbaren Vorgeschichte und Geschichte der Krankheit selbst. Vor allem darf nicht versäumt werden, von allem Anfang an mit Nachdruck nach etwaigen Gelegenheitsursachen zu fahnden, da solche vielfach nachträglich zu Unrecht behauptet werden (Versuch, eine Rente zu bekommen, ein endogenes Leiden als exogenes zu deuten usw.). 
Soweit dies möglich ist, wird man auch durch den Kranken selbst in der „subjektiven" Anamnese alle die genannten Punkte einzeln darstellen lassen.

Von höchster Bedeutung ist in jedem einzelnen Falle seelischer Abnormisierung die eingehende, den Gesamtkörper und alle seine Funktionen umfassende körperliche Untersuchung. Es geht nicht an, bloß den neurologischen Befund festzustellen. Nie versäume man die Untersuchung des Blutes und des Urins, des Blutdrucks und des Augenhintergrunds. Die Verfahren, die hier Anwendung zu finden haben, sind der Psychiatrie mit der inneren Medizin gemein und brauchen nicht eigens dargestellt zu werden.

Nur einige Punkte seien als wichtig hervorgehoben. Man bilde sich ein Urteil über den Körperbautyp und hebe die gröberen und feineren dysplastischen Merkmale hervor. Hier handelt es sich um Dinge, die diagnostisch und prognostisch von Bedeutung werden können. Wichtig ist auch, daß man der Sprache besonderes Augenmerk schenkt und die Schrift prüft. Am besten veranlaßt man jeden Kranken zu einer Abschrift und zur Niederschrift seines Lebenslaufs. Endlich wird man sich nicht mit der Feststellung von „Krämpfen" in der Anamnese begnügen, sondern versuchen, jede Einzelheit der Entstehung und des Verlaufs der einzelnen Anfälle deutlich zu machen.

Die Untersuchung des seelischen Zustandes bereitet dem wenig Erfahrenen große Schwierigkeiten. Er hält sich daher am besten im Anfang an ein bestimmtes Schema, etwa das im Anhang wiedergegebene von So m mer. Zunächst verschafft man sich durch Orientierungsfragen Klarheit über den Zustand des Bewußtseins. Dabei wird zugleich das Verhalten der Auffassung und der Aufmerksamkeit deutlich werden. Freilich soll man nicht mit Fragen nach Art eines Lehrers, der das Wissen des Zöglings feststellen will, beginnen, sondern das Gespräch ungezwungen, wie in der natürlichen Unterhaltung führen und dem Kranken nach Möglichkeit so begegnen wie einem Gesunden. Ohne Schwierigkeit wird man dann ein Bild vom formalen Denken gewinnen (also von Hemmung oder Ideenflucht, Sperrung und Zerfahrenheit, Haften und Inkohärenz) und in der Regel sehr rasch auch Anhaltspunkte gewinnen, inhaltliche Denkstörungen zu erfragen, also Wahnideen, überwertige und Zwangsideen. Nach dem Bestehen von Sinnestäuschungen braucht man meist nicht eigens zu forschen. Man erfährt von ihnen, zum mindesten in Andeutungen, von den meisten Schizophrenen und kann dann präzisierende Fragen stellen. Unzweckmäßig ist es, gleich im Anfang etwa zu fragen: „Hören Sie Stimmen?“ Gelegentlich kann man an Mimik und Haltung sehen, daß halluziniert wird.

In solchem Gespräch wird über die Grundstimmung bald Klarheit gewonnen werden und bei den in keiner natürlichen Unterhaltung ausbleibenden Meinungsverschiedenheiten wird man auch rasch über die Affektbereitschaft (Reizbarkeit, Zornmut, Empfindlichkeit) Bescheid wissen. Die Mehrzahl der groben Willensstörungen (Manieren, Stereotypien, Grimassen, Negativismus) fallen ohne weiteres auf. Hält man sich daran, die einzelnen seelischen Sphären nacheinander zu beachten, dann pflegt in einigermaßen klarliegenden Fällen schon beim ersten länger dauernden Gespräch ein recht eingehendes Bild zu entstehen. Erst wenn wirkliche Fühlung mit dem Kranken gewonnen, insbesondere auch die Einstellung zur Untersuchung geklärt ist, gehe man auf die Prüfung der Intelligenz ein. Ergebnisse, die man ohne diese Vorbereitung 
erhält, sind vielfach nicht verwertbar, da Unwillen, Sperrungen, läppisches Verhalten, Hemmung zu grobem Versagen führen können, wo die Intelligenz ganz ungeschädigt ist.

Über das Gedächtnis und die Reproduktionsfähigkeit wird man schon bei der Befragung über die Vorgeschichte ein leidliches Urteil gewinnen. Die Merkfähigkeit wird mit Zahlen und Worten geprüft, die man mit und ohne Ablenkung nach einer Minute, beim Versagen nach 30 Sekunden und nach kürzerer Zeit wiederholen läßt. Es ist zweckmäßig, das Merken auch an optischem Material (Bilder, Photographien, die man dann aus anderen heraussuchen oder beschreiben läßt) zu prüfen. Dabei muß man wissen, daß der durchschnittlich Gesunde ohne Mühe 6-7 Ziffern unmittelbar wiederholt, daß er eine Minute lang auch bei Ablenkung vierstellige Zahlen und neue Worte behält. Im übrigen halte man sich bei der sonstigen Prüfung der Intelligenz, insbesondere der Urteilsfähigkeit, zunächst an ein Schema. Im Anhang ist ein in München verwandter Fragebogen mitgeteilt, aus dem man sich am besten eine Reihe von Tests herauswählt. Diese brauche der Arzt später regelmäßig, um auch eigene Erfahrungen über die normale Leistungsfähigkeit zu gewinnen.

Bei der Prüfung der Kenntnisse muß man wissen, daß nach ausgedehnten Reihenuntersuchungen nur die allereinfachsten Dinge unbedingt gefordert werden dürfen. Die Kenntnisprüfung liefert einen wirklichen Maßstab der Intelligenz im allgemeinen überhaupt nicht. Zweckmäßiger sind daher Methoden, die wesentliche Kenntnisse nicht voraussetzen. Hat man wenig Zeit zur Verfügung, so läßt man einige Rechenaufgaben, auch eingekleidete, lösen, einige Sprichwörter erklären, ein paar Unterschiedsfragen beantworten und schließlich eine Fabel nacherzählen und erklären. Gerade dies Verfahren gibt vielfach einen raschen und weiten Einblick. Gut ist es immer, die einzelnen Antworten möglichst wörtlich festzuhalten. Wo die Sprache schwerfällig ist, kann man sich an Bildmethoden halten, etwa die einzelnen Bilder eines einfacheren oder schwierigeren Münchener Bilderbogens ordnen lassen. Die Intelligenzentwicklung von Kindern prüft man auch heute noch am besten nach der Methode von Binet und Simon. Diese sieht für jede Altersstufe vom Schulwissen unabhängige Fragereihen vor, die vom durchschnittlichen Kind richtig beantwortet werden. Man stellt so das "Intelligenzalter ${ }^{6}$ fest und gewinnt durch Vergleich mit dem Lebensalter den Intelligenzquotienten, der den Vorsprung oder Rückstand anzeigt. Auch den erwachsenen Schwachsinnigen kann man so prüfen, darf aber nicht vergessen, daß dieser doch nicht einem Kinde in seiner Intelligenz gleichgesetzt werden darf, da er ja über ganz andersartige Lebenserfahrungen verfügt. Die Frạgereihen von Binet und Simon sind im Anhang wiedergegeben. Sie sind vielfach ergänzt und vor allem durch Methoden erweitert worden, die sich weniger an die Sprachentwicklung halten Für die Zwecke des praktischen Arztes aber reicht das mitgeteilte Verfahren aus.

Bei allen seelischen Leiden, abgesehen von Hirnerkrankungen, die, wie etwa die Paralyse, bei völlig durchgeführter Untersuchung eine eindeutige Diagnose und Prognose zulassen, ist die Beobachtung des Verlaufs von der größten Wichtigkeit, vor allem wegen der Vieldeutigkeit der Syndrome. In vielen Fällen läßt erst die Verlaufsbeobachtung Diagnose und Strecken- 
prognose zu. Bei den psychopathischen Persönlichkeiten vollends wird erst die längere Beobachtung ein klares Bild von dem Ausmaß der Abnormität geben, wenn nicht schon eine besonders gute objektive Anamnese über alles Wesentliche belehrt.

Die psychiatrische Krankengeschichte muß mit besonderer Sorgfalt geführt werden, da sie in zahlreichen Zusammenhängen, die über den Kranken selbst weit hinausreichen, von entscheidender Bedeutung werden kann. Dies gilt für Erbgesundheitsfragen im familiären Umkreis wie für die Erbforschung überhaupt, die immer noch in den Anfängen steckt. In vielen Fällen tauchen später forensische Fragen auf, solche strafrechtlicher wie zivilrechtlicher Natur (also vor allem auch die nach der strafrechtlichen Verantwortlichkeit in einem bestimmten Zeitpunkt, nach der Nichtigkeit von Geschäften, nach der Testierfähigkeit, Ehescheidungsfragen). Unzureichende oder gar falsche ärztliche Unterlagen sind meist schlimmer als gar keine. Auch für die Unfallsbegutachtung können Befunde, wie vor allem auch Anamnesen nachträglich wichtig werden. Dies muß der Arzt immer vor Augen haben. Die sorgfältige Krankengeschichte erlaubt manchmal auch bei anfänglichem diagnostischen Irrtum nachträglich die Diagnose im entscheidenden Augenblick.

Der Arzt in der Sprechstunde wird sich aus Zeitmangel im allgemeinen darauf beschränken müssen, neben den wesentlichen anamnestischen Punkten vor allem die pathologischen Befunde zu vermerken. Dies ist zureichend, wenn die Untersuchung eine erschöpfende war und der Arzt seiner Befunde völlig sicher ist. In Krankenhaus und Klinik aber soll die Krankengeschichte eine erschöpfende objektive und subjektive Anamnese und einen vollen Status des körperlichen und seelischen Befundes enthalten. Gerade auch die ordnungsgemäßen Befunde können nachträglich von Wichtigkeit werden, und ebenso scheinbar unbeträchtliche Nebenbefunde, die etwa für die Forschung, für die Kontrolle therapeutischer Maßnahmen, aber auch für spätere Haftpflichtansprüche u. a. m. unersetzlich sind.

Die ordnungsmäßig geführte Krankengeschichte enthält also neben den Generalien (bei den Frauen auch Mädchennamen) eine sorgfältige objektive Anamnese, in der auch die bekannten Blutsverwandten mit Namen, Altersangabe und Geburtsort erfaßt sind. Zu der objektiven Anamnese gehören auch die aktenkundigen Tatsachen (Krankengeschichten aus anderen Krankenanstalten, Auszüge aus Renten- und forensischen Akten, gegebenenfalls Strafregisterauszüge). Der objektiven schließt sich die subjektive Anamnese an. Ihr folgt der eingehende körperliche Befund, der am besten nach Organsystemen zu gliedern ist, aber auch nach Körperregionen gegliedert werden kann. Nur soll man nicht die verschiedensten Ordnungsprinzipien durcheinandergehen lassen. In der psychiatrisch-neurologischen Krankengeschichte ist es zweckmäßig, die Befunde am Zentralnervensystem zusammenfassend darzustellen. Gut ist es auch, die Ergebnisse etwaiger chemischer, experimenteller und röntgenologischer Untersuchungen und jene anderer Sachverständiger durch die Anordnung herauszuheben. Sodann folgt der psychische Status, den man, wie erwähnt, am besten nach einem bestimmten, ein für allemal festgelegten Plan entwirft. Nur der Erfahrene wird sich hier jeweils dem Einzelfall anpassen. Dem Status fügt 
man etwaige Niederschriften der Kranken selbst bei, abgesehen von der Schriftprobe, die man in jedem Falle zur Krankengeschichte nehmen soll.

Schon nach der ersten Untersuchung wird man eine Diagnose zu stellen versuchen und differentialdiagnostische Erörterungen anschließen, die vor allem den Anfänger zwingen, sich jeweils volle Rechenschaft zu geben, und damit besonderen erzieherischen Wert haben.

Dieser Erörterung folgt der Entwurf des Heilplans und endlich die regelmäßige Niederlegung der Beobachtungsergebnisse.

\section{Diagnose}

Für die Diagnose kann schon die Beachtung einiger ganz allgemeiner Gesichtspunkte von Bedeutung werden. So läßt etwa das Lebensalter manche vorläufige Schlüsse zu. Bei Kindern wird man zunächst keine endogene Geistesstörung erwarten, aber an Schwachsinn, psychogene Störungen, an Epilepsie und, wenn nach gehöriger Entwicklung ein geistiger Rückgang deutlich wurde, an Paralyse denken. Bei alten Menschen kommen demgegenüber Arteriosklerose, senile Demenz, wesentlich seltener schon Paralyse und Hirnlues, aber fast nur bei entsprechender Vorgeschichte endogene Geisteskrankheiten in Frage. Bei Jugendlichen vor dem 30. Lebensjahre wird man am ehesten an Schizophrenie, nächstdem an manisch-depressives Irresein denken, wenn nicht bei der ganzen Lage des Falles eine abnorme seelische Reaktion von vornherein das wahrscheinlichste ist. Bei Leuten im mittleren Lebensalter, besonders bei Männern, wird sich der Verdacht vorerst auf die Paralyse, sodann auf Alkoholismus lenken und erst dann auf die erblichen Geisteskrankheiten.

Neben dem Lebensalter ist von entscheidender diagnostischer Wichtigkeit der Allgemeinzustand. Hat der Kranke bei Beginn der Seelenstörung Fieber, ist er körperlich elend, so denke man an eine symptomatische Psychose, die wahrscheinlich wird, wenn das Bewußtsein getrübt ist (Auffassung erschwert, Orientierung aufgehoben oder unvollkommen, Merkschwäche, Inkohärenz, traumhafte optische Sinnestäuschungen) und die Schwere der Veränderung der Fieberbewegung parallel geht. Bewußtseinstörungen und Verwirrtheiten kommen im übrigen aber auch bei Epilepsie (man fahnde daher in allen diesen Fällen auf Anfälle, die nicht erst während des krankhaften Zustandes aufgetreten sein dürfen), bei Vergiftungen, zumal bei schwerem Alkoholismus vor, dann unter Umständen neben Anfällen. Tremor, Druckschmerzhaftigkeit der Nervenstämme, Schwitzen, Gleichgewichtsstörungen, aber auch das Aussehen werden den Verdacht auf Alkoholdelir verstärken. Andere chronische Vergiftungen (Schlafmittel, Paraldehyd), aber auch Paralyse bleiben trotzdem möglich. Hier wird die Anamnese leicht Klarheit bringen. Auch andere organische Hirnkrankheiten können mit deliranten Zuständen einhergehen.

Die körperliche, insbesondere die eingehende neurologische Untersuchung ist daher in jedem Falle so rasch als möglich durchzuführen. Pupillenstörungen, sodann Steigerung oder Aufhebung der Sehnenreflexe, Fazialisschwäche, mimisches Beben und artikulatorische Sprachstörung von der leichten Verwaschenheit bis zum Stolpern und Lallen machen die Diagnose Paralyse wahrscheinlich, um so mehr, wenn auch Zeichen geistiger Schwäche, 
Stimmungslabilität und Bestimmbarkeit, haltlose Euphorie oder leere Depression, Rechenstörungen, besonders Unsicherheit der zeitlichen Einordnung und Merkschwäche auch nur in den Anfängen vorhanden sind. Absolute Pupillenstarre und ausgesprochenere Herdstörungen, wenn sie nicht ganz flüchtiger Natur sind, werden an Hirnlues denken lassen. Sicherheit wird dann immer die serologische Untersuchung bringen, die in keinem Fall versäumt werden sollte, mit aller Bestimmtheit aber durchzuführen ist, wo Zeichen der organischen Geistesstörung erkennbar sind. Auch bei endogenen Syndromen ist die genaue neurologische Untersuchung unumgänglich nötig, da sich hinter diesen Zustandsbildern organische Hirnkrankheiten verbergen können. Aus dem gleichen Grunde versäume man nie, die Merkfähigkeit zu prüfen, die bei deutlich erkennbarer Störung immer einen organischen Hirnschaden anzeigt, vor allem wenn der Kranke besonnen ist.

Die Merkschwäche geht freilich auch in alle akuten exogenen Syndrome ein. Bei besonnenen Zuständen ist gleich wichtig die Konzentrationsschwäche. Vervollkommnen sich die Erscheinungen durch grobe Orientierungsstörungen und Konfabulationen zum Korsakowschen Zustand, so denke man an Alkoholismus, wo nicht spezifische Pupillenstörung und Sprachstörung die Paralyse, hohes Lebensalter die senile Demenz, der Zustand des Gefäßsystems und Herdstörungen die Arteriosklerose, die Vorgeschichte ein grobes Hirntrauma wahrscheinlich machen. Nie vergesse man freilich, auf Scheinblödsinn zu fahnden, der, abgesehen von sonstigem demonstrativem Beiwerk, das nicht zu fehlen pflegt, im Vorbeiantworten meist rasch erkennbar ist.

Bei Anfällen achte man vor allem auf die Symptome, die organische Störungen anzeigen. Besteht im Anfall Pupillenstarre, kommt es zu Babinski, zum Fehlen der Bauchdecken- und der Grundgelenkreflexe, zum groben Zungenbiß und Sezessus auch in peinlicher Lage, dann läßt sich der hysterische Anfall ausschließen. Hysterische Bewegungsstürme dauern meist auch lange, sie sind durch äußere Maßnahmen zu steigern oder zu kupieren, sie haben immer theatralische Züge. Bleibt nach einem organisch anmutenden Anfall eine Parese zurück, beginnt der Anfall immer in einem bestimmten Muskelabschnitt, um dann erst systematisch über den Körper fortzuschreiten, schwindet vollends das Bewußtsein nicht ganz, so wird man immer an einen Hirnherd denken, also an symptomatische Epilepsie; indes begnüge man sich hier nicht mit neurologischen Untersuchungen, sondern ergänze sie wenn möglich durch Röntgenaufnahme und evtl. Enzephalographie. Absenzen, aber auch Dämmerzustände und Verstimmungen sind häufiger und ausgesprochener bei genuiner als bei symptomatischer Epilepsie.

Fehlen neurologische Erscheinungen, Bewußtseinsveränderung, Störungen der Intelligenz wie der Gedächnisfunktionen, ist von Anfällen nichts bekannt, dann rücken, zumal bei Menschen im jugendlichen und mittleren Lebensalter, die endogenen Geisteskrankheiten in den Bereich der Wahrscheinlichkeit. Natürliches, einfühlbares Verhalten spricht dann mehr für manisch-depressives Irresein, alles Unnatürliche, Bizarre, Manierierte, Unverständliche und Steife eher für Schizophrenie. Zur Melancholie gehören echte Traurigkeit, oft mit Angst und einem Zug der Schwere, Willens- und Denkhemmung sowie zur Stimmung passende Inhalte (Versündigungs-, Unwerts-, 
Verarmungs-, hypochondrische Ideen), die im Bereiche des Möglichen bleiben, zur Manie aber heitere oder doch expansive Stimmung, gehobenes Selbstbewußtsein, Willenserregung mit einem Zug der Geschäftigkeit, Ablenkbarkeit und Ideenflucht oder doch wenigstens Weitschweifigkeit.

Demgegenüber legen alle inadäquaten gemütlichen Regungen, Stumpfheit, Faseligkeit und Zerfahrenheit des Denkens, Sperrungen und negativistische Züge den Verdacht auf schizophrene Seelenstörungen nahe. Als hebephren wird man Kranke bezeichnen, welche die genannten Störungen mehr oder weniger rein darbieten, also vor allem jene eigenartige Zerfahrenheit im Fühlen, Denken und Handeln, neben denen eine eigenartige läppische Euphorie, unberechenbares Wesen, impulsive Entgleisungen, Manieriertheiten im Benehmen und Sprechen hervortreten, während Wahnideen und Sinnestäuschungen keine wesentliche Rolle spielen, wenn sie auch selten ganz fehlen. Die Verstimmungen der Schizophrenen, die häufig die Krankheit einleiten, sind meist eigenartig leer und haben eine negativistische Note. Für katatone Störungen sind der negativistische Stupor, vor allem wenn er von einzelnen impulsiven Akten durchbrochen wird, sodann die hyperkinetischen Erregungen mit sinnlosen Stereotypien, Verbigeration, Manieren, impulsiven Akten, Wechsel zwischen Negativismus und Befehlsautomatie bei vielfach indifferenter Stimmungslage und Besonnenheit kennzeichnend. Halluzinationen und absonderliche Wahnbildungen, die bei Hebephrenie wie bei Katatonie vorkommen, stehen bei der paranoiden Demenz im Vordergrund. Fast niemals fehlen die "Stimmen", das Halluzinieren von Sprachäußerungen. Unter den Wahninhalten sind besonders Beeinflussung durch magische Mittel (Hypnose, Fernwirkungen aller Art), geschlechtliche Beeinflussungen, unsinnige hypochondrische Ideen und körperliche Erlebnisse, sodann Gedankenecho, eingegebene, gemachte, übertragene Gedanken zu nennen. Im Beginn stehen meist Beziehungsideen und vage Verfolgungsvorstellungen. Gedankliche Zerfahrenheit, Verschrobenheiten im Ausdruck, Neigung zu Bildung neuer Wörter, Diskrepanz zwischen Stimmung und Wahninhalten vervollständigen das Bild. Man wird all diesen typischen Syndromen gegenüber aber nicht vergessen, daß sie gelegentlich auch organische Hirnkrankheiten verdecken können, also immer nach körperlichen Störungen (Pellagra, luische Prozesse, Infektionen, Vergiftungen) fahnden, bei den Halluzinosen vor allem an Alkohol, dann aber auch an Lues, Paralyse und Enzephalitis denken.

Endlich wird man, zumal bei Jugendlichen, im Auge behalten, daß auch abnorme Erlebnisreaktionen unter den allerverschiedensten, auch sonderbaren Bildern verlaufen können. Treten seelische Störungen im unmittelbaren $\mathrm{Zu}$ sammenhang mit ernsten seelischen Konflikten (Liebesenttäuschungen, Ehrenkränkungen, Strafdrohung) auf, so wird man meist rasch davon unterrichtet werden. Besonders vorsichtig wird man mit der Annahme endogener Störungen bei Untersuchungs- und Strafgefangenen sein, aber auch bei Unfallkranken. In der Regel werden dann unechte, theatralische, aufdringliche Züge, die Erscheinungen des Scheinblödsinns, hysterische Bewegungsstürme, phantastische Erlebnisse mit inhaltlichen Beziehungen zu den Konflikten, weitgehende äußere Beeinflußbarkeit des Zustandes durch Änderung der Konfliktslage und nachhaltige ärztliche Maßnahmen (Nichtbeachtung, scharfes Zupacken) die Sachlage durchsichtig machen. 


\section{Begutachtung}

Der Psychiater wird im allgemeinen in viel größerem Umfang als Gutachter in Anspruch genommen als die Vertreter der anderen Disziplinen. Es liegt dies einmal an den so häufigen forensisch bedeutsamen Verwicklungen, welche die seelischen Störungen mit sich bringen, dann aber auch an den weit verbreiteten nervösen Erscheinungen nach Unfällen aller Art. Auch der praktische Arzt steht aber nicht selten vor der, für ihn immer unangenehmen, Notwendigkeit, als Gutachter in psychiatrischen Fragen vor Gericht aufzutreten. Es wäre ein Irrtum, anzunehmen, daß der Arzt dann auch in jedem Fall ein bündiges Gutachten wirklich abgeben muß. Bei allem Tun ist es eine der bittersten, aber zugleich der höchsten Aufgaben des Arztes, die Grenzen des eigenen Sachverständnisses ständig vor Augen zu haben. Wo Richter, Rechtsanwälte und Staatsanwälte Fragen stellen, ist dies nicht anders als dort, wo der Arzt angesichts eines nicht ganz durchsichtigen Falles sich selbst Fragen stellt. Wie er hier sich bescheidet, abwartet und all das vermeidet, was schaden könnte, so wird er sich auch vor Gericht verhalten.

Allenthalben wird er also die Grenzen seines Sachverständnisses betonen, nur urteilen, so weit das Sachverständnis reicht, im übrigen aber die sachverständige Beobachtung anregen. Eine solche ist z. B. im $\S 81$ Strafprozeßordnung vorgesehen, aber auch bei der Entmündigung ist eine solche möglich ( $§ 656$ Zivilprozeßordnung). Wichtig ist, daß der Arzt selbst einen entsprechenden Antrag stellen muß. Was der praktische Arzt aus seinem Wissen heraus als Zeuge oder als sachverständiger Zeuge an Tatsachen bekunden kann, ist meist wichtiger als sein Gutachten selbst. Ein falsches Gutachten, gutachtliche Äußerungen, die ohne weiteres das unzureichende Sachverständnis ablesen lassen, entwerten dagegen, zum Schaden des Kranken und des Rechts, oft genug auch gute, sachverständig bekundete Tatsachen.

Der Arzt muß ferner immer im Rahmen seiner Aufgaben bleiben. Er ist nicht Richter, sondern Helfer des Richters, und er hat sich an die Fragen zu halten, die ihm gestellt sind. Nicht er hat etwa zu entscheiden, ob ein Kranker nach $\S 51$ freizusprechen sei, sondern nur nach bestem Wissen und Gewissen sein Gutachten dahin abzugeben, ob die Voraussetzungen des $\S 51 \mathrm{ihm}$ gegeben erscheinen. Bei der mündlichen Verhandlung soll der Arzt sich bei jeder Frage des Richters, wie vor allem der Anwälte, peinlich genau überlegen, daß er nicht bloß an Tatsachen - das ist ja selbstverständlich das bekundet, was er wirklich weiß, vielmehr auch, ob er nicht über die Grenzen seines Sachverständnisses hinausgelockt und in Widersprüche verwickelt werden soll.

Jeder Arzt soll die ärztlich wichtigsten Bestimmungen des Strafgesetzbuches und des Bürgerlichen Gesetzbuches kennen, um sich im gegebenen Falle die Fragen selbst zu stellen, die an ihn herantreten können, und auch seine Beobachtung und seine Aufzeichnungen danach einzurichten.

\section{Strafrecht}

$\S 51$ StGB.: „Eine strafbare Handlung ist nicht vorhanden, wenn der Täter zur Zeit der Tat wegen Bewußtseinsstörung, wegen krankhafter Störung der Geistestätigkeit oder wegen Geistesschwäche unfähig ist, das Unerlaubte der Tat einzusehen oder nach dieser Einsicht zu handeln. 
War die Fähigkeit, das Unerlaubte der Tat einzusehen oder nach dieser Einsicht zu handeln, zur Zeit der Tat aus einem dieser Gründe erheblich vermindert, so kann die Strafe nach den Vorschriften über die Bestrafung des Versuchs gemildert werden."

Diese neue Fassung des $\S 51$, welche die nationale Revolution mit sich gebracht hat, ist so klar, daß ihr hier nur wenig hinzugefügt werden muß. Alle ausgesprochenen Geisteskrankheiten, grobe epileptische Ausnahmezustände und verwandte Störungen fallen unter den Absatz 1 des Paragraphen, während der Absatz 2 etwa für schwere Formen der Psychopathie in Betracht kommen kann, wenn die strafbare Handlung gerade aus der Abnormität herauswächst. Wenn früher die Anwendung des $\S 51$ von sehr vielen Rechtsbrechern angestrebt wurde, ist dies in der neuen Zeit nicht mehr der Fall, da zugleich mit der Aufhebung oder Minderung der Verantwortlichkeit die sehr einschneidenden Maßnahmen der ,Sicherung und Besserung $^{6}$ zur Erörterung kommen müssen, nämlich

$\S 42 \mathrm{~b}$ : „Hat jemand eine mit Strafe bedrohte Handlung im Zustand der Zurechnungsunfähigkeit (§51 Abs. 1, 58 Abs. 1) oder der verminderten Zurechnungsfähigkeit (§ 51 Abs. 2, $\S 58$ Abs. 2) begangen, so ordnet das Gericht seine Unterbringung in eine Heil- und Pflegeanstalt an, wenn die öffentliche Sicherheit es erfordert. Dies gilt nicht für Übertretungen.

Bei vermindert Zurechnungsfähigen tritt die Unterbringung neben die Strafe."

Ergänzend zum $\S 51$ sind die Bestimmungen des $\S 330 \mathrm{a}$ und des $\S 42 \mathrm{c}$ wichtig:

§ 330 a lautet: „,Wer sich vorsätzlich oder fahrlässig durch den Genuß geistiger Getränke oder durch andere berauschende Mittel in einen die Zurechnungsfähigkeit (§51 Abs. 1) ausschließenden Rausch versetzt, wird mit Gefängnis bis zu zwei Jahren oder mit Geldstrafe bestraft, wenn er in diesem Zustand eine mit Strafe bedrohte Handlung begeht.

Die Strafe darf jedoch nach Art und Maß nicht schwerer sein, als die für die vorsätzliche Begehung der Handlung angedrohte Strafe.

Die Verfolgung tritt nur auf Antrag ein, wenn die begangene Handlung nur auf Antrag verfolgt wird."

Und § $42 \mathrm{c}:$, Wird jemand, der gewohnheitsmäßig im Übermaß geistige Getränke oder andere berauschende Mittel zu sich nimmt, wegen eines Verbrechens oder Vergehens, das er im Rausch begangen hat oder das mit einer solchen Gewöhnung in ursächlichem Zusammenhang steht, oder wegen Volltrunkenheit $(\S 330 \mathrm{a})$ zu einer Strafe verurteilt, und ist seine Unterbringung in einer Trinkerheilanstalt oder einer Entziehungsanstalt erforderlich, um ihn an ein gesetzmäßiges und geordnetes Leben zu gewöhnen, so ordnet das Gericht neben der Strafe die Unterbringung an."

Wichtig ist, daß hier nicht nur der Mißbrauch des Alkohols, sondern auch der anderen Rauschmittel, also besonders von Morphin und Kokain, getroffen ist.

Endlich sei hier noch der erste Satz des $§ 42 f$ genannt: „Die Unterbringung dauert so lange, als es ihr Zweck erfordert ${ }^{66}$, wobei jene in einer Heil- und Pflegeanstalt an keine Frist gebunden, aber jeweils nach 3 Jahren nachzuprüfen ist. In den Anstalten können die Untergebrachten zu angemessenen Arbeiten herangezogen werden (§ 42i).

Zu den Maßnahmen der Sicherung und Besserung gehören auch die Bestimmungen des $\S 42 \mathrm{k}$, wonach Sexualverbrechen neben der Strafe auch eine Entmannung zur Folge haben können. Der $§ 42 \mathrm{k}$ lautet in seinen zwei ersten Absätzen:

„Das Gericht kann neben der Strafe anordnen, daß ein Mann, der zur Zeit der Entscheidung das einundzwanzigste Lebensjahr vollendet hat, zu entmannen ist,

1. wenn er wegen eines Verbrechens der Nötigung zur Unzucht, der Schändung, der Unzucht mit Kindern oder der Notzucht ( $§ 176$ bis 178) oder wegen eines zur Erregung 
oder Befriedigung des Geschlechtstriebes begangenen Vergehens oder Verbrechens der öffentlichen Vornahme unzüchtiger Handlungen oder der Körperverletzung (§ 183, 223 bis 226) $\mathrm{zu}$ Freiheitsstrafe von mindestens 6 Monaten verurteilt wird, nachdem er schon einmal wegen einer solchen Tat zu Freiheitsstrafe rechtskräftig verurteilt worden ist, und die Gesamtwürdigung der Taten ergibt, daß er ein gefährlicher Sittlichkeitsverbrecher ist;

2. wenn er wegen mindestens zwei derartiger Taten zu Freiheitsstrafe von mindestens einem Jahr verurteilt wird und die Gesamtwürdigung der Taten ergibt, daß er ein gefährlicher Sittlichkeitsverbrecher ist, auch wenn er früher wegen einer solchen Tat noch nicht verurteilt worden ist.

Diese Maßnahme soll nur dann angewandt werden, wenn sie den Erfolg verspricht, den Sexualverbrecher von weiteren Straftaten gleicher Art abzuhalten. Der Gutachter wird sich daher vor allem dann für die Entmannung aussprechen, wenn das Sexualverbrechen auf einem gesteigerten oder doch starken Geschlechtstrieb beruht, so daß eine Aufhebung oder doch Herabminderung der Potenz die Neigung zur Wiederholung der Straftat beseitigt. (Bezüglich der freiwilligen Kastration bei sexuell Perversen siehe S. 238.)

Jugendliche werden strafrechtlich nach den folgenden Bestimmungen des Jugendgerichtsgesetzes behandelt:

§ 1: „Ein Jugendlicher im Sinne dieses Gesetzes ist, wer über vierzehn, aber noch nicht achtzehn Jahre alt ist."

§ 2: „Wer eine mit Strafe bedrohte Handlung begeht, ehe er vierzehn Jahre alt geworden ist, ist nicht strafbar."

§ 3: „Ein Jugendlicher, der eine mit Strafe bedrohte Handlung begeht, ist nicht strafbar, wenn er zur Zeit der Tat nach seiner geistigen und sittlichen Entwicklung unfähig war, das Ungesetzliche der Tat einzusehen oder seinen Willen dieser Einsicht gemäß zu bestimmen."

§ 5: „Hat ein Jugendlicher eine mit Strafe bedrohte Handlung begangen, so hat das Gericht zu prüfen, ob Erziehungsmaßnahmen erforderlich sind.“

§ 7: „Als Erziehungsmaßregeln sind zulässig:

1. Verwarnung.

2. Überweisung in die Zucht der Erziehungsberechtigten oder der Schule.

3. Auferlegung besonderer Verpflichtungen.

4. Unterbringung.

5. Schutzaufsicht.

6. Fürsorgeerziehung."

\section{Bürgerliches Gesetzbuch}

§ 104: „Geschäftsunfähig ist:

1. Wer nicht das 7. Lebensjahr vollendet hat.

2. Wer sich in einem die freie Willensbestimmung ausschließenden Zustande krankhafter Störung der Geistestätigkeit befindet, sofern nicht der Zustand seiner Natur nach ein vorübergehender ist.

3. Wer wegen Geisteskrankheit entmündigt ist."“

Der Absatz 2 wird ergänzt durch

§ 105: „Die Willenserklärung eines Geschäftsunfähigen ist nichtig.

Nichtig ist auch eine Willenserklärung, die im Zustande der Bewußtlosigkeit oder vorübergehender Störung der Geistestätigkeit abgegeben wird.“

Mit dem Geschäftsunfähigen sind Rechtsgeschäfte unmöglich, tatsächlich abgeschlossene Geschäfte unwirksam. Nur durch einen Vormund kann der Geschäftsunfähige am Rechtsverkehr teilnehmen. Die Entmündigung ist geregelt in

§ 6: „Entmündigt kann werden, wer infolge von Geisteskrankheit oder von Geistesschwäche seine Angelegenheiten nicht zu besorgen vermag." 
Dabei meint Geistesschwäche nicht das, was in der Psychiatrie darunter verstanden wird, sondern nur mindere Grade geistiger Störung, die dem Betroffenen noch einige wirksame Rechtsgeschäfte, auch ohne den Vormund, ermöglichen, und zwar entsprechend den Minderjährigen zwischen 7 und 21 Jahren. Diese beschränkt Geschäftsfähigen können etwa ein Testament widerrufen. Von ihnen abgeschlossene Verträge sind wirksam, auch wenn sie erst nachträglich vom Vormund genehmigt werden. Der Vormund kann ihnen das Recht einräumen, ein Geschäft zu betreiben, eine Dienst- oder Arbeitsstelle anzunehmen. Dagegen ist unter Geisteskrankheit im Sinne des $\S 6$ ein stärkerer Grad geistiger Störung verstanden und eine Entmündigung wegen Geisteskrankheit macht den Betroffenen geschäftunfähig.

Da das Entmündigungsverfahren unter Umständen lange dauert, kann bei Gefährdung nach $\S 1906$ vorläufige Vormundschaft angeordnet werden.

Wo, wie vielfach bei Geisteskranken, nur ein beschränkter Kreis von Geschäften in Frage kommt, so daß die umständliche Entmündigung nicht angezeigt ist, besonders auch bei kurzdauernden Psychosen, ist die Pflegschaft oft ausreichend.

$\S 1910$ Abs. 2: „Vermag ein Volljähriger, der nicht unter Vormundschaft steht, infolge geistiger und körperlicher Gebrechen einzelne seiner Angelegenheiten oder einen bestimmten Kreis seiner Angelegenheiten, insbesondere seine Vermögensangelegenheiten, nicht zu besorgen, so kann er für diese Angelegenheiten einen Pfleger erhalten.

Die Pflegschaft darf nur mit Einwilligung des Gebrechlichen angeordnet werden, es sei denn, daß eine Verständigung mit ihm nicht möglich ist."

Bei der Handhabung der Pflegschaft, die immer rasch zu erreichen ist, können alle Rechte des Kranken gut geschützt werden, wenn zugleich $\S 104$ Abs. 2 berücksichtigt wird. Die Unmöglichkeit der Verständigung darf bei jedem die freie Willensbestimmung ausschließenden Zustand angenommen werden. Ganz allgemein wird der Begriff, ,freie Willensbestimmung ${ }^{66}$, der auch im alten $\S 51$ erschien, im Sinne des neuen $\S 51$ auszulegen sein. Nach $\S 1920$ kann die Pflegschaft auf Antrag des Pflegebefohlenen aufgehoben werden. Das Vormundschaftsgericht wird hier meist dem Arzt die Frage der Geschäftsfähigkeit stellen.

Auch $\S 6$ Abs. 3 muß der Arzt kennen: „Entmündigt kann werden, wer infolge von Trunksucht seine Angelegenheiten nicht zu besorgen vermag oder sich oder seine Familie der Gefahr des Notstandes aussetzt oder die Sicherheit anderer gefährdet."

Aus dem neuen Eherecht vom 6. Juli 1938 seien folgende Bestimmungen wiedergegeben:

$\S 2$. Wer geschäftsunfähig ist, kann eine Ehe nicht eingehen.

$\S 22$ Abs. 1. Eine Ehe ist nichtig, wenn einer der Ehegatten zur Zeit der Eheschließung geschäftsunfähig war oder sich im Zustand der Bewußtlosigkeit oder vorübergehenden Störung der Geistestätigkeit befand. BGB.)

(Diese Bestimmung deckt sich inhaltlich mit dem früheren $§ 1325$ Abs. 2

\section{Aufhebung der Ehe (früher Anfechtung).}

§ 37. (1) Ein Ehegatte kann Aufhebung der Ehe begehren, wenn er sich bei der Eheschließung über solche die Person des anderen Ehegatten betreffende Umstände geirrt hat, die ihn bei Kenntnis der Sachlage und bei richtiger Würdigung des Wesens der Ehe von der Eingehung der Ehe abgehalten hätten.

(2) Die Aufhebung ist ausgeschlossen, wenn der Ehegatte nach Entdeckung des Irrtums zu erkennen gegeben hat, daß er die Ehe fortsetzen will, oder wenn sein Verlangen nach 
Aufhebung der Ehe mit Rücksicht auf die bisherige Gestaltung des ehelichen Lebens der Ehegatten sittlich nicht gerechtfertigt erscheint.

$\S 40$ Abs. 1. Die Aufhebungsklage kann nur binnén eines Jahres erhoben werden.

Gegenüber dem früheren $\S 1333$ ist hervorzuheben, daß jetzt nicht mehr von persönlichen Eigenschaften, sondern von die Person des anderen Ehegatten betreffenden Umständen die Rede ist. Damit ist eine weitherzigere Auslegung möglich, und es ist z. B. angängig, wegen des Vorhandenseins von Krankheitsanlagen (z. B. zur Schizophrenie) Aufhebungsklage einzureichen. Das Vorliegen solcher Krankheitsanlagen wird in der Regel durch die Erkrankung des veranlagten Ehepartners während der Ehe erkennbar.

Die Ehescheidung wegen Geisteskrankheit ist nunmehr geregelt in $\S 50$ und $\S 51$ :

§5: „Ein Ehegatte kann Scheidung begehren, wenn die Ehe infolge eines Verhaltens des anderen Ehegatten, das nicht als Eheverfehlung betrachtet werden kann, weil es auf einer geistigen Störung beruht, so tief zerrüttet ist, daß die Wiederherstellung einer dem Wesen der Ehe entsprechenden Lebensgemeinschaft nicht erwartet werden kann.“

Der Begriff ,geistige Störung ${ }^{66}$ ist nicht ganz fest umrissen. Offenbar wird - das ergibt sich aus der Begründung - an psychopathisches Verhalten gedacht. Da wir aber andererseits gewohnt sind, Psychopathen im allgemeinen für das, was sie tun, verantwortlich zu machen, so kann man im Zweifel sein, ob man berechtigt ist, in diesem die Ehe störenden Verhalten keine Eheverfehlung, also keine ${ }_{, S}$ Schuld $^{66}$ zu sehen. Für die endgültige Auslegung wird man daher noch obergerichtliche Entscheidungen abzuwarten haben.

§ 51: „Ein Ehegatte kann Scheidung begehren, wenn der andere geisteskrank ist, die Krankheit einen solchen Grad erreicht hat, daß die geistige Gemeinschaft zwischen den Ehegatten aufgehoben ist und eine Wiederherstellung dieser Gemeinschaft nicht erwartet werden kann."“

Dieser $\S 51$ ist der Nachfolger des $\S 1569$ BGB. Geisteskrankheit bedeutet hier einen stärkeren Grad geistiger Abwegigkeit als die geistige Störung im Sinne des $\S 50$. Es muß sich also immer um eine Psychose im engeren Sinne handeln, die so stark ist, daß die geistige Gemeinschaft voraussichtlich dauernd aufgehoben ist. In Betracht kommen würde also wohl z. B. die Schizophrenie, während der Paragraph bei manisch-depressivem Irresein nicht anwendbar ist. 


\section{E. Anhang}

\section{Intelligenzprüfung nach Binet-Simon}

Mit 3 Jahren:

\section{Ein Kind soll können:}

1. Mund, Nase, Auge auf Aufforderung zeigen.

2. Familiennamen angeben.

3. Zwei einstellige Zahlen nachsprechen.

4. Einen Satz von sechs Silben nachsprechen.

5. Auf Bildern die einzelnen dargestellten Gegenstände erkennen.

Mit 4 Jahren:

1. Vorgezeigte bekannte Gegenstände benennen (Messer, Schlüssel, Münze).

2. Drei vorgesprochene Zahlen wiederholen.

3. Das eigene Geschlecht angeben.

4. Von zwei untereinander gezeichneten Linien die längere herausfinden.

Mit 5 Jahren:

1. Von zwei gleichgroßen, sehr verschieden schweren Pappkästchen das schwerere herausfinden.

2. Einen Satz von zehn Silben nachsprechen.

3. Vier Gegenstände (Münzen) abzählen.

4. Ein Quadrat mit Tinte und Feder abzeichnen.

5. Ein diagonal in zwei Teile zerschnittenes Rechteck richtig zusammensetzen.

Mit 6 Jahren:

1. Vor- und Nachmittag unterscheiden.

2. Auf dem Bilde hübsche und häßliche Gesichter unterscheiden.

3. Den Zweck von gebräuchlichen Gegenständen (Gabel, Tisch, Stuhl, Pferd) angeben.

4. Dreizehn gleichartige Münzen abzählen.

5. Einen Rhombus abzeichnen.

\section{Mit 7 Jahren:}

1. Rechts und Links unterscheiden.

2. Drei gleichzeitig gegebene kleine Aufträge ausführen (Buch auf den Tisch legen, Tür öffnen, Stuhl holen).

3. Einen bildlich dargestellten Vorgang beschreiben.

4. Neun ungleichartige Münzen zusammenzählen.

5. Vier Farben benennen.

Mit 8 Jahren:

1. Lücken in Zeichnungen bemerken (Fehlen der Nase, der Augen, der Arme).

2. Fünf Zahlen nachsprechen.

3. Von 20-0 rückwärts zählen.

4. In Gedanken bekannte Gegenstände vergleichen (Schmetterling und Fliege, Holz und Glas, Fleisch und Knochen).

5. Das vollständige Datum angeben.

Mit 9 Jahren:

1. $\mathrm{Zu}$ Sachvorstellungen (Rose und Veilchen, Hund und Katze) den Oberbegriff finden.

2. Herausgeben auf ein Geldstück.

3. Benennen aller Münzen.

4. Aufsagen der Monate.

5. Entschlüsse in einfachen Lebenslagen fassen (Was tut man, wenn man den Zug verpaßt, etwas zerschlagen hat, zu spät zur Schule kommt?). 
Mit 10 Jahren:

1. Fünf abgestufte, gleich aussehende Gewichte nach der Schwere ordnen.

2. Beurteilung schwieriger Lebensverhältnisse (Was tut man, wenn man von einem Freund aus Versehen geschlagen wird, wenn man Wichtiges unternehmen will, über jemand gefragt wird, den man wenig kennt? Inwiefern kann Zorn eine böse Tat entschuldigen? Warum soll man Menschen nach ihren Taten, nicht nach ihren Worten beurteilen?).

3. Drei gegebene Worte in zwei Sätzen unterbringen.

4. Zeichnungen aus dem Gedächtnis wiedergeben.

5. Widersprüche in unsinnigen Aussagen auffinden. Als Beispiele werden angeführt:

a) Ein Radfahrer zerschlug sich den Kopf und starb auf der Stelle; man brachte ihn in ein Krankenhaus und fürchtet, daß er nicht davonkommen wird.

b) Ich habe drei Brüder, Paul, Ernst und ich.

c) Man hat gestern den Leichnam eines jungen Mädchens gefunden, der in 18 Stücke zerschnitten war; man glaubt an Selbstmord.

d) Gestern fand ein Eisenbahnunfall statt. Er war nicht schwer, die Zahl der Toten betrug nur 48.

e) Jemand äußerte: Wenn ich mich aufhänge, tue ich's nicht an einem Freitage, denn das ist ein Unglückstag.

Mit 11 und 12 Jahren:

1. Drei Worte in einem Satz unterbringen.

2. In drei Minuten mehr als 60 Worte finden.

3. Den Inhalt von Begriffen (Neid, Mitleid, Gerechtigkeit) erklären.

4. Durcheinandergeworfene Worte eines Satzes richtig ordnen (ein verteidigt Herrn mutig Hund guter seinen - wir Ferien auf gereist das sind in Land den - ich habe Lehrer meine verbessern gebeten zu Arbeit meinen).

5. Bei Linienpaaren mit stetig abnehmendem Längenunterschiede den Gleichheitspunkt richtig erkennen.

\section{Untersuchung des psychischen Zustandes nach Sommer}

I. Sprache: Nach Prüfung des motorischen Gebietes (Stottern, Stammeln, Paresen, Zuckungen, Mitbewegungen usw.), Feststellung der Erscheinungen im sensorischen Gebiet (Wortgedächtnis, Paraphasie, Iterativerscheinungen usw.).

II. Bewußtsein, Selbstbewußtsein und Orientiertheit. Genaue Darstellung der Reaktionen in sprachlicher und physiognomischer Beziehung auf folgende Fragen:
1. Wie heißen Sie?
2. Was sind Sie?
3. Wie alt sind Sie?
4. Woher sind Sie?
5. Welches Jahr haben wir jetzt?
6. Welchen Monat haben wir jetzt?
8. Welchen Wochentag haben wir heute?
9. Wie lange sind Sie hier?
10. In welcher Stadt sind Sie hier?
11. In was für einem Haus sind Sie hier?
12. Wer bin ich?
13. Was sind die anderen Leute hier?

7. Der wievielte Monat ist heute?

III. Gedächtnis: Fähigkeit der Reproduktion a) für längst Erlebtes, b) für jüngst Vergangenes; Gedächtnislücken; Fähigkeit, neue Eindrücke zu merken.

IV. Schulkenntnisse: besonders betreffend folgende Fragen:

1. Alphabet.

2. Zahlenreihe.

3. Monatsnamen.

4. Wochentage.

5. Vaterunser.

6. Zehn Gebote.

7. Deutschland, Deutschland über alles.

8. Wie heißen die größten Flüsse in Deutschland?

9. Wie heißt die Hauptstadt von a) Deutschland?

b) Preußen?

c) Sachsen?

d) Bayern?

e) Württemberg?

f) Hessen?

10. Wer führte 1870 Krieg?

11. Wer führte 1866 Krieg?

12. Wie heißt der Reichskanzler?

13. Wie heißt der jetzige Ministerpräsident?

14. Wann starb Kaiser Wilhelm I.? 
V. Rechenvermögen: Zahlreiche Aufgaben von verschiedener Schwierigkeit: Additionen, Subtraktionen, Divisionen, Multiplikationen.

VI. Untersuchung der Schrift: Schriftprobe (womöglich Name, Heimat, Geburtstag, Stand). Auffallende Merkmale der Schrift, u. a. Beschaffenheit der einzelnen Buchstaben (z. B. Zittererscheinungen), Verbindung derselben zu Worten, z. B. Auslassungen von Buchstaben, Verbindung zu Sätzen, z. B. Fehlen des grammatikalischen Zusammenhanges, Umstellungen.

VII. Sinnestäuschungen: Verursachung durch äußere Eindrücke oder Reizzustände im Nervensystem. Bezeichnung des oder der Sinnesgebiete. Konstanter oder wechselnder Charakter der Sinnestäuschungen. Beziehung zur Vorstellungsbildung. Elementare Sinnestäuschungen, Gedankenlautwerden.

VIII. Wahnideen: Vorsichtige Prüfung, ob Wahnbildung überhaupt vorliegt, besonders bei Klagen über Zurücksetzung, Eifersuchtsideen u. a. Qualität der Wahnbildung; Verfolgungs- und Größenwahn; konstanter oder wechselnder Charakter der Wahnbildung: Art der Verknüpfung der Ideen; Beeinflussung durch Stimmungen.

IX. Beeinflußbarkeit. Einfluß von psychiscben Momenten, besonders Beeinflussung durch Vorstellungen. Suggestibilität im Gebiet der Muskelzustände.

X. Assoziationen. Assoziative Verknüpfung in den spontanen Äußerungen des Kranken. Prüfung der Reaktionen auf zugerufene Reizworte.

XI. Urteilsvermögen: Mangelhafte Beurteilung der Umgebung, Mangel an Selbstkritik. Mangel an Urteil in geschäftlichen Angelegenheiten, Zeichen von Schwachsinn.

XII. Stimmungsanomalien. Qualität der Stimmung. Innere oder äußere Ursachen derselben. Konstanz oder Wechsel der Stimmung, physiognomischer Ausdruck der Stimmung, sonstige körperliche Begleiterscheinungen, z. B. bei Angst, Einfluß auf den Vorstellungsablauf.

XIII. Störungen des Willens. Unterscheidung der psychomotorischen von den unwillkürlichen Muskelspannungen. Erreglichkeit der motorischen Sphäre. Ausdauer der Innervationen. Katalepsie, Negativismus, Stereotypie von Haltungen und Bewegungen. Beziehung auf bestimmte Vorstellungskomplexe. Abnorme Richtungen des Wollens: Perversitäten.

XIV. Zwangsvorstellungen. Art der zwangsmäßig auftretenden Antriebe. Einfache Antriebe bei Tic convulsif. Zwangshewegungen, Zwangshandlungen, besonders im sprachlichen Gebiet. Zwangsmäßig auftretende Ideen. Reaktion des Bewußtseins auf die Zwangsimpulse, subjektives Gefühl des Zwanges bei „Zwangsvorstellungen“" im engeren Sinne. Beziehung derselben zur sozialen Umgebung.

XV. Soziales Verhalten. Unreinlichkeit. Störung der Umgebung durch Schreien usf., aggressives Verhalten, Gemeingefährlichkeit.

\section{Münchener Fragebogen}

\section{Schulkenntnisse}

A. Zeitliche Orientierung. 1. Wieviel Tage hat a) das Jahr, b) der Monat? 2. Wieviel Stunden hat der Tag? 3. Wie wird eine Minute eingeteilt? 4. Wann sind die Tage lang, wann kurz? 5. Wann beginnen Frühling, Sommer, Herbst und Winter?

B. Örtliche Orientierung. 6. Wie heißt die Hauptstadt von Bayern und wieviel Einwohner hat sie? 7. An welchem Fluß liegt sie, woher kommt dieser Fluß, wohin fließt er? 8. Wie heißen die Kreise von Bayern? 9. Wie heißen die Erdteile? 10. Wie reist man nach Amerika?

C. Geschichte. 11. Wie hieß der letzte König von Bayern? 12. Wer war der erste Deutsche Kaiser? 13. Was war 1870? 14. Welche Bundesgenossen, welche Feinde hatten wir im Weltkrieg? 15. Wer war Bismarck?

D. Religion. 16. Wer war Christus? 17. Wer war Luther? 18. Was gibt es für Religionen? 19. Was bedeutet die Taufe? 20. Was bedeuten die christlichen Feste?

E. Kulturgeschichte. 21. Wer war Schiller? 22. Was wissen Sie von ihm? 23. Nennen Sie große deutsche Dichtwerke!

F. Naturgeschichte usw. 24. Bei welcher Temperatur siedet das Wasser, bei welcher gefriert es? 25. In welchen Erdteilen kommen Löwen vor? 26. Nennen Sie eine giftige Pflanze! 27. Nennen Sie eine giftige Schlange! 28. Woher kommt die Wolle, die Baumwolle? 29. Was ist ein Kilometer? 30. Wie wird ein Kilogramm eingeteilt? 


\section{Erfahrungswissen}

A. Praktische Fragen. 31. Was kostet ein Ei? 31. Was kostet ein Pfund Brot? 33. Welche Klassen gibt es auf der Eisenbahn? 34. Wie lang ist Ihr Mittelfinger? 35. Woraus wird Papier gemacht?

B. Wirtschaftliche Fragen. 36. Wozu dienen die Invaliditätskarten? 37. Welcher Arbeiter verdient bei der Akkordarbeit am meisten? 38. Wen nennt man einen Kapitalisten? 39. Wer bekommt Zinsen? 40. Warum muß man Steuern zahlen?

C. Politische Fragen. 41. Wer ist wahlberechtigt? 42. Wer gibt die Gesetze? 43. Was für Aufgaben hat der Staatsrat? 44. Was will die Arbeitsfront? 45. Was für eine Verfassung haben wir in Deutschland?

D. Gericht. 46. Wofür sind die Gerichte da? 47. Weshalb wird man bestraft? 48. Wofür sind die Schutzleute da? 49. Welche Aufgaben hat a) der Rechtsanwalt, b) der Staatsanwalt? 50. Nennen Sie die bürgerlichen Ehrenrechte.

\section{Ethische Vorstellungen}

1. Was für Pflichten hat man gegen die Mitmenschen? 2. Warum ist der Wucher verwerflich? 3. Warum darf man Tiere töten, aber nicht quälen? 4. Ist man den Eltern unbedingt Gehorsam schuldig? 5. Was ist der Zweck der Ehe? 6. Wann würden Sie sich glücklich, wann unglücklich fühlen? 7. Was würden Sie tun, wenn Sie das große Los gewännen?

\section{Begriffsbildung}

Klarheit der Begriffe, Begriffsbestimmungen. Was bedeutet das: 1. Eine Insel? 2. Ein Pflug? 3. Miete? 4. Onkel? 5. Gemeinde? 6. Wehrpflicht? 7. Geiz? 8. Mut?

Stellen Sie von den folgenden Worten jeweils die zusammen, die eine ähnliche Bedeutung haben: 1. Übelwollen. 2. Absicht. 3. Barmherzigkeit. 4. Streit. 5. Vorsatz. 6. Teilnahme. 7. Vorhaben. 8. Zwietracht. 9. Mitleid. 10. Ziel. 11. Händel. 12. Mißgunst. 13. Zwist. 14. Scheelsucht. 15. Hader. 16. Vornehmen. 17. Zank. 18. Eifersucht. 19. Zweck. 20. Nächstenliebe. 21. Neid.

Vorstellungsreichtum. Subsumptionen: 1. Nennen Sie soviel Bäume im Wald, als Sie kennen! 2. Raubtiere! 3. Metalle!

4. Was sind Hammer, Amboß, Feile, Säge, Zange, Bohrer alle zusammen? 5. Was sind Neid, Haß, Eifersucht, Lügenhaftigkeit alle zusammen? Nennen Sie jedesmal weiter entsprechende Dinge!

6. Nennen Sie alle roten Dinge, die Sie kennen! 7. Alle durchsichtigen! 8. Alle elastischen!

Gliederung der Vorstellungen. 1. Nennen Sie alle Eigenschaften des Zuckers! 2. Des Wassers! 3. Alle Teile eines Baumes! 4. Des menschlichen Körpers!

Ordnung der Vorstellungen. Bringen Sie die folgenden Begriffsreihen in eine sinngemäße zeitliche Ordnung: 1. Mähen, Säen, Mahlen, Backen, Dreschen, Pflügen. 2. Waffenstillstand, Schlacht, Kriegserklärung, Friedensschluß, Ausmarsch der Truppen, Sieg. 3. Arzt, Fußballspiel, Heilung, Verband, Beinbruch, Besserung, Sturz. 4. Sinkendes Schiff, Landung, Nebel, Rettungsboote, Leck im Schiff, Schiffszusammenstoß (nach Petzer und Stern).

\section{Urteil}

Gleichsinnige Sprichwörter. Stellen Sie von den folgenden Sprichwörtern jeweils die zusammen, die annähernd den gleichen Sinn haben! 1. Wie man in den Wald hineinschreit, so schallt's zurück. 2. Wo die Menge, da ist Irrtum. 3. Lügen haben kurze Beine. 4. Erst wägen, dann wagen. 5. Der Apfel fällt nicht weit vom Stamm. 6. Es ist nichts so fein gesponnen, es kommt doch an die Sonnen, 7. Viele Köche verderben den Brei. 8. Ein finstrer Blick kommt finster zurück. 9. Vorgetan und nachbedacht, hat schon manchem groß Leid gebracht. 10. Wie die Alten sungen, so zwitschern die Jungen.

Unterscheidungen. Wie unterscheiden sich: 1. Ochs und Pferd? 2. Vogel und Schmetterling? 3. Wasser und Eis? 4. Glas und Holz? 5. Kind und Zwerg? 6. Haß und Neid? 7. Geiz und Sparsamkeit?

Ordnen von Worten zu Sätzen: 1. Blüten war ganz schneeweißen Baum mit bedeckt der. 2. Der Dunkelheit vor kaum die Augen sehen konnte den in man Hand.

Sinnfehler. In dem folgenden sind einige Sinnfehler enthalten, bezeichnen Sie diese:

Um 4 Uhr an einem windstillen Morgen im Winter - die Sonne war eben aufgegangen wurden die Einwohner des Fischerdorfs durch das Nebelhorn geweckt. Wegen der schneidenden 
Kälte dicht in Pelze gehüllt, eilten Sie zum See hinunter, der ganz eingefroren war. Es konnte einer den anderen in dem dichten Nebel kaum auf zwei Schritte erkennen. Draußen auf dem Wasser, etwa $15 \mathrm{~km}$ entfernt, sahen sie ein großes Schiff im Sinken. Man hörte deutlich die Hilferufe der Schiffbrüchigen. Auf den vom Sturm gepeitschten Wellen schwamm ein kleines Boot daher. Die Insassen ruderten mit aller Gewalt, konnten aber nicht ans Ufer kommen. Da warf ein von der Sommersonne gebräunter Junge seine dünnen. Kleider ab und ging mutig ins Wasser. Obgleich er riesengroß und kräftig war, gelang es ihm doch, das Boot ans Ufer zu ziehen und die Insassen zu retten.

Ebbinghaus. Ergänzen Sie sinngemäß die Lücken in dem folgenden! Gegen vier kam Günther wieder an - Strand. Er war vom langen Gehen - geworden und legte nieder. Wenige Schritte - ihm ent - spielten ein - Kinder im Sande. Plötzlich - - er ein kläg- - Geheul. Die Kinder hatten - - Hund - Wasser gew - - Das Tier versuchte verg - _, den Boden wieder zu _ _ _ . Es konnte kaum noch - - Günther vers- den Hund mit - Stock heranzuz_ - . Es _ - ihm nicht. Da ging er bis an die Hüften ins - und hob den - her-. Sowie er den Rücken ge - - hatte, ergr- der größte Knabe den — wieder, um ihn noch — - ins _ - zu — - Günther hielt den — - fest und _ — ihm, daß das Tier - - würde.

Bindewortergänzung. Anleitung wie beim obigen Text.

Nachdem der Schuß gefallen war, war plötzlich alles ganz still. Er rief den Freund an; es kam - keine Antwort. Lange rief er - horchte, - er sich entschloß, in den Nebel hineingehen. Noch - er den Freund erreichte, fand er am Boden Blut. Wenige Schritte weit lag der Freund selbst - einem Strauch verdeckt. Der Schuß hatte ihn in die Herzgrube getroffen, - er höchstens noch ganz kurze Zeit gelebt haben konnte. Man hätte meinen können, - er sofort gestorben wäre, - sich nicht weiter entfernt das Blut gefunden hätte. Er nahm die Leiche in die Arme - trug sie quer über die Insel - dem Boote hin, - - sie gekommen waren. Dann nahm er die Ruder auf, - ans Land - rudern. - er ruderte, überlegte er sich, - er über den Unglücksfall sagen sollte, zermarterte sich - umsonst das Gehirn. Er wußte nur, - er die Angehörigen schonend vorbereiten müsse. - er ans Land gekommen war, ging er nach einem Bauernhof hin, - ein Fuhrwerk - bekommen. - der Mann fragte, - das Unglück gekommen sei, erzählte er den Hergang wahrheitsgemäß, - ihm das schaden konnte. - sollte er aber lügen, - er sich keine Vorwürfe zu machen hatte.

\section{Einbildungskraft}

Ergänzung von Sätzen. Suchen Sie die folgenden Sätze sinngemäß zu ergänzen: 1. Da für den erkrankten Versammlungsredner ein Ersatz in der Eile nicht beschafft werden konnte, -

2. Damit in der Wohnung, in welcher der Vorfall stattgefunden hatte, die Spuren des Täters nicht verwischt würden, -

3. Wenn auch die Arbeit eine gewaltige gewesen ist -

Worte aus Buchstaben zusammensetzen. Aus folgenden Buchstabenreihen lassen sich verschiedene Worte zusammensetzen. Aus jeder Reihe sollen mehrere Worte gebildet werden. Weitere Buchstaben dürfen nicht verwendet werden. Es müssen alle angeführten in den betreffenden Worten vorkommen.

1. e, e, g, i, r, s.

2. $d, e, e, i, n, r$.

Masselon. Aus jeder der folgenden Zusammenstellungen von je drei Worten sollen Sie so viel als möglich Sätze von verschiedenem Sinn bilden! Es dürfen auch Erzählungen sein.

1. Bauer, Hund, Bettler.

2. Junge, Katze, Zucker.

3. Jäger, Hund, Hase. 


\section{Literaturhinweise}

Der junge Mediziner, der sich eingehender mit der Psychiatrie beschäftigen will, wird am besten zunächst umfangreichere Gesamtdarstellungen, welche auch die offenen Fragen eingehend behandeln, zur Hand nehmen. Ich nenne:

O. Bumke, Lehrbuch der Geisteskrankheiten. 4. Aufl., München 1936. Das Buch enthält vortreffliche anatomische Abschnitte von H. Spatz.

E. Kraepelin, Psychiatrie. 8. Aufl. 4 Bde. Leipzig 1909-15. Das Buch, von dessen 9. Aufl. die ersten beiden Bände (gemeinsam mit J. Lange) vorliegen, spiegelt die gesamte Entwicklung der modernen Psychiatrie wider und galt zu Lebzeiten des großen Forschers als das klinische Werk nicht bloß in Deutschland.

O. Bumke, Handbuch der Geisteskrankheiten. Berlin 1928-30. 11 Bde.

Wer sich der Psychiatrie zuwenden will, muß vordringlich auch die Lehrbücher von

C. Wernicke, Grundriß der Psychiatrie in klinischen Vorlesungen, 2. Aufl., Leipzig 1906, und E. Bleuler, Lehrbuch der Psychiatrie, Berlin 1937, 6. Aufl., zur Hand nehmen.

Von Einzeldarstellungen seien nur wenige von klassischer Bedeutung und daneben andere, welche die moderne Problemlage besonders gut spiegeln, genannt.

Zur allgemeinen Psychiatrie

Jaspers, Allgemeine Psychopathologie. 3. Aufl. Berlin 1923. Kretschmer, Medizinische Psychologie. 4. Aufl. Leipzig 1930.

\section{Zur Ursachen- und Strukturlehre}

A. Hoche, Die Bedeutung der Symptomenkomplexe in der Psychiatrie. Z. Neur. 12 S. 540 (1912). Kraepelin, E., Die Erscheinungsformen des Irreseins. Ebenda 62 S. 1 (1920). E. Kretschmer, Gedanken über die Fortentwicklung der klinischen Systematik. Ebenda 48 S. 370 (1919).

\section{Zur Konstitutions- und Erblehre}

H. Hoffmann, Vererbung und Seelenleben. Berlin 1922. Gütt, Rüdin, Ruttke, Gesetz zur Verhütung erbkranken Nachwuchses. 2. Auflage. München 1936. F. Kehrer und E. Kretschmer, Die Veranlagung zu seelischen Störungen. Berlin 1924. Luxenburger, Psychiatrische Erblehre. Ferner das im Erscheinen begriffene Handbuch der Erbkrankheiten, herausgegeben von Gütt. Leipzig 1938.

\section{Zum angeborenen Schwachsinn}

T. Sjögren, Die juvenile amaurotische Idiotie. Klinische und vererbungsmedizinische Untersuchungen, 1930. Hereditas XIV und Klinische und vererbungsmedizinische Untersuchungen über die Oligophrenie in einer nordschwedischen Bauernpopulation. Kopenhagen 1932. W. Weygandt, Der jugendliche Schwachsinn. Stuttgart 1936.

\section{Zur Paralyse}

A. Hoche, Dementia paralytica. 1912, Aschaffenburgs Handbuch, und Bostroem in Bumkes Handbuch.

Zur Encephalitis epidemica

F. Stern, Die epidemische Enzephalitis. 2. Aufl. Berlin 1928.

\section{Zum Alkoholismus}

K. Bonhoeffer, Die akuten Geisteskrankheiten der Gewohnheitstrinker, Jena 1901, und Meggendorfer in Bumkes Handbuch der Geisteskrankheiten. 


\section{$-273-$ \\ Vergiftungen}

K. Pohlisch und F. Panse, Schlafmittelmißbrauch. Leipzig 1934.

Andere symptomatische Psychosen

K. Bonhoeffer, Die Psychosen im Gefolge von akuten Infektionen, Allgemeinerkrankungen und inneren Erkrankungen, 1912, in Aschaffenburgs Handbuch. Ewald in Bumkes Handbuch.

$$
\text { Epilepsie }
$$

Mauz, Die Veranlagung zu Krampfanfällen. Leipzig 1937. Stauder, Konstitution und Wesensveränderung der Epileptiker. Leipzig 1938.

\section{Schizophrenie}

E. Bleuler, Dementia praecox oder Gruppe der Schizophrenien, 1911, in Aschaffenburgs Handbuch. K. Kleist, Untersuchungen zur Kenntnis der psychomotorischen Bewegungsstörungen bei Geisteskranken, und Weitere Untersuchungen usw. Leipzig 1908 und 1909. Die beiden Bücher von Bleuler und Kleist sollten nebeneinander gelesen werden. Man sollte sie nach Jaspers zuerst vornehmen.

$$
\text { Manisch-depressives Irresein }
$$

E. Reiß, Konstitutionelle Verstimmung und manisch-depressives Irresein. Z. Neur. 2 S. 347 (1910). J. Lange, in Bumkes Handbuch. F. Mauz, Die Prognose der endogenen Psychosen. Leipzig 1930.

\section{Psychopathische Persönlichkeiten}

Kurt Schneider, Die psychopathischen Persönlichkeiten. Leipzig und Wien 1923 (seitdem mehrere Auflagen). J. Lange, Psychopathie und Erbpflege: Berlin, Metzner 1934.

\section{Abnorme seelische Reaktionen}

Kurt Schneider, Die abnormen seelischen Reaktionen, 1927, in Aschaffenburgs Handbuch. R. Gaupp, Zur Psychologie des Massenmordes. Berlin 1914. E. Kretschmer, Der sensitive Beziehungswahn. Berlin 1927. 2. Aufl.

\section{Behandlung}

Max Müller, Prognose und Therapie der Geisteskrankheiten. Leipzig 1936. H. Prinzhorn, Psychotherapie. Leipzig 1929. J. H. Schultz, Die seelische Krankenbehandlung (Psychotherapie). Jena 1919.

\section{Begutachtung}

M. Reichardt, Einführung in die Unfall- und Invaliditätsbegutachtung. 2. Aufl. Jena 1921. A. Hoche, Handbuch der gerichtlichen Psychiatrie. 3. Auf. Berlin 1934. 


\section{Sachverzeichnis}

Ablenkbarkeit 42, 203

Absenzen 157

Abulie 23

Addisonsche Krankheit 134

Affektabschaltung 230

Affekterlebnisse, abnorme 30

Affektillusionen 35

Affektivitätsstörungen 28

Akinese 23

Akrozyanose 182

Akte, impulsive 24

Alkoholepilepsie 146

Alkoholismus 137

Alzheimersche Krankheit 117

Ambitendenz 175

Ambivalenz 172

Amentia 71

Amnesie 54, 55

Anankasten 218

Angstreaktion 229

Angstsyndrom 76

Anstaltsbehandlung 250

Arbeitstherapie 249

Arteriosklerose 120

Arzneimittelvergiftung 153

Assoziationen 40

Ataxie, intrapsychische 170 , 196

Athetose 128

Atropinvergiftung 154

Aura 72, 156, 168

Autismus 182, 190

Basalmeningitis 107

Befehlsautomatie 25, 174

Begriffsstörungen 38

Begutachtung 262

Behandlung der Geisteskrankheiten 245

Benommenheit 49, 70

Beruhigungsmittel 252

Bewußtseinsstörungen $49 \mathrm{ff}$.

Bewußtseinsveränderungen, psychogene 235

Beziehungswahn, schizophrener 177

-, sensitiver 230

Binet-Simon, Intelligenzprüfung $82,257,267$
Bradyphrenie 110

Brombehandlung bei Epilepsie 166

Bromvergiftung 154

Charakter, hysterischer 222

Chorea gravidarum 137

-, Huntington 124

- minor 127

Commotio cerebri 89

Dämmerzustand 71, 158, 236

Debilität 84

Degenerationspsychosen 207

Déjà vu 58

Delirien 37, 70, 130, 236

Delirium tremens 140

Dementia paralytica 92

- praecox 169

- simplex 184

Demenz 59

-, epileptische 161

-, senile 112

Demenzsyndrome 68

Denkstörungen, formale 39

-, inhaltliche 43

Depersonalisationssyndrom 78

Depression, klimakterische 123

-, melancholische 199

-, psychogene 228

-, senile 115

- bei Arteriosklerose 121

—, zyklothyme 206

Diagnose, psychiatrische 259

Dipsomanie 160, 221

Drangzustände 23, 110

Dysmegalopsie 33

Echolalie 25, 174

Echopraxie 25, 174.

Eidetik 34

Eigenbeziehung, primäre 44

Einbildungen, wahnhafte 47 , 76,237

Einfälle 57

Eklampsie 137

Emotionstupor 230

Engramme 52
Entwicklungen, paranoische 46

Entziehungserscheinungen 148

Enzephalitis epidemica 109

-, Endhirn- 125

-, Stammhirn- 126

Epilepsie, genuine 155

—, habituelle 146

-, symptomatische 155,167

-, syphilitische 108

-, traumatische 92

Epilepsieäquivalente 159

Epilepsie, Alkohol- 146

- Myoklonus- 155

Erblichkeit 64

Erinnerungshalluzinationen 57

Erinnerungstäuschungen 56

Erregung, zyklothyme 206

Erregungen, epileptiforme138

-, katatone 174

Erschöpfungspsychosen 132

Erwartungsneurose 227

Exhibitionismus 241

Fetischismus 242

Flexibilitas cerea 25

Fugues 160

Gedächtnis 34, 52

Gedächtnisstörungen 54

Gefangenenwahnsinn 234.

Gefühlserlebnisse, abnorme 30

Gegenstandsbewußtsein 32,49

Gehirnverletzungen 89

Gemeinschaftstriebe 13

Generationsphasen 136

Geschwistermethode 65

Gesetz zur Verhütung erbkranken Nachwuchses 245

-, Ehegesundheits- 245

Gesetz, bürgerliches 264

-, Straf- 262

Gewöhnungswirkung bei Morphin 147

Gifte, gewerbliche 152

Grimassen 24

Größenideen 46

Grundtriebe 13 
Halluzinationen 36

- der Erinnerung 57, 180

Halluzinose 74

Hebephrenie 183

Heboide 225

Herderscheinungen, verwaschene 118

Herdparalyse 97

Heroinismus 150

Hirndurckerscheinungen 91

Hirnerschütterung 89

Hirngeschwülste 128

Hirnmantelsymptomenkomplex 79

Hirnquetschung 91

Hirnschwellung 182, 194

Hirnstammsyndrome 79

Homosexualität 241

Hyperkinese 74

Hypermetamorphose 4.2

Hypertonie 123

Hyperventilation 158

Hypnose 51

Hypobulie 23

Hypomanie 206

Hypophysenstörungen 134

Hysterie 222, 235

Ideen, überwertige 4.5

Ideenflucht 4.2, 202

Idiotie 82

-, amaurotische 87

Illusionen 35

Imbezillität 82

Insanity, moral 224

Intelligenzstörungen 58

Irresein, impulsives 222

-, induziertes 241

-, manisch-depressives 199

Kastration 134

Katarrh, meningealer 106

Katatonie 184

Kinderkrämpfe 164

Kohlenoxydvergiftung 153

Kokainismus 150

Kollapsdelirien 130

Koma 50

Komplexe 31

Konfabulationen $57,69,144$

Konstitutionslegierung 207

Kontrastideen 219

Körperbau, pyknischer 209

Körperbautypen 65, 191

Korsakowsche Krankheit 144

Krankengeschichte 258

Krankheitsformen 80

Kretinismus 87
Liquorsyndrome 103

Lues cerebri 105 ff.

- neurotrope 101

Luminalbehandlung bei Epilepsie 166

Luophobie 106

Makropsie 33

Malariatherapie 99

Manie 202

-, senile 116

-, verworrene 204

Manieren 24, 173

Melancholie 199

Meningitiden 126

Meningitis, syphilitische 104.

-, Basal- 107

Merkfähigkeit 54ff.

Mikropsie 33

Mischzustände, manischdepressive 206

Mongolismus 86

Morphinismus 146

Mutismus 25, 174

Myoklonusepilepsie 155

Myxödem 134

Narkolepsie 168

Negativismus 25, 173

Neologismen 180

Neurasthenie, konstitutionelle 70,226

-, syphilitische 106

Neurose, traumatische 239

Oligoepilepsie 165

Oligophrenien 81

Onanie 241

Opiumbehandlung 211

Parakinesen 24.

Paralyse, juvenile 102

-, progressive 92

- - stationäre 98

-, Lissauersche 97

Paralysis agitans 128

Paramnesie, reduplizierende 58

Paramimie 173

Paranoia Kraepelin 233

Paranoid, seniles 116

Paraphrenie 191, 193

Pareidolien 37

Parkinsonismus 110

Pellagra 133

Perseveration 41

Persönlichkeiten, psychopathische 214
Perversitäten 241

Pfropfhebephrenie 85

Phantomglied 36

Phobien 49, 219

Picksche Krankheit 119

Polioenzephalitis 126, 142

Polyneuritis gravidarum 137

Poriomanie 160

Porropsie 33

Präparalyse 102

Präsenile Seelenstörungen 123

Proportion, psychästhetische 190

Pseudodemenz 236

Pseudohalluzinationen 35

Pseudologia phantastica 57, 223

Pseudologie 57

Pseudoparalyse 102

Pseudospontanbewegungen 74

Psychoanalyse 247

Psychopathien 214ff.

Psychosen, paranoide präsenile 124

-, symptomatische 129

-, Struktur der 67

Psychotherapie 247

Pyknolepsie 168

Pyriferkur 99

Querulanten 45

- -wahn 231

Querulanz 78

Rausch, pathologischer 137

Reaktionen, abnorme 62, 227

-, querulatorische 231

Reaktionstypen, exogene 60 , 129

Rentenneurose 239

Reproduktionsstörungen 54, 55

Sadismus 242

Schizoidie 190

Schizophrenie 169

Schizothymie 190

Schlafmittel 252

Schlafmittelvergiftung 154

Schreckreaktion 229

Schwachsinn 59

-, angeborener 81

_, früherworbener 81

- nach Hirnschädigungen 85

Schwächezustand, hyperästhetisch-emotioneller 69 
Sklerose, multiple 127

Sodomie 242

Spasmophilie 169

Spätkatatonie 124

Spontanremissionen 98

Status epilepticus 156

- paralyticus 95

Stereotypien 24, 41, 173

„Stimmen 36,180

Strafrecht 262

Struktur der Psychosen 64

Stupor 73

-, depressiver 200

-, katatoner 24, 173

-, manischer 206

Suchten 146

Symptome, katatone 74, 174

-, psychogene körperliche 237

Symptomenkomplex, amnestischer 69

Syndrome 67
Tabespsychosen 108

Taboparalyse 99

Tetanie, kindliche 169

Transitivismus 178

Triebleben, Störungen des 13

Unbewußte, das 51

Untersuchung, psychiatrische 256

Ursachen des Irreseins 59

Verbigeration 25, 173

Verfolgungswahn der Schwerhörigen 234

Verhältnisblödsinn 84

Verstimmungen, dranghafte 77

-, epileptische 160

Vitalgefühle 28

Vorstellungen 34

Wahnbildungen, besonnene 46
Wahnerkrankungen, chronische 144

Wahnideen 44

-, affektive 45, 201

-, besonnene 46

-, mobile 45,201

-, primäre 44

Wahninhalte 47

Wahnstimmung, schizophrene 178

Wahnsyndrome 75

Wahrnehmungsstörungen 32

Wandertrieb 160

Zuwendungsstörungen 22

Zwangserscheinungen 19

- -menschen 218

- -neurosen 219

Zwangssyndrome 78

- -vorstellungen 48

Zwillingsmethode 65, 198

Zykloidie 210

Zyklothymie 210 


\section{Verbrechen als Schicksal \\ Studien an kriminellen Zwillingen}

Von Professor Dr. Johannes Lange

Oberarzt am Krankenhause München-Schwabing und Abteilungsleiter an der Deutschen Forschungsanstalt für Psychiatrie (Kaiser-Wilhelm-Institut) in München

1929. Gr. $-8^{0}$. 96 Seiten. Mit 5 Abbildungen. Kartoniert RM 6.30

\section{Die Folgen der Entmannung Erwachsener \\ An Hand der Kriegserfahrungen dargestellt}

Von Professor Dr. Johannes Lange

Direktor der Psychiatrischen und Nervenklinik an der Universität Breslau

(Arbeit und Gesundheit, Heft 24)

1934. Gr.-80. 178 Seiten. Mit 2 Abbildungen. RM 5.-

\section{Medizinische Psychologie}

Von Professor Dr. Ernst Kretschmer, Marburg

Fünfte, vermehrte und verbessserte Auflage

1939. Gr.-80 . Etwa 270 Seiten. Mit 23 Abbildungen. Erscheint im März 1939

\section{Psychiatrische Vorlesungen für Ärzfe}

Von Professor Dr. Kurt Schneider

Direktor des Klinischen Instituts der Deutschen Forschungsanstalt für Psychiatrie (Kaiser-Wilhelm-Institut) in München

Zweite, verbesserte und vermehrte Auflage

1936. 80 $^{\circ} 196$ Seiten. Kartoniert RM 6.20, in Ganzleinen gebunden RM 6.80

\section{Probleme der klinischen Psychiatrie}

Von Professor Dr. Kurt Schneider

Leiter der Klinischen Abteilung der Deutschen Forschungsanstalt für Psychiatrie (Kaiser-Wilhelm-Institut) in München

1932. $8^{0}$. 46 Seiten. Kartoniert RM 2.60

\section{Vom Wesen der Neurose und von ihren Erscheinungsformen}

Von Dr. Ernst Speer

Nervenarzt in Lindau, Bodensee

1938. $8^{0}$. 122 Seiten. Mit 1 Abbildung. RM 3.60, in Ganzleinen gebunden RM 4.80

\section{Sellabrücke und Konstitution}

Ein Beitrag zur Diagnose und Therapie gefarnt-hypophysärer Krankheiłsfälle der ärzflichen Praxis

Von Dr. med. J. A. Schneider

Assistenzarzt am Institut für Konstitutionsforschung und der Poliklinik für Konstitutionsmedizin an der Charitê, Berlin

1939. Lex.-8 ${ }^{0}$. 58 Seiten. Mit 9 Tafeln. Kartoniert RM 6.50 
Anatomie. Lehrbuch und Atlas (Rauber-Kopsch). Prof. Dr. Friedrich Kopsch. 15. Aufl. In 3 Bänden. Lex.-8

B and I: Allgemeines - Skelettsystom - Muskelsystem. Mit 723, z. Teil farbigen Abb. 1939. VI, $635 \mathrm{~S}$.

B and II: Wingeweide - GefmRsystem. Geb. RM 26.-

B a nd III: Nervensystem - Sinnesorgane. Mit 562, z. Teil farbigen Abb. 1939. V, 555 S. Geb. RM 26.-

Bis zum Vorliegen des vollständigen Werkes in 15. Aufl. mit neuer Nomenklatur kann das Werk noch in 14. Auflage geliefert werden (6 Abteilungen in 5 Bänden. Lex..-80)

Abteilung I: Allgemeiner Teil melost Zellen- und Gewebelehre. Besonderer Teil: Außere Haut. Mit 324, z. T. farbigen Abb. 1934. VI, 249 Seiten. Geb. RM 11.40 Abteilung II: KKmochen, Bänder. Mit 443, z. T. farbigen Abb. 1933. III, 350 S. Geb. RM 13.40 A b teil ung III: Muskeln, Gefäße. Mit 394, z. T. farbigen Abb. 1933. IV, 471 S. Geb. RM 18.10

Käufer der 15. Aufl. können den Abschnitt „Gefäße" gesondert zum Preise von geb. RM 11.- erhalten Abteilung IV: Cingeweide. Mit 468, z. T. farbigen Abb. 1936. IV, 412 Seiten. Geb. RM 16.60 A bteilung V/VI: Nervensystem - Simmesorgane. Mit den Jenaer anatomischen Namen. Mit 479 , z. T. farbigen Abb. 1938. V, 492 Seiten.

Geb. RM 23.50

Zu Abt. I-IV: Die Nomina anatomica des Iahres 1895 (BB. N. A.) nach der Buchstaben reihe geordnet u. gegenübergestellt den Nomina anatomica des Jahres 1935 (I. N. A.) Von Prof. Dr. Fried. Kopsch. 2., verbesserte Aufl. 1938. Lex.-8 ${ }^{\circ}$. IV, 103 Seiten. Kart. RM 2.50

Anatomie, Taschenbneh der pathologisehen. Prof. E. v. Gierke. 13. Aufl. (46.-50. Tsd.) I. Allgemeiner Teil. $68 \mathrm{Abb}$. 1936.

II. Spezieller Teil. 65 Abb. 1937.

Kart. RM 4.50 Kart. RM 5.85

Anatomicum. Repetitorium. Prof. Dr. G. Broesike †. 4., durchgesehene Aufl. von Prof. Dr. Rudolf Mair, Halle. 73, zumeist mehrfarbige Abb. im Text. 1937.

Geb. RM 15.

Der , A rzate-Knigge". Uber den Umgang mit Kranken und über Pflichten, Kunst und Dienst der Krankenhausärzte. Prof. Dr. med. et phil. C. Seyfarth. 3. Aufl. 1938.

Augenheilkunde. Grundriß. Prof. Dr. A. Brückner und Prof. Dr. W. Meisner. Für Studierende und praktische Ärzte. 2., verbesserte Aufl. $221 \mathrm{Abb}$. und 9 farbige Tafeln. 1929. RM 10.-, geb. RM 12.-

Augenkrankheiten, Atlas der. Sammlung typischer Krankheitsbilder mit kurzen diagnostischen u. therapeutischen Hinweisen. Prof. Dr. R. Thiel. 420, meist farbige Abb. 1937. Ganzlein. geb. RM 24.-

Festallungsordnumg für Arzate vom 25. März 1936 in der Fassung vom 21. Juli 1938. 3. Aufl. 1938.

$\mathrm{RM}-.90$

Blutmorphologio, Leitfaden der. Lydia Schudel. 2. Aufl. 14 farbige Tafeln. 1938. Text in Deutsch, Englisch, Französisch.

Kart. RM 6.80

Botanik, Miehes Taschenbuch der. I. Teil: Morphologie, Anatomie, Fortpfianzung, Fntwicklungsgeschichte, Physiologie. 10, verbess. Aufl., bearbeitet von Dr. W. Mevius. $318 \mathrm{Abb} .1938$.

Kart. RM 5.85 II. Teil: Systematik. 5., verb. Aufl., bearbeitet von Dr. W. Mevius. $143 \mathrm{Abb}$. 1933. Kart. RM 3.90

Chemie, Grumdriß der organischen. 15. Aufl. Bearb. von Prof. Dr. C. Naegeli. 1938. Kart. RM 6.80

Chemie, Lehrbuch der organischen. Prof. Dr. Paul Karrer. 5., umgearbeitete und vermehrte Aufl. $6 \mathrm{Abb}$. im Text und 1 Tafel. 1937.

RM 34.-, geb. RM 36.-

Chemie und Mikroskopie, Klimische. Med.-Rat Dr. L. Hallmann. 113 Abb. 1 Spektral-Tafel. Erscheint im März 1939.

Differentialdiagnose in der immeren Medivin. Prof. Dr. O. Naegeli. 162 Abbildungen. 1937. RM 32.-, geb. RM 34.-

Einführung in Geist und Studium der Medivin. Prof. Dr. Georg B. Gruber. 1 Abb. 1934 Kart. RM 4.80, geb. RM 5.70

Einrichtung und ordnungsgemäßer Betrieb der chirurgischen Kranlkenstation. Dr. R. Goldhahn. $33 \mathrm{Abb} .1936$.

Kart. RM 4.-

Wntwicklungsgeschichte des Menschen. Leitfaden. Dr. Horst Boenig. 316, z. T. farbige Abb. 1938.

RM 10.20, geb. RM 11.80

Wrbforschung, Methodik der medivinischen (mit besonderer Berücksichtigung der Psychiatrie). Dr. B. Schulz. $16 \mathrm{Abb}$. und 1 Verwandtschaftstafel. 1936.

RM 10.50, geb. RM 12.-

Erbpflege, Die deutsche. Ein Grundriß von Dr. med. Gerhard Friese und Gerichtsassessor Hansjoachim Lemme. 1937.

Kart. RM 4.80

Erb- und Rassenpflege. Win Leitfaden für Krankenschwestern und Krankenpfleger. (Sonderausgabe des Abschnittes B des Krankenpflegelehrbuches.) 1938. Kart. RM 1.-

Fragen, Arztliche. Vorlesungen über allgemeine Therapie. Viktor v. Weizsäcker. 2., durchgesehene Aufl. 1935.

Gelourtshilfliche Operationen. Ihre Ausführung und Anwendung. Ein Lehrbuch für Studierende und Gebrauchsbuch für Arzte. Prof. Dr. med. Heinrich Martius. 276, zum Teil farbige Abbildungen. 1934

Geburtshilflicher Operationskurs. Leitfaden. Geh. Rat, emer. o. ö. Prof. Dr.med. et Dr. art. obs. h. c. Albert Döderlein. 16., verb. Aufl. 175 Abb. 1937.

Kart. RM 4.-

Gefäßstörungen der Gliedmaßen. Wine Darstellung für praktische Arrate und Studierende. Thomas Lewis. Ubersetzt von Dr.med. W. Heß, Freiburg/Brsg. 5 Abb. 1937. Kart. RM 6.-

Geisteskrankheiten. Prognose u. Therapie. Priv.-Doz.Dr. M. Mäller. 1936. RM 7.20, geb. RM 8.70

G EOR G T H I E M E / VERLA G / LE I P Z I G 
Gerichtliche und soziale Medizin. Abriß. Für Studierende und Arzte. Doz. Dr. H. Koopmann 1939.

Kart. RM 2.-

Geschlechtskrankheiten. IK. Zielers Grumdriß. 3. Aufl. Neubearbeitet von Dr. Georg Birnbaum. $18 \mathrm{Abb}$. im Text und auf 1 Tafel. 1938.

Geb. RM 4.90

Fämatologie. Einführung. Dr. A. von Domarus. Zugleich 4. Aufl. des „Taschenbuches der Klinischen Hämatologie". 14 Textabb. und 3 farbige Tafeln. 1929. Geb. RM 9.60

Hämatologie, Lehrbuch der klinischen. Prof.Dr. H. Schulten. 78 Abb., dav. 42 farb. Erscheint im März 1939 .

Histologie. Grumdriß der normalen Histologie und mikroskopisehen Anatomie. Dr. Alfred Brauchle. 3., neubearbeitete u. verbesserte Aufl. Prof. Dr. H. V o B. 75 Abb. 1935. Kart. RM 6.50

Kamp istofierkrankungen, Pathologie mud Therapie der. Leitfaden. Dr. 0 . Muntsch, 5., verbesserte und vermehrte Aufl. 58, davon 21 farbige Abb. 1938.

Kart. RM 10.50

Kb̈rperform, Wesensart und Fasse. Skizzen zu einer medizinisch-biologischen Konstitutionslehre. Privatdozent Dr. W. Jaensch. 24 Abb. 1934.

Kart. RM 4.80

R. Ruge +, P. Mühlens, M. zur Verth. Kramkheiten und Hygiene der warmen Länder. Ein Lehrbuch für die Praxis. Prof. Dr. P. Mühlens, Prof. Dr. E. Nauck, Doz. Dr. H. Vogel, Prof. Dr. H. Ruge. 4., völlig neu bearbeitete Aufl. 431 Textabb., 6 farbige und 1 schwarze Tafel. 1938.

RM 43.-, geb. RM 45.-

Krankenpflegelehrbuch. Neu bearbeitet und herausgegeben im Auftrage des Reichsministeriums des Innern vom Reichsausschuß für Volksgesundheitsdienst, Berlin. 12., neubearbeitete und erweiterte Aufl, $136 \mathrm{Abb}, 1938 . \quad$ Geb. RM 5.30 Vorzugspreis für staatlich anerkannte Krankenpflegeschulen bei geschlossenem Bezug. Geb. RM 3.85 Für Besitzer früherer Auflagen: Sonderausgabe des Abschnittes B: Erb- und Rassenpflege. Ein Leitfaden für Krankenschwestern und Krankenpfleger. 1938. Kart. RM 1.-

Cungenkrankheiten, Lehrbueh der. Prof. Dr. A. Bacmeister. 4., neubearbeitete Aufl. 222 Abb. im Text und auf 6, teilweise farbigen Tafeln. 1931.

RM 20.-, geb. RM 22.-

Nährboden-Technik, Bakteriologiseho. Leitfaden zur Herstellung bakteriologischer Năhrbőden. Ratschläge und Winke für die wichtigsten technischen Laboratoriumsarbeiten, für die Herstellung der Impfstoffe und Ausführung der Wassermannschen und Kahnschen Reaktionen. F. Kahlfeld und A. Wahlich + . 3., wesentlich verbesserte Aufl. $29 \mathrm{Abb}$. 1937 . Kart. RM 6.75

Neurose, Lebensmot, ärztlliche Pfilcht. Klinische Vorlesungen über Psychotherapie für Årzte und Studierende. Prof. J. H. Schultz. 1936.

Kart. RM 4.-

Neuzeitliche Frnährung des deutschen Menschen. Mrundlagen. Ein Leitfaden für Studierende und Ärzte. Doz. Dr. F. Bertram. 6 Abb. und 25 Tabellen. 1939.

Kart. RM 5.80

Nieren. Die Kranklheiten der Nieren und ableitenden Harnwege. Prof. Dr. $H$. Lucke. 1936.

Kart. RM 2.50

Nomina anatomica des Jahres 1895 (H. N. A.) nach der Buchstabenreihe geordnet und gegenübergestellt den Nomina anatomica des Jahres 1935 (I. N. A.). 2., verbesserte Aufl. Prof. Dr. Friedr, Kopsch. 1938.

Pathologie, Morphologische. Eine Darstellung morphologischer Grundlagen der allgemeinen und speziellen Pathologie. Prof. Dr. Werner Hueck. 811, z. T. farbige Abbildungen. 1937. RM 52.-, in Ganzleinen geb. RM 54.-

Pharmakologie, Theoretische und klinische. Lehrbuch für Studierende und Arzte. Prof. Dr. H. v. Hoeßlin und Prof. Dr. Fr. Müller. 4. Aufl. 1933. Geb. RM 10.20

Physiologie, KurzgefaBtes Lehrbuch der. Prof. Dr. Ph. Broemser. 2., umgearbeitete und vermehrte Aufl. $198 \mathrm{Abb} .1938$.

RM 12.-, geb. RM 13.50

Physiologie der Tiere und des Menschen. Einfiihrung. Priv.-Doz. Dr. G. Koller. 38 Abb. und 81 Tabellen. 1934.

RM 9.80, geb. RM 11.-

Respirationssystem, Vorlesungen iiber Frkranlrungen mit AusschlnB der Tulberkulose. Prof. H. v. Hoeßlin. 1935.

Kart. RM 4.20

Röntgenologie. Finführung. Ein Lehrbuch für Ärte und Studierende. Prof. Dr. G. F. Haenisch und Prof. Dr. Holthusen. 2. Aufl. in Vorbereitung.

Sportkumde, Kleine. Für Årzte, Lehrer, Studierende der Medizin und der Leibesübungen. Prof. Dr. H. Altrock. 43 Abb. 1928.

Geb. RM 6.-

Therapie, Pflanzliche. Eine Anleitung mit Beispielen zur Rezeptur. Dr. E. Meyer. 1935. Kart. RM 4.80

Tuberkulosefragen. Gedanken und BBetrachtungen. Prof. Dr. K. Klare. 1939. Geb. RM 3.20

Vererbungslehre. Lehrbuch. Dr. G. Benl. 79, davon 2 farbige Abb. $1936 . \quad$ Kart. RM 1.90

Versicherungsmedivin, Kompendium der soxialen. Prof. Dr. J. Weicksel. 6 Abb. 1938. Kart. RM 6.80

Zoologie, Grundriß der allgemeinen. Prof. Dr. A. Kühn. 5., verbesserte und vermehrte Aufl. $208 \mathrm{Abb} .1936$.

RM 9.80, geb. RM 11.65

Zoologisches Taschenbuch für Studierende. Selenka-Goldschmidt. 8., verbesserte Aufl. von Prof. Dr. J. Seiler.

1. Heft: Wirbellose and allgemeine Zoologie. $435 \mathrm{Abb} .1931$.

Kart. RM 6.45 2. Heft: Wirbeltiere. 364 Abb. 1929.

Kart. RM 6.30

Zuekerkrankheit, Die. Leitfaden für Studierende and A 2., vollig umgearbeitete Auflage. $17 \mathrm{Abb}$. und 9 Tab. Erscheint Ende März 1939.

G EOR G THIEME, VER LA G / LE I P Z I G 


\section{Fortschritte der Neurologie, Psychiatrie und ihrer Grenzgebiete}

Ubersichten und Forschungsergebnisse

Unter Mitarbeit von zahlreichen Fachgelehrten herausgegeben von

Professor Dr. A. Bostroem und Professor Dr. J. Lange $\dagger$ Königsberg i. Pr. Breslau

11. Jahrgang 1939 / Jährlich 12 Hefte

Bezugspreis vierteljährlich RM 6.- zuzüglich Postgebühren

\section{Fortschritte der Erbpathologie, Rassenhygiene und ihrer Grenzgebiete}

Unter Mitwirkung von zahlreichen Fachgelehrten herausgegeben von

Ober-Medizinalrat Dr. Johannes Schottky, Hildburghausen und Professor Dr. Frhr. v. Verschuer, Frankfurt a. M.

3. Jahrgang 1939/40 / Jährlich 6 Hefte

Bezugspreis jährlich RM 16.- zuzüglich Postgebühren

\section{Kinderärztliche Praxis}

Eine Zeitschrift für den praktischen Arzt, den Facharzt und den Sozialarzt

Herausgegeben von Professor W. Catel, Leipzig - Professor H. Kleinschmidt, Köln - Professor M. Klotz, Lübeck - Professor H. Rietschel, Würzburg Professor K. Stolte, Breslau - Professor E. Wieland, Basel

Schriftwalter: Professor Dr. H. Opitz, Berlin

10. Jahrgang 1939 / Jährlich 12 Hefte

Bezugspreis vierteljährlich RM 6.30 zuzüglich Postgebühren

\section{Deutsche Medizinische Wochenschrift}

Organ der Berliner Medizin. Gesellschaft und anderer Vereinigungen Schriftleitung:

Professor Dr. R. von den Velden; Privatdozent Dr. Artur Pickhan Monatliche Beilage: „Deułsches Tuberkulose-Blatt"

Herausgegeben von Professor Dr. Kurt Klare, Scheidegg im Allgäu 65. Jahrgang 1939

Bezugspreis vierteljährlich RM 6.20 zuzüglich Postgebühren

Für Studierende der Medizin und Ärzte, die noch nicht fest angestellt sind (Medizinalpraktikanten, Volontär-, Assistenzärzte), vierteljährlich RM 4.80 zuzüglich Postgebühren

G E O G T H I EME I VERLAG I LEIPZIG 


ROTANOX

oczyszczanie

naj 2015 


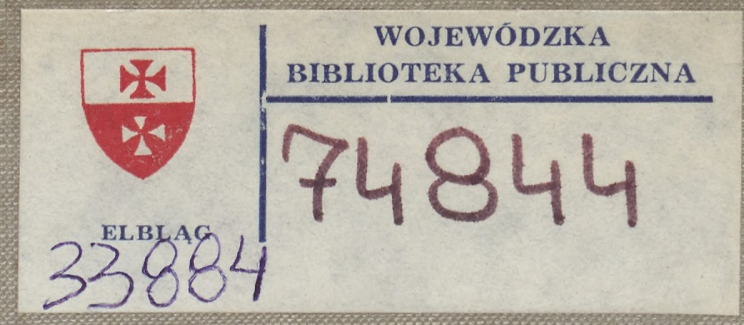

